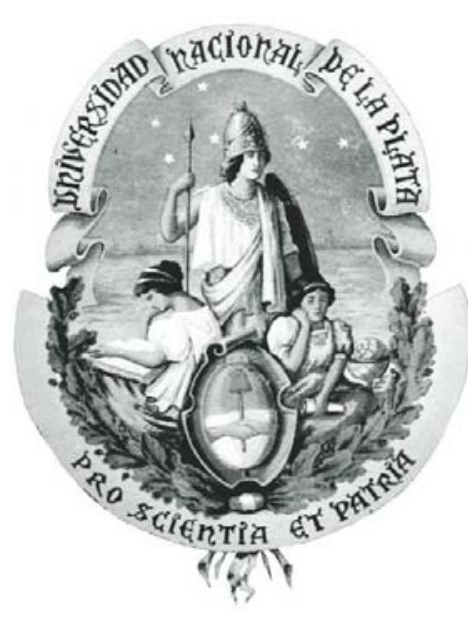

\title{
ELECTRODOS DE TECNOLOGÍA AVANZADA PARA SISTEMAS DE CONVERSIÓN DE ENERGÍA
}

Tesis doctoral presentada por

\section{Silvina Gabriela Ramos}

ante la Facultad de Ingeniería de la Universidad Nacional de La Plata para acceder al grado académico de

\section{DOCTOR EN INGENIERÍA}

Departamento Ingeniería Química

\author{
Director \\ Prof. Dr. Walter E. Triaca \\ Co-director
}

Ing. Gustavo Andreasen

La Plata, marzo de 2013. 
El presente trabajo se llevó a cabo en el Instituto de Investigaciones Fisicoquímicas Teóricas y Aplicadas (INIFTA), Facultad de Ciencias Exactas, Universidad Nacional de La Plata, bajo la dirección del Prof. Dr. Walter E. Triaca y co-dirección del Ing. Gustavo Andreasen. El mismo se presenta a consideración de las autoridades de la Facultad de Ingeniería de la UNLP para acceder al grado académico de Doctor en Ingeniería.

La Plata, marzo de 2013. 
A mi buen Dios y Señor, de quien he recibido toda clase de bendiciones y a quien me debo por completo.

A mis padres, Beatriz y Juan, por el amor, la comprensión y el apoyo durante toda mi vida. 
Agradecimientos

Quiero agradecer a todos los que han colaborado en el desarrollo de esta tesis y a quienes me han acompañado durante este tiempo:

- A mi director, el Dr. Walter Triaca, por haberme orientado con rigurosidad científica en cada etapa de la tesis y por haber manifestado su gran interés por el desarrollo de todos los trabajos realizados. Su amplia experiencia, enseñanzas y apoyo continuo han sido mi guía y ejemplo durante todo este tiempo, demostrando su calidad tanto científica como humana.

- A mi co-director, el Ing. Gustavo Andreasen, por brindarme sus conocimientos y experiencias de trabajo, que han contribuido de manera valiosa a mi formación científica. Agradezco su paciencia, consejos y estímulo diario desde mis comienzos como becaria doctoral.

- A mis compañeros del grupo de trabajo, Diego, Daniela y Willi, por el aliento día a día y por generar un cálido ambiente de trabajo.

- A todo el personal del INIFTA, por la ayuda que me brindaron.

- A los integrantes de cada uno de los talleres del instituto, siempre dispuestos a darme una mano, especialmente al Ing. Massarutti por su colaboración y asesoramiento técnico en las medidas experimentales.

- A la bibliotecaria Alicia, por su constante ayuda durante todo este tiempo y su amistad.

- A mis amigos del cuarto piso y del subsuelo del instituto, en especial a "las chicas": Jackeline, Mariela y Mavi, por todos los momentos compartidos. Gracias por tanto cariño y por haber sido compañeras de ideas, intereses y gustos. Con su compañía han hecho que mis días fueran de mucha risa y alegría.

- A Pablo, por su paciencia y amor. Gracias por escucharme, por comprenderme y haber sido mi apoyo durante todo este tiempo. Ha sido una gran bendición en mi vida contar con su compañía.

- A Claudia y Bochi por haberme orientado e incentivado en mis primeros pasos en la investigación.

- A todos mis amigos de Posadas y de la facultad, que en esas comunicaciones diarias me han hecho sentir más cerca de mi ciudad natal, en especial a Fátima, Isaura y Mariana.

- A mi familia y muy especialmente a mis padres, Beatriz y Juan, por su presencia a pesar de la distancia, por confiar en mí y apoyarme siempre. Gracias por haberme acompañado en todo este tiempo con sus oraciones, por todo el aliento y el amor incondicional que siempre me han dado. Gracias por todo lo que me han enseñado.

- A todas las personas que he tenido la gracia de conocer en La Plata, que han enriquecido mi vida de una $u$ otra manera y a todos aquellos con quienes he podido compartir todo este tiempo de crecimiento tanto personal como académico. 
- Por último, y no por ello menos importante, quiero dar gracias a mi buen Dios y Señor Todopoderoso, por haberme dado fuerzas cada día para superar cualquier inconveniente, por permitirme esta experiencia de aprendizaje y haberme ayudado a llegar hasta aquí.

Gracias a Dios tuve el privilegio de conocer tanta gente maravillosa en este camino de la ciencia. A todos, muchas gracias de corazón. 



\title{
ELECTRODOS DE TECNOLOGÍA AVANZADA PARA SISTEMAS DE CONVERSIÓN DE ENERGÍA
}

\author{
ÍNDICE \\ CAPÍTULO I \\ Introducción general a la temática de la tesis
}

I.1. Sistemas de conversión de energía en base a tecnologías del hidrógeno 1

I.2. Electrodos de alto rendimiento para celdas de combustible de tecnología avanzada

I.3. Temática y plan de tesis

\section{CAPÍTULO II}

Electrocatálisis de las reacciones electródicas de celdas de combustible

II.1. Electrocatálisis $\quad 7$

II.2. Electrocatalizadores $\quad 9$

II.3. Catalizadores metálicos dispersados $\quad 12$

II.3.i. Impregnación 12

II.3.ii. Intercambio iónico y adsorción 13

II.3.iii. Dispersión coloidal 13

II.3.iv. Método de Adams $\quad 14$

II.3.v. Método Raney 14

$\begin{array}{ll}\text { II.3.vi. Liofilizado } & 14\end{array}$

II.4. Electrocatalizadores dispersados para celdas de combustible $\quad 15$

II.5. Electrodos porosos de difusión de gas catalizados 16

II.6. Electrocatálisis de la reacción de electrorreducción de oxígeno 19

II.7. Influencia de la morfología superficial del electrodo sobre la cinética de reacciones electrocatalíticas

\section{CAPÍTULO III}

\section{Métodos de preparación de materiales de electrodo con superficies bien definidas}

III.1. Métodos de preparación de superficies metálicas con estructuras bien definidas

III.1.a. Métodos no electroquímicos de preparación de superficies metálicas con estructuras superficiales bien definidas y caracterizadas

III.1.b. Métodos electroquímicos de preparación de metales con superficies bien definidas y caracterizadas

III.1.b.i. Reestructuración superficial de metales policristalinos

II.1.b.ii. Facetado electroquímico de superficies de metales monocristalinos

III.2. Técnicas de electrólisis pulsante para obtención de electrodepósitos metálicos facetados 
III.3. Características generales de los electrodepósitos metálicos obtenidos mediante la técnica de $O C P R$

III.3.a. Dependencia de los límites de potencial

III.3.b. Dependencia de la frecuencia

III.3.c. Efectos capacitivos de la electrólisis pulsante

ANEXO

\section{CAPÍTULO IV}

\section{Técnicas experimentales de caracterización de materiales de electrodo}

IV.1. Técnicas electroquímicas

IV.1.a. Voltamperometría cíclica

IV.1.b. Aplicaciones de la voltamperometría cíclica

IV.1.b.i. Aproximación al fenómeno capacitivo y determinación del área superficial electroquímicamente activa de electrodos

IV.1.b.ii. Procesos de electrosorción de hidrógeno

IV.1.b.iii. Determinación de $Q_{H, s}$

IV.1.a.iv. Cálculo de la carga voltamperométrica

IV.1.a.v. Perfil voltamperométrico de monocristales de $P t$ en la región de adsorción de hidrógeno

IV.1.a.vi. Procesos de electrosorción de hidrógeno y oxígeno sobre Pt policristalino

IV.2. Técnicas físicas

IV.2.a. Microscopía electrónica de barrido (SEM)

IV.2.b. Microscopía electrónica de transmisión (TEM)

IV.2.c. Difracción de rayos $\mathrm{X}(X R D)$

IV.2.d. Espectrofotometría

IV.2.d.i. Espectrofotómetro

IV.2.d.ii. Leyes de absorción

IV.2.d.iii. Métodos de disolución del $P t$ de las muestras $P t /$ carbono

\section{CAPÍTULO V}

\section{Preparación y caracterización de sustratos de carbono para electrodepositar Pt}

V.1. Sustratos de carbono

V.1.a. Estructura de los materiales carbonosos

V.1.b. Estructura cristalina del grafito

V.2. Preparación y pretratamiento de sustratos carbonosos

V.3. Pretratamiento de sustratos grafíticos para electrodepositar platino

V.4. Caracterización del sustrato grafítico

V.4.a. Caracterización física del sustrato grafítico empleado

V.4.b. Caracterización voltamperométrica del sustrato grafítico empleado 


\section{CAPÍTULO VI}

\section{Metodología experimental para la preparación y caracterización de electrodepósitos de Pt dispersados sobre sustratos de carbono}

VI.1. Soluciones electrolíticas y reactivos utilizados

VI.2. Electrodos

VI.2.a. Electrodos de trabajo

VI.2.b. Contraelectrodos

VI.2.c. Electrodos de referencia

VI.3. Celdas electroquímicas

VI.3.a. Celda para electrodepósitos de Pt 92

VI.3.b. Celda para la caracterización electroquímica de electrodepósitos de Pt 93

VI.4. Equipos e instrumentación electrónica $\quad 94$

VI.4.a. Potenciostato $\quad 95$

VI.4.b. Generador de función de onda $\quad 95$

VI.4.c. Conformador de onda 96

VI.4.d. Osciloscopio $\quad 97$

VI.4.e. Culombímetro electrónico $\quad 97$

VI.5. Calibración y puesta a punto de la técnica espectrofotométrica para la determinación de la cantidad de Pt electrodepositado 98

VI.5.a. Equipamiento y reactivos utilizados 98

VI.5.b. Preparación de la solución estándar de $P t \quad 98$

VI.5.c. Calibración de la técnica espectrofotométrica 98

VI.6. Preparación y caracterización de electrodepósitos de Pt dispersados sobre sustratos de carbón

VII.6.a. Obtención de nanopartículas de Pt por OCPR $\quad 100$

VI.6.b. Electrodepósitos de Pt con orientación cristalográfica preferencial tipo (100) 102

VI.6.c. Electrodepósitos de Pt con orientación cristalográfica preferencial tipo (111) 104

VI.7.a. Caracterización por imágenes TEM de los electrodepósitos con orientación cristalográfica preferencial tipo (111)

VI.7.b. Caracterización por difracción de rayos $\mathrm{X}$ de los electrodepósitos con orientación cristalográfica preferencial tipo (111)

VI.8. Determinación de la cantidad de Pt electrodepositado sobre sustratos carbonosos $\quad 109$

VI.8.a. Procedimiento de digestión de las muestras $\quad 109$

VI.8.b. Determinación de la cantidad de Pt electrodepositado y del rendimiento de electrodeposición

VI.9. Estudio del efecto de la variación de parámetros de la OCPR sobre las características de los electrodepósitos de $P t$

VI.9.a. Condiciones generales de trabajo

VI.9.b. Efecto del tiempo de electrodeposición 
VI.9.c. Efecto de la variación del potencial inferior a potencial superior constante de 1,2 V

VI.9.d. Efecto de la variación del potencial inferior Ei a potencial superior constante de $E s=1,38 \mathrm{~V}$

VI.9.e. Efecto de la variación del potencial superior Es a potencial inferior constante de $E i=-0,2 \mathrm{~V}$

\section{CAPÍTULO VII}

\section{Aspectos generales de las celdas de combustible}

VII.1. Historia de las celdas de combustible

VII.2. Eficiencia de una celda de combustible 136

VII.3. Clasificación de las celdas de combustible 138

VII.4. Comportamiento típico de la celda de combustible en operación

\section{CAPÍTULO VIII}

\section{Celdas de combustible de hidrógeno/oxígeno de tecnología PEM}

VIII.1. Componentes de una celda PEM

VIII.2. Zona de triple fase

VIII.3. Capa difusora de gas (CDG)

VIII.4. Capa activa $(C A)$

VIII.5. Placas monopolares y bipolares

VIII.6. Colectores de corriente

VIII.7. Membrana electrolítica

VIII.8. Stack de celdas de combustible

\section{CAPÍTULO IX}

\section{Diseño, construcción y caracterización de una celda de combustible PEM prototipo de} $\mathrm{H}_{2} / \mathrm{O}_{2}$

IX.1. Fabricación de electrodos porosos de difusión de gas

IX.1.a. Preparación de la capa difusora de gases $(C D G)$

IX.1.b. Preparación de la capa activa (CA)

IX.2. Tratamiento de la membrana de intercambio de protones

IX.3. Construcción de ensambles electrodo-membrana PEM-electrodo

IX.4. Diseño y construcción de un prototipo de celda de combustible unitaria de $\mathrm{H}_{2} / \mathrm{O}_{2}$ de baja temperatura

IX.5. Caracterización voltamperométrica de los electrodos de celdas de combustible tipo PEM

IX.5.b Voltamperometría cíclica "in situ" de los electrodos de la celda de combustible unitaria bajo distintas condiciones de operación 
IX.5.c. Voltamperometría cíclica "in situ" de los electrodos de la celda unitaria para tiempos largos

IX.6. Evaluación de la resistencia de la celda de combustible unitaria, $R_{\text {celda }}$

\section{CAPÍTULOX}

\section{Evaluación del comportamiento en operación de la celda combustible unitaria prototipo de tecnología PEM}

X.1. Consideraciones generales

X.2. Comportamiento de la celda combustible unitaria bajo diferentes condiciones de operación

X.2.a. Ensayo 1: Comportamiento de la celda unitaria a $25{ }^{\circ} \mathrm{C}$ y sin humidificación de gases. Activación del electrodo

X.2.b. Ensayo 2: Efecto de la disminución del caudal de $\mathrm{H}_{2}$ y $\mathrm{O}_{2}$

X.2.c. Ensayo 3: Efecto del aumento del caudal de $\mathrm{H}_{2}$

X.2.d. Ensayo 4: Efecto de la humidificación del gas $\mathrm{H}_{2}$

X.2.e. Ensayo 5: Efecto de la temperatura de operación de la celda y humidificación del gas $\mathrm{H}_{2}$

X.3. Evaluación del comportamiento de la celda bajo condiciones particulares de operación

X.4. Evaluación del comportamiento en operación de la celda de combustible a tiempos largos

X.5. Influencia de la morfología de las nanopartículas de Pt sobre el comportamiento en operación de la celda de combustible unitaria de hidrógeno/oxígeno

X.6. Implementación de la rutina de trabajo para la evaluación del comportamiento de celdas de combustible unitarias

\section{CAPÍTULO XI}

Discusión general y conclusiones

LISTA DE TABLAS 


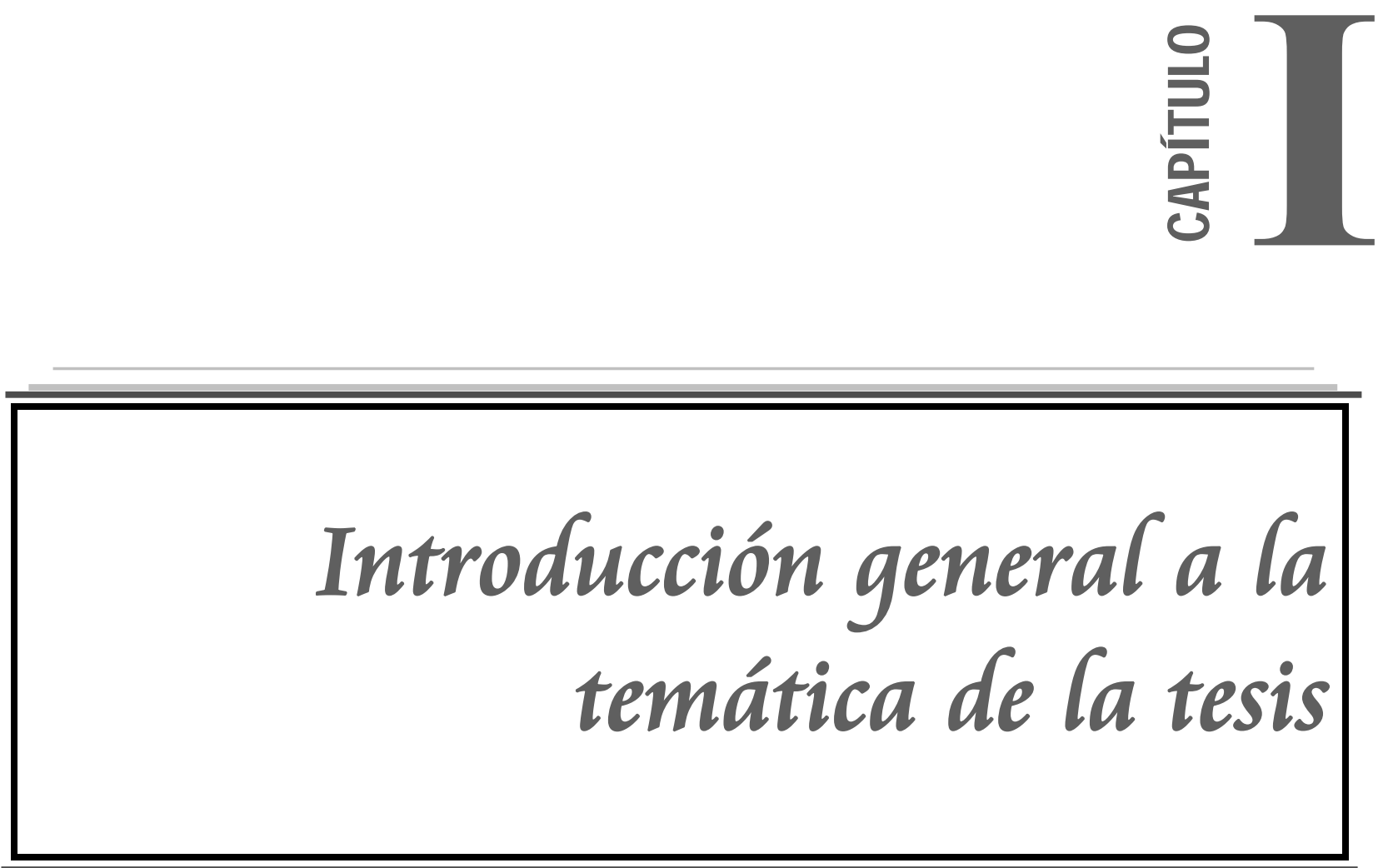



\section{CAPÍTULO I}

\section{Introducción general a la temática de la tesis}

\section{I.1. Sistemas de conversión de energía en base a tecnologías del hidrógeno}

La producción de energía mediante la combustión térmica convencional de fuentes fósiles presenta serias desventajas, ya que es un método indirecto e ineficiente que implica una etapa intermedia de conversión de calor en trabajo mecánico con un límite de eficiencia intrínseca impuesto por el ciclo de Carnot. Así, por ejemplo, una máquina térmica que opera entre $350^{\circ} \mathrm{C}$ y $100^{\circ} \mathrm{C}$, tiene una eficiencia máxima intrínseca de $40 \%$ y, en la práctica, existen otras pérdidas de energía extrínsecas, tales como disipación de calor a los alrededores, calor generado por fricción en las partes móviles, combustión incompleta, etc., que disminuyen aún más el rendimiento. De este modo, en los motores de combustión interna, la eficiencia práctica es del $15 \%$ al $20 \%$, esto es, se desperdicia más del 80 \% de la energía química contenida en el combustible [1]. Además, como productos de la combustión se arrojan al ambiente principalmente agua y dióxido de carbono, que contribuye al calentamiento global, y otros contaminantes, tales como monóxido de carbono, óxidos de nitrógeno $\left(N O_{x}\right)$, óxidos de azufre $\left(S O_{x}\right)$, hidrocarburos no saturados, material particulado, etc., que provocan desequilibrios ecológicos (Iluvias ácidas, reducción de la capa de ozono, formación de smog, etc.) y/o dañan la salud. Por otra parte, debido a la baja eficiencia de conversión del método, se desaprovechan las limitadas reservas de combustibles fósiles, que han tardado millones de años en formarse.

Para resolver estos problemas se han desarrollado sistemas para el aprovechamiento integral de las fuentes primarias de energía limpias y renovables que puedan sustituir a los combustibles fósiles, tales como energías solar, eólica, hidráulica, geotérmica, mareomotriz, etc. [2]. Cabe destacar que en la actualidad, la mayor parte de al energía que se consume mundialmente proviene de la combustión térmica de fuentes fósiles (petróleo, carbón, gas natural) que son de carácter no renovable. En nuestro país el panorama es similar ya que se consumen alrededor de $6 \times 10^{7}$ toneladas de combustible fósiles, principalmente para la producción de electricidad en usinas térmicas y en el transporte vehicular [3], [4].

En la Tabla I se observa la evolución de la matriz energética argentina desde 1970 a 2009 [5]. La matriz energética de un país se construye con las energías primarias, estableciendo las diferentes fuentes energéticas de las que se dispone y su incidencia relativa en el total de la oferta. Sirve para posibles comparaciones a lo largo de los años, así como también como referencia a un momento determinado con otros países de la región o a nivel mundial. La matriz energética consiste en una tabla en la que se ubican los distintos tipos de energía utilizadas, de dónde provienen y cómo se utilizan. Así, en la Tabla I se observa el aumento de la contribución relativa del gas natural en los últimos años, superando a la del petróleo, como así también el incremento gradual de la participación de la energía 
hidroeléctrica que alcanza su máximo en el año 2006. En años recientes se reactivó el Plan Nuclear Argentino, aunque los valores de su contribución no se reflejan todavía en la tabla.

Tabla I. Evolución de la matriz energética argentina: 1970/2009 [5].

\begin{tabular}{|c|c|c|c|c|c|c|}
\hline Año & $\begin{array}{c}\text { Petróleo } \\
\text { (\%) }\end{array}$ & $\begin{array}{c}\text { Gas natural } \\
\text { (\%) }\end{array}$ & $\begin{array}{c}\text { Carbón } \\
\text { mineral (\%) }\end{array}$ & $\begin{array}{c}\text { Hidroenergía } \\
\text { (\%) }\end{array}$ & Nuclear (\%) & $\begin{array}{c}\text { Biomasa } \\
\text { (\%) }\end{array}$ \\
\hline $\mathbf{1 9 7 0}$ & 71,2 & 18,1 & 3,2 & 0,5 & 0 & 7,0 \\
\hline $\mathbf{1 9 8 0}$ & 62,0 & 25,4 & 2,7 & 3,7 & 1,9 & 4,3 \\
\hline $\mathbf{1 9 9 0}$ & 48,5 & 36,5 & 2,3 & 4,0 & 4,6 & 4,1 \\
\hline $\mathbf{2 0 0 0}$ & 41,2 & 46,2 & 1,3 & 4,7 & 2,7 & 3,9 \\
\hline $\mathbf{2 0 0 9}$ & 35,5 & 51,2 & 1,5 & 4,7 & 2,7 & 4,4 \\
\hline
\end{tabular}

Por tanto, resulta claro que actualmente los hidrocarburos son la fuente principal de la energía que consumimos [6]. Sin embargo, el agotamiento de estos recursos naturales es irreversible, por lo cual, en los últimos años, se ha propiciado el uso de fuentes renovables de energía, con la finalidad de llevar a cabo la sustitución gradual de las fuentes convencionales, que además son contaminantes.

El uso de fuentes de energía basadas en recursos renovables ha sido ampliamente reconocido como la alternativa más viable para resolver los problemas asociados con la combustión térmica convencional, tales como su ineficiencia operacional, el agotamiento de las reservas de los combustibles fósiles y el aumento de la contaminación ambiental. La incorporación masiva en el sector productivo local de sistemas de generación de electricidad por métodos alternativos no contaminantes, tales como convertidores solares fotovoltaicos o turbinas eólicas, contribuirá a reducir la demanda de combustibles derivados del petróleo, preservar el medio ambiente y mejorar la calidad de vida.

Por sus características de funcionamiento intermitente estos sistemas deben complementarse con dispositivos electroquímicos de acumulación de electricidad, tales como baterías avanzadas o sistemas de almacenamiento de hidrógeno producido por electrólisis a partir de excedentes de energía eléctrica, esto es, en base a la conversión de energía eléctrica en energía química del hidrógeno.

Si bien se puede imaginar un escenario futuro donde las fuentes primarias renovables, principalmente energía eólica y solar, ocupen un lugar predominante en la matriz energética sustituyendo a los combustibles fósiles, existen problemas relacionados con el almacenamiento y el transporte de la energía primaria y la facilidad de su conversión de acuerdo a la demanda. En este aspecto, debe señalarse que, en el lugar de consumo final, sólo el $25 \%$ de la energía primaria se usa como electricidad y el $75 \%$ restante como combustible [7]. Por lo tanto, las energías primarias renovables deben usarse tanto para generar electricidad como para manufacturar combustibles.

En este escenario es donde aparece el hidrógeno como combustible ideal para el reemplazo de los combustibles fósiles fluidos (gases y líquidos), ya que puede obtenerse fácilmente por electrólisis del 
agua a partir de fuentes primarias renovables. El hidrógeno electrolítico convenientemente almacenado, ya sea como gas comprimido, líquido a bajas temperaturas o sólido bajo la forma de hidruro metálico, puede reconvertirse a electricidad en celdas de combustible durante las horas de mayor consumo o períodos nocturnos o de ausencia de viento y transportarse al centro de consumo donde su combustión térmica produce calor y agua, aunque también se genera algo de $N O_{x}$ si se utiliza aire como comburente, o alternativamente, alimentar a celdas de combustible produciendo directamente electricidad y agua, que vuelve al ambiente, sin emisión de contaminantes. De este modo, el ciclo del hidrógeno constituye un sistema cerrado, a diferencia del ciclo de combustibles fósiles, ya que el combustible se regenera (Figura 1) [3], [4].

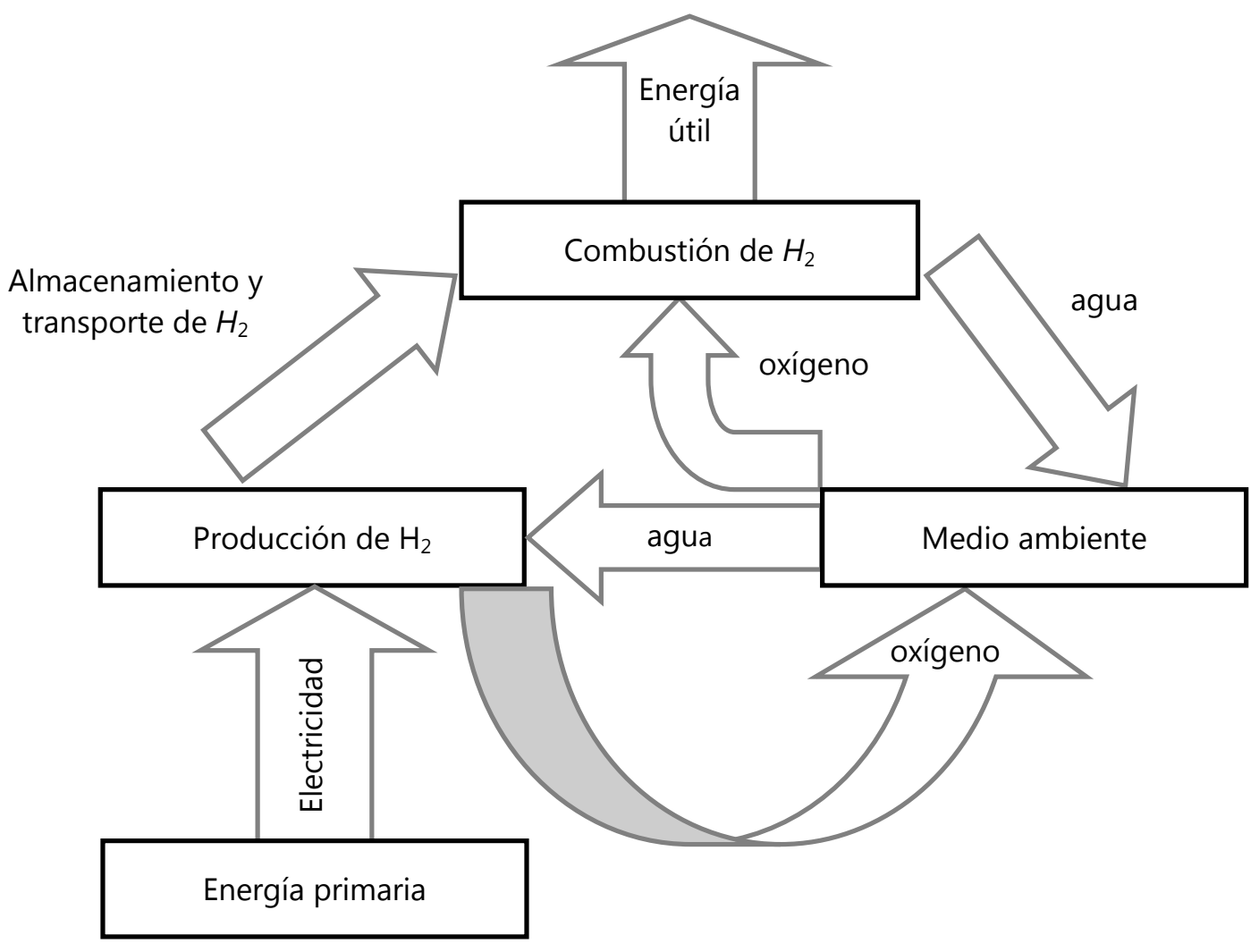

Figura 1. Ciclo del hidrógeno.

El hidrógeno se encuentra en abundancia en la naturaleza, principalmente como constituyente del agua. Almacena mayor cantidad de energía por unidad de peso $(33,3 \mathrm{kWh} / \mathrm{kg})$ que cualquier otra sustancia y su combustión produce agua, sin contaminar el ambiente. Por otra parte puede almacenarse fácilmente como gas comprimido ( 200 bar), como líquido a bajas temperaturas $\left(-253^{\circ} \mathrm{C}\right)$ o como hidruro metálico, formando estructuras sólidas. El hidrógeno también es fácilmente transportable por tuberías y se puede usar directamente en quemadores o motores produciendo calor por combustión limpia, o convertir directamente su energía química en electricidad en celdas de combustible, en un proceso de alta eficiencia. Puesto que el hidrógeno no se encuentra libre en la naturaleza, se debe gastar energía para producirlo, tal como en el caso de la electricidad. El hidrógeno, por lo tanto, no es 
una fuente energética sino un intermediario entre la fuente primaria y el dispositivo de conversión de energía donde se lo utilice, i.e, es un portador de energía. Por lo tanto, para la utilización masiva del hidrógeno en sistemas sustentables de energía se lo debe producir a bajo costo.

Por otra parte, se debe destacar que una de las principales fuentes de contaminación ambiental en las grandes ciudades está constituida por los gases y el particulado provenientes de los escapes de los motores de los vehículos de transporte. En este aspecto, la introducción gradual en el medio local de sistemas de conversión electroquímica de energía de tecnología avanzada, tales como las celdas de combustible, para el reemplazo de los motores de combustión interna en la propulsión de vehículos ofrece la ventajas del funcionamiento silencioso de estos dispositivos, debido a la ausencia de partes móviles, y a la emisión nula de contaminantes (el producto de reacción es generalmente agua). Cabe mencionar también que la alta eficiencia de conversión (> $50 \%$ ) de las celdas de combustible permite un aprovechamiento máximo de la energía química contenida en los combustibles (hidrógeno, gas natural, biocombustibles, etc.), asegurando de este modo el uso racional de los recursos.

\section{I.2. Electrodos de alto rendimiento para celdas de combustible de tecnología avanzada}

En los últimos años, se han producido avances importantes a nivel mundial con el desarrollo de celdas de combustible de hidrógeno/oxígeno que emplean la nueva tecnología de electrolito de polímero sólido, con la cual se alcanzan altas eficiencias de conversión y densidades de potencia. Sin embargo, existen todavía pérdidas de energías importantes asociadas a problemas de electrocatálisis de las reacciones electródicas que disminuyen la eficiencia de conversión a 50-60 \%.

Uno de los inconvenientes en las celdas de combustible que operan a bajas temperaturas y a altas densidades de potencia, se debe al alto sobrepotencial de la reacción de reducción de oxígeno (RRO) [8]. Por ello, para reducir las pérdidas de energía asociadas, se requiere del desarrollo de materiales de electrodos con estructuras superficiales de alta actividad catalítica que permitan minimizar las pérdidas de energía relacionadas con los sobrepotenciales de electrodo, particularmente los correspondientes a la reducción de oxígeno, y así conducir los procesos de conversión de energía a velocidad y eficiencia máximas.

Las investigaciones sobre celdas de combustible abarcan el estudio de la producción, el almacenamiento y el transporte de hidrógeno, como así también la obtención de catalizadores que proporcionen una buena actividad electrocatalítica con bajas cantidades de material a fin de lograr disminuir los costos, la elaboración de electrolitos poliméricos que sean económicos y eficientes, etc. Se han estudiado diversos aspectos para la optimización de las celdas de combustible, tanto desde el punto de vista de la construcción de las celdas en sí, como de los materiales que se utilizan para el desarrollo de los electrodos porosos de difusión de gas. Sin embargo, como se ha mencionado anteriormente, una de las principales limitaciones en las celdas de combustible de hidrógeno/oxígeno que operan a bajas 
temperaturas está asociada a la cinética lenta de la reacción catódica de electrorreducción de oxígeno. Debido a que la composición y estructura superficial de los electrodos son factores determinantes sobre la performance global de la celda, resulta importante el diseño y desarrollo de electrodos con nanocatalizadores dispersados sobre sustratos de alta área específica que presenten alto rendimiento en celdas de combustible, tal como se ha propuesto en esta tesis.

A través de numerosas investigaciones se han determinado correlaciones fundamentales entre la estructura superficial, composición química y actividad catalítica del material de electrodo, que posibilitan establecer bases racionales para el diseño y construcción de electrodos de alta tecnología para su uso en celdas de combustible avanzadas [9-17]. Así, pueden encontrarse trabajos relacionados con la aplicación de microscopía de efecto túnel "in situ", para la determinación de la topografía a nivel del nanómetro de superficies de electrodos modificadas electroquímicamente [18]. Se ha estudiado también la determinación de la relación existente entre la estructura superficial de electrocatalizadores de platino de baja y alta área superficial y su actividad y selectividad para la electrorreducción de oxígeno y se ha desarrollado un procedimiento para obtener electrocatalizadores de nanopartículas de platino dispersadas de alta área superficial y morfologías bien definidas y caracterizadas a nivel atómico [19].

A partir de estos trabajos previos, se consideró interesante estudiar como aquellos electrocatalizadores de nanopartículas de Pt con una determinada morfología, que exhiben la mayor actividad electrocatalítica para la reacción de electrorreducción de oxígeno, influyen en el comportamiento de una celda de combustible de hidrógeno/oxígeno de tecnología PEM, lo cual se desarrolla también en esta tesis.

\section{I.3. Temática y plan de tesis}

En base a la información y resultados obtenidos previamente por el grupo de Conversión y Almacenamiento de Energía (CAE) del Instituto de Investigaciones Fisicoquímicas Teóricas y Aplicadas (INIFTA), se planteó como objetivo general de la tesis el desarrollo de electrodos selectivos de tecnología avanzada para su uso en celdas de combustible de hidrógeno/oxígeno de alta eficiencia de que operan a baja temperatura.

Para ello, se propuso alcanzar las siguientes metas:

i. Desarrollo de electrocatalizadores de Pt con orientación cristalográfica preferencial bajo la forma de nanopartículas dispersadas sobre sustratos carbonosos para las reacciones electródicas relacionadas con procesos de conversión de energía (electrooxidación de hidrógeno, electrorreducción de oxígeno).

ii. Caracterización de la estructura superficial de los electrocatalizadores obtenidos y evaluación de su actividad catalítica para las reacciones electródicas involucradas en celdas de combustible de 
hidrógeno/oxígeno que operan a bajas temperaturas.

iii. Diseño y construcción de electrodos porosos de difusión de gas catalizados con platino y evaluación de su comportamiento en operación en hemiceldas. Optimización de la técnica utilizada para la fabricación de los electrodos de celdas de combustible.

iv. Desarrollo, caracterización y evaluación del comportamiento en operación de ensambles electrodo-membrana de intercambio de protones (PEM)-electrodo.

v. Diseño y construcción de un prototipo de celda de combustible unitaria de hidrógeno/oxígeno de tecnología PEM. Evaluación de su comportamiento en operación y estabilidad a tiempos largos.

Los resultados obtenidos y su análisis crítico se describen en los capítulos siguientes de la tesis. Se presenta también una discusión general que incluye los logros y conclusiones. 


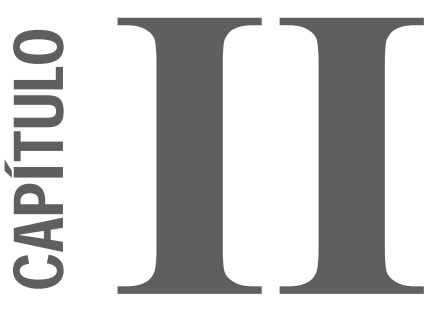

\section{Electrocatálisis}

de las reacciones electródicas de celdas de combustible 



\section{CAPÍTULO II}

\section{Electrocatálisis de las reacciones electródicas de celdas de combustible}

\section{1. Electrocatálisis}

La electrocatálisis es una extensión y, al mismo tiempo, una especialidad de la catálisis. Se define la electrocatálisis como la aceleración de una reacción electródica por una sustancia que no se consume en la reacción global. La sustancia está generalmente en la superficie del electrodo, haciendo que el mismo sea catalíticamente activo.

El concepto de electrocatálisis se aplica generalmente a aquellas reacciones electroquímicas que requieren, para proseguir a velocidad razonable, una quimisorción disociativa inicial o un paso de reordenamiento que implique la participación de la superficie del electrodo [20], [21].

La electrocatálisis permite maximizar las velocidades de las reacciones electroquímicas para la formación de ciertos productos específicos. Esto se logra generalmente utilizando materiales de alta área específica y que presentan determinadas estructuras superficiales como, por ejemplo, sitios de reacción preferidos.

El término electrocatálisis comienza a utilizarse en 1963 [22] para correlacionar las características cinéticas de la reacción de desprendimiento de hidrógeno, sobre diferentes electrodos metálicos, con parámetros fisicoquímicos relacionados con la interfase de reacción, tales como la energía de enlace hidrógeno-metal y la entalpía de sublimación del metal [23].

En electrocatálisis se puede variar la energía de activación de la reacción modificando el potencial de la interfase electrodo/solución. Participan, generalmente, procesos de transferencia de carga, que ocurren asistidos por la diferencia de potencial en la región interfacial correspondiente, de modo que la cinética del proceso electrocatalítico resulta dependiente de la estructura de la doble capa electroquímica [24], [25].

Las reacciones electrocatalíticas están estrechamente relacionadas con la catálisis heterogénea debido a que, por lo menos, una etapa de la reacción electroquímica ocurre en la interfase electrodoelectrolito. Para una dada diferencia de potencial electrodo-electrolito, las propiedades de la superficie del electrodo afectan la velocidad global de la reacción [26], [27]. La relación entre reacciones electrocatalíticas y catálisis heterogénea se puede ilustrar mediante la reacción de formación del compuesto $A B$ partiendo de $A$ y $B$, ambos en solución, por dos vías independientes, la catalítica heterogénea y la electrocatalítica. Así, por ejemplo, para la reacción global:

$A_{\text {(solución) }}+B_{\text {(solución) }}=A B_{\text {(solución) }}$

Si la formación de $A B$ en solución transcurre en presencia de un catalizador $(C T)$, la reacción global 
puede ocurrir siguiendo una secuencia de reacciones intermediarias como se muestra a continuación:

$$
\begin{aligned}
& A_{\text {(solución) }}+C T=C T(A) \\
& B_{\text {(solución) }}+C T=C T(B) \\
& C T(A)+C T(B)=C T(A B)=A B_{\text {(solución) }}+2 C T
\end{aligned}
$$

En las reacciones (2) y (4) se admiten estados adsorbidos de $A$ y $B$ sobre $C T$, representados entre paréntesis. La suma de las etapas (2) a (4) da la reacción global (1). Entre las etapas (2) y (4) no se contempla ninguna contribución de procesos de transporte. Las reacciones (2) y (3) representan procesos de adsorción y la reacción (4) corresponde a una reacción superficial entre $A$ y $B$ adsorbidos para producir $A B$ adsorbido que estabiliza posteriormente en solución y libera dos sitios de adsorción en el catalizador.

La formación de $A B$ a través de una reacción electrocatalítica implica una transferencia de carga. Esto significa el pasaje de una corriente eléctrica a través del electrocatalizador (ECT). El hecho de que la reacción electrocatalítica esté acompañada por transferencia de carga no impide que participen en la reacción global procesos semejantes a los indicados por las reacciones (2) y (3). Por lo tanto las reacciones que representan el proceso electrocatalítico pueden escribirse de la siguiente manera:

$$
\begin{aligned}
& A_{\text {(solución) }}+E C T=E C T(A) \\
& B_{\text {(solución) }}+E C T=E C T(B)
\end{aligned}
$$

a las que se agregan procesos de transferencia de carga asistidos por la diferencia de potencial en la interfase electrodo $(E C T)$ /solución, que se representan mediante las reacciones:

$$
\begin{aligned}
& A_{\text {(solución) }}+E C T=E C T\left(A^{+}\right)+e^{-} \\
& B_{\text {(solución) }}+E C T=E C T\left(B^{+}\right)+e^{-}
\end{aligned}
$$

con los equilibrios correspondientes:

$$
\begin{aligned}
& E C T\left(A^{+}\right)=E C T+A^{+}{ }_{\text {(solución) }} \\
& E C T\left(B^{+}\right)=E C T+B^{+}{ }_{\text {(solución) }}
\end{aligned}
$$

El compuesto $A B$ se puede formar entonces por varios caminos representados por las reacciones:

$$
\begin{aligned}
& E C T\left(A^{+}\right)+B_{\text {(solución) }}+e^{-}=E C T(A B)=A B_{\text {(solución) }}+E C T \\
& E C T\left(B^{+}\right)+A_{\text {(solución) }}+e^{-}=E C T(A B)=A B_{\text {(solución) }}+E C T \\
& E C T\left(A^{+}\right)+E C T\left(B^{+}\right)+2 e^{-}=E C T(A B)+A B_{\text {(solución) }}+E C T
\end{aligned}
$$

Comparando los dos procesos de formación de la especie $A B$ en solución, se puede observar como la electrocatálisis mantiene una estrecha relación con la catálisis heterogénea [25]. En vista de esta analogía, se puede también definir la electrocatálisis como una rama de la catálisis heterogénea relacionada con el estudio de reacciones catalíticas heterogéneas que involucran reactivos que transfieren electrones a través de una interfase catalizador-electrolito. 
El interés creciente en esta área de la catálisis heterogénea se debe, en gran parte, a los requerimientos para el desarrollo de sistemas avanzados de conversión de energía, tales como las celdas de combustible y las baterías de alta potencia.

Las celdas de combustible de baja temperatura necesitan electrocatalizadores para acelerar las reacciones involucradas en los procesos electródicos, principalmente la reacción catódica. En una celda de combustible de hidrógeno/oxígeno, la reacción catódica de electrorreducción de oxígeno es de suma importancia por el consumo energético involucrado, que es aproximadamente cuatro veces mayor que el de la reacción anódica de electrooxidación de hidrógeno. La reacción de reducción de oxígeno $(R R O)$ es la reacción determinante del proceso global, debido a que es aproximadamente cinco órdenes de magnitud más lenta que la reacción de oxidación de hidrógeno $(R O H)$ [8], [28]. La reducción lenta del oxígeno conduce a pérdidas en la tensión de las celdas de combustible e impone restricciones en las densidades de potencia. De ahí la necesidad de desarrollar de nuevos materiales electrocatalíticos para acelerar esta reacción y obtener así la mayor eficiencia energética posible.

\section{II.2. Electrocatalizadores}

Un electrocatalizador es un material que sirve para aumentar la velocidad de una reacción electroquímica o para modificar la selectividad del proceso de modo de obtener un producto determinado. Los metales del grupo del Pt presentan alta actividad catalítica, adecuada conductividad eléctrica y resistencia a la corrosión en varios medios electrolíticos. Estas propiedades hacen que estos materiales resulten muy atractivos para una gran variedad de aplicaciones dentro de las que se incluyen los electrocatalizadores para dispositivos tales como las celdas electroquímicas.

En la Figura 1 se puede ver que los metales del grupo del $P t(P t, P d, R u, I r, O s, R h)$ se encuentran a la cabeza de los materiales utilizados como electrocatalizadores, ya que son capaces de quimisorber distintas sustancias reversiblemente y poseen una función electrocatalítica destacada [29].

A través de los años se han realizado numerosas investigaciones sobre los metales del grupo del $P t$, debido a su buen comportamiento electroquímico en procesos como el desprendimiento de hidrógeno, la oxidación de metanol y la reducción de oxígeno, entre otros [30]. Se ha podido determinar que uno de los mejores electrocatalizadores para la reacción de desprendimiento de hidrógeno $(R D H)$ y la reacción de oxidación de hidrógeno $(R O H)$ es el Pt [31]. Se ha establecido también que, en el caso de nanoestructuras, la actividad del Pt depende fuertemente de la morfología y del material soporte utilizado [32].

A partir de la década del $70^{\prime}$ se ha estudiado intensivamente el efecto de los electrocatalizadores de $P t$ en la $R R O$ y en la $R D H$ en medios ácidos. Los electrocatalizadores estudiados han sido preparados por diferentes técnicas tales como "sputtering" [33], mezclas coloidales [34-36], impregnación [37], dispersión coloidal [38-41] y liofilizado [42-45], entre otras. 


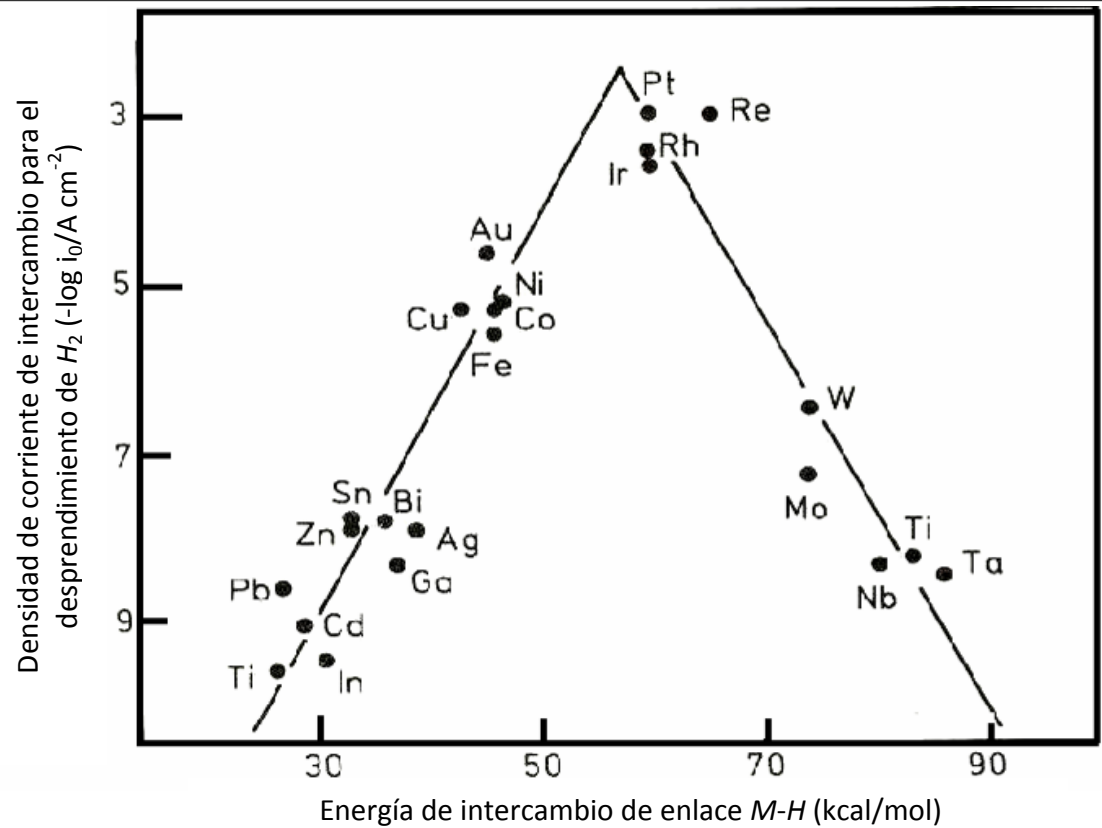

Figura 1. Gráfica de la densidad de corriente de intercambio para la reacción de desprendimiento de hidrógeno vs. energía de enlace $\boldsymbol{M}-\boldsymbol{H}$ de diferentes materiales [29].

Los electrocatalizadores de Pt así producidos han sido probados principalmente en las reacciones de desprendimiento de hidrógeno y de reducción de oxígeno en $\mathrm{H}_{2} \mathrm{SO}_{4}$. Para la evaluación de los electrocatalizadores las técnicas electroquímicas más comúnmente empleadas son la voltamperometría cíclica y la de curvas de polarización lineal de Tafel [33-37], [46-49].

La Tabla I muestra los estudios más relevantes a partir de los años 70’ sobre la preparación de electrocatalizadores de Pt y su desempeño electroquímico. Se puede destacar que la tendencia general ha sido la preparación de partículas finas de Pt con tamaños que varían entre 1 y $100 \mathrm{~nm}$. La ventaja de usar partículas del orden del nanómetro es el aumento de la relación superficie/volumen con una mayor área superficial disponible para la reacción electroquímica.

Tabla I. Preparación de electrocatalizadores de Pt y su desempeño electroquímico.

\begin{tabular}{|c|c|c|c|c|c|}
\hline $\begin{array}{l}\text { Método de } \\
\text { preparación }\end{array}$ & $\begin{array}{c}\text { Tamaño } \\
\text { partícula } \\
\text { de } P t \\
(\mathrm{~nm})\end{array}$ & $\begin{array}{c}\text { Reacción de } \\
\text { prueba }\end{array}$ & $\begin{array}{c}\text { Técnica } \\
\text { electroquímica }\end{array}$ & Objeto de estudio & Ref. \\
\hline $\begin{array}{c}\text { a) Comerciales } \\
\text { b) Sinterización } \\
\text { en } \mathrm{H}_{3} \mathrm{PO}_{4} 96 \% \mathrm{a} \\
800 \mathrm{mV}\end{array}$ & $\begin{array}{l}\text { a) } 3 \text { a } 40 \\
\text { b) } 2 \text { a } 12\end{array}$ & $R R O$ & $\begin{array}{c}\text { Voltamperometría } \\
\text { cíclica } \\
\text { Tafel }\end{array}$ & $\begin{array}{l}\text { Comportamiento electroquímico } \\
\text { de la superficie activa de Pt con } \\
\text { diferentes soportes. Efecto de la } \\
\text { distribución del tamaño de } \\
\text { partícula }\end{array}$ & $\begin{array}{c}\text { [46] J. Bett } \\
1973\end{array}$ \\
\hline $\begin{array}{l}\text { Electrodos } \\
\text { fabricados con } \\
\text { láminas de } P t\end{array}$ & 5 a 10 & $R D H$ & $\begin{array}{c}\text { Voltamperometría } \\
\text { cíclica }\end{array}$ & $\begin{array}{l}\text { Comportamiento electroquímico } \\
\text { del Pt disuelto y área superficial } \\
\text { de } P t \text {, así como los cambios que } \\
\text { estos presentan al aplicar } \\
\text { diferentes ciclos de potencial }\end{array}$ & $\begin{array}{c}\text { [50] K. } \\
\text { Kinoshita1 } \\
973\end{array}$ \\
\hline $\begin{array}{l}\text { Electrodos de } \\
\text { difusión de gas }\end{array}$ & 2 a 12 & $R R O$ & Curvas de Tafel & $\begin{array}{l}\text { Comportamiento catalítico de } \\
\text { negro de platino e influencia de } \\
\text { soporte de carbón }\end{array}$ & $\begin{array}{l}\text { [47] L. } \\
\text { Bregoli } \\
1978\end{array}$ \\
\hline
\end{tabular}


CAPÍTULO II. Electrocatálisis de las reacciones electródicas de celdas de combustible

\begin{tabular}{|c|c|c|c|c|c|}
\hline $\begin{array}{c}\text { Técnica de } \\
\text { Clavilier para } \\
\text { obtener } \\
\text { microesferas de } \\
\text { Pt } \\
\text { monocristalinos }\end{array}$ & $3 \times 10^{6}$ & $R D H$ & $\begin{array}{l}\text { Voltamperometría } \\
\text { cíclica }\end{array}$ & $\begin{array}{l}\text { Comportamiento electroquímico } \\
\text { de los diferentes planos } \\
\text { cristalográficos expuestos a la } \\
\text { solución de prueba, planos } \\
\text { Pt(100) y Pt(111) }\end{array}$ & $\begin{array}{l}\text { [51] J. } \\
\text { Clavilier, } \\
1982\end{array}$ \\
\hline $\begin{array}{l}\text { Impregnación } \\
\text { por método de } \\
\text { humedad } \\
\text { incipiente con } \\
\text { soluciones de } \\
\mathrm{H}_{2} \mathrm{PtCl}_{6}\end{array}$ & 1 a 12 & $R R O$ & Quimisorción & $\begin{array}{l}\text { Influencia del porcentaje de } P t \\
\text { depositado sobre la adsorción de } \\
\text { gas y la velocidad de reducción } \\
\text { electrocatalítica de dioxígeno }\end{array}$ & $\begin{array}{l}\text { [37] M. } \\
\text { Peuckert } \\
1986\end{array}$ \\
\hline $\begin{array}{l}\text { Evaporación al } \\
\text { vacío para } \\
\text { obtención de } \\
\text { catalizadores de } \\
\text { Pt/GC }\end{array}$ & 2 a 8 & $R D H$ & $\begin{array}{l}\text { Voltamperometría } \\
\text { cíclica }\end{array}$ & $\begin{array}{l}\text { Efecto del tamaño de partícula en } \\
\text { la oxidación electrocatalítica del } \\
\text { hidrógeno adsorbido y en la } \\
\text { reacción de desprendimiento de } \\
\text { hidrógeno }\end{array}$ & $\begin{array}{l}\text { [48] } \\
\text { Y. Takasu, } \\
1989\end{array}$ \\
\hline $\begin{array}{l}\text { Técnicas } \\
\text { coloidales }\end{array}$ & 1,4 a 4 & $R R O$ & $\begin{array}{l}\text { Adsorción de } \\
\text { hidrógeno y } \\
\text { monóxido de } \\
\text { carbono }\end{array}$ & $\begin{array}{l}\text { Efecto del tamaño de partícula y } \\
\text { su dispersión como factores de } \\
\text { dependencia para la reacción de } \\
\text { reducción de oxígeno }\end{array}$ & $\begin{array}{c}\text { [34] M. } \\
\text { Watanabe } \\
1989\end{array}$ \\
\hline Dispersión & 2 a 7 & $R D H$ & $\begin{array}{l}\text { Voltamperometría } \\
\text { cíclica }\end{array}$ & $\begin{array}{l}\text { Influencia del tamaño de partícula } \\
\text { y de efectos estructurales de los } \\
\text { electrodos en la reacción de } \\
\text { desprendimiento de hidrógeno }\end{array}$ & $\begin{array}{l}\text { [52] S. } \\
\text { Mukerjee } \\
1990\end{array}$ \\
\hline $\begin{array}{l}\text { Depósito por } \\
\text { medio de } \\
\text { "sputtering", } \\
\text { técnica de } \\
\text { Hummer }\end{array}$ & 30 a 900 & $R R O$ & $\begin{array}{l}\text { Técnica de } \\
\text { electrodo de disco } \\
\text { rotante, } \\
\text { voltamperometría } \\
\text { cíclica, Tafel } \\
\end{array}$ & $\begin{array}{l}\text { Determinación de la influencia } \\
\text { microestructural y morfológica } \\
\text { del catalizador en la actividad de } \\
\text { la reducción de oxígeno }\end{array}$ & $\begin{array}{l}{[33] \mathrm{J} .} \\
\text { Poirier } \\
1994\end{array}$ \\
\hline $\begin{array}{l}\text { Depósito químico } \\
\text { vía } \mathrm{NaBH}_{4} \\
\text { reducción de } \\
\mathrm{H}_{2} \mathrm{PtCl}_{6}\end{array}$ & $<50$ & $\begin{array}{l}\text { Reducción } \\
\text { de } \mathrm{H}_{2} \mathrm{PtCl}_{6}\end{array}$ & $\begin{array}{l}\text { Voltamperometría } \\
\text { cíclica }\end{array}$ & $\begin{array}{c}\text { Influencia de la morfología y } \\
\text { composición de los depósitos de } \\
\text { Pt, relación con la concentración } \\
\text { de la sal de } P t \text { y la agitación de la } \\
\text { solución durante la deposición } \\
\text { química }\end{array}$ & $\begin{array}{l}\text { [49] S. } \\
\text { Sheppard } \\
1998\end{array}$ \\
\hline $\begin{array}{c}\text { Deposición } \\
\text { química desde } \\
\text { fase vapor (CVD) }\end{array}$ & 200 & $R D H$ & $\begin{array}{l}\text { Técnicas } \\
\text { electroquímicas }\end{array}$ & $\begin{array}{c}\text { Comportamiento electroquímico } \\
\text { de electrodos de } P t \text { y } P d\end{array}$ & $\begin{array}{l}\text { [53] M. } \\
\text { Kajiwara } \\
1999\end{array}$ \\
\hline $\begin{array}{c}\text { Suspensión } \\
\text { coloidal de } P t \text { en } \\
\text { electrodos de } \\
\text { polianilina } \\
\end{array}$ & 10 a 100 & $R D H$ & $\begin{array}{l}\text { Impedancia } \\
\text { faradaica }\end{array}$ & $\begin{array}{l}\text { Parámetros cinéticos de la } \\
\text { reacción de desprendimiento de } \\
\text { hidrógeno }\end{array}$ & $\begin{array}{l}\text { [35] M. } \\
\text { Grzeszczuk } \\
2000\end{array}$ \\
\hline $\begin{array}{l}\text { Coloidal con una } \\
\text { modificación del } \\
\text { método } \\
\text { Prototech }\end{array}$ & 4 & $\begin{array}{l}\text { Electrooxida } \\
\text { ción de } \\
\text { metanol en } \\
\text { electrolito } \\
\text { sólido } \\
\end{array}$ & $\begin{array}{l}\text { Polarización } \\
\text { galvanostática }\end{array}$ & $\begin{array}{l}\text { Comportamiento de las celdas de } \\
\text { combustible de metanol con } \\
\text { ánodos no soportados y } \\
\text { soportados en carbón }\end{array}$ & $\begin{array}{c}\text { [36] A. } \\
\text { Aricó } 2000\end{array}$ \\
\hline $\begin{array}{l}\text { Depósito } \\
\text { electroquímico }\end{array}$ & 200 & $R D H$ & $\begin{array}{l}\text { Voltamperometría } \\
\text { cíclica y lineal }\end{array}$ & $\begin{array}{l}\text { Actividad catalítica de los } \\
\text { electrodos e influencia de las } \\
\text { condiciones de depósito }\end{array}$ & $\begin{array}{l}{[54] \mathrm{G} .} \\
\text { Kokkinidis2 } \\
000\end{array}$ \\
\hline $\begin{array}{c}\text { Depósito } \\
\text { electroquímico a } \\
\text { potencial de } \\
\text { circuito abierto }\end{array}$ & $30-40$ & $R R O$ & $\begin{array}{l}\text { Electrodo de disco } \\
\text { rotante }\end{array}$ & $\begin{array}{l}\text { Actividad catalítica para la } \\
\text { reacción de reducción de oxígeno }\end{array}$ & $\begin{array}{l}{[55] \mathrm{G} .} \\
\text { Kokkinidis } \\
2001\end{array}$ \\
\hline
\end{tabular}




\begin{tabular}{|c|c|c|c|c|c|}
\hline $\begin{array}{c}\text { Depósito } \\
\text { electroquímico }\end{array}$ & & $R D H$ & $\begin{array}{l}\text { Simulación de la } \\
\text { técnica de } \\
\text { voltamperometría } \\
\text { cíclica }\end{array}$ & $\begin{array}{l}\text { Determinación del área } \\
\text { electroquímica de los electrodos } \\
\text { por medio de simulación de las } \\
\text { mediciones de voltamperometría } \\
\text { cíclica }\end{array}$ & $\begin{array}{l}\text { [56] M. } \\
\text { Sogaard } \\
2001\end{array}$ \\
\hline & & $R R H$ & $\begin{array}{c}\text { Voltamperometría } \\
\text { cíclica }\end{array}$ & $\begin{array}{l}\text { Estimación de los átomos de } P t \text { en } \\
\text { una red cristalina y propuesta de } \\
\text { un mecanismo de } R R H\end{array}$ & $\begin{array}{l}\text { [57] L. } \\
\text { Blum } 2002\end{array}$ \\
\hline $\begin{array}{l}\text { Métodos } \\
\text { colodales }\end{array}$ & $4,5-5,5$ & $R R O$ y $R D H$ & Voltamperometría & $\begin{array}{c}\text { Evaluación del Pt como } \\
\text { catalizador y su comparación con } \\
\text { otros materiales }(R u, O s \text { y } R u+l r)\end{array}$ & $\begin{array}{l}\text { [58] } \\
\text { U. } \\
\text { Koponen, } \\
2003 \\
\end{array}$ \\
\hline $\begin{array}{l}\text { Técnica de } \\
\text { Clavilier }\end{array}$ & 3 & & $\begin{array}{c}\text { Voltamperometría } \\
\text { cíclica }\end{array}$ & $\begin{array}{l}\text { Caracterización superficial de } \\
\text { electrodos de } P t \text { y obtención de } \\
\text { información cuali y cuantitativa } \\
\text { de sitios superficiales activos }\end{array}$ & $\begin{array}{l}{[18] \mathrm{J} .} \\
\text { Solla- } \\
\text { Gullón } \\
2008\end{array}$ \\
\hline
\end{tabular}

En celdas de combustible el catalizador más comúnmente utilizado es $P t$, bajo la forma de nanopartículas, dispersado sobre carbón, aunque también suelen emplearse catalizadores metálicos bifuncionales con base Pt. Así, por ejemplo, cuando el combustible utilizado para alimentar a la celda no es hidrógeno puro, sino una mezcla de gases rica en hidrógeno proveniente del reformado, se utilizan aleaciones de PtRu que tienen la propiedad de hacer al electrodo más resistente al envenenamiento por monóxido de carbono.

A continuación se describen las técnicas más utilizadas para la preparación de catalizadores metálicos dispersados.

\section{II.3. Catalizadores metálicos dispersados}

Las técnicas convencionales para preparar catalizadores dispersados sobre sustratos inertes, conductores o no, son las que se mencionan a continuación:
i. Impregnación
ii. Intercambio iónico y adsorción
iii. Dispersión coloidal
iv. Método de Adams
v. Método Raney
vi. Liofilizado

\section{II.3.i. Impregnación}

Ha sido el método más utilizado para preparar catalizadores de metales nobles altamente dispersados soportados sobre sustratos inertes. Se ha empleado esta técnica en la preparación de catalizadores para la industria petroquímica y también para la obtención de electrocatalizadores de $P t$ soportados sobre carbón, para ser utilizados en sistemas de conversión electroquímica de energía. La 
técnica consiste en impregnar el material soporte con una solución de una sal del metal catalizador, luego calentarlo hasta sequedad para remover los solventes y posteriormente realizar una reducción con hidrógeno para descomponer la sal y obtener el catalizador metálico. En este método es de suma importancia la interacción entre la especie iónica del metal que se encuentra en solución con la superficie del soporte, ya que esto determinará la distribución y el tamaño final de las cristalitas del metal.

\section{II.3.ii. Intercambio iónico y adsorción}

En el caso de sustratos que adsorben iones metálicos puede haber interacciones específicas entre el ión y la superficie metálica. Así, por ejemplo, el ácido cloroplatínico se adsorbe sobre sílico-alúmina ácida y también sobre carbones altamente oxidados, pero no lo hace sobre la superficie de sílica gel. La técnica más conveniente para adsorber iones metálicos sobre soportes de catalizadores es mediante el intercambio iónico de un amino complejo del metal catalizador, $\left[\mathrm{M}\left(\mathrm{NH}_{3}\right)_{n}\right]^{+\mathrm{z}}$, por un protón del material soporte $(R H)$. Este intercambio se puede representar mediante la siguiente ecuación:

$$
z R H+\left[M\left(N_{3}\right)_{n}\right]^{+z} \Leftrightarrow R z M\left(N H_{3}\right)_{n}+z H^{+}
$$

El intercambio puede ser controlado cuantitativamente regulando el pH de la solución. Esta técnica ha sido utilizada para obtener metales nobles altamente dispersados sobre sílice, alúmina y sobre superficies de carbón [59-65].

Kinoshita et al. [66] utilizaron el catión complejo $\mathrm{Pt}\left(\mathrm{NH}_{3}\right)_{4}{ }^{2+}$ para adsorber $\mathrm{Pt}$ sobre carbón previamente oxidado para aumentar el número de sitios de adsorción. Los resultados obtenidos muestran que los electrocatalizadores preparados mediante esta técnica presentan una relación lineal entre el área superficial y la cantidad total del $P t$ similar a la correspondiente para catalizadores de $P t$ sobre sílica gel, obtenidos por este mismo método.

Esta dependencia lineal indica que el tamaño promedio de las cristalitas de $P t$ permanece constante independientemente de la cantidad de Pt presente en el catalizador. Contrariamente, para los catalizadores obtenidos por impregnación, el tamaño medio de las cristalitas de Pt aumenta con el contenido de Pt del electrocatalizador.

\section{II.3.iii. Dispersión coloidal}

Los catalizadores soportados pueden prepararse también por la adsorción directa de partículas metálicas coloidales sobre el soporte, en lugar de realizar la adsorción previa de especies iónicas y luego reducirlas. Una técnica usual para preparar dispersiones coloidales de metales electrocatalíticos consiste en disolver la sal que contiene el catalizador en un solvente adecuado y luego reducirla químicamente a la forma metálica. Existen numerosos procedimientos que permiten obtener dispersiones de metales nobles de diferentes áreas específicas [38-41]. 
Así, por ejemplo, mediante la reducción de soluciones de ácido cloroplatínico con diversos agentes reductores, tales como citrato de sodio, formaldehído, acroleína, peróxido de hidrógeno, fósforo en éter, tanino, hidracina, etc., es posible obtener dispersiones coloidales de $P t$ de diversas características. Cuando el reductor es citrato sódico se obtienen partículas de pequeño tamaño (20-60 Å), en cambio cuando el reductor es tanino se obtienen partículas de tamaño uniforme de mayores dimensiones (500 $\AA ̊$ ). Otros agentes reductores para reducir el ácido cloroplatínico son $\mathrm{KBH}_{4}$ y $\mathrm{Na}_{2} \mathrm{~S}_{2} \mathrm{O}_{4}$. En todos los casos la preparación de dispersiones coloidales implica extremar las precauciones tanto de pureza de los reactivos y solventes como de la limpieza del material de vidrio a utilizar.

Se han desarrollado técnicas que permiten también llevar a cabo la reducción de la sal del metal en presencia del sustrato obteniéndose en un solo paso la estructura catalítica fina [67]. Los métodos coloidales, en particular, han sido utilizados para preparar catalizadores bimetálicos con una distribución de tamaño de partícula reducida [68].

\section{II.3.iv. Método de Adams}

Este método ha sido ampliamente utilizado para obtener negros de metales nobles no soportados [69-75]. La técnica consiste en preparar un óxido del metal noble por fusión de una sal del mismo con un nitrato de un metal alcalino. Así, por ejemplo, al mezclar ácido cloroplatínico con nitrato de sodio y luego fundirlo a $300-700{ }^{\circ} \mathrm{C}$ se forma un óxido de $\mathrm{Pt}$, el $\mathrm{PtO}_{2}$, de acuerdo a las siguientes reacciones [76]:

$$
\begin{aligned}
& \mathrm{H}_{2} \mathrm{PtCl}_{6}+6 \mathrm{NaNO}_{3} \rightarrow 6 \mathrm{NaCl}+\mathrm{Pt}\left(\mathrm{NO}_{3}\right)_{4}+2 \mathrm{HNO}_{3} \\
& \mathrm{Pt}\left(\mathrm{NO}_{3}\right)_{4} \rightarrow \mathrm{PtO}_{2}+4 \mathrm{NO}_{2}+\mathrm{O}_{2}
\end{aligned}
$$

Luego de eliminar las sales sódicas mediante lavados con agua se reducen los óxidos y se obtiene el metal noble con una alta área específica, la cual es mayor que la que se obtiene cuando se realiza la reducción de una sal del metal en solución.

\section{II.3.v. Método Raney}

Es una técnica mediante la cual se pueden preparar catalizadores no soportados [77], [78]. Originalmente se desarrolló para obtener catalizadores de $\mathrm{Ni}$ [79]. También se han obtenido catalizadores de metales nobles y sus aleaciones [80]. El método consiste en formar una aleación del metal catalítico con aluminio u otro metal básico y posteriormente tratar con álcali para disolver el metal básico, dejando una superficie porosa de alta área específica constituida por el metal catalítico.

\section{II.3.vi. Liofilizado}

Esta técnica ha sido muy utilizada para preparar una variedad de materiales de alta área específica en los campos de la cerámica [81-84], metalurgia [85] y catálisis [42], [43], [45].

La técnica involucra las siguientes etapas: 
i. Disolución de una sal que contenga un elemento catalítico en un solvente adecuado, usualmente agua.

ii. Inyección de la solución por aspersión en un medio frío, por ejemplo, nitrógeno líquido o hexano a baja temperatura, produciéndose un congelado instantáneo de las microgotas de la solución.

iii. Regulación de las condiciones de presión y temperatura, para que el solvente sublime y, de este modo, resulte una estructura homogénea y porosa de la sal.

iv. Reducción o tratamiento térmico para obtener la forma activa del elemento catalítico.

Con esta técnica se han preparado catalizadores soportados y no soportados. En el caso de catalizadores soportados, para soportes de carbón inicialmente impregnados con sales de platino y luego liofilizados se obtuvieron partículas de menor tamaño y con una distribución más uniforme que con la técnica de impregnación convencional.

De todas las técnicas aquí descriptas, la más empleada ha sido la de impregnación, poniéndose énfasis en su desarrollo y perfeccionamiento para lograr una dispersión óptima del catalizador sobre el sustrato conductor.

\section{II.4. Electrocatalizadores dispersados para celdas de combustible}

Los electrocatalizadores para celdas de combustible deben cumplir una serie de requisitos. En primer lugar, deben poseer una alta actividad catalítica específica tanto para la oxidación electroquímica del hidrógeno en el ánodo como para la reducción del oxígeno en el cátodo. La actividad del material catódico debe ser alta para favorecer y mejorar la cinética de la $R R O$, disminuyendo la barrera de sobrepotencial del paso lento de 4 electrones.

Otro requisito clave de los electrocatalizadores para celdas de combustible es la estabilidad temporal que deben presentar, ya que se requiere que las celdas de combustible operen durante mucho tiempo sin pérdida de performance. Además los electrocatalizadores deben poseer una buena conductividad eléctrica para minimizar las pérdidas óhmicas en la capa catalítica y se deben poder fabricar a bajo costo en grandes volúmenes con buena reproducibilidad.

El electrocatalizador más empleado en los electrodos de celdas de combustible es el Pt, puro o como aleación, ya que es el material catalítico más efectivo tanto en términos de actividad como de estabilidad. Para su utilización en celdas de combustible, este metal debe estar adecuadamente soportado en el electrodo poroso de difusión de gas (ver sección II.5), de manera que sea fácilmente accesible para los gases de alimentación. En general, para alcanzar el máximo número de sitios activos de una dada fase activa, se requiere la dispersión de esta fase activa sobre un soporte inerte. Para el caso de celdas de combustible el $P$ t se dispersa bajo la forma de nanopartículas sobre soportes de carbón poroso. La utilización de nanopartículas dispersadas sobre sustratos porosos tiene la ventaja de aumentar considerablemente el área electroactiva, además de dificultar su sinterizado y mejorar la 
estabilidad a largo plazo del electrocatalizador [86].

Puesto que el $P t$ es un electrocatalizador muy costoso se han realizado numerosas investigaciones orientadas a disminuir la cantidad empleada de material y se ha trabajado también en la búsqueda de nuevos materiales electrocatalíticos alternativos. En la actualidad, se utilizan partículas de Pt y de sus aleaciones del orden del nanómetro ( 2 a $6 \mathrm{~nm}$ ) dispersas de manera optimizada sobre el soporte carbonoso [87]. La aleación más común es PtRu, cuya principal característica es prevenir el envenenamiento por $\mathrm{CO}$ en celdas de combustible de alcoholes. Otro ejemplo de aleación, para ser utilizada como catalizador en la reacción de reducción de oxígeno en el cátodo de celdas de combustible, fue desarrollada por Stamenkovic et al. [88], quienes estudiaron una variación de la aleación PtNi, que consta de una superficie externa donde átomos de Pt y Ni se encuentran en igual proporción y de capas sucesivas donde están presentes 3 átomos de $\mathrm{Pt}$ por cada átomo de $\mathrm{Ni}$. La configuración propuesta, $\mathrm{Pt}_{3} \mathrm{Ni}$ (111), actúa atenuando las interacciones de los oxhidrilos con la superficie del cátodo, disminuyendo así su degradación y permitiendo una mayor actividad para la reducción de oxígeno. En cuanto a materiales alternativos al Pt como electrocatalizador, por el momento no se conoce ninguno que cumpla plenamente todos los requisitos que exige un buen catalizador, aunque se pueden mencionar algunos estudios que mostrado resultados promisorios. Así, por ejemplo, Gang Liu et al., han presentado un material no precioso basado en zirconio como catalizador para el cátodo de celdas de combustible [89]. Por otra parte, Hexiang Zhong et al., han propuesto al nitruro de tungsteno como catalizador para la reducción de oxígeno [90]. En celdas de combustible de ácido fosfórico, Strmcnik et al. [91], han centrado su atención en manipular los átomos presentes en la superficie del Pt modificando el tamaño y estructura geométrica de los grupos de átomos de $P t$ expuestos al electrolito y manteniendo las propiedades químicas de los átomos superficiales. Así han retenido moléculas de cianuro sobre la superficie del electrodo de $P t$, con el objeto de que queden 2 o 3 átomos de $P t$ en línea, necesarios para que se rompa el enlace $O-O$ de la molécula de oxígeno [91].

Si bien numerosas investigaciones se han focalizado en estudiar la mejor manera de garantizar la durabilidad del catalizador en operación, hasta la fecha no se ha podido demostrar con total certeza que catalizadores alternativos al $P t$ sean lo suficientemente estables y eficientes para favorecer las reacciones electródicas involucradas en celdas de combustible, razón por la cual el estudio de distintas estructuras superficiales de $P t$ de alta actividad catalítica resulta de gran importancia e interés tecnológico para su aplicación en celdas de combustible.

\section{II.5. Electrodos porosos de difusión de gas catalizados}

En electrocatálisis es importante aumentar el área de contacto entre los electrodos y el electrolito, a fin de conseguir el mayor pasaje de corriente posible y obtener, de esta manera, la mayor 
velocidad de reacción. Este objetivo puede conseguirse mediante el uso de electrodos porosos. Por otra parte, se debe tener en cuenta que la actividad electrocatalítica aparente de electrodos lisos puede resultar muy baja, en comparación con aquellos electrodos preparados en forma de polvo altamente dispersado. Tal es el caso de los catalizadores tipo Raney frente a los correspondientes metales compactos. Así, por ejemplo, una hoja de $\mathrm{Ni}$ compacto de $1 \mathrm{~cm}^{2}$ requiere aumentar su área $10^{5}$ veces para igualar la actividad electrocatalítica de un electrodo de Ni de Raney de igual área geométrica [92].

Los electrodos que se utilizan en celdas de combustible de hidrógeno/oxígeno son del tipo poroso de difusión de gas, ya que permiten establecer un buen contacto entre las fases gas, electrolito y catalizador que participan en la reacción, esto es, posibilitan la formación de una interfase ternaria. En capítulos posteriores se hará referencia con mayor detalle a este tipo de interfase.

Un electrodo poroso está conformado por un cuerpo (estructura conductora) de alta relación huecos/volumen, en cuya superficie se encuentra el catalizador donde se produce el intercambio de electrones relacionados con una reacción electroquímica. La superficie del cuerpo poroso abarca su parte externa visible y la parte interna que es accesible al electrolito. Los poros, por lo general, son espacios de dimensiones microscópicas dentro de los cuales la penetración de un líquido está principalmente determinada por fuerzas capilares y viscosas. La Figura 2 muestra el esquema de un electrodo poroso [25]. Por un extremo entra el gas y en el otro extremo se encuentra el electrolito. La zona del menisco corresponde a la zona de reacción.

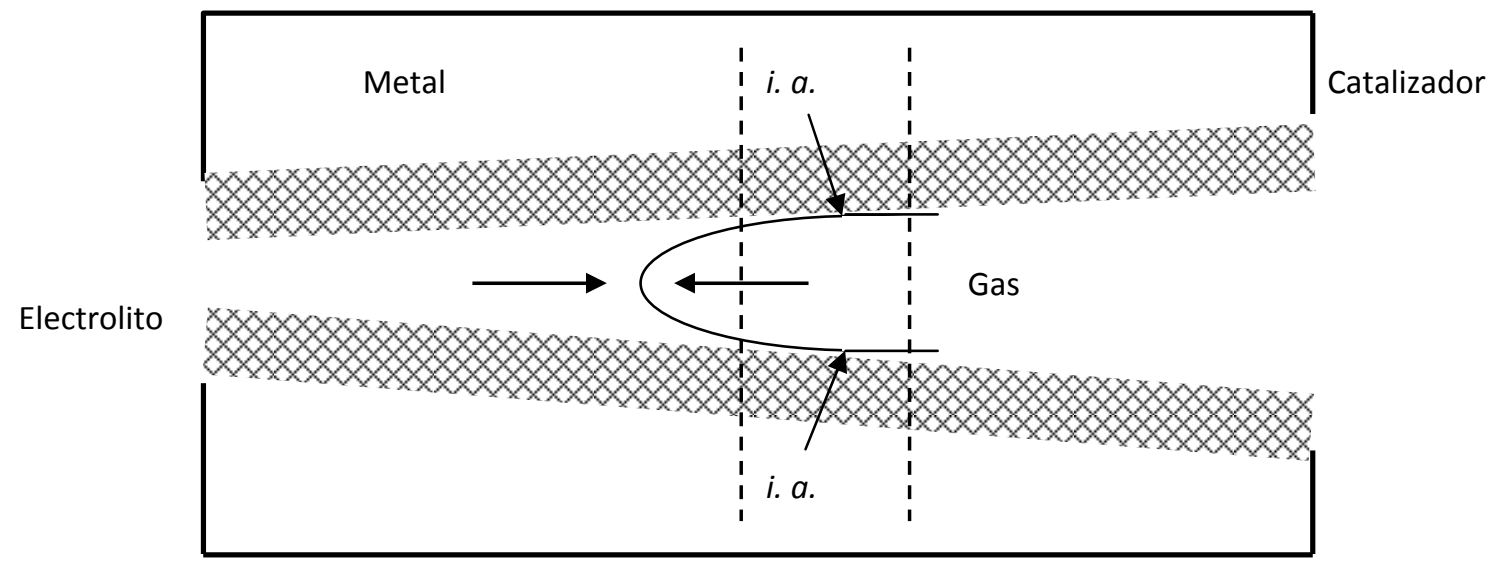

Figura 2. Esquema simplificado de un poro. Representación de la interfase activa (i. a.).

Para mantener el menisco dentro del poro se debe cumplir el siguiente equilibrio de presiones:

$P_{\text {(hidrostática) }}+P_{\text {(capilar) }}=P_{\text {(gas) }}$

En los poros en los que se establece este equilibrio tiene lugar la reacción en la que se genera la corriente eléctrica. Por lo tanto, en un electrodo poroso sólo contribuyen a la generación de energía eléctrica aquellos poros que se encuentran en equilibrio de presiones.

Cuando $P_{\text {(gas) }}$ es mayor que $\left(P_{\text {(hidrostática) }}+P_{\text {(capilar) }}\right)$ el poro se llena de gas desalojando el electrolito $y$, cuando ocurre la inversa, el poro se inunda de electrolito. Los poros muy pequeños se llenan de 
electrolito por efecto de la presión capilar, por lo que la interfase ternaria desaparece y su contribución a la reacción es despreciable. En los poros demasiado grandes el gas circula libremente sin llegar a reaccionar.

El modelo más simple de electrodos porosos trifásicos (sólido/líquido/gas) considera poros cilíndricos paralelos de radio constante [93]. Mediante tratamiento matemático es posible deducir la distribución del tamaño de poro y prever las desviaciones para poros no cilíndricos. Cuando el componente radial del campo eléctrico es despreciable frente al componente axial, el poro se denomina pequeño. Esto ocurre cuando el producto del radio del poro por la conductividad específica del electrolito es mucho menor que la resistencia de polarización, situación que suele alcanzarse en la práctica.

Un modelo de electrodo poroso más completo, macrohomogéneo y continuo, consiste en una superposición de dos fases, líquida y sólida [94]. Este modelo es, tal vez, el que más se aproxima a la realidad. Las dimensiones de las partículas que componen el electrodo y el diámetro de los poros son del orden de algunos micrómetros. Cualquier elemento de volumen del electrodo tiene la misma resistencia específica y porosidad. Por este motivo las fases sólido/líquido se pueden considerar como estructuras macrohomogéneas. El modelo continuo toma en cuenta el efecto de la tortuosidad de los poros que produce un decrecimiento de los parámetros de transporte. El tratamiento matemático no requiere suposiciones respecto de la forma de los poros y puede ser generalizado a electrodos porosos con superposición de tres fases continuas, como es el caso de los electrodos porosos de celdas de combustible de hidrógeno/oxígeno.

La teoría de los electrodos porosos para celdas de combustible que operan con gases se basa en los modelos anteriormente mencionados. Los estudios fundamentales se aplicaron en principio a ánodos de Ni sintetizados, empleados en la electrooxidación de hidrógeno molecular. Para este caso, se supone que las paredes de la porción de los poros llena de gas están recubiertas por hidrógeno adsorbido que alcanza al electrolito por difusión superficial. También se considera que la reacción anódica tiene lugar en el límite de las tres fases, es decir, en las zonas vecinas al menisco correspondiente del lado líquido. La corriente estaría limitada entonces por la difusión superficial del hidrógeno adsorbido [95]. Otra explicación del modo de operación de electrodos porosos para gases supone la existencia de una película delgada de electrolito del orden de $10^{-5} \mathrm{~cm}$ de espesor llena de gas sobre las paredes de los poros [96]. El gas se disuelve en la película, difunde rápidamente a la interfase catalizador/electrolito donde es adsorbido y reacciona electroquímicamente. El producto de reacción difunde a lo largo de la película de electrolito hacia la parte inundada del poro y eventualmente al seno del electrolito. Sin embargo, estos modelos de electrodos para gases describen parcialmente su comportamiento. Otro tratamiento admite un concepto estadístico para la estructura del poro [97]. El proceso de electrodo tiene lugar en la intersección de poros vacíos con los poros llenos. Estas intersecciones están distribuidas estadísticamente en igual forma a través del electrodo poroso, siempre 
y cuando su espesor no sea muy grande. Este concepto resulta adecuado para electrodos de carbón hidrofóbico, donde es dudosa la existencia de una película de electrolito que moje los poros.

En el electrodo poroso los poros inundados se diferencian en poros intergranulares, que sirven para la conducción iónica de corriente, y microporos con el catalizador. Un modelo más elaborado [98] explica mejor el comportamiento de un electrodo poroso de tres fases. Consiste en un sistema macrohomogéneo formado por los poros bifásicos y el gas. Las dimensiones de los microelectrodos bifásicos son muy pequeñas en comparación con el sistema total que es llamado electrodo poroso de segundo orden. El gas electroactivo se disuelve en el electrolito contenido en el microporo del catalizador y difunde en profundidad. Se supone que el camino entre la interfase gas/electrolito y la interfase electrolito/catalizador es extremadamente corto (menor que $1 \mu \mathrm{m}$ ) frente al área específica del microporo que es suficientemente grande. De esta manera se explica la alta eficiencia de los electrodos porosos para gases. El transporte en la fase líquida se puede describir de manera convencional mediante las contribuciones de migración, convección y difusión [99]. Los problemas más complicados aparecen con los electrodos porosos hidrofóbicos, principalmente de carbón. Para estos electrodos se puede suponer que los poros mayores están hidrofobizados y llenos con gas mientras que los más pequeños son hidrofílicos y están inundados. Bajo esta suposición se puede aplicar el modelo estadístico descripto anteriormente [97].

Para electrodos constituidos con mezclas de teflón y catalizador metálico se ha desarrollado un modelo representado por poros cilíndricos paralelos de material catalítico impregnados con electrolito, cuya longitud es igual a la del espesor del electrodo y su radio muy pequeño [100], [101]. El espacio remanente entre las partículas de teflón está lleno con el gas electroactivo. De esta manera aparecen dos tipos de poros y el modelo tiende al de los electrodos porosos de segundo orden.

\section{II.6. Electrocatálisis de la reacción de electrorreducción de oxígeno}

El interés en el desarrollo de dispositivos eficientes y limpios para la conversión de energía, tales como las celdas de combustible, ha dado origen a estudios intensivos sobre la temática de la electrocatálisis de las reacciones electródicas involucradas, principalmente, la electrorreducción de oxígeno que se caracteriza por su cinética lenta. Esta es una de las reacciones electroquímicas más estudiadas y, sin embargo, debido a su complejidad, su mecanismo continúa siendo controversial.

Se conoce que el $P t$ es uno de los mejores electrocatalizadores para la reducción de $O_{2}$ [28]. Se han planteado distintos caminos de reacción a fin de explicar el mecanismo de la electrorreducción de oxígeno sobre $P t$, tanto en medio ácido como alcalino [102-106]. La mayoría de los autores considera como primera etapa la adsorción química o electroquímica del reactivo gaseoso $\left(\mathrm{O}_{2}\right)$, con la posible formación de diferentes configuraciones para el adsorbato (estados lineal, bicoordinado y de mayor número de coordinación). Una revisión de los trabajos sobre la electrorreducción de oxígeno en 
electrodos de Pt policristalino se puede encontrar en varios artículos y libros [28], [107-122]. En general, se ha concluido que la cinética y el mecanismo de la $R R O$ dependen de varios factores como la naturaleza del electrocatalizador, el tamaño de partícula, el tipo de electrolito, etc. [123].

Para el caso particular de la reacción de electrorreducción de oxígeno en soluciones ácidas se puede plantear un mecanismo que comprende tres pasos, como se indica a continuación:

$$
\begin{array}{ll}
\mathrm{O}_{2}+P t \leftrightarrow\left(\mathrm{O}_{2}\right)_{\text {ads }} P t & \text { (paso I) } \\
\left(\mathrm{O}_{2}\right)_{\text {ads }} P t+H^{+}+e^{-} \rightarrow\left(\mathrm{O}_{2} H\right)_{\text {ads }} P t & \text { (paso II) } \\
\left(\mathrm{O}_{2} \mathrm{H}\right)_{\text {ads }} P t+H^{+}+e^{-} \rightarrow \text { productos } & \text { (paso III) }
\end{array}
$$

esto es, un proceso reversible de adsorción de $O_{2}$ (paso I) seguido de una transferencia monoelectrónica lenta al adsorbato oxigenado (paso II), que constituye la etapa determinante de la velocidad a altas densidades de corriente y, finalmente, la electrodescomposición del adsorbato peroxídico en diferentes compuestos, indicados en la reacción (20) como productos (paso III). La composición de estos productos oxigenados, $\mathrm{HO}_{2}, \mathrm{H}_{2} \mathrm{O}_{2}, \mathrm{H}_{2} \mathrm{O}$, etc., depende de la estructura y morfología de la superficie de Pt. Los adsorbatos de $\mathrm{O}_{2}$ y $\mathrm{O}_{2}^{-}$se consideran como intermediarios en la superficie del electrodo. Sin embargo, otro tipo de intermediario, no enlazado a la superficie, puede actuar y reaccionar en el electrodo. Así, por ejemplo, el $\mathrm{H}_{2} \mathrm{O}_{2}$ puede completar toda la secuencia de reacción o bien puede difundir desde el electrodo y descomponerse posteriormente. Para el caso de monocristales de Pt la adsorción de oxígeno molecular sobre el monocristal constituye el primer paso en el mecanismo de la RRO [109].

Los primeros estudios sobre el mecanismo de la RRO consideran la competición entre dos procesos principales en paralelo: la electrorreducción de $\mathrm{O}_{2}$ a $\mathrm{H}_{2} \mathrm{O}$ a través de un proceso global de 4 electrones y la electrorreducción de $\mathrm{O}_{2}$ vía 2 electrones a $\mathrm{H}_{2} \mathrm{O}_{2}$ como producto, el cual se descompone posteriormente a $\mathrm{H}_{2} \mathrm{O}$. Las medidas realizadas con la técnica de electrodo de disco rotante muestran que la $R R O$ sobre superficies de $P t$ se lleva a cabo principalmente mediante el proceso de transferencia de 4 electrones, tanto en soluciones ácidas como alcalinas [124].

De todos los esquemas de reacción propuestos para la $R R O$, un esquema simplificado y modificado por Wroblowa [102] (Figura 3), es el que mejor describe el camino de reacción, por el cual el $\mathrm{O}_{2}$ se reduce sobre superficies metálicas en soluciones ácidas. Las constantes de velocidad para los diferentes pasos están indicadas en el esquema como $k_{i}$ y la especie en su estado adsorbido como (ads).

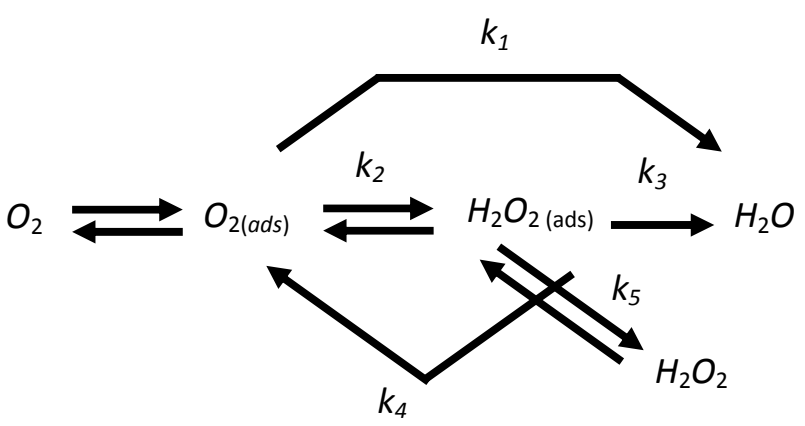

Figura 3. Mecanismo de la $R R O$ sobre superficies metálicas [124]. 
Este modelo involucra una serie de pasos elementales y varios intermediarios de reacción. De acuerdo a la Figura 3, la $R R O$ puede ocurrir por una vía directa de 4 electrones $\left(k_{1}\right)$, dando agua como producto final sin la formación de intermediarios:

$$
\mathrm{O}_{2}+4 \mathrm{H}^{+}+4 e^{-} \rightarrow 2 \mathrm{H}_{2} \mathrm{O} \quad E^{\circ}=1,229 \mathrm{~V} \text { vs. } \mathrm{ENH}
$$

o bien por un camino indirecto de 2 electrones $\left(k_{2}\right)$ dando peróxido de hidrógeno:

$$
\mathrm{O}_{2}+2 \mathrm{H}^{+}+2 e^{-} \rightarrow \mathrm{H}_{2} \mathrm{O}_{2} \quad E^{\circ}=0,67 \mathrm{~V}
$$

El peróxido de hidrógeno puede reducirse posteriormente para dar agua $\left(k_{3}\right)$

$$
\mathrm{H}_{2} \mathrm{O}_{2}+2 \mathrm{H}^{+}+2 e^{-} \rightarrow 2 \mathrm{H}_{2} \mathrm{O} \quad E^{\circ}=1,77 \mathrm{~V}
$$

o alternativamente descomponerse catalíticamente $\left(k_{4}\right)$ sobre la superficie del electrodo, lo que se conoce como desprotonación, y/o desorberse pasando a la solución $\left(k_{5}\right)$.

$$
2 \mathrm{H}_{2} \mathrm{O}_{2} \rightarrow 2 \mathrm{H}_{2} \mathrm{O}+\mathrm{O}_{2}
$$

A pesar de la aparente simplicidad, estas reacciones representan una cadena electrocatalítica compleja que involucra numerosos pasos, donde la etapa determinante depende de variables como el material del electrodo, el pH de la solución, el potencial de electrodo, etc. [109], [125].

En celdas de combustible de hidrógeno/oxígeno que operan a baja temperatura interesa siempre la conversión directa vía 4 electrones. Esta es deseable no sólo porque aumenta la eficiencia eléctrica (mayor número de electrones intercambiados por molécula de oxígeno) sino también porque se evita la formación de $\mathrm{H}_{2} \mathrm{O}_{2}$, que puede atacar químicamente los materiales del electrodo, particularmente al grafito. Este ataque no es severo, pero puede ser suficiente para provocar la pérdida de contacto eléctrico entre las partículas del catalizador y las de grafito.

Como consecuencia de las distintas características fisicoquímicas de los sitios de Pt en las estructuras cristalográficas, existe una dependencia entre la cinética de la $R R O$ y la morfología del electrodo. Así, se ha encontrado que la RRO sobre superficies de Pt electrofacetadas [126] y sobre monocristales de Pt [111], se comporta como una reacción sensible a la estructura, tanto en medio ácido como alcalino, siendo favorecida sobre superficies (111). Este aspecto se describe con más detalle en la siguiente sección.

\section{II.7. Influencia de la morfología superficial del electrodo sobre la cinética de reacciones} electrocatalíticas

El desarrollo de electrodos de alta área real con estructura cristalográfica bien definida resulta de gran interés dado que varias reacciones de oxidación de relevancia industrial ocurren en forma preferente sobre determinadas caras cristalinas [127]. La primera reacción electrocatalítica que mostró una marcada influencia de la estructura superficial electródica sobre su cinética y mecanismo, fue la 
electrooxidación de ácido fórmico, estudiada por Adzic et al. trabajando con monocristales metálicos [128], [129]. Este efecto fue confirmado posteriormente por Clavilier et al. [130] y por Motoo et al. [131]. Las medidas realizadas en estado estacionario para superficies de $P t$ de bajos índices de Miller muestran que la superficie de Pt (111) presenta la mejor actividad electrocatalítica para la reacción estudiada debido a su bajo grado de envenenamiento por los productos de reacción, mientras que la menos activa es Pt (110) [132], [133].

Otro ejemplo es la reacción de electrooxidación de metanol, de gran interés en electrocatálisis debido a su utilización como reactivo en celdas de combustible. Adzic et al. [132], [133] y Clavilier et al. [13] observaron efectos estructurales en la oxidación electrocatalítica del metanol sobre superficies de $P t$ de bajos índices de Miller. Las medidas de estado estacionario indicaron que las superficies de $P t$ (332) y Pt (331) poseen la mayor actividad electrocatalítica [134].

Como se destacó en la sección II.6, la reacción de electrorreducción de $O_{2}$ es también un proceso electrocatalítico que depende marcadamente de la orientación cristalina de la superficie del electrodo. El ejemplo más claro lo muestran las superficies de $A u$ que presentan actividades superiores para la reacción sobre la cara (111) con respecto a las otras caras estudiadas, ya que sobre ella se obtienen mayores densidades de corriente para un mismo potencial de trabajo [135]. Sin embargo, se conoce que el mejor electrocatalizador para la reacción de electrorreducción de $\mathrm{O}_{2}$ es el $P t$, y se ha encontrado que para este metal las superficies con orientación cristalográfica preferencial tipo (111) son las más activas, como se describirá a continuación.

Hasta la década de los 80 se pensaba que la reacción de electrorreducción de $O_{2}$ no dependía de la estructura de la superficie [11], [110], [136]. Esto surgía principalmente debido a la irreproducibilidad en las medidas, como consecuencia de la inadecuada preparación de las superficies de baja área superficial bajo estudio. Por otro lado, también se debe tener en cuenta, que los potenciales para los cuales la $R R O$ adquiere velocidad razonable coinciden con los de la formación de óxidos de $P t$, lo que origina una reestructuración superficial importante.

Damjanovic et al. [136] informaron diferencias en la cinética y el mecanismo de la RRO sobre electrodos de $P t$ libres y cubiertos de óxidos, en medio ácido y alcalino, bajo condiciones donde se obedecen isotermas de adsorción de Langmuir y Temkin. En soluciones ácidas no observaron efectos de los planos cristalinos en el comportamiento de los electrodos, ya que las relaciones potencial/corriente fueron las mismas tanto para electrodos de Pt policristalinos $(p c)$ como monocristalinos [(100), (110) y (111)]. En soluciones alcalinas los resultados no fueron tan reproducibles. Posteriormente, técnicas adicionales como las de electrodo de disco rotante, complementaron los estudios aportando conocimientos sobre la etapa controlante de la velocidad de la $R R O$ [108]. Ross, por su parte, concluyó que la reacción no era sensible a la orientación cristalina, a pesar de una aleatoriedad del $50 \%$ de las medidas realizadas [11]. Kadiri et al. remarcaron diferencias en la actividad superficial del $P t$ en electrolitos con capacidad de adsorción específica, trabajando en la región de bajas densidades de 
corriente (rectas de Tafel de pendiente $-60 \mathrm{mV} /$ década) [111]. El efecto del cambio en la actividad catalítica se interpretó en base a la adsorción específica diferencial de aniones fuertemente adsorbidos como $\mathrm{PO}_{4}^{-3}$ y $\mathrm{Cl}$. Por su parte, Zinola et al. estudiaron la cinética de la electrorreducción de $\mathrm{O}_{2}$ en una amplia zona de potenciales mediante isotermas de adsorción y cálculos de órdenes de reacción para los reactivos involucrados en diferentes electrolitos, encontrando un efecto de la morfología del electrodo de Pt. Posteriormente, se dieron a conocer estudios sobre los cambios en las rectas de Tafel para la zona de adsorción de $H$ atómico [137]. En estos trabajos se ha demostrado que los electrodos de $P t$ tipo (100) en solución $\mathrm{H}_{2} \mathrm{SO}_{4} 1 \mathrm{M}$ saturada de $\mathrm{O}_{2}$ exhiben, en la zona de altas densidades de corriente, una pendiente de Tafel de -0,165 V/década y que esta pendiente es independiente del electrolito soporte en el medio. Sin embargo, las superficies de $P t$ tipo (111) y policristalino mostraron una pendiente de $-0,120 \mathrm{~V} /$ década en la misma zona de densidades de corriente.

En trabajos reportados por Zubimendi et al. se ha considerado el efecto de la morfología superficial de cristalitas de $P t$ dispersadas sobre la cinética de la reacción de electrorreducción de $\mathrm{O}_{2}$ [19]. Las curvas de Tafel para esta reacción en $\mathrm{H}_{2} \mathrm{SO}_{4}$ 0,5 $\mathrm{M}$ a $25{ }^{\circ} \mathrm{C}$ exhiben dos regiones lineales: una a bajas densidades de corriente donde la pendiente presenta un valor de - $0,058 \mathrm{~V} /$ década tanto para $P t$ (111) como para Pt (100) y Pt policristalino y otra región, a altas densidades de corriente, donde la pendiente de Tafel depende de la morfología superficial de las cristalitas de Pt. Así, para cristalitas de Pt facetadas tipo (111), la pendiente es de -0,098 V/década, para cristalitas de $P t$ facetadas tipo (100) es de $-0,150 \mathrm{~V} /$ década y para cristalitas de $P t$ policristalino soportadas sobre carbón es de $-0,105 \mathrm{~V} /$ década [19] (Figura 4).

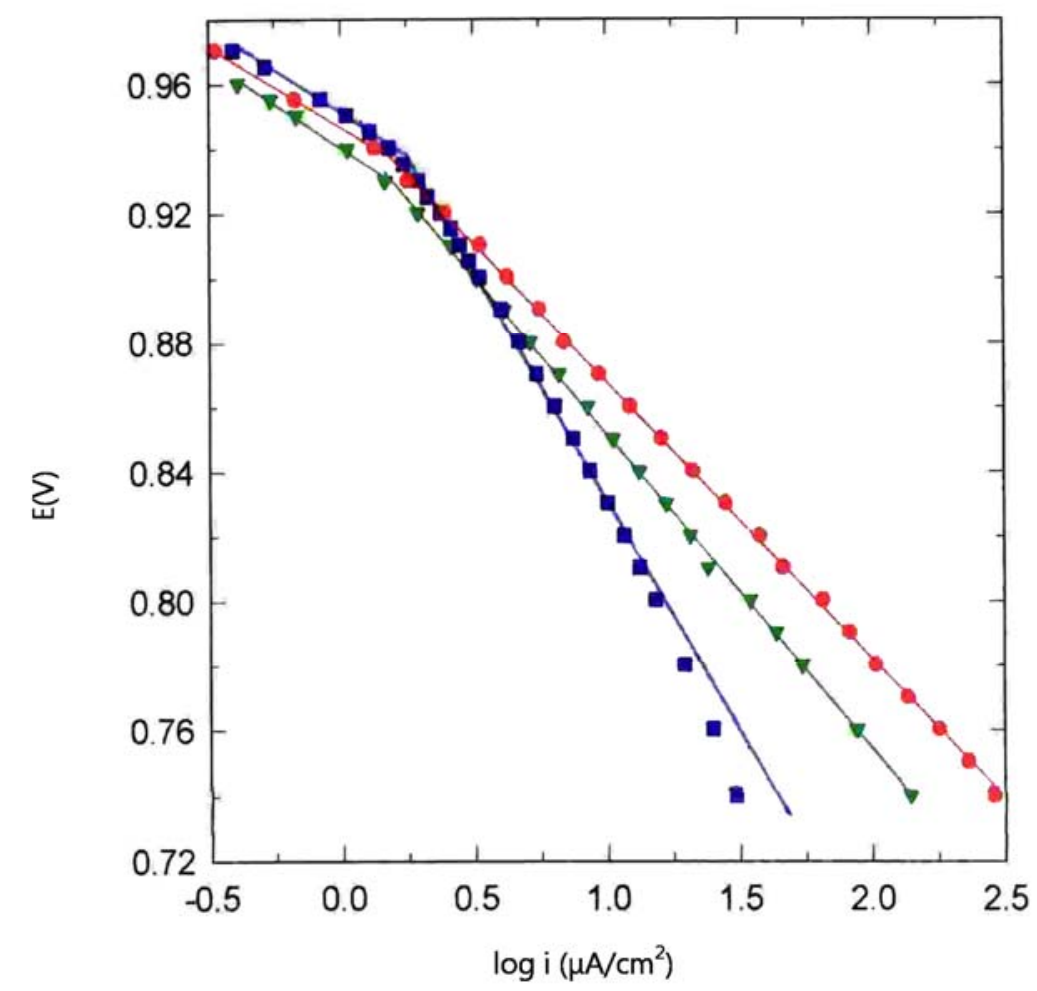

Figura 4. Curvas de polarización para la electrorreducción de $\mathrm{O}_{2}$ en solución $\mathrm{H}_{2} \mathrm{SO}_{4} 0,5 \mathrm{M}$ a $25{ }^{\circ} \mathrm{C}$ para (匚) Pt (100), (•) Pt (111) y ( $)$ ) Pt policristalino [19]. 
La región de baja pendiente de Tafel comprende el dominio de potenciales superiores a 0,92 V vs. $E H N$ hasta el potencial de reposo del sistema $\mathrm{O}_{2} / \mathrm{H}_{2} \mathrm{O}$. La otra zona se extiende por debajo de $0,92 \mathrm{~V}$ hasta que la contribución difusional aparta la gráfica de Tafel de la linealidad. La transición entre las dos regiones lineales se produce a un valor característico de potencial, conocido como potencial de transición, el cual varía con el pH y la composición del electrolito y corresponde a un cambio en la cinética del proceso, como consecuencia de una variación en la composición superficial del electrodo. Así, se ha establecido que por encima de $0,92 \vee$ la superficie se encuentra recubierta por especies precursoras de óxidos metálicos y la interacción de las especies reactivas adsorbidas con la superficie oxidada, se refleja en el bajo valor de la pendiente de Tafel que es independiente de la morfología superficial. En la zona de altas densidades de corriente, esto es, por debajo de 0,92 V, la superficie de Pt está libre de óxidos y la pendiente de Tafel depende de la orientación de las caras cristalinas.

Los resultados de Zubimendi et al. con catalizadores dispersados de alta área superficial se corresponden con los encontrados por Zinola et al. [106] quienes han trabajado con electrodos de Pt de disco rotante de baja área superficial, y han reportado una pendiente de Tafel de -0,6 V/década a bajas densidades de corriente para las dos orientaciones preferenciales $P t(100)$ y $P t(111)$ y pendientes de $-0,120 \mathrm{~V} /$ década y $-0,165 \mathrm{~V} /$ década para $P t(111)$ y $P t(100)$ respectivamente, a altas densidades de corriente.

El valor de la pendiente de Tafel es indicativo del mecanismo de reacción y de la actividad electrocatalítica del electrodo. Si la pendiente de Tafel tiene un valor alto esto indica que el electrodo tiene una alta actividad electrocatalítica para la reacción estudiada. Desde el punto de vista práctico, se dice que un determinado electrodo presenta mayor actividad electrocatalítica que otro cuando para un mismo potencial aplicado, medido en la misma escala de referencia, la reacción ofrece una densidad de corriente más alta. Para la situación ilustrada en la Figura 4, se observa que, para la reacción de electrorreducción de oxígeno $(R R O)$, en la región de altos sobrepotenciales, se obtienen mayores densidades de corriente en el caso de cristalitas de Pt (111) que para las cristalitas de Pt (100) o Pt pc. Esto estaría de acuerdo con lo informado por Markovic et al. quienes mostraron que en la región de altos sobrepotenciales y, para un potencial constante, la actividad catalítica de Pt (111) para la electrorreducción de oxígeno era mayor que la del Pt (100), tanto en electrodos de baja como alta área superficial [137].

Finalmente, se puede concluir en base a los trabajos antes mencionados, que la reacción de electrorreducción de oxígeno en medio ácido es fuertemente dependiente de la morfología superficial del Pt en un amplio intervalo de potenciales, siendo favorecida sobre superficies tipo (111) y dificultada sobre las del tipo (100). Este efecto está principalmente relacionado al grado de adsorción de especies peroxídicas producidas durante el proceso de electrorreducción, que causan el bloqueo de los sitios activos de la superficie del electrodo y, en consecuencia, producen una disminución de la velocidad de la reacción de electrorreducción de oxígeno, la cual llega a ser más significativa sobre superficies de $P t$ tipo 
(100) [19]. Por el contrario, la adsorción disociativa del $O_{2}$ resulta más favorable sobre $P t$ tipo (111), con lo cual el proceso global de electrorreducción ocurre por la vía rápida en la que se ponen en juego 4 electrones [reacción (21)]. 


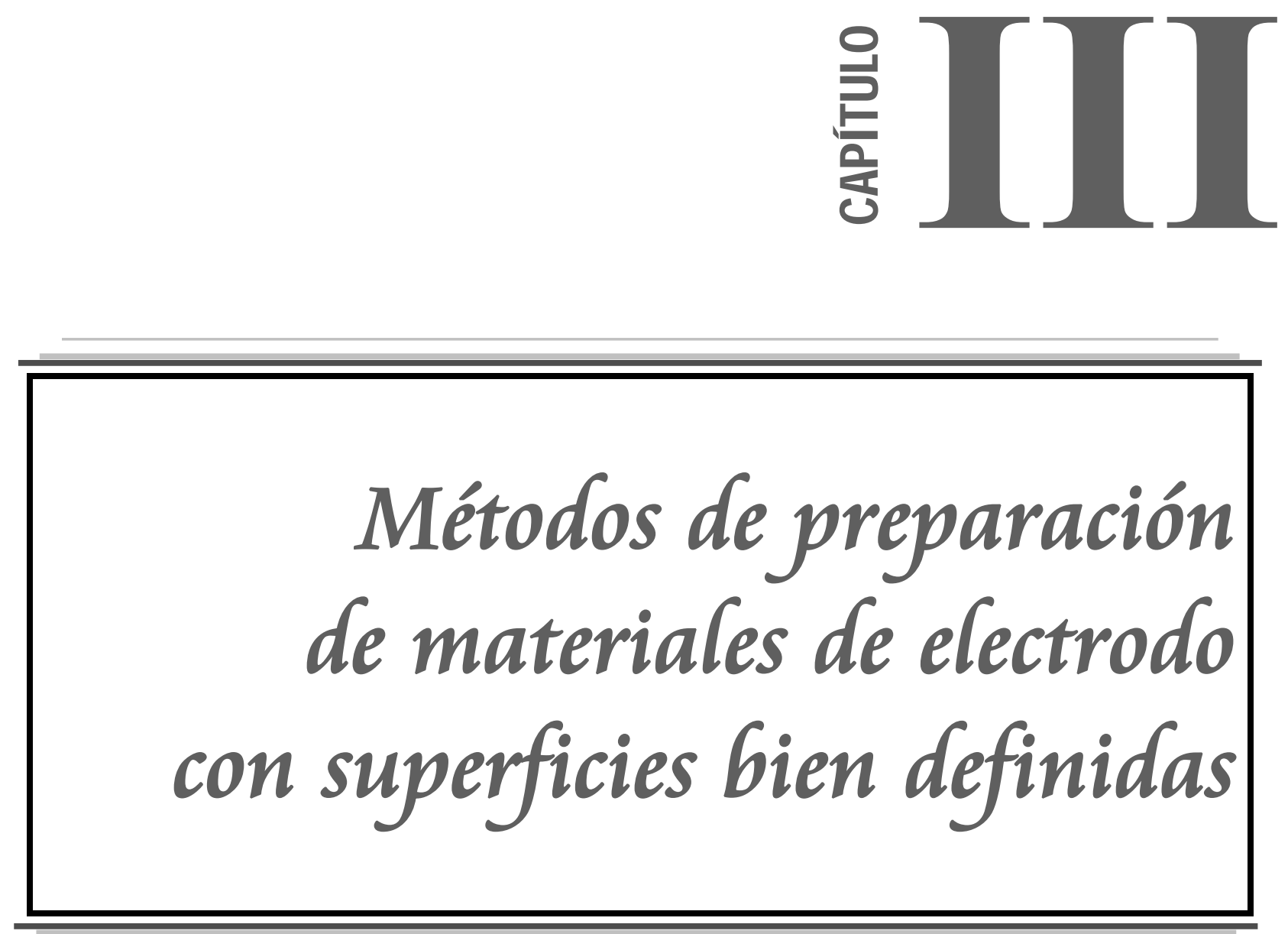


\section{CAPÍTULO III}

\section{Métodos de preparación de materiales de electrodo con superficies bien definidas}

\section{III.1. Métodos de preparación de superficies metálicas con estructuras bien definidas}

En el capítulo anterior se ha destacado la influencia de la estructura superficial del electrodo sobre la cinética de las reacciones electródicas. De ahí, que el conocimiento preciso de la estructura superficial de los electrodos sólidos sea de fundamental importancia en electrocatálisis. Para una reacción electrocatalítica dada, la adsorción de los reactivos e intermediarios, la migración superficial de los adsorbatos, las reacciones químicas superficiales y la desorción de los productos de reacción dependerán de la orientación cristalina de la superficie del electrodo. Además, la coordinación de los átomos superficiales, las distancias entre sitios de adsorción y la distribución de energía superficial dependerán de los planos cristalinos expuestos en la superficie del metal. Por consiguiente, el conocimiento y manejo de la estructura superficial y la distribución de energía en electrodos sólidos es de fundamental importancia para conducir las reacciones electrocatalíticas a velocidad y eficiencia de conversión máximas. Dentro de este marco, interesa obtener materiales de electrodo con estructuras superficiales bien definidas y caracterizadas, para lo cual se han desarrollado varios métodos. A continuación se describen los distintos procedimientos que permiten obtener determinadas estructuras superficiales en metales poli y monocristalinos.

\section{III.1.a. Métodos no electroquímicos de preparación de metales con estructuras superficiales} bien definidas y caracterizadas

Existen varios métodos no electroquímicos que producen la reestructuración superficial de metales. Así, por ejemplo, el ataque químico de las superficies metálicas con electrolitos ácidos fuertes, produce la disolución de capas superficiales y, dependiendo de las condiciones experimentales, se logra facetar la superficie metálica tratada [138]. Tal es el caso de Pt policristalino en agua regia caliente que cambia su respuesta electroquímica indicando una mayor proporción de sitios activos que favorecen la electrosorción de hidrógeno débilmente adsorbido [139]. La respuesta voltamperométrica en $\mathrm{H}_{2} \mathrm{SO}_{4} 0,5$ $\mathrm{M}$ a $25{ }^{\circ} \mathrm{C}$ de un electrodo de $\mathrm{Pt}$ expuesto previamente en agua regia a ebullición durante 1 minuto, muestra cambios en las alturas relativas de los picos de corriente asociados a la electroadsorciónelectrodesorción de átomos de hidrógeno (ver CAPÍTULO IV), con respecto a la respuesta antes de realizar el ataque químico. Bajo esta situación se observa también una disminución de 10 \% de la carga total de electrodesorción de hidrógeno. Esto se atribuye a la exposición en la superficie de una mayor proporción de planos cristalinos con menor densidad superficial de átomos, como es el caso de las superficies (110). 
Cuando se exponen alambres y láminas de Pt a calentamiento en atmósfera de distintos gases, experimentan cambios en su estructura superficial. Se observa la aparición de caras planas a $90^{\circ}$ una de otra, con predominio de planos (100) [140-142]. Cuando superficies de Pt (111) son bombardeadas a $320{ }^{\circ} \mathrm{C}$ con iones $\operatorname{Ar}(1000 \mathrm{eV})$, desarrollan escalones con bordes en la dirección (110), mientras que superficies de Pt policristalino bombardeadas con iones $\mathrm{Hg}$ incidiendo normalmente a las mismas, desarrollan facetas. Estos son algunos ejemplos de modificaciones estructurales producidas por métodos no electroquímicos, que permiten preparar superficies metálicas con estructuras bien definidas.

\section{III.1.b. Métodos electroquímicos de preparación de metales con superficies bien definidas y} caracterizadas

También se han desarrollado procedimientos electroquímicos que permiten modificar la estructura superficial de metales [15], los cuales pueden agruparse de la siguiente manera:

a) electrodeposición de metales bajo condiciones de potencial periódico [143], [144];

b) electroformación y electrorreducción cíclica de partículas de óxido, con posterior electrorreducción a bajas velocidades de barrido de potencial [145-147];

c) ciclados de potencial lentos usando electrolitos fundidos a temperatura relativamente altas [148];

d) ciclos rápidos de electroadsorción y electrodesorción de átomos de hidrógeno y especies oxigenadas [149], [150].

Los tres primeros procedimientos involucran modificaciones tanto en la textura superficial como en la rugosidad de las superficies tratadas. El procedimiento d) implica efectos de orientación cristalográfica preferencial, sin cambios apreciables en el factor de rugosidad.

Los aspectos relevantes de la reestructuración superficial promovida por estos procedimientos en metales poli y monocristalinos se describen a continuación.

\section{III.1.b.i Reestructuración superficial de metales policristalinos}

La electrodeposición de metales por aplicación de un potencial periódico [procedimiento a)] ofrece la posibilidad de obtener superficies rugosas que exhiben cierto grado de orientación cristalográfica preferencial de acuerdo a los límites de potencial y a la frecuencia de la señal perturbante. Mediante esta técnica se han obtenido electrodepósitos de $P t$ facetados sobre superficies de Pt y grafito [144].

Respecto al procedimiento b) existen antecedentes bibliográficos, trabajando bajo condiciones experimentales variadas. Así, Hoare observó aumentos en el factor de rugosado aplicando señales de corriente alterna de 60 ciclos/segundo a electrodos de Pt policristalinos, en electrolito ácido a $25{ }^{\circ} \mathrm{C}$ [151]. Gilman, aplicando una secuencia de pulsos de potencial a electrodos de $P t$ policristalino, en $\mathrm{H}_{3} \mathrm{PO}_{4}$ 
al $85 \%$ y a $120{ }^{\circ} \mathrm{C}$, obtuvo superficies cuyo factor de rugosado aumentaba cuando el potencial era mayor que 1,6 V seguido de una reducción rápida [152]. Biegler observó efectos similares en electrodos de Pt policristalino luego de la aplicación de distintos programas de potencial [153]. Estos efectos fueron atribuidos a la formación de películas de óxido y su rápida reducción [152], [153].

En trabajos posteriores, se aplicó el procedimiento b) fue aplicado por primera vez a electrodos de Pt policristalinos en $\mathrm{H}_{2} \mathrm{SO}_{4}$ 0,5 $\mathrm{M}$ a temperatura ambiente. El electrodo fue sometido a un tratamiento de onda cuadrada de potencial repetitiva $(O C P R)$ con las siguientes características: $-0,3 \mathrm{~V} \leq E i \leq 0,5 \mathrm{~V} ; 2,0$ $\mathrm{V} \leq E s \leq 2,8 \vee$ y $0,5 \mathrm{kHz} \leq f \leq 10 \mathrm{kHz}$. Bajo estas condiciones operativas se produce el crecimiento de una película gruesa de óxido de $P t$ que ocurre sin contribución apreciable de reacciones irreversibles, como procedimientos de envejecimiento o deshidratación [145]. Si luego del tratamiento la película de óxido es reducida con un barrido lineal de potencial a 0,003 V/s se obtiene una superficie altamente rugosa libre de poros. Los voltamperogramas de la superficie resultante ensayadas bajo estas condiciones muestran, en la región de potencial correspondiente a la electroadsorción/electrodesorción de átomos de hidrógeno y de oxígeno, un aumento considerable en las correspondientes cargas voltamperométricas y cambios menores en la altura relativa de los picos de corriente con respecto a los voltamperogramas de un electrodo sin tratar (Figura 1).

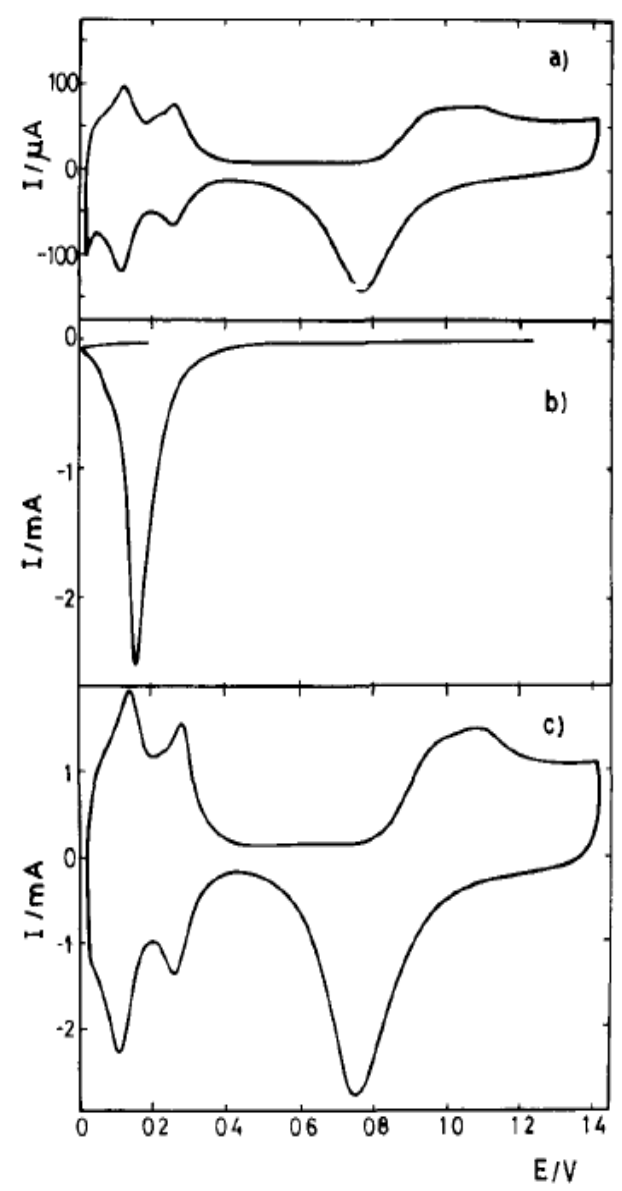

Figura 1. Perfiles E/I en $\mathrm{H}_{2} \mathrm{SO}_{4} 0,5 \mathrm{M}$ a $30^{\circ} \mathrm{C}$ : a) electrodo de $P$ t sin tratamiento de $O C P R$ después de 5 min de ciclado a $0,3 \mathrm{~V} / \mathrm{s}, \mathrm{b}$ ) perfil de electrorreducción a $0,003 \mathrm{~V} / \mathrm{s}$ inmediatamente después del tratamiento de $O C P R$ ( $E s=2,4 \mathrm{~V} ; E i=0,4 \mathrm{~V}$; período $\tau=560 \mu \mathrm{s}$; tiempo de duración $t=3 \mathrm{~min}$ ), c) electrorreducción de $P t$ después de 5 min de ciclado a $0,3 \mathrm{~V} / \mathrm{s}$. 
El primer cambio se asoció a un aumento en la rugosidad de la superficie electródica y también se observaron cambios asociados a la variación en la distribución de los planos cristalográficos, lo cual se verificó por medio de difractogramas de rayos X [145]. Se observó un predominio de los planos (111) paralelos a la superficie del metal. Resultados similares fueron obtenidos con oro [147], rodio [154] y paladio [155], para los cuales la distribución y tipos de planos cristalográficos dependían de la naturaleza del metal. Estas superficies de alta área real fueron examinadas por microscopía de barrido por efecto túnel [156]. Las imágenes a escala del nanómetro para Pt altamente rugoso mostraron tres características bien definidas:

i. regiones de escalones grandes,

ii. regiones lisas con corrugaciones paralelas de altura de unos pocos diámetros atómicos,

iii. regiones de estructura abovedada formadas por apilamiento de partículas aproximadamente esféricas del orden de los $100 \AA$, que constituyen la mayor contribución al aumento de la rugosidad superficial.

El procedimiento c) consiste en la aplicación de ciclos triangulares de potencial lento en electrolitos fundidos. Con esta técnica se trataron electrodos de $P t$ platinado en bisulfato de potasio fundido a $250{ }^{\circ} \mathrm{C}$ ciclándolos durante 10 horas a $0,04 \mathrm{~V} / \mathrm{s}$ entre 0,04 y $0,75 \mathrm{~V}$ vs. ERH [148]. Después del tratamiento, el voltamperograma de la superficie resultante, realizado en $\mathrm{H}_{2} \mathrm{SO}_{4} 1 \mathrm{M}$ a 20 ${ }^{\circ} \mathrm{C}$, mostraba cambios respecto a un electrodo no tratado. Se observó una disminución del área superficial electroquímicamente activa del electrodo y cambios en la altura relativa de los picos de corriente voltamperométricos, que fueron atribuidos a un correspondiente cambio en la distribución de caras cristalográficas. Posteriores barridos potenciodinámicos hacia potenciales donde se produce la electroadsorción/electrodesorción de especies oxigenadas mostraron el perfil voltamperométrico modificado tanto en las alturas relativas de los picos como en sus anchos medios. Esto significa que el tratamiento electroquímico modifica la rugosidad superficial, la distribución de energías de los sitios de adsorción y la proporción de planos cristalinos en la superficie electródica. Todo esto involucra procesos complejos y reordenamientos atómicos de corto y largo alcance.

En otro método, aplicando ondas de potencial repetitivas cuadradas, triangulares o sinusoidales, a electrodos metálicos policristalinos se obtienen superficies facetadas con orientación cristalográfica preferencial (ocp) y sin cambio apreciable en la rugosidad [procedimiento d)] [150], [157], [158]. Las primeras aplicaciones de estas técnicas se realizaron con alambres de $P t$ policristalino electropulidos que fueron sometidos a tratamientos de perturbación de potencial de alta frecuencia, tales como barridos triangulares de potencial repetitivos o bien ondas cuadradas de potencial repetitivas [150], [157]. El tratamiento con onda cuadrada de potencial repetitiva resultó más adecuado que el de barrido triangular para la definición precisa de los límites de potencial asociados con el fenómeno de la ocp [158], [159]. A través de ensayos sistemáticos se obtuvieron las condiciones óptimas para el desarrollo de facetados específicos. Se encontró que los parámetros óptimos de la OCPR para obtener superficies 
de $P t$ facetadas con ocp (100) eran $E i=0,25 \vee ; E s=1,25 \vee$ y $f=4 \mathrm{kHz}$ [158], [160]. En este caso, los correspondientes voltamperogramas barridos a $0,1 \mathrm{~V} / \mathrm{s}$ en $\mathrm{H}_{2} \mathrm{SO}_{4} 1 \mathrm{M}$ en la región de potencial de adátomos de hidrógeno, resultaron similares a los de superficies (100) de monocristales de Pt [13], [161]. Para la obtención de superficies de Pt facetadas con ocp (111), por aplicación de una OCPR, se encontró que el conjunto de parámetros óptimos era $E i=0,7 \mathrm{~V} ; E s=1,4 \mathrm{~V}$ y $f=2 \mathrm{kHz}$ [158], [160]. Después del tratamiento de OCPR bajo estas condiciones se obtuvieron respuestas voltamperométricas a $0,1 \mathrm{~V} / \mathrm{s}$ entre $0,05 \mathrm{~V}$ y $0,6 \mathrm{~V}$, comparables a la correspondiente al estado inicial de superficies (111) de monocristales de $P t$ preparadas en ultra alto vacío (bombardeo con $\operatorname{Ar}$ y $\mathrm{O}_{2}$ ) y caracterizadas a través de las técnicas de difracción de electrones de baja energía y espectroscopia Auger [162]. La observación de las superficies facetadas con ocp (111), mediante microscopia electrónica de barrido, mostró partículas que exhibían un facetado característico [158]. La estructura superficial obtenida puede modificarse por tratamientos electroquímicos posteriores, al igual que lo que sucede con electrodos monocristalinos $P t$ (111). Luego de realizar un único barrido de potencial entre $0,05 \vee$ y $1,5 \mathrm{~V}$ a $0,1 \mathrm{~V} / \mathrm{s}$ en $\mathrm{H}_{2} \mathrm{SO}_{4} 1 \mathrm{M}$, el voltamperograma muestra una respuesta similar a la que se describe en la bibliografía como el estado estándar de Pt (111). Ciclando en estas condiciones durante 30 minutos, se obtiene la respuesta voltamperométrica del denominado estado estable de un monocristal de Pt (111) [14], [161], [163]. De modo similar, se han establecido las condiciones óptimas para el facetado electroquímico de rodio, oro y paladio [147], [155].

El facetado electroquímico de metales nobles en electrolitos ácidos ha sido interpretado a través de un mecanismo que involucra una etapa inicial que ocurre a nivel de la monocapa de especies oxigenadas adsorbidas y otra de propagación que corresponde a la penetración en profundidad del reordenamiento de átomos metálicos [15], [158]. Teniendo en cuenta que el facetado de varios metales $(P t, A u, R h)$ sólo se produce cuando el límite superior del potencial de la OCPR alcanza un valor cercano al potencial umbral para la descarga de agua a subpotencial formando especies $\mathrm{OH}$ adsorbidas y que la frecuencia es del orden del milisegundo, valor coincidente con el tiempo de vida media de especies $\mathrm{OH}$ adsorbidas sobre metales nobles [164], [165], la etapa inicial de reordenamiento superficial se asigna a la siguiente reacción:

$$
\mathrm{H}_{2} \mathrm{O}+\mathrm{M} \leftrightarrow(\mathrm{OH}) \mathrm{M}+\mathrm{H}^{+}+e^{-}
$$

De este modo se descarta que, en principio, bajo estas condiciones ocurran reacciones subsiguientes irreversibles formando especies oxigenadas estables. Se consideró que la etapa inicial provoca un debilitamiento de las uniones metal-metal a través de la reacción de electroadsorción.

Por otra parte, habiéndose determinado que para las condiciones óptimas de facetado tiene lugar la electrodisolución neta del electrodo metálico [166] aunque la cantidad disuelta por ciclo, por ejemplo, para el caso del Pt es $10^{2}$ a $10^{3}$ veces menor que bajo perturbaciones de potencial de baja frecuencia $(v=0,04 \mathrm{~V} / \mathrm{s})$, se sugirió que procesos de electrodisolución y electrodeposición locales del metal base y sus especies solubles, respectivamente, contribuían a la propagación del fenómeno. Se señaló también 
que durante el tratamiento de la $O C P R$ se establece un gradiente de concentración fluctuante de especies del metal soluble y que las características de la capa difusional pulsante, dependientes de la frecuencia, influyen marcadamente sobre la cinética del proceso global [15]. Así, bajo las condiciones de perturbación de potencial de alta frecuencia, donde se produce facetado, no hay aumento de rugosidad ya que el espesor promedio de la capa difusional pulsante resulta menor que las irregularidades superficiales y, en consecuencia, durante la electrodeposición de especies solubles del metal, se tiene un flujo de difusión constante a todos los puntos de la superficie del electrodo.

Se encontró también que el ordenamiento cristalográfico resultante depende no sólo de los parámetros de la señal de potencial perturbante, sino también de las especies que puedan ser adsorbidas o electroadsorbidas sobre el electrodo en la región de potencial abarcada por la perturbación periódica. Este es el caso del facetado de Pt con desarrollo de la ocp (100), que requiere valores de límite inferior de potencial ubicados en la región de potencial de electroadsorción/electrodesorción de átomos de hidrógeno.

\section{III.1.b.ii. Facetado electroquímico de superficies de metales monocristalinos}

Un electrodo monocristalino esférico perfecto exhibe en su superficie, en principio, todos los planos del sistema cristalino con una cierta distribución definida. Si el electrodo es sometido a alguno de los tratamientos electroquímicos antes descriptos, se obtendrá un nuevo reordenamiento atómico en la superficie, quedando expuesto algún plano cristalográfico en particular en mayor proporción a la original.

Una reestructuración superficial de este tipo, debido a la geometría del sistema, involucrará cambios en la superficie de la esfera con una simetría definida dada por el sistema cristalino del metal. Se producirá así un facetado de la superficie, desarrollándose los planos cristalográficos favorecidos por el tratamiento y tenderán a desaparecer los restantes [167].

La respuesta voltamperométrica de la superficie de una esfera monocristalina de $P t$ en medio ácido es similar a la de un electrodo de Pt policristalino. Cuando una esfera monocristalina [Figura 2 (a)] se trata con las técnicas indicadas para obtener un determinado facetado electroquímico se producen cambios fácilmente observables mediante microscopia electrónica de barrido. Por ejemplo, cuando el electrodo tratado presenta una respuesta voltamperométrica similar a la que se obtiene con una superficie Pt (100), la observación de la superficie muestra una estructura donde cada polo [100] pasa a ser el origen de cuatro bandas simétricas perpendiculares de escalones paralelos que se desarrollan en la dirección (110) hasta alcanzar el polo [100] más cercano [Figura 2 (b)]. Siguiendo la línea imaginaria que une un polo [100] con su vecino [111] se encuentra un facetado superficial que presenta triedros con sus caras paralelas a los polos [100]. Análogamente, empleando distintos tratamientos de perturbaciones de potencial, se pueden obtener para cada tipo de facetado electroquímico, cambios específicos en la estructura superficial. En la Figura 2 (c) y (d) se muestran esquemáticamente los 
patrones que se obtienen para los tratamientos que producen facetados (111) y (110), respectivamente [159].

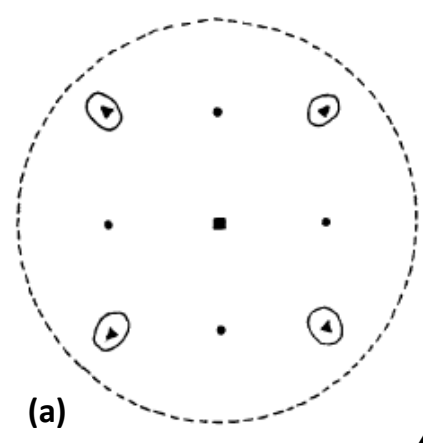

$\Delta[111]$

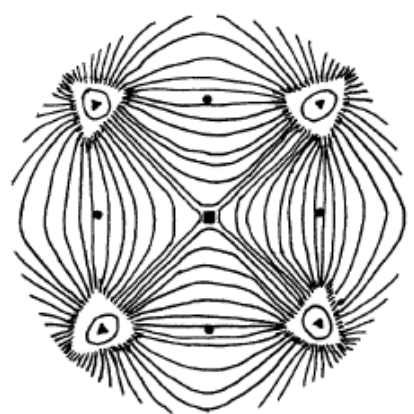

- $[110]$

(c)

- $[100]$
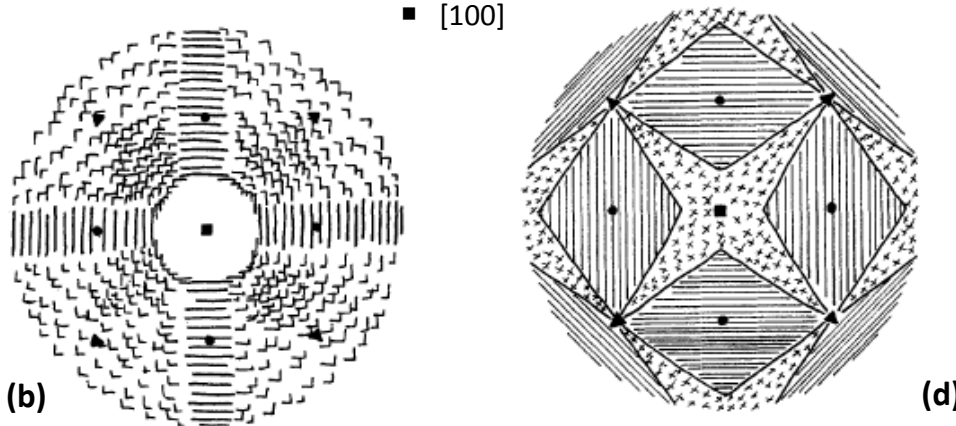

Figura 2. Esquema de los patrones superficiales observados por microscopía electrónica de barrido con electrodos esféricos monocristalinos de Pt: (a) esfera monocristalina sin tratar, (b) facetado (100), (c) facetado (111), (d) facetado (110).

\section{III.2. Técnicas de electrólisis pulsante para obtención de electrodepósitos metálicos facetados}

Las técnicas de eletrólisis pulsante para electrodepositar metales con estructuras superficiales facetadas se pueden agrupar en cuatro categorías:

i. Corriente inversa. Es una técnica galvanostática donde la señal cíclica de corriente aplicada está caracterizada por la densidad de corriente catódica, $i_{c}$, la densidad de corriente anódica, $i_{a}$, y los tiempos de aplicación para los hemiciclos catódicos y anódicos, $\tau_{c}$ y $\tau_{a}$, respectivamente. Para la situación presentada en la Figura 3 i., se cumple que

$$
\tau=\tau_{c}+\tau_{a}
$$

y la corriente promedio aplicada <i> viene dada por

$$
<i>=\frac{i_{c} \tau_{c}+i_{a} \tau_{a}}{\tau_{c}+\tau_{a}}
$$

ii. Corriente pulsante. Esta técnica consiste en aplicar al sistema pulsos cuadrados repetitivos de corriente. Similar al anterior pero carece de componente anódica (Figura 3 ii.).

iii. Corriente alterna superpuesta a una corriente continua. Se suma a la corriente continua catódica convencional, $i_{c c}$, una componente alterna sinusoidal de amplitud $2 i_{p}$ (Figura 3 iii.). Resulta así una corriente alterna asimétrica y se tiene que 
$<i>=i_{c c}$

De acuerdo a la amplitud de la componente alterna se pueden diferenciar tres casos: a) $i_{p}<i_{c c}$; b) $i_{p}=i_{c c}$ y c) $i_{p}>i_{c c}$, siendo esta última la condición más usada en la práctica.
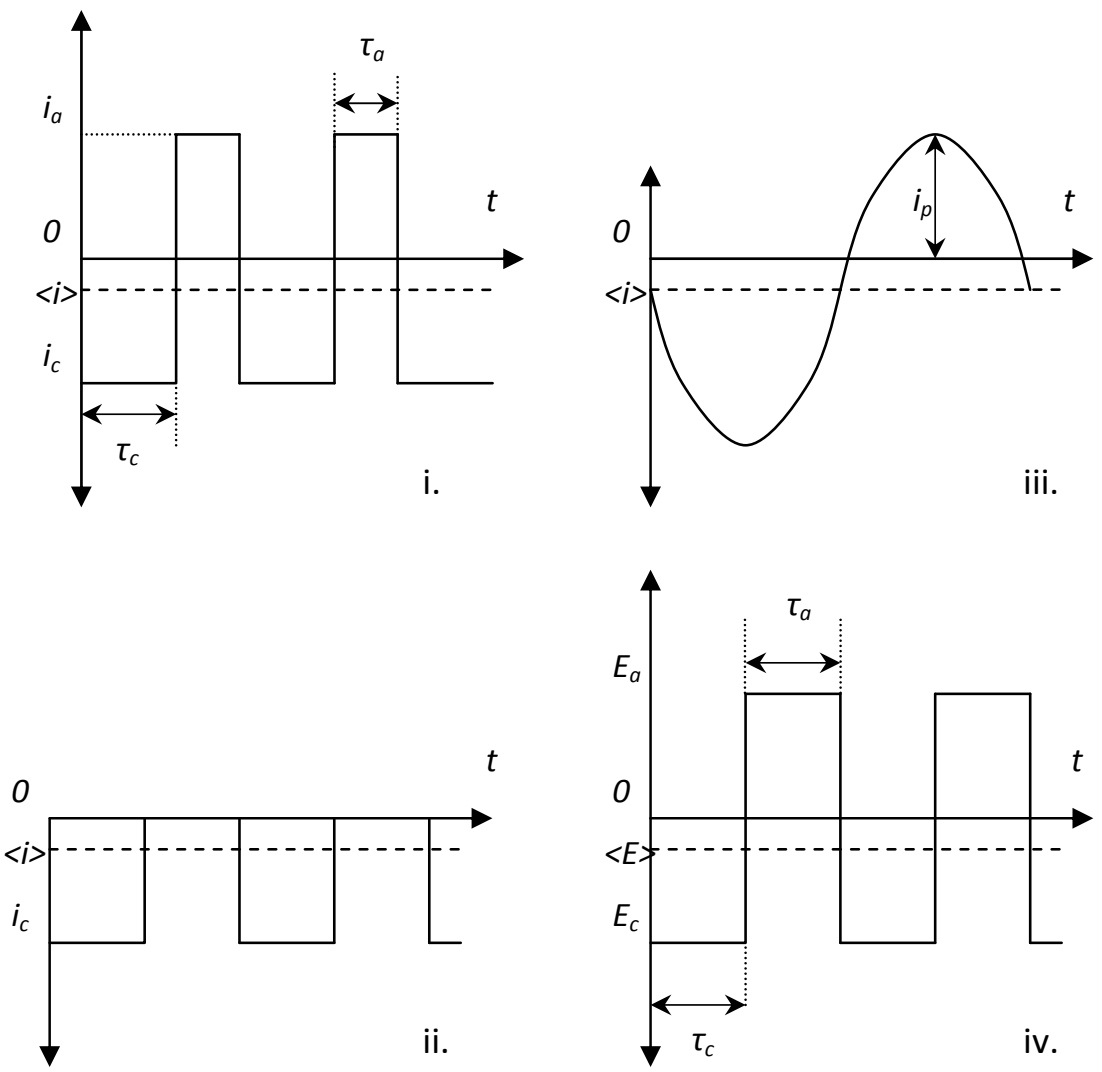

Figura 3. Modos de operación en electrólisis pulsante: i. corriente inversa, ii. corriente pulsante, iii. corriente alterna sobrepuesta a una corriente continua, iv. ondas cuadradas de potencial repetitivas.

iv. Ondas de potencial repetitivas. Consiste en la aplicación repetitiva de pulsos de potencial de diferentes formas (Figura 3 iv). En el desarrollo de esta tesis se ha usado, en particular, esta técnica aplicando ondas cuadradas de potencial repetitivas $(O C P R)$ de alta frecuencia sobre sustratos de carbono en solución acuosa de ácido cloroplatínico, para favorecer la formación y crecimiento de nanopartículas de $P t$ facetadas con orientación cristalográfica preferencial. En siguientes secciones se darán más detalles de la técnica y el modo en que se relacionan los parámetros que la caracterizan.

III.3. Características generales de los electrodepósitos metálicos obtenidos mediante la técnica de OCPR

\section{III.3.a. Dependencia de los límites de potencial}

La Figura 3 iv muestra un esquema de pulsos de onda cuadrada de potencial repetitivos, donde se indican los principales parámetros distintivos de la técnica. Así encontramos la frecuencia $f$ de la onda que se define como una medida para indicar el número de repeticiones del proceso que se producen en 
la unidad de tiempo y que se relaciona de manera inversa con el tiempo $\tau$ mediante la siguiente expresión:

$$
f=\frac{1}{\tau}
$$

siendo $\tau$ el período que designa el intervalo de tiempo necesario para completar un ciclo repetitivo completo.

El potencial promedio $<E>$ aplicado viene dado por la siguiente ecuación:

$$
<E>=\frac{E_{c} \tau_{c}+E_{a} \tau_{a}}{\tau_{c}+\tau_{a}}
$$

siendo $E_{c}$ el potencial catódico o inferior $E i$ y $E_{a}$ el potencial anódico o superior Es. Para el caso de ondas simétricas $\tau_{c}=\tau_{a}$, de modo que resulta la siguiente expresión:

$$
<E>=\frac{E_{c}+E_{a}}{2}
$$

Los valores de potencial superior $(E s)$ e inferior (Ei) determinan los procesos electródicos faradaicos anódicos y catódicos, respectivamente, involucrados en el proceso global de electrodeposición metálica. Para el proceso de electrodepósito de Pt desde soluciones de ácido hexacloroplatínico se ha encontrado que el valor del potencial reversible del sistema redox $P t / P t^{4+}$, en las condiciones de trabajo empleadas en las experiencias, es de aproximadamente 0,7 V [168]. Cuando un electrodo monocristalino polifacetado de $P t$ es sometido a OCPR en una solución conteniendo iones complejos de Pt se producen cambios tanto en la rugosidad superficial como en la orientación cristalográfica de las facetas expuestas a la solución. Para que esto ocurra es necesario que los valores del Es y Ei se ubiquen a valores más positivos y más negativos, respectivamente, que el potencial reversible del sistema $\mathrm{Pt} / \mathrm{Pt}^{4+}$. Por lo tanto las características estructurales de los electrodepósitos obtenidos dependerán fuertemente de los límites de potencial inferior Ei y superior Es, con respecto al potencial reversible de la cupla redox $P t /\left[P t C l_{6}\right]^{2-}$, y de la frecuencia $f$ de la señal eléctrica cíclica aplicada.

\section{III.3.b. Dependencia de la frecuencia}

La frecuencia de la señal eléctrica empleada en la electrólisis pulsante influye sobre los procesos de transporte involucrados, determinando el espesor de la capa límite difusional pulsante, $\left\langle\delta_{p}\right\rangle$, asociada con el transporte de especies solubles de $P t$ a través de la solución [169], [170]. El valor de $<\delta_{p}>$ disminuye con la recíproca de la raíz cuadrada de $f$ [143], [171], de acuerdo con la ecuación:

$$
<\delta_{p}>=\frac{D^{1 / 2} \pi^{1 / 2}}{0,606 f^{1 / 2}}=K f^{1 / 2}
$$

donde $D$ es el coeficiente de difusión de las especies solubles de $P t$ y $K$ una constante.

De acuerdo al valor de $f$ es posible distinguir distintas situaciones: 
i. Para bajos valores de $f$, dentro del intervalo $0,025-0,1 \mathrm{kHz},<\delta_{p}>$ es del orden de $10^{-3} \mathrm{~cm}$ [143], [169], [171] y los procesos electroquímicos involucrados son controlados por mecanismos difusionales. Bajo estas condiciones los electrodepósitos de Pt exhiben una gran rugosidad superficial y no desarrollan ninguna orientación cristalográfica preferencial. Se obtienen capas metálicas de crecimiento dendrítico, con grandes áreas activas superficiales, lo cual es característico de procesos controlados por difusión.

ii. Para frecuencias $1 \mathrm{kHz} \leq f \leq 6 \mathrm{kHz},<\delta_{p}>$ disminuye a valores entre $10^{-4}$ y $10^{-5} \mathrm{~cm}$ [143], [160], [169], los cuales son mucho más bajos que los encontrados para la electrodeposición convencional de $P t$ controlada por transporte de materia. Por consiguiente, la cinética del proceso global llega a estar controlada por activación y los procesos de electrodeposición/electrodisolución de $P t$, que tienen lugar a Ei y Es, respectivamente, ocurren selectivamente y llegan a ser fuertemente dependientes de las propiedades de las diferentes caras cristalográficas [15], [160]. Bajo estas condiciones de control activado, la superficie tratada desarrolla facetas con ocp.

iii. Para frecuencias muy altas el efecto del facetado con ocp no se observa debido a que el desplazamiento cuadrático medio de los adátomos metálicos de la superficie $\left\langle\Delta x^{2}\right\rangle$ es un valor muy pequeño, que depende del hemiperíodo catódico $\tau_{c}$, esto es, $\left\langle\Delta x^{2}\right\rangle=2 D$ [172]. Sin embargo, se ha observado que para frecuencias superiores a $50 \mathrm{kHz}$ las modificaciones superficiales que se obtienen son comparables a las registradas con un tratamiento térmico tal como el recocido [169].

La resolución de la ecuación de Fick para perturbaciones de potencial de onda cuadrada repetitivas, ha permitido evaluar la capa difusional pulsante correspondiente a los ciclos de electrodisolución y electrodepósito del metal [170], [173], explicando el hecho experimental de acumulación de especies $P t^{2+}$ en la solución [166] durante el facetado electroquímico. Mayores detalles se pueden encontrar en las referencias antes mencionadas.

En el caso particular de la tesis desarrollada, el procedimiento se llevó a cabo en una solución conteniendo una especie compleja del metal con un exceso del agente complejante de modo de evitar la formación de óxidos de $P t$, y permitiendo que tengan lugar así sólo los procesos de electrodisolución y electrodepósito del metal.

En solución de ácido cloroplatínico la formación de óxidos superficiales de $P t$ se encuentra desfavorecida con respecto a otras reacciones electroquímicas con participación de especies complejas de $P t$

$$
\begin{array}{llrl}
\mathrm{PtCl}_{4}{ }^{2-}+2 e^{-} \leftrightarrow \mathrm{Pt}+4 \mathrm{Cl} & E_{1}{ }^{\circ}=0,755 \mathrm{~V} \\
\mathrm{PtCl}_{6}{ }^{2-}+2 e^{-} \leftrightarrow \mathrm{PtCl}_{4}{ }^{2-}+2 \mathrm{Cl} & E_{2}{ }^{\circ}=0,68 \mathrm{~V}
\end{array}
$$

Por otro lado, la presencia de una elevada concertación de ion cloruro favorece, a potenciales positivos, el proceso de oxidación del Pt directamente a especies complejas solubles. Esta característica del sistema hace posible que durante el hemiciclo anódico de la OCPR se produzca la electrodisolución selectiva de Pt y durante el hemiciclo catódico se produzca el electrodepósito selectivo de Pt, con una 
mayor o menor especificidad dependiendo de la contribución faradaica de la reacción de electrodesprendimiento de hidrógeno.

Variando adecuadamente los límites de potencial y la frecuencia de la perturbación de la señal eléctrica utilizada, se pueden distinguir tres situaciones:

i. que durante el tratamiento se igualen las cargas faradaicas anódica y catódica;

ii. que la carga faradaica catódica prevalezca sobre la anódica, favoreciendo así la electrorreducción del metal en el proceso global;

iii. que predomine la electrodisolución mientras se aplica la perturbación de potencial repetitiva, al prevalecer la carga faradaica anódica sobre la catódica.

De acuerdo a esto, la morfología final desarrollada en los electrodos dependerá del balance neto de las cargas faradaicas anódica y catódica involucradas. Durante el tratamiento de electrólisis pulsante los procesos involucrados distan mucho de encontrarse en situaciones de equilibrio termodinámico. Sin embargo, como punto de partida y para una primera predicción de los procesos electroquímicos que se producen, se pueden considerar los datos termodinámicos existentes referidos a las distintas cuplas redox que involucren las especies oxidadas y reducidas del metal [166], [172]. En el caso específico del $P t$ en soluciones ácidas y en ausencia de agentes acomplejantes se deben tener en cuenta las siguientes reacciones:

$$
\begin{array}{ll}
P t^{2+}+2 e^{-} \leftrightarrow P t & E_{1}^{\circ}=1,188 \mathrm{~V} \\
P t O H+H^{+}+e^{-} \leftrightarrow P t+H_{2} \mathrm{O} & E_{2}^{\circ}=0,850 \mathrm{~V} \\
P t O+2 H^{+}+2 e^{-} \leftrightarrow P t+H_{2} \mathrm{O} & E_{3}^{\circ}=0,980 \mathrm{~V} \\
\mathrm{PtO}_{2}+2 \mathrm{H}^{+}+2 e^{-} \leftrightarrow P t O+\mathrm{H}_{2} \mathrm{O} & E_{4}^{\circ}=1,045 \mathrm{~V} \\
\mathrm{PtO}_{2}+4 \mathrm{H}^{+}+2 e^{-} \leftrightarrow P t^{2+}+2 \mathrm{H}_{2} \mathrm{O} & E_{5}^{\circ}=0,837 \mathrm{~V}
\end{array}
$$

De acuerdo a los valores de potencial superior Es e inferior Ei de la onda cuadrada empleados en el facetado electroquímico del $P t$ se pueden distinguir los siguientes procesos globales:

i. $E S>E_{1}^{\circ}$ y $E_{1}^{\circ}>E i>0,4 \mathrm{~V}$

Para valores de Es más positivos que el valor de potencial redox de la cupla $P t^{2+} / P t$, el $P t$ se electrodisolverá y el $P t^{2+}$ difundirá hacia el seno de la solución durante el hemiciclo anódico. Durante el hemiciclo catódico ocurrirá la reacción complementaria de electrodepósito del metal.

ii. $E S>E_{1}^{\circ}$ y $E_{1}^{\circ}>E i \leq 0,4 \mathrm{~V}$

Bajo esta situación, durante el hemiciclo anódico ocurre lo mismo que en el caso anterior pero la reacción complementaria de electrodepósito del metal ocurrirá simultáneamente con la electroadsorción de átomos de hidrógeno y, para valores de Ei suficientemente negativos, con la electroformación de $H_{2(g)}$.

iii. Formación de óxidos de Pt a Es

En este caso el valor de Es es tal que se forma una capa de óxido del metal durante el hemiciclo anódico, la cual luego es total o parcialmente reducida durante el hemiciclo catódico, dependiendo del 
valor de Ei. Se pueden obtener así superficies facetadas con aumentos apreciables de rugosidad superficial.

Por consiguiente, bajo las condiciones planteadas en las ecuaciones (11) a (15), a valores de Es se pueden formar especies superficiales oxigenadas y especies $\mathrm{Pt}^{2+}$ solubles. Del mismo modo, a valores de Ei las especies superficiales oxigenadas y las especies $P t^{2+}$ solubles pueden electrorreducirse total o parcialmente produciendo una nueva superficie electródica de $P t$.

\section{III.3.c. Efectos capacitivos de la electrólisis pulsante}

En la interfase electrodo/solución existe una región que tiene una determinada carga espacial, es decir una zona donde no se cumple la condición de electroneutralidad que se mantiene en el seno de la solución. Esta región se denomina doble capa eléctrica y puede ser modelizada como un condensador de placas paralelas separadas por una distancia de unos pocos angstroms. La doble capa eléctrica debe ser provista de carga para elevar su potencial al valor requerido para depositar el metal a una velocidad acorde a las condiciones operativas empleadas en la electrólisis.

Considerando la aplicación de pulsos de corriente constante se puede analizar como influye la capacidad de la doble capa eléctrica en la eficiencia de la electrólisis. Cabe señalar que un análisis similar se aplica en el caso de $O C P R$. En la Figura 4 se representa en trazo grueso la señal galvanostática aplicada y en trazo fino la contribución faradaica, $i_{f}$, a la corriente catódica total, $i_{t}$. Al comienzo del primer pulso el potencial se encuentra a valores cercanos al de equilibrio y por lo tanto la mayor parte de $i_{t}$ se utiliza para cargar la doble capa eléctrica. A medida que ésta se carga, el potencial se torna más negativo e $i_{f}$ comienza a tener mayor importancia, llegando a ser igual a la corriente total una vez que se ha cargado la doble capa eléctrica.

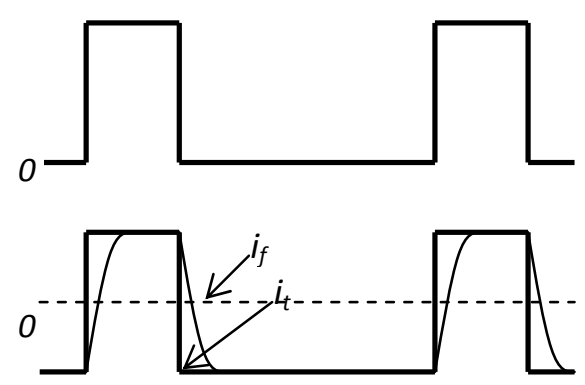

(a)
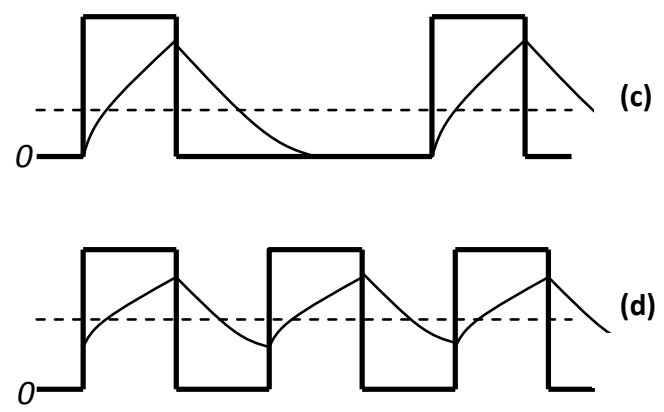

Figura 4. Influencia de la capacidad de la doble capa: (a) efecto despreciable, (b) efecto medio (c) y (d) efecto marcado. 
Dependiendo de las condiciones empleadas, el tiempo de carga de la doble capa eléctrica puede ser mayor o menor que la duración del pulso. Si se considera el final de cada pulso se observa que la corriente de depósito $i_{f}$ no cae inmediatamente a cero, debido a que la descarga de la doble capa eléctrica no es instantánea y durante ese tiempo el potencial se aproxima al valor de equilibrio, para el cual $i_{f}=0$. En la Figura 4 (c) y (d) se muestra este fenómeno y en (d) se ve que $i_{f}$ nunca cae a cero debido a que la doble capa eléctrica no se descarga nunca en forma completa. Para estos casos, la corriente faradaica de electrodepósito comienza a aproximarse a una corriente continua de valor $\langle i\rangle$, ya que $i_{f}$ oscila en torno a <i> y deja de ser pulsante. En estas condiciones los electrodepósitos que se obtienen son similares a los producidos por electrólisis convencional.

Se debe destacar que la eficiencia del depósito no disminuye por los efectos capacitivos, ya que cuando $i_{f}=0$ en el circuito externo, la corriente generada por la descarga de la doble capa eléctrica produce el depósito del metal. Por lo tanto, estos efectos no limitan la utilidad de la técnica de pulsos, la cual resulta solo limitada por la aproximación de una corriente continua. Al aplicar técnicas de electrólisis pulsante siempre se deben tener presentes los tiempos de carga y descarga de la doble capa eléctrica.

Una característica específica de la electrólisis pulsante, comparada con otros métodos para producir depósitos metálicos, es que se puede variar la fuerza impulsora (la energía libre) del proceso mediante la aplicación de un cierto potencial al electrodo de trabajo. También puede prefijarse una cierta velocidad de reacción ajustando el valor de la densidad de corriente aplicada.

En la electrólisis pulsante los elevados sobrepotenciales que se alcanzan pueden modificar la velocidad de nucleación en un proceso de electrodeposición, debido a que la elevada energía disponible puede ser utilizada para formar nuevos núcleos. Otro aspecto sobresaliente de la electrólisis pulsante está relacionado con los procesos de adsorción y desorción, recristalización y redisolución del depósito que pueden ocurrir durante los hemiperíodos anódicos. Debido a la gran sensibilidad de la electrocristalización a estos procesos, las propiedades de los depósitos dependerán en gran medida de la relación de tiempo de pausa a tiempo de aplicación o de la frecuencia de la señal aplicada.

También se conoce que la formación de una película metálica sobre un sustrato inerte en sistemas que involucran mecanismos de nucleación, produce una distribución del flujo no uniforme. Por lo tanto, para obtener un cierto grado de cubrimiento se debe depositar una mayor cantidad de metal que la predicha por una relación de primer orden entre cubrimiento y tiempo de depósito. Se ha demostrado que para la misma densidad de corriente promedio, la electrodeposición pulsante produce una distribución más uniforme del metal que en el caso de una electrólisis convencional. Un caso particular derivado de estas características específicas de la electrólisis pulsante, es la reestructuración superficial que se produce en electrodos de metales nobles sometidos a tratamientos de OCPR. 


\section{ANEXO}

En la implementación de la técnica de electrólisis pulsante hay que tener en cuenta los fenómenos ocasionados por el pasaje de la corriente eléctrica a través de la interfase electrodo de trabajo/solución, que conduce a que el sistema de reacción se aparte del equilibrio. Surge entonces una diferencia entre el potencial de equilibrio, $E_{r}$, y el de operación, $E$, denominada sobrepotencial $\eta$

$\eta=E-E_{r}$

Los procesos que pueden contribuir a la aparición de $\eta$ son:

a) Transferencia de carga

b) Transporte de masa

c) Cristalización

d) Reacción química

e) Pasaje de corriente eléctrica en la solución

a) Transferencia de carga (sobrepotencial de activación $\eta_{T}$ )

El proceso característico de una reacción electroquímica es el pasaje de los portadores de carga eléctrica a través de la interfase electródica, que se denomina reacción de transferencia de carga y ocurre sobrepasando una barrera de potencial asociada a una cierta energía de activación. Teniendo en cuenta la teoría del complejo activado se puede obtener una relación densidad de corrientesobrepotencial para un proceso de transferencia de carga puro [174]

$$
i=i_{0}\left\{\exp \left(B Z F \eta_{T} / R T\right)-\exp \left[-(1-6) Z F \eta_{T} / R T\right]\right\}
$$

Donde 6 , el factor de simetría, es una medida directa de la variación de energía de activación de una reacción de transferencia de carga con el potencial, $i_{0}$ es la densidad de corriente de intercambio y corresponde al valor de la densidad de corriente en sentido anódico o catódico en las condiciones de equilibrio $\left(\left|i_{a}=i_{c}\right|=i_{0}\right.$ con $\left.E=E_{r} \circ \eta=0\right) ; Z$ es el número de cargas transferidas en la reacción, $R$ es la constante universal de los gases y $T$ es la temperatura absoluta.

b) Transporte de masa

En toda reacción electroquímica ocurren procesos de transporte de materia por los cuales los reactivos y productos se aproximan o se alejan de la interfase electródica. Este transporte puede ocurrir por difusión, migración o convección.

\section{i. Difusión}

Un proceso de difusión ocurre siempre que el potencial químico $\mu_{i}$ de una especie tenga valores diferentes en el interior de una fase, es decir, bajo condiciones de gradiente de potencial químico. El flujo de masa tiene sentido opuesto al del gradiente y viene dado por [174]:

$$
\frac{1}{A} \frac{d n_{i}}{d t}=-\frac{D_{i} c_{i}}{R T} \nabla \mu_{i}
$$


donde $n_{i}$ es el número de moles de la especie $i, c_{i}$ su concentración, $A$ el área de la superficie a través de la cual se produce el flujo difusional y $D_{i}$ el coeficiente de difusión de la especie $i$.

Si la solución utilizada es suficientemente diluida (coeficientes de actividad unitarios) o si existe en la solución un exceso suficientemente grande de otro electrolito de concentración constante en toda la fase, de modo que la fuerza iónica de la solución y, por lo tanto, los coeficientes de actividad sean constantes, la ecuación (18) se puede simplificar:

$$
\frac{1}{A} \frac{d n_{i}}{d t}=-D_{i} \nabla c_{i}
$$

que corresponde a la primera ley de Fick, siendo $D_{i}$ constante.

Cuando la especie $i$ es un portador de $Z_{i}$ cargas, el flujo difusional corresponde a una densidad de corriente eléctrica, $i_{i}$ dada por:

$$
i_{i}=-Z_{i} F \frac{D_{i} c_{i}}{R T} \nabla \mu_{i}
$$

Para el caso de difusión lineal en la dirección x, perpendicular a la interfase electródica se tiene:

$$
i_{i}=-\frac{Z_{i} F D_{i}}{n_{i}}\left(\frac{d c_{i}}{d x}\right)_{x=0}
$$

y de acuerdo al modelo de película difusional de Nernst [174],

$$
i_{i}=-\frac{Z_{i} F D_{i}}{n_{i}} \cdot\left(\frac{c_{i}-c_{i}^{*}}{\delta}\right)
$$

donde $c_{i}{ }^{*}$ es la concentración de la especie $i$ en $\mathrm{x}=0$ y $\delta$ es el espesor de la película difusional. Cuando $c_{i}{ }^{*}=0$ se alcanza un valor límite de $i_{i}$, designado como $i_{L i}$, dado por

$$
i_{L i}=-\frac{Z_{i} F D_{i}}{n_{i}} \frac{c_{i}}{\delta}
$$

y realizando el cociente entre estas dos últimas ecuaciones resulta

$$
\frac{c_{i}^{*}}{c_{i}}=1-\frac{i_{i}}{i_{L i}}
$$

Además, para el sobrepotencial de difusión, $\eta_{D}$, en condiciones de coeficientes de actividad constantes se cumple:

$$
\eta_{D}=\frac{R T}{Z F} \sum n_{i} \ln \frac{c_{i}^{*}}{c_{i}}
$$

Relacionando las últimas dos ecuaciones se obtiene una relación general entre $i_{i}$ y $\eta_{D}$

$$
\eta_{D}=\frac{R T}{Z F} \sum n_{i} \ln 1-\frac{i_{i}}{i_{L i}}
$$




\section{ii. Migración}

Las distintas fases que conforman un sistema electrolítico contienen generalmente portadores móviles de carga que son conductores eléctricos. Si dentro de un conductor existe un gradiente de potencial eléctrico, $\nabla_{\varphi}$, fluye una corriente dada por [174]:

$$
i=-\chi \nabla_{\varphi}
$$

donde $\chi$ es la conductividad específica de la fase y depende del número de cargas $Z_{i}$, de la concentración $c_{i}$ y de la conductancia equivalente $\Lambda_{i}$ del portador $i$ :

$$
\chi_{i}=\left|Z_{i}\right| c_{i} \Lambda_{i}
$$

Por lo tanto:

$$
i_{i}=-\left|Z_{i}\right| c_{i} \Lambda_{i} \nabla_{\varphi}
$$

La contribución migratoria al transporte de una sustancia que interviene en una reacción electroquímica complica, en muchos casos, la interpretación de la cinética del proceso, por eso es conveniente mantenerla tan baja como sea posible. Esto puede lograrse agregando a la solución un exceso de electrolito conductor que no tome parte en la reacción.

\section{iii. Convección}

Otro modo de transporte de masa en una solución electrolítica es por convección, es decir, el del flujo hidrodinámico de la solución. La intensidad y tipo de convección depende de la forma geométrica del electrodo y de su disposición. La convección también puede variar por la influencia de agentes externos tales como agitación de la solución o movimientos del electrodo.

La influencia de la convección en el transporte de materia se puede describir mediante las leyes fundamentales de la hidrodinámica.

Para el caso de una especie $i$, la variación de la concentración de dicha especie con el tiempo en un punto dentro de la solución $(x, y, z)$ y despreciando la contribución migratoria, viene dada por la siguiente expresión:

$$
\frac{\partial c_{i}}{\partial t}=D_{i}\left(\frac{\partial^{2} c_{i}}{\partial x^{2}}+\frac{\partial^{2} c_{i}}{\partial y^{2}}+\frac{\partial^{2} c_{i}}{\partial z^{2}}\right)-\left(u \frac{\partial c_{i}}{\partial x}+v \frac{\partial c_{i}}{\partial y}+w \frac{\partial c_{i}}{\partial z}\right)
$$

donde $u, v$ y $w$ son las componentes de la velocidad de flujo paralelas a los ejes $x, y$ y $z$, respectivamente, de un sistema de coordenadas ortogonales.

En general los procesos de convección aparecen en las reacciones electroquímicas aún cuando no se efectúe ningún movimiento en la solución o al electrodo, debido a que durante el transcurso de la reacción surgen diferencias de densidades en la interfase electródica por variaciones en la concentración o en la temperatura. Esto origina un flujo de convección natural y puede influir considerablemente en la velocidad de reacción [174]. 
Como surge de la ecuación (23) la corriente difusional depende de $\delta$ y en consecuencia de las condiciones de movimiento de la solución y del electrodo. La dependencia exacta de $\delta$ con la convección se puede encontrar resolviendo la ecuación (30). Su resolución general conduce a sistemas de ecuaciones bastante complejas, de modo que su aplicación es aproximada para sistemas de geometría y condiciones hidrodinámicas sencillas. Así por ejemplo, para el caso de un electrodo plano, sobre el cual circula la solución en flujo laminar y paralelo al mismo y, considerando una reacción de transferencia iónica simple, se obtienen relaciones corriente-potencial como la siguiente [174], para el caso potenciostático

$$
i=Z F \sqrt{D / \pi t} c\left[\exp \left(Z F \eta_{D} / R T\right)-1\right]
$$

y para el caso galvanostático se obtiene la siguiente ecuación:

$$
\eta_{D}=\frac{R T}{Z F} \sum n_{i} \ln \left(1 \pm \sqrt{t / \tau_{t}}\right)
$$

Donde $\tau_{t}$ es el tiempo de transición a partir del cual $c^{*}{ }_{i}=0$ y $t$ es el tiempo transcurrido. Cuando la especie $i$ se genera en la reacción se utiliza el signo positivo en la ecuación (32) y el signo negativo cuando dicha especie se consume.

c) Cristalización

El sobrepotencial de cristalización $\eta_{C R}$ se debe a la inhibición del pasaje de los iones metálicos del estado de adátomo superficial a la red cristalina ordenada o viceversa y está dado por:

$$
\eta_{C R}=\frac{R T}{Z F} n_{a d} \ln \frac{a_{a d}}{a_{a d, e q}}
$$

donde $n_{a d}$ es el número estequeométrico y $a_{a d}$ y $a_{a d, e q}$ son las actividades de los adátomos cuando circula corriente y en el equilibrio $(i=0)$, respectivamente [174].

d) Reacción química

Se debe contemplar también el caso en el cual la cinética de reacción total está determinada por la velocidad de reposición de uno de los reactivos de la reacción de transferencia de carga por medio de una reacción química parcial. La disminución o el aumento de concentración del reactivo en la interfase conducen a un sobrepotencial de concentración denominado sobrepotencial de reacción química $\eta_{R Q}$.

Considerando el caso de una reacción heterogénea precedente o posterior a la de transferencia de carga, para coeficientes de actividad constantes, se obtiene para $\eta_{R Q}$ la siguiente expresión [174]:

$$
\eta_{R Q}=-\frac{n R T}{Z_{r} F p} \ln \left[1-\left(i / i_{L, R}\right)\right]
$$

donde $p$ es el orden de reacción, $Z_{r}$ el número de cargas de reacción y $i_{L, R}$ es la corriente límite de reacción dada por: 


$$
i_{L . R}=\frac{Z_{r} F}{n} v_{o}
$$

donde $v_{o}$ es la velocidad de reacción de intercambio.

e) Pasaje de corriente eléctrica en la solución

Otro tipo de sobrepotencial asociado a la resistencia del electrolito al pasaje de la corriente eléctrica es el sobrepotencial óhmico $\eta_{\Omega}$. Si la resistencia óhmica de la solución es $R_{\Omega}$ y el electrodo de trabajo y contraelectrodo son de igual superficie y paralelos, se puede aplicar la ley de Ohm:

$$
R_{\Omega}=(1 / \chi)(\ell / a)
$$

donde $\ell$ es la distancia entre los electrodos, $a$ es el área de los electrodos (igual al área transversal de la celda) y $\chi$ la conductividad específica de la solución electrolítica. El sobrepotencial óhmico correspondiente será:

$$
\eta_{\Omega}=I R_{\Omega}=(I / \chi)(\ell / a)
$$

Si se coloca una sonda (electrodo de referencia) cercana a uno de los electrodos para medir su potencial se detecta una contribución óhmica que será menor cuanto más próxima al electrodo esté situada. Esta sonda no debe alterar la distribución de potencial del sistema y esto se logra mediante un fino capilar llamado capilar de Luggin. La magnitud de la contribución óhmica al sobrepotencial total dependerá del diseño de la celda, la distancia entre la punta del capilar de Luggin y el electrodo de trabajo y el valor de la corriente eléctrica empleada. 


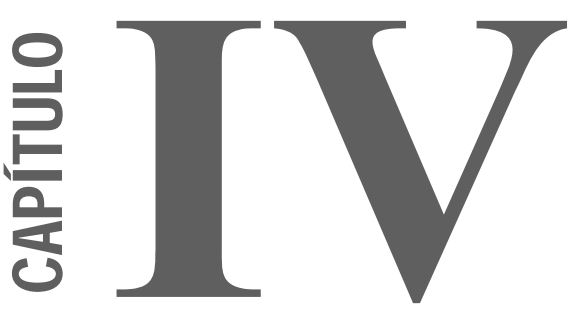

\section{Técnicas experimentales de}

caracterización de materiales de electrodo 



\section{CAPÍTULO IV}

\section{Técnicas experimentales de caracterización de materiales de electrodo}

\section{IV.1. Técnicas electroquímicas}

Las técnicas electroquímicas experimentales para el estudio de los materiales de electrodo consisten en medir la respuesta del sistema a una señal eléctrica impuesta. La señal eléctrica perturba el estado de equilibrio del sistema y el comportamiento resultante constituye la respuesta, cuya detección permite obtener información sobre las propiedades del sistema. La perturbación del equilibrio de un sistema electroquímico se consigue mediante la variación del potencial del electrodo, el pasaje de corriente eléctrica o por algún procedimiento de excitación como cambios de presión, temperatura, variación de especie electroactiva, etc. En general, se utiliza una variación del potencial o la aplicación de una corriente y el sistema responde a estas perturbaciones con cambios en su comportamiento, que pueden seguirse por las variaciones de la corriente circulante, del potencial de electrodo o de la carga asociada.

En el caso de una reacción electroquímica simple, ésta puede representarse por la siguiente ecuación:

$$
\mathrm{O}+n e^{-} \leftrightarrow \mathrm{R}
$$

donde $\mathrm{O}$ y $\mathrm{R}$ son las especies oxidada y reducida, respectivamente.

La característica principal es el flujo de electrones que se establece en la región interfacial y que además determina el carácter de reacción heterogénea. La teoría de la transferencia de carga para reacciones simples, basada en la teoría del complejo activado, permite establecer la relación entre la densidad de corriente $i$ y el sobrepotencial total $\eta_{T}$, mediante la ecuación de Butler-Volmer [25], [172], [175], [176]:

$$
i=i_{0}\left\{\exp \left(B Z F \eta_{T} / R T\right)-\exp \left[-(1-6) Z F \eta_{T} / R T\right]\right\}
$$

donde $i_{0}$ es la corriente de intercambio, $b$ el factor de simetría, $Z$ el número de electrones intercambiados, $F$ la constante de Faraday, $\eta_{T}$ la diferencia entre el potencial aplicado y el potencial reversible, $R$ la constante general de los gases y $T$ la temperatura.

Para valores de $\eta_{T}<R T / B Z F$, se realiza un desarrollo en serie de los exponenciales. Tomando sólo los primeros términos se obtiene una relación lineal del tipo

$$
i=i_{0} B Z F \eta_{T} / R T
$$

Para valores de $\left|\eta_{T}\right| \gg R T / B Z F$ es posible, matemáticamente, despreciar el aporte de uno de los exponenciales frente al otro, con lo que se llega a la expresión de Tafel: 


$$
\eta_{T}=a+b \log i
$$

donde $a$ y $b$ son las constantes de Tafel que involucran términos cinéticos [176]. En la deducción anterior se considera que la concentración de las especies y el sobrepotencial permanecen constantes. Estas condiciones son válidas tanto para el estado estacionario como para los estados de equilibrio en los que se cumple la ecuación de Nernst.

En una medida experimental se polariza el electrodo de trabajo y, dependiendo de varios factores, como la constante de velocidad del proceso involucrado, la concentración del electrolito, la temperatura de operación, el material electródico, etc., el electrodo de trabajo tiende a ajustarse a las condiciones impuestas. Durante ese tiempo el proceso se encuentra en estado transitorio y cuando la reacción procede a velocidad constante, se dice que alcanzó el estado estacionario. La ecuación de Butler-Volmer describe el estado de la interfase en estado estacionario.

Experimentalmente se disponen de varias maneras de estimular a la interfase para analizar sus variaciones en el tiempo. Se parte de un sistema en equilibrio al cual se le aplica un estímulo y se observa su respuesta en función del tiempo. En la parte experimental de la tesis desarrollada, las medidas se realizaron aplicando principalmente las siguientes técnicas electroquímicas al sistema electrodo/medio electrolítico:

i. Perturbaciones de potencial de onda cuadrada: para el desarrollo de los facetados de $P t$, ya descripto en el CAPÍTULO III.

ii. Voltamperometría cíclica para la caracterización de los electrodepósitos de Pt.

\section{IV.1.a. Voltamperometría cíclica}

La voltamperometría cíclica consiste en aplicar un barrido triangular repetitivo de potencial que varía linealmente con el tiempo, dando como respuesta un flujo de corriente como una función del potencial aplicado. En la Figura 1 se muestra una representación esquemática de la perturbación de una experiencia de voltamperometría cíclica. En esta técnica se polariza el electrodo de trabajo con un potencial que varía en forma lineal con el tiempo a una velocidad de barrido $v$ dada, de modo que:

$$
v=\frac{d E}{d t}
$$

El barrido de potencial puede ser en una única dirección o repetitivo. En este último caso se denomina voltamperometría cíclica. En cada punto del registro el potencial viene dado por una expresión del tipo

$$
E=E_{i 0} \pm v t
$$

donde $E_{i 0}$ es el potencial inicial. Para el potencial aplicado $(E)$, se registra la corriente que circula en el electrodo. En voltamperometría cíclica, el potencial se aplica en las direcciones anódica (hacia 
potenciales más positivos) y catódica (hacia potenciales menos positivos), obteniéndose un pico de corriente anódica y otro pico de corriente catódica de la misma altura y al mismo potencial para el caso de reacciones reversibles. De este modo la altura y posición de los picos anódico y catódicos permite estimar la reversibilidad de un proceso electródico. La respuesta del sistema se grafica en curvas corriente/potencial que se denominan voltamperogramas (ver Figura 1 del CAPÍTULO III) y constituyen verdaderos espectros electroquímicos de la interfase estudiada [25].

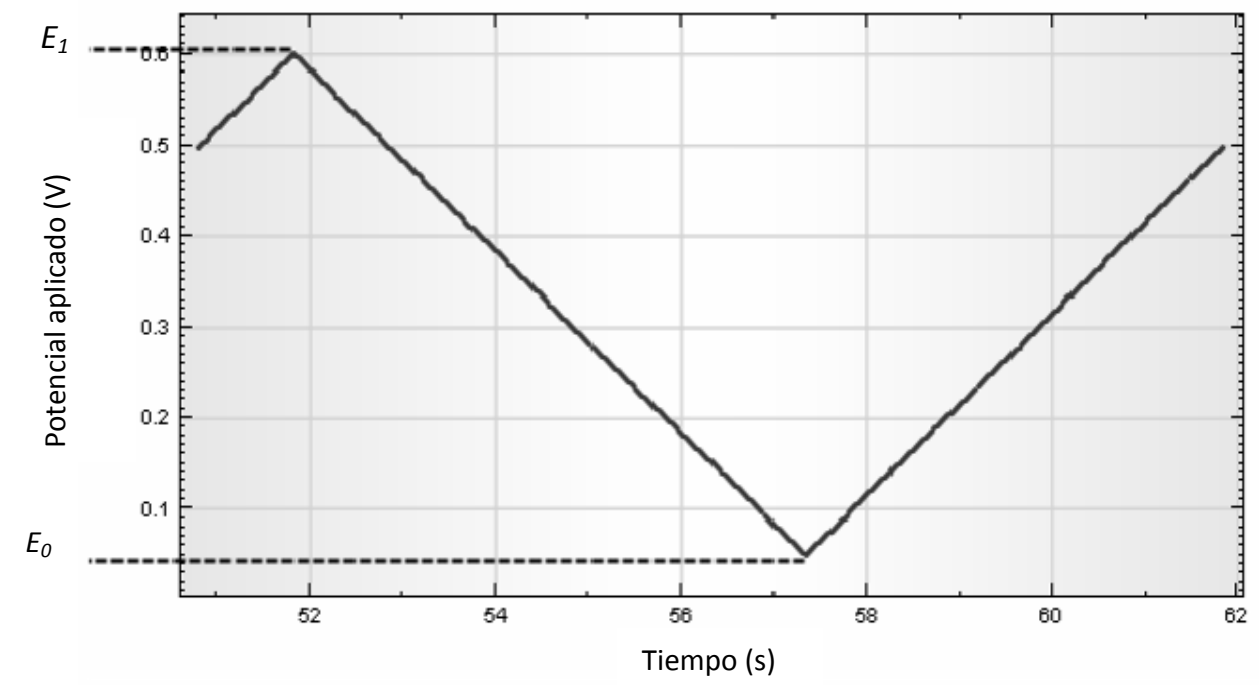

Figura 1. Esquema de la perturbación aplicada para una experiencia de voltamperometría cíclica.

El potencial aplicado al sistema en estudio (electrodo de trabajo) se mide respecto a un electrodo de referencia. La corriente que pasa en la interfase se mide entre el electrodo de trabajo y el contraelectrodo (Figura 2).

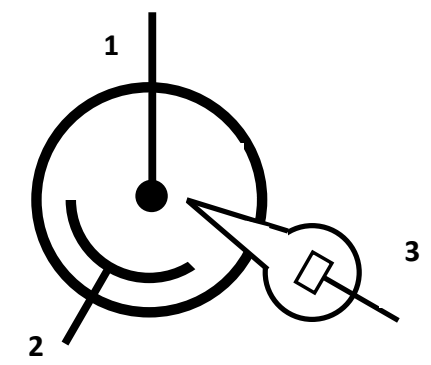

Figura 2. Esquema de una celda electroquímica: 1. electrodo de trabajo, 2. contraelectrodo, 3. electrodo de referencia.

Según el sistema en estudio se eligen convenientemente la velocidad de barrido y los extremos de potencial. Las respuestas corriente/potencial se caracterizan por presentar máximos de corriente a determinados potenciales del intervalo establecido, los cuales pueden asociarse a los potenciales termodinámicos estándares para reacciones electroquímicas particulares en la interfase metal/electrolito [177], pudiéndose obtener conclusiones respecto de mecanismos probables para la reacción en estudio. 
La técnica permite estudiar procesos de transferencia de carga, la influencia del transporte de materia en la solución o desde la interfase y reacciones superficiales de interés en electrocatálisis, tales como adsorción y desorción de distintas especies.

De acuerdo a la velocidad de variación del potencial se pueden distinguir comportamientos a altas o bajas velocidades de barrido. En las medidas a bajas velocidades de barrido se supone que la variación del potencial es suficientemente lenta como para que se establezcan las condiciones de estado estacionario. La región de bajas velocidades de barrido puede estar comprendida entre 1 a $10 \mathrm{mV} / \mathrm{s}$, pero depende marcadamente de la cinética de la reacción en cada caso específico. Con estas velocidades de barrido se obtienen respuestas corriente/potencial que permiten evaluar los mecanismos de estado estacionario de las reacciones involucradas. A altas velocidades de barrido, resulta una técnica dinámica comparable a los transitorios galvanostáticos. En este caso, la técnica se utiliza para determinar la concentración de las especies adsorbidas en la superficie del electrodo, así como también detectar intermediarios de reacción formados sobre la superficie del electrodo en un proceso de transferencia de carga [178].

Cuando las reacciones electroquímicas están controladas por difusión y la velocidad de barrido es lo suficientemente baja, se alcanza el estado estacionario en cada punto, obteniéndose finalmente como respuesta una determinada corriente límite. Si la velocidad de barrido es más alta de modo que el reactivo se consume totalmente, en la región interfacial se obtienen máximos de corriente. En estos casos, la relación entre la corriente y el potencial puede obtenerse en el marco del caso de la difusión plana semiinfinita.

La voltamperometría cíclica, a diferencia de la voltamperometría de barrido único, no brinda parámetros cinéticos con precisión. Se restringe generalmente más bien a dilucidaciones rápidas cualitativas de mecanismos de reacción, pero de todas maneras permite la caracterización de un sistema electroquímico.

A fin de fundamentar teóricamente la voltamperometría cíclica se resuelve la segunda ley de Fick para las diferentes especies que participan en la reacción bajo estudio [172], [179]. Para el caso de difusión plana semiinfinita, considerando las condiciones iniciales y de contorno correspondientes y la ecuación de Nernst (reacciones reversibles) o la ecuación de Butler-Volmer (reacciones no reversibles), se obtiene la siguiente expresión:

$$
I=Z F A_{G} c_{i}(\pi D k)^{1 / 2} X(k t)
$$

donde $Z$ es el número de electrones intercambiados, $A_{G}$ es el área del electrodo, $c_{i}$ es la concentración de la especie electroactiva en el seno de la solución, $k=(Z F / R T) v$ y $X(k t)$ es una función del potencial que determina la forma de la curva. Las soluciones teóricas de las relaciones corriente/potencial fueron desarrolladas por Srinivasan et al. [178] y por Hale et al. [180] considerando que son válidos los postulados de las isotermas de Langmuir y de Temkin, respectivamente. 
Se pueden considerar distintos casos de reacciones:

i. En reacciones reversibles para las cuales las velocidades de las reacciones directa e inversa son iguales, se llega a expresiones en las que la corriente de pico es directamente proporcional a la velocidad de barrido y el potencial de pico guarda una función logarítmica con la constante de velocidad de reacción.

ii. Para reacciones irreversibles, en las que la velocidad de la reacción directa es considerablemente superior a la de la inversa, la velocidad de barrido de potencial influye sobre las dos variables electroquímicas, dependiendo en forma directa con la corriente y en forma logarítmica con el potencial.

En los sistemas reales, los efectos resistivos son importantes, con lo cual se produce una deformación de la respuestas corriente/potencial. Los hechos más notables pueden ser una disminución de la corriente de pico, picos de corriente anchos, corrimientos de los potenciales de los máximos de corriente hacia valores positivos en reacciones de electrooxidación y hacia valores negativos para reacciones de electrorreducción.

En la bibliografía se encuentran modelizadas y resueltas diversas reacciones tipo que incluyen procesos irreversibles, reacciones consecutivas, reacciones químicas asociadas y distintos órdenes de reacción [25]. A través de diversos trabajos se han encontrado resultados que muestran la alta sensibilidad y especificidad del método para reflejar propiedades cristalinas de las superficies de los electrodos sólidos [161], [181-188].

El método de voltamperometría cíclica también es muy sensible a las impurezas que pueden encontrarse en el electrolito, las cuales modifican marcadamente la forma y posición de los picos voltamperométricos característicos del sistema en estudio. Por lo tanto, se puede utilizar también la técnica para establecer criterios de pureza de los electrolitos y sustratos a emplear.

La voltamperometría cíclica, a través de la corriente faradaica, brinda también información sobre los procesos que suceden en la interfase electrolito-electrodo, como reacciones de transferencia de carga, reacciones redox en estado sólido, etc. Sin embargo, debe destacarse que además de las cargas de origen faradaico existe una contribución de origen capacitivo, producida por la introducción continua de carga sobre la superficie del electrodo, que debe ser compensada por cargas de signo opuesto procedentes de la disolución y el electrolito soporte.

\section{IV.1.b. Aplicaciones de la voltamperometría cíclica}

IV.1.b.i. Aproximación al fenómeno capacitivo y determinación del área superficial electroquímicamente activa de electrodos

A través de la técnica de voltamperometría cíclica se puede calcular en casos particulares el área superficial electroquímicamente activa. Para ello se determina la dependencia lineal de la corriente con 
la velocidad de barrido del potencial en aquella región del voltamperograma donde el comportamiento es puramente capacitivo. A continuación se expondrá una aproximación sencilla al fenómeno capacitivo.

En un experimento de voltamperometría cíclica la corriente medida, $l$, es el flujo de carga por unidad de tiempo a través de la superficie del electrodo

$$
I=\frac{d Q}{d t}
$$

siendo $Q$ la carga eléctrica acumulada en la doble capa electroquímica.

El potencial del electrodo varía con el tiempo a una determinada velocidad de barrido $v$, que es expresada por:

$$
v=\frac{d E}{d t}
$$

Teniendo en cuenta la definición de capacidad, $C$,

$$
C=\frac{d Q}{d E}
$$

Por lo tanto, la corriente de origen capacitivo, $I_{c}$, se puede definir como:

$$
I_{c}=\frac{d Q}{d t}=\frac{d Q}{d E} * \frac{d E}{d t}=C_{d c} v
$$

siendo $C_{d c}$ la capacidad de la doble capa eléctrica.

La expresión (11) muestra que la corriente capacitiva depende linealmente de la velocidad de barrido para un sistema dado.

Para realizar una medida de la capacidad de la doble capa eléctrica de una interfase electrodoelectrolito es necesario llevar a cabo medidas voltamperométricas a diferentes velocidades de barrido en una zona de potencial donde no se produzcan reacciones de transferencia de carga faradaica. Para ello se selecciona un potencial donde toda la corriente que circule corresponda a la carga y descarga de la doble capa eléctrica. A este potencial se lo denomina potencial de lectura $E_{L}$. Se procede entonces a variar la velocidad de barrido y determinar los distintos valores de $I_{c}$ al potencial $E_{L}$. Se obtiene así una relación lineal entre la corriente y la velocidad de barrido al potencial constante $E_{L}$, a partir de cuya pendiente se calcula $C_{E L}$. Cabe destacar que $C_{E L}$ corresponde el valor de capacidad, medido experimentalmente, que puede incluir, según el caso, la contribución de los intermediarios adsorbidos que puede dar origen a la así denominada pseudocapacidad.

El valor de la capacidad de la doble capa eléctrica depende tanto del área del electrodo como del material de electrodo. Se puede definir entonces una capacidad específica del material de electrodo $C^{*}$ como

$$
C^{*}=C_{E L} / A_{G}
$$

siendo $A_{G}$ el área geométrica del electrodo. 
Una vez obtenida $C_{E L}$ se puede calcular $C^{*}$. Teniendo como dato la capacidad específica del material de electrodo liso, $C_{B}$, que se indica en la bibliografía [189], [190], se puede calcular el área superficial electroquímica $A^{*}$, mediante la siguiente ecuación:

$$
A^{*}=A_{G} C^{*} / C_{B}
$$

y también el correspondiente factor de rugosado, $R^{*}$, que se define como:

$$
R^{*}=A^{*} / A_{G}
$$

\section{IV.1.b.ii. Procesos de electrosorción de hidrógeno}

Los procesos de electrosorción de hidrógeno pueden ser estudiados de manera directa mediante la voltamperometría cíclica o el uso de otras técnicas transitorias, tales como:

i. Técnicas que utilizan como perturbación una señal de corriente alterna de pequeña amplitud, que permite estudiar la pseudocapacidad originada por la transferencia de carga [191].

ii. Técnicas galvanostáticas donde se aplica un corriente constante y se mide el potencial en función del tiempo [192], [193].

La técnica que utiliza corriente alterna para el estudio de la adsorción de hidrógeno mide la pseudocapacidad, originada por la adsorción de intermediarios sobre la superficie, como una función del potencial, relacionando la capacidad diferencial, $C$, con el potencial y la carga mediante la relación:

$$
C=d Q / d E
$$

La fracción de superficie cubierta (grado de recubrimiento) por electroadsorción de hidrógeno atómico, $\theta$, se define como:

$$
\theta=Q / Q_{H, S}
$$

siendo $Q_{H, S}$ el recubrimiento de la superficie por hidrógeno correspondiente a una monocapa, esto es, cada átomo del sustrato está bloqueado por un átomo de hidrógeno, y $Q$ la carga experimental obtenida asociada al proceso de electrosorción de hidrógeno a un potencial dado.

Por lo tanto, considerando las ecuaciones (15) y (16), resulta:

$d Q=Q_{H, s} d \theta$

y sustituyendo $d Q$ en (14) se obtiene

$$
C=Q_{H, S}(d \theta / d E)
$$

Dado que una isoterma electroquímica relaciona el grado de recubrimiento con el potencial, la técnica con corriente alterna determina, por consiguiente, la derivada de la isoterma como una función del potencial. Una curva típica de pseudocapacidad-potencial se muestra en la Figura $3 a$, junto con su integral (Figura 3 b), es decir, su isoterma electroquímica [194]. 


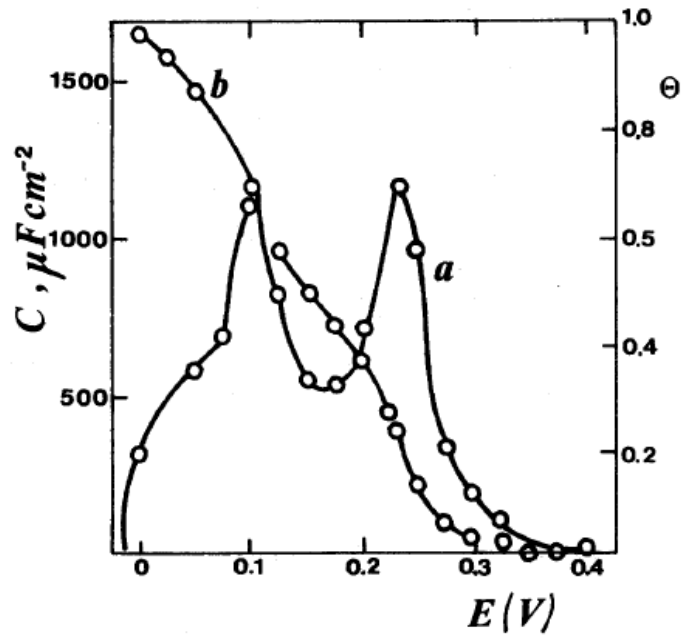

Figura 3. Variación de la pseudocapacidad en función del potencial (Curva $a$ ). Integral de la curva $a$ representando la isoterma electroquímica (Curva $b$ ) para la electrosorción de hidrógeno sobre $\mathrm{Pt}$ en $\mathrm{H}_{2} \mathrm{SO}_{4} 4 \mathrm{M}$ a $25^{\circ} \mathrm{C}[194]$.

En el caso de voltamperometría cíclica se mide la corriente como una función del potencial. Esta corriente se relaciona a los parámetros eléctricos a través de:

$$
I=C \frac{d E}{d t}
$$

y considerando la ecuación (17) resulta

$$
I=\left(Q_{H, s} d E / d t\right) d \theta / d E
$$

El proceso de electrosorción de hidrógeno sobre $P t$ es reversible, por lo tanto, el valor de la capacidad diferencial se puede considerar constante, excepto a altas velocidades de barrido o a frecuencias muy elevadas.

\section{IV.1.b.iii. Determinación de $Q_{H, s}$}

Para llevar a cabo la determinación de $Q_{H, S}$ es necesario conocer si la contribución debida al proceso de adsorción de hidrógeno puede ser separada de aquellas debidas a otros procesos que ocurren simultáneamente, como la carga de la doble capa y el desprendimiento de hidrógeno.

La carga de la doble capa eléctrica puede ser eliminada para el cálculo de $Q_{H, s}$ a través de la extrapolación del voltamperograma en la zona no faradaica [195]. La exactitud de la extrapolación se basa en el hecho de que la capacidad de la doble capa eléctrica es constante en el intervalo de potencial 0,0 y 0,6 V donde tiene lugar el proceso de adsorción de hidrógeno [195]. Además la contribución de otros procesos, aparte del de carga de la doble capa eléctrica, resultan despreciables en esta región [196]. La línea horizontal punteada de la Figura 4 muestra como efectuar esta corrección.

Otra cuestión algo más difícil de resolver se debe al solapamiento que existe entre el proceso de adsorción de hidrógeno y el proceso faradaico de desprendimiento de hidrógeno molecular sobre el 
electrodo. Existe una región de potencial donde ambos procesos se producen simultáneamente y esto no puede evitarse por un simple cambio de técnica utilizada. Sin embargo, ambas contribuciones pueden estudiarse midiendo la pseudocapacidad como función de la frecuencia de la señal de corriente alterna, mediante el uso de un modelo de circuito equivalente apropiado. Este método no es adecuado para hacer mediciones rutinarias de la cantidad de $Q_{H, s}$, pero es útil tenerlo en cuenta ya que permite el estudio del fenómeno de adsorción en la región de potencial donde aparece la reacción de desprendimiento de hidrógeno.

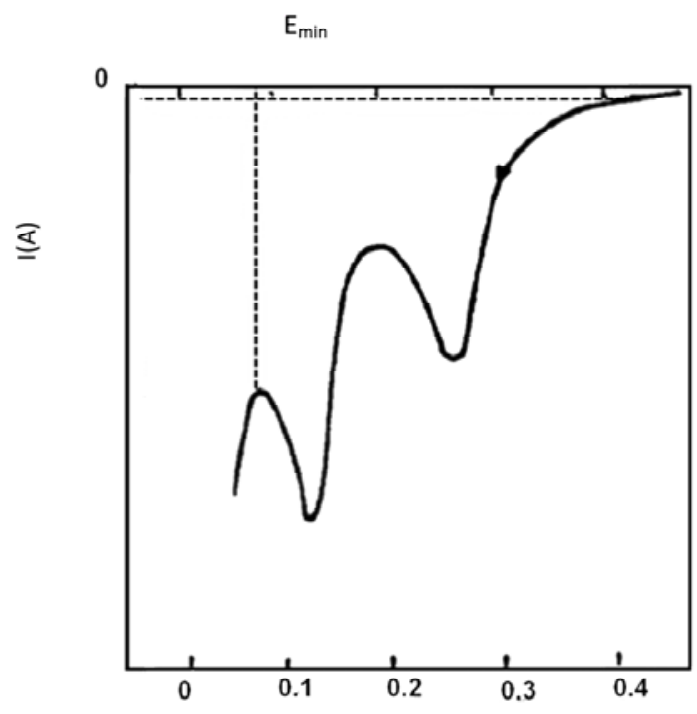

Figura 4. Perfil voltamperométrico que muestra la extrapolación del proceso de adsorción de hidrógeno sobre Pt en $\mathrm{H}_{2} \mathrm{SO}_{4} 0,5 \mathrm{M}$ a $25^{\circ} \mathrm{C}$.

Los voltamperogramas cíclicos a temperatura ambiente no pueden registrarse hasta $-0,01 \mathrm{~V}$ sin que ocurra un importante desprendimiento de hidrógeno molecular. A fin de evitar este inconveniente y poder establecer un método que permita comparar los resultados obtenidos por varios autores, Gilman [197] sugirió que el potencial $E_{\min }$ que corresponde a la corriente mínima, después del segundo pico catódico de hidrógeno, se tome como límite para la integración de la corriente de adsorción de hidrógeno, en la determinación de la cantidad de $Q_{H, s}$. Evidencias posteriores sobre procedimientos más realistas de extrapolación, confirmadas por experiencias sobre electrodos de disco-anillo [196] condujeron a Biegler et al. [198] a recomendar que la cantidad $Q_{H, S}$ determinada por integración de la carga pasada hasta $0,08 \mathrm{~V}$, segundo mínimo de la curva catódica para la adsorción de hidrógeno, fuera dividida por el grado de recubrimiento por hidrógeno a ese potencial, interpolado de la isoterma derivada de los datos capacitivos.

Para el caso del $P t$, si la carga de adsorción de hidrógeno se determina por integración del perfil voltamperométrico de la Figura 4, con $E_{\min }$ igual a 0,08 V, la división de esta carga por 0,84 (valor determinado por interpolación de la isoterma electroquímica de electrosorción de hidrógeno sobre $P t$ en $\mathrm{H}_{2} \mathrm{SO}_{4} 4 \mathrm{M}$ a $25{ }^{\circ} \mathrm{C}$ ) [198], [199], proporciona el valor de la carga asociada al total de sitios recubiertos por hidrógeno del electrodo, esto es $Q_{H, s}$. Una vez conocido $Q_{H, s}$ se puede estimar el valor 
del área real del electrodo considerando el estándar convencional determinado para el metal. La carga integrada involucrada en el proceso de adsorción da una idea del número de átomos de hidrógeno recubriendo el electrodo. Para el caso particular del $P t$ se ha determinado que un átomo de hidrógeno se adsorbe sobre un átomo del metal, según la siguiente reacción [200], [201]:

$$
P t+H^{+}+e^{-} \rightarrow P t(H)_{a d s}
$$

Esto permite relacionar el número de átomos de hidrógeno adsorbidos con una cantidad definida de electricidad, ya que un átomo de hidrógeno se adsorbe por intercambio de un electrón. Así, la carga por $\mathrm{cm}^{2}$ de área real asociada con la adsorción de una monocapa de hidrógeno sobre los planos de bajo índice de Miller del Pt son: $208 \mu \mathrm{C}$ para el plano (100), $241 \mu \mathrm{C}$ para el plano (111) y 147 o $295 \mu \mathrm{C}$ para el plano (110), según si los definidos como átomos superficiales corresponden a 7 o a 7 y 11 átomos de coordinación (Figura 5).
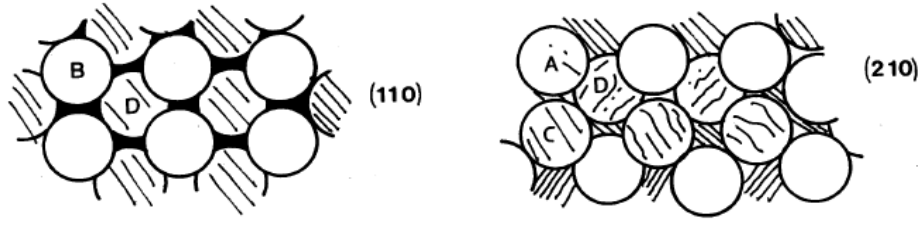

Figura 5. Diferentes tipos de átomos superficiales en los planos (110) y (210) en una red fcc. Las coordinaciones de A, B, C y D son 6, 7, 9 y 11 respectivamente.

Para superficies policristalinas se supone que la superficie consiste en una distribución igual de los tres planos de bajo índice [202], aunque también se ha supuesto que el plano (100) es el predominante [203]. Biegler et al. [198] y otros autores han sugerido que se use $210 \mu \mathrm{C} / \mathrm{cm}^{2}$ como estándar convencional para la carga del $P t$, considerando el plano (100) como predominante y para el cual corresponde una población de $1,3 \times 10^{15}$ átomos $/ \mathrm{cm}^{2}$.

\section{IV.1.a.iv. Cálculo de la carga voltamperométrica}

La densidad de carga eléctrica registrada durante un proceso de oxidación o reducción es un parámetro cuantitativo muy utilizado en la caracterización voltamperométrica de una superficie de electrodo. A partir de la carga voltamperométrica se pueden obtener datos estructurales importantes como la fracción de superficie bloqueada por un proceso de adsorción (hidrógeno, especies oxigenadas, etc.) o el número de electrones intercambiados por sitio de adsorción.

El cálculo de la carga implica la integración del área voltamperométrica comprendida dentro del contorno de un pico de oxidación (o reducción), siendo función de la velocidad de barrido empleada. Así resulta:

$$
Q_{h}=\int_{t_{1}}^{t_{2}} i(t) d t=\frac{1}{v} \int_{E_{1}}^{E_{2}} i(E) d E
$$




$$
E=E_{i 0} \pm v t
$$

donde $t$ es el tiempo, $i$ la intensidad, $d E=v d t, E$ es el potencial y $v$ la velocidad de barrido. La densidad de carga voltamperométrica suele expresarse en $\mu \mathrm{C} / \mathrm{cm}^{2}$.

\section{IV.1.a.v. Perfil voltamperométrico de monocristales de Pt en la región de adsorción de} hidrógeno

Desde 1986 se han realizado numerosos trabajos experimentales mediante los cuales se han podido interpretar los picos característicos de los voltamperogramas de electrodos de monocristales de $P t$, en términos de los procesos de adsorción que ocurren sobre sitios superficiales con una dada simetría [204-206]. Estos conocimientos pueden ser utilizados para comprender los procesos que ocurren sobre la superficie del Pt policristalino.

El perfil voltamperométrico de un electrodo de $P t$ policristalino, realizado en $\mathrm{H}_{2} \mathrm{SO}_{4} 0,5 \mathrm{M}$, contiene la contribución de todos los sitios presentes sobre la superficie. Dado que los diferentes sitios sobre la superficie dan una señal característica es posible, en principio, deconvolucionar el perfil voltamperométrico obteniendo información sobre los diferentes sitios presentes en la superficie [18]. Se puede utilizar la respuesta voltamperométrica de un monocristal de Pt para asignar las diferentes contribuciones de los sitios.

En la Figura 6 se muestran los perfiles voltamperométricos de diferentes electrodos monocristalinos de $P t$, bajo tratamiento de calentamiento a la llama y enfriamiento en atmósfera reductora. Se muestra también a los efectos de comparación una superficie de Pt poliorientado.

Las superficies mostradas son: Pt (111) y dos superficies escalonadas, Pt (554) y Pt (544), con terrazas amplias (111) de 9 átomos y un escalón monoatómico (100) y (110), respectivamente, (Figura 6A); Pt (100) y una superficie escalonada con terrazas amplias de 11 átomos y un escalón monoatómico (111) (Figura 6B); Pt (110) (Figura 6C) y finalmente la superficie poliorientada (Figura 6D). Como se puede observar, la contribución de la terraza (111) da solamente una señal sin rasgos distintivos que se extiende a través de todo el intervalo de potencial (el pico a $0,45 \mathrm{~V}$ es muy agudo pero involucra una cantidad pequeña de carga), y las contribuciones de los escalones (110) y (100) sobre las terrazas (111) dan picos estrechos y bien definidos a $0,125 \vee$ y $0,26 \mathrm{~V}$, respectivamente. Por otro lado, se pueden distinguir tres contribuciones diferentes para la superficie escalonada con terrazas (100). La señal a 0,37 V corresponde a las amplias terrazas (100) y el pico a 0,27 V está asociado con las terrazas ubicadas cercas del escalón, mientras las contribuciones de escalones aparecen a potenciales por debajo de $0,2 \mathrm{~V}$ [18], [207]. El voltamperograma del electrodo de $P t(110)$ se caracteriza por un pico principal a 0,125 V y una contribución sin rasgos distintivos alrededor de 0,2 V-0,25 V. Esta última contribución desaparece cuando el electrodo se prepara bajo diferentes condiciones experimentales y puede estar asociado con facetas (110). 
E (V) (RHE)

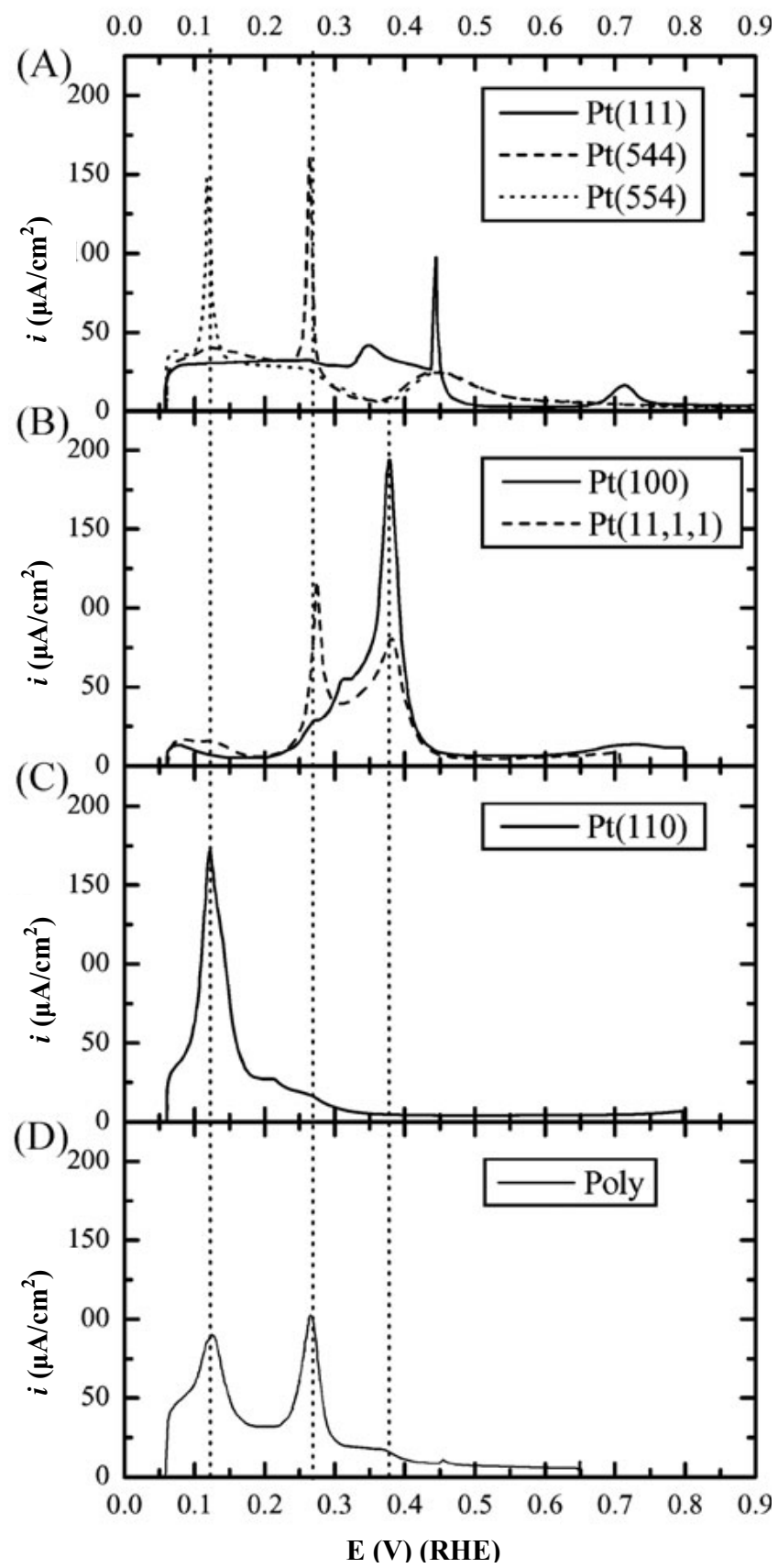

Figura 6. Perfiles voltamperométricos para diferentes electrodos monocristalinos de $P t$ y un electrodo de $P \boldsymbol{t}$ poliorientado en $\mathrm{H}_{2} \mathrm{SO}_{4} \mathrm{O}, 5 \mathrm{M}, \mathrm{v}=50 \mathrm{mV} / \mathrm{s}$ [18].

Todas estas señales reportadas para un electrodo monocristalino deberían aparecer en una superficie poliorientada. Los rasgos voltamperométricos principales de esta superficie son el pico a $0,125 \mathrm{~V}$, el cual debe ser asociado a los sitios tipo (110), y el pico a 0,27 V. Este último pico es el resultado de dos contribuciones diferentes que tienen potenciales similares: una proveniente de sitios con escalones (100) sobre dominios (111) y otra contribución que surge de sitios de un dominio ordenado (100) cerca de un escalón o defecto.

Con esta información es posible deconvolucionar el perfil voltamperométrico de una muestra policristalina. Sin embargo, los sitios con terrazas (111) presentan más bien corrientes planas y sin 
rasgos distintivos entre $0,06 \mathrm{~V}$ y $0,27 \mathrm{~V}$, lo cual impide una deconvolución efectiva y significativa del perfil voltamperométrico.

\section{IV.1.a.vi. Procesos de electrosorción de hidrógeno y oxígeno sobre Pt policristalino}

En la Figura 7 se observa el voltamperograma típico de un electrodo de $P$ t policristalino, realizado en $\mathrm{H}_{2} \mathrm{SO}_{4}$ 0,5 $\mathrm{M}$ a temperatura ambiente, donde se muestran los picos de corriente característicos de los planos cristalográficos presentes en el electrodo. El voltamperograma exhibe tres regiones de potencial bien definidas, que son características para este tipo de electrodos metálicos que se designan como: (a) región de adsorción/desorción de hidrógeno, (b) región de la doble capa eléctrica y (c) región de óxidos.

En la región (a), por debajo de 0,4 V vs. $E R H$, se pueden distinguir varios picos de corriente relacionados con la adsorción/desorción de hidrógeno, cuyas posiciones dependen de los planos cristalográficos predominantes. En esta zona el hidrógeno se adsorbe durante el barrido hacia potenciales positivos decrecientes (catódico) y se desorbe durante el barrido hacia potenciales positivos crecientes (anódico), lo cual se expresa mediante la siguiente reacción

$$
P t+H^{+}+e^{-} \leftrightarrow P t-H_{a d s}
$$

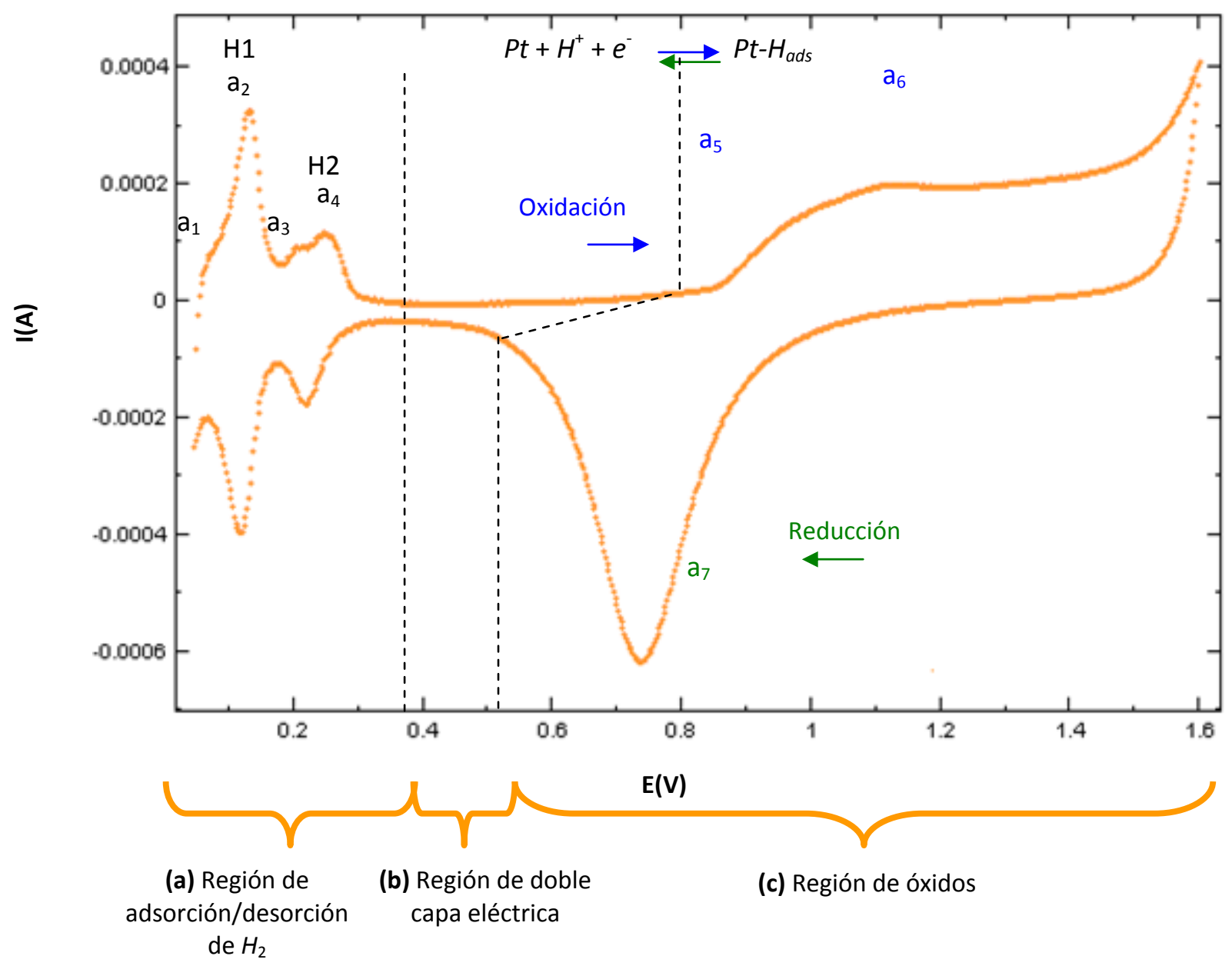

Figura 7. Respuesta voltamperométrica a $0,1 \mathrm{~V} / \mathrm{s}$ registrada en $\mathrm{H}_{2} \mathrm{SO}_{4} 0,5 \mathrm{M}$ a $25^{\circ} \mathrm{C}$, correspondiente a un electrodo de $P$ t polifacetado. 
Los picos de corriente que aparecen en el perfil voltamperométrico de esta región están asociados a diferentes energías de enlace para átomos de hidrógeno sobre los distintos sitios activos del Pt. En la Figura 8 se muestras estos picos de corriente en detalle.

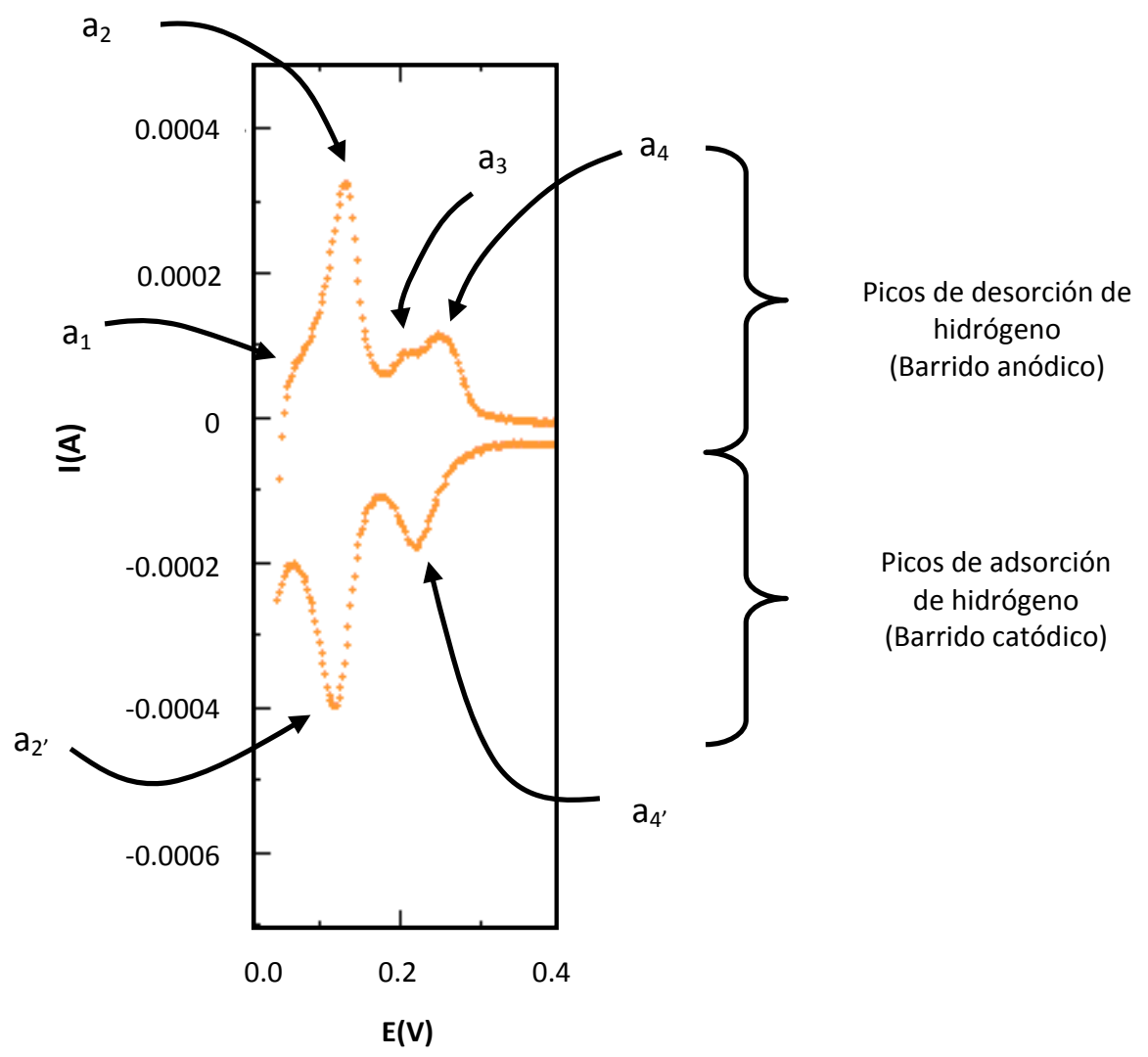

Figura 8. Picos de corriente presentes en la zona de hidrógeno para un electrodo de $\mathrm{Pt}$ policristalino en $\mathrm{H}_{2} \mathrm{SO}_{4}$ $0,5 \mathrm{M}$ a $25^{\circ} \mathrm{C}$.

El proceso de adsorción de hidrógeno se caracteriza por la aparición de dos picos de corriente catódica, los cuales para propósitos de identificación se han designado en la Figura 8 como $\mathrm{a}_{4^{\prime}} \mathrm{y}^{\mathrm{a}^{\prime} \text {, }}$ aduciendo a la naturaleza del enlace $P t-H_{a d s}$. El pico $\mathrm{a}_{4^{\prime}}$ es el primero en aparecer durante la adsorción y el último en desaparecer durante la desorción, por lo que ha sido asociado a la adsorción de hidrógeno sobre los sitios más energéticos de la superficie de $P t$, generando por lo tanto el enlace $P t-H$ más fuerte. Una vez cubiertos los sitios de mayor energía, los restantes comenzarán a ser ocupados, lo cual se manifiesta por la aparición del pico $\mathrm{a}_{2}$, que corresponde al segundo pico de corriente catódica que aparece durante el proceso de adsorción de hidrógeno y que está, por lo tanto, relacionado con el enlace $P t-H$ más débil. La inversión del sentido del barrido de potencial, hacia la dirección de valores de potencial positivos crecientes, da lugar al proceso de desorción de hidrógeno, siendo éste caracterizado por la porción anódica del voltamperograma en la región (a). Los picos de corriente identificados como $a_{2}$ y $a_{4}$ son los equivalentes anódicos a los picos de corriente catódica $a_{2^{\prime}}$ y $a_{4^{\prime}}$, respectivamente. El pico $a_{1}$ se asocia al comienzo de la reacción de desprendimiento de hidrógeno sobre ciertos planos cristalográficos del Pt. En esta región también se encuentra la contribución de la corriente relacionada 
con la oxidación del hidrógeno molecular durante el barrido anódico [208]. El pico $a_{2}$ está relacionado con el hidrógeno adsorbido débilmente sobre los planos (111) y el pico de corriente anódico intermedio $\mathrm{a}_{3}$ está asociado a la desorción de hidrógeno desde los sitios de Pt correspondientes al plano de bajo índice de Miller (110) y cuya energía de enlace es intermedia con respecto a los sitios de planos preferenciales. Este pico no se observa en el barrido catódico del espectro electroquímico debido al solapamiento entre los picos de adsorción preferenciales. El pico $a_{3}$ se suele asociar también a la desorción de hidrógeno en los sitios de Pt cubiertos con oxígeno. [172]. El pico $\mathrm{a}_{4}$ corresponde a la desorción de hidrógeno sobre sitios correspondientes al plano cristalográfico (100) [50].

La zona (b) de la Figura 7, denominada región de la doble capa eléctrica, se caracteriza por la ausencia de reacciones electroquímicas. En esta región se observan fundamentalmente los procesos de carga y descarga de la doble capa eléctrica, la cual para fines prácticos se puede considerar que permanece inalterable en todo el intervalo de potencial estudiado.

Finalmente, en la región (c) del voltamperograma de la Figura 7, ocurren los procesos característicos de adsorción-desorción de oxígeno y, eventualmente, el proceso de desprendimiento de oxígeno molecular. Esta zona se define por la aparición de los hombros $a_{5}$ y $a_{6}$. A potenciales superiores a 0,70 V comienza la formación de una monocapa de óxidos metálicos durante el barrido anódico, determinando la llamada región de óxidos. En esta región el aumento de corriente anódica se origina por el inicio del proceso de oxidación de la superficie del electrodo de $P t$, el cual durante el barrido de potencial y hasta un valor de alrededor de 1,5 V recubre la superficie de $P t$ con una monocapa monomolecular de oxígeno adsorbido. Cuando el límite superior de potencial se incrementa más allá de 1,5 V tienen lugar los procesos de formación de óxidos y de desprendimiento de oxígeno molecular. Debe tenerse en cuenta, sin embargo, que el valor de potencial de 1,5 V no define con precisión el límite entre los procesos de adsorción y desprendimiento de oxígeno en $P t$, ya que éste depende de varios factores tales como electrolito soporte, factor de rugosidad, velocidad de barrido de potencial, etc. Cuando la dirección del barrido de potencial se invierte, partiendo del límite superior de potencial programado, la porción catódica del voltamperograma mostrado en la Figura 7 exhibe un pico de corriente ancho y centrado alrededor de $0,78 \mathrm{~V}$, designado como $\mathrm{a}_{7}$. En este caso, a diferencia de lo que ocurre en la porción anódica, la única contribución al pico de corriente catódica observado es el proceso de desorción de oxígeno de la superficie de Pt. Esto se debe a que cualquier contribución por desprendimiento de oxígeno y/o formación de óxidos, sólo se observa a valores altos de potencial (>2 V) y bajo condiciones de anodización extrema. Por lo tanto, es lógico esperar que la altura y, en alguna medida, la forma del pico de corriente catódica sea sólo función del grado de recubrimiento de la superficie de $P t$ por el oxígeno adsorbido, $\theta_{P t}$ alcanzando una altura máxima cuando $\theta_{P t}=1$. La dependencia en la altura del pico de corriente catódica con el grado de recubrimiento por oxígeno, puede analizarse variando el límite superior de potencial. Los voltamperogramas obtenidos a diferentes valores del límite superior de potencial se muestran en la Figura 9 [209]. Se puede observar que, 
conforme el límite superior de potencial aumenta, los perfiles voltamperométricos anódico y catódico se vuelven más irreversibles, lo cual es una consecuencia de la diferencia de energía involucrada en los procesos de adsorción y desorción correspondientes.

Sin embargo, se ha demostrado que la relación entre la carga involucrada en la adsorción, $Q_{a}$ y la carga involucrada en el proceso de desorción, $Q_{d}$, es siempre aproximadamente igual a la unidad. Por lo tanto, se puede suponer que la cantidad de oxígeno adsorbida es la misma que se desorbe en el barrido inverso de potencial. A valores del límite superior de potencial mayores a 1,15 $\vee$ la relación $Q_{a} / Q_{d}$ es mayor que 1, reflejando la contribución de un proceso adicional al de adsorción de oxígeno durante el barrido anódico de potencial. Esto determina, en cierta forma, la imposibilidad de utilizar la carga involucrada en el proceso de adsorción de oxígeno para cálculos estimativos de parámetros superficiales.

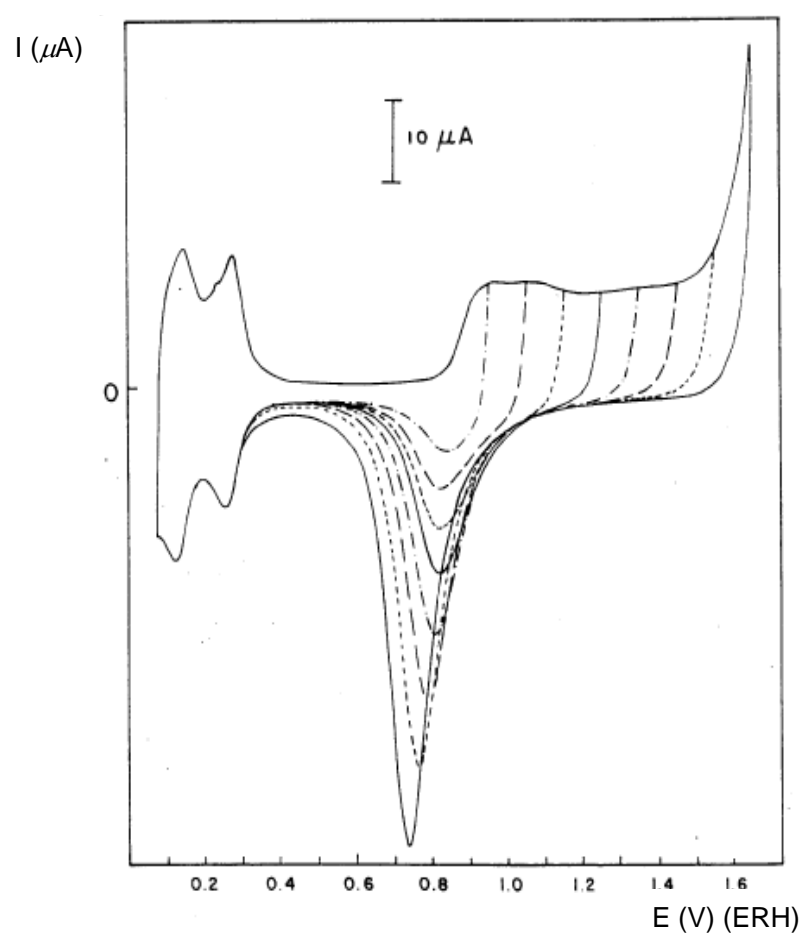

Figura 9. Voltamperogramas de $\mathrm{Pt}$ en $\mathrm{H}_{2} \mathrm{SO}_{4}$ 0,5 M. Potenciales límites superiores de barrido desde 0,91 V hasta $1,66 \mathrm{~V}$, con incrementos de $0,1 \mathrm{~V}, v=50 \mathrm{mV} / \mathrm{s}, A_{G}=0,25 \mathrm{~cm}^{2}$.

Otro aspecto a considerar es el hecho de que la posición del pico de corriente catódica es prácticamente independiente del límite superior de potencial. Hay una variación no mayor de 0,07 V para valores del límite superior entre $1,0 \mathrm{~V}$ y $1,6 \mathrm{~V}$, lo cual permite suponer que en el proceso de reducción, caracterizado por este pico de corriente catódica, sólo un tipo de especie está involucrado.

Por lo tanto, al igual que el hidrógeno, el oxígeno también se adsorbe sobre metales como Pt y el proceso de adsorción tiene lugar a potenciales más positivos, como se puede observar en los voltamperogramas mostrados en la Figuras 7 y 9.

Se ha establecido que un probable mecanismo para la adsorción de oxígeno es el siguiente [210212]: 


$$
\begin{aligned}
& P t+\mathrm{H}_{2} \mathrm{O} \leftrightarrow P t(\mathrm{OH})_{a d s}+H^{+}+e^{-} \\
& P t(\mathrm{OH})_{a d s} \leftrightarrow P t(\mathrm{O})_{a d s}+H^{+}+e^{-}
\end{aligned}
$$

siendo la etapa (25) una reacción de equilibrio rápida, donde se intercambia el primer electrón. Esta etapa sólo es susceptible de evidenciarse a través de métodos rápidos de perturbación, por ejemplo, un barrido de potencial a velocidades mayores a $5 \mathrm{~V} / \mathrm{s}$. La especie oxigenada inicialmente formada, $\operatorname{Pt}(\mathrm{OH})_{a d s}$, continúa su proceso de oxidación [etapa (26)] formando la especie oxigenada $\operatorname{Pt}(\mathrm{O})_{a d s}$, la cual se conserva hasta que se alcanza el grado de recubrimiento $\theta_{p t} \sim 1$, aunque existen ciertas controversias en la bibliografía respecto al tipo final de la especie oxigenada formada [213], [214]. Aunque los aspectos más característicos del proceso de adsorción ya han sido prácticamente aclarado a lo largo de los años, aún existen ciertas controversias respecto a la naturaleza de la capa de oxígeno. La capa de oxígeno ha sido descripta por varios modelos en términos de: i) quimisorción [215], ii) incorporación bajo la superficie formando una capa "dermasorbida" o aleación metal-oxígeno [107], [216] e iii) formación de una fase de óxido metálico [217], [218].

Por lo tanto, de acuerdo a lo presentado hasta aquí, puede decirse que las características voltamperométricas de un electrodo de $P t$ policristalino proveen información valiosa. La variación en la ubicación de los picos de oxidación y reducción es una medida de la irreversibilidad del proceso global. Por otro lado, los picos de corriente principales de los voltamperogramas pueden identificarse fácilmente con su correspondiente sitio activo.

Cuando se analizan reacciones superficiales mediante voltamperometría cíclica es importante tener en cuenta que, además de la información sobre estados de carga (estados de oxidación) de la superficie, también es posible detectar contribuciones de la doble capa eléctrica. El efecto de esta contribución no faradaica debido a la carga de la doble capa sobre la carga total depende de la velocidad de barrido. Así, para bajas velocidades de barrido, la contribución de la carga capacitiva es relativamente pequeña, por ejemplo, para $50 \mathrm{mV} / \mathrm{s}$, pero es mayor comparada con la carga debido a los procesos superficiales. En los voltamperogramas la corrección de la contribución capacitiva puede calcularse a partir de la corriente de la doble capa eléctrica.

La forma del perfil voltamperométrico para Pt (100) se caracteriza por una alta contribución de sitios que corresponden a adátomos de hidrógeno fuertemente adsorbidos y una pequeña contribución de los débilmente adsorbidos. La forma del perfil corriente/potencial es similar al informado para superficies escalonadas con facetas (100) [219] [Figura 10 (a)]. Por otro lado, los voltamperogramas cíclicos para Pt tipo (111) en solución de $\mathrm{H}_{2} \mathrm{SO}_{4}$ 0,5 M, muestran una alta contribución de adátomos de hidrógeno débilmente enlazados (o adsorbidos) [Figura 10 (b)]. La forma de estos perfiles voltamperométricos se asemeja a la de las superficies escalonadas con una alta proporción de facetas (111).

Por lo tanto, de acuerdo a lo visto en esta sección, para el caso de electrocatalizadores de Pt se puede utilizar la adsorción de hidrógeno para definir ciertas propiedades superficiales de interés, debido 
a que la carga de adsorción total es directamente proporcional al número de átomos superficiales. De este modo, como ya se ha descripto, se puede utilizar este dato para calcular el área superficial electroquímicamente activa. Además la distribución de la carga entre los diferentes picos voltamperométricos da una primera estimación de la presencia de los diferentes sitios superficiales en la superficie total [220], [221].
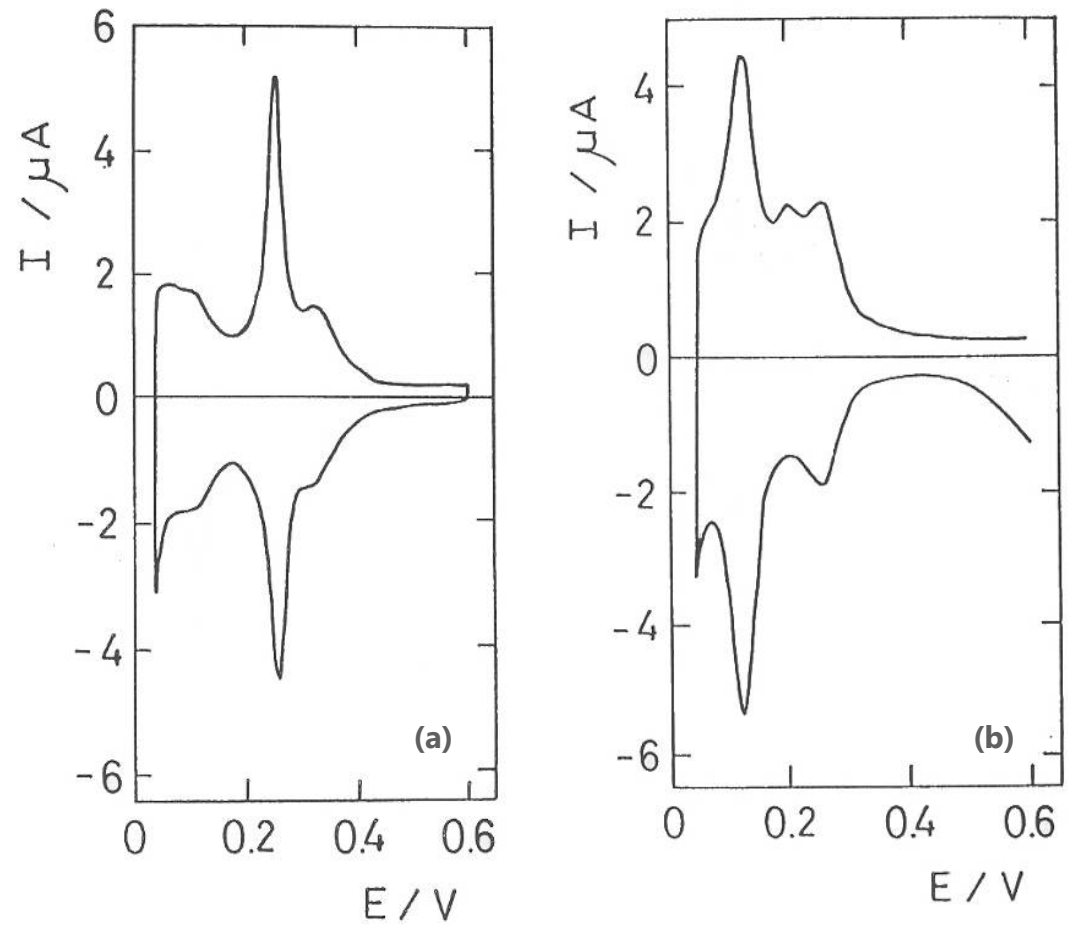

Figura 10. Respuestas voltamperométricas a $0,1 \mathrm{~V} / \mathrm{s}$ registradas en $\mathrm{H}_{2} \mathrm{SO}_{4} 0,5 \mathrm{M}$ a $25^{\circ} \mathrm{C}$ para electrodos de $\mathrm{Pt}$ con orientaciones cristalográficas preferenciales tipo (a) (100) y (b) (111).

\section{IV.2. Técnicas físicas}

\section{IV.2.a. Microscopía electrónica de barrido (SEM)}

La microscopía electrónica de barrido (SEM: "Scanning Electron Microscopy") es una técnica ampliamente utilizada para el análisis de superficies que permite determinar el tamaño y la morfología de los electrocatalizadores. En esta técnica la superficie es barrida por un haz de electrones focalizados sobre una determinada zona de la muestra y, mediante un detector apropiado, se registra el resultado de esa interacción.

Cuando un haz de electrones de suficiente energía incide sobre la superficie de un sólido, se producen diferentes señales que proporcionan información acerca de la zona de interacción de dicho haz con los átomos de la superficie. En esta interacción con la materia se producen varios fenómenos, entre ellos la reemisión de una parte de la radiación incidente, emisión de luz, emisión de electrones secundarios y Auger y rayos X (Figura 11). 


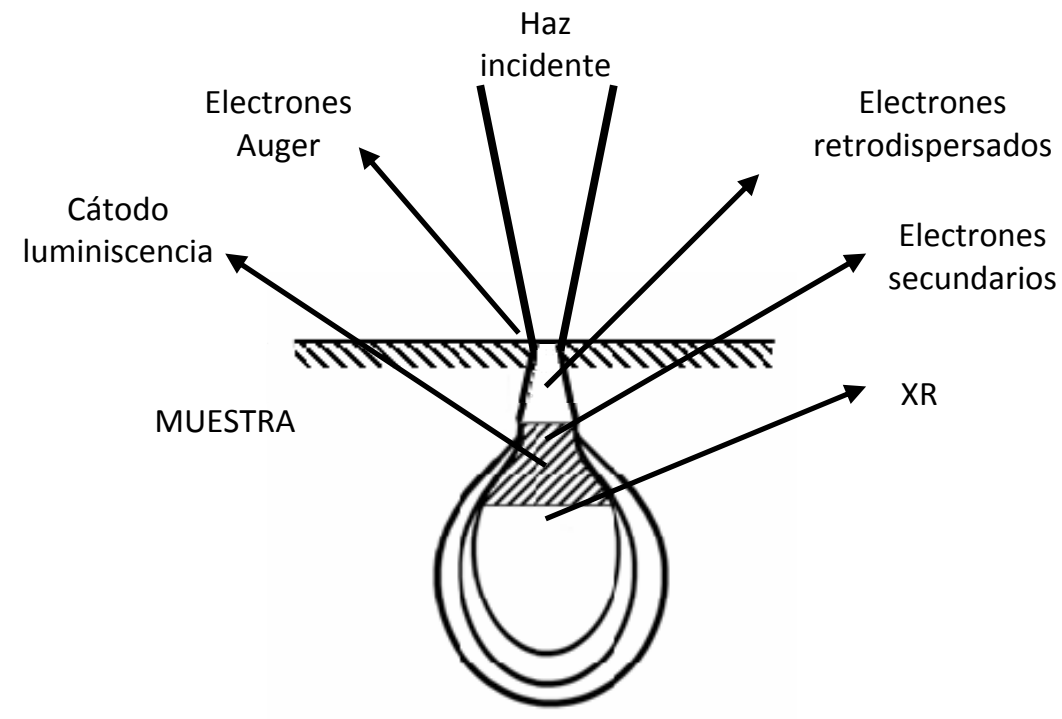

Figura 11. Señales generadas por la interacción de un haz de electrones con una muestra.

En el microscopio electrónico de barrido generalmente el detector utilizado es un tubo de rayos catódicos, de tal forma que la intensidad de la imagen varía en cada punto con la intensidad del haz de electrones generado en la superficie. En la Figura 12 se muestra un microscopio SEM y cada una de las partes constituyentes.

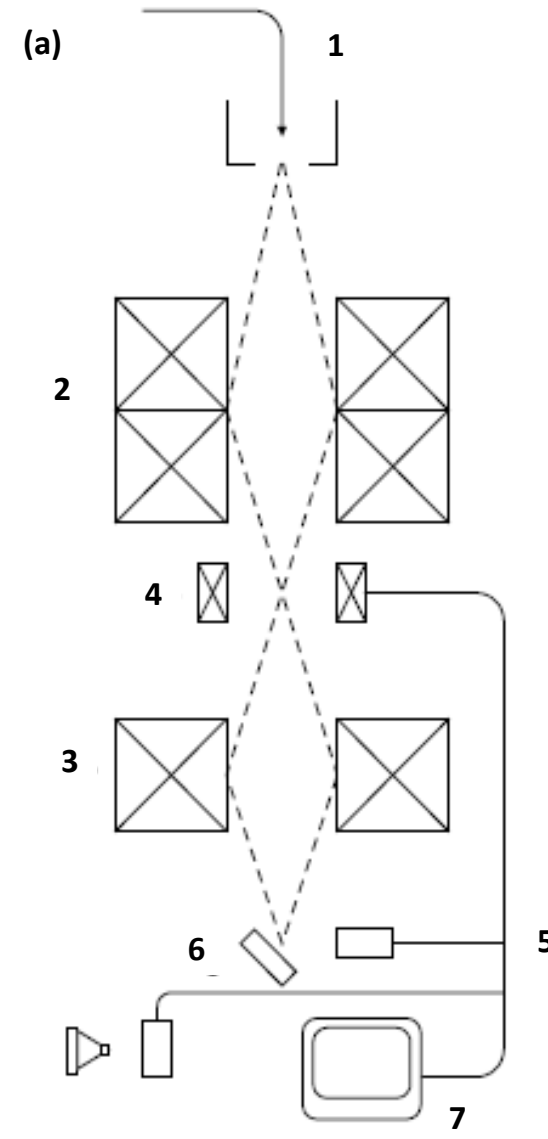
1. Cañón de electrones
2. Lente condensador
(b)
3. Lente final
4. Bobinas deflectoras
5. Detector de electrones secundarios
6. Muestra
7. Tubo de rayos catódicos

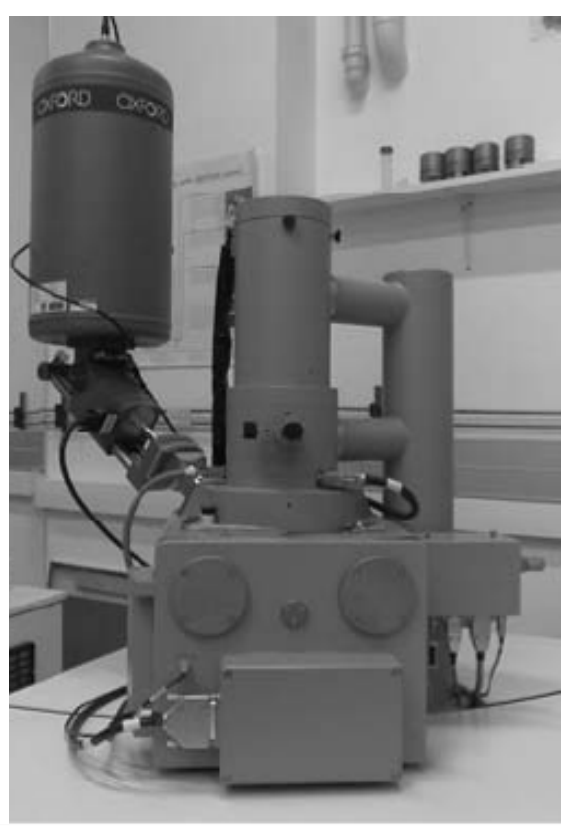

Figura 12. (a) Esquema de los componentes de un microscopio electrónico de barrido, (b) fotografía de un microscopio SEM. 
Las imágenes que se obtienen, por lo general, corresponden a electrones secundarios o electrones retrodispersados emitidos tras la interacción de la muestra con un haz incidente de entre 5 y $30 \mathrm{KeV}$, teniendo un mayor poder de penetración cuando se aplica un mayor voltaje al haz y, por lo tanto, obteniendo la información de un área mayor de la muestra. En cuanto a la resolución depende de distintos factores como el tamaño del haz de electrones, la cantidad de electrones secundarios o retrodispersados y la relación señal/ruido [222].

Los electrones arrancados a los átomos de la muestra por la acción del bombardeo de electrones del haz primario se denominan electrones secundarios y proporcionan información acerca de la topografía (o morfología) superficial. Al ser grande el número de electrones emitidos se puede establecer un buen contraste. Por otra parte, al ser electrones de baja energía, entre 5 a $10 \mathrm{eV}$, pueden ser desviados fácilmente de su trayectoria emergente inicial y se puede obtener información de zonas que no están a la vista del detector. Esta particularidad es fundamental para otorgar a esta señal la posibilidad de aportar información "en relieve" y por este motivo es la señal con la que comúnmente se obtienen las imágenes de la muestra. Debido a la baja energía de los electrones secundarios, en su viaje hacia el exterior de la muestra van perdiendo energía por diferentes interacciones, de forma que sólo los que están muy próximos a la superficie tienen alguna probabilidad de escapar del material y llegar al detector. La señal de electrones secundarios procede de la misma superficie y de una pequeñísima zona por debajo de ella, del orden de 50 a $100 \AA ̊$.

Los electrones que rebotan elásticamente sobre la superficie se denominan electrones retrodispersados y tienen energías del mismo orden que la de los electrones incidentes. La principal utilidad de la señal de los electrones retrodispersados reside en que su emisión depende fuertemente del número atómico de la muestra. A mayor número atómico, mayor intensidad de la señal. Este hecho permite distinguir fases de un material de diferente composición química. Por lo tanto, dos partes de la muestra que tengan distinta composición se muestran con distinta intensidad aunque no exista diferencia topográfica entre ellas. Las zonas con menor número atómico se verán más oscuras que las zonas que tienen mayor número atómico. Esta es la aplicación principal de la señal de electrones retrodispersados.

El microscopio electrónico de barrido puede estar equipado con varios detectores: un detector de electrones secundarios $(S E)$ para obtener imágenes de topografía superficial de alta resolución, un detector de electrones retrodispersados $(B S E)$ que permite obtener imágenes de composición y topografía de la superficie y un detector de energía dispersiva (EDS) que permite colectar los rayos $\mathrm{X}$ generados por la muestra y realizar diversos análisis e imágenes de distribución de elementos de muestra.

En la Figura 13 se muestra la disposición de los detectores antes mencionados y en la Tabla I los diferentes modos de operación del microscopio electrónico de barrido. 


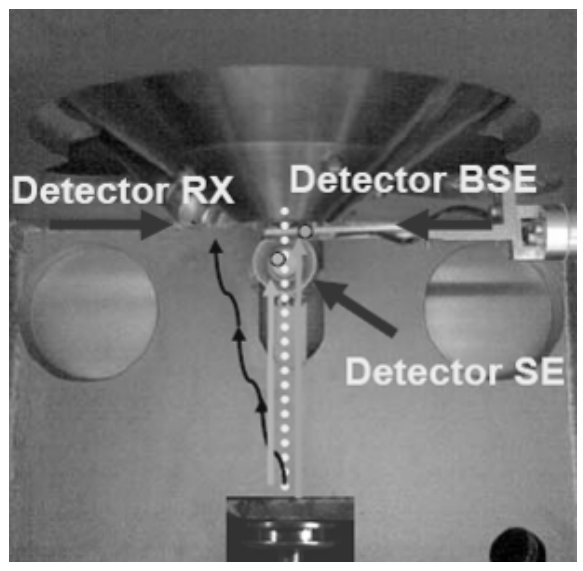

\section{Electrones Secundarios}

(SE) ("Secondary Electron Image")

Imagen: Topografía superficial

Electrones Retrodispersados

$(B S E)$ o $B E I$ ("Backscattered Electron Image")

Imagen: Composición y topografía

\section{Rayos X}

(EDS) ("Energy Dispersive Spectroscopy")

Espectroscopia de rayos $\mathrm{X}$

Microanálisis cuantitativo, semicuantitativo

Mapping, perfil de línea

Figura 13. Detectores de un microscopio electrónico de barrido.

Tabla I. Modos de operación del microscopio electrónico de barrido.

\begin{tabular}{|c|c|c|c|}
\hline Modo & $\begin{array}{l}\text { Señal detectada y } \\
\text { visualizada }\end{array}$ & Información de la imagen & Resolución aproximada \\
\hline Emisivo & Electrones secundarios & $\begin{array}{l}\text { Topografía, voltaje, campos } \\
\text { eléctricos y magnéticos }\end{array}$ & 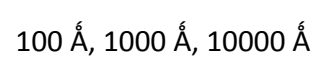 \\
\hline Reflexivo & Electrones retrodifundidos & Composición, topografía & 1000 Á \\
\hline Cátodoluminiscencia & Fotones & Composición & $1000 \AA ̊$ \\
\hline Absorción & $\begin{array}{c}\text { Corriente absorbida por la } \\
\text { muestra }\end{array}$ & Topografía & $1 \mu \mathrm{m}$ \\
\hline Conductivo & $\begin{array}{l}\text { Corrientes inducidas en la } \\
\text { muestra }\end{array}$ & Conductividad inducida & $1000 \AA ̊$ \\
\hline Rayos X & Rayos X característicos & Composición & $1 \mu \mathrm{m}$ \\
\hline Transmisión & Electrones transmitidos & Cristalografía de la muestra & 10 a $100 \AA ̊$ \\
\hline Auger & Electrones Auger emitidos & Composición & $1 \mu \mathrm{m}$ \\
\hline
\end{tabular}

El modo de operación que se utilizó principalmente para la caracterización de los electrodepósitos de $P t$ fue el modo emisivo, en el cual se detectan los electrones secundarios emitidos por la muestra, obteniéndose en la pantalla una imagen donde las variaciones de intensidad sugieren al observador sensaciones de relieve que se corresponden, con muy buena aproximación, a la topografía de la superficie observada.

En esta tesis, para la caracterización y determinación de la morfología superficial de las partículas de Pt electrodepositadas se utilizó un microscopio electrónico de barrido marca FEI, modelo Quanta 200, con las siguientes características: resolución $3 \mathrm{~nm}$, detector de centelleo para electrones retrodispersados y cámara $284 \mathrm{~mm}$. Las condiciones generales de operación fueron 20 a 25 kV y una distancia de trabajo entre 7,7 y $11,5 \mathrm{~mm}$. Cabe aclarar que a fines comparativos las imágenes de los capítulos siguientes siempre se mostrarán bajo las mismas condiciones de trabajo. 


\section{IV.2.b. Microscopía electrónica de transmisión (TEM)}

El microscopio electrónico de transmisión (TEM: "Transmission Electron Microscopy") más sencillo consta de dos lentes formadoras de la imagen de modo parecido a los microscopios ópticos convencionales. La iluminación proviene de un cañón de electrones emitidos por un filamento de $W$ o $L a B_{6}$. Los electrones son acelerados al aplicar un potencial negativo y focalizados mediante dos lentes condensadoras sobre una muestra delgada, transparente a los electrones. Después de pasar a través de la muestra los electrones son recogidos y focalizados por la lente objetivo dentro de una imagen intermedia ampliada. La imagen se puede ampliar aún más gracias a las lentes proyectoras, las cuales controlan la amplificación de la imagen en la pantalla fluorescente. La imagen final se proyecta sobre una pantalla fluorescente o una película topográfica [223]. En la Figura 14 se muestra un esquema de un microscopio TEM y sus partes.

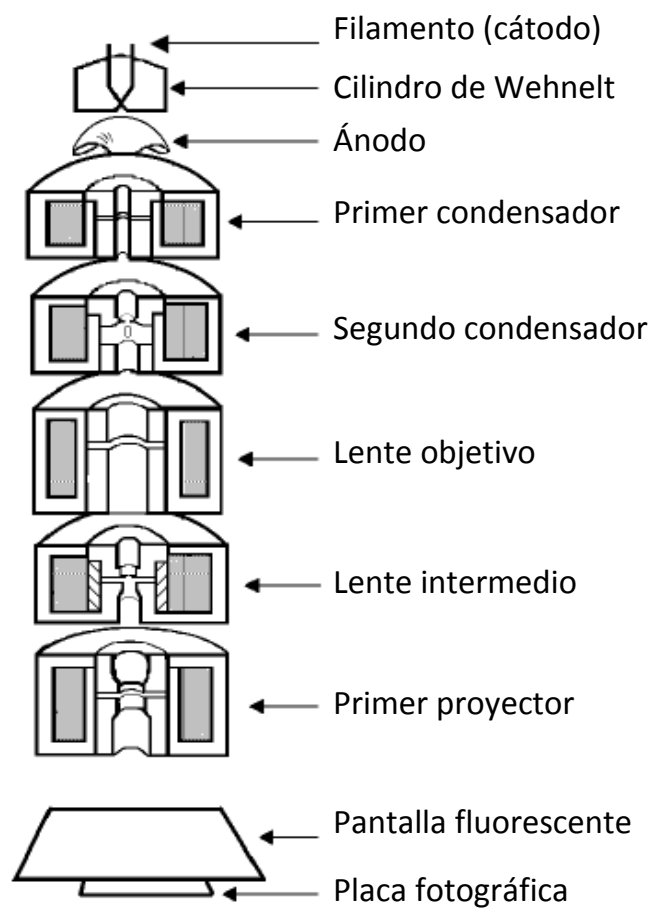

Figura 14. Esquema de un microscopio electrónico de transmisión.

Con un microscopio de dos lentes se puede llegar a aumentar la imagen alrededor de 1000 veces. El poder de resolución podría llegar hasta $5 \mathrm{~nm}$ siempre y cuando se consiguieran aumentos de 50000, lo que es posible utilizando un vidrio de aumento sobre la imagen fluorescente en el microscopio, o un aumento fotográfico de la imagen registrada en la película.

En cuando al modo de operación del microscopio TEM, una muestra delgada se irradia con un haz de electrones de densidad de corriente uniforme, cuya energía se encuentra dentro del intervalo de 100 a $200 \mathrm{keV}$. Parte de esos electrones son transmitidos, otros son dispersados y otra parte de los electrones da lugar a las interacciones ya mencionadas. El TEM emplea la transmisión/dispersión de los 
electrones para formar imágenes, la difracción de los electrones para obtener información acerca de la estructura cristalina y la emisión de rayos $X$ característicos para determinar la composición elemental de la muestra [222].

Para que se produzca la transmisión de electrones a través de la muestra es necesario que ésta sea delgada y, por lo tanto, transparente a los electrones. Se recomienda utilizar muestras con un espesor menor a $100 \mathrm{~nm}$ ya que cuanto menor sea el espesor de la muestra las imágenes obtenidas tienen mejor calidad.

Los electrones poseen características tanto de onda como de partícula. En cuanto a su comportamiento ondulatorio se pueden observar variaciones tanto en la amplitud como en la fase de la onda al atravesar la muestra y ambos tipos de variaciones dan lugar al contraste en la imagen obtenida. En TEM se hace una distinción fundamental entre contraste de amplitud y contraste de fase. En la mayoría de situaciones ambos tipos contribuyen a la formación de la imagen pero uno de ellos tiende a dominar. En las imágenes de contraste de amplitud se obtienen imágenes de campo claro o campo oscuro seleccionando, mediante diafragmas o aperturas, el haz directo o los haces dispersados, respectivamente. Dentro del contraste de amplitud existen dos tipos principales: el contraste debido al espesor de la muestra y el contraste debido a la difracción de los electrones. En el primer caso, el contraste se produce debido a la dispersión incoherente y elástica de los electrones al atravesar la muestra y depende fuertemente del número atómico y del espesor de la misma. Este contraste es el más importante en el caso de muestras no cristalinas, como polímeros, y es el contraste crítico de las muestras biológicas. El contraste de difracción se produce debido a la dispersión coherente y elástica de los electrones al atravesar la muestra y está controlado por la estructura cristalina y la orientación de la misma. Se da cuando la dispersión de los electrones se produce a un ángulo de Bragg determinado y por tanto sólo aparece en muestras cristalinas.

Las imágenes de contraste de fase se forman seleccionando más de un haz de electrones y generalmente se asocia con la microscopía electrónica de alta resolución (HRTEM) aunque a bajos aumentos también se produce este tipo de contraste. Este contraste se utiliza ampliamente de tres formas:

i. imágenes que se relacionan directamente con la estructura periódica de una muestra cristalina,

ii. imágenes de franjas de Moiré e

iii. imágenes de contraste de Fresnel.

Como se mencionó anteriormente, en los microscopios TEM la imagen puede formarse en campo claro o en campo oscuro. En campo claro la imagen se forma a partir del haz transmitido, que no ha sufrido dispersión, y la imagen del objeto es oscura sobre un fondo brillante. Si por el contrario se utilizan los electrones dispersados, en este caso la imagen aparece brillante sobre un fondo oscuro (imagen en campo oscuro). La Figura 15 ilustra la formación de imagen en campo claro y oscuro. 
(a)

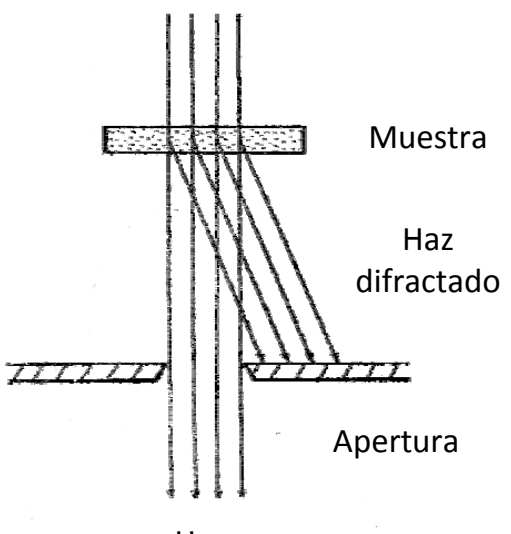

Haz

transmitido

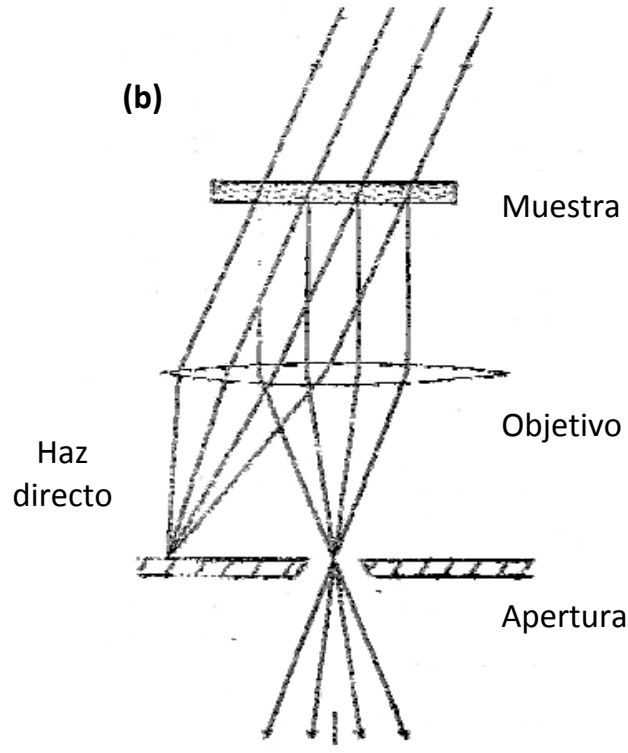

Eje óptico

Figura 15. Formación de la imagen en (a) campo claro y (b) oscuro.

Con un microscopio TEM se puede obtener un diagrama de difracción de la muestra, que permite conocer la estructura cristalina. Esto es posible si se hace incidir el haz de electrones sobre un cristal con un ángulo capaz de satisfacer la ley de Bragg [ver ecuación (27)], para una determinada distancia entre planos atómicos $d_{h k l}$. Como la longitud de onda de los electrones es muy pequeña, ese ángulo también lo es, por lo que el haz de electrones debe incidir prácticamente paralelo a los planos reticulares. El diagrama de difracción está formado por los puntos de corte de los haces difractado y transmitido con el plano de la pantalla. Representa, por lo tanto, la sección de la red recíproca del cristal en el plano normal al haz de electrones [224]. En la Figura 16 se ilustra la obtención del diagrama de difracción de electrones de un cristal.
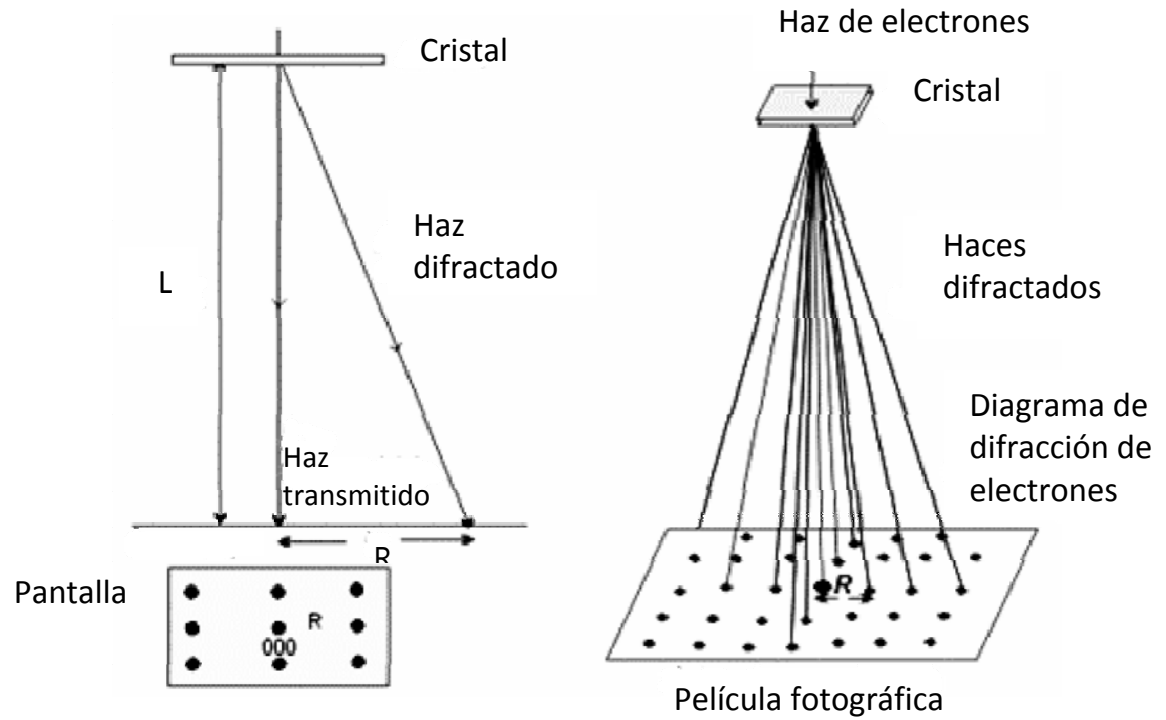

Figura 16. Obtención del diagrama de difracción de electrones. 
En la tesis, para la caracterización de las muestras electrodepositadas se utilizó un equipo Philips CM 200 UT configurado para alta resolución, que trabaja con una tensión de aceleración variable desde 20 a $200 \mathrm{kV}$, con filamento de hexaboruro de lantano $L a B_{6}$, resolución entre líneas de 0,14 nm, resolución entre puntos de 0,19 nm y magnificación de $600000 \mathrm{X}$ en modo TEM y $300000 \mathrm{X}$ en modo STEM (permite la formación de imágenes de barrido de los electrones transmitidos). El microscopio está equipado con una cámara $C C D$ para la adquisición de imágenes y diagramas de difracción de electrones de alta calidad, tiene alto rango dinámico y elevada sensibilidad, y está integrada dentro del programa de adquisición y tratamiento de imágenes. También dispone de un portamuestras con una copa de Faraday, adecuado para el estudio del daño por irradiación en materiales.

\section{IV.2.c. Difracción de rayos X (XRD)}

La difracción de rayos X (XRD: "X Ray Diffraction") corresponde a la interacción de los electrones incidentes con los electrones de las capas internas del material. Como resultado de la colisión un electrón es expulsado y un electrón de mayor energía ocupa ese lugar emitiendo un fotón de rayos X.

La difracción de rayos $\mathrm{X}$ por un plano cristalino ocurre sobre aquellos ángulos de incidencia que cumplen con la ley de Bragg

$$
n \lambda=2 d_{h k l} \operatorname{sen} \theta
$$

donde $\lambda$ es la longitud de onda de los rayos $X, n$ es el orden de la difracción, $\theta$ es el ángulo de incidencia de la radiación y $d_{h k l}$ es la distancia entre planos cristalinos. Usando la ley de Bragg se pueden obtener los espaciados de red.

Durante la medición se hace incidir un haz de rayos $X$ sobre un cristal que posee una familia de planos atómicos paralelos definidos por sus índices de Miller $(h, k, l)$ y separados una distancia $d$. Cada plano refleja una porción de la radiación. El haz incidente forma un ángulo $\theta$ sobre la familia de planos, por el cual se obtienen únicamente haces difractados cuando las reflexiones en los sucesivos planos atómicos paralelos interfieren aditivamente. Esto sucede cuando la diferencia de trayectoria entre los rayos reflejados por dos planos adyacentes es un múltiplo entero de su longitud de onda. Siendo la longitud de onda de los electrones muy pequeña esta ley se satisface para ángulos $\theta$ muy pequeños, es decir, rayos casi paralelos a los planos cristalinos [225-227]. Si no se cumple la ley de Bragg, la interferencia es de naturaleza no constructiva y el campo del haz difractado es de muy baja intensidad. En la Figura 17 se representan las bases de la ley de Bragg.

Los espectros se miden con una fuente estacionaria de rayos $\mathrm{X}$, generalmente $K \alpha, \mathrm{y}$ un detector móvil que registra la radiación difractada como función del ángulo $2 \theta$ entre el haz que llega y el que es difractado.

Mediante esta técnica se pueden identificar las fases cristalográficas, incluso en medidas "in situ" [228], [229]. La técnica también puede utilizarse para seguir la cinética de reacciones en estado sólido 
usadas en la activación de los catalizadores, tales como reducción, oxidación y sulfuración. Mediante un análisis cuidadoso se puede llegar a obtener información sobre el tamaño de las partículas.

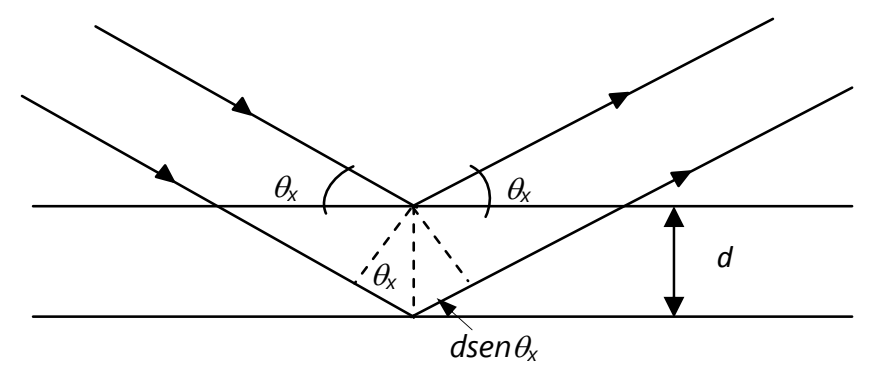

Figura 17. Representación de la ley de Bragg.

La técnica $X R D$ permite analizar la estructura cristalina de los materiales. Los rayos $X$ interactúan con las muestras, por lo tanto para que exista difracción es necesario que el material tenga alguna fase cristalina, es decir, contar con sistemas cristalinos con orden de largo alcance. Este es el motivo por el cual un material amorfo no se puede detectar. Las fases amorfas y las pequeñas partículas dan bandas anchas o no muestran nada. Para el caso particular de catalizadores, si existe una distribución de tamaños de partículas, el espectro sólo reflejará las de mayor tamaño presentes. Para poder ser analizadas, las muestras deben encontrarse en forma de polvo fino policristalino, material policristalino compacto soportado (laminas delgadas) o material policristalino con forma irregular.

Como los rayos $X$ tienen longitudes de onda en el orden de los $\AA$, son suficientemente energéticos como para penetrar en los sólidos y, por lo tanto, dan información de la estructura interna del material. La región superficial, donde realmente el catalizador actúa, es prácticamente insensible para esta técnica.

Las muestras medidas en este trabajo de tesis fueron preparadas de forma tal que en el portamuestra las partículas de polvo de material electrodepositado estuvieran orientadas al azar y fueran de tamaño muy pequeño (del orden de micrones). Las muestras fueron analizadas en un difractómetro de rayos X marca Philips Analytical X-Ray B. V., con una radiación $\mathrm{Cu} K \alpha(\lambda=1,54 \AA$ A), 40 $\mathrm{kV}, 30 \mathrm{~mA}$, colimador $6 \mathrm{~mm}$, a $2^{\circ} /$ minuto, en un intervalo $2 \theta$ de escaneo de 30 a $60^{\circ}$ con una velocidad de escaneo de 0,01 grados. Los resultados obtenidos fueron analizados, comparando difractogramas con los de una base de datos PDF ("Powder Diffraction File").

Para una mayor comprensión de la técnica, así como también para la interpretación de los difractogramas de rayos $X$, se pueden consultar las referencias [226], [227].

\section{IV.2.d. Espectrofotometría}

\section{IV.2.d.i. Espectrofotómetro}

Un espectrofotómetro es un instrumento que proporciona información sobre la intensidad de la radiación en función de la longitud de onda. Permite comparar la radiación absorbida o transmitida por 
una solución que contiene una cantidad desconocida de soluto con otra que contiene una cantidad conocida de la misma sustancia. Este instrumento tiene la capacidad de proyectar un haz de luz monocromática a través de una muestra y medir la cantidad de luz absorbida. Esto permite obtener información sobre la naturaleza y cantidad de la sustancia presente en la muestra.

\section{IV.2.d.ii. Leyes de absorción}

Cuando un haz de luz pasa a través de un medio, se registra una cierta pérdida de intensidad, debido a la absorción por parte de la sustancia.

Se llama transmitancia, $T_{r}$, a la relación entre la luz incidente y la luz transmitida:

$$
\begin{aligned}
& T_{r}=I_{1} / I_{0} \\
& \% T_{r}=\left(I_{1} / I_{0}\right) \times 100
\end{aligned}
$$

siendo $I_{1}$ e $I_{0}$, las intensidades saliente y entrante, respectivamente (Figura 18).

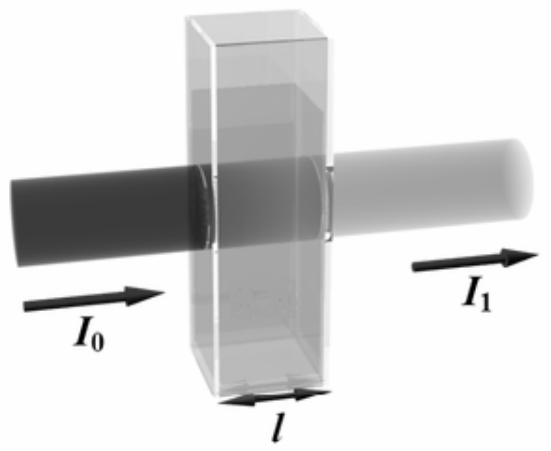

Figura 18. Diagrama de absorción de un haz de luz que atraviesa una cubeta con un camino óptico $l$.

En la práctica se emplea más determinar la absorbancia, $A$, que la transmitancia, $T_{r}$, debido a que la relación entre $A$ y concentración de una solución es directamente proporcional, mientras que la $T_{r}$ es inversamente proporcional.

La relación entre la absorbancia y la transmitancia es la siguiente:

$$
A=-\log _{10} T_{r}=-\log _{10} \frac{I_{1}}{I_{0}}
$$

0

$$
A=2-\log _{10} \% T_{r}
$$

Si $\% T_{r}=100, A=2-\log T_{r}=2-\log 100=0$, mientras que si $\% T_{r}=0, A=2-\log 0=\infty$

Los equipos que se utilizan para las determinaciones presentan como resultado absorbancias, pero lo que realmente miden es $\% T_{r}$ que luego transforma a absorbancia.

Debido a que se puede perder intensidad por la interacción con la cubeta o el solvente se hace una primera medida con una solución de referencia o blanco, que contiene todas las posibles sustancias 
que intervienen en la lectura excepto la que se va a medir. Todas las medidas posteriores se refieren a esta medida inicial y se realizan en la misma cubeta que se utilizó en la medida del blanco.

La ley de Lambert-Beer relaciona linealmente la intensidad de luz incidente en un medio, $I_{0}$, con la intensidad saliente, $l_{1}$, después que en el medio se produce absorción. La relación entre ambas intensidades puede expresarse a través de la siguiente relación:

$A=\mathbf{a} \cdot \mathbf{b} \cdot \mathbf{c}$

siendo $A$ la absorbancia, a una constante de proporcionalidad llamada absortividad, b la longitud de paso de la luz y c la concentración del absorbente. La absorbancia $A$ es adimensional, en tanto que la absortividad a es una magnitud que depende de las unidades empleadas para b y c. A menudo b viene dada en términos de $\mathrm{cm}$ y $\mathrm{c}$ en $\mathrm{g} / \mathrm{l}$. Así la absortividad tiene unidades de $\mathrm{l} / \mathrm{g} \mathrm{cm}$. Cuando la concentración se expresa en moles/l y la longitud de la celda en $\mathrm{cm}$, la absortividad se llama absortividad molar, se designa como $\varepsilon$ y tiene unidades $\mathrm{de} \mathrm{l} / \mathrm{mol} \mathrm{cm}$.

A partir de la relación (32) se puede ver que la absorbancia de una solución es directamente proporcional a la concentración y a la longitud del paso de la luz. Una aplicación práctica de la ley de Lambert-Beer es que, conociendo la absorbancia de una sustancia, es posible determinar su concentración a través de una curva de calibración, donde se representa gráficamente la absorbancia $A$ (eje de ordenadas) frente a la concentración c (eje de abscisas). Se ensaya con varias soluciones de concentración conocida determinando sus absorbancias, a partir de las cuales se construye la curva de calibrado, $A$ vs. c, la cual da una línea recta. Las concentraciones de las soluciones problemas se determinan por interpolación de sus absorbancias en la curva de calibración. Se debe tener en cuenta la linealidad, es decir, el intervalo de concentraciones del cromógeno (grupo responsable del fenómeno de absorción) entre las cuales existe una relación lineal entre absorbancia y concentración. Cuando la concentración del cromógeno sobrepasa los límites de linealidad deja de cumplirse la ley de LambertBeer, convirtiéndose la recta en una curva. La lectura de la absorbancia fuera de los límites de linealidad se traduce en una concentración falsamente baja de cromógeno. Bajo esta situación, es necesario diluir la muestra para que su concentración se encuentre dentro en los límites de la linealidad.

El método espectrofotométrico que se emplea en esta tesis se basa en consideraciones de los espectros de absorción de las soluciones preparadas por disolución de las muestras de Pt electrodepositado. En el caso de mezclas de metales, los espectros de absorción se encuentran solapados y mediante procesamientos matemáticos pueden ser aislados para obtener una señal individual de espectro para cada elemento en particular. Los efectos de interferencia pueden ser eliminados seleccionando un orden de derivación apropiado y un valor de longitud de onda adecuado. El espectro derivativo puede ser calculado fácilmente con ayuda de un software apropiado. Los aspectos teóricos e instrumentales de la técnica espectrofotométrica derivativa pueden encontrarse en la bibliografía [230]. 


\section{IV.2.d.iii. Métodos de disolución del Pt de las muestras $P t /$ carbono}

Un aspecto crítico para la determinación de la cantidad de Pt electrodepositado por aplicación de electrólisis pulsante es la separación del metal del sustrato carbono. Esta separación se puede llevar a cabo por disolución del Pt, formando cloruros complejos con ayuda de agentes oxidantes, siendo ácido nítrico el preferido por su alta eficiencia y velocidad de disolución. La ecuación siguiente representa, en forma simplificada, el proceso de disolución de $P t$ en agua regia:

$$
3 \mathrm{Pt}+4 \mathrm{HNO}_{3}+18 \mathrm{HCl} \rightarrow 3 \mathrm{H}_{2} \mathrm{PtCl}_{6}+4 \mathrm{NO}+8 \mathrm{H}_{2} \mathrm{O}
$$

La disolución del Pt con agua regia es eficiente y rápida a $70-90{ }^{\circ} \mathrm{C}$, pero presenta algunos inconvenientes a causa de la descomposición del ácido nítrico con producción de óxidos de nitrógeno, el consumo excesivo de cloruros debido a su oxidación a cloro gaseoso y los efectos tóxicos y corrosivos del ácido nítrico y sus óxidos. Las pérdidas de agente oxidante (ácido nítrico) y agente complejante (cloruro) retardan la velocidad de disolución e incrementan el tiempo de lixiviación [231]. 


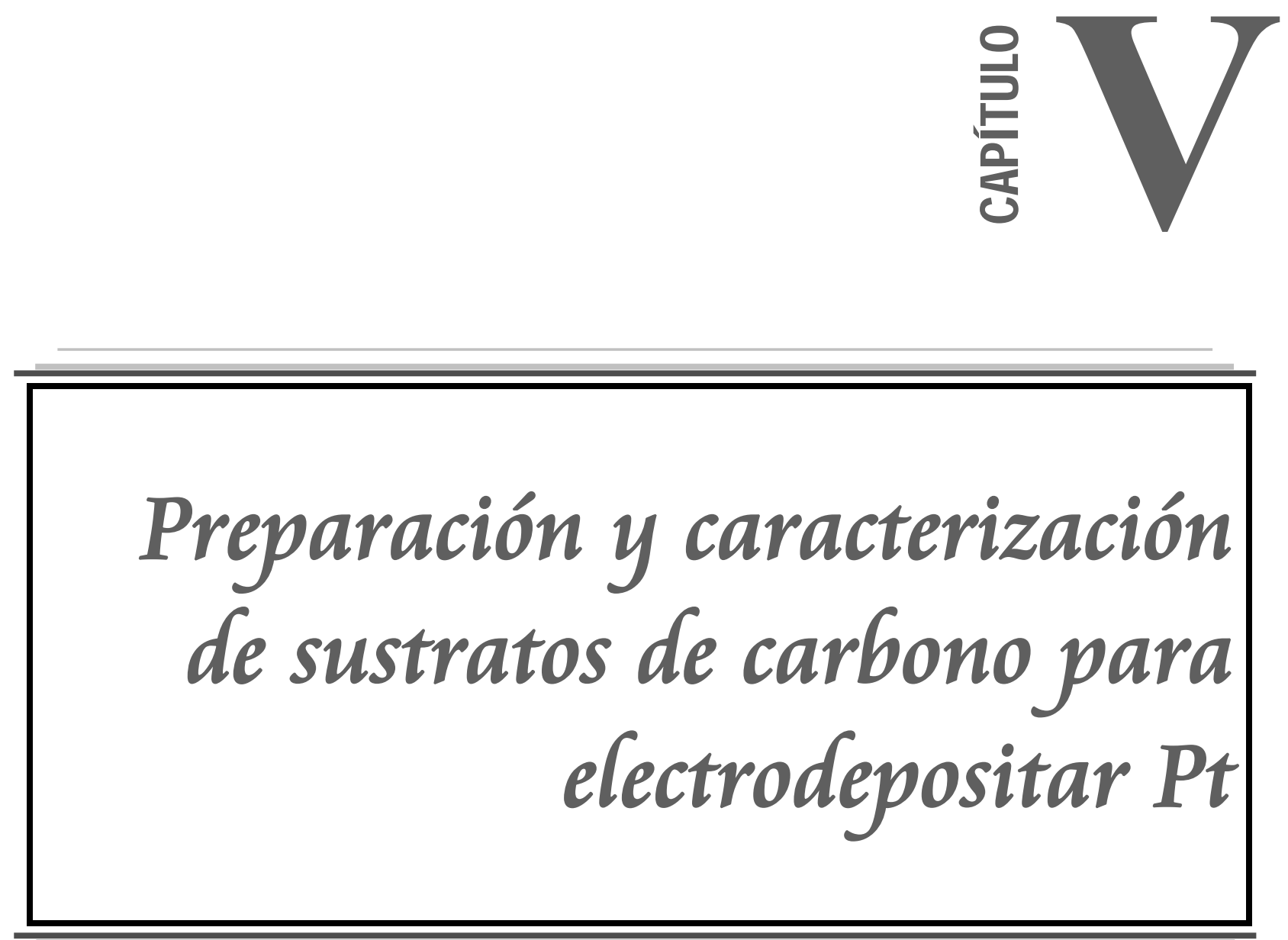


\section{CAPÍTULO V}

\section{Preparación y caracterización de sustratos de carbono para electrodepositar Pt}

\section{V.1. Sustratos de carbono}

Existen ciertos requisitos fundamentales para la selección del material apropiado a ser empleado como sustrato para electrodepositar nanopartículas de platino. El sustrato debe ser químicamente estable en el medio electrolítico utilizado, bajo las condiciones de operación, y además buen conductor eléctrico. Por otro lado, debe tener bajo costo de modo que sea versátil para diferentes aplicaciones electroquímicas. Estos requisitos han dado lugar a que el grafito y distintos tipos de carbones se encuentren dentro de los materiales de electrodo más ampliamente utilizados en el campo de la electroquímica. Estos materiales, además de ser químicamente estables en la mayoría de los medios electrolíticos utilizados, se pueden obtener bajo la forma de polvos de muy alta área específica, que constituyen por sí sólo el soporte y la estructura de electrodo. Tal es el caso de los electrodos porosos para celdas de combustible de hidrógeno/oxígeno, donde el metal noble se soporta sobre polvo de grafito de muy alta área específica dentro de una matriz ligada con politetrafluoretileno (PTFE).

A continuación se describirán las propiedades fisicoquímicas del material carbonoso empleado como sustrato y se presentarán sus aspectos estructurales y su caracterización.

\section{V.1.a. Estructura de los materiales carbonosos}

El carbono, dependiendo de las condiciones de formación, puede encontrarse en la naturaleza en distintas formas alotrópicas, carbono amorfo y cristalino en forma de grafito o diamante. También existen formas estructurales artificiales del carbono, dentro de las cuales se pueden mencionar: carbón activado, negro de carbón, grafito pirolítico, carbón vítreo, monocristales y fibras. Esta variedad de formas estructurales es muy singular, ya que representa un caso poco común de variación continua de las propiedades físicas y químicas de un sistema con un único componente, dependiendo esto solamente de su estructura y no de su composición. Las distintas características estructurales de las diversas formas del carbono están determinadas esencialmente por los enlaces carbono-carbono.

Para explicar las diferentes estructuras de los carbones es conveniente comenzar a escala atómica. Los átomos de carbono poseen una estructura electrónica $1 s^{2} 2 s^{2} 2 p^{2}$, lo cual permite que los orbitales atómicos de los átomos de carbono puedan presentar hibridaciones del tipo: $\mathrm{sp}_{\mathrm{s}} \mathrm{sp}^{2}$ y $\mathrm{sp}^{3}$.

Cuando se combinan átomos de carbono con hibridación sp dan lugar a cadenas de átomos, en las que cada átomo de carbono está unido a otro átomo de carbono por un enlace triple y a un segundo átomo de carbono por un enlace sencillo (Figura 1). 


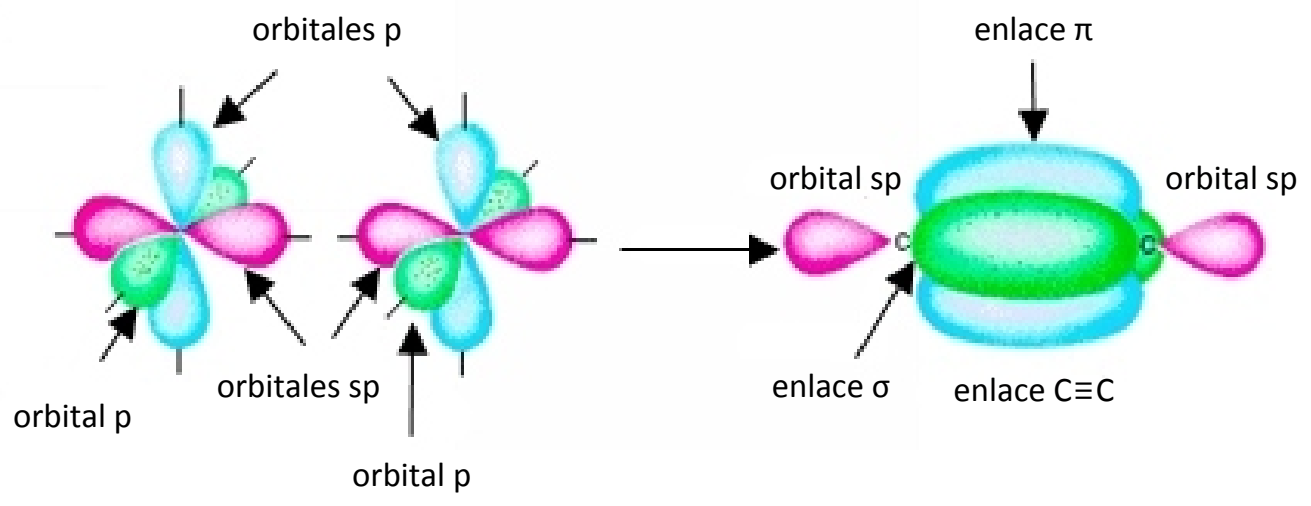

Figura 1. Átomos de carbono con hibridación sp.

Este tipo de estructuras constituyen una forma alotrópica del carbono poco común, esto es, carbonos que pueden presentar una estructura lineal o cíclica (Figura 2).

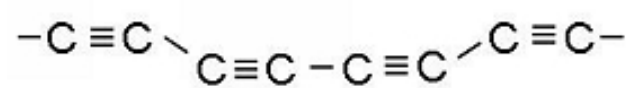
LarpI

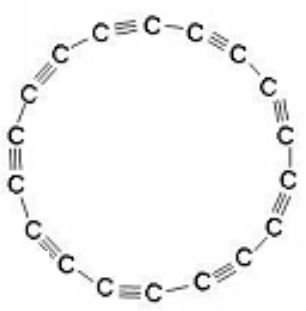

Carbino (C18): modelo cíclico

Figura 2. Dos de las estructuras propuestas para los átomos de carbono.

Cuando se combinan átomos de carbono con hibridación $\mathrm{sp}^{2}$, cada átomo de carbono se une a otros tres en una estructura plana, que da lugar a la forma alotrópica del grafito (Figura 3).

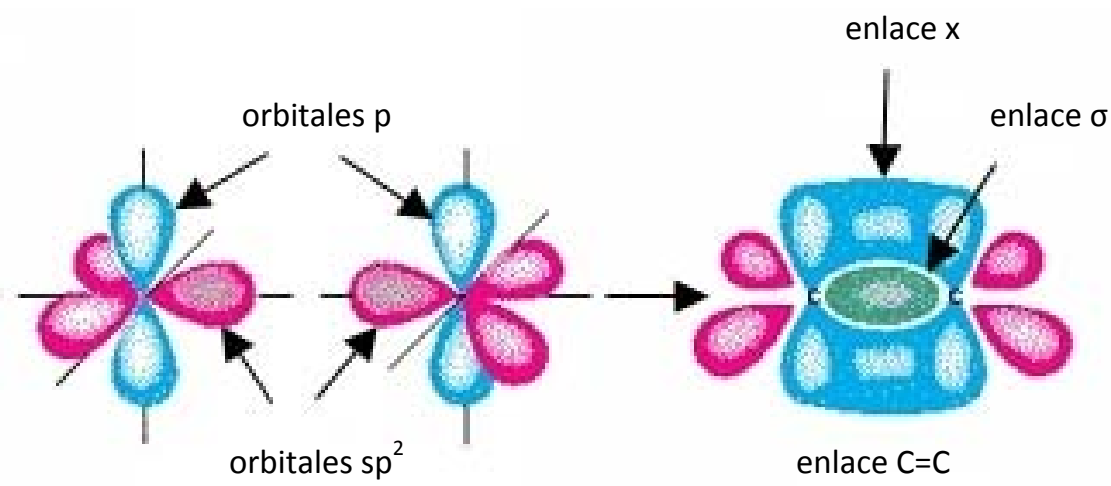

Figura 3. Átomos de carbono con hibridación $\mathrm{sp}^{2}$.

Cuando se combinan átomos de carbono con hibridación $\mathrm{sp}^{3}$ cada átomo de carbono se une a otros cuatro formando una estructura tridimensional que da lugar a la forma alotrópica del diamante (Figura 4). 


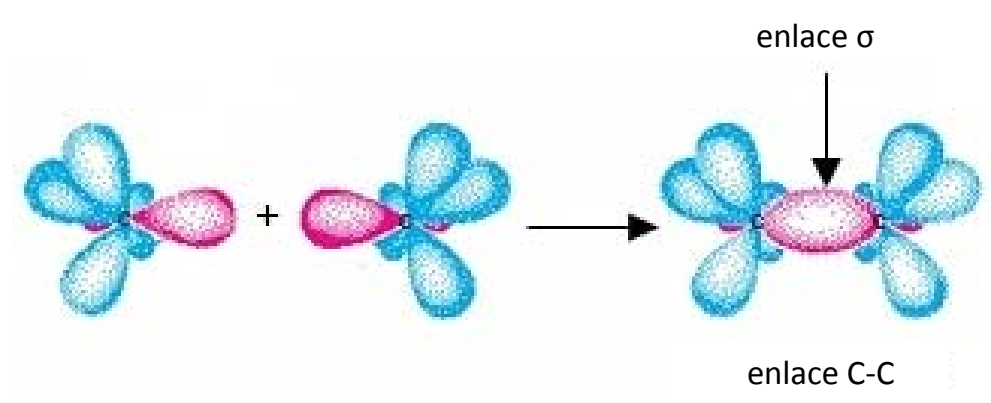

Figura 4. Átomos de carbono con hibridación $\mathrm{sp}^{3}$.

El diamante cúbico es la estructura más habitual de esta forma alotrópica. Sin embargo, bajo ciertas condiciones, el carbono cristaliza como diamante hexagonal (Figura 5).

(a)

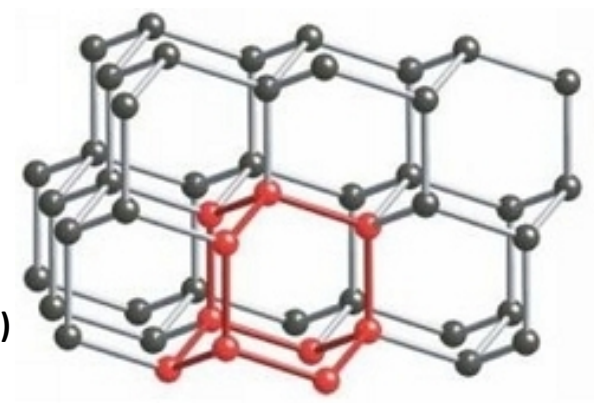

(b)

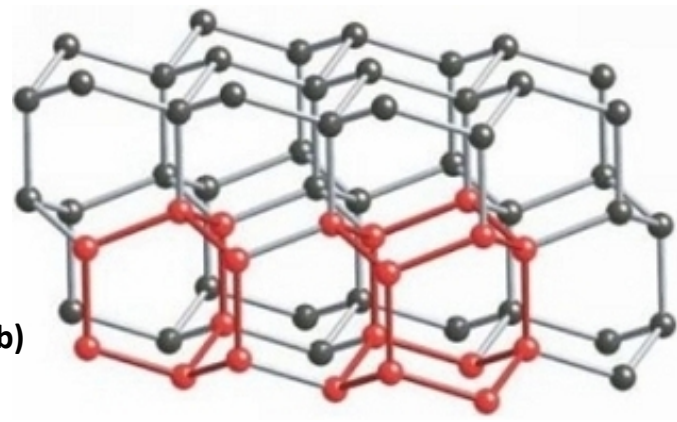

Figura 5. Diamante (a) cúbico y (b) hexagonal.

Una forma alotrópica del carbono, en la cual los átomos de carbono presentan hibridación intermedia entre la $\mathrm{sp}^{2}$ y la $\mathrm{sp}^{3}$, es el fullereno. Este tipo de hibridación hace posible que los átomos de carbono puedan combinarse formando hexágonos y pentágonos en estructuras tridimensionales cerradas. El fullereno más común es el de 60 átomos de carbono (Figura 6).

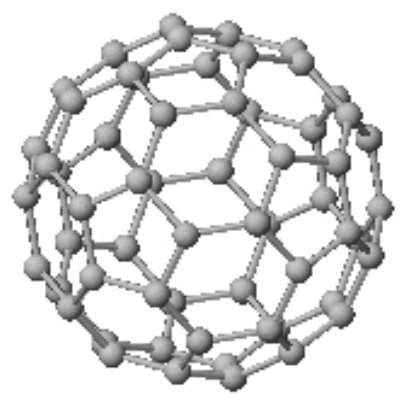

Figura 6. Estructura del fullereno $\mathrm{C60}$.

Los nanotubos de carbono presentan también estas hibridaciones intermedias y pueden considerarse como láminas de grafito enrolladas en forma de tubos (Figura 7). 


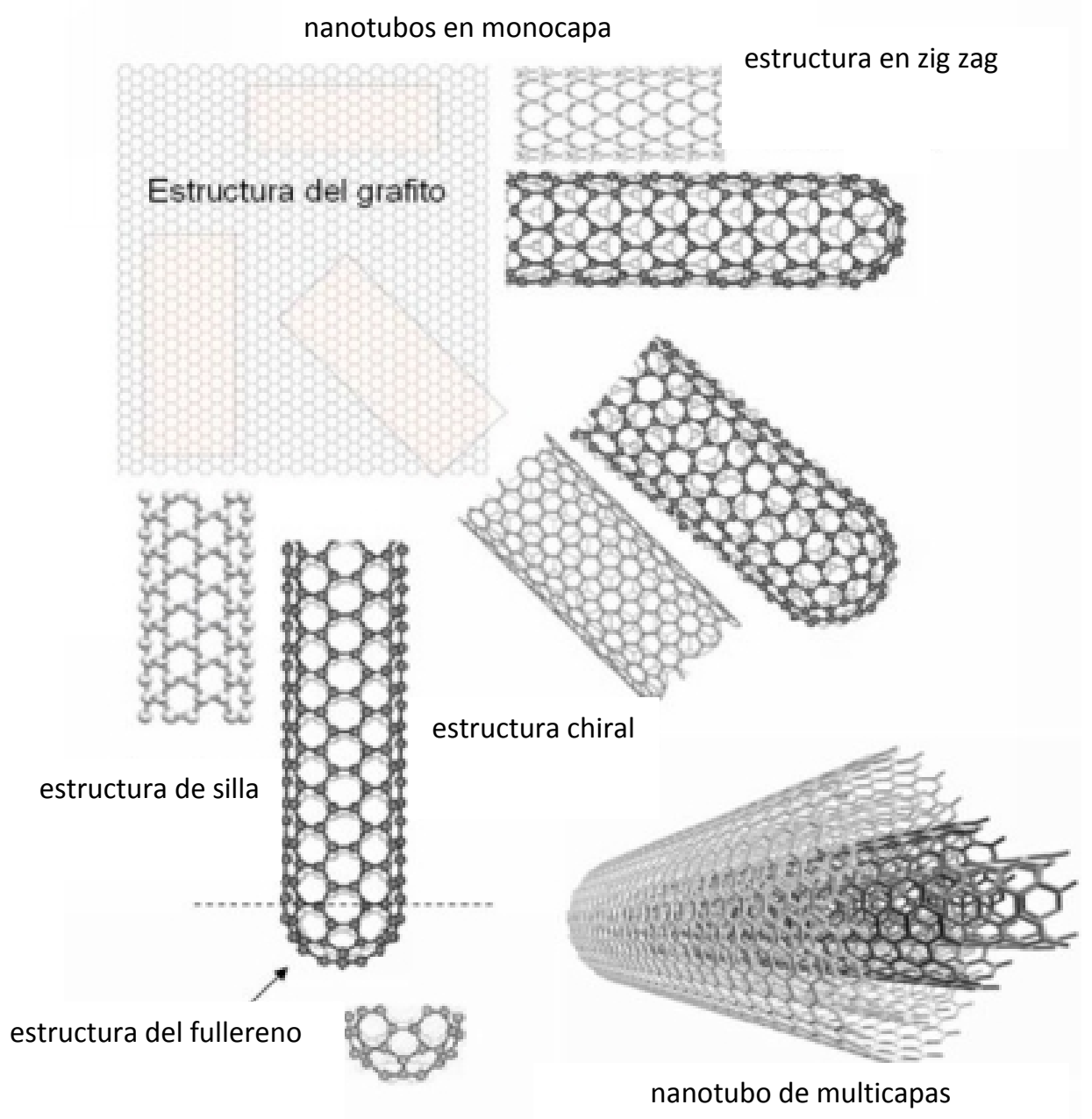

Figura 7. Diversas estructuras de nanotubos de carbono.

Los nanotubos pueden ser abiertos o cerrados, en cuyo caso la estructura que cierra el nanotubo es similar a la mitad de un fullereno. Los nanotubos también pueden estar conformados por una monocapa o por multicapas en forma de varias capas concéntricas.

Considerando los planos basales los carbones se pueden dividir en:

i. Carbones grafíticos: todo tipo de sustancia formada por el elemento carbono bajo la forma de grafito, independientemente de la presencia de defectos estructurales.

ii. Carbones no grafíticos: todo tipo de sustancia constituida principalmente por el elemento carbono. La estructura presenta un orden bidimensional de átomos de carbón en láminas planas hexagonales, pero no hay ningún orden cristalográfico en la tercera dimensión (dirección c), aparte del hecho de que las láminas sean más o menos paralelas.

En 1951, Franklin [232] estableció una clasificación de los carbones no grafíticos basándose en que los carbones grafitizables se convierten en grafito por tratamiento térmico a $2273 \mathrm{~K}$ y propuso los modelos estructurales que se muestran en la Figura 8. Según Franklin, los sólidos grafitizables contienen un conjunto de unidades turbostráticas orientadas de modo aproximadamente paralelo entre sí (pre- 
grafítico), mientras que en los no grafitizables estas unidades están dispuestas de modo aleatorio, encontrándose puenteadas unas con otras por especies de carbono desordenado.

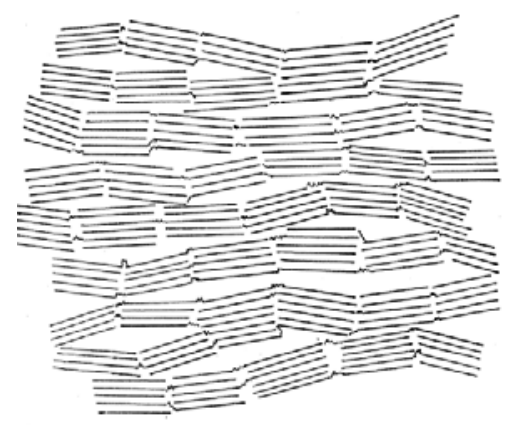

(a)

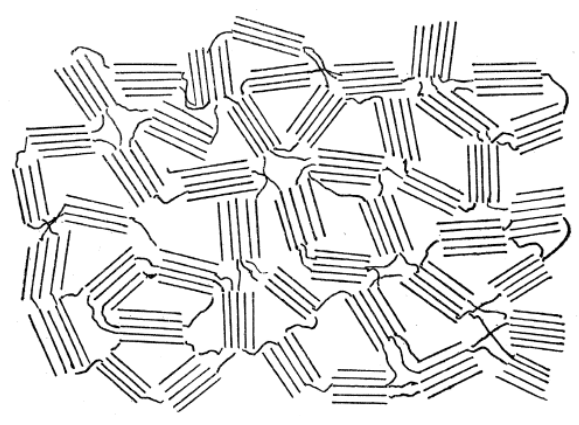

(b)

Figura 8. Esquemas originales de Franklin para las estructuras de carbones no grafíticos: (a) grafitizable y (b) no grafitizable [232].

A escala mucho mayor y considerando ahora la manera en que se estructuran los grupos de láminas grafíticas, se puede encontrar una gran variedad de tipos de carbones, que pueden ir desde el grafito con una simetría plana y altamente orientado hasta carbón activado en el cual los planos basales son de pequeño tamaño y los apilamientos de estos apenas alcanzan unos pocos planos. Los negros de carbono presentan unidades cristalinas grafíticas ordenadas en forma concéntrica, mientras que las fibras de carbono pueden ser de varios tipos dependiendo del tipo de ordenamiento de los planos grafíticos (Figura 9).

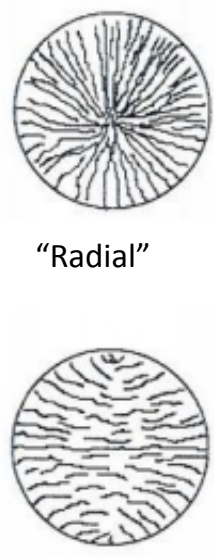

"Flat-layer"

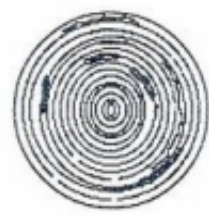

“Onion-skin"

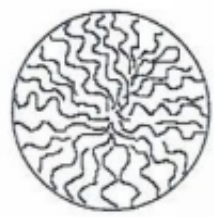

"Radial-folded"

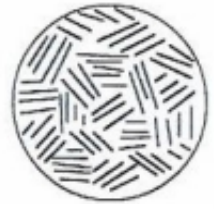

"Random"

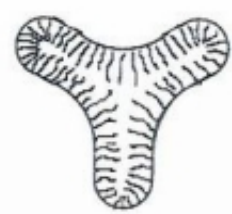

"Line-origin"

Figura 9. Fibras de carbono con diferentes estructuras.

A escala microscópica los carbones presentan formas muy diferentes, en tanto que a escala macroscópica pueden presentarse en formas muy diversas como granos, polvos, monolitos, fibras, etc. (Figura 10). 


\section{trozado \\ carbón activo \\ conformado}
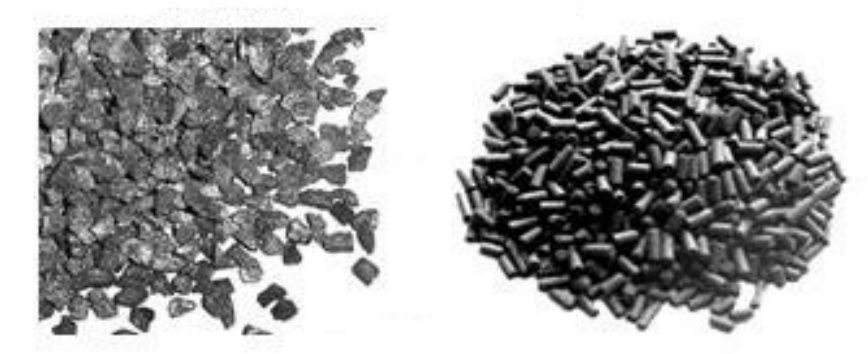

monolitos hechos íntegramente de carbón activo en forma de polvo carbón
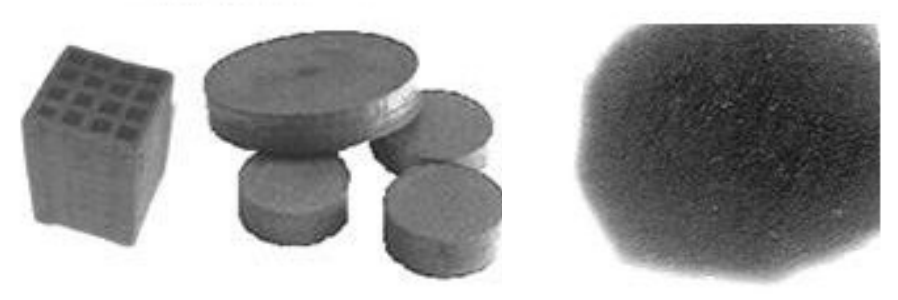

monolitos cubiertos por una capa de carbono

fibras de carbono
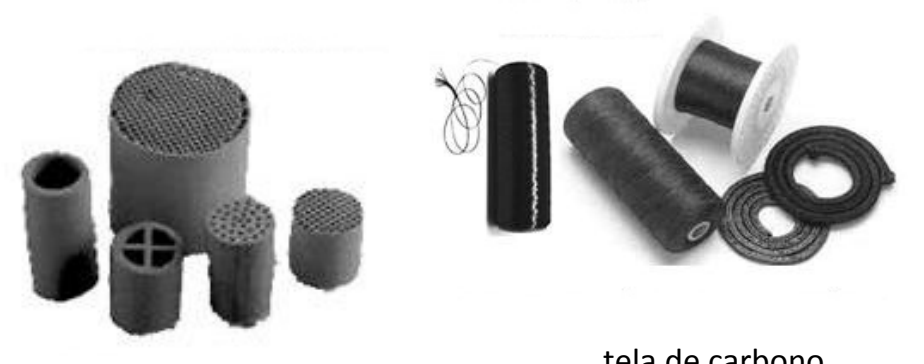

tela de carbono
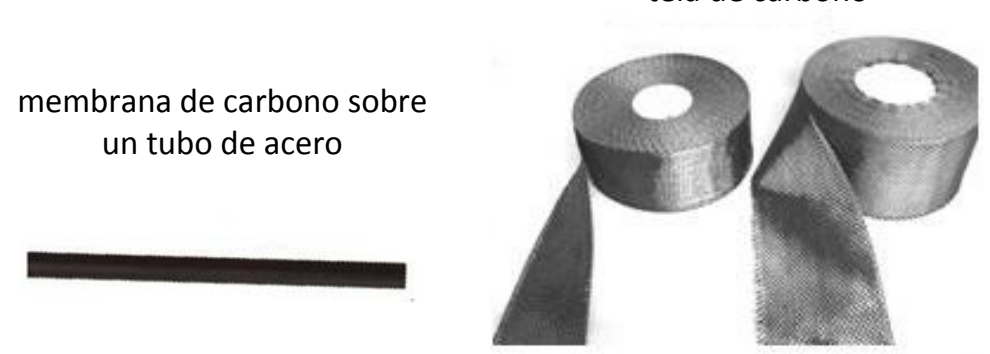

Figura 10. Carbones con diferentes estructuras macroscopıcas.

En la Figura 11 se presenta un resumen de los carbones y sus diferentes estructuras microscópicas. Respecto a las formas alotrópicas del carbono antes mencionadas, se hará referencia específicamente al grafito, que se utilizó en esta tesis como soporte para los electrodepósitos de Pt. 

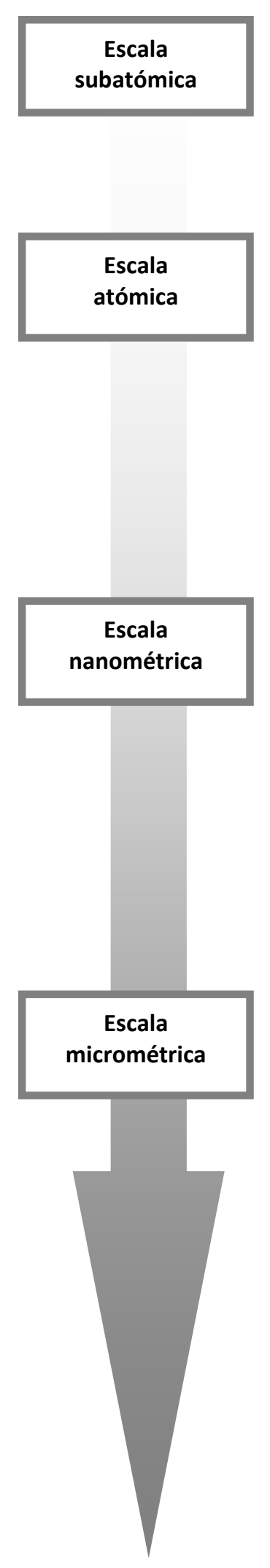

Hibridación del carbono $\quad \mathbf{s p}^{2} \quad \mathbf{s p}^{2+\mathrm{x}} \quad \mathbf{s p}^{3}$

Formas

alotrópicas
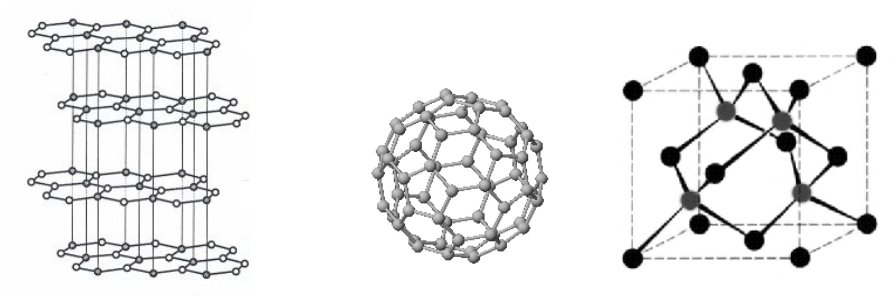

Grafito h

Carbones no grafíticos

Carbones no grafitizables

(carbonizados)
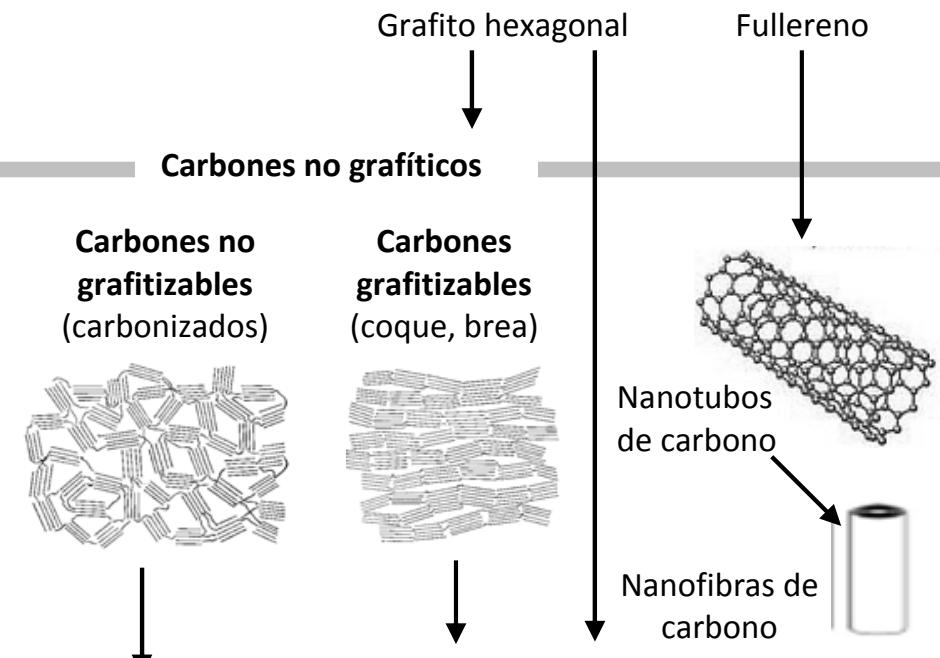

Diamante

Carbones grafíticos

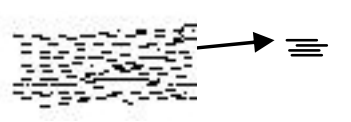

Grafito pirolítico (simetría plana altamente orientada)

Fibra de carbono (ordenamiento concéntrico)

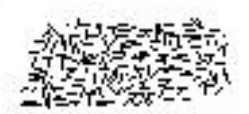

Grafito isótropo (microcristales de grafito sin orientación preferencial)

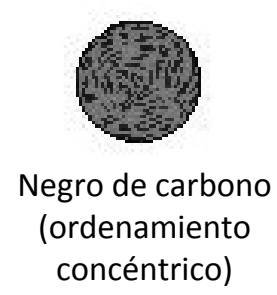

Figura 11. Carbones y sus diferentes estructuras microscópicas. 


\section{V.1.b. Estructura cristalina del grafito}

El grafito es un polímero bidimensional estructurado en forma hexagonal, constituido por átomos de carbono en un estado de valencia correspondiente a la hibridación $\mathrm{sp}^{2}$, como ya se ha mencionado anteriormente. Este material está formado por una serie continua de capas de átomos de carbono unidos hexagonalmente, siendo las capas paralelas al plano basal. La distancia entre átomos vecinos en un mismo plano es de 1,42 Á y la distancia interplanar es de 3,345 Á. La energía de enlace carbonocarbono en un mismo plano es de 340 a $420 \mathrm{~kJ} / \mathrm{mol}$, mientras que la energía de enlace interplanar está comprendida entre 4,2 a $8,4 \mathrm{~kJ} / \mathrm{mol}$ [233].

Hay dos tipos posibles de redes cristalinas ideales para el grafito, que dependen del apilamiento de las láminas (Figura 12):

(a) la estructura hexagonal: que es la forma termodinámicamente estable en la que la secuencia de apilamiento de las láminas es ABAB y,

(b) la estructura romboédrica: que es una forma termodinámicamente inestable, y mucho menos abundante con una secuencia de apilamiento ABCA.

(a)

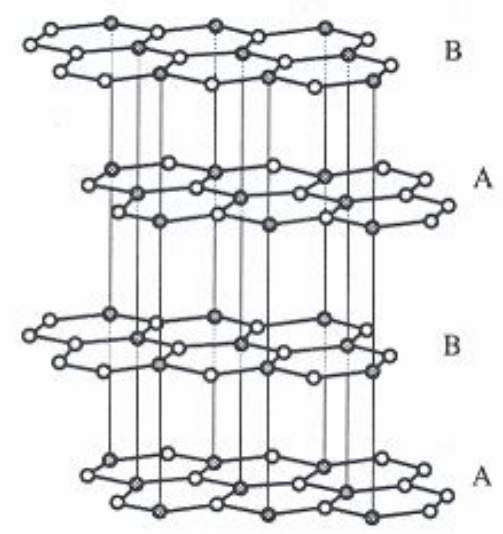

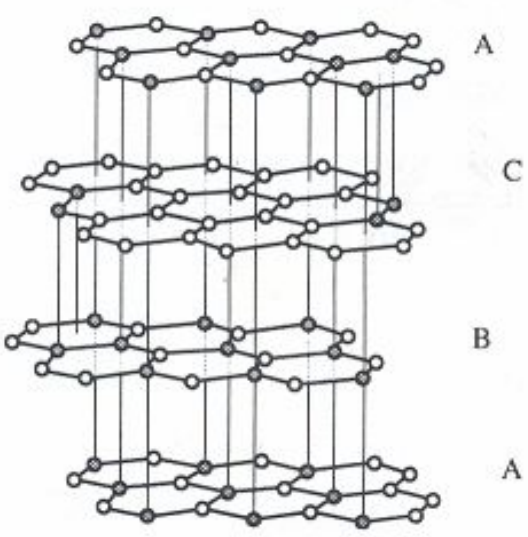

A (b)

Figura 12. Estructuras del grafito: (a) hexagonal (ABAB) y (b) romboédrica (ABCA).

A temperaturas mayores de $2000{ }^{\circ} \mathrm{C}$ el empaquetamiento romboédrico se transforma en hexagonal. Desde el punto de vista cristalográfico formal ambas estructuras deberían considerarse como redes infinitas construidas con hexágonos, los cuales se ubican en capas paralelas. En la práctica, sin embargo, es más conveniente considerar a cada red finita de hexágonos como una macromolécula de carbono grafítico.

\section{V.2. Preparación y pretratamiento de sustratos carbonosos}

La preparación y el pretratamiento de los materiales carbonosos influyen significativamente en la calidad y características del sustrato sobre el que se lleva a cabo el crecimiento de los electrodepósitos 
de Pt. Algunas investigaciones indican que el pretratamiento al que se somete el soporte carbonoso puede afectar la respuesta final del catalizador [234].

Se conoce que el pretratamiento de materiales en base a carbono puede mejorar la actividad catalítica de la reacción de reducción de oxígeno $(R R O)$ y cambiar su comportamiento electroquímico. A pesar de que aún no se encuentran totalmente definidos los fenómenos por los cuales se produce la mejora, se puede considerar que el estado superficial modificado favorece la cinética de la reacción, debido a la presencia de sitios que facilitan la adsorción de la especie $\mathrm{O}_{2}$.

En revisiones bibliográficas se pueden encontrar varios métodos de tratamiento de sustratos carbonosos que involucran pulido de los electrodos, calentamiento a bajas presiones, tratamientos de calor en vacío, oxidación química, oxidación electroquímica, etc. [235-238].

Se ha demostrado que el pretratamiento del sustrato puede crear grupos funcionales superficiales, exponer sitios libres de carbón y micropartículas y defectos que muchas veces actúan como centros de nucleación y crecimiento [235], [237], [238]. El pretratamiento de los electrodos aumenta el área superficial del carbón, generando superficies porosas. Así por ejemplo se ha encontrado que la oxidación superficial del sustrato carbonoso en $\mathrm{H}_{2} \mathrm{SO}_{4}$ conduce a la formación de un film poroso, cuyo espesor aumenta linealmente con el tiempo de oxidación [239].

Se conoce también que la formación de núcleos y el crecimiento de cristales del electrodepósito están marcadamente influenciados por el estado superficial del sustrato utilizado como electrodo de trabajo. De ahí la importancia de los procesos de preparación y pretratamiento de los sustratos carbonosos para el desarrollo de los facetados de Pt.

Algunos autores han estudiado la influencia de la oxidación electroquímica de diferentes tipos de sustratos carbonosos y su empleo como soporte de catalizadores bimetálicos preparados por electrodeposición. Encontraron que la oxidación de los diferentes sustratos, previo a la deposición de los catalizadores, conducía a una dispersión más uniforme de los catalizadores acompañada por una considerable reducción del tamaño de partícula y un apreciable aumento del área superficial específica del catalizador, en comparación con electrodos catalizados obtenidos con el sustrato sin oxidar [240]. Esto se debería a que el sustrato puede modificarse sustancialmente por un pretratamiento electroquímico, generando una mayor concentración de óxidos superficiales que actuarían como sitios activos en el posterior proceso de nucleación del metal durante la electrodeposición del catalizador. Resultados similares fueron observados por otros autores, quienes oxidaron electroquímicamente los sustratos carbonosos hasta potenciales de $2,0 \mathrm{~V}$ vs. $E R H$ con el fin de obtener catalizadores con mayor área específica, generando de este modo una mayor concentración de óxidos superficiales y aumentando el número de sitios activos disponibles para la nucleación de las cristalitas metálicas [241]. Para el caso particular de celdas de combustible es bien conocida la activación de carbones, comúnmente utilizados como soportes para catalizadores, bajo condiciones de oxidación [242]. El ejemplo más relevante es el tratamiento del carbón negro de acetileno con ácido nítrico hirviente, 
previo a la deposición de $P$ t, en el proceso de preparación de catalizadores soportados para usar en celdas de combustible de ácido fosfórico [243]. Otros autores han demostrado que tratamientos con ácido nítrico y otros métodos oxidativos de los soportes de carbono, antes de la deposición del metal, pueden incrementar la adsorción de los precursores del Pt, $\left[\mathrm{Pt}\left(\mathrm{NH}_{3}\right)_{4}\right]^{2+}[244]$, e incrementar la dispersión de Pt [245-247].

Jia et al. [236] han investigado en detalle los efectos de la oxidación superficial con ácido nítrico de los soportes de carbono de catalizadores de $P t$ usados en celdas de combustible. Se ha encontrado que la oxidación de los soportes, antes de la deposición de $P t$, conduce a una disminución del tamaño de partícula y mejora la performance de la $R R O$ en los electrodos de difusión de gas. Se ha evidenciado también que el pretratamiento de los soportes de carbón produce una disminución de la resistencia iónica, dada por la generación de grupos funcionales superficiales como grupos ácidos carboxílicos que mejoran la humedad de la capa catalítica. Por otro lado, se ha informado que con Pt depositado sobre soportes de carbón sin tratamiento se obtienen corrientes de $0,3 \pm 0,1 \mathrm{~mA}$ a 0,6 V vs. SCE, mientras que con Pt depositado sobre carbón pretratado las corrientes obtenidas son mayores, del orden de 1,6 $\pm 0,7$ $\mathrm{mA}[236]$.

\section{V.3. Pretratamiento de sustratos grafíticos para electrodepositar platino}

En esta tesis doctoral, los sustratos de carbono utilizados como soportes para los electrodepósitos de $P t$ fueron maquinados hasta obtener láminas de grafito de aproximadamente $2 \mathrm{~mm}$ de espesor y luego desbastados con lija de diferente granulometría a fin de obtener superficies homogéneas. Posteriormente, las láminas de grafito así obtenidas fueron enjuagadas con agua tridestilada y llevadas a sonicador, logrando remover de esta manera restos de material carbonoso y posibles impurezas superficiales. Seguidamente fueron secadas con una corriente de aire caliente, disponiendo de esta manera de material limpio para armar los electrodos de trabajo.

Antes de cada electrodepósito se llevó a cabo una rutina de tratamiento del soporte grafítico, de acuerdo a pruebas experimentales realizadas previamente. De esta forma los sustratos fueron oxidados electroquímicamente hasta $1,4 \mathrm{~V}$ a altas velocidades de barrido $(0,5 \mathrm{~V} / \mathrm{s})$ en $\mathrm{H}_{2} \mathrm{SO}_{4}$ 0,5 M, logrando así eliminar oxidativamente las impurezas de la superficie del electrodo, sin modificarlo profundamente.

La Figura 13 muestra un voltamperograma del sustrato grafítico durante el tratamiento de oxidación, donde se pueden observar un pico de oxidación y el correspondiente pico de reducción. Estos picos de corriente se atribuyen, generalmente, a la presencia de cuplas redox de especies orgánicas oxigenadas e impurezas [190].

Luego del tratamiento de oxidación se realizó un ciclado voltamperométrico en la zona de electrosorción de hidrógeno, barriendo hasta $0,6 \mathrm{~V}$, a una velocidad de barrido de $0,1 \mathrm{~V} / \mathrm{s}$ y sobre las superficies así tratadas en cada caso se realizaron los electrodepósitos de $P t$. 


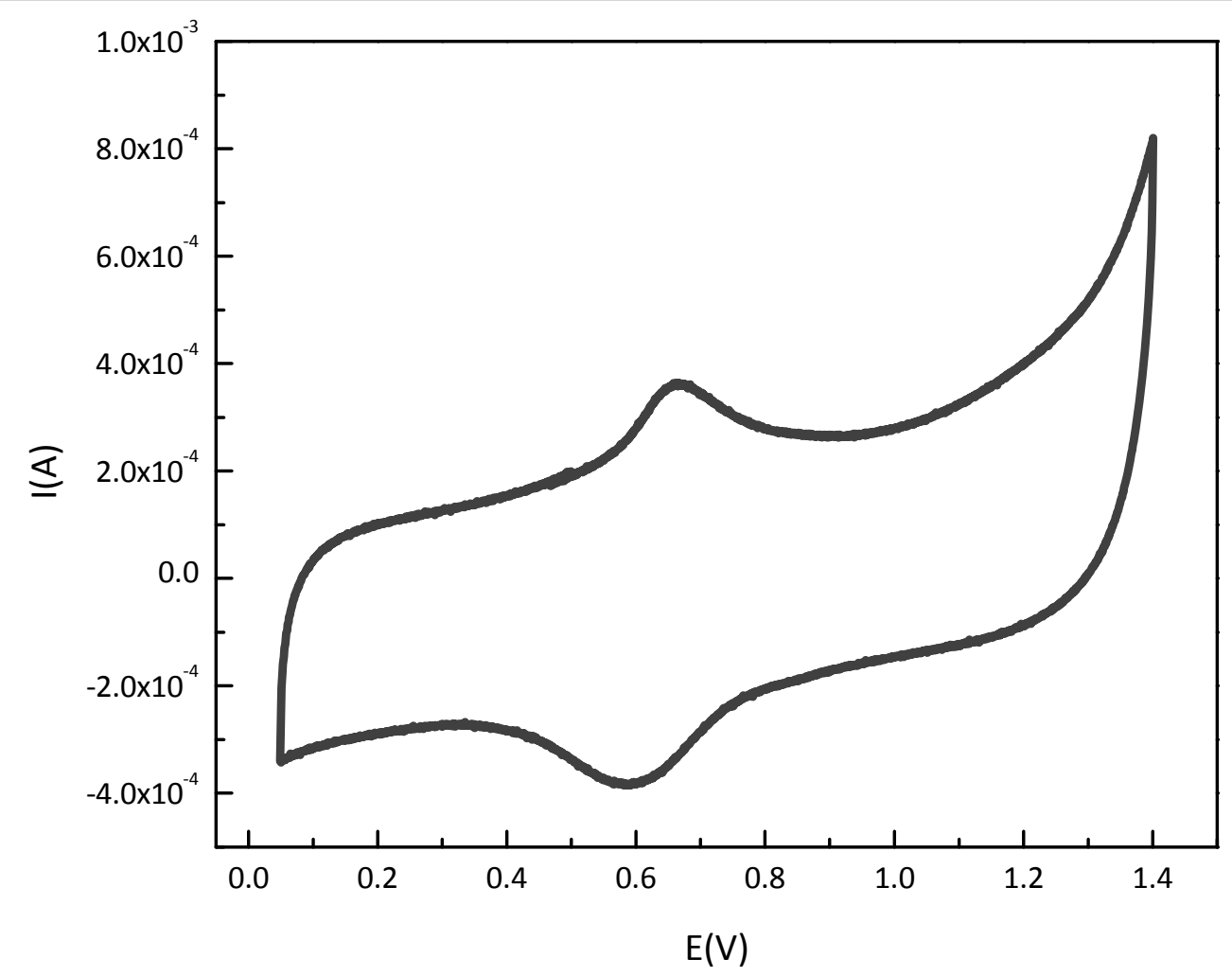

Figura 13. Voltamperograma correspondiente al tratamiento de oxidación del sustrato grafítico.

La Figura 14 muestra los voltamperogramas de control de un electrodo de grafito antes y después del tratamiento de oxidación. Se observa un aumento en el ancho de la zona correspondiente a la doble capa electroquímica, debido al efecto del aumento de la porosidad del sustrato.

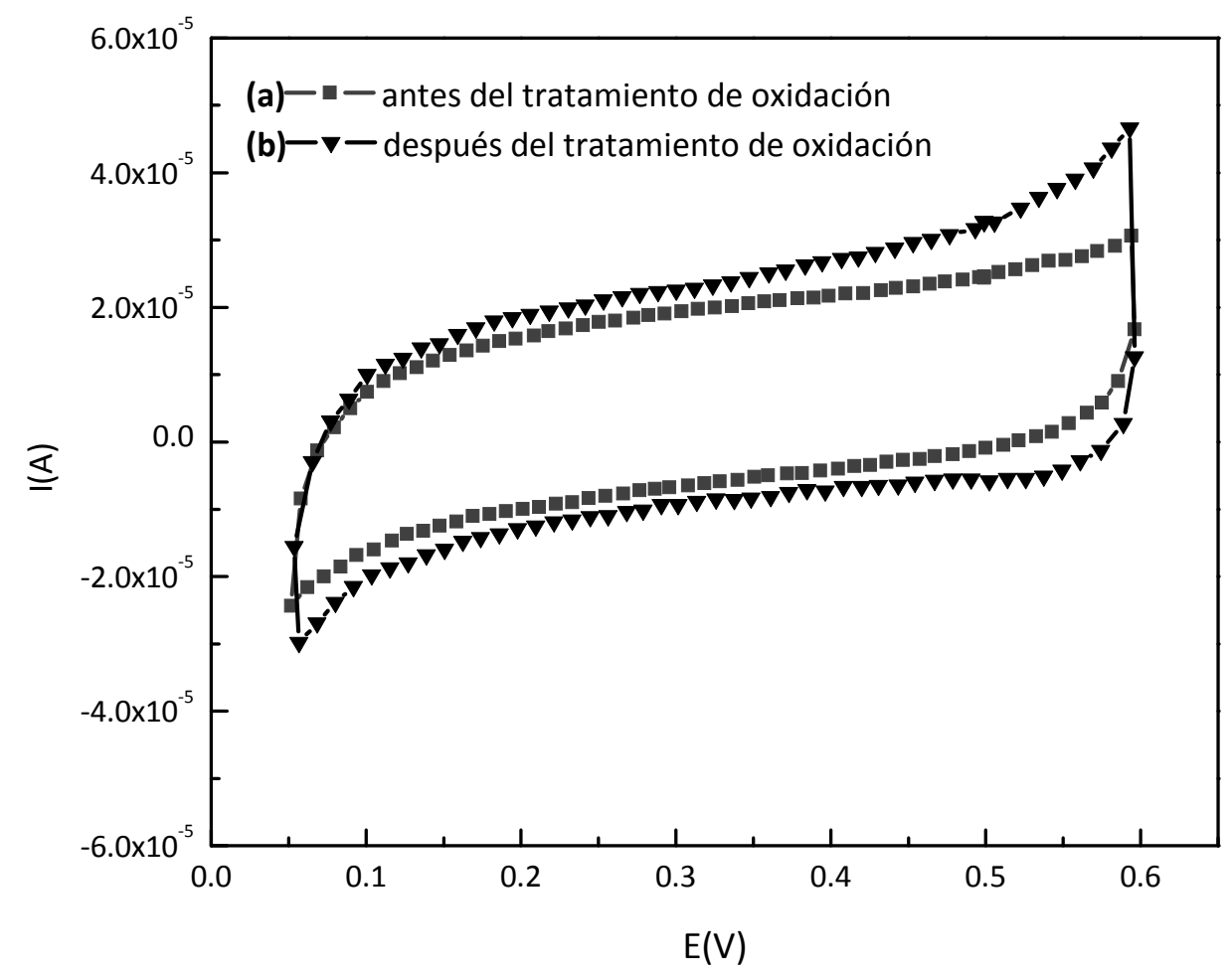

Figura 14. Voltamperograma a $0,1 \mathrm{~V} / \mathrm{s}$ del sustrato de grafito en $\mathrm{H}_{2} \mathrm{SO}_{4} 0,5 \mathrm{M}(\mathrm{a})=$ antes y (b) $\nabla$ después del tratamiento de oxidación. 
A modo ilustrativo, en la Figura 15, se muestran imágenes SEM de electrodepósitos de Pt, realizados bajo las mismas condiciones de operación, sobre un sustrato grafítico oxidado (a) y sin oxidar (b). Se observa que los electrodepósitos de Pt desarrollados sobre el sustrato oxidado presentan una distribución superficial de partículas más homogéneo que para el caso del sustrato no oxidado.
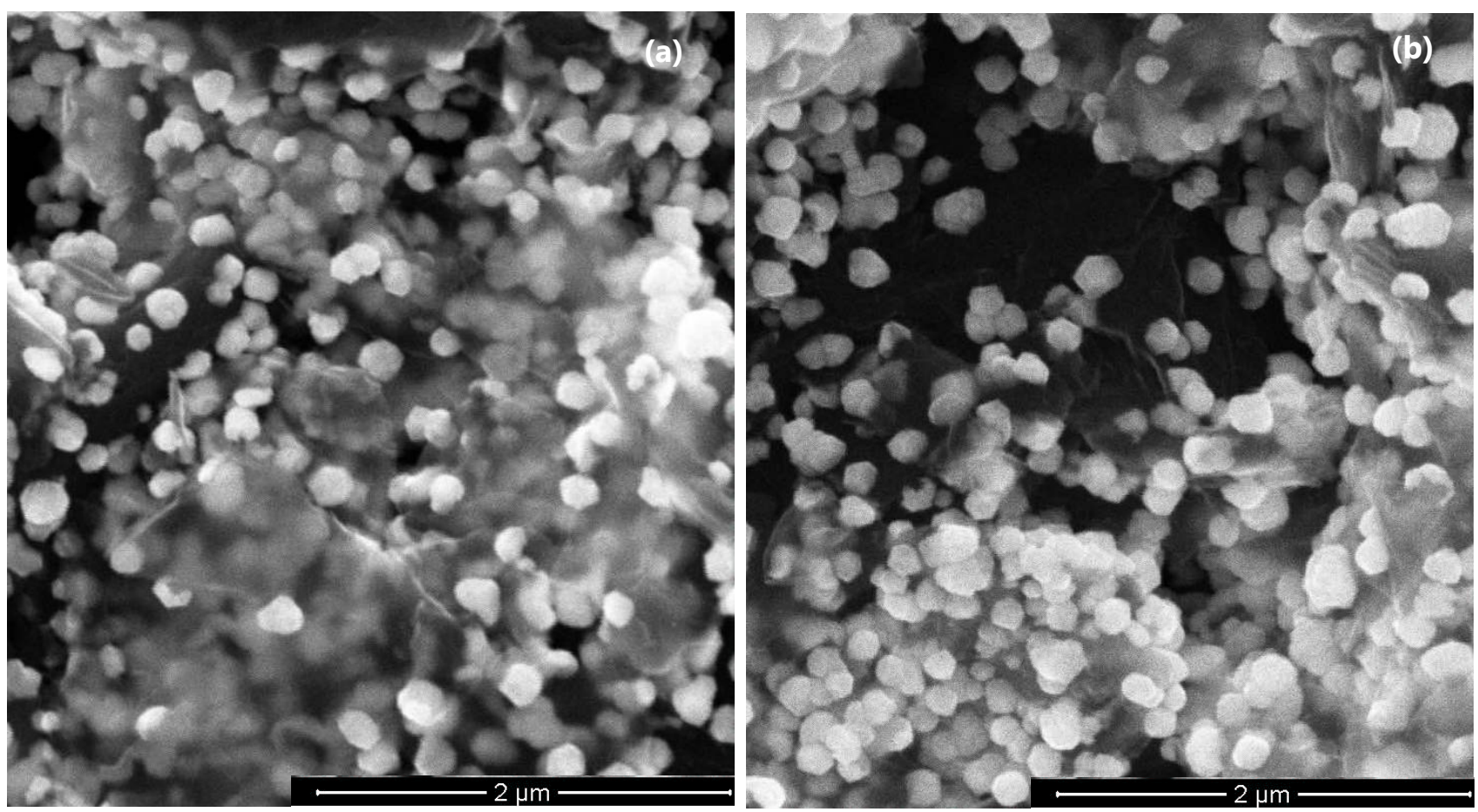

Figura 15. Imágenes SEM de electrodepósitos de $P t$ sobre sustrato (a) oxidado y (b) sin oxidar. Condiciones de operación $E s=1,38 \mathrm{~V} ; E i=-0,24 \mathrm{~V} ; f=1 \mathrm{kHz}, t=5 \mathrm{~min}$.

Por lo tanto, de acuerdo a los resultados y evidencias obtenidos en todas las experiencias de electrodeposición de Pt se aplicó previamente el procedimiento de oxidación anteriormente descripto a todos los soportes carbonosos. De este modo, también se logró obtener mayor reproducibilidad de las experiencias, partiendo de superficies con igual tratamiento inicial.

\section{V.4. Caracterización del sustrato grafítico}

\section{V.4.a. Caracterización física del sustrato grafítico empleado}

Se utilizaron soportes conductores inertes de grafito de alta área específica para obtener los electrodepósitos de Pt con orientación cristalográfica preferencial por aplicación de la OCPR. El material empleado consiste en láminas de aproximadamente $2 \mathrm{~mm}$ de espesor con un área expuesta de trabajo de $0,3 \mathrm{~cm}^{2}$. Se tomaron muestras del sustrato gafítico y se las observó en un microscopio electrónico de barrido, obteniéndose las imágenes que se muestran en la Figura 16, a diferentes magnificaciones.

A modo de ejemplo se muestran, en la Figura 17, electrodepósitos de $P t$ realizados sobre este sustrato bajo las siguientes condiciones de operación: $E s=1,2 \mathrm{~V} ; E i=-0,05 \mathrm{~V} ; f=1 \mathrm{kHz}$ y $t=5 \mathrm{~min}$. 

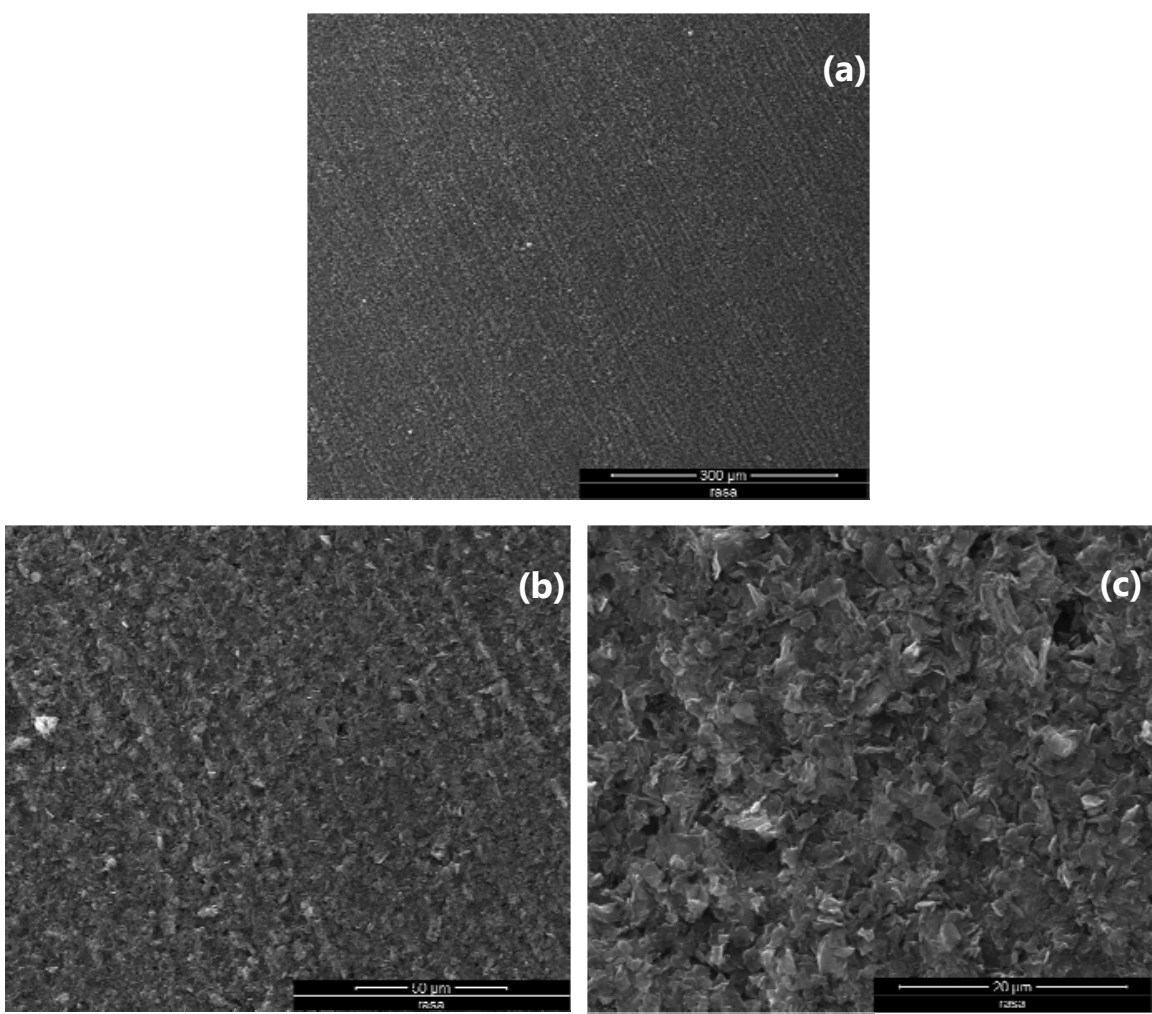

Figura 16. Imágenes SEM del sustrato grafítico: (a) Magnificación 400 X, escala 300 m; (b) Magnificación 1600 X, escala $50 \mu \mathrm{m}$; (c) Magnificación $6000 \mathrm{X}$, escala $20 \mu \mathrm{m}$.

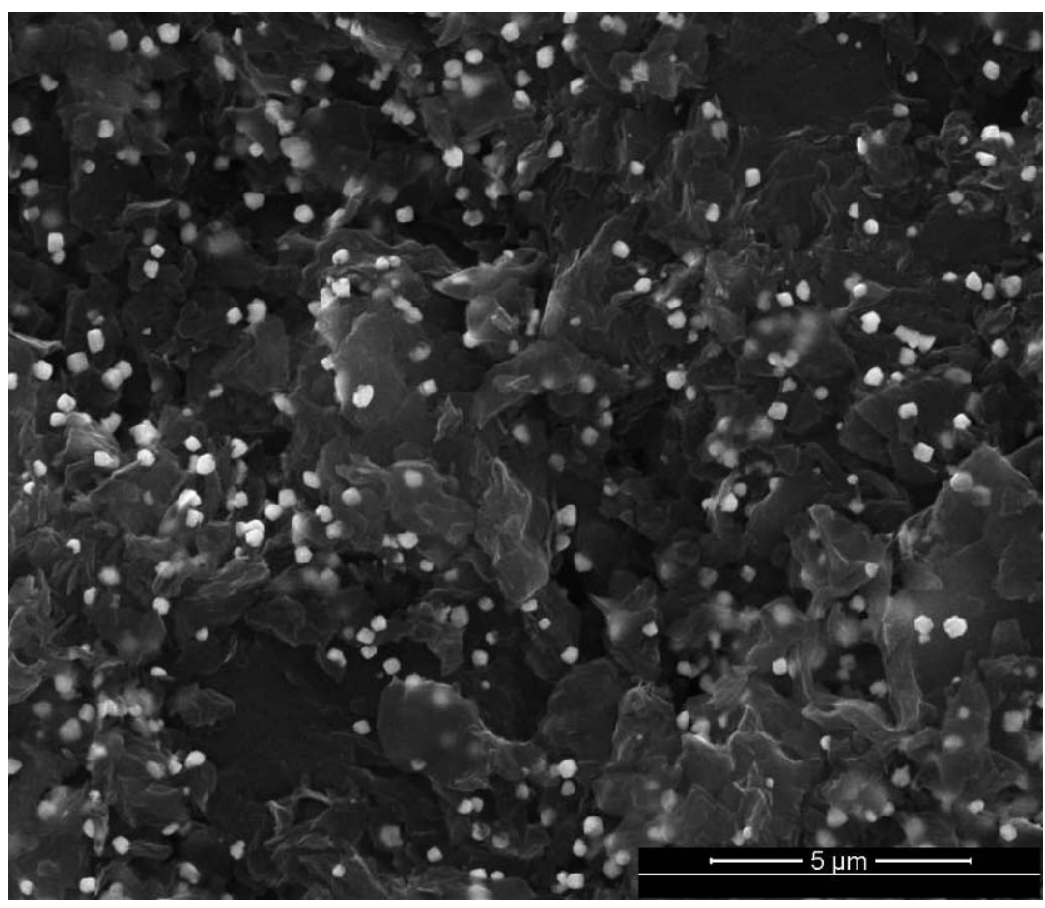

Figura 17. Imagen SEM de los electrodepósitos de Pt sobre grafito como sustrato electródico. Magnificación $15000 \mathrm{X}$, escala $5 \mu \mathrm{m}$.

Se puede observar claramente la naturaleza laminar del grafito y la disposición desordenada de las láminas. Se observa además una distribución de huecos que determinan la macroporosidad del material. La densidad calculada fue de $1,97 \mathrm{~g} / \mathrm{cm}^{3}$, coincidente con grafito SPK de Union Carbide Corporation [248], [249]. 


\section{V.4.b. Caracterización voltamperométrica del sustrato grafítico empleado}

Se registraron voltamperogramas cíclicos a $0,1 \mathrm{~V} / \mathrm{s}$ del sustrato grafítico en solución $\mathrm{H}_{2} \mathrm{SO}_{4} 0,5 \mathrm{M}$ a $25^{\circ} \mathrm{C}$ antes de realizar los electrodepósitos (Figura 18).

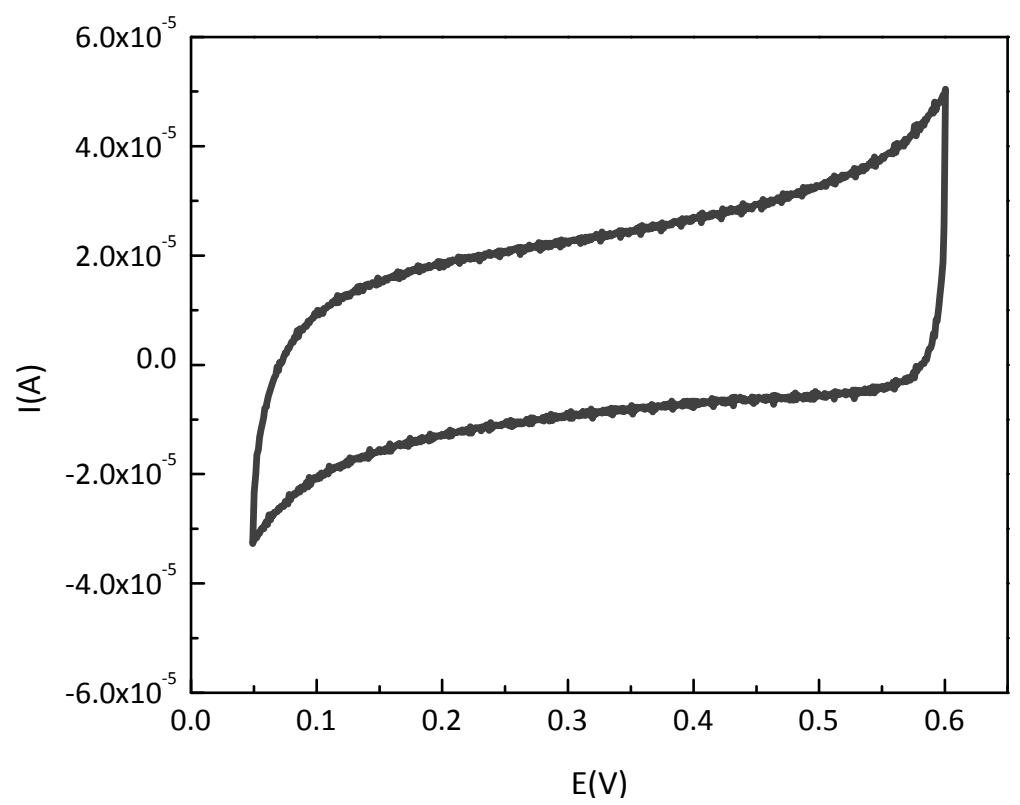

Figura 18. Voltamperograma cíclico a $0,1 \mathrm{~V} / \mathrm{s}$ de un electrodo de grafito en $\mathrm{H}_{2} \mathrm{SO}_{4} 0,5 \mathrm{M}$ a $25^{\circ} \mathrm{C}$.

El procedimiento para calcular $A^{*}$ consiste en determinar la dependencia lineal de la corriente con la velocidad de barrido del potencial, en una región del voltamperograma donde el comportamiento sea puramente capacitivo. Para ello se registraron voltamperogramas de grafito en solución de $\mathrm{H}_{2} \mathrm{SO}_{4} \mathrm{0,5} \mathrm{M}$ a diferentes velocidades de barrido (Figura 19).

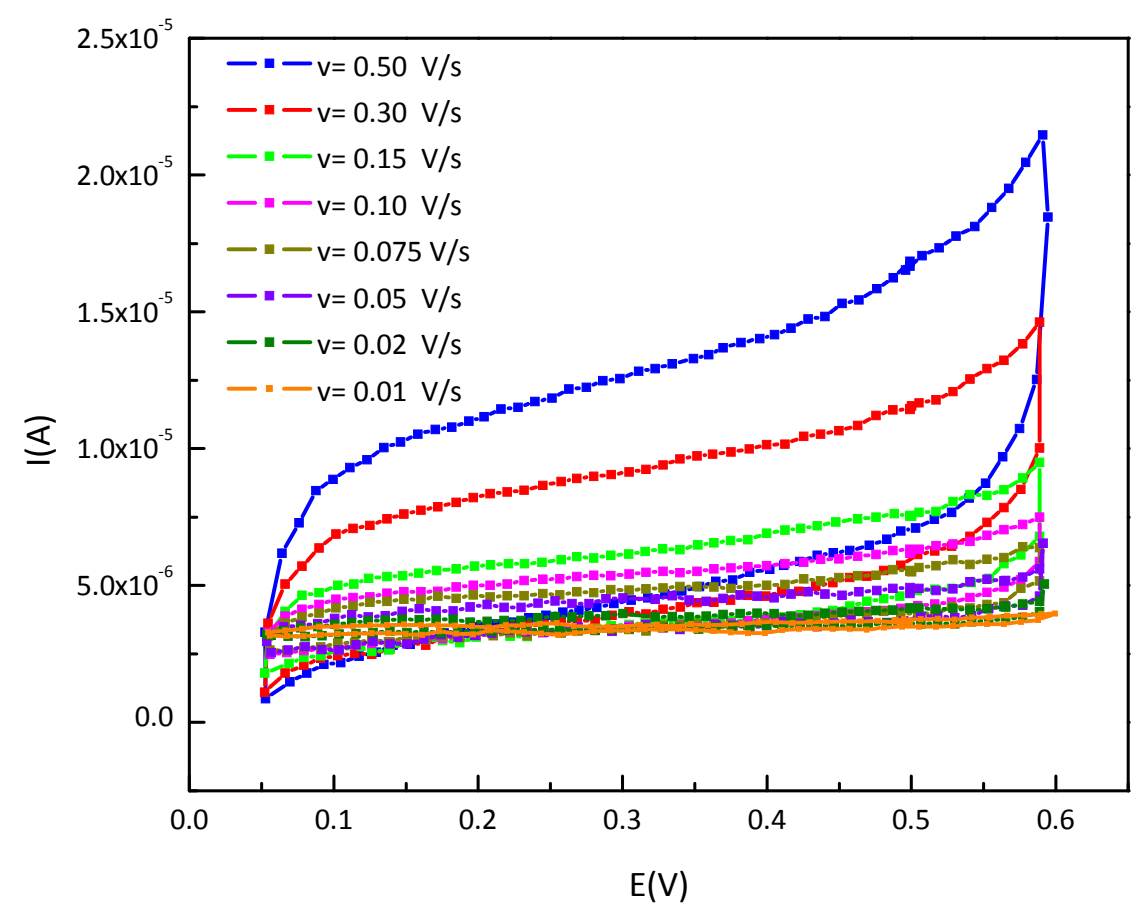

Figura 19. Voltamperogramas cíclicos de un electrodo de grafito en $\mathrm{H}_{2} \mathrm{SO}_{4} 0,5 \mathrm{M}$ a $25^{\circ} \mathrm{C}$ registrados a diferentes velocidades de barrido de potencial entre 0,01 y $0,5 \mathrm{~V} / \mathrm{s}$. 
Luego, se selecciona un potencial de lectura fijo $E_{L}$ igual a $0,3 \vee$ y se determina la corriente para cada velocidad de barrido a ese potencial, obteniéndose la gráfica de la Figura 20.

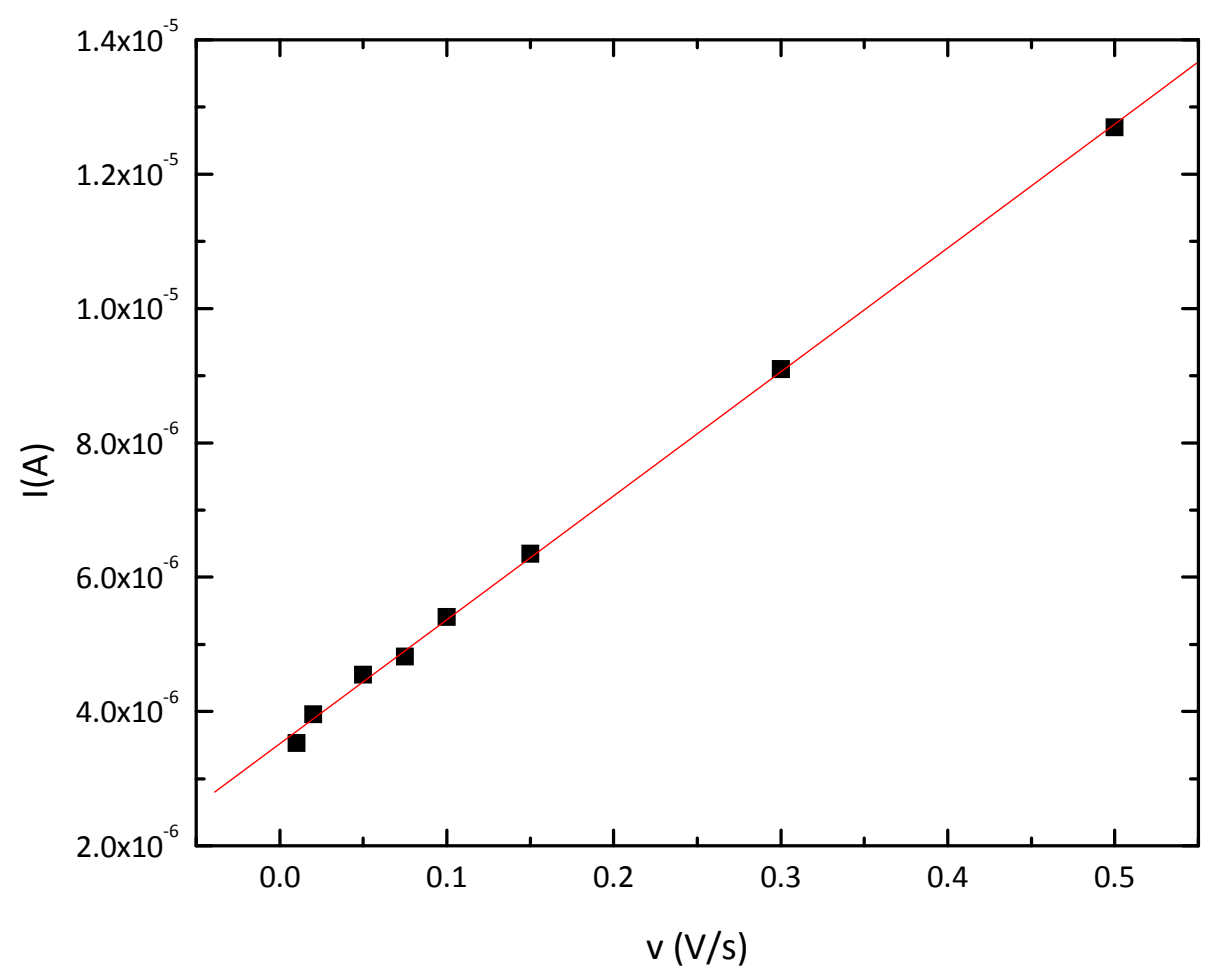

Figura 20. Gráfica que muestra la dependencia de la corriente capacitiva en función de la velocidad de barrido de potencial para $E_{L}=0,3 \mathrm{~V}$.

El valor para la capacidad $C_{E L}$ se calcula a partir de la pendiente de la recta de la Figura 20, esto es, $C_{E L}$ a $0,3 \mathrm{~V}$ que es igual a $18 \mu \mathrm{F}$. Teniendo en cuenta que la capacidad específica $C^{*}$ viene dada por:

$$
C^{*}=C_{E L} / A_{G}
$$

siendo $A_{G}$ es el área geométrica del electrodo, se obtiene un valor de $C^{*}=60 \mu \mathrm{F} / \mathrm{cm}^{2}$, valor coincidente con la capacidad de la doble capa informado por Ibl [171]. En base al valor estimado de $10 \mu \mathrm{F} / \mathrm{cm}^{2}$ para la capacidad específica de electrodos de grafito, $C_{B}$, [190] resulta:

$$
A^{*}=A_{G} C^{*} / C_{B}=1,8 \mathrm{~cm}^{2}
$$

Por lo tanto, teniendo en cuenta la aproximación al fenómeno capacitivo, se calcula el área electroquímicamente activa del sustrato carbonoso, con lo que se encuentra que el área accesible por vía electroquímica es mayor que el área geométrica expuesta.

Mediante la relación entre área activa y área geométrica se obtiene un factor de rugosado de:

$$
R^{*}=A^{*} / A_{G}=6
$$

Se debe destacar que, realizando el cálculo de $A^{*}$ para otros valores de $E_{L}$ se obtuvieron valores muy cercanos a los obtenidos para $0,3 \mathrm{~V}$ con un error inferior al $4 \%$. 


\section{V.5. Efecto del tratamiento de OCPR sobre el sustrato grafítico}

Se aplicó la técnica de OCPR sobre sustratos de grafito pretratados oxidativamente a fin de verificar que el tratamiento electroquímico a utilizar para el desarrollo de los electrodepósitos de $P t$ no afecta el sustrato conductor.

Los voltamperogramas de control del sustrato grafítico en $\mathrm{H}_{2} \mathrm{SO}_{4} 0,5 \mathrm{M}$ a $25^{\circ} \mathrm{C}$ antes y después de la aplicación de la perturbación de potencial no mostraron cambios apreciables en el perfil potencialcorriente, lo cual indica que la aplicación de la técnica de OCPR no afecta al sustrato sobre los que se realizan los electrodepósitos de $P t$. 



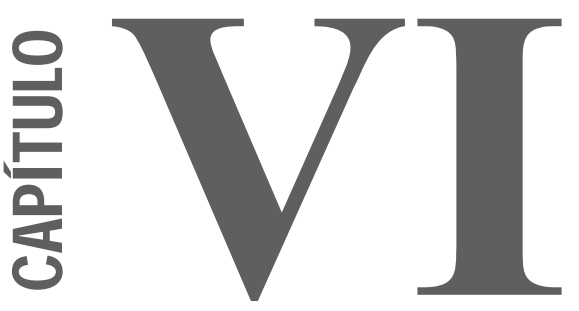

Metodología experimental para la preparación y caracterización de electrodepósitos de Pt dispersados sobre sustratos de carbono 


\section{CAPÍTULO VI}

Metodología experimental para la preparación y caracterización de electrodepósitos de Pt dispersados sobre sustratos de carbono

\section{VI.1. Soluciones electrolíticas y reactivos utilizados}

Las soluciones electrolíticas empleadas fueron preparadas utilizando agua ultrapura proporcionada por un sistema Millipore, Milli-Q (Figura 1). El equipo se alimenta con agua monodestilada y posee una serie de filtros por los que circula el agua, de acuerdo a:

a) Membrana de ósmosis inversa.

b) Filtro de carbón activado.

c) Dos lechos de resinas de intercambio iónico.

d) Filtro bacteriológico con un diámetro de poro $22 \mu \mathrm{m}$.

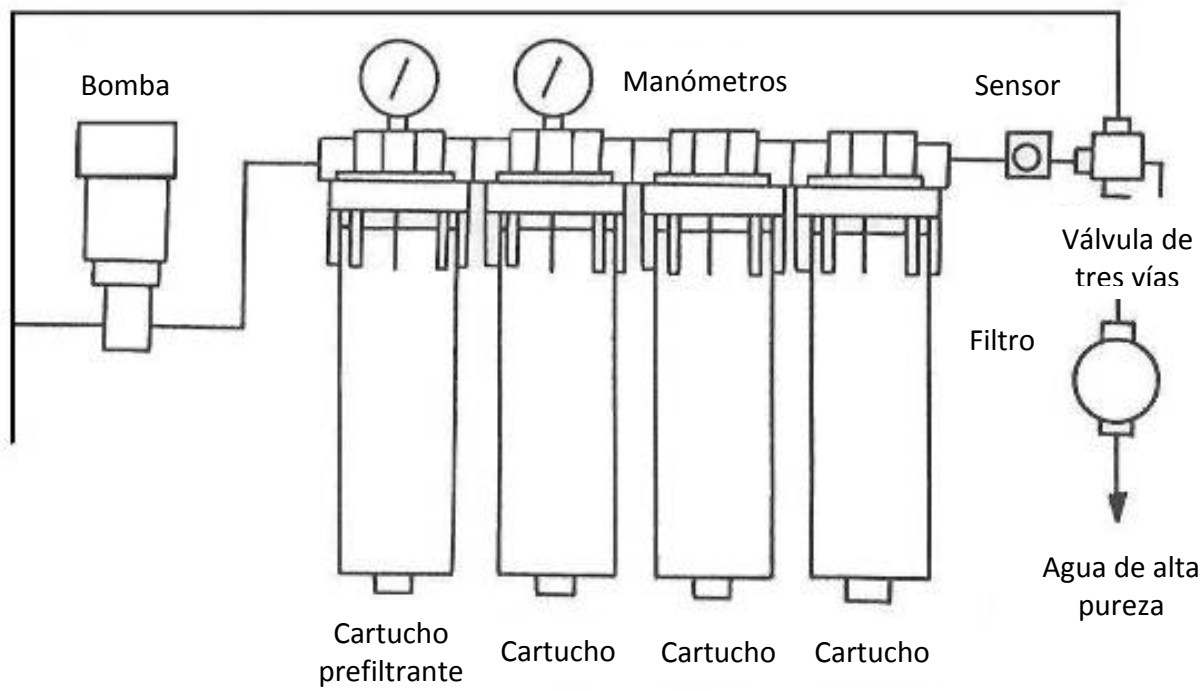

Figura 1. Esquema del sistema purificador de agua, etapas b) - d).

La materia orgánica se elimina mediante un filtro de carbón activado, pasando luego por dos filtros de resinas de intercambio iónico. En este proceso se obtiene agua desionizada y finalmente las partículas de tamaño superior a $0,22 \mu \mathrm{m}$ son retenidas en un filtro bacteriológico. El agua obtenida mediante este sistema tiene una resistencia específica de $18 \mathrm{M} \Omega . \mathrm{cm}$ a $25{ }^{\circ} \mathrm{C}$ y su pureza se puede verificar por el método que se indica en la referencia [250].

En todas las experiencias las soluciones de trabajo se desairearon previamente a su utilización mediante burbujeo con una corriente de nitrógeno de alta pureza, provisto por LINDE, División Gases Especiales (pureza 99,998\%, con $\mathrm{H}_{2} \mathrm{O}<4,0 \mathrm{ppm} / \mathrm{v} ; \mathrm{O}_{2}<4,0 \mathrm{ppm} / \mathrm{v} ; \mathrm{CO}_{2}<1,0 \mathrm{ppm} / \mathrm{v} ; \mathrm{THC}<1,0 \mathrm{ppm} / \mathrm{v}$; 
$C O<1,0 \mathrm{ppm} / \mathrm{v})$. Para una mayor purificación del gas inerte nitrógeno se intercaló en el tren de alimentación una trampa de aire líquido para condensar la humedad y las sustancias orgánicas volátiles. Seguidamente se colocó una trampa de $\mathrm{H}_{2} \mathrm{SO}_{4}$ concentrado (98 \%) para oxidar impurezas orgánicas y finalmente una trampa de agua calidad Milli- $Q$ para retener el ácido que se arrastra en el procedimiento [251], [252]. Desde el tubo de nitrógeno y de la salida del tren purificador, los gases se conducen a la celda por cañerías de teflón, conectadas desde el tren de alimentación por esmeriles esféricos y cónicos.

Para los electrodepósitos de Pt se utilizó solución de ácido hexacloroplatínico de concentración 0,04 M; de calidad síntesis, marca Aldrich (A.C.S. reagent, Aldrich Chem Co.), preparado en una solución ácida de $\mathrm{HCl}$ 1,1 M (p.a. Merck).

Los voltamperogramas de caracterización de los electrocatalizadores se realizaron en $\mathrm{H}_{2} \mathrm{SO}_{4}$ 0,5 M preparado a partir de ácido de calidad analítica proporcionado por Merck, empleando agua ultrapura.

Las soluciones destinadas a la limpieza de las celdas electroquímicas y del material de vidrio fueron generalmente agua regia o $\mathrm{KMnO}_{4}$, preparados a partir de drogas pro-análisis y agua tridestilada. En particular las celdas electroquímicas se limpiaron con $\mathrm{KMnO}_{4}$ concentrado en medio alcalino, estacionando el material por 24 horas y posterior enjuague con agua tridestilada calidad Milli-Q.

\section{VI.2. Electrodos}

\section{VI.2.a. Electrodos de trabajo}

Para la obtención de los electrodepósitos de Pt se utilizó como electrodo de trabajo grafito de calidad espectroscópica, provisto por Nacional Carbon Company, Division of Union Carbide Corporation, con un contenido de impurezas total inferior a $6 \mathrm{ppm}$ y porosidad relativamente baja. En la Figura 2 se muestra el electrodo de trabajo utilizado para los electrodepósitos.

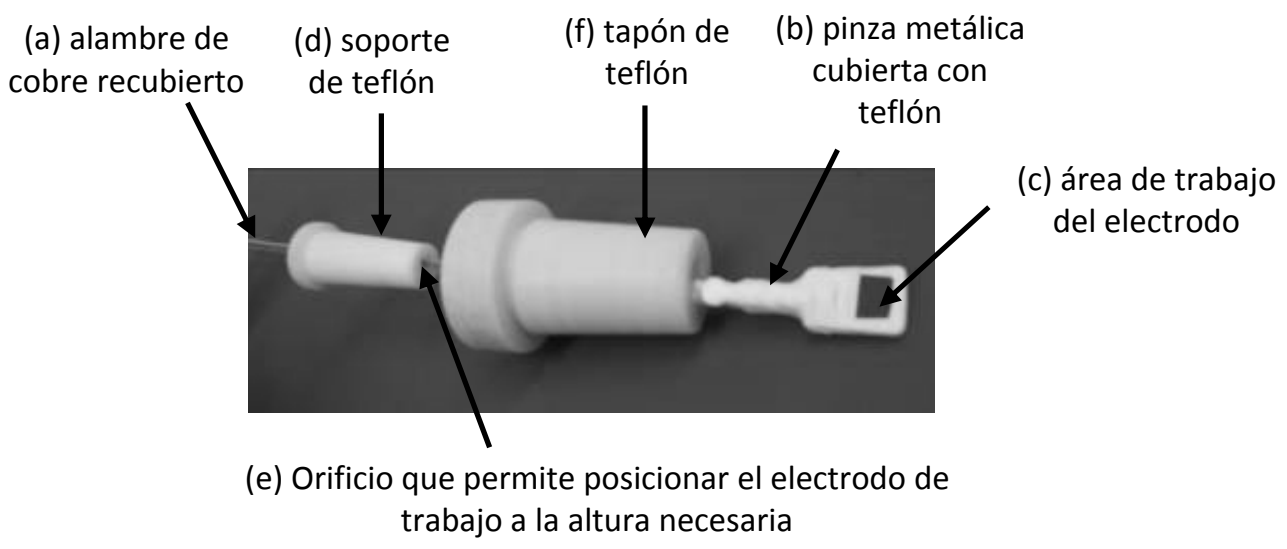

Figura 2. Electrodo de trabajo para los electrodepósitos de Pt.

Un alambre de cobre (a), protegido con una cobertura de teflón y soldado a una pinza metálica (b), permite la conexión entre el electrodo de trabajo y el potenciostato. Todo el conjunto se encuentra 
recubierto con cinta teflón, dejando el área de trabajo (c) del electrodo expuesta a la solución electrolítica. En todas las experiencias se trabajó con un área definida de $0,3 \mathrm{~cm}^{2}$. Un soporte de teflón, tipo tapón (d), permite mantener al electrodo de trabajo en una posición fija y regular su altura respecto a la solución electrolítica, deslizándolo a través de un orificio centrado en este soporte (e). A su vez, el soporte actúa como sujetador del electrodo de trabajo. El conjunto se acopla a la celda electroquímica mediante un tapón de teflón (f) que se ajusta perfectamente a la celda.

\section{VI.2.b. Contraelectrodos}

Los contraelectrodos utilizados fueron construidos con alambre y chapas de platino. Son de alta rugosidad superficial, lo cual posibilita que la relación de áreas electrodo de trabajo/contraelectrodo sea lo suficientemente baja como para que el contraelectrodo actúe como electrodo no polarizable [174].

Para el caso de las celdas utilizadas para electrodepositar $P t$ se probaron diferentes geometrías de contraelectrodo, con el objetivo de lograr un campo eléctrico lo más homogéneo posible en dirección al electrodo de trabajo. Finalmente, se seleccionó una geometría como la indicada en la Figura 3, enfrentando el contraelectrodo de $P t$ al electrodo de trabajo.

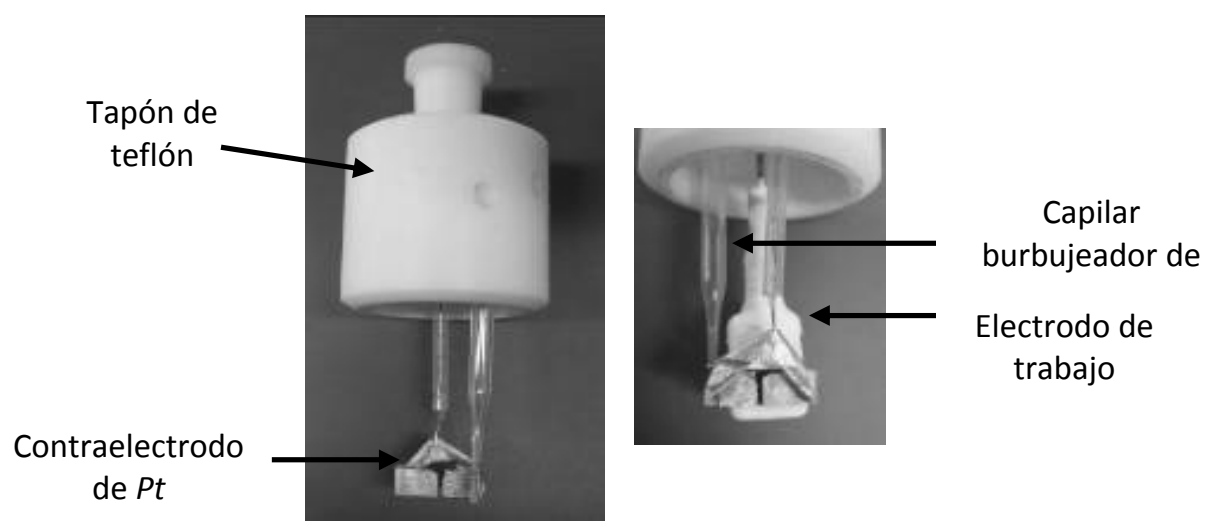

Figura 3. Geometría seleccionada para el contraelectrodo de la celda para electrodepositar.

Las dimensiones geométricas del contraelectrodo permiten una relación de área que garantiza que la densidad de corriente en el contraelectrodo sea despreciable frente a la del electrodo de trabajo. De este modo la velocidad de los procesos que ocurren en el contraelectrodo es muy baja y, en el caso de que se formen productos durante la reacción, no contaminen la solución.

\section{VI.2.c. Electrodos de referencia}

En todas las experiencias se utilizaron electrodos reversibles de hidrógeno, del tipo burbuja de gas. Este electrodo consta de un alambre o lámina de platino recubierta de negro de platino (platino 
platinado) dentro de un bulbo de vidrio. En un extremo tiene soldado un alambre de Pt para la conexión y en el otro extremo el bulbo finaliza en un capilar tipo Luggin (Figura 4).

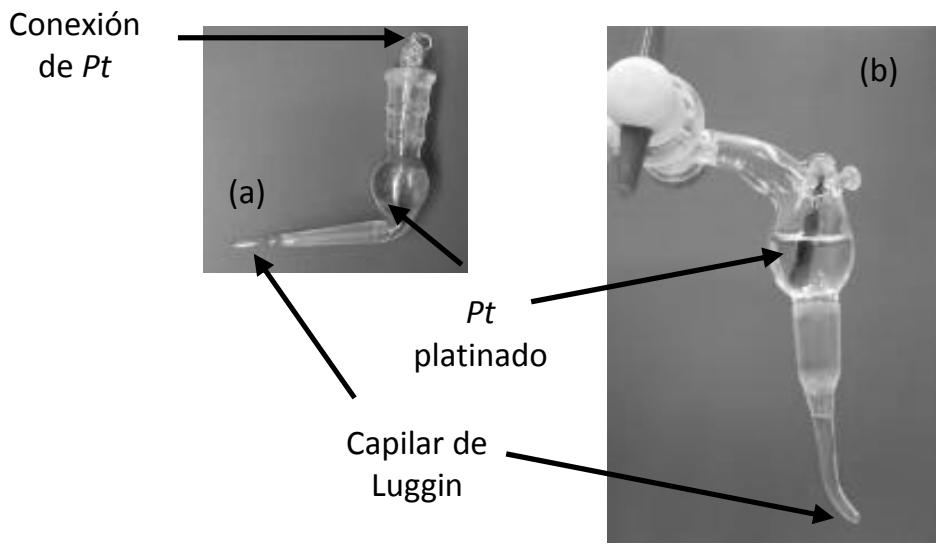

Figura 4. Electrodos de referencia (a) para electrodepositar Pt y (b) para voltamperometría cíclica.

Por medio de una trampa de vacío se llena el bulbo con una solución de $\mathrm{HCl}$ 1,1 M de actividad unitaria de protones [253] y se conecta el alambre de Pt como cátodo en un circuito electrolítico. De este modo, se genera gas hidrógeno que satura la solución formando una interfase triple $H_{2(\mathrm{~g})} / H^{+}(a: 1) / P t$. Este sistema trifásico se utiliza como electrodo de referencia.

Para el caso de obtención de los electrodepósitos de $P t$, el electrodo de referencia está ubicado en la zona central del área expuesta del electrodo de trabajo. De esta manera se asegura que su presencia no altere el campo eléctrico y no distorsione el proceso de electrodeposición.

\section{VI.3. Celdas electroquímicas}

Se utilizaron dos tipos de celdas: (a) para electrodepositar Pt y (b) para la caracterización electroquímica de los electrodepósitos de Pt.

\section{VI.3.a. Celda para electrodepósitos de Pt}

Para realizar los electrodepósitos de Pt se empleó una celda de pequeñas dimensiones, como la mostrada en la Figura 5. Una de las consideraciones para dicha selección fue la necesidad de utilizar volúmenes reducidos de solución electrolítica de trabajo, debido a su alto costo. Por otro lado, en esta celda, se obtiene una buena orientación y distancia entre el electrodo de trabajo y el electrodo de referencia, con lo que se logra retardar la difusión de especies iónicas metálicas que pueden llegar a alterar el valor del potencial del electrodo de referencia.

La celda se compone de un cuerpo central con un vástago de vidrio en su parte inferior (a), que permite su rápida colocación en un soporte de teflón, sujeto mediante un pie metálico, que otorga la estabilidad. En su parte lateral inferior posee un esmeril hembra (b) donde se coloca el electrodo de 
referencia que se prolonga hacia el interior de la celda por medio de un fino capilar de unas pocas décimas de milímetro de diámetro [capilar de Luggin (c)]. La celda posee un tapón hembra de teflón con un orificio lateral para la entrada de gas nitrógeno burbujeante en la solución electrolítica, a través de un capilar de vidrio. En el centro del tapón existe un agujero cónico autocentrante, dentro del cual se introduce el sujetador del electrodo de trabajo, como se mencionó anteriormente y se señaló en la Figura 2 (d). El sujetador de teflón, junto con el electrodo de trabajo, se desliza dentro del tapón cónico, el cual se asienta sobre la parte superior de la celda electroquímica sellándola herméticamente. De esta manera se logra asegurar la posición del electrodo de trabajo, el contraelectrodo y el electrodo de referencia.

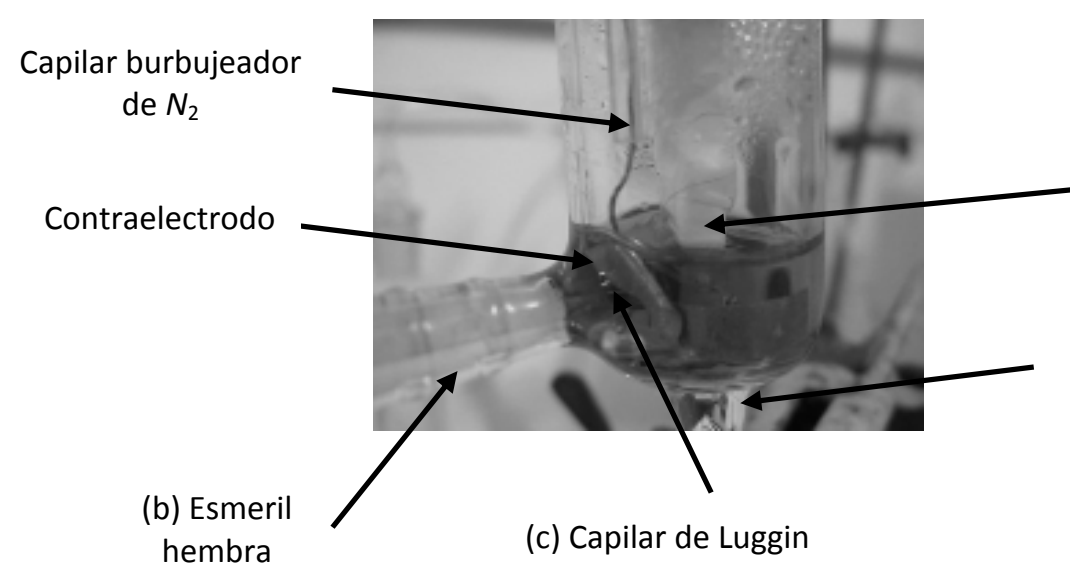

Electrodo de trabajo

(a) Vástago de vidrio para soporte de la celda

Figura 5. Celda electroquímica para electrodepositar $P t$.

Otra ventaja para la selección de una celda de pequeñas dimensiones para realizar los electrodepósitos de Pt, es la posibilidad de obtener mayor uniformidad en la distribución de corriente. Teniendo en cuenta la geometría del contraelectrodo, y con el electrodo de trabajo en el eje central de la celda, la morfología de los electrodepósitos no se ve alterada por efectos de distribución primaria de corriente. Como consecuencia de la corriente que circula entre el electrodo de trabajo y el contraelectrodo existe una caída óhmica entre el extremo del electrodo de referencia y el electrodo de trabajo, por lo cual resulta necesario acercar suficientemente el electrodo de trabajo a la punta del capilar de Luggin y tener en cuenta además la compensación por caída óhmica propia del potenciostato. Por otro lado, se debe tener en cuenta que si se acerca demasiado el electrodo de trabajo al capilar se pueden distorsionar las líneas de campo eléctrico. Para un electrodo de trabajo plano, la separación entre el electrodo de trabajo y el capilar debe ser de $3 d$, siendo $d$ el radio externo del capilar [254].

\section{VI.3.b. Celda para la caracterización electroquímica de electrodepósitos de $P t$}

Se utilizó una celda convencional de tres electrodos (Figura 6), con el electrodo de referencia de burbuja de hidrógeno (a) y como contraelectrodo una lámina de Pt (b) previamente platinada en una solución de $\mathrm{H}_{2} \mathrm{PtCl}_{6} .6 \mathrm{H}_{2} \mathrm{O}$ al $2 \%$, con lo que se obtiene una alta rugosidad superficial. La celda posee una 
entrada lateral que permite acoplar un capilar para el ingreso del gas nitrógeno (c), que burbujea la solución y cuenta con otra entrada para el ingreso de nitrógeno sobrenadante (d). La celda queda herméticamente cerrada mediante un tapón de teflón (e) acoplada a la misma. En esta celda electroquímica se realizaron los voltamperogramas de control de los electrodos de trabajo antes y después del tratamiento de electrólisis pulsante.

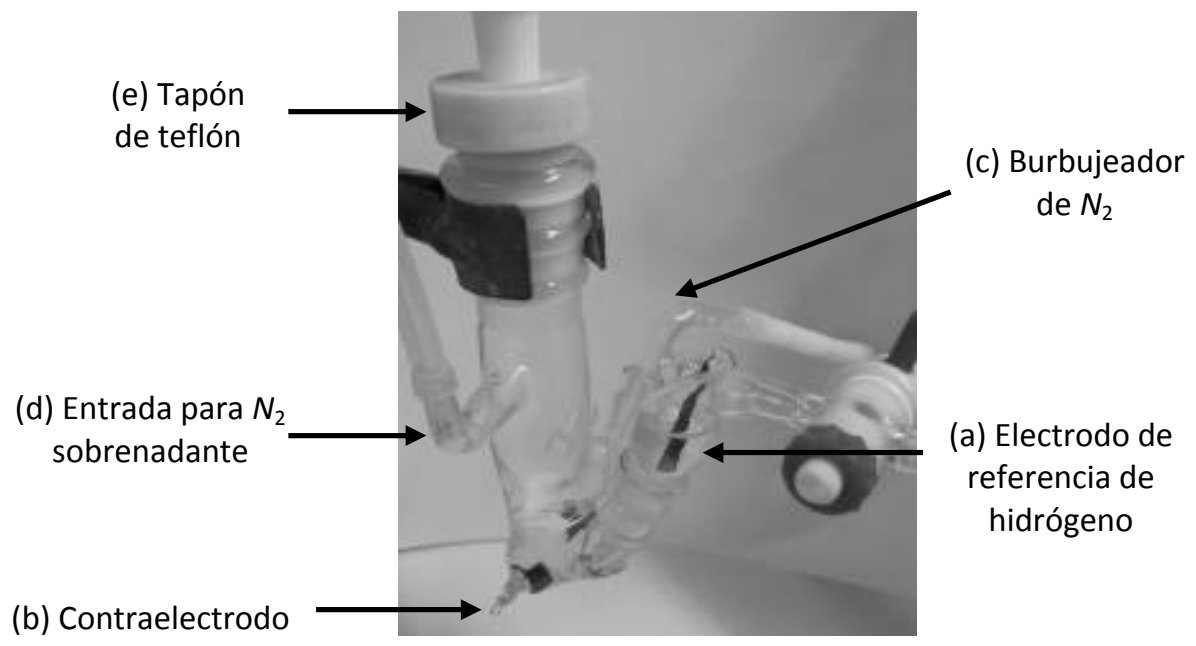

Figura 6. Celda electroquímica para la caracterización voltamperométrica.

\section{VI.4. Equipos e instrumentación electrónica}

Las variables electroquímicas medidas en las experiencias realizadas son continuas, por lo que es necesario medir y controlar potenciales, corrientes y cargas en forma constante.

Para la realización de las diferentes experiencias se utilizaron los siguientes equipos: potenciostato, generador de función, osciloscopio, conformador de onda, culombímetro electrónico y sistema de registro (computadora, multímetro adquisidor de datos); interconectados como se muestra en la Figura 7. La descripción y detalles de cada uno de los dispositivos empleados se presentan a continuación.

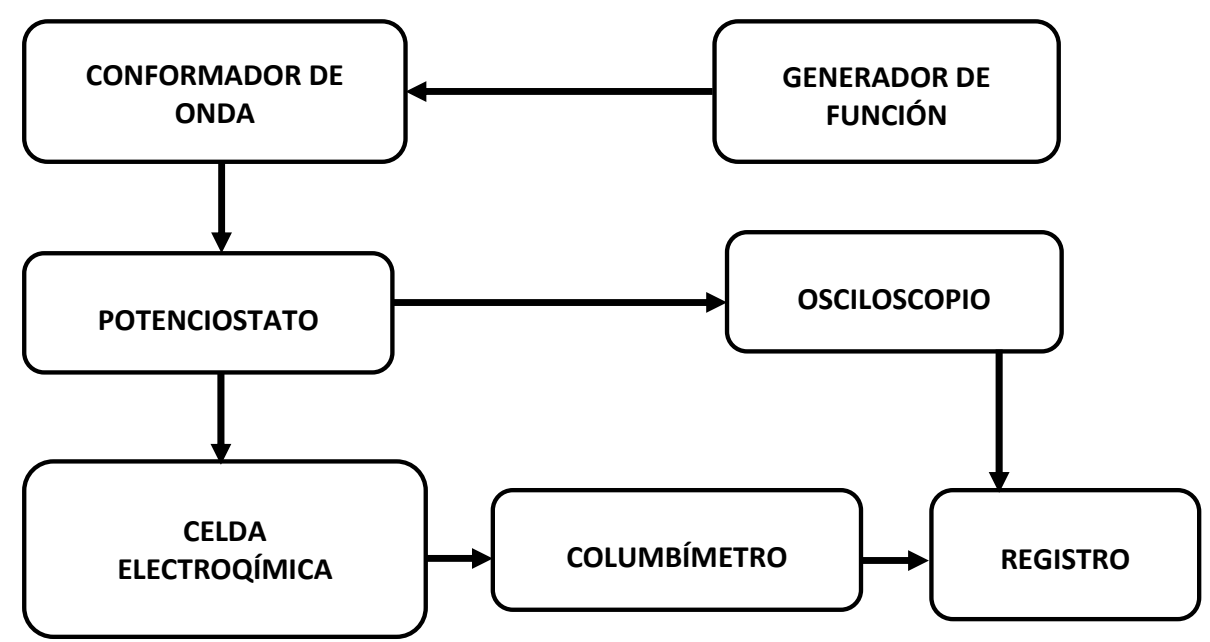

Figura 7. Sistema de equipos interconectados utilizados en las experiencias. 


\section{VI.4.a. Potenciostato}

Es un dispositivo que opera con una diferencia de potencial entre el electrodo de trabajo (por el cual circula la corriente de la celda) y el electrodo de referencia (por el cual no circula corriente). Este potencial se compara continuamente con una tensión prefijada constante y la diferencia entre ambos (Ilamada señal error) se utiliza como alimentación de un amplificador operacional. De este modo se regula la corriente que circula entre el electrodo de trabajo y el contraelectrodo, para que dicha señal error se mantenga nula, pudiendo así controlar el valor de la diferencia de potencial entre el electrodo de trabajo y el de referencia [255].

La diferencia de potencial entre el electrodo de trabajo y el electrodo de referencia depende del flujo de corriente que circula a través de la celda, de las características eléctricas de la celda y de los electrodos.

El potenciostato consiste básicamente en un circuito de realimentación negativa donde el lazo de realimentación lo constituye la celda y un amplificador operacional cuya entrada no inversora está conectada a un potencial de referencia [256].

El equipo utilizado en las medidas experimentales fue un potenciostato-galvanostato Autolab/PGSTAT 30 (EcoChemie), con una amplitud de corriente de $10 \mathrm{nA}$ a 1 A en 9 rangos, tensión de salida $\pm 30 \mathrm{~V}$, rango de potencial $\pm 10 \mathrm{~V}$, resolución del potencial aplicado de $150 \mu \mathrm{V}$, resolución del potencial medido 300 o $30 \mu \mathrm{V}$, posibilidad de trabajar en alta estabilidad o alta velocidad y tiempo de crecimiento $<250 \mathrm{~ns}$. Cuenta con una interfase USB controlada mediante software. Para una descripción más detallada se puede consultar el manual técnico [257]. En la mayoría de lo casos fue necesario drenar corrientes superiores al amperio para lo cual se acopló al sistema un módulo, BOOSTER $10 \mathrm{~A}$ Autolab, que permite incrementar la corriente máxima del potenciostato a $10 \mathrm{~A}$, con una resolución de $0,0003 \%$. El potenciostato tiene entrada de señal externa a la que se conecta el generador de función de onda, para la aplicación de la onda cuadrada de potencial repetitiva que permite obtener los electrodepósitos de $P t$.

\section{VI.4.b. Generador de función de onda}

El potencial impuesto a la celda por el potenciostato se suministra mediante un generador de función de onda, que consiste en un conjunto de canales cada uno de los cuales produce una señal lineal de potencial en función del tiempo, cuyos parámetros de definición se pueden fijar. Mediante este equipo se genera una tensión constante o variable que puede ser utilizada como señal externa en el potenciostato para manejar adecuadamente el potencial del electrodo de trabajo.

Para las experiencias se utilizó un generador de señales programable de alta frecuencia Agilent $33220 A$ capaz de generar ondas cuadradas, sinusoidales, rampas, triangulares, pulsos y ondas de forma arbitraria en un rango de frecuencias desde $1 \mu \mathrm{Hz}$ a $20 \mathrm{MHz}$, con una frecuencia de pulso de $500 \mu \mathrm{Hz}$ a 5 
$\mathrm{MHz}$ y amplitud entre $10 \mathrm{mVpp}$ y $10 \mathrm{Vpp}$. El generador de función empleado se caracteriza por una velocidad de rampa lineal superior a los $200 \mathrm{kHz}$ y, para el caso de ondas cuadradas, subida y bajada rápidas de $20 \mathrm{MHz}$ con un tiempo $<13 \mathrm{~ns}$. Cuenta con un modo gráfico para verificar la forma de la onda aplicada y permite ajustar el ancho de pulso para trabajar con ondas simétricas o asimétricas. Con el generador de función se puede además regular la densidad de corriente de la onda aplicada, fijando los valores de potencial superior e inferior con muy buena precisión. La salida del generador de función fue intercalada con un conformador de onda, cuya descripción y utilidades se proporcionan a continuación.

\section{VI.4.c. Conformador de onda}

En la práctica existen varios factores que pueden provocar un apartamiento de la respuesta ideal de la onda cuadrada. En este caso, podemos tener una caída óhmica no compensada entre el electrodo de trabajo y el de referencia, lo que origina una disminución del potencial efectivamente aplicado y que difiere del valor real $E$, que viene dado por la siguiente expresión:

$$
E=E_{a p}-I R_{s}
$$

donde I es la intensidad que circula entre el electrodo de trabajo y el contraelectrodo, $R_{s}$ es la resistencia de la solución entre el electrodo de trabajo y el de referencia y $E_{a p}$ es la diferencia de potencial aplicada entre los dos electrodos.

Aún disponiendo de un potenciostato ideal, con respuesta instantánea, se requiere de un cierto tiempo para alcanzar el potencial deseado, debido a los procesos de carga de todas las capacidades incluidas dentro del circuito del sistema formado por el electrodo de trabajo y el de referencia.

En las medidas de electrodeposición de $P$ t, al aplicar la onda cuadrada de potencial repetitiva con el generador de función al potenciostato, se observa una deformación de la onda de potencial a la salida del mismo. Para solucionar este inconveniente fue necesario diseñar y construir un dispositivo electrónico (Ilamado de ahora en adelante conformador de onda) capaz de regular la forma de la onda aplicada a los electrodepósitos de Pt. Este dispositivo se intercaló entre el generador de función de onda y el potenciostato. De esta manera, se logró optimizar la onda aplicada con el generador de función a la salida del amplificador de la señal, con lo cual se consiguió aplicar los valores de potencial adecuados para el desarrollo de los facetados de $P t$, regulando la forma de la onda cuadrada óptima deseable.

El conformador de onda está integrado por una serie de resistencias y capacitores que permiten modular la onda aplicada. Mediante la incorporación de los diferentes elementos se logró optimizar la forma de la onda como se muestra en la Figura 8. 


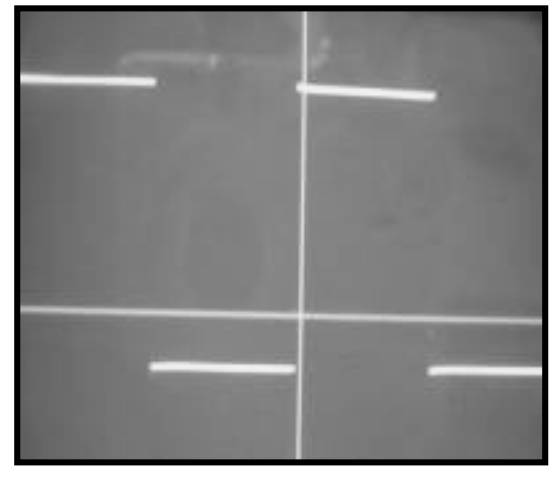

(a) OCPR aplicada con el generador de función

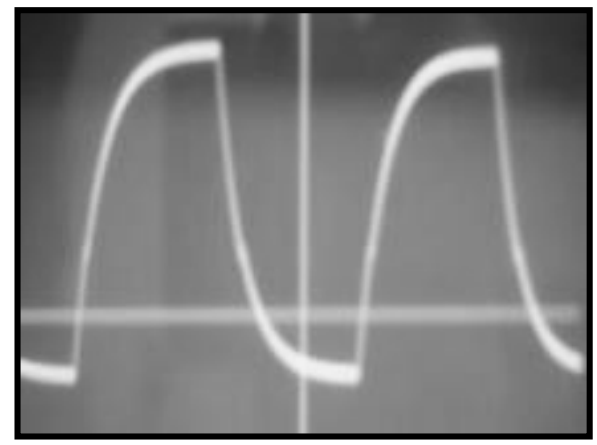

(c) Evolución de la OCPR a la salida del conformador de onda

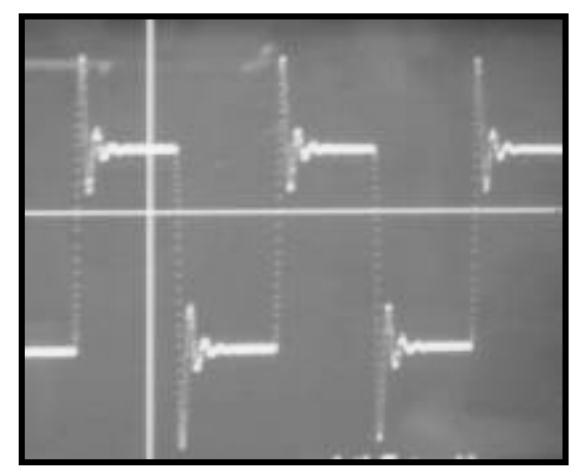

(b) OCPR a la salida del amplificador sin conformador de onda

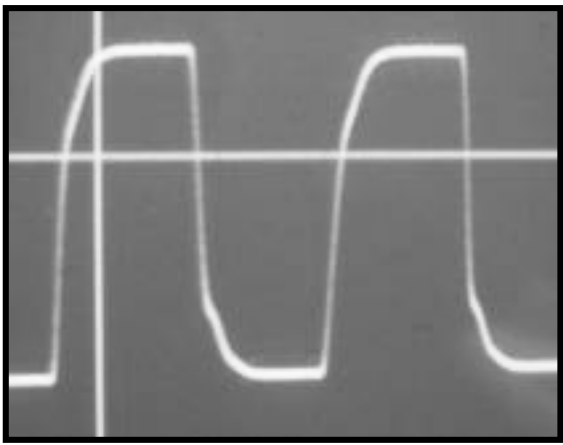
da

Figura 8. Evolución de la OCPR a la salida del conformador de onda.

\section{VI.4.d. Osciloscopio}

A fin de monitorear las señales de potencial cíclicas de alta frecuencia y poder visualizar los parámetros de manera precisa y rápida se utilizó un osciloscopio digital marca Nicolet, serie 2090. Mediante este dispositivo se puede registrar la señal en tiempo real y caracterizar los transitorios electroquímicos, congelar su imagen y expandir los detalles de la señal. Algunas de sus especificaciones técnicas son: resolución $0,025 \%$, exactitud $0,2 \%$ a fondo de escala, linealidad 0,1 \%, sensibilidad máxima $100 \mathrm{mV}$ a fondo de escala, impedancia de entrada $1 \mathrm{M} \Omega$, velocidad máxima de muestreo 0,2 $\mu \mathrm{s}$.

\section{VI.4.e. Culombímetro electrónico}

La carga neta para electrodepositar Pt se registró mediante un culombímetro electrónico, que consiste en un dispositivo que opera integrando la corriente en cada momento para los hemiciclos anódico y catódico de la onda cuadrada de potencial repetitiva y luego se traduce, mediante calibraciones apropiadas, a unidades de carga en culombios.

Cabe destacar que este dispositivo electrónico considera la carga total durante el proceso de electrodeposición, con lo cual se estaría contando con el aporte de la carga para la propia obtención de los electrodepósitos de Pt y también con el debido a la reacción de electrodesprendimiento de hidrógeno, que se produce a 0,05 V. Por lo tanto, es necesario determinar cuál es la carga asociada 
específicamente a la electrodeposición de Pt. Para ello, se implementó la técnica espectrofotométrica para la determinación de la cantidad neta de Pt electrodepositado, que se describe a continuación.

\section{VI.5. Calibración y puesta a punto de la técnica espectrofotométrica para la determinación de la} cantidad de Pt electrodepositado

\section{VI.5.a. Equipamiento y reactivos utilizados}

El registro de los espectros de absorción y las medidas de absorbancia se llevaron a cabo con un espectrofotómetro Hewlett Packard 8452A utilizando celdas de $1 \mathrm{~cm}$ de camino óptico. Los espectros de absorción de las diferentes soluciones consideradas fueron registrados en el rango espectral de 350 a $700 \mathrm{~nm}$, a una velocidad de barrido de $480 \mathrm{~nm} / \mathrm{min}$ y ancho de ranura de $1 \mathrm{~nm}$. El tiempo de integración utilizado fue de 1 segundo con una resolución de $1 \mathrm{~nm}$.

Para la calibración de la técnica se utilizó una solución madre preparada a partir de una cantidad conocida de Pt (99,99 \%) disuelta en agua regia. Se obtuvo de esa manera una solución patrón de concentración conocida. Como agente revelador del color se utilizó solución de $\mathrm{SnCl}_{2} 1 \mathrm{M}$ en solución $\mathrm{HCl} 2 \mathrm{M}$, preparados a partir de reactivos grado analítico.

\section{VI.5.b. Preparación de la solución estándar de $P t$}

Se prepara una solución estándar de Pt disolviendo una cantidad conocida del metal (100 mg) en agua regia $(16 \mathrm{ml})$. La solución obtenida se evapora llevándola a condición de casi sequedad. Se adicionan $3 \mathrm{ml}$ de $\mathrm{HCl}$ concentrado y se evapora nuevamente hasta sequedad. El residuo obtenido se disuelve en $\mathrm{HCl} 1 \mathrm{M}$ y la solución lograda se diluye en $100 \mathrm{ml}$ de $\mathrm{HCl} 1 \mathrm{M}$. Se adiciona solución $\mathrm{SnCl}_{2} 1 \mathrm{M}$ y se obtiene de esta forma una solución patrón de Pt de concentración conocida, a partir de la cual se preparan diluciones de diferentes concentraciones.

\section{VI.5.c. Calibración de la técnica espectrofotométrica}

Se prepararon seis diluciones, a partir de la solución patrón de $P t$, con las siguientes concentraciones: (a) 0,035 mg/ml; (b) $0,02 \mathrm{mg} / \mathrm{ml}$; (c) $0,015 \mathrm{mg} / \mathrm{ml}$; (d) $0,01 \mathrm{mg} / \mathrm{ml}$; (e) $0,004 \mathrm{mg} / \mathrm{ml}$ y (f) $0,0025 \mathrm{mg} / \mathrm{ml}$. Se registraron los espectros de absorción para cada una de las soluciones preparadas. En la Figura 9 se muestran los espectros de los complejos de $P t$ con $\mathrm{SnCl}_{2}$ para la solución patrón a diferentes concentraciones.

Para cada una de las diluciones obtenidas se determina el valor de la absorbancia $A$ a la longitud de onda de máxima absorción $\lambda_{\text {máx }}$ de $402 \mathrm{~nm}$. Se verifica el cumplimiento de la ley de Lambert-Beer y se obtiene una gráfica como la mostrada en la Figura 10, la cual se construye a partir de la lectura de las absorbancias de las soluciones [(a) a (f)] de diferentes concentraciones conocidas. 


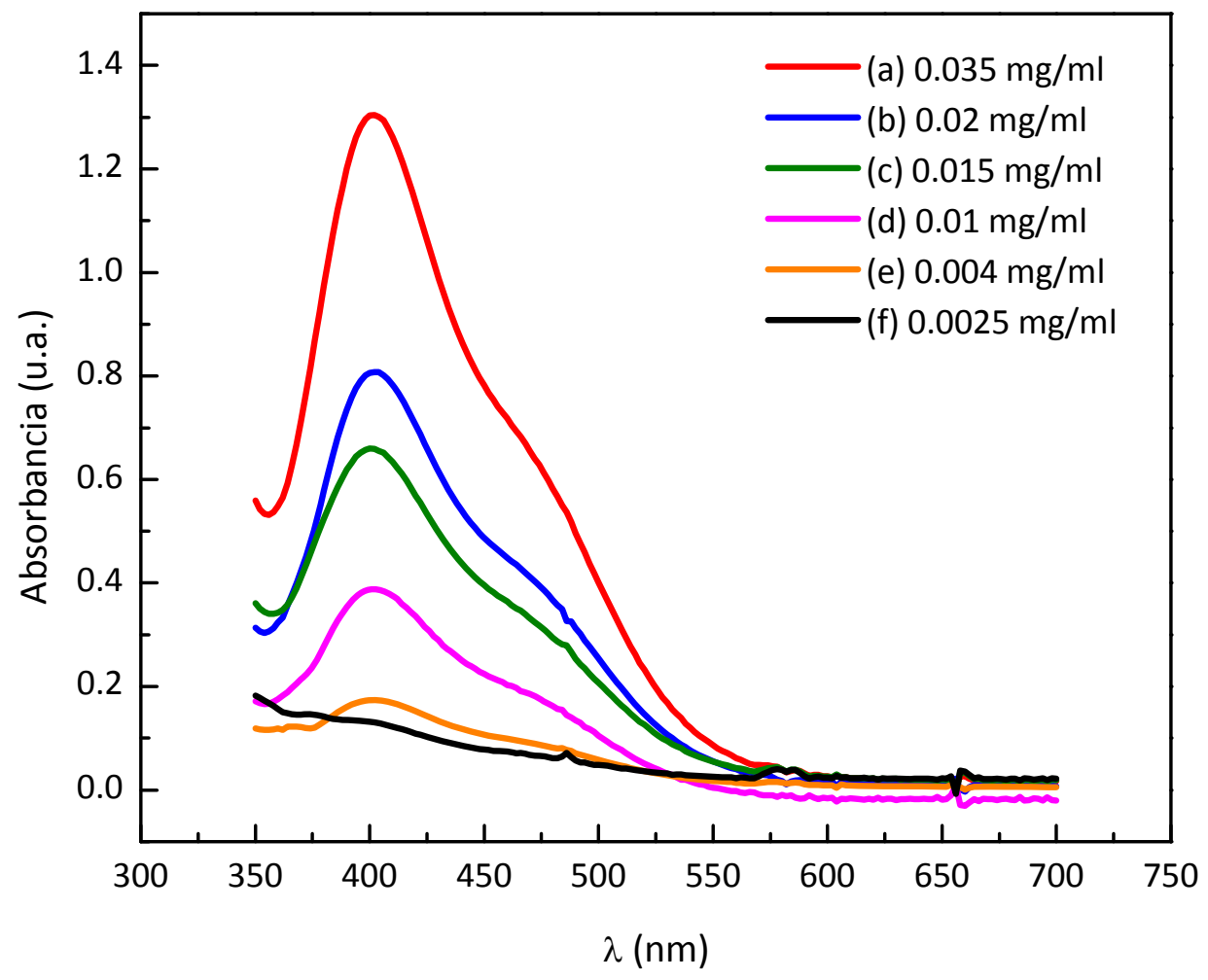

Figura 9. Espectros de los complejos de $\mathrm{Pt}$ con $\mathrm{SnCl}_{2}$ para la solución patrón a diferentes concentraciones.

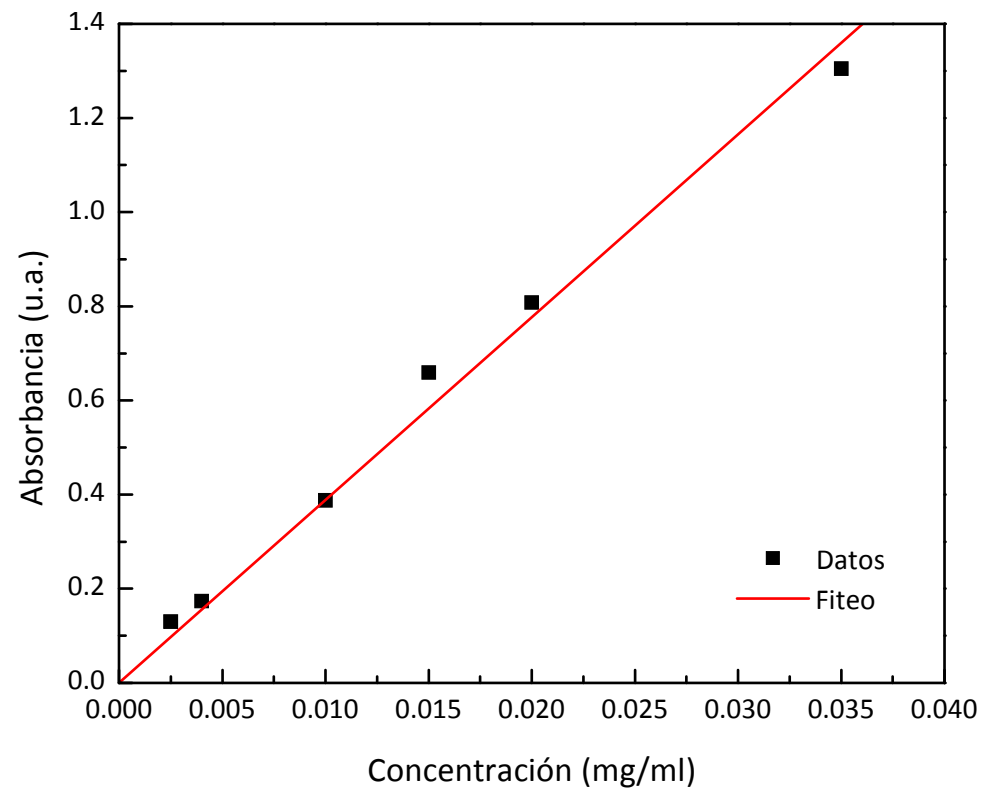

Figura 10. Recta de ajuste para la calibración de la técnica. Verificación de la ley de Lambert-Beer para Pt a $\lambda_{\text {máx }}=402 \mathrm{~nm}$.

Se debe utilizar un intervalo de concentración tal que el comportamiento sea lineal, ya que a concentraciones elevadas se obtiene un comportamiento que se aparta de la linealidad. Cuando se mide la absorbancia de soluciones patrón, conteniendo concentraciones conocidas del analito, y se grafican los resultados de las absorbancias con respecto a la concentración, se establece una relación de calibración. La Figura 10 representa la recta de ajuste para la calibración de la técnica 
espectrofotométrica, donde puede observarse un buen ajuste lineal en cumplimiento con la ley de Lambert-Beer. Dado que la absorbancia es directamente proporcional a la longitud del camino $\mathbf{b}$ a través de la solución y la concentración c de la especie absorbente, como se indicó en la ecuación (32) del CAPÍTULO IV $A=\mathbf{a}$. b. c a partir de la pendiente de la gráfica presentada en la Figura 10 , se determina un valor de absortividad de $\mathbf{a}=38,84 \mathrm{l} / \mathrm{g} \mathrm{cm}$, a la longitud de onda $\lambda_{\text {máx }}$ de $402 \mathrm{~nm}$, con una buena correlación $(R=0,9968)$.

De este modo, el método espectrofotométrico implementado se puede utilizar para determinar con precisión las pequeñas cantidades de Pt electrodepositado sobre los sustratos carbonosos, ya que a partir de la curva de calibración se estima que la cantidad mínima de Pt detectable por medio de esta técnica se encuentra en el orden de $0,0025 \mathrm{~g} / \mathrm{l}$.

\section{VI.6. Preparación y caracterización de electrodepósitos de Pt dispersados sobre sustratos de} carbón

\section{VII.6.a. Obtención de nanopartículas de Pt por OCPR}

Las nanopartículas facetadas de Pt se obtuvieron sobre sustratos de carbono (por lo general se utilizó grafito) inmersos en solución 0,04 $\mathrm{M} \mathrm{H}_{2} \mathrm{PtCl}_{6} \cdot 6 \mathrm{H}_{2} \mathrm{O}$ (A.C.S. reagent, Aldrich Chem Co.) $+1,1 \mathrm{M} \mathrm{HCl}$ (p.a. Merck) a 25 으 por aplicación de una rutina de ondas cuadradas de potencial repetitivas, entre límites de potencial inferior, $E i$, y superior, Es, a frecuencia, $f$, constante durante un tiempo, $t$. El potencial promedio aplicado, $\langle E\rangle=(E s+E i) / 2$, fue siempre negativo respecto al potencial de la cupla redox $P t /\left[P t C l_{6}\right]^{2-}$, el cual dentro de las condiciones experimentales es $c a .0,70 \mathrm{~V}$ vs. $E R H$, a fin de lograr una electrodeposición neta de $P t$.

Los parámetros de potencial de la señal eléctrica cíclica fueron seleccionados para obtener características óptimas de facetado de las nanopartículas de $P t$. De este modo, mediante la selección apropiada de $E i$, Es y $f$, se obtuvieron nanopartículas de facetado cúbico que exhiben orientación cristalográfica preferencial tipo (100) y nanopartículas de $P t$ altamente facetadas con orientación cristalográfica preferencial (111) sobre sustratos de carbono.

En todas las experiencias realizadas se fijaron los tiempos de aplicación de cada escalón de potencial, $\tau_{i}$ y $\tau_{s}$, de modo que la señal eléctrica aplicada fuera simétricas, es decir $\tau_{i}=\tau_{s}$, siendo $\tau_{s}$ la duración del escalón de potencial superior y $\tau_{i}$ la duración del escalón de potencial inferior.

Los voltamperogramas cíclicos de control se realizaron en todos los casos a una velocidad de barrido de $0,1 \mathrm{~V} / \mathrm{s}$ entre $0,05 \mathrm{~V}$ y $0,6 \mathrm{~V}$ en solución $\mathrm{H}_{2} \mathrm{SO}_{4} 0,5 \mathrm{M}$, a $25{ }^{\circ} \mathrm{C}$. Todos los potenciales se expresan en la escala del $E R H$.

Para determinar el grado de desarrollo del facetado en las nanopartículas y el área superficial electroquímicamente activa se utilizó la adsorción de hidrógeno como reacción testigo, debido a que: 
- la carga de adsorción total de hidrógeno es directamente proporcional al número de átomos superficiales, por lo que se puede utilizar este valor de carga para calcular el área superficial electroquímicamente activa y,

- la distribución de la carga entre los diferentes picos voltamperométricos da una primera estimación de la presencia de los diferentes sitios superficiales sobre la superficie total [220], [221].

De esta manera, el desarrollo del facetado de las nanopartículas de Pt con orientación cristalográfica preferencial, puede seguirse a través de los cambios en la altura relativa de los picos de corriente voltamperométricos de los adátomos de hidrógeno fuerte y débilmente adsorbidos, $h_{2}$ y $h_{1}$, respectivamente [19], [126], [186] (Figura 11). El valor promedio de la relación $h_{2} / h_{1}$ para un esfera monocristalina de Pt polifacetada es de 0,64 y para Pt policristalino electropulido 0,7 [15], [158], [169].

El grado de desarrollo de la orientación cristalográfica preferencial (100) fue obtenido a través del parámetro $\mathrm{Fg}$ definido como [160]:

$$
\mathrm{Fg}=h_{2} / h_{1}
$$

donde las alturas de los picos de corriente de electrodesorción de hidrógeno fuertemente y débilmente adsorbidos, $h_{2}$ y $h_{1}$, respectivamente, se obtienen de los voltamperogramas realizados en $\mathrm{H}_{2} \mathrm{SO}_{4}$ 0,5 M.

De manera análoga, el grado de desarrollo de la orientación cristalográfica preferencial (111) se obtiene a través del parámetro $F g$ definido como [160]:

$$
F g=h_{1} / h_{2}
$$

Así, se puede seguir voltamperométricamente el desarrollo de los facetados según las orientaciones cristalográficas preferenciales, asociadas con sitios reactivos que favorezcan la electroadsorción de adátomos de hidrógeno.

La carga voltamperométrica asociada con la electrodesorción de hidrógeno, $Q_{h}$, de los electrodepósitos de Pt se determinó según la siguiente expresión:

$$
Q_{h}=Q_{h}^{T}-Q_{d c}
$$

donde $Q_{h}^{T}$ es la carga de desorción total y $Q_{d c}$ es la carga asociada la doble capa eléctrica.

En la Figura 11 se muestra el voltamperograma de un electrodepósito de Pt obtenido por aplicación de la $O C P R$ entre valores de potencial superior $E s=1,2 \vee$ e inferior $E i=-0,2 \vee$ a frecuencia $f=1 \mathrm{kHz}$ durante 5 minutos de electrodeposición.

El valor correspondiente a $Q_{h}$ se determina por integración de los picos voltamperométricos de la región de electrosorción de hidrógeno, considerando una línea base a partir de la cual se elimina la contribución de la doble capa electroquímica. El área rayada corresponde a $Q_{h}$, cuyo valor se obtiene por integración de la corriente de electrodesorción de hidrógeno adsorbido sobre $P t$ y es utilizado para el cálculo del área superficial electroquímicamente activa. En la Figura 11 se muestran también los picos 
de corriente voltamperométricos asociados a los adátomos de hidrógeno fuerte y débilmente adsorbidos, $h_{2}$ y $h_{1}$, respectivamente.

Variando los parámetros de la OCPR se pudieron obtener electrodepósitos de Pt sobre grafito con diferentes morfologías, pudiéndose regular el tamaño de las partículas de $P t$ y la cantidad de material electrodepositado.

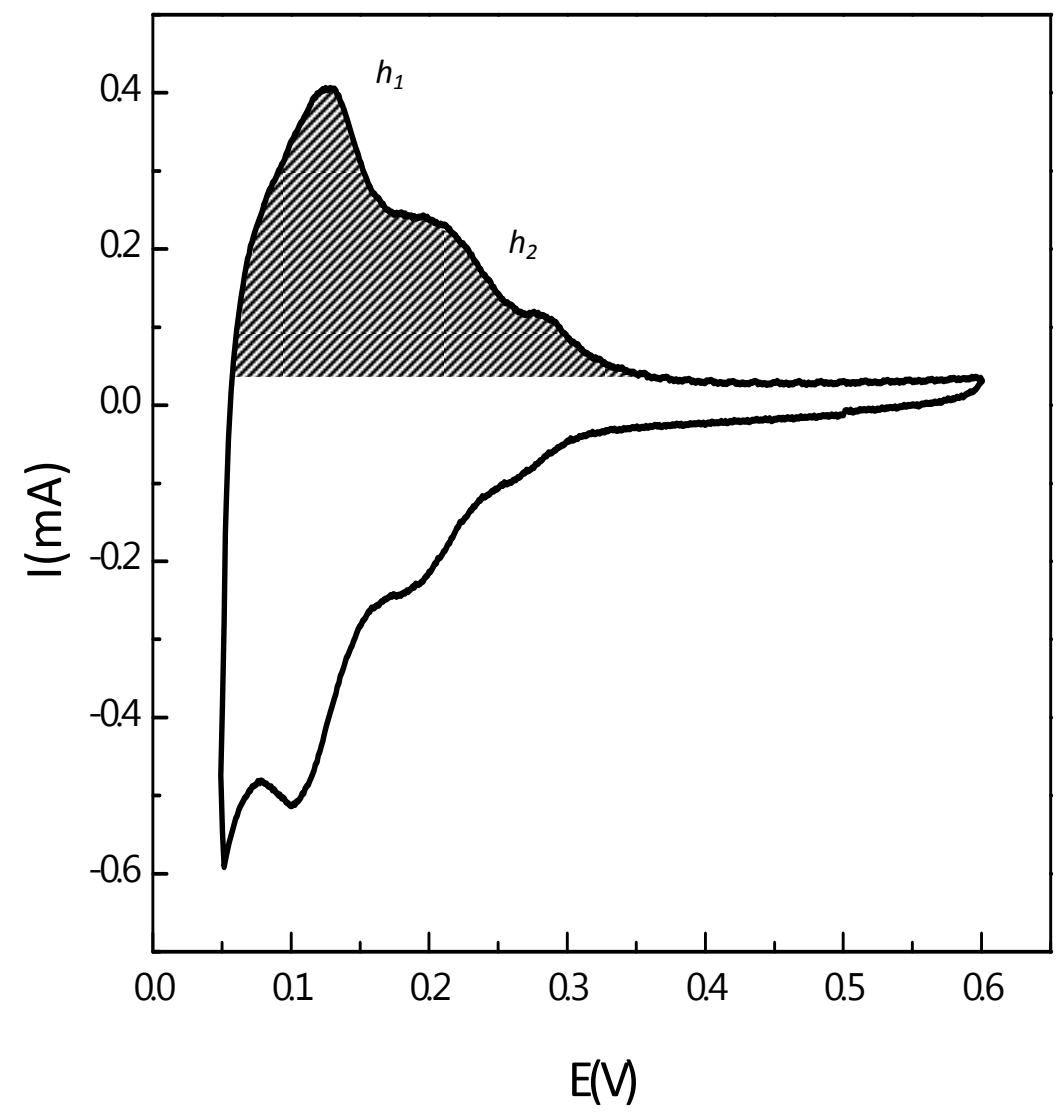

Figura 11. Voltamperograma cíclico a $0,1 \mathrm{~V} / \mathrm{s}$ correspondiente a electrodepósitos de $P$ t obtenidos por aplicación de una $O C P R$ entre $E s=1,2 \mathrm{~V} ; E i=-0,2 ; f=1 \mathrm{kHz} ; t=5 \mathrm{~min}$.

A continuación se muestran los resultados obtenidos para las nanopartículas de $P t$ facetadas tipo (100) y (111), obtenidas por aplicación de la técnica de OCPR, bajo condiciones particulares de operación que favorecen el desarrollo de orientaciones cristalográficas preferenciales de alto índice de Miller.

\section{VI.6.b. Electrodepósitos de Pt con orientación cristalográfica preferencial tipo (100)}

Después del tratamiento de electrólisis pulsante $(O C P R)$ en solución de ácido hexacloroplatínico, entre valores de potencial superior $E s=0,9 \mathrm{~V}$ e inferior $E i=-0,2 \mathrm{~V} ;(\langle E\rangle=0,35 \mathrm{~V})$ y $f=1 \mathrm{kHz}$, el sustrato queda cubierto por cristalitas de Pt uniformemente distribuidas. La Figura 12 muestra la imagen SEM de cristalitas de Pt electrodepositadas bajo las condiciones antes mencionadas. 


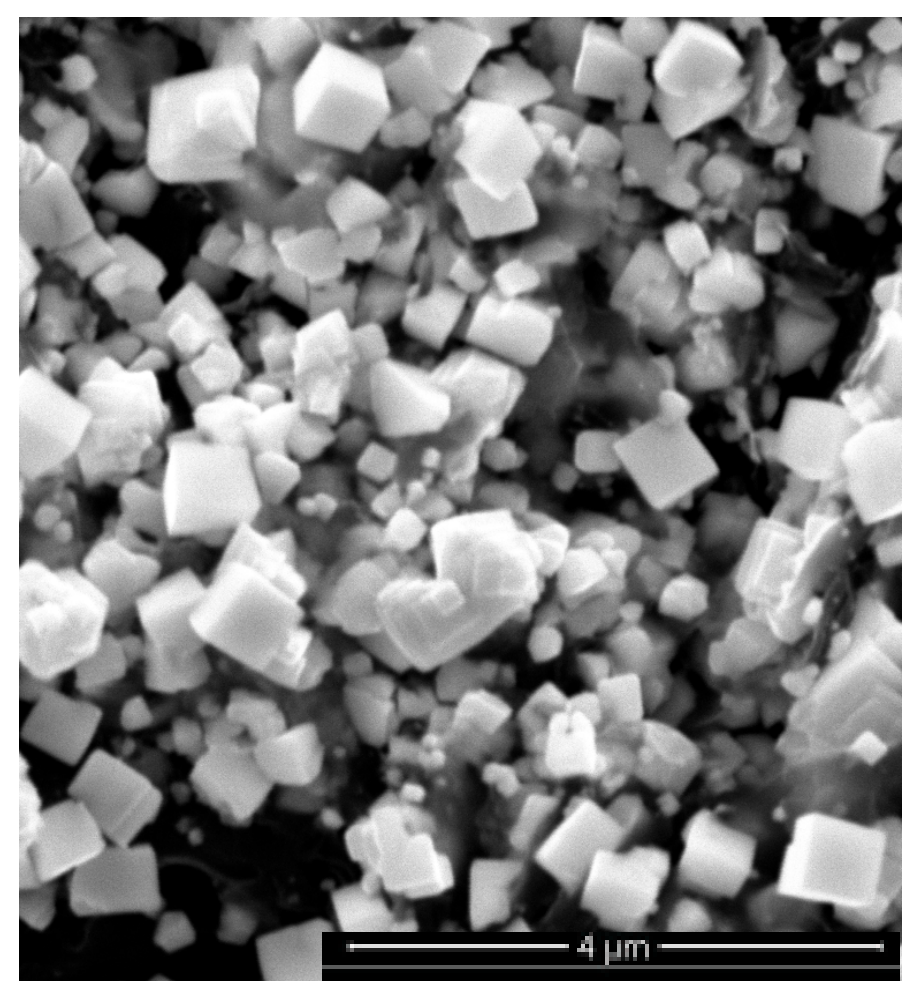

Figura 12. Imagen SEM de electrodepósitos de $P t$ obtenidos bajo condiciones de operación Es = 0,9 V; Ei = -0,2 V $(<E>=0,35 \mathrm{~V}) ; f=1 \mathrm{kHz} ; t=5 \mathrm{~min}$.

De acuerdo a consideraciones cristalográficas, se prevé que la forma geométrica de un monocristal fcc (cúbica centrada en las caras), facetado en forma perpendicular a las 6 direcciones correspondientes a la familia $\{100\}$, sea cúbica como se muestra en el esquema de la Figura 13. En este caso todas sus caras exhiben un ordenamiento atómico correspondiente a una cara cristalina con índices de Miller (100).

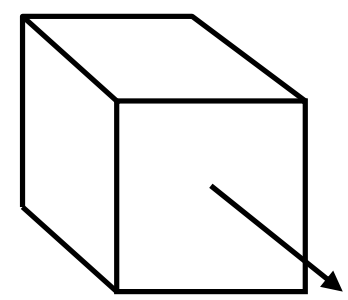

[100]

Figura 13. Monocristal ideal facetado en forma perpendicular a las direcciones [100].

En la imagen SEM mostrada en la Figura 12 se puede distinguir claramente la morfología cúbica bien definida de los electrodepósitos de Pt obtenidos, característica de los facetados tipo (100), de acuerdo a lo anteriormente mencionado.

En la Figura 14 se muestra la respuesta voltamperométrica para un electrodepósito de $P t$ sobre grafito, obtenido bajo las condiciones de electrodeposición que favorecen el desarrollo de la orientación cristalográfica preferencial (100). Para comparación, se muestra también el voltamperograma del sustrato grafítico sobre el que se realizaron los electrodepósitos de Pt. Puede observarse que en la 
región de electrosorción de hidrógeno, comprendida entre $0,05 \mathrm{~V}$ y $0,6 \mathrm{~V}$, se registra un aumento relativo de la corriente de electrodesorción de hidrógeno fuertemente adsorbido, respecto a la respuesta que se esperaría para un electrodo de Pt policristalino.

El perfil voltamperométrico observado en la Figura 14 se aproxima al que se informa para superficies de $P t$ con una alta proporción de sitios de reacción para los átomos de hidrógeno fuertemente adsorbidos y superficies escalonadas de monocristales de $P t$ con terrazas estrechas (100) [13], [161], [185], [204], aunque en ese caso es mucho más definido al no existir la contribución de corriente capacitiva del sustrato grafítico. De este modo, el comportamiento voltamperométrico de los electrodepósitos de Pt es consistente con orientaciones cristalográficas preferenciales del tipo (100), es decir, con superficies facetadas de altos índices de Miller con una contribución importante de la familia de planos $\{100\}$. Por otra parte, la altura relativa de los picos de corriente voltamperométricos de electrooxidación de hidrógeno fuertemente adsorbido, $h_{2}$, a hidrógeno débilmente adsorbido, $h_{1}$, es aproximadamente 1,16 , que se aproxima al valor para el desarrollo de la orientación cristalográfica preferencial (100).

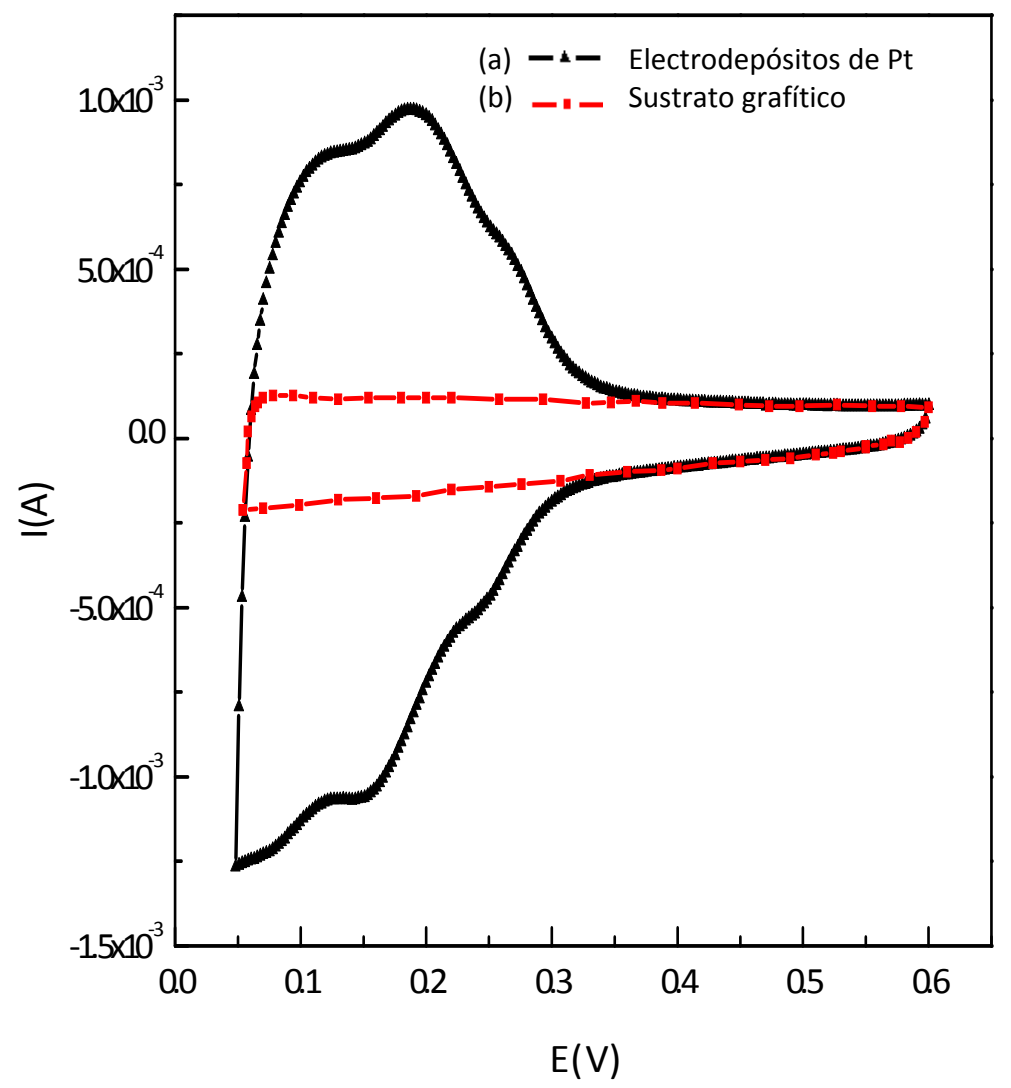

Figura 14. Respuesta voltamperométrica a $0,1 \mathrm{~V} / \mathrm{s}$ en $\mathrm{H}_{2} \mathrm{SO}_{4} 0,5 \mathrm{M}$ a $25^{\circ} \mathrm{C}$ de: (a) $\triangle$ electrodepósitos de $P t$ sobre grafito ( $E s=0,9 \mathrm{~V} ; E i=-0,2 \mathrm{~V} ; f=1 \mathrm{kHz} ; t=10 \mathrm{~min}$ ) y (b) $\square$ sustrato grafítico.

\section{VI.6.c. Electrodepósitos de Pt con orientación cristalográfica preferencial tipo (111)}

Variando los límites de la perturbación periódica de potencial, Es y Ei, la frecuencia de la señal eléctrica $f$ y la simetría de la onda, cabe esperar el desarrollo de cristalitas de $P t$ facetadas con una 
morfología diferente. A partir de este conocimiento, se aplicó una rutina de tratamiento de OCPR bajo las siguientes condiciones de operación: potencial superior $E s=1,2 \mathrm{~V}$; potencial inferior $E i=-0,2 \mathrm{~V} ;(<E>$ $=0,5 \mathrm{~V}$ ); frecuencia constante $f=1 \mathrm{kHz}$, obteniéndose cristalitas distribuidas uniformemente sobre el sustrato como se muestran en las Figuras 15 y 16.

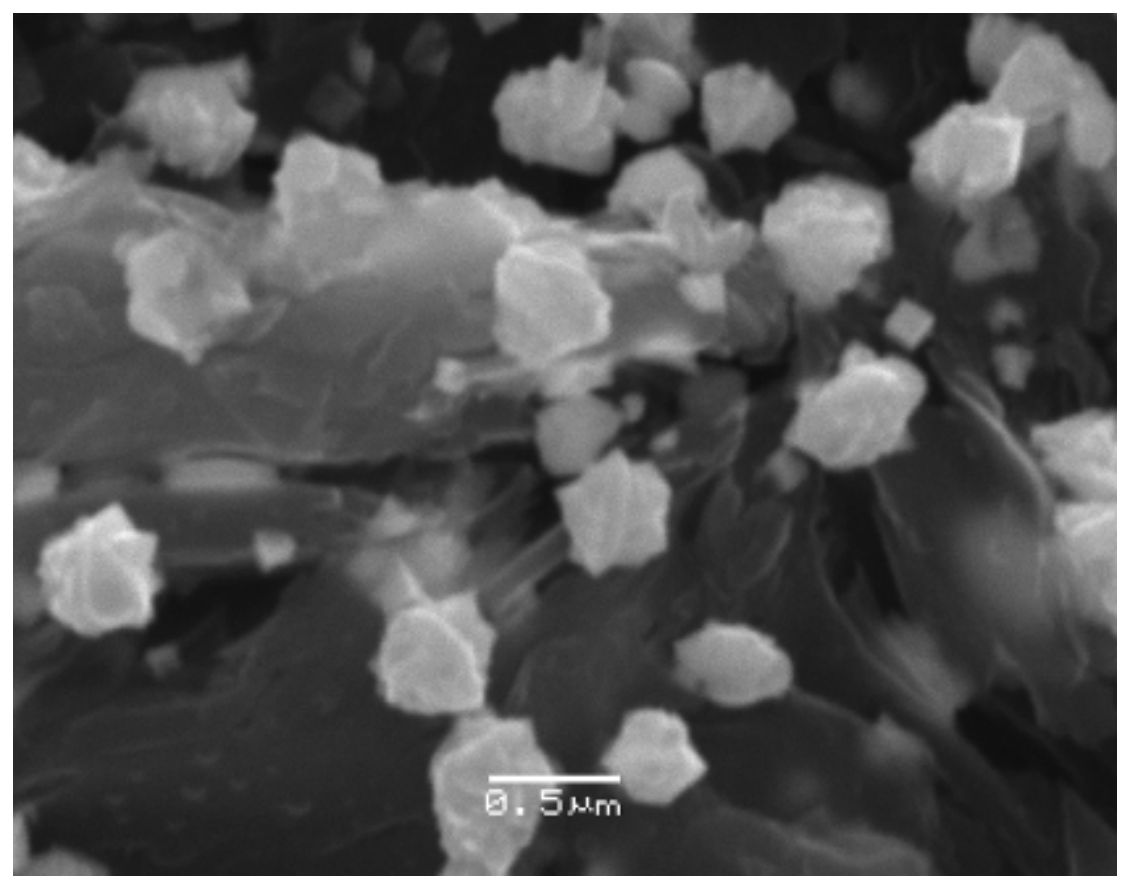

Figura 15. Imagen SEM de electrodepósitos de Pt obtenidos bajo condiciones $E s=1,2 \mathrm{~V} ; E i=-0,2 \mathrm{~V} ; f=1 \mathrm{kHz}$. Magnificación $30000 \mathrm{X}$.

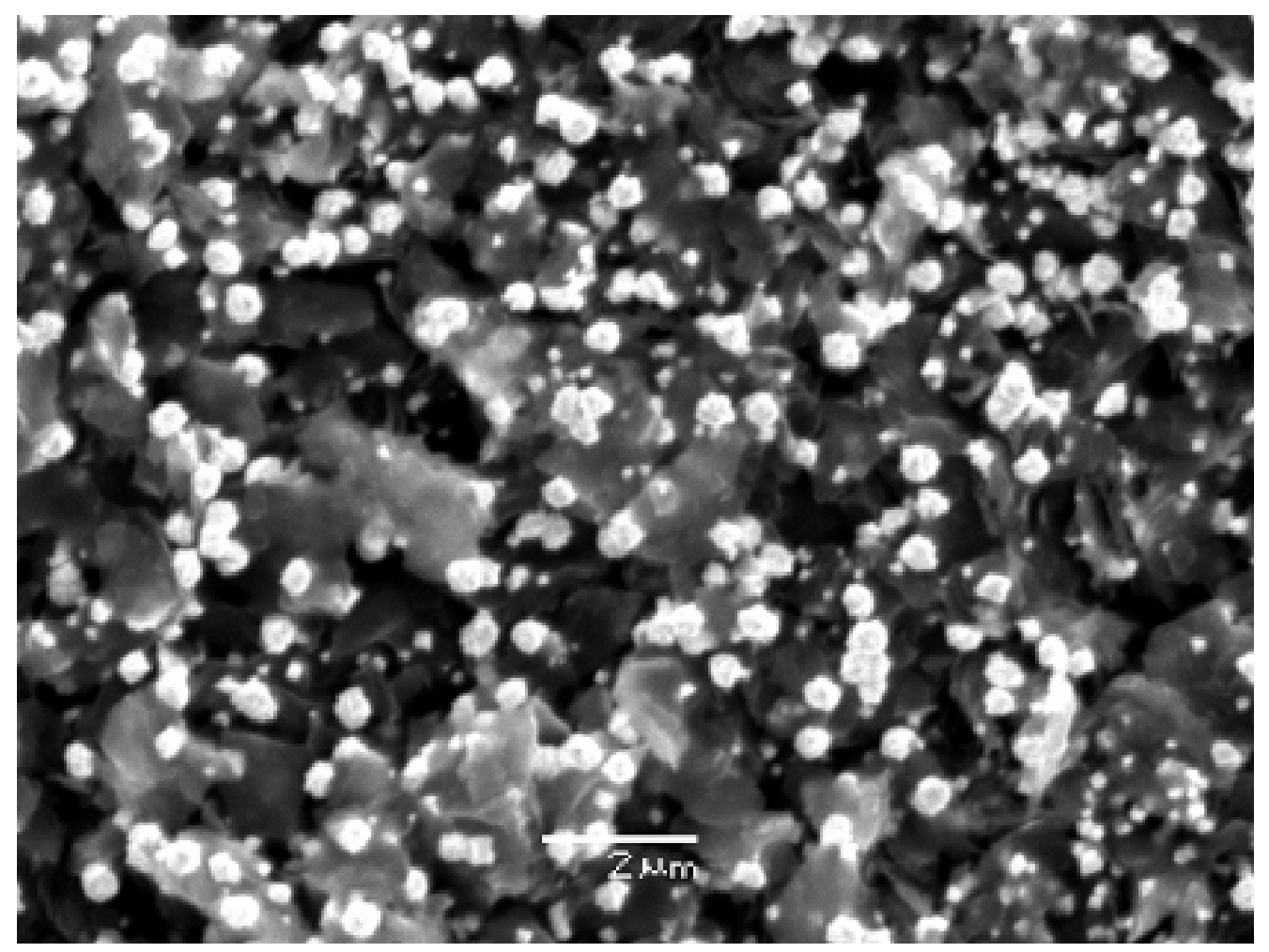

Figura 16. Imagen SEM de electrodepósitos de Pt obtenidos bajo condiciones $E s=1,2 \mathrm{~V} ; E i=-0,2 \mathrm{~V} ; f=1 \mathrm{kHz}$. Magnificación $8000 \mathrm{X}$. 
En las Figuras 15 y 16 se presentan imágenes SEM a dos magnificaciones diferentes donde se puede observar claramente una morfología de tipo poliédrica, con predominio de caras triangulares y ángulos agudos, coincidentes con el desarrollo de la orientación cristalográfica preferencial tipo (111), ya que se puede prever por consideraciones cristalográficas que la forma geométrica de un monocristal $f c c$ facetado en forma perpendicular a las 8 direcciones correspondientes a la familia $\{111\}$ será octaédrica, con las caras exhibiendo un ordenamiento atómico correspondiente a superficies con índices de Miller (111), tal como se muestra en el esquema de la Figura 17.

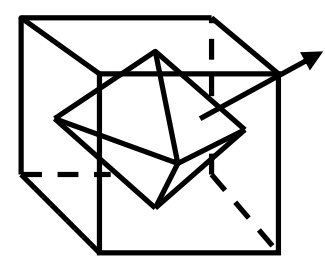

[111]

Figura 17. Monocristal ideal facetado en forma perpendicular a las direcciones [111].

La Figura 18 muestra la respuesta voltamperométrica para un electrodepósito de Pt sobre grafito, obtenido mediante aplicación de la OCPR bajo las condiciones de operación antes mencionadas. Se presenta también la respuesta voltamperométrica del sustrato de carbón sobre el que se realizaron los electrodepósitos.

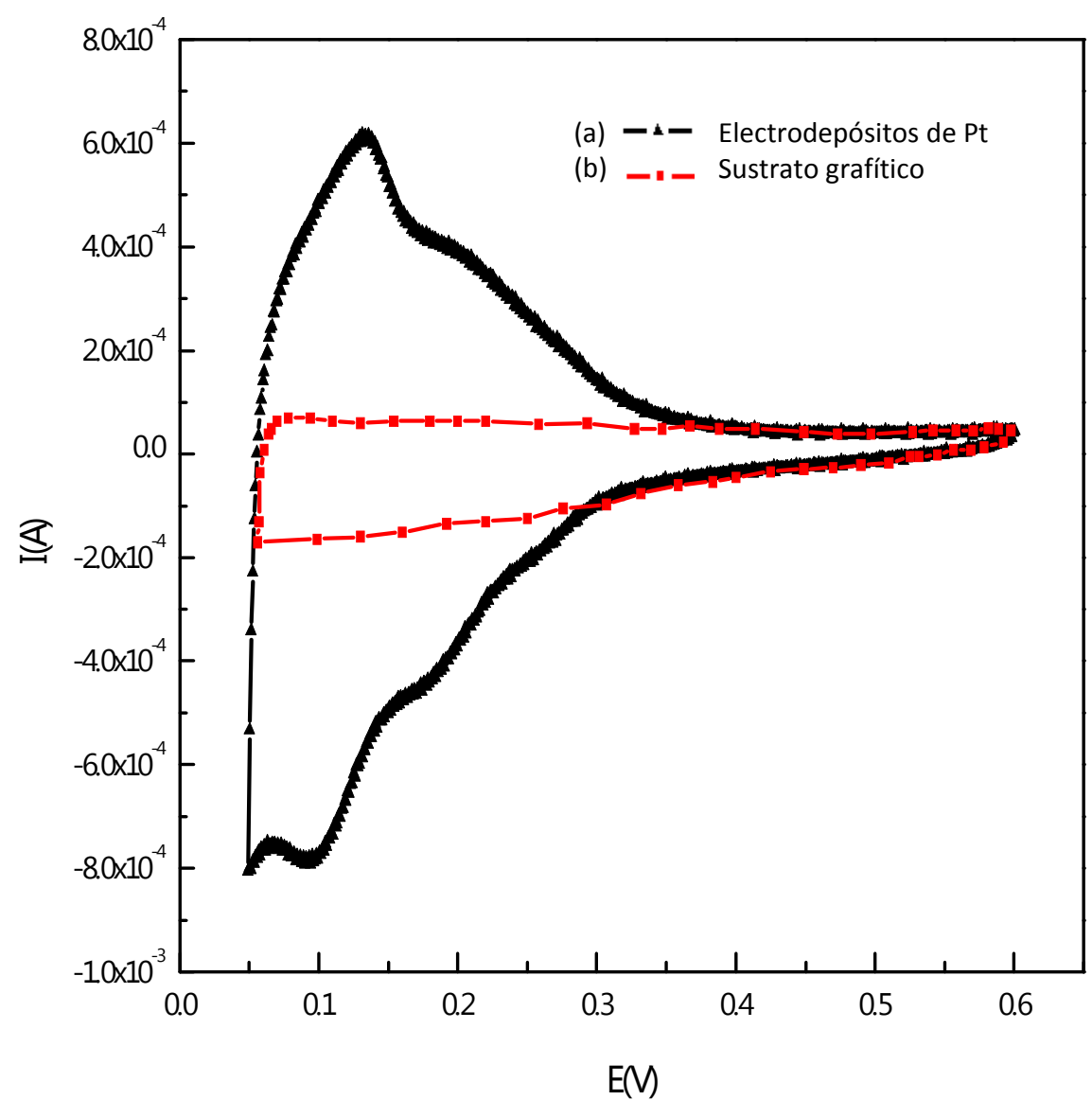

Figura 18. Respuesta voltamperométrica a $0,1 \mathrm{~V} / \mathrm{s}$ en $\mathrm{H}_{2} \mathrm{SO}_{4}$ a $25^{\circ} \mathrm{C}$ de: (a) $\Delta$ electrodepósitos de $P t$ sobre grafito ( $E s=1,2 \mathrm{~V} ; E i=-0,2 \mathrm{~V} ; f=1 \mathrm{KHz} ; t=20 \mathrm{~s}$ ) y (b) a sustrato grafítico. 
El voltamperograma del electrodepósito muestra, al compararlo con Pt policristalino, un incremento relativo en la contribución de los picos de corriente referidos a los átomos de hidrógeno débilmente adsorbidos, aproximando la respuesta voltamperométrica de una superficie escalonada de monocristal de Pt con terrazas estrechas (111) [169], [185], [186], [258]. Esta respuesta voltamperométrica se correlaciona directamente con los voltamperogramas de superficies de $P t$ con orientaciones cristalográficas preferenciales tipo (111) o con las superficies de altos índices de Miller con una gran contribución de la familia de planos \{111\} [10], [11], [163], [185], [259-261].

Mediante la relación de alturas relativas $h_{1} / h_{2}$ de los picos de corriente voltamperométricos de electrodesorción de hidrógeno débilmente adsorbido, $h_{1}$, a fuertemente adsorbido, $h_{2}$, se obtiene un valor de 1,48, mostrando un gran aumento de las cargas de electroadsorción/electrodesorción de átomos de hidrógeno débilmente adsorbidos. El valor de la relación $h_{1} / h_{2}$ es mayor que el que corresponde a Pt policristalino, como cabe esperar para el desarrollo de la orientación cristalográfica preferencial (111). Cabe destacar que la relación promedio $h_{1} / h_{2}$ para una esfera de $P t$ monocristalino es aproximadamente de 1,56 [169].

\section{VI.7.a. Caracterización por imágenes TEM de los electrodepósitos con orientación cristalográfica} preferencial tipo (111)

Los datos obtenidos mediante microscopía electrónica de transmisión (TEM) proveen información valiosa sobre el tamaño medio y la distribución de las nanopartículas de $P$ t electrodepositadas y también sobre su morfología. Cabe señalar que las técnicas TEM y XRD (que se describieron en el CAPÍTULO IV, secciones IV.2.b. y IV.2.c.) se aplicaron exclusivamente para una caracterización adicional de las nanopartículas de $P t(111)$, que son las que presentan mayor actividad catalítica para la $R R O$.

La técnica de preparación de las muestras para ser observadas en TEM requiere separar mecánicamente las nanopartículas electrodepositadas sobre el sustrato carbonoso. Luego se forma una suspensión en un solvente orgánico utilizando un baño ultrasónico. Finalmente, la suspensión se coloca sobre la grilla del microscopio y se deja secar para su posterior análisis. De esta forma se analizaron electrocatalizadores de $P t$ facetados obtenidos por aplicación de una OCPR bajo las condiciones $E s=1,2$ $\mathrm{V} ; E i=-0,2 ; f=1 \mathrm{kHz}$.

En las Figuras 19 y 20 se muestran las imágenes TEM de los electrocatalizadores de $P t$ obtenidos luego de 12 minutos de aplicación de la OCPR. Se observa un alto grado de aglomeración de las nanopartículas de Pt electrodepositadas, lo cual podría deberse, en principio, al tratamiento previo de la muestra para ser observada en el microscopio TEM. La aglomeración dificulta, en cierto modo, la determinación precisa del tamaño de partícula. Sin embargo, pese a esta limitación, se pudo estimar un tamaño promedio de partícula de $5 \mathrm{~nm}$. 

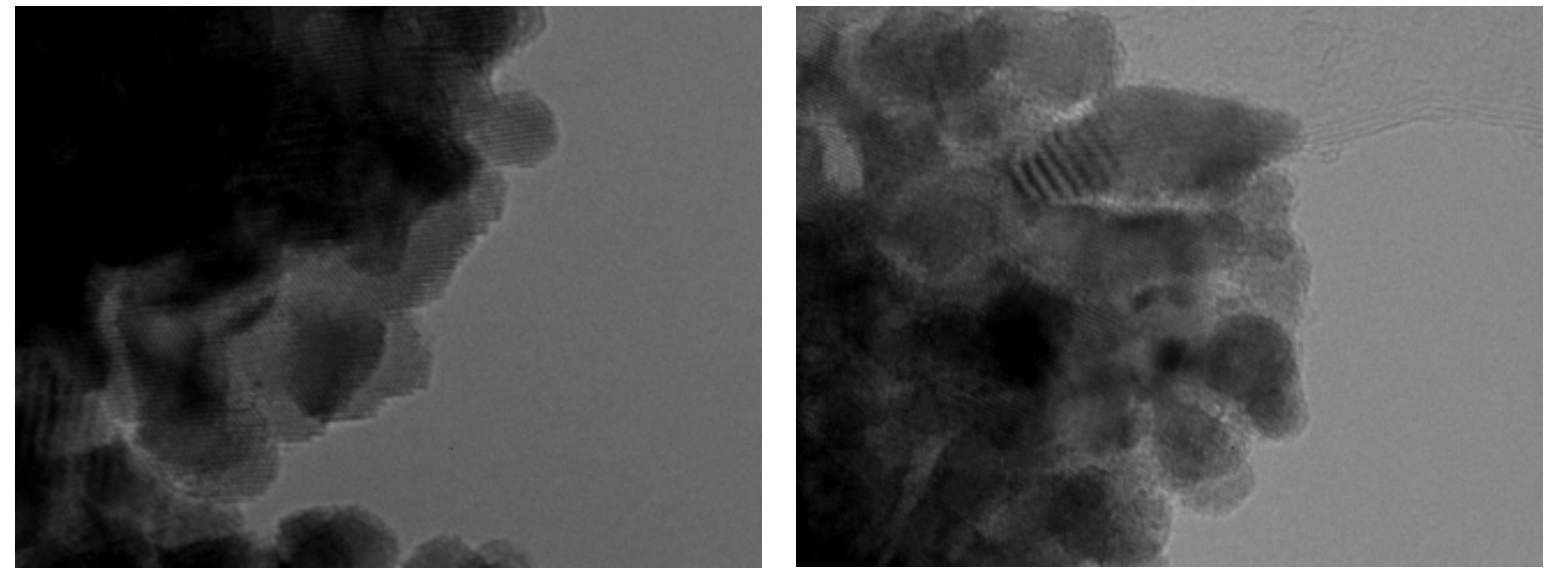

Figura 19. Imágenes TEM de las nanocristalitas de Pt electrodepositadas por aplicación de la técnica de $O C P R$.

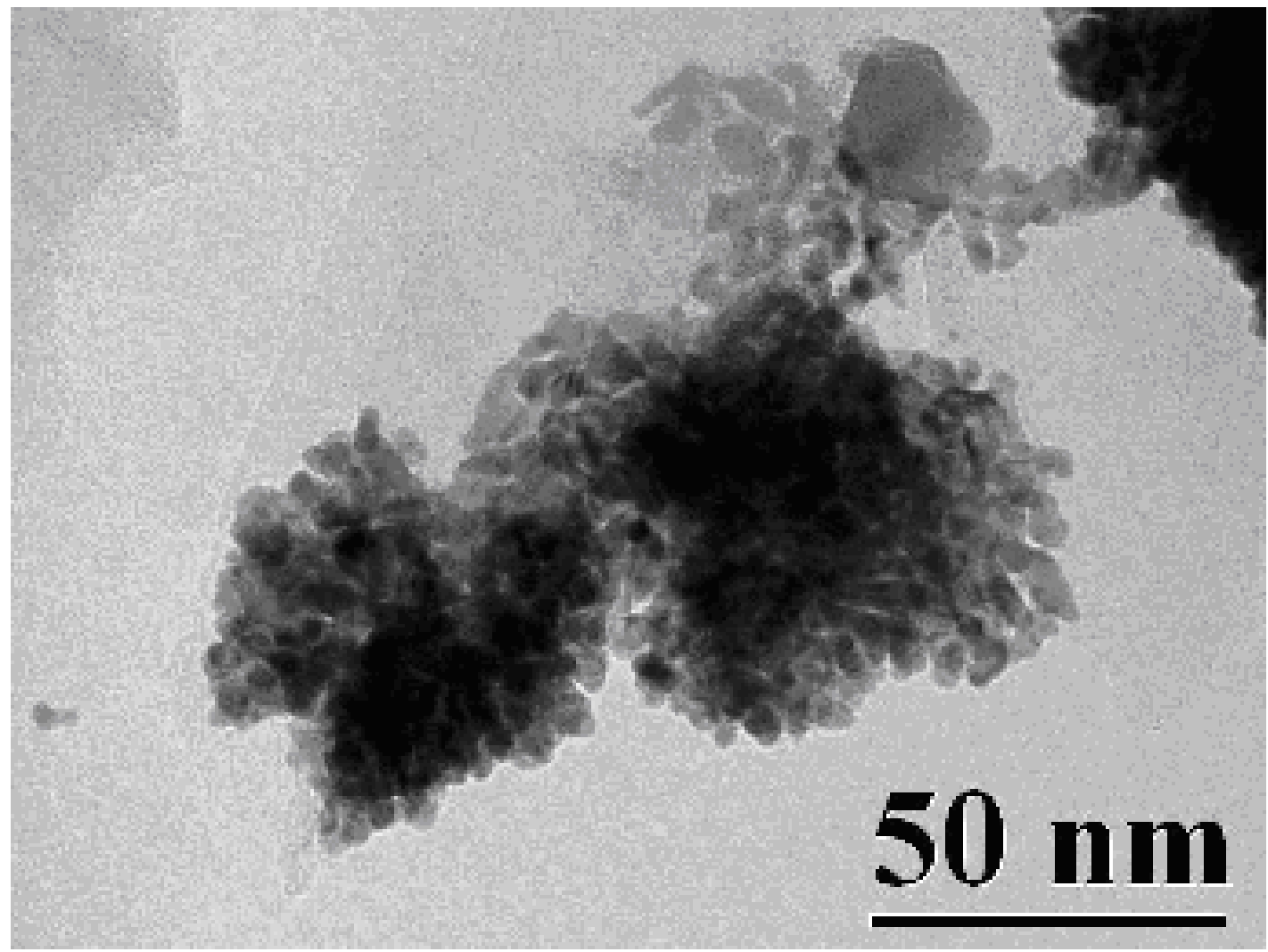

Figura 20. Imagen TEM de las nanocristalitas de Pt electrodepositadas por aplicación de la técnica de $O C P R$.

VI.7.b. Caracterización por difracción de rayos $\mathrm{X}$ de los electrodepósitos con orientación cristalográfica preferencial tipo (111)

Por medio de esta técnica se puede obtener información de la estructura cristalográfica y estimar el tamaño de partícula. En la Figura 21 se muestra el patrón de difracción para nanopartículas de $P t$ obtenidas bajo condiciones de electrodeposición $E s=1,2 \mathrm{~V} ; E i=-0,2 \mathrm{~V}$ y $f=1 \mathrm{kHz}$. A fines comparativos se muestra también el patrón de difracción correspondiente a una muestra comercial de cristalitas de $P t$ $20 \%$ p/p soportadas sobre carbón Vulcan XC-72 (E-Tek, Inc.). 
En este caso, los picos de difracción para los planos (111) y (200) de la muestra están localizados a ángulos $2 \theta$ de aproximadamente 40 y 46 grados, respectivamente [Figura 21 (a)], con una relación de intensidad de pico (111) al pico (200) que se corresponde con los datos de difracción del polvo de Pt policristalino estándar. Por el contrario, los difractogramas de rayos $\mathrm{X}$ para polvos de las nanopartículas de $P t$ altamente facetadas [Figura 21 (b)], muestran prácticamente un solo pico de difracción (111) de fuerte intensidad, lo cual estaría indicando el desarrollo de un facetado con orientación cristalográfica preferencial, en este caso con el plano (111) paralelo a la superficie de las cristalitas de Pt, lo cual concuerda con la información obtenida mediante las técnicas precedentemente descriptas.

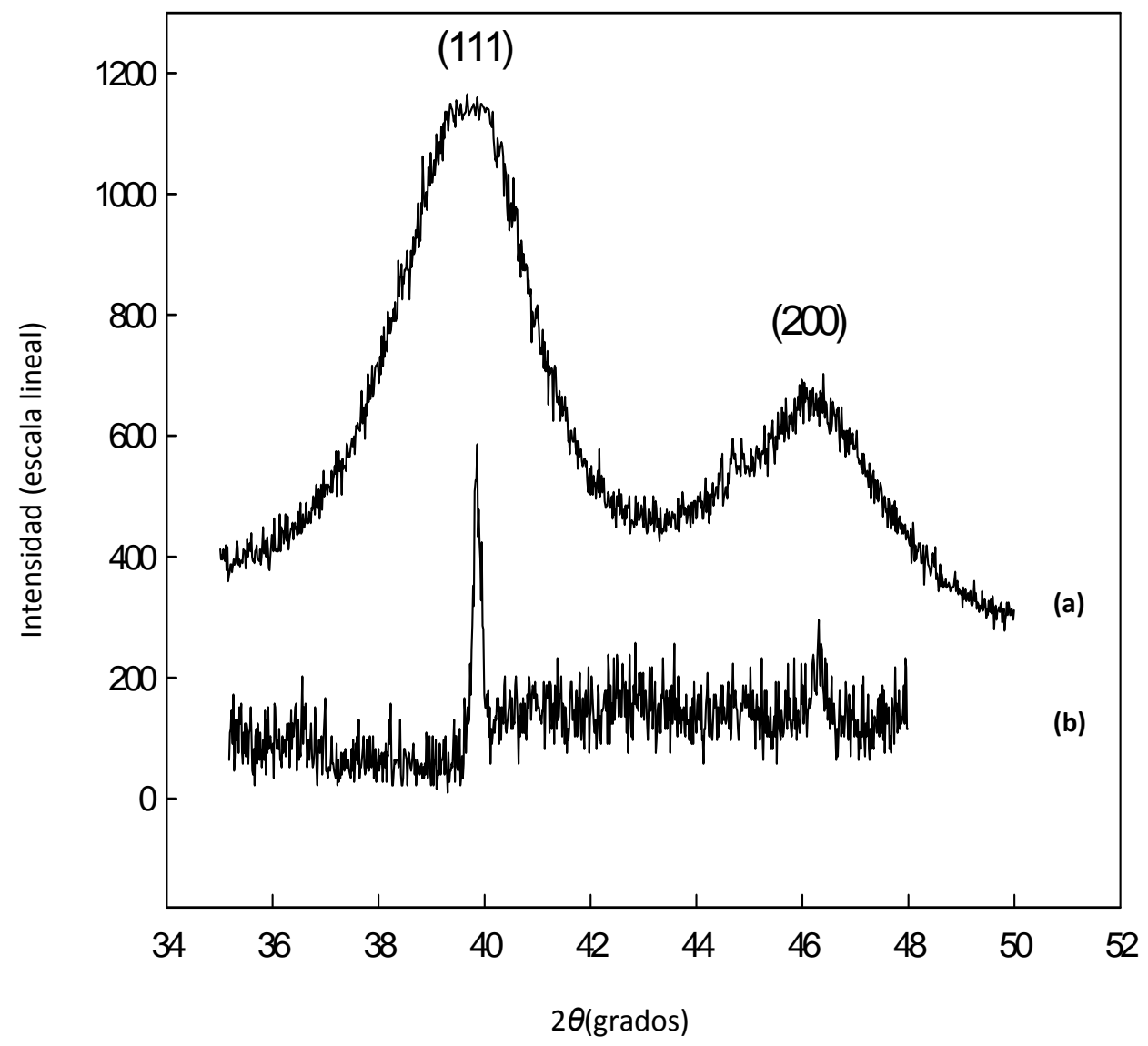

Figura 21. Patrón XRD para diferentes tipos de nanocristalitas de Pt: (a) policristalinas soportadas sobre sustratos de carbono, (b) altamente facetadas con orientación preferencial (111).

\section{VI.8. Determinación de la cantidad de Pt electrodepositado sobre sustratos carbonosos}

\section{VI.8.a. Procedimiento de digestión de las muestras}

La muestra de Pt electrodepositado sobre el sustrato carbonoso se coloca en una cápsula de cuarzo. El carbón se remueve de la muestra mediante quemado, lo cual debe llevarse a cabo de manera cuidadosa debido a las posibles pérdidas del metal que puede escapar con las pequeñas partículas de carbón eliminadas. El residuo generado en esta etapa se disuelve en agua regia caliente y la solución 
obtenida se evapora hasta sequedad. A continuación se adiciona $\mathrm{HCl}$ concentrado y la solución se vuelve a evaporar hasta sequedad. El residuo obtenido se disuelve en solución de $\mathrm{HCl} 2 \mathrm{M}$.

Mediante el tratamiento de disolución del metal con agua regia el $P t$ se convierte en complejos de cloruro y, eventualmente, también pueden llegar a formarse complejos nitrosos de platino, que se descomponen por evaporación de la solución utilizando $\mathrm{HCl}$. El exceso de ácido nítrico, proveniente de la mezcla del agua regia $\mathrm{HCl}_{\mathrm{HNO}}$, se remueve de las muestras antes de la determinación de la cantidad de Pt mediante una doble evaporación con $\mathrm{HCl}$.

La solución obtenida, luego de la disolución en $\mathrm{HCl} 2 \mathrm{M}$, se transfiere a un matraz y se adiciona solución $\mathrm{SnCl}_{2} 1 \mathrm{M}$, enrasándose luego con $\mathrm{HCl} 2 \mathrm{M}$. Se obtiene de este modo una solución que contiene el Pt que se encontraba electrodepositado sobre la muestra.

Se mide la absorbancia de esta solución a la longitud de onda de $402 \mathrm{~nm}$ contra el blanco y la concentración de Pt se calcula con la ecuación de Lambert-Beer, habiendo determinado previamente el valor de absortividad mediante calibración de la técnica con la solución patrón.

\section{VI.8.b. Determinación de la cantidad de Pt electrodepositado y del rendimiento de} electrodeposición

El Pt, así como otros metales nobles, reacciona con cloruro de estaño (II) en $\mathrm{HCl}$, formando un complejo aniónico de color amarillo con los ligandos $\mathrm{SnCl}_{3}^{-}$[262-266]. Este complejo se forma a temperatura ambiente inmediatamente después de mezclar los reactivos. Se debe tener en cuenta que el ácido nítrico, proveniente del agua regia que se utilizó para disolver el metal, debe ser removido de la solución antes de la reacción del platino con el cloruro de estaño (II), para lo cual son fundamentales las etapas de evaporación de la solución con el agregado de $\mathrm{HCl}$.

De este modo, el Pt electrodepositado puede ser determinado directamente en la solución obtenida luego del proceso de digestión de la muestra y de la transformación del metal en un complejo con ligandos $\mathrm{SnCl}_{3}^{-}$.

A modo de ejemplo se muestra la aplicación de la técnica espectrofotométrica para la determinación de la cantidad exacta en masa de $P t$ de un electrodepósito obtenido bajo las condiciones de $O C P R$ de potencial superior $E s=1,2 \mathrm{~V}$; potencial inferior $E i=-0,24 \mathrm{~V}$ y frecuencia constante de $1 \mathrm{kHz}$.

Se preparan dos soluciones a partir de una muestra original de $P t$ electrodepositado sobre grafito, siguiendo la metodología de la técnica espectrofotométrica antes descripta. Se obtienen así las soluciones, designadas como (a) y (b), siendo (b) una solución preparada por dilución de (a).

En la Figura 22 se muestran los espectros de absorción de las soluciones (a) y (b), cuya concentración se desea conocer. 


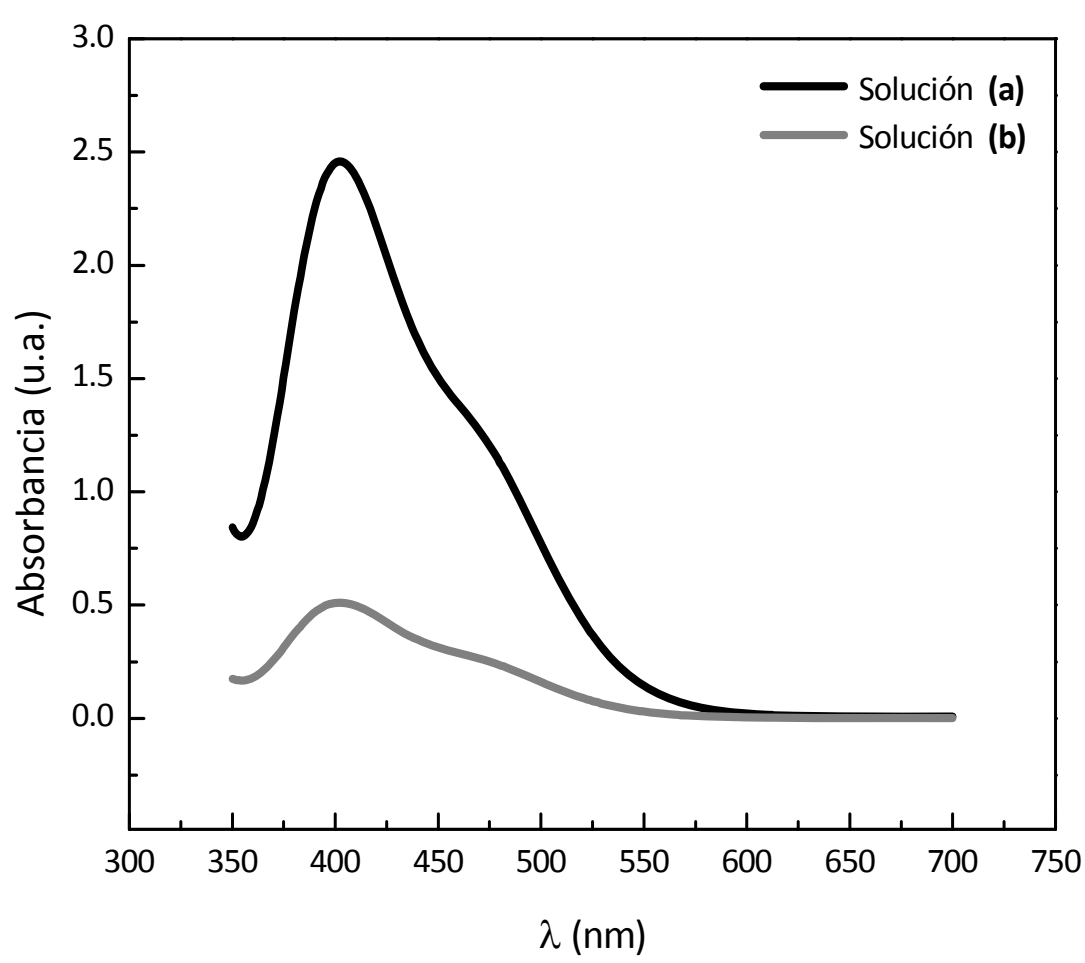

Figura 22. Espectros de los complejos de $\mathrm{Pt}$ con $\mathrm{SnCl}_{2}$ para las soluciones (a) y (b) preparadas a partir de una muestra de Pt electrodepositado.

Para cada solución se determina el valor de absortividad $A$ a la longitud de onda de $402 \mathrm{~nm}$. Para los cálculos de la cantidad de Pt electrodepositado se utilizó el coeficiente de absortividad, a, obtenido, como se ha mencionado en la sección VI.5.c en la calibración de la técnica. Se calcula la cantidad de Pt electrodepositado para la solución (a), registrándose un valor de 0,633 mg de Pt, considerando el volumen total de la solución. Realizando el cálculo de la misma manera para la solución (b), el valor calculado para la cantidad de Pt electrodepositado muestra un error inferior al $4 \%$ con respecto al valor obtenido con la solución (a). Esto estaría indicando, en principio, que la técnica espectrofotométrica introduce un error muy pequeño para muestras diluidas. Por lo tanto, se podría aplicar con bastante confiabilidad aún para muestras que contengan poca cantidad de Pt electrodepositado. Este es un aspecto crítico a considerar ya que para cada electrodepósito realizado sobre sustratos de grafito, debido al área de trabajo reducida y a las condiciones propias de la técnica de obtención de los electrodepósitos, se consiguen, por lo general, cantidades de Pt relativamente bajas. Por este motivo es necesario asegurar que la técnica espectrofotométrica implementada continúe dando buenos resultados aún para bajas cantidades de $P t$, lo cual se refleja como se indicó previamente en el bajo error cometido para una dilución de la muestra original.

La técnica espectrofotométrica implica la disolución del Pt electrodepositado por lo cual el material deja de estar disponible para su utilización como electrocatalizador de los electrodos porosos de celda de combustible. Interesa, por lo tanto, conocer la cantidad de Pt electrodepositado sin destrucción de la muestra. Para ello, en base a una serie de experiencias realizadas bajo las condiciones 
de $O C P R$ de $E s=1,2 \vee$ y $E i=-0,2 \vee$ se llevó a cabo una extrapolación de la técnica espectrofotométrica a fin de conocer la cantidad de Pt electrodepositado sin necesidad de disolver cada una de las muestras obtenidas por aplicación de una rutina de OCPR.

Para ello se procede de la siguiente manera:

i. A partir de la cantidad en masa de $P t$, obtenida espectrofotométricamente se determina la carga neta de $P t$ electrodepositado, suponiendo que la reacción de reducción involucra 4 electrones:

$$
\mathrm{PtCl}_{6}{ }^{2-}+4 e^{-} \rightarrow \mathrm{Pt}+6 \mathrm{Cl}^{-}
$$

ii. A partir de la ley de Faraday, se calcula la carga neta asociada exclusivamente al Pt electrodepositado, $Q_{1}$, en culombios (C):

$$
Q_{1}=\frac{W \cdot Z \cdot F}{M}
$$

siendo $W$ la cantidad de $P t$ electrodepositado $(\mathrm{mg})$ obtenida de la técnica espectrofotométrica, $M$ la masa molar del Pt, $195 \mathrm{~g} / \mathrm{mol}, Z$ el número de electrones intercambiados durante el proceso de reducción, en este caso 4, y $\mathrm{F}$ la constante de Faraday, $96485 \mathrm{C} / \mathrm{mol}$.

Para el proceso global de electrodeposición, que involucra tanto la electrodeposición de $P t$ como la reacción de desprendimiento de hidrógeno, que ocurre a aproximadamente $0,05 \mathrm{~V}$, la carga neta del proceso global de electrodeposición, $Q_{2}$, se obtiene a partir del culombímetro electrónico, el cual integra en cada momento la carga completa a los ciclos anódicos y catódicos de la OCPR aplicada para obtener los electrodepósitos de $P t$.

iii. Relacionando $Q_{2}$ con la carga neta de $P t$ electrodepositado $Q_{1}$ es posible determinar un rendimiento del proceso de electrodeposición, $R$, definido como:

$$
\% R=\frac{Q_{1}(C)}{Q_{2}(C)} \times 100
$$

Así, para las condiciones de la $O C P R$ de $E s=1,2 \vee$ y $E i=-0,2 \vee$ a $f=1 \mathrm{kHz}$ y un tiempo de electrodeposición de 5 minutos se obtiene un rendimiento del $20 \%$, el cual se tiene en cuenta para determinar la cantidad de Pt electrodepositado, sin necesitad de disolver cada una de las muestras de Pt.

A fin de evaluar el rendimiento de electrodeposición para otras condiciones de operación de la $O C P R$, se realizaron una serie de experiencias manteniendo fijo el límite de potencial superior en un valor de 1,2 V y variando el límite de potencial inferior de la OCPR entre los siguientes valores: -0,2 V; $-0,24 \mathrm{~V} ;-0,26 \mathrm{~V}$ y $-0,28 \mathrm{~V}$. En todos los casos se mantuvo constante la frecuencia en $1 \mathrm{kHz}$ y se aplicó una onda simétrica.

Mediante la técnica espectrofotométrica se determina, en cada caso, la cantidad de Pt electrodepositado a carga constante $Q_{1}$. Relacionando este valor con la carga asociada al proceso global 
de electrodeposición $Q_{2}$ se obtienen los valores de rendimiento de los electrodepósitos para cada situación particular estudiada.

En la Figura 23 se muestra el rendimiento $R$ en función de la variación del potencial inferior Ei. Se observa una disminución del rendimiento a medida que el potencial inferior se hace más negativo, lo cual indica una mayor contribución de la corriente correspondiente a la reacción de electrodesprendimiento de hidrógeno en la corriente total del proceso global de electrodeposición. Por otro lado, también se puede observar que para la condición de operación de $E s=1,2 \vee$ y $E i=-0,2 \mathrm{~V}$, se obtiene el mayor rendimiento para la carga constante considerada.

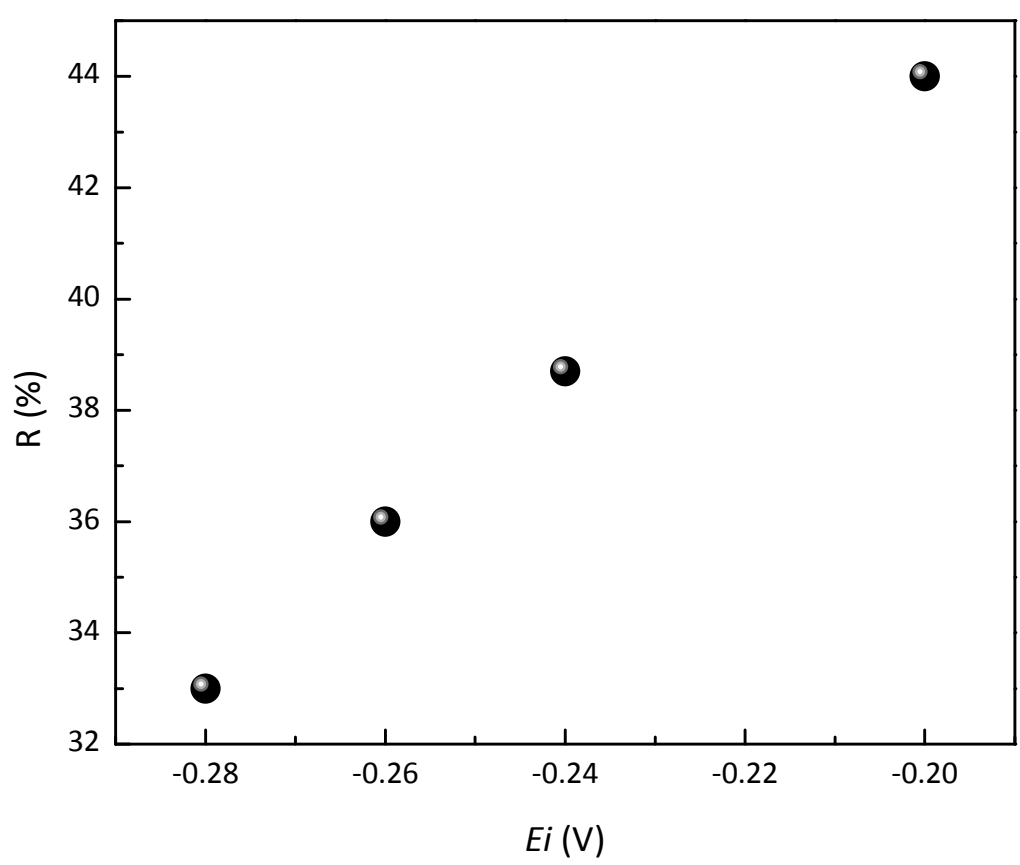

Figura 23. Rendimiento de la electrodeposición de Pt a potencial superior constante en función del potencial inferior Ei.

VI.9. Estudio del efecto de la variación de parámetros de la OCPR sobre las características de los electrodepósitos de $P t$

\section{VI.9.a. Condiciones generales de trabajo}

En la serie de experiencias que se presentan a continuación se analizó la influencia de la variación de los parámetros de la OCPR sobre las características cristalográficas y morfológicas de los electrodepósitos de Pt obtenidos. En todos los casos los electrodepósitos de Pt se realizaron en solución de ácido hexacloroplatínico sobre sustratos de grafito en superficies tratadas convenientemente a fin de asegurar su reproducibilidad, de acuerdo a la rutina de tratamiento del sustrato especificada en detalle en capítulos anteriores. De esta manera se desarrollaron electrodepósitos de Pt sobre grafito con diferentes morfologías, pudiéndose regular el tamaño de las partículas y la cantidad total de material electrodepositado. 


\section{VI.9.b. Efecto del tiempo de electrodeposición}

Se estudió el efecto del tiempo de electrodeposición sobre el desarrollo de las cristalitas de Pt facetadas. Para ello se aplicó una OCPR simétrica a frecuencia constante de $1 \mathrm{kHz}$, manteniendo los límites de potencial superior e inferior fijos, en los valores $E s=1,2 \vee$ y $E i=-0,2 \vee$ y variando los tiempos de aplicación de la señal eléctrica empleada.

La morfología de las nanopartículas de Pt electrodepositadas fue analizada mediante imágenes SEM. El sustrato queda cubierto por partículas de $P t$ facetadas según la orientación cristalográfica preferencial (111) (ver Figuras 24 y 25). En todos los casos se observa una distribución uniforme de las cristalitas de $P t$ sobre el sustrato grafítico.

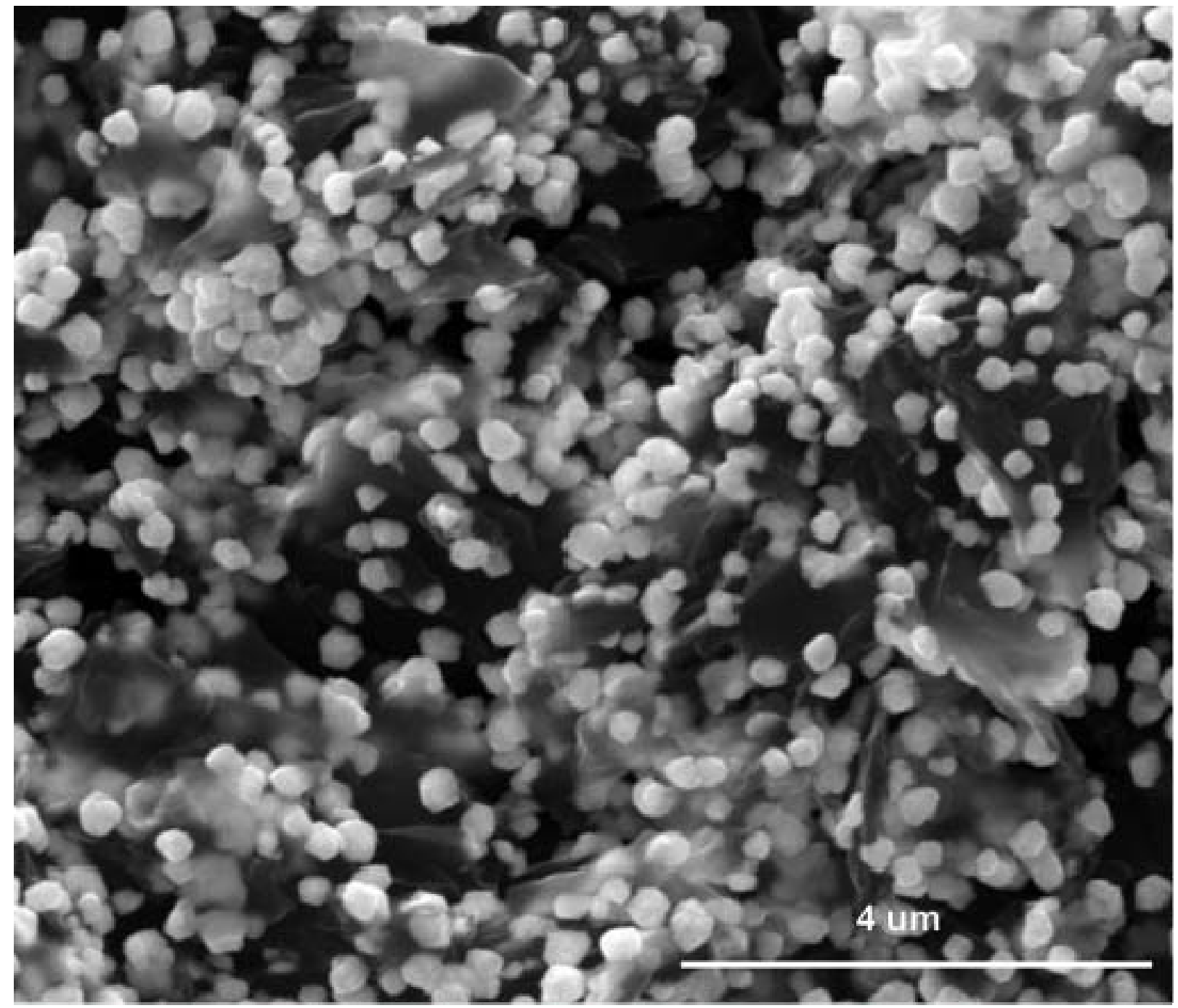

Figura 24. Imagen SEM de electrodepósitos de Pt sobre grafito correspondiente a una muestra bajo tratamiento de $E s=1,2 \mathrm{~V} ; E i=-0,2 \mathrm{~V} ; f=1 \mathrm{kHz}, t=5 \mathrm{~min}$. Magnificación $30000 \mathrm{X}$.

Se determinó la dependencia del tamaño medio de las nanopartículas de Pt electrodepositadas con el tiempo de aplicación de la OCPR. Para ello se realizaron estimaciones del tamaño medio de las cristalitas de Pt desarrolladas y para cada una de las experiencias consideradas se evaluaron 
aproximadamente poblaciones de 50 nanopartículas, a partir de las imágenes SEM obtenidas. Para 5 minutos de electrodeposición se estimó un tamaño medio de partícula de 0,25 $\mu \mathrm{m}$. En la Figura 24 se puede observar la imagen SEM correspondiente a una muestra electrodepositada, aplicando una OCPR durante 5 minutos.

Disminuyendo el tiempo de electrodeposición a 30 segundos y bajo las mismas condiciones de aplicación de la $O C P R$, el tamaño medio de partícula disminuye alrededor de un $28 \%$ respecto al valor encontrado para 5 minutos de aplicación de la OCPR. Se estimaron valores promedios de partícula de 0,18 $\mu \mathrm{m}$. En la Figura 25 se muestra una imagen SEM de las cristalitas de Pt obtenidas luego de 30 segundos de electrodeposición.

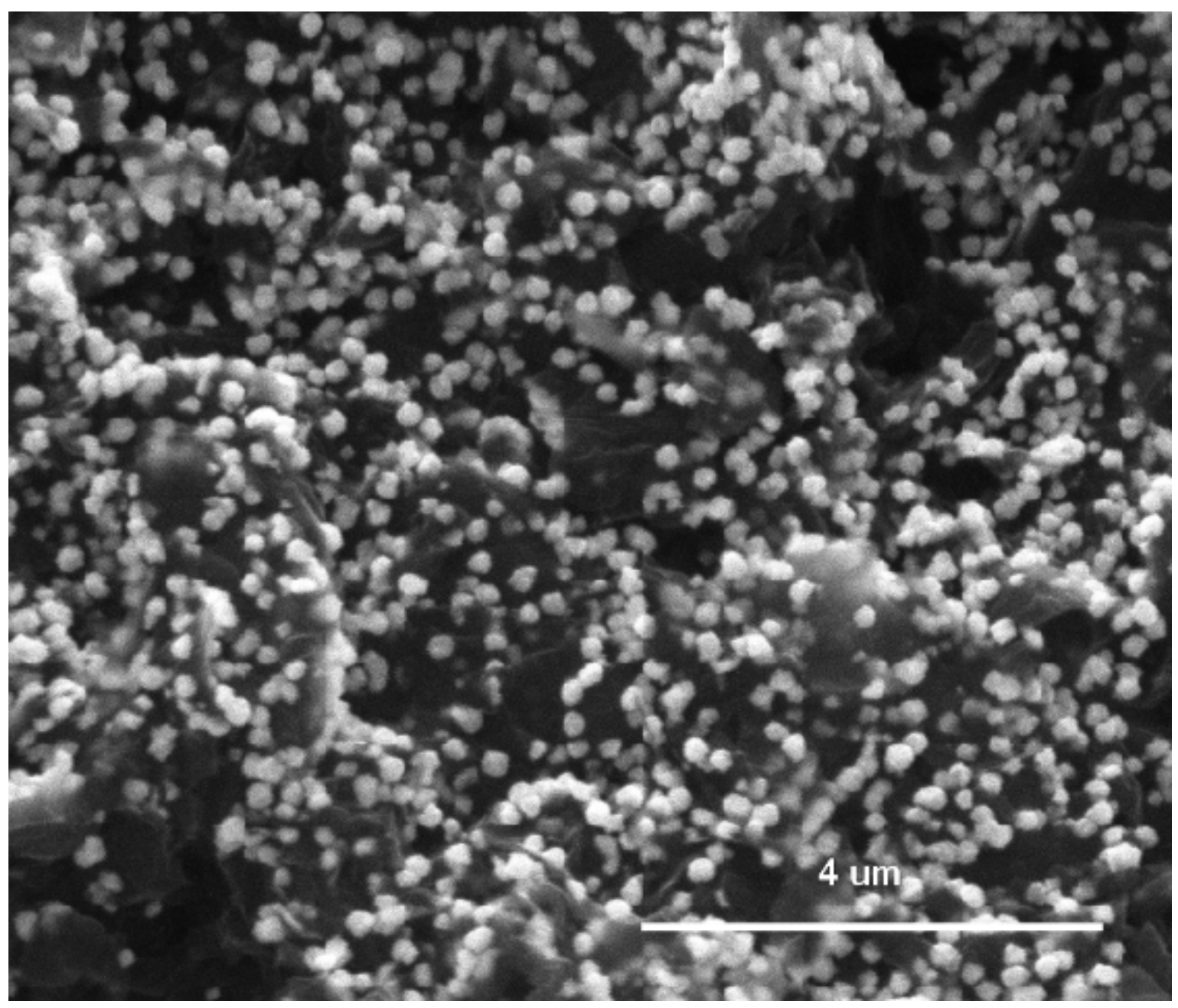

Figura 25. Imagen SEM de electrodepósitos de $P t$ sobre grafito correspondiente a una muestra bajo tratamiento de $E s=1,2 \mathrm{~V} ; E i=-0,2 \mathrm{~V} ; f=1 \mathrm{kHz} ; t=30 \mathrm{~s}$. Magnificación $30000 \mathrm{X}$.

En la Figura 26 se muestra la variación del tamaño medio de partícula en función del tiempo de aplicación de la OCPR. Se observa que al disminuir el tiempo de electrodeposición, para condiciones de operación dadas, se obtienen menores tamaños de partícula hasta alcanzar un valor límite de aproximadamente $0,18 \mu \mathrm{m}$. 


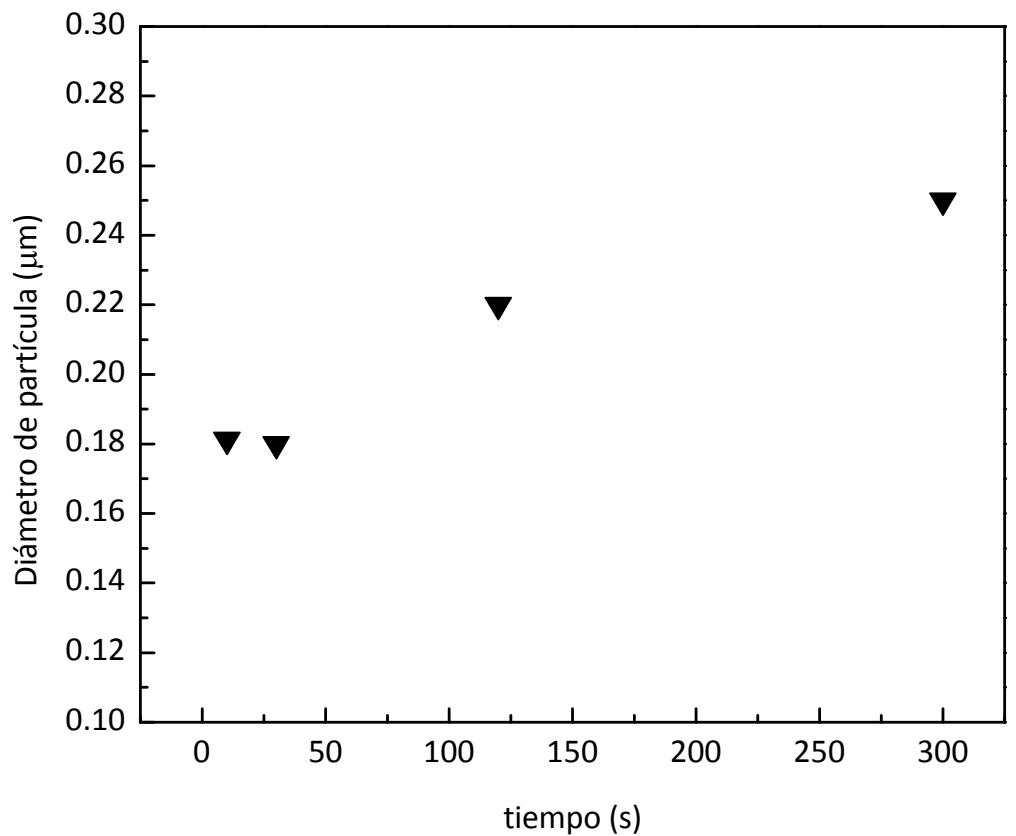

Figura 26. Efecto del tiempo de electrodeposición sobre el tamaño de partícula para las condiciones de operación $E s=1,2 \mathrm{~V} ; E i=-0,2 \mathrm{~V} ; f=1 \mathrm{kHz}$.

Los voltamperogramas de los electrodepósitos obtenidos bajo las condiciones de $O C P R E S=1,2 \mathrm{~V}$; $E i=-0,2 \mathrm{~V} ; f=1 \mathrm{kHz}$ a diferentes tiempos de electrodeposición, hasta 5 minutos, se muestran en la Figura 27.

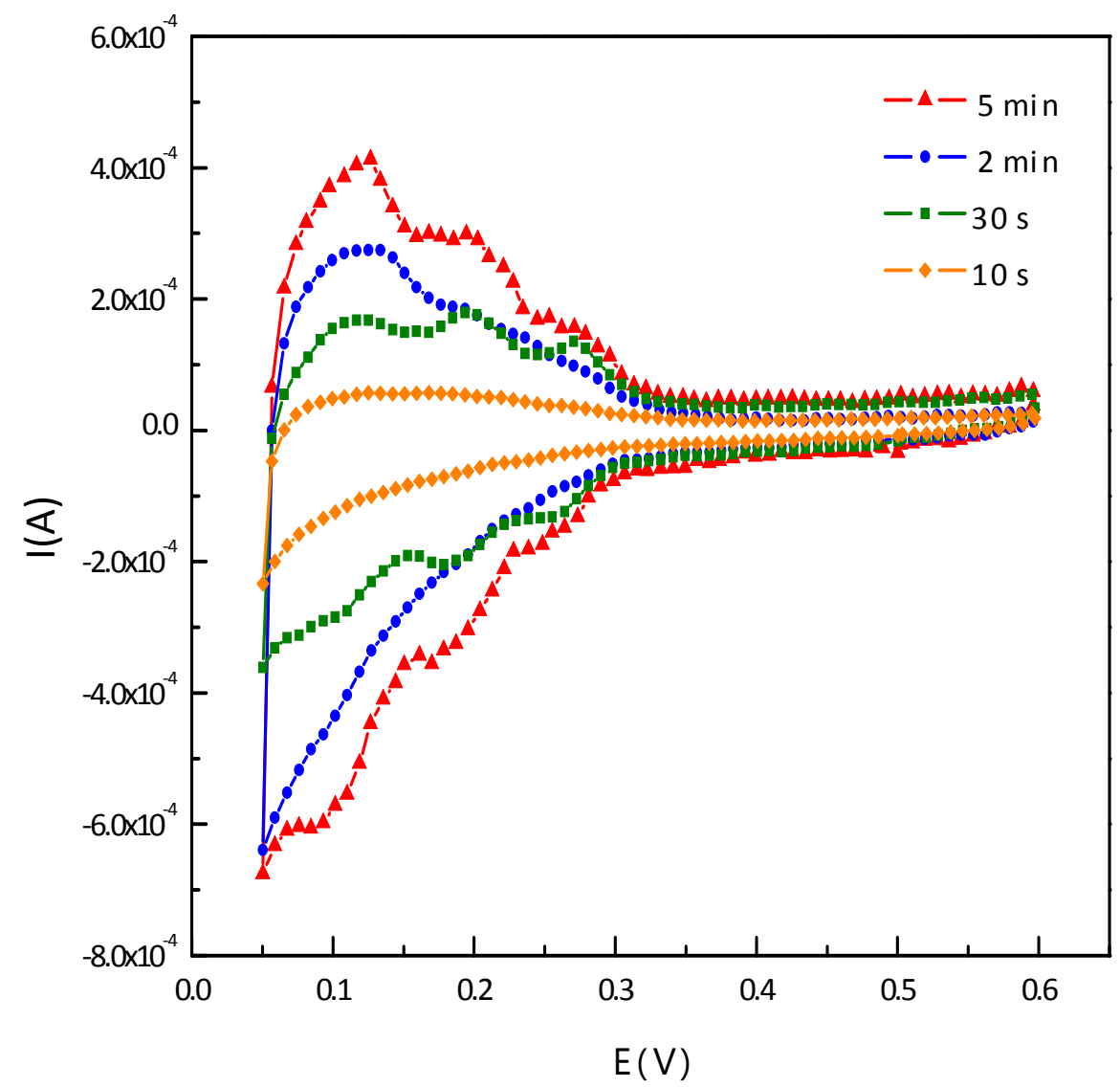

Figura 27. Respuesta voltamperométrica de los electrodepósitos de Pt para diferentes tiempos de electrodeposición. Condiciones de OCPR Es = 1,2 V; Ei = -0,2 V; $f=1 \mathrm{kHz}$. 
Se observa un incremento relativo en la contribución de los picos de corriente referidos a los átomos de hidrógeno débilmente adsorbidos, característicos de superficies con orientación cristalográfica preferencial según la dirección (111), con el tiempo de electrodeposición, salvo para el menor tiempo donde los picos de corriente no se llegan a definir por completo.

En la Figura 28 se muestran los correspondientes voltamperogramas para altos tiempos de electrodeposición. En este caso, si bien los picos de corriente asociados a los átomos de hidrógeno débilmente absorbidos están bien definidos, se observa una caída de la carga voltamperométrica asociada con respecto a la correspondiente a 5 minutos.

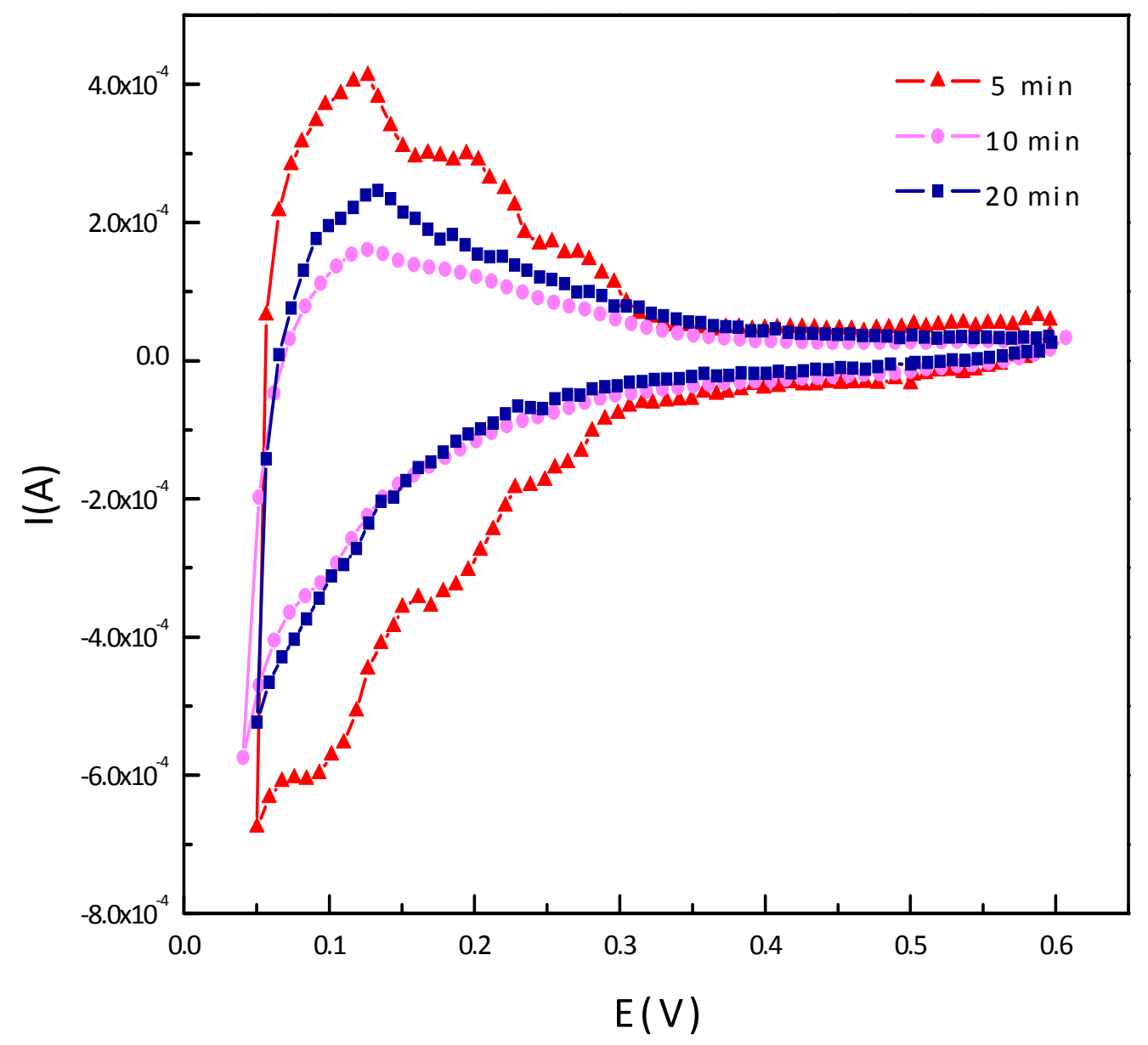

Figura 28. Respuesta voltamperométrica de los electrodepósitos de Pt para altos tiempos de electrodeposición.

La Figura 29 muestra la influencia del tiempo de electrodeposición sobre la carga voltamperométrica de electrodesorción de hidrógeno del platino depositado, $Q_{h}$. En todos los casos se descontó la contribución de la doble capa eléctrica, a través de la ecuación (4). Se observa como a medida que aumenta el tiempo de electrodeposición hasta 5 minutos se incrementa $Q_{h}$. Este aumento de $Q_{h}$ se podría relacionar, en principio, con la cantidad superficial de $P t$ electrodepositado que va aumentando conforme transcurre el tiempo de electrodeposición. Sin embargo, para tiempos mayores de electrodeposición, esto es, 10 y 20 minutos, se registran menores valores de $Q_{h}$. Esta situación podría 
explicarse por un efecto de coalescencia de las partículas de Pt electrodepositadas que ocurre a los mayores tiempos de electrodepósito.

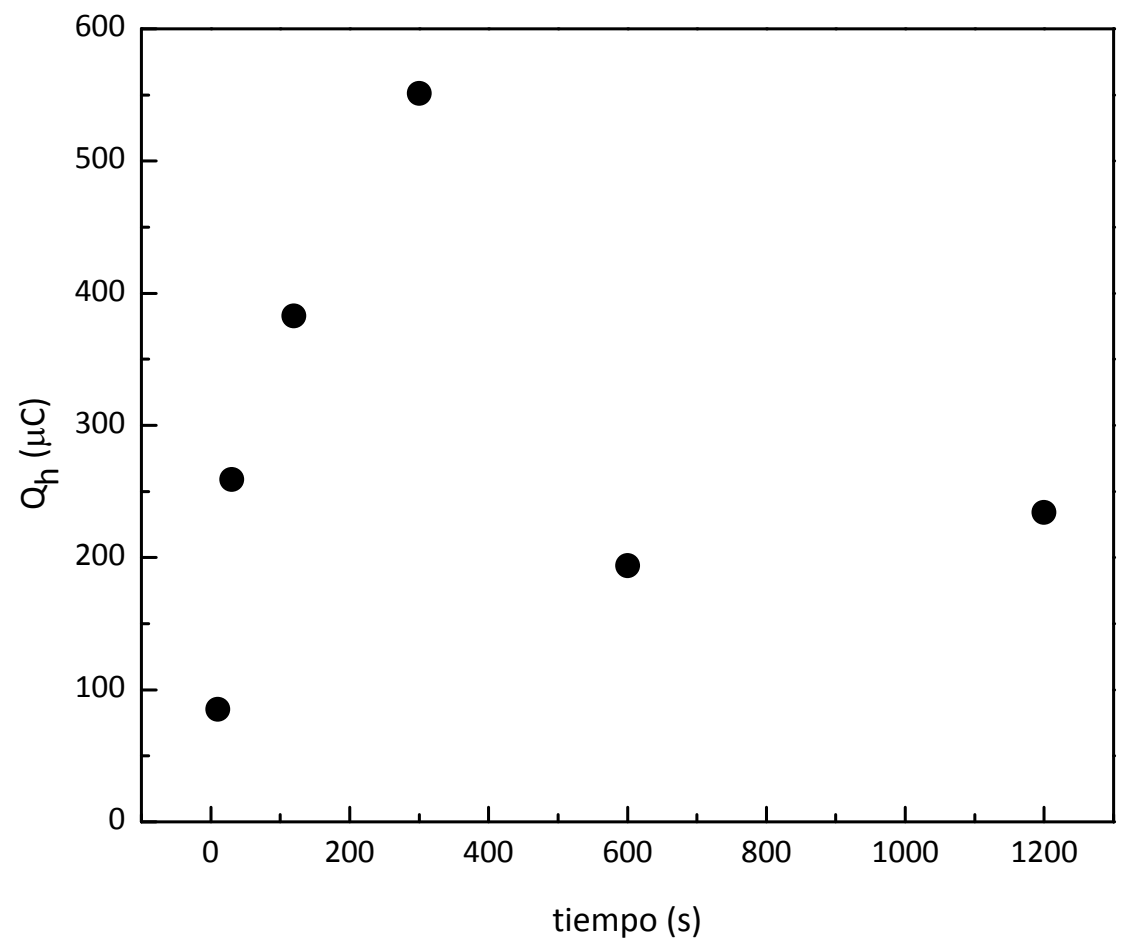

Figura 29. Carga voltamperométrica asociada a la electrodesorción de hidrógeno sobre Pt electrodepositado en grafito en función del tiempo de electrodeposición. Condiciones de la $O C P R E s=1,2 \mathrm{~V} ; E i=-0,2 \mathrm{~V} ; f=1 \mathrm{kHz}$.

En la Figura 30 se presenta, de manera esquemática, la situación antes planteada, donde por simplicidad se muestran partículas de Pt esféricas.

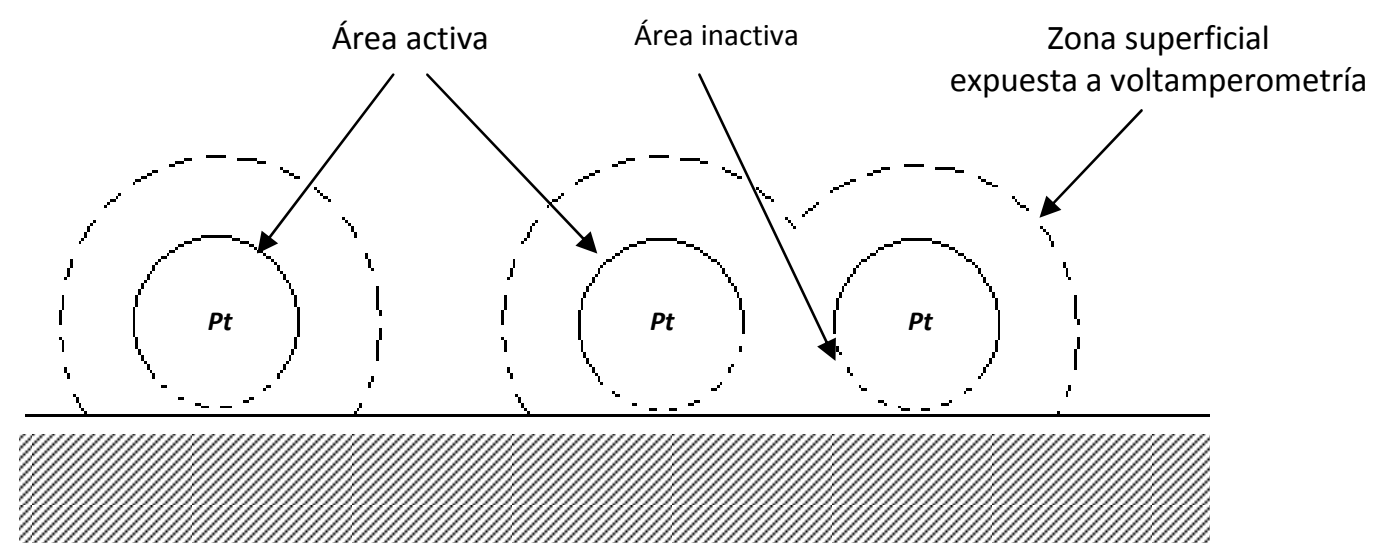

Figura 30. Posible efecto de aglomeración de partículas de Pt a medida que transcurre el tiempo de electrodeposición.

Cuando las partículas de $P t$ se encuentran lo suficientemente separadas unas de otras el área superficial electroquímicamente activa no se ve afectada y la carga asociada a la superficie específica de las partículas de $P t$ expuestas muestra un determinado valor $Q_{h}$. Cuando las partículas se encuentran 
muy próximas unas de otras se forman aglomerados, dando lugar a una región crítica inactiva, como se indica en la Figura 30. Bajo esta situación no toda el área superficial de las partículas se encuentra disponible, por lo cual cabe esperar que la carga $Q_{h}$ registrada resulte menor. Por este motivo, para los mayores tiempos de electrodeposición (10 y 20 minutos), la carga asociada a la superficie específica de las partículas de $P t$ expuestas es menor que para tiempos cortos, debido a este efecto de coalescencia de las partículas de Pt electrodepositadas.

En términos generales, las nanopartículas metálicas poseen una tendencia inherente a aglomerarse, formando partículas de mayor tamaño para reducir de este modo su alta energía superficial.

Teniendo en cuenta la carga específica para una monocapa de hidrógeno adsorbido sobre Pt [267] se determinó el área superficial electroquímicamente activa del $P t$ electrodepositado, registrándose valores casi 9 veces superiores del electrodo soporte.

Por otra parte, se determinó la cantidad en masa de $P t$ electrodepositado mediante la técnica espectrofotométrica [268]. Se consideró para los cálculos un rendimiento del $20 \%$, tal como se mencionó en la descripción de la implementación de la técnica espectrofotométrica para la determinación de la cantidad de Pt electrodepositado.

La Figura 31 muestra la variación en la cantidad en masa de Pt en función del tiempo de electrodeposición. Se observan mayores cantidades de $P t$ electrodepositado a medida que aumenta el tiempo de electrodeposición.

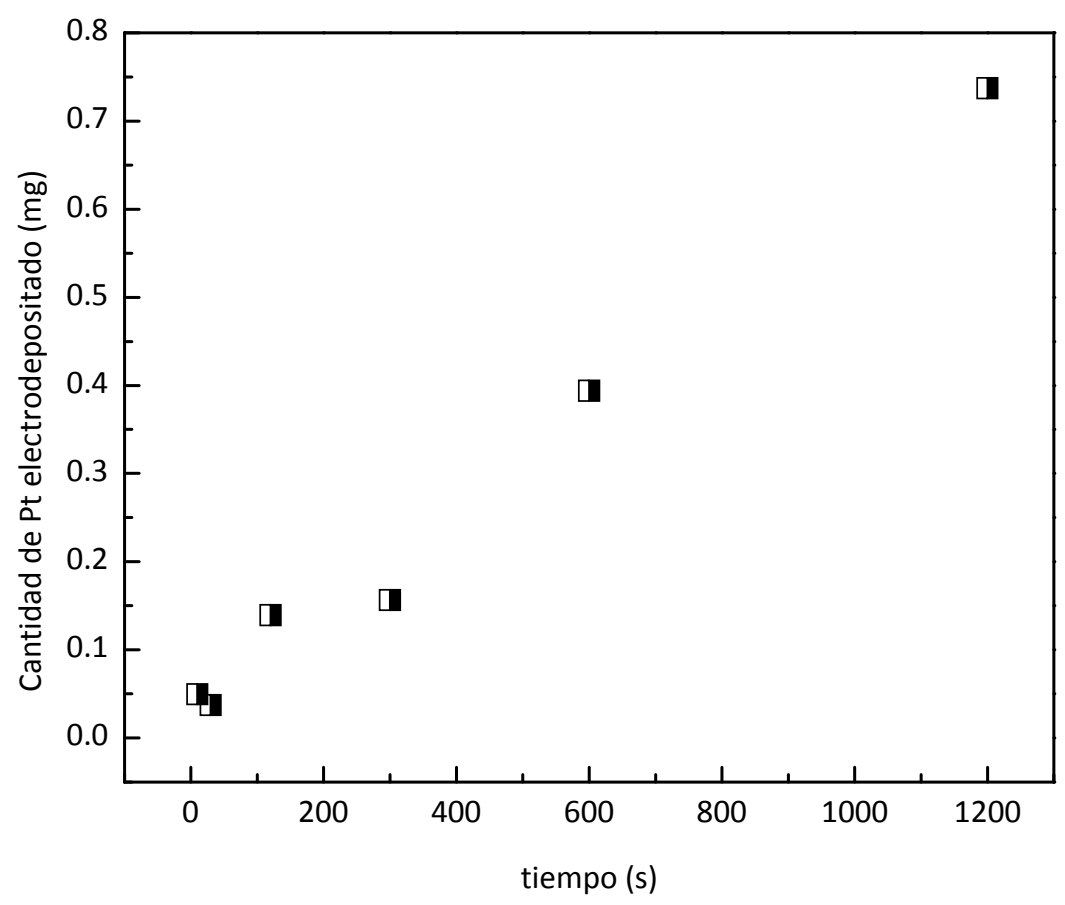

Figura 31. Cantidad en masa de Pt electrodepositado en función del tiempo de aplicación de la OCPR.

Para aplicación en celdas de combustible de hidrógeno/oxígeno interesa desarrollar partículas de Pt de tamaño pequeño, a fin de lograr un aumento del área superficial disponible para las reacciones 
electródicas involucradas en los procesos electroquímicos de conversión de energía. Este efecto se puede conseguir disminuyendo el tiempo de electrodeposición, tal como se demostró en el análisis anterior, cuando se evaluó el efecto del tiempo de electrodeposición sobre el tamaño de partícula (Figura 26). En la medida en que disminuye el tiempo de aplicación de la OCPR se logra desarrollar partículas de $P t$ facetadas de menor tamaño. Sin embargo, se obtienen también menores cantidades en masa de Pt electrodepositado, tal como lo muestra la Figura 31. Se establece, por lo tanto, una situación de compromiso entre tamaño de partícula y cantidad de Pt electrodepositado.

\section{VI.9.c. Efecto de la variación del potencial inferior a potencial superior constante de 1,2 V}

En esta serie de experiencias los parámetros de potencial de la señal eléctrica cíclica aplicada fueron seleccionados a fin de estudiar el efecto de la variación del potencial inferior Ei sobre las características de facetado de las cristalitas de Pt. Para ello se aplicó una rutina de OCPR a frecuencia de $1 \mathrm{kHz}$ manteniendo el potencial superior $E s$ en un valor de 1,2 $\vee$ y variando el potencial inferior Ei a -0,2 $\mathrm{V} ;-0,24 \mathrm{~V} ;-0,26 \mathrm{~V}$ y $-0,28 \mathrm{~V}$. En todas las experiencias realizadas se fijaron los tiempos de duración de cada escalón de potencial de manera que la señal eléctrica aplicada fuese simétrica, esto es con una relación $\tau_{s} / \tau_{i}=1$.

Para la determinación de la cantidad de Pt electrodepositado los tiempos de aplicación de la OCPR se variaron entre 5 y 10 minutos, a fin de trabajar a carga constante.

La morfología superficial de las partículas de Pt electrodepositadas se analizó mediante imágenes SEM (Figura 32), donde se muestran cristalitas de Pt altamente facetadas con estructuras poliédricas con predominio de caras triangulares y ángulos agudos, característicos del desarrollo de la orientación cristalográfica preferencial (111). De acuerdo a la secuencia mostrada en la Figura 32 (a)-(e) se registra un aumento de la densidad de recubrimiento de los electrodepósitos de $P t$ a medida que el potencial inferior Ei aumenta.

A un tiempo constante de electrodeposición de 5 minutos se calculó el tamaño medio de partícula para cada una de las situaciones estudiadas, evaluándose una población de 30 a 40 partículas aproximadamente. Se observó un aumento del tamaño de las nanopartículas electrodepositadas con el aumento del potencial inferior, como se muestra en la Figura 33. Los mayores tamaños de partícula se obtuvieron a un potencial inferior de $E i=-0,28 \mathrm{~V}$, con un valor estimado de tamaño medio de partícula de $1,1 \mu \mathrm{m}$. A medida que el potencial inferior disminuye se distinguen dos grupos de tamaño de partículas, que prácticamente no difieren entre sí. Así, para los potenciales $E i=-0,24 \vee$ y $E i=-0,26 \vee$ (grupo I), el tamaño medio de partícula permanece prácticamente constante $(0,52 \mu \mathrm{m}$ para $E i=-0,26 \mathrm{~V}$ y $0,51 \mu \mathrm{m}$ para $E i=-0,24 \mathrm{~V})$, con una variación menor al $2 \%$. Para Ei menores, entre $-0,2 \vee$ y $-0,05 \vee$, se encuentra el grupo II, para el cual el tamaño de partícula disminuye aproximadamente un $53 \%$ con respecto al valor medio de partícula del grupo I. En este caso se registran valores de tamaño medio de partícula que se encuentran en el orden de los 0,24 $\mu \mathrm{m}$. 

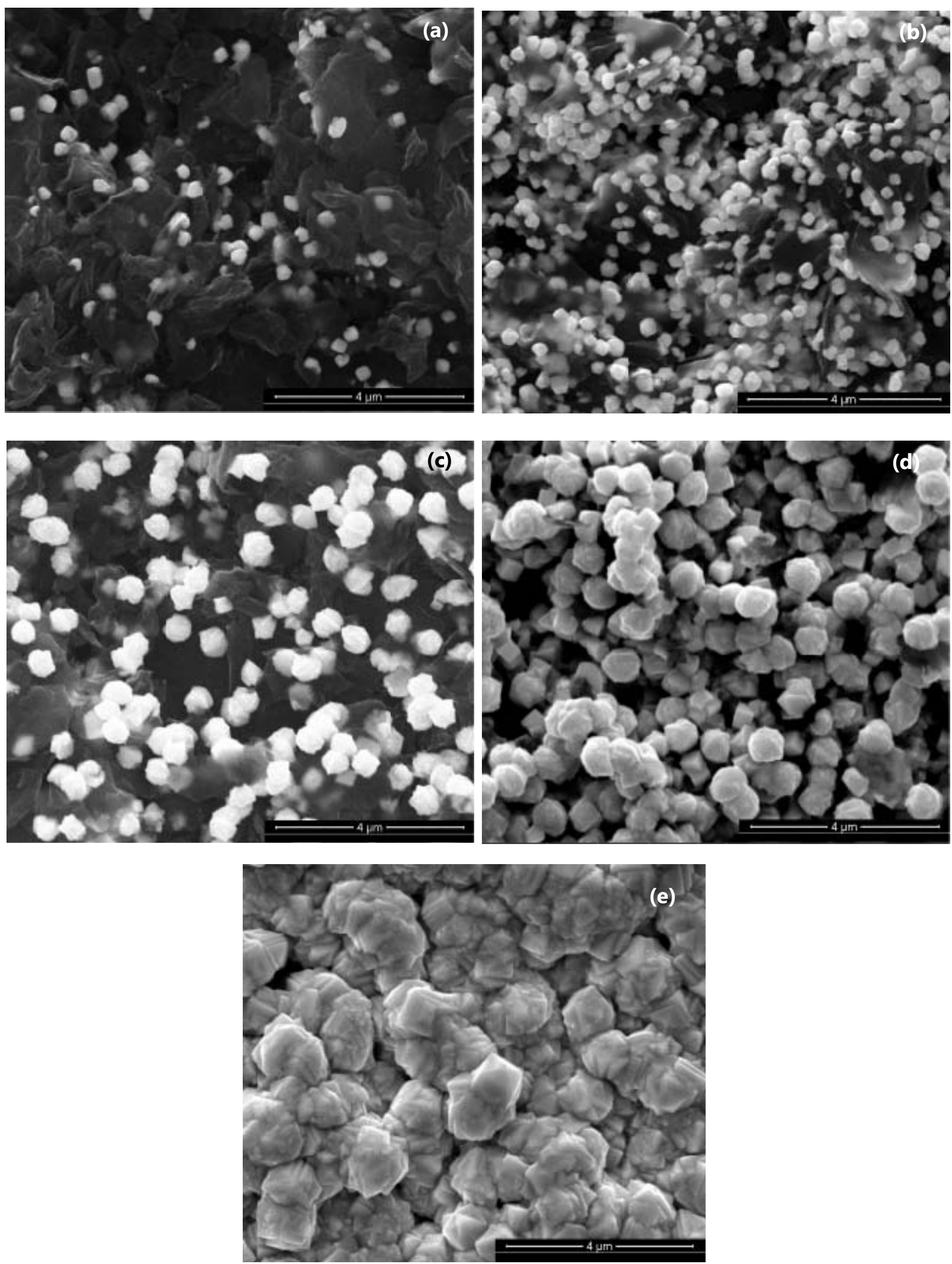

Figura 32. Imágenes SEM de nanocristalitas de Pt electrodepositadas por aplicación de $O C P R$ a $1 \mathrm{kHz}$ y Es $=1,2 \mathrm{~V}$ con variación de Ei (a) -0,05 V; (b) -0,2 V; (c) -0,24 V; (d) -0,26 V; (e) -0,28 V. 


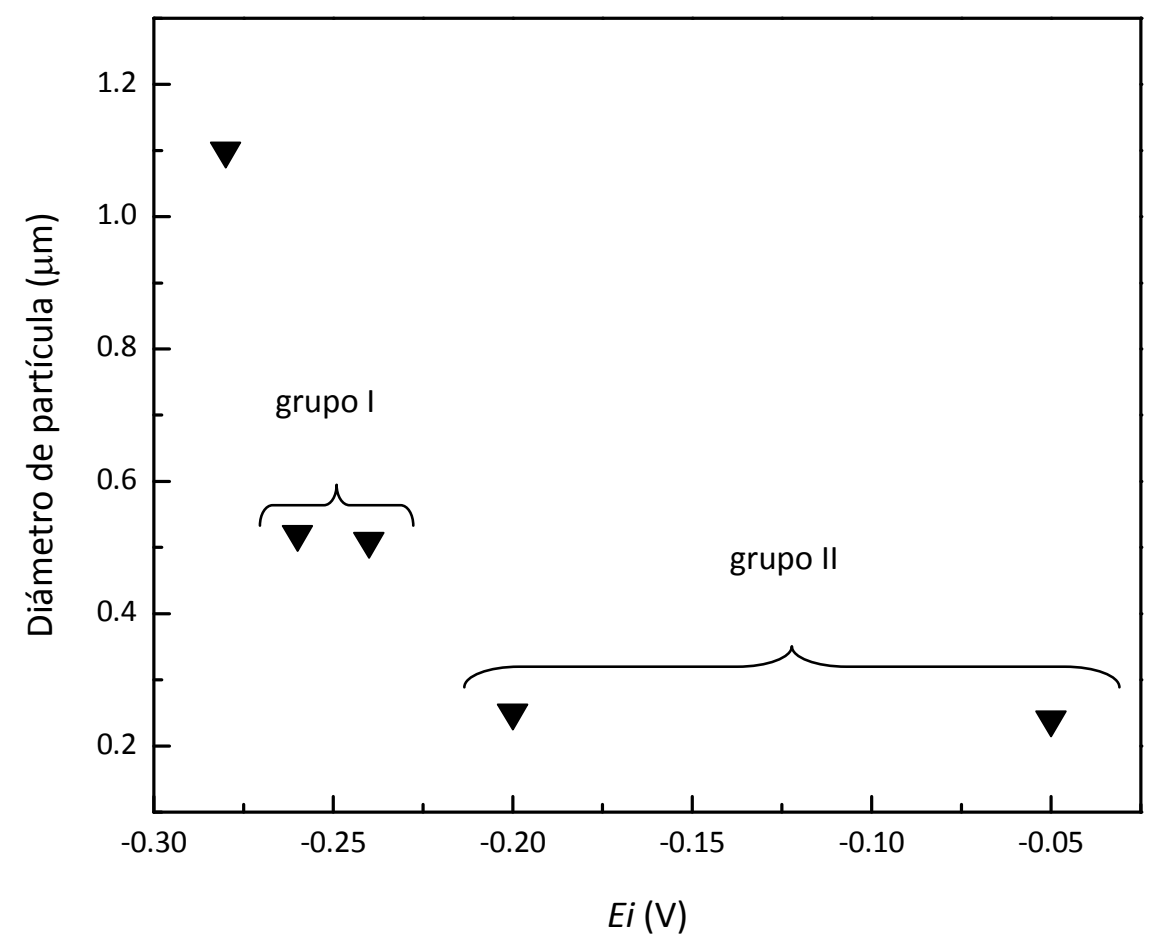

Figura 33. Influencia del potencial inferior Ei en el tamaño de partícula a $E s=1,2 \mathrm{~V}$.

Relacionando el diámetro de partícula con el número de partículas distribuidas en una determinada área de electrodo, se puede observar que para valores de $E i-0,2 \vee$ y $-0,05 \vee$ el tamaño de partícula no varía considerablemente, en tanto que el número de partículas por unidad de área resulta menor para $E i=-0,05 \mathrm{~V}$. Para el potencial inferior $E i=-0,2 \mathrm{~V}$ se obtiene el mayor número de partículas por unidad de área correspondiente al menor tamaño de partícula alcanzado bajo las condiciones de operación ensayadas, es decir, $0,24 \mu \mathrm{m}$.

En la Figura 34 se muestran los voltamperogramas realizados a $0,1 \mathrm{~V} / \mathrm{s}$ en $\mathrm{H}_{2} \mathrm{SO}_{4} \quad 0,5 \mathrm{M}$ a temperatura ambiente, para cada una de las situaciones evaluadas.

Se calculó la carga asociada a los electrodepósitos de Pt sobre los sustratos de carbono por integración del área correspondiente a la región de electrosorción de hidrógeno en los voltamperogramas. Se determinó el área superficial electroquímicamente activa del $P t$ electrodepositado teniendo en cuenta la carga específica para una monocapa de hidrógeno adsorbido sobre Pt [267], obteniéndose valores entre dos a veinte veces superiores al área geométrica del electrodo.

Los voltamperogramas de las muestras evaluadas muestran un incremento relativo en la contribución de los picos de corriente referidos a los átomos de hidrógeno débilmente adsorbidos, aproximando la respuesta voltamperométrica de una superficie escalonada de monocristal de $P t$ con terrazas estrechas (111). No se observan diferencias apreciables en la región de potenciales estudiados, salvo a - $0,05 \mathrm{~V}$ donde no se llega a distinguir la contribución de los picos de corriente asociados a los sitios preferenciales. 


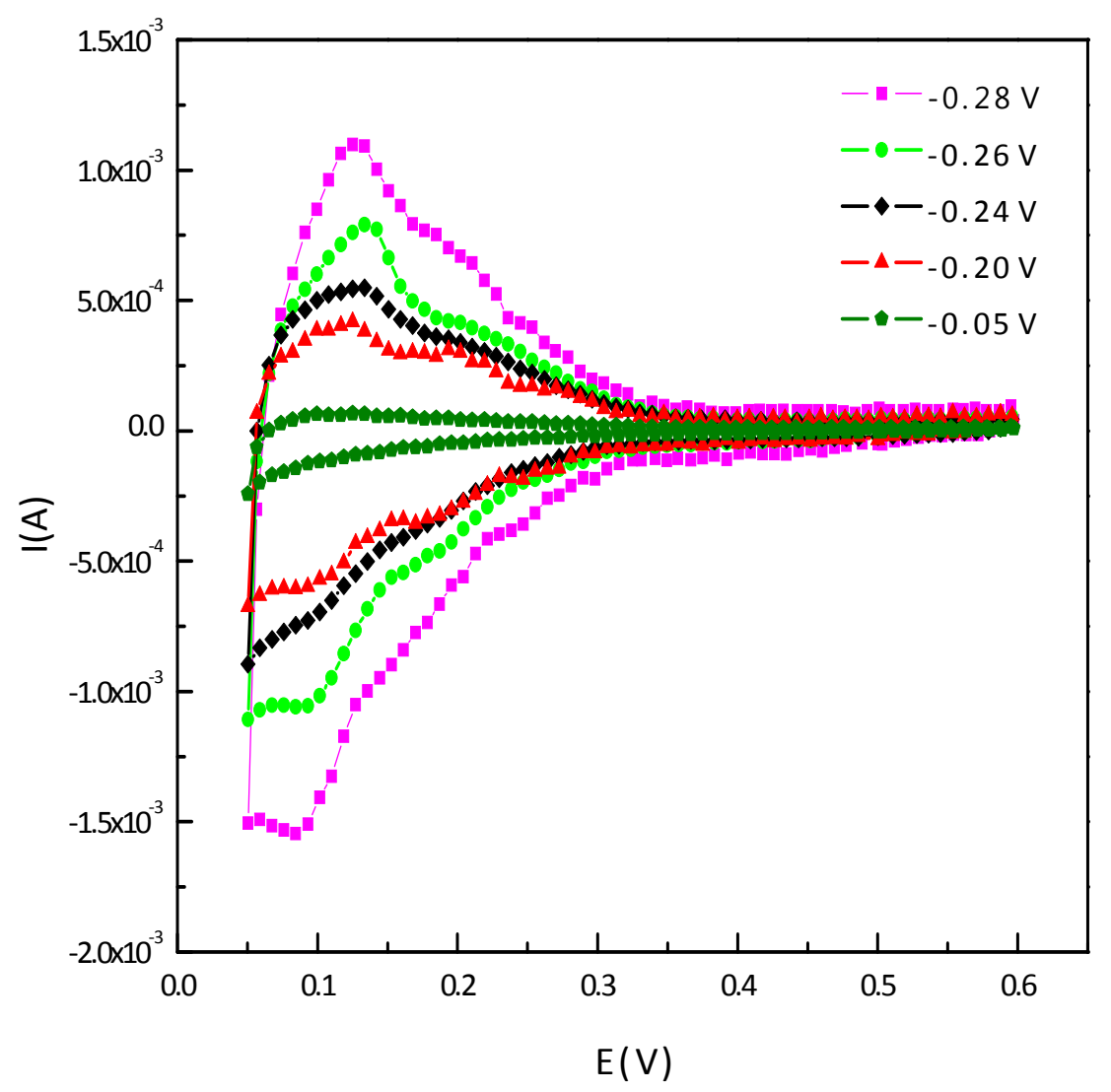

Figura 34. Respuesta voltamperométrica de los electrodepósitos de Pt por aplicación de una OCPR variando Ei.

En la Figura 35 se muestra la carga voltamperométrica de electrodesorción de hidrógeno de los electrodepósitos de $P t, Q_{h}$, en función de la variación del potencial inferior Ei de la OCPR aplicada. Se observa una disminución de $Q_{h}$ a medida que el potencial inferior disminuye, lo cual estaría asociado, en principio, a que la cantidad de Pt electrodepositado disminuye de manera exponencial cuando el potencial inferior de la OCPR se hace menos negativo.

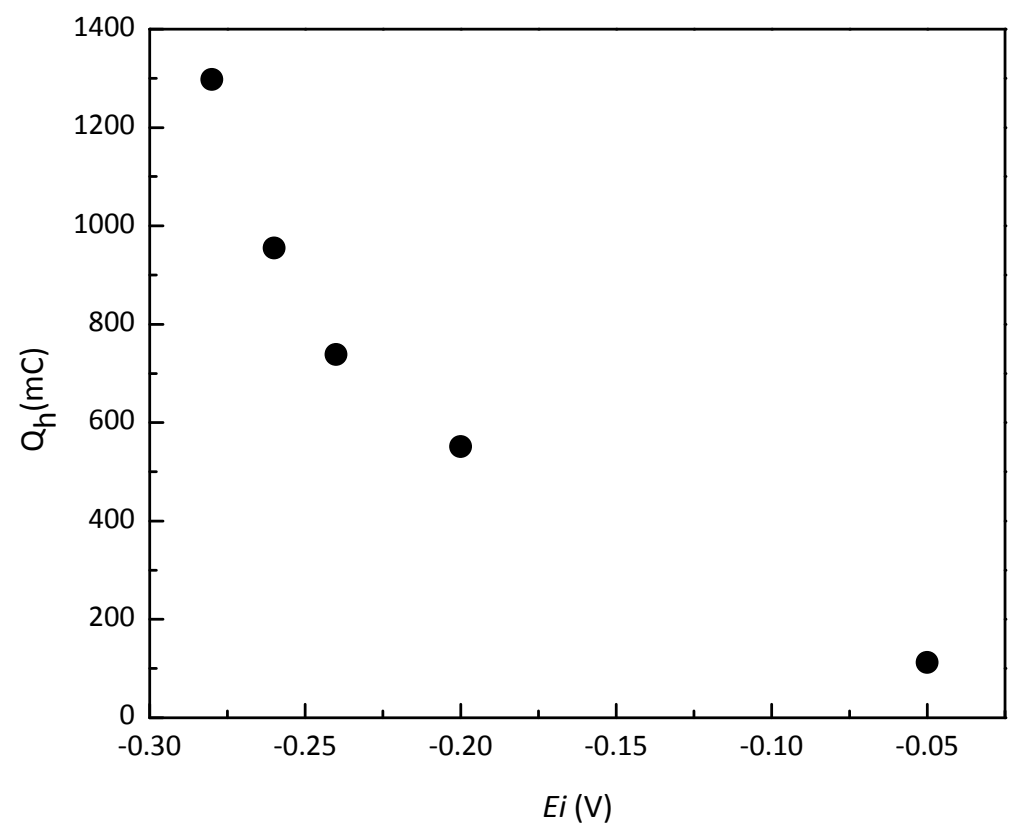

Figura 35. Carga voltamperométrica asociada a la electrodesorción de hidrógeno sobre Pt electrodepositado. 
La masa de Pt electrodepositado se determinó, para cada una de las muestras evaluadas, mediante la técnica espectrofotométrica implementada. En la Figura 36 se observa la cantidad en masa de $P t$ electrodepositado para una misma carga. Se registra una disminución de la cantidad neta de $P t$ electrodepositado, a carga constante, con el desplazamiento de Ei hacia potenciales más negativos. La mayor cantidad de Pt electrodepositado se obtiene para la condición de operación $E s=1,2 \vee$ y Ei $=-0,2$ V. Estas condiciones de operación se corresponden, a su vez, con la obtención de partículas de Pt de menor tamaño, de acuerdo a lo demostrado previamente (Figura 33) para las experiencias de electrodeposición realizadas bajo las condiciones antes mencionadas.

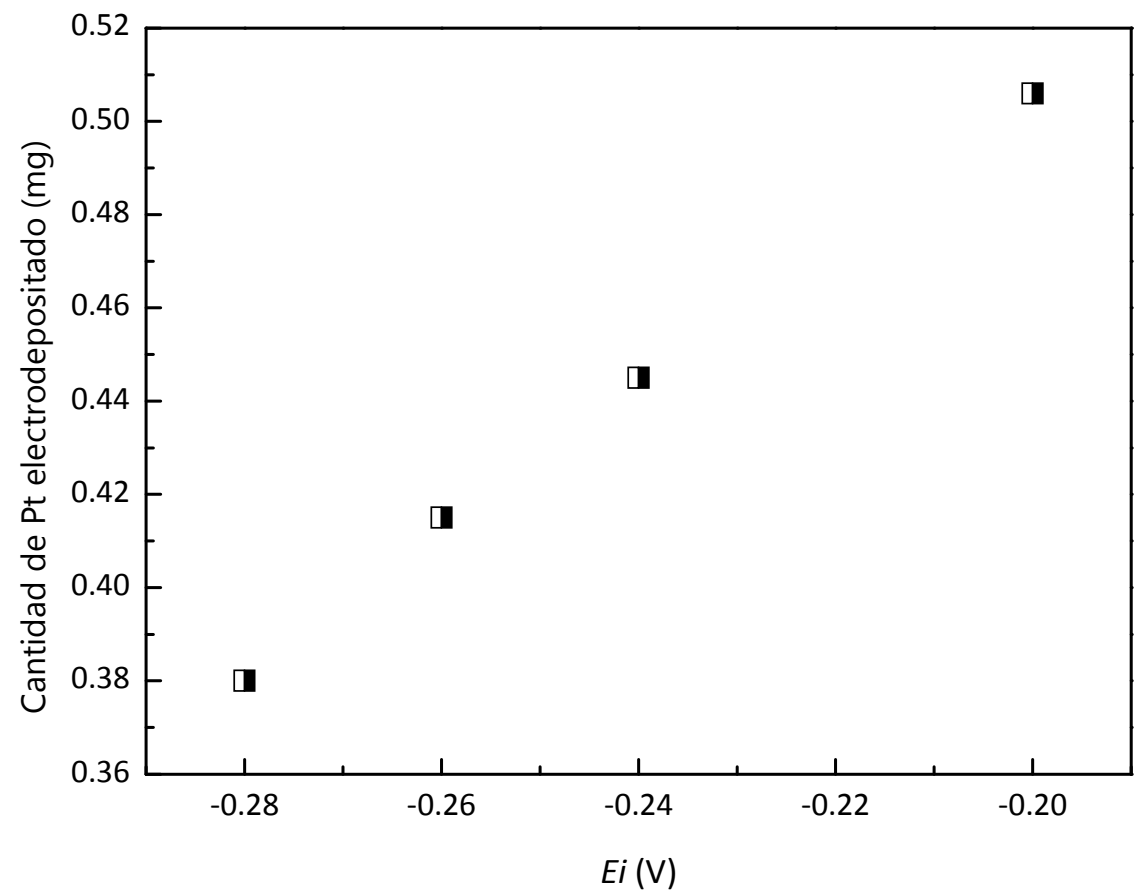

Figura 36. Cantidad en masa de Pt electrodepositado en función del potencial inferior.

VI.9.d. Efecto de la variación del potencial inferior Ei a potencial superior constante de $E s=1,38 \mathrm{~V}$

Se evaluó el efecto de la variación del potencial inferior Ei sobre el desarrollo de las cristalitas de $P t$ facetadas, manteniendo fijos el potencial superior Es a $1,38 \mathrm{~V}$ y la frecuencia $f$ a $1 \mathrm{kHz}$ de una onda simétrica, esto es, $\tau_{s} / \tau_{i}=1$, con un tiempo de electrodeposición $t$ de 5 minutos. Los potenciales inferiores seleccionados para realizar las pruebas fueron $-0,28 \mathrm{~V},-0,26 \mathrm{~V},-0,24 \vee \mathrm{y}-0,2 \mathrm{~V}$.

La morfología superficial de los electrodepósitos obtenidos fue observada mediante imágenes SEM. En la Figura 37 se muestran los electrodepósitos de Pt para cada una de las situaciones analizadas.

Se puede observar una distribución homogénea de las cristalitas de Pt electrodepositadas sobre los sustratos de carbono para todas las situaciones evaluadas. Se registra nuevamente una disminución de la densidad superficial de las partículas de Pt electrodepositado con el desplazamiento de Ei hacia valores menos negativos. 

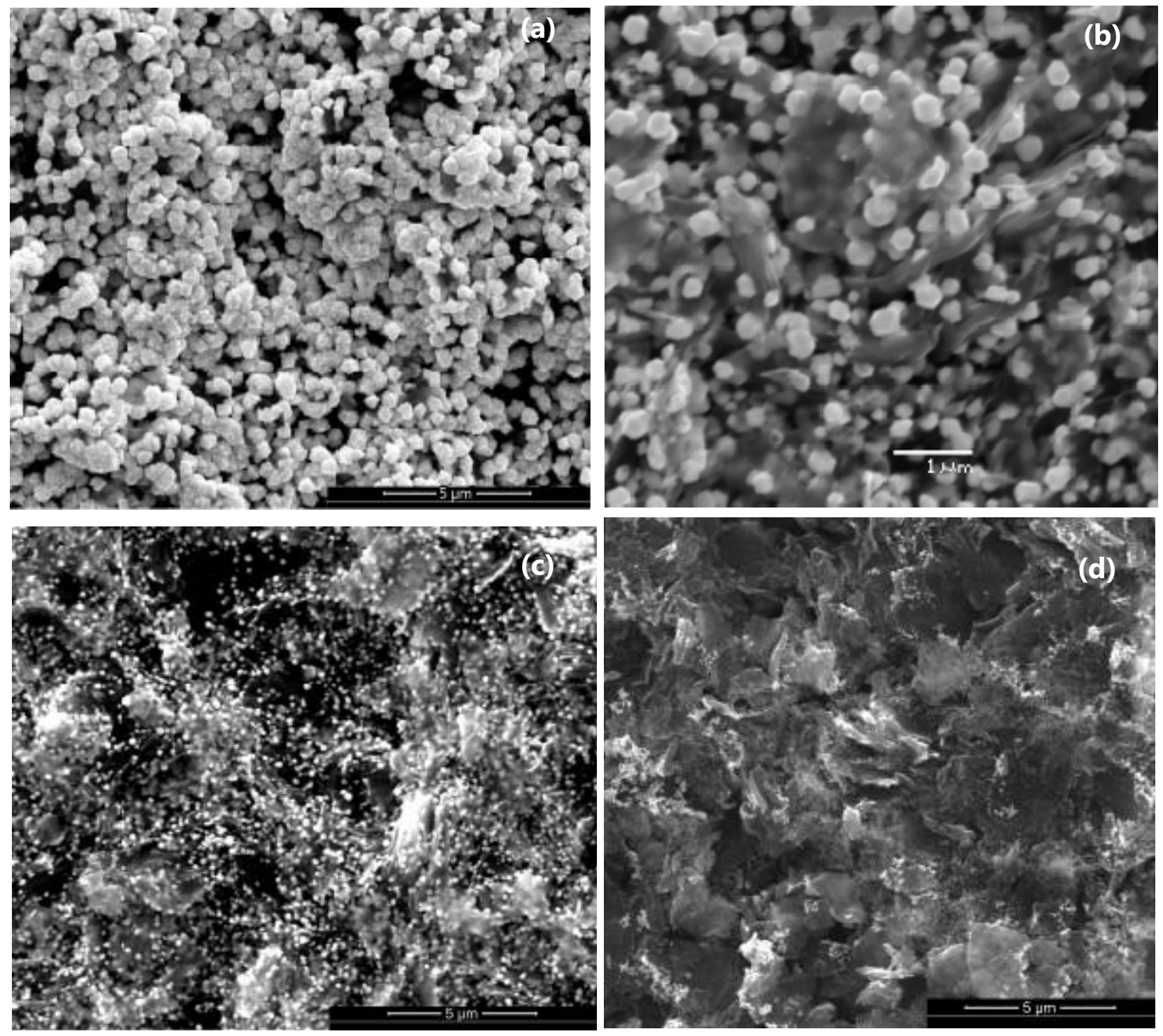

Figura 37. Imágenes SEM de nanocristalitas de Pt electrodepositadas por aplicación de OCPR manteniendo fijo $E s=1,38 \mathrm{~V}$ y variando $E i$ (a) $-0,28 \mathrm{~V}$; (b) -0,26 V; (c) -0,24 V; (d) -0,2 V. Magnificación $15000 \mathrm{X}$.

Se determinó la dependencia del tamaño de partícula con la variación del potencial inferior Ei. Los resultados se muestran en la Figura 38 donde se observa una disminución del tamaño de partícula de tipo exponencial a medida que el potencial inferior $E i$ se hace menos negativo. Para $E s=1,38 \vee$ y $E=-0,2$ $V$ se obtiene el menor tamaño de partícula, que se encuentra en el orden de los 0,034 $\mu \mathrm{m}$. Sin embargo, pese a que generalmente un menor tamaño de partícula se asocia a una mayor actividad catalítica, esto no es evidencia suficiente porque existen otros factores que juegan un rol significativamente importante, en particular, los planos cristalográficos expuestos en la superficie de las partículas de $P t$ electrodepositadas. 


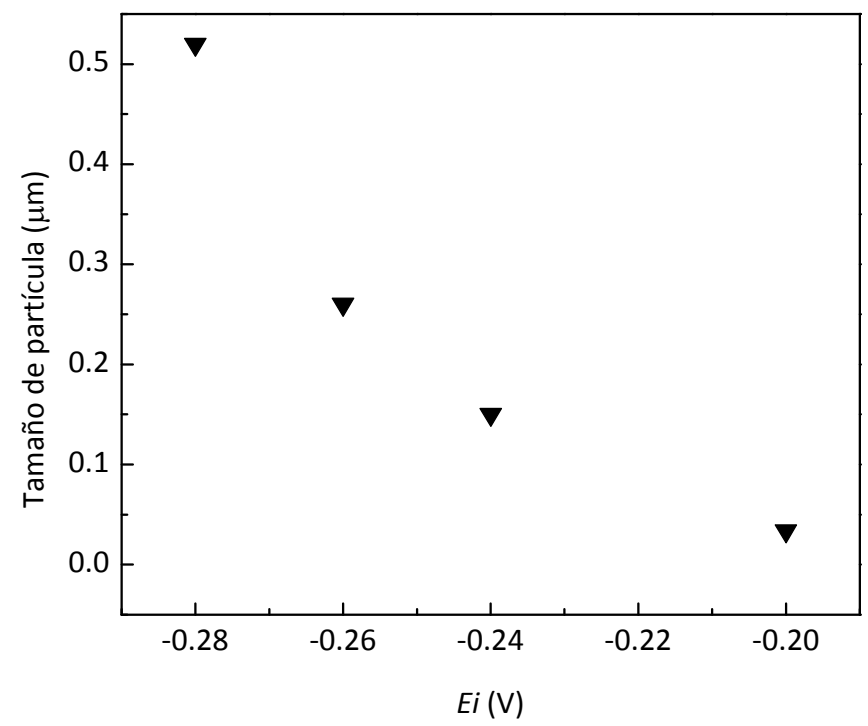

Figura 38. Influencia del potencial inferior Ei en el tamaño de partícula para $E s=1,38 \mathrm{~V}$.

El desarrollo del facetado de cristalitas de Pt con orientación cristalográfica preferencial (111) fue seguido a través del cambio en la altura relativa de los picos de corriente voltamperométricos de los adátomos de hidrógeno débilmente adsorbidos. En la Figura 39 se muestran los voltamperogramas correspondientes a las condiciones de operación evaluadas, donde se distinguen los picos relacionados con la orientación cristalográfica preferencial tipo (111), salvo para la condición del potencial inferior $E i=-0,2 \mathrm{~V}$ donde no llegan a distinguirse picos de corriente.

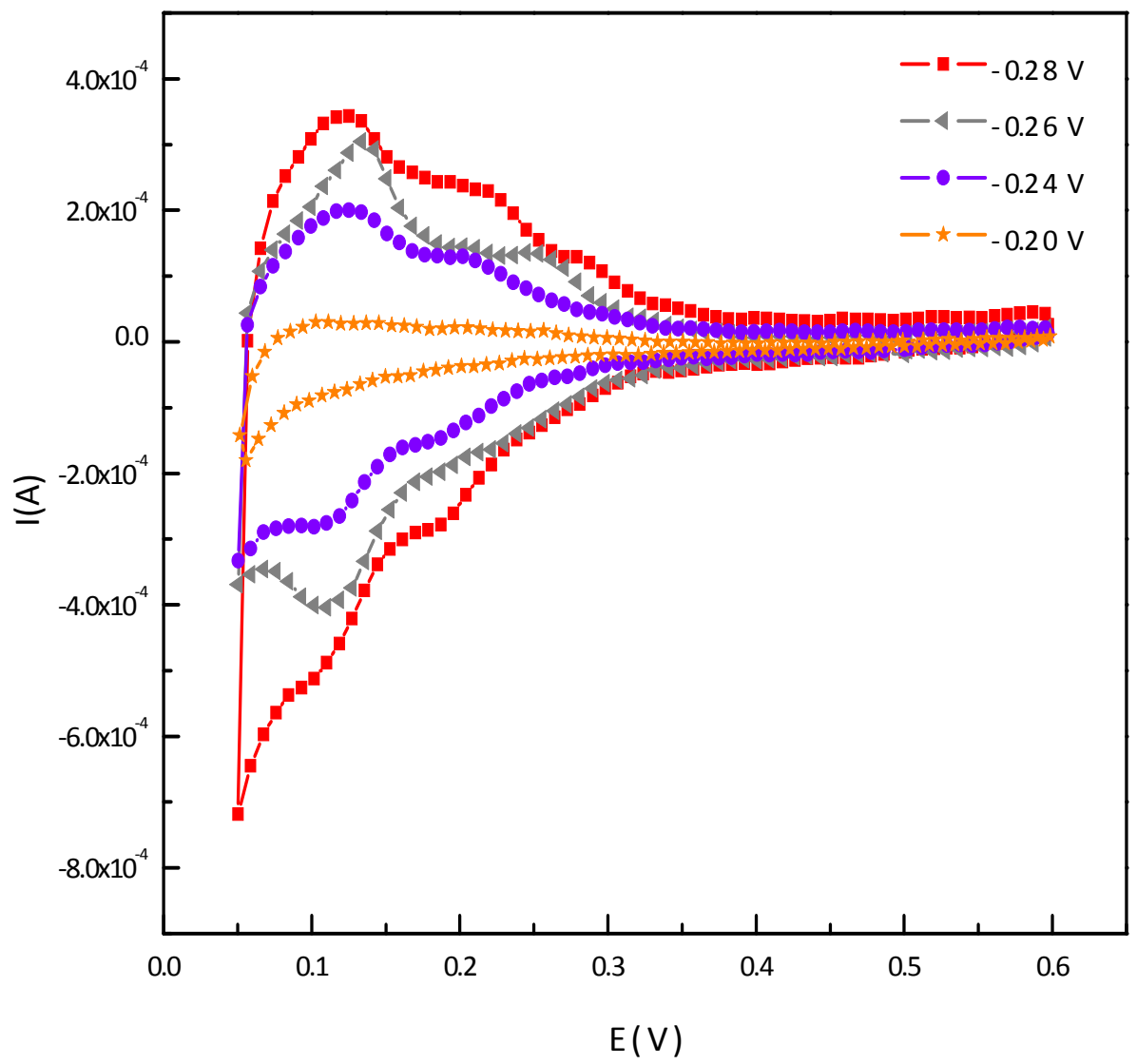

Figura 39. Respuesta voltamperométrica de los electrodepósitos de Pt por aplicación de OCPR a 1 kHz y a $E s=1,38 \mathrm{~V}$. 
Se determinó también la carga voltamperométrica de electrodesorción de hidrógeno, $Q_{h}$, asociada a los electrodepósitos de Pt en función de la variación del potencial inferior Ei. Se observa una disminución de $Q_{h}$ siguiendo una tendencia de tipo lineal a medida que el potencial inferior se hace menos negativo (Figura 40).

Por otra parte, con el valor de $Q_{h}$ y teniendo en cuenta la carga específica para una monocapa de hidrógeno adsorbido sobre Pt [267], se determinó el área superficial electroquímicamente activa del Pt electrodepositado, obteniéndose valores hasta 7 veces superiores al área geométrica del electrodo soporte.

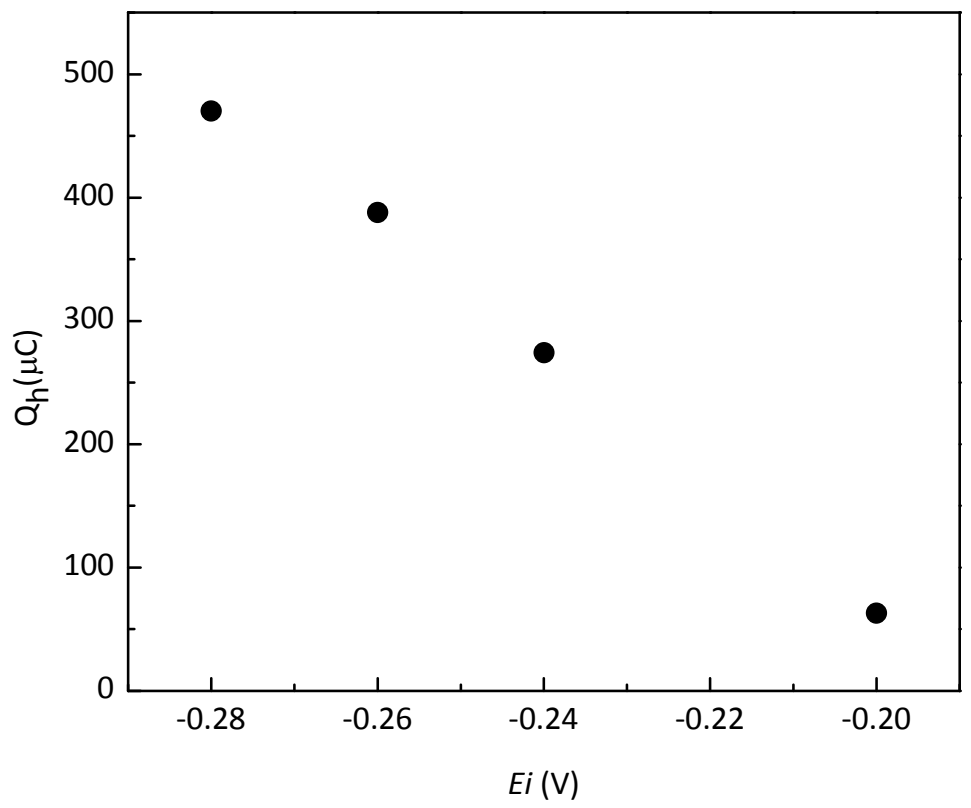

Figura 40. Carga voltamperométrica asociada a la electrodesorción de hidrógeno sobre Pt electrodepositado.

VI.9.e. Efecto de la variación del potencial superior Es a potencial inferior constante de $E i=-0,2$ V

Se aplicaron rutinas de $O C P R$ a $1 \mathrm{kHz}$ manteniendo fijo el potencial inferior $E i$ a $-0,2 \mathrm{~V}$ y variando el potencial superior $E s$ entre $1,2 \vee$ y $1,38 \mathrm{~V}$. En todas las experiencias se fijaron tiempos de electrodeposición de 5 minutos y se utilizó una $O C P R$ simétrica, de modo que $\tau_{s} / \tau_{i}=1$.

La morfología de los electrodepósitos de Pt así obtenidos se observó mediante imágenes SEM. En la Figura 41 se muestran las imágenes de los electrodepósitos de Pt obtenidos para los potenciales superiores Es de 1,38 V y Es 1,2 V a diferentes magnificaciones. En ambos casos se observa una distribución homogénea de las partículas de Pt que difieren considerablemente en tamaño. Al potencial superior más alto examinado, $1,38 \mathrm{~V}$, no se logra distinguir claramente la morfología superficial de las partículas de $P t$ electrodepositadas, ya que presentan tamaños de partícula muy pequeños que se encuentran en el orden de los 0,034 $\mu \mathrm{m}$. Para el potencial superior más bajo, esto es, 1,2 V, el tamaño de partícula estimado fue de $0,25 \mu \mathrm{m}$. Se registra, por lo tanto, un aumento considerable del tamaño de partícula, de aproximadamente el $86 \%$, a $E s=1,2 \mathrm{~V}$, con respecto al de $E s=1,38 \mathrm{~V}$. 

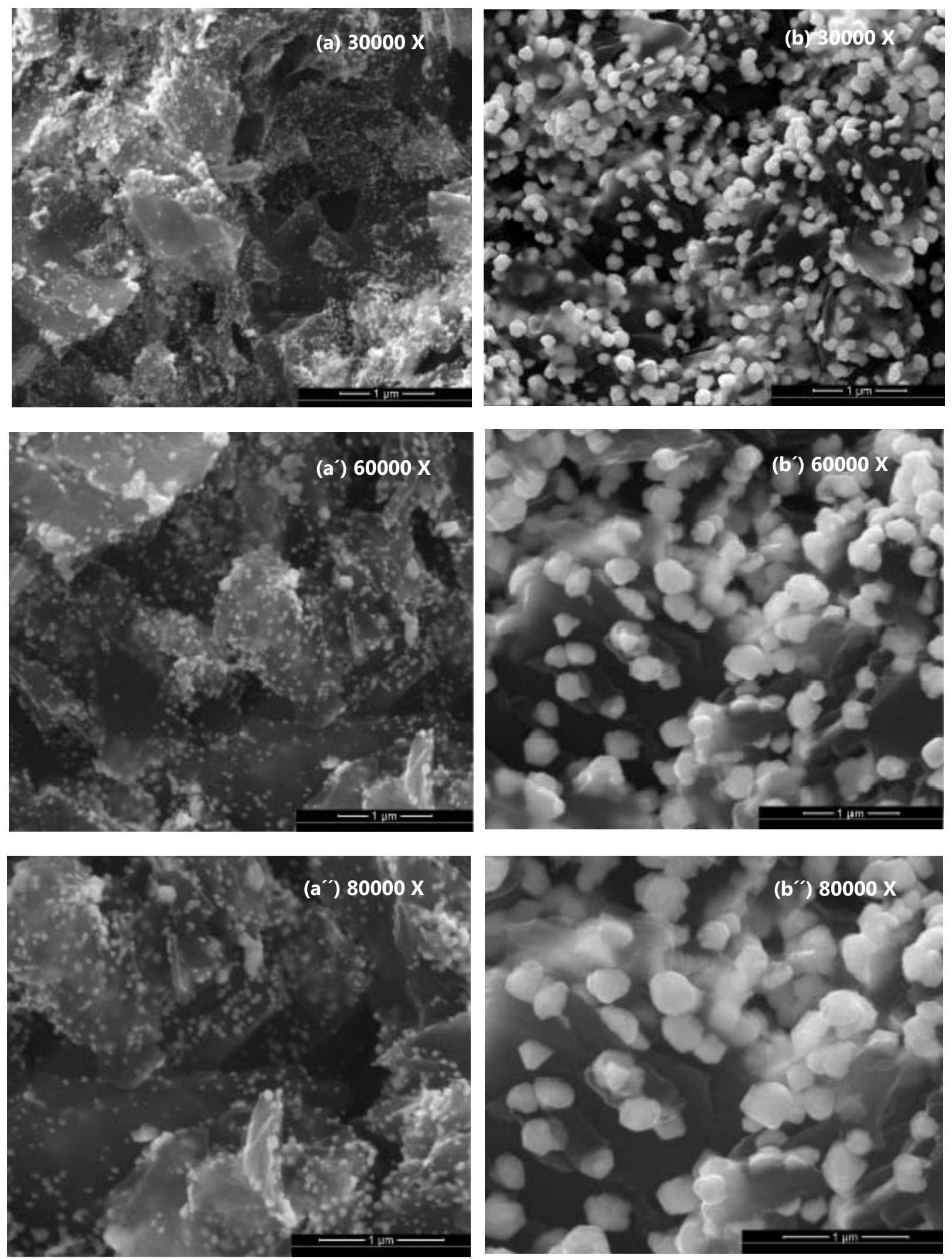

Figura 41. Imágenes SEM de partículas de Pt obtenidas por aplicación de la OCPR manteniendo Ei fijo en -0,2 V y variando Es (a) 1,38 V; (b) 1,2 V. 
Por integración del área correspondiente a la región de electrodesorción de hidrógeno de los voltamperogramas realizados en solución $\mathrm{H}_{2} \mathrm{SO}_{4}$ 0,5 M, se calculó la carga de electrosorción de hidrógeno, $Q_{h}$, asociada a los electrodepósitos de $P t$ para cada una de las experiencias realizadas. Se determinó también el área superficial electroquímicamente activa del $P t$ electrodepositado y se obtuvieron valores entre uno a nueve veces mayores que el área geométrica del electrodo. En la Figura 42 se muestran los voltamperogramas correspondientes.

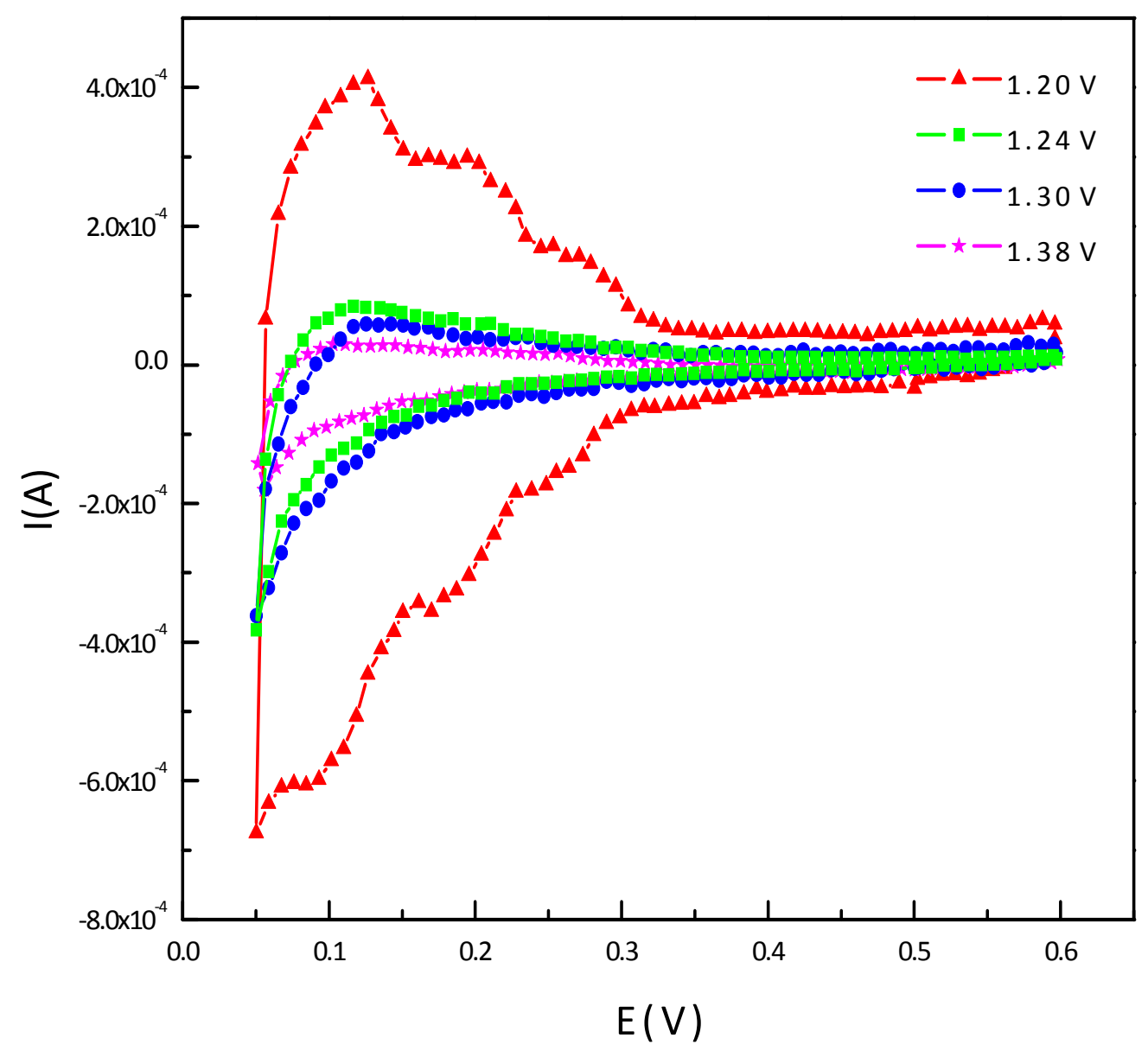

Figura 42. Respuesta voltamperométrica de los electrodepósitos de Pt por aplicación de una OCPR variando el límite de potencial superior.

La distribución de la carga entre los diferentes picos voltamperométricos de la Figura 42 da una primera estimación de la presencia de los diferentes sitios superficiales. Puede observarse claramente que, para la condición $E s=1,2 \vee$ y $E i=-0,2 \vee$, se obtiene una mayor contribución de la corriente asociada a los átomos de hidrógeno débilmente adsorbidos, asemejando la respuesta voltamperométrica de superficies escalonadas con una alta proporción de facetas (111).

Se observó que la carga de electrosorción de hidrógeno, $Q_{h}$, disminuye con el aumento del potencial superior Es, tal como se muestra en la Figura 43.

Considerando que cada átomo de hidrógeno se adsorbe a un átomo de Pt [200], [201], surge también que la cantidad de Pt electrodepositado disminuye con el aumento de Es. 


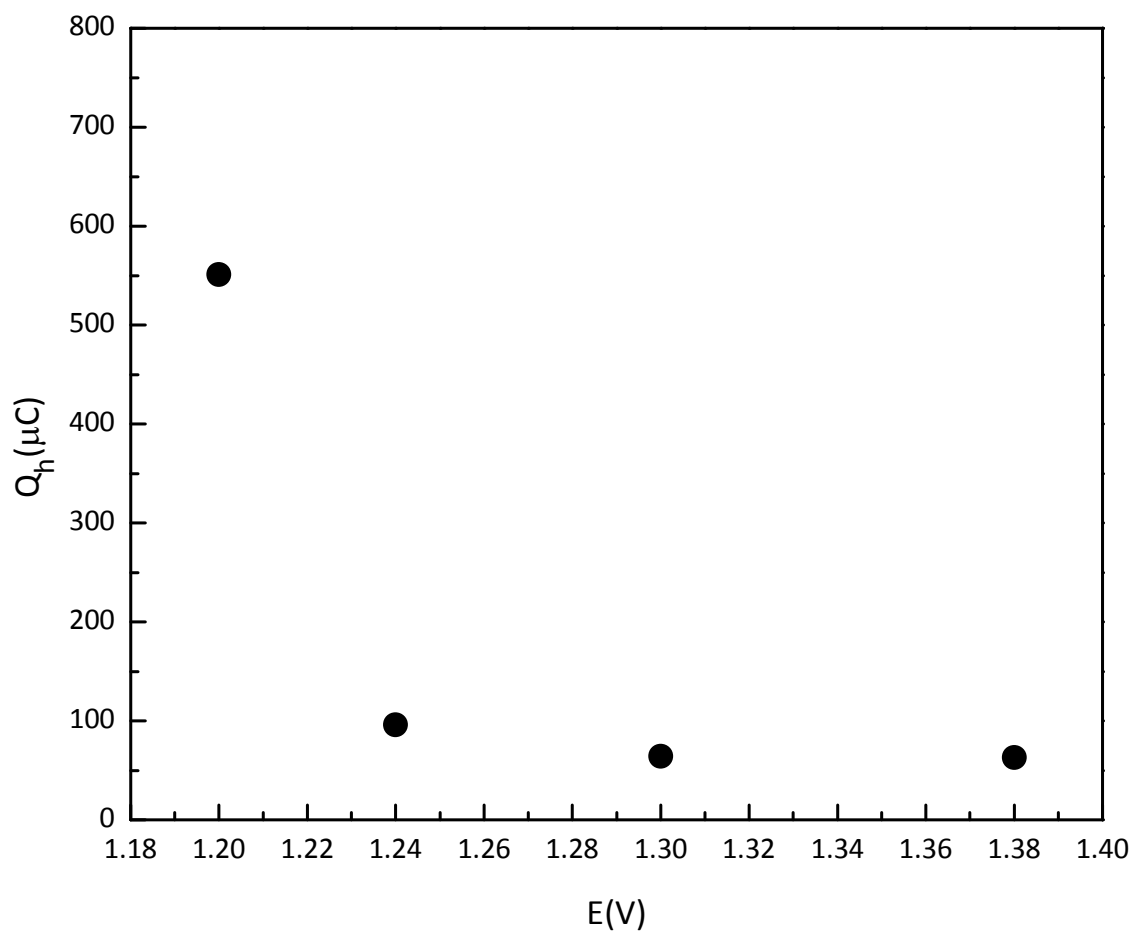

Figura 43. Carga voltamperométrica asociada a la electrodesorción de hidrógeno sobre Pt electrodepositado.

Estos resultados indican que la cantidad de $P$ t disuelto en los hemiciclos anódicos durante la aplicación de la OCPR y que no se redeposita, aumenta con el potencial superior Es, tal como cabe esperar bajo condiciones de control activado del proceso de electrodisolución. 


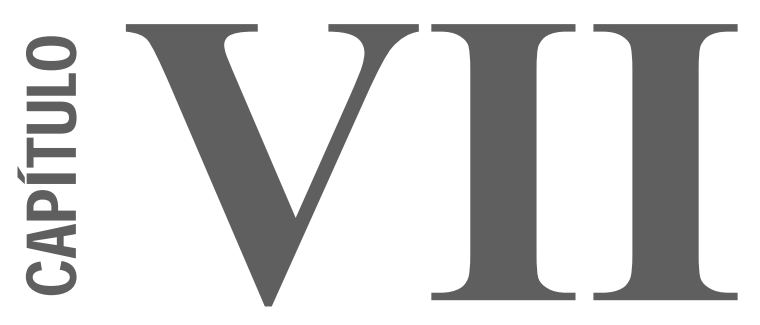

Aspectos generales de las celdas de combustible 



\section{CAPÍTULO VII}

\section{Aspectos generales de las celdas de combustible}

\section{VII.1. Historia de las celdas de combustible}

Las celdas de combustible son dispositivos electroquímicos que transforman la energía de una reacción química en energía eléctrica. En una celda de combustible de hidrógeno/oxígeno, el hidrógeno (combustible) alimenta al ánodo, donde se produce la reacción de oxidación. El oxígeno (oxidante) ingresa a la celda a través del cátodo, donde se lleva a cabo la reacción de reducción correspondiente. A continuación se muestras las reacciones parciales que se llevan a cabo en cada uno de los electrodos de una celda de combustible de hidrógeno/oxígeno:

Ánodo: reacción de oxidación de hidrógeno $(\mathrm{ROH})$

$$
2 H_{2(g)} \rightarrow 4 H^{+}{ }_{(s o l)}+4 e^{-} \quad E^{\circ}=0 \text { V vs. } E H N
$$

siendo $E H N$ el electrodo de hidrógeno estándar o normalizado.

Los electrones liberados en el ánodo fluyen por un circuito externo hacia el cátodo donde reaccionan con el $\mathrm{O}_{2}$ y los protones para formar agua según:

Cátodo: reacción de reducción de oxígeno (RRO)

$$
\mathrm{O}_{2(g)}+4 H^{+}+4 e^{-} \rightarrow 2 \mathrm{H}_{2} \mathrm{O}_{(l)} \quad E^{\circ}=1,23 \mathrm{~V} \text { vs. } E H N
$$

La reacción química global es la siguiente:

$$
2 \mathrm{H}_{2(g)}+\mathrm{O}_{2(g)} \rightarrow 2 \mathrm{H}_{2} \mathrm{O}_{(l)}
$$

El flujo de electrones del ánodo al cátodo es una corriente eléctrica que puede realizar trabajo útil.

Las celdas de combustible, comparadas con fuentes de energía convencionales en base a combustibles fósiles, son limpias y eficientes. Prácticamente su único producto de desecho es agua y generan en el proceso global electricidad y calor aprovechables, como se detallará más adelante.

La historia de las celdas de combustible comienza en el año 1839 con los primeros estudios de William Grove [269] y continúa en la actualidad con su empleo como fuente energética para alimentar numerosos dispositivos a tal punto que, actualmente, la investigación y desarrollo en el tema es una de las áreas más activas en el campo de los dispositivos de conversión y almacenamiento de energía.

En 1842 Grove presentó la así denominada "batería voltaica de gas" [270], esto es, un dispositivo que consistía de dos electrodos de Pt sumergidos en un electrolito acuoso de ácido sulfúrico, alimentados por hidrógeno y oxígeno gaseosos (Figura 1). Grove conectó eléctricamente 50 de estas celdas, generando el potencial suficiente para producir la reacción de electrólisis del agua, formando hidrógeno y oxígeno. 


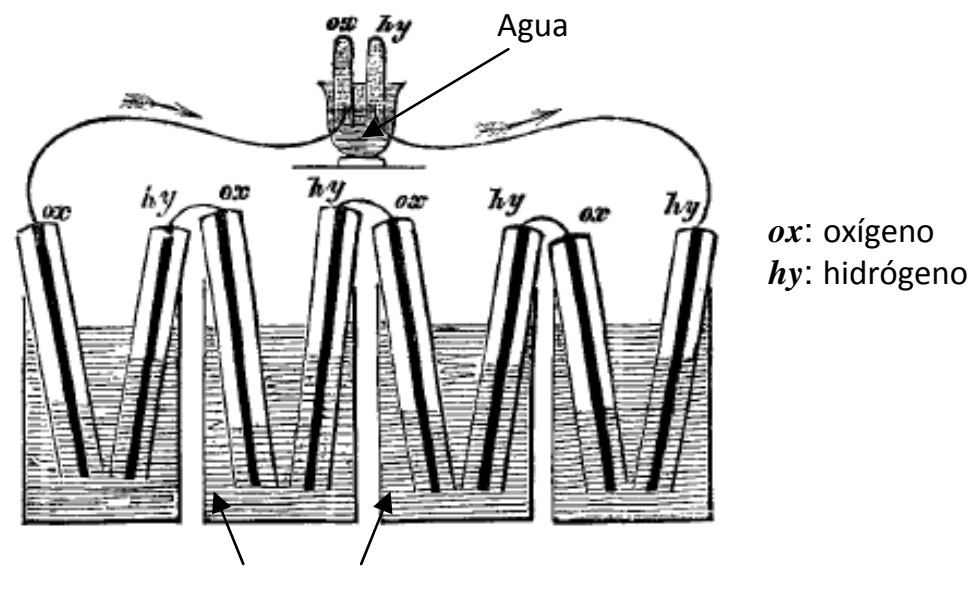

Ácido sulfúrico

Figura 1. Batería voltaica en base a reactivos gaseosos propuesta por Grove [270].

En 1882 Rayleigh planteó una nueva versión de la batería en base a gases, mejorando su eficiencia al aumentar la superficie de contacto entre el $P t$, los gases reactivos y el electrolito [271].

En 1889, Mond y Langer realizaron un importante avance en el concepto de las baterías gaseosas, resolviendo el problema asociado a la inmersión de los electrodos en un electrolito líquido y, por lo tanto, a la dificultad del acceso de los gases reactivos a los puntos activos [272]. Estos autores plantearon un prototipo que permitía retener el electrolito en una matriz sólida no conductora, cuya superficie era cubierta por una fina capa de platino u oro. Utilizaba un diafragma para contener el electrolito de ácido sulfúrico (Figura 2).

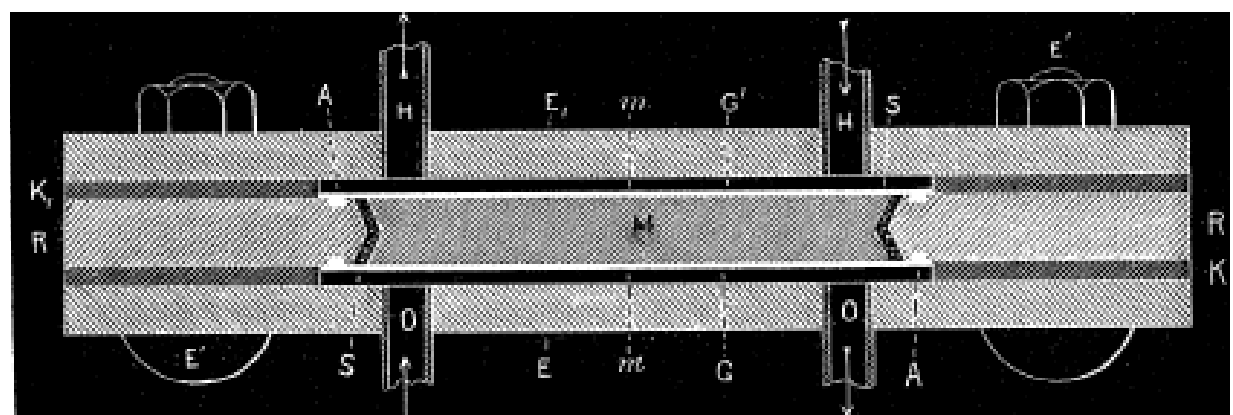

Figura 2: Diseño de la batería gaseosa de Mond y Langer. A: tiras de conducción, E: platos de ebonita, G: cámaras de gas selladas, $\mathrm{H}$ : hidrógeno, $\mathrm{K}$ : marcos de goma, O: oxígeno, $\mathrm{M}$ : plato de cerámica, $\mathrm{R}$ : marco de ebonita, S: electrodo [272].

La propuesta de Mond y Langer era muy similar a los diseños de celdas de combustible actuales, sin embargo, se degradaba a un ritmo del $10 \%$ por cada hora de funcionamiento.

Simultáneamente, Wright y Thomson construyeron un dispositivo similar, empleando una matriz de cerámica no vitrificada para retener el electrolito acuoso de ácido sulfúrico [273]. Estudiaron el efecto de distintos catalizadores sobre la tensión en circuito abierto y demostraron que el $P t$ era el catalizador con el que se obtenían mejores resultados. 


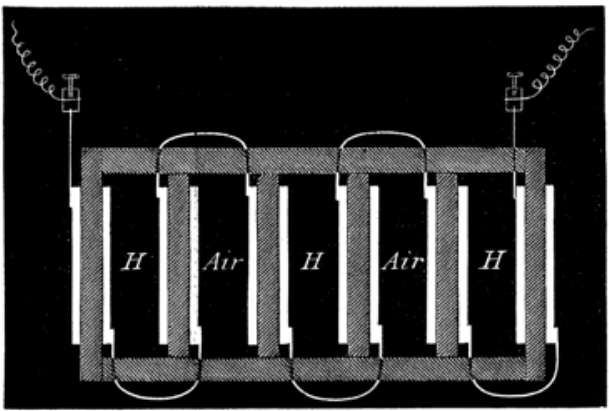

Figura 3. Prototipo construido por Wright y Thomson [273].

La experiencia en celdas de combustible con electrolito acuoso ácido llevó al desarrollo de electrolitos sólidos, los cuales presentan menores dificultades técnicas. En 1960 Grubb y Niedrach, de General Electric Company, presentaron un electrolito sólido ácido, que consistía en una membrana de polímero (poliestireno) con terminaciones de cadena con grupos $\mathrm{HSO}_{3}{ }^{-}$[274]. Con esta membrana la celda alcanzaba una tensión en circuito abierto de $0,3 \vee$ y requería de hidratación total del electrolito para que su conductividad fuera máxima.

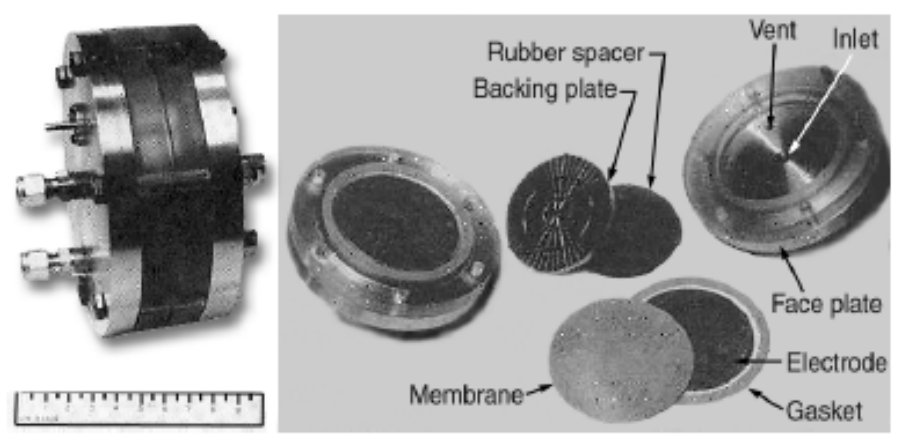

Figura 4. Celda de combustible con electrolito de membrana de intercambio de protones desarrollada por General Electric Company [274].

En 1962, el empleo de una celda con electrolito polimérico de intercambio protónico (PEM) se impuso a otras opciones, como los paneles solares y otros tipos de celdas de combustible, como generador eléctrico de la nave de la misión Gemini V de la NASA para orbitar la tierra [275]. Un "stack" de 32 celdas de combustible fue diseñado por General Electric y desarrollado por McDonnell Aircraft Corporation, capaz de producir $1 \mathrm{~kW}$ de pico. Cabe mencionar que en la primera misión Gemini se utilizaron 2 "stacks" de 1 kW [276] y la celda de combustible operó sin interrupciones durante 7 días [277]. Los reactivos, hidrógeno y oxígeno, eran almacenados criogénicamente y el agua producida era utilizada como agua potable para el equipo en misiones largas.

En 1967 las membranas Nafion ${ }^{\circledR}$ fueron implementadas en celdas de combustible para la misión de la NASA Biosatellite 2, que duró 3 meses [277]. Sin embargo, la dependencia del contenido de agua de la membrana para el adecuado funcionamiento de este tipo de celdas, hizo que no se volvieran a utilizar en las misiones espaciales. 
Una nueva formulación de polímeros, por parte de Grot en 1972, mejoró el funcionamiento y la durabilidad del electrolito y, con mejoras en la fabricación de electrodos, las celdas de combustibles desarrolladas fueron consideradas como un tipo de celda práctica especialmente para vehículos. El desafío era superar el efecto perjudicial que el $\mathrm{CO}$, un subproducto de las reacciones de la extracción del hidrógeno, tenía sobre el catalizador de base Pt. Este polímero conductor derivado del Teflón fue desarrollado por DuPont y se denominó Nafion. Se degradaba más lentamente que sus antecesores, era estable y capaz de soportar el mecanismo químico de la degradación con $\mathrm{H}_{2} \mathrm{O}_{2}$, que destruía las membranas a base de poliestireno en poco tiempo como las usadas por General Electric en los módulos de las misiones Gemini.

Actualmente hay numerosas empresas de diferentes rubros que emplean celdas de combustible con este tipo de electrolito. Así, por ejemplo, la empresa canadiense Ballard, ha cooperado con la automovilística Mercedes-Daimler AG en vehículos que emplean celdas de combustible PEM. Se han desarrollado modelos de baja potencia como el Mark 9, que ofrece potencias desde 4,4 kW con un peso de 7,2 Kg o el Mark 902 para uso automovilístico que es capaz de generar $85 \mathrm{~kW}$ de manera continua y con un peso inferior a los $100 \mathrm{~kg}$. El vehículo prototipo Necar 5, con tecnología PEM de Ballard, utiliza un sistema de celdas de combustible de $75 \mathrm{~kW}$ abastecidas con hidrógeno, proveniente del reformado a bordo de metanol, y alcanza una velocidad máxima de $150 \mathrm{~km} / \mathrm{h}$. El tanque de almacenamiento de metanol es de 40 litros y proporciona una autonomía de $450 \mathrm{~km}$, superior a al de un vehículo de combustión interna a gasolina. Por otra parte, emite menos del $10 \%$ de las emisiones tóxicas de los motores de combustión interna. Para evitar problemas asociados al uso de un reformador de metanol a bordo, otros fabricantes han privilegiado el desarrollo de vehículos eléctricos impulsados por celdas de combustible de muy alta eficiencia y alimentación directa con hidrógeno comprimido a alta presión. Al respecto, uno de los vehículos eléctricos que al momento exhibe el mejor rendimiento, es el Honda FCX, prototipo totalmente calificado para uso en ruta. Pesa $1.670 \mathrm{~kg}$, su autonomía es de $430 \mathrm{~km}$ (hidrógeno a 350 bar) y desarrolla una velocidad máxima de $150 \mathrm{~km} / \mathrm{h}$. La fuente de potencia es una celda de combustible de $50 \mathrm{~kW}$, con un volumen de 33 litros y un peso de $48 \mathrm{~kg}$. El excelente rendimiento alcanzado se debe al empleo de una nueva membrana de electrolito tipo $\mathrm{C}-\mathrm{H}$ con grupos sulfonato, con una conductividad eléctrica que es el doble de la de la clásica membrana de $\mathrm{Nafion}^{\circledR}$ a $-20^{\circ} \mathrm{C}$. El bajo peso de la celda de combustible se ha logrado mediante la fabricación de placas separadoras de metal estampado que ofrecen una menor resistencia de contacto $(<1 / 4)$ y pesan un $20 \%$ menos que las placas de carbón convencionales. La empresa Nuvera, formada por De Nora Fuel Cells y Epyx Corporation, comercializan celdas para uso residencial como el modelo Avanti, que genera $5 \mathrm{~kW}$ de electricidad y 7 kW de calor o el modelo PowerFlow 5 para uso automovilístico, que es capaz de generar 5 kW. Por otro lado, empresas automovilísticas como General Motors-Opel han desarrollado sus propias celdas de combustible. En 2004, General Motors-Opel junto con Linde AG y Shell Hydrogen B.V., desarrollaron el 
proyecto Marathon, empleando el prototipo HydroGen3 Liquid basado en el modelo Zafira de Opel. El prototipo recorrió 10000 km en condiciones climatológicas muy diversas y sin mantenimiento.

Existen otros numerosos prototipos y modelos de vehículos en base a la tecnología de celdas de combustible. Es así como las compañías automovilísticas DaimlerChrysler, Ford, Volvo, Mazda, General Motors, BMW, Hyundai, Honda y Nissan, entre otras, continúan trabajando en la fabricación de prototipos que utilizan esta tecnología. Honda ha obtenido la homologación para empezar a comercializar su vehículo impulsado por este sistema, el FCX Clarity, en Japón y Estados Unidos en 2008. La fuente de potencia de este vehículo es una celda de combustible de $100 \mathrm{~kW}$ de 57 litros de volumen y $67 \mathrm{~kg}$ de peso que proporciona una autonomía de $410 \mathrm{~km}$ y una velocidad máxima de $160 \mathrm{~km} / \mathrm{h}$. El vehículo también posee una batería de ion litio como fuente suplementaria de potencia para capturar la energía de la desaceleración y del frenado.

En 2009 varias compañías firmaron un acuerdo para uniformar el desarrollo y la introducción en el mercado de vehículos eléctricos impulsados con celdas de combustible, lo que se consideró un gran paso hacia la producción en serie de vehículos de emisión nula de contaminantes. En el acuerdo, las compañías anticipaban que, a partir del año 2015, una cantidad significativa de vehículos eléctricos con celas de combustible podrían ser comercializados.

Las celdas de combustible de electrolito polimérico, también denominado membrana de intercambio de protones, (PEM) se encuentran entre los sistemas más estudiados, ya que presentan diversas ventajas para aplicaciones en transporte y dispositivos portátiles. La optimización del funcionamiento de una celda de combustible PEM implica un estudio complejo y requiere un conocimiento profundo del comportamiento de la celda en función del drenaje de corriente, de acuerdo al diseño de los diferentes elementos que la componen y las condiciones de operación. Con este objetivo, desde fines de la década de los 90, se han desarrollado gran cantidad de trabajos experimentales [278-281] y simulaciones numéricas [282-284], donde se puede destacar el esfuerzo realizado para comprender la influencia del flujo de agua en el transporte de masa de la celda para la producción de energía eléctrica [285], [286].

Se han abordado también aspectos prácticos relativos a la optimización de la estructura y las condiciones de operación de los electrodos de difusión de gas [285-290] y aspectos tecnológicos relacionados con el transporte de agua y la ingeniería de módulos y tamaño operacional [291-297]. En muchos de estos trabajos se han obtenidos resultados satisfactorios en relación al desempeño de los electrodos con contenidos de catalizador de 0,15 a 0,4 mg de $P t / \mathrm{cm}^{2}$ en celdas unitarias [286-290]. Sin embargo, los módulos de celdas de combustible, por lo general utilizaban electrodos con alto contenido en catalizador, en el intervalo de 2 a $4 \mathrm{mg}$ de $P t / \mathrm{cm}^{2}$ [291-297], aunque en los últimos tiempos se ha despertado un gran interés en lograr reducir la cantidad de catalizador de los electrodos de celdas de combustible. 
Desde las primeras descripciones de electrodos de difusión de gas para las celdas $P E M$, utilizando bajas cantidades de catalizador soportado sobre carbón [298-300], se han realizado varias mejoras en el diseño, composición y contenido de Pt de estos sistemas [301-311]. Un avance significativo se produjo cuando Raistrick [298] y Srinivasan et al. [299], [301], lograron disminuir a la décima parte la cantidad de catalizador, pasando de 4 a $0,4 \mathrm{mg}$ de $P t / \mathrm{cm}^{2}$, impregnando los electrodos de difusión de gas desarrollados para celdas de combustible de ácido fosfórico con el ionómero Nafion ${ }^{\circledR}$ (DuPont) solubilizado y luego prensándolos en caliente sobre la membrana polimérica. Otras mejoras fueron realizadas por Wilson et al. [308], [309] quienes prepararon la película catalizadora mezclando el ionómero solubilizado con el catalizador $P t / C$. Ferreira et al. lograron posteriormente mejorar el desempeño preparando la película catalizadora mediante un método de prensado [310]. Otros investigadores realizaron diferentes mejoras respecto a la preparación de la película catalizadora de los electrodos, que se pueden encontrar en bibliografía [312-320]. Como resultado de todos estos desarrollos e investigaciones, los electrodos actuales pueden llegar a funcionar con cantidades de catalizador muy bajas, favoreciendo de este modo las reacciones electroquímicas que se producen en el ánodo y en el cátodo $\left[0,05 \mathrm{mg}\right.$ de $P t / \mathrm{cm}^{2}$ para el electrodo de hidrógeno y $0,1 \mathrm{mg}$ de $P t / \mathrm{cm}^{2}$ para el electrodo de oxígeno (aire)] [299-301], [308], [309].

\section{VII.2. Eficiencia de una celda de combustible}

La fuerza impulsora en una celda de combustible está vinculada al cambio de energía libre de la reacción global. El hidrógeno y el oxígeno reaccionan espontáneamente formando agua mediante la reacción global (3), la cual posee una energía libre menor que los reactivos (Figura 5) y es, por lo tanto, la situación de menor energía preferida por el sistema.

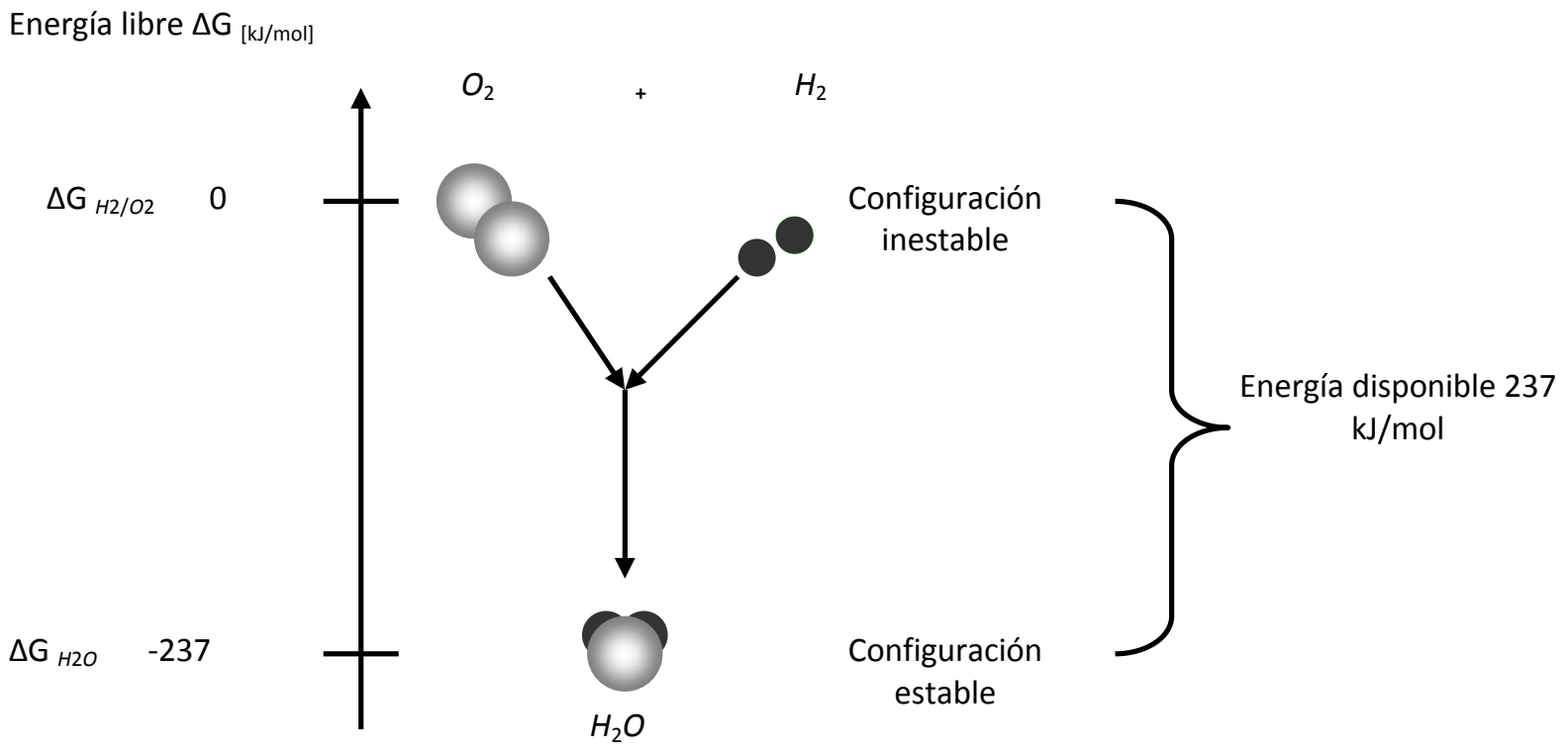

Figura 5. Reacción de los reactivos, $\mathrm{H}_{2}$ y $\mathrm{O}_{2}$, para formar agua. 
De esta manera, cuando la oxidación del $\mathrm{H}_{2}$ y la reducción del $\mathrm{O}_{2}$ se producen sobre los correspondientes electrodos (ánodo y cátodo, respectivamente) ubicados a ambos lados del electrolito, la diferencia de energía libre entre reactivos y productos puede ser convertida en energía eléctrica.

La energía libre de Gibbs, $\Delta G$, para la reacción química global [reacción (3)], en condiciones estándar, es $-237 \mathrm{~kJ} / \mathrm{mol}$ presentando un potencial de celda estándar $E_{0}$ para la reacción de $1,23 \mathrm{~V}$ a 25 ${ }^{\circ} \mathrm{C}$, y la entalpía para esta reacción, $\Delta H$, es de $-286 \mathrm{~kJ} / \mathrm{mol}$ [321]. Esto indica que la eficiencia de conversión, $\varepsilon_{T,}$ sería, bajo condiciones estándar:

$$
\varepsilon_{T}=\frac{\Delta G}{\Delta H}
$$

que se conoce como eficiencia teórica o rendimiento termodinámico. Si tanto $\Delta G$ como $\Delta H$ se dividen por $Z F$, siendo $Z$ el número de electrones que interviene en la reacción y $F$ la constante de Faraday, entonces la $\varepsilon_{T}$, puede expresarse en función de los potenciales $E_{0}$ y $E_{N T}$, donde $E_{0}=1,23 \mathrm{~V}$ es el potencial teórico o ideal de la celda y $E_{N T}=1,48 \mathrm{~V}$ es el potencial asociado al cambio de entalpía de la reacción (3) [321-323].

$$
\varepsilon_{T}=\frac{\Delta G}{\Delta H}=\frac{\Delta G / Z F}{\Delta H / Z F}=\frac{E_{0}}{E_{N T}}=\frac{1,23}{1,48}=0,83
$$

resultando que $\varepsilon_{T}$ es 0,83 a $25{ }^{\circ} \mathrm{C}$ y 1 atm. Por otra parte, para una celda de combustible de hidrógeno/oxígeno a $150{ }^{\circ} \mathrm{C}$, la eficiencia es de 0,91, esto es, el $91 \%$ de la energía total se puede convertir en electricidad a esta temperatura [324].

Sin embargo, por varias razones, entre las cuales la cinética lenta de la $R R O$ es la de mayor importancia, difícilmente se obtiene en una celda en operación eficiencias superiores al $60 \%$. Desde el punto de vista ingenieril, la eficiencia de una celda de combustible se expresa frecuentemente en términos de voltaje real a ideal. Debido a las pérdidas asociadas a la polarización y a la resistencia óhmica, como se describirá más adelante, el voltaje real es inferior al ideal. Por lo tanto, la eficiencia de una celda de combustible de hidrógeno/oxígeno a $25{ }^{\circ} \mathrm{C}$ se puede expresar en función de los voltajes real, $V_{\text {real }}$, e ideal, $V_{\text {ideal }}$, de la celda, que se conoce como eficiencia de voltaje, $\varepsilon_{v}$ :

$$
\varepsilon_{v}=\frac{\text { Energía generada }}{\Delta H}=\frac{V_{\text {real }} * I}{\Delta G / 0,83}=\frac{V_{\text {real }} * I}{V_{\text {ideal }} * I / 0,83}=\frac{0,83 * V_{\text {real }}}{1,23}=0,675 * V_{\text {real }}
$$

siendo I la corriente drenada. En la ecuación anterior se supone que el combustible se consume por completo en la celda. Sin embargo, normalmente el combustible no se consume totalmente, por lo cual se multiplica la eficiencia de voltaje por un factor de utilización del combustible, para calcular así la eficiencia real o práctica, $\varepsilon_{P,}$

$$
\varepsilon_{P}=\frac{V_{\text {real }} * I}{G_{H_{2}} * H H V_{H_{2}} \eta_{H_{2}}}
$$


donde $V_{\text {real }}$ es el voltaje, $I$ es la corriente de salida de la celda $(\mathrm{A}), G_{H 2}$ es el flujo de hidrógeno en el ánodo (mol/h), $H H V_{H 2}$ es el valor del calor más alto cedido en la reacción del hidrógeno para dar vapor de agua $(\mathrm{J} / \mathrm{mol})$ y $\eta_{\mathrm{H} 2}$ es el factor de utilización del hidrógeno en el ánodo, esto es, la fracción del hidrógeno total que ingresa a la celda de combustible y que reacciona electroquímicamente en el ánodo [325-327]. En celdas de combustible de $\mathrm{H}_{2} / \mathrm{O}_{2}$ de baja temperatura la determinación de $\eta_{\mathrm{H}_{2}}$ es sencilla, ya que el hidrógeno es el único reactivo involucrado en la reacción electroquímica anódica, y se puede calcular a partir de la siguiente ecuación:

$$
\eta_{H 2}=\frac{H_{2, e}-H_{2, s}}{H_{2, e}}=\frac{H_{2, c}}{H_{2, e}}
$$

donde $H_{2, e}$ e $H_{2, s}$ son los flujos de gas de hidrógeno a la entrada y salida de la celda, respectivamente, y $H_{2, c}$ es el flujo del gas consumido. Una revisión detallada de la determinación de $\eta_{H 2}$ se puede encontrar en la bibliografía [325], [326].

\section{VII.3. Clasificación de las celdas de combustible}

Existen diferentes tipos de celdas de combustible. Una clasificación habitual tiene en cuenta el tipo de electrolito utilizado, el cual sirve como puente para el intercambio de iones entre el ánodo y el cátodo. En base a los iones transportados en el electrolito, que pueden ser protones $\left(H^{+}\right)$, oxhidrilos $\left(\mathrm{OH}^{-}\right)$, carbonatos $\left(\mathrm{CO}_{3}{ }^{2-}\right)$ y óxidos $\left(\mathrm{O}^{2-}\right)$, las celda de combustible se clasifican en 4 categorías: celdas de combustible ácidas, alcalinas (AFC: "Alcaline Fuel Cell"), de carbonato fundido (MCFC: "Molten Carbonate Fuel Cell") y de óxido sólido (SOFC: "Solid Oxide Fuel Cell"), respectivamente. A su vez, las ácidas se dividen en celdas de membrana de intercambio de protones (PEMFC: "Proton Exchange Membrane Fuel Cell"), de metanol directo (DMFC: "Direct Methanol Fuel Cell") y de ácido fosfórico (PAFC: "Phosphoric Acid Fuel Cell").

En la Tabla I se muestran las reacciones electroquímicas para los diferentes tipos de celdas [328].

Tabla I. Reacciones electroquímicas para los diferentes tipos de celdas de combustible [328].

\begin{tabular}{|c|c|c|c|}
\hline Tipo de celda & Reacción anódica & Reacción catódica & lón \\
\hline $\begin{array}{l}\text { Membrana de intercambio de } \\
\text { protones }\end{array}$ & $H_{2} \rightarrow 2 H^{+}+2 e^{-}$ & $1 / 2 \mathrm{O}_{2}+2 \mathrm{H}^{+}+2 e^{-} \rightarrow \mathrm{H}_{2} \mathrm{O}$ & $\mathrm{H}^{+}$ \\
\hline Ácido fosfórico & $\mathrm{H}_{2} \rightarrow 2 \mathrm{H}^{+}+2 e^{-}$ & $1 / 2 \mathrm{O}_{2}+2 \mathrm{H}^{+}+2 e^{-} \rightarrow \mathrm{H}_{2} \mathrm{O}$ & $H^{+}$ \\
\hline Metanol directo & $\mathrm{CH}_{3} \mathrm{OH}+\mathrm{H}_{2} \mathrm{O} \rightarrow \mathrm{CO}_{2}+6 \mathrm{H}^{+}+6 e^{-}$ & $1 / 2 \mathrm{O}_{2}+2 \mathrm{H}^{+}+2 e^{-} \rightarrow \mathrm{H}_{2} \mathrm{O}$ & $H^{+}$ \\
\hline Alcalina & $\mathrm{H}_{2}+2 \mathrm{OH}^{-} \rightarrow 2 \mathrm{H}_{2} \mathrm{O}+2 e^{-}$ & $1 / 2 \mathrm{O}_{2}+\mathrm{H}_{2} \mathrm{O}+2 e^{-} \rightarrow 2 \mathrm{OH}^{-}$ & $\mathrm{OH}^{-}$ \\
\hline Carbonato fundido & $\mathrm{H}_{2}+\mathrm{CO}_{3}{ }^{2-} \rightarrow \mathrm{H}_{2} \mathrm{O}+\mathrm{CO}_{2}+2 e^{-}$ & $1 / 2 \mathrm{O}_{2}+\mathrm{CO}_{2}+2 e^{-} \rightarrow \mathrm{CO}_{3}{ }^{2-}$ & $\mathrm{CO}_{3}{ }^{2-}$ \\
\hline Óxido sólido & $\mathrm{H}_{2}+\mathrm{O}^{2-} \rightarrow \mathrm{H}_{2} \mathrm{O}+2 e^{-}$ & $1 / 2 O_{2}+2 e^{-} \rightarrow O^{2-}$ & $O^{2-}$ \\
\hline
\end{tabular}


En la Figura 6 se presenta un esquema general de una celda de combustible, donde se indican los iones que pasan a través de la membrana.

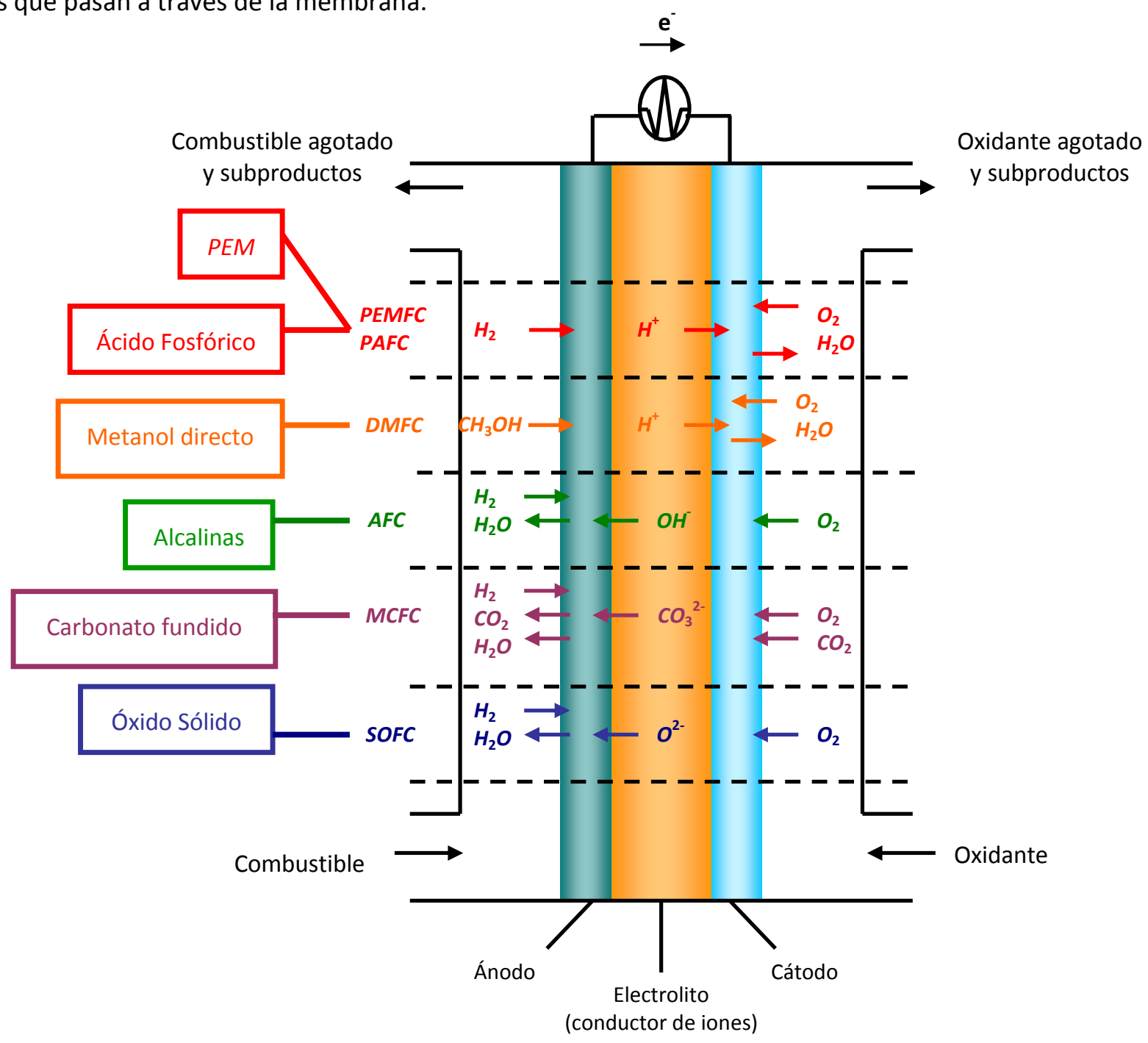

Figura 6. Tipos de celdas de combustible.

En la Tabla II se resumen las principales características de las celdas de combustible y en la Tabla III se mencionan sus ventajas y desventajas.

Tabla II. Principales características de las celdas de combustible en función del electrolito.

\begin{tabular}{|c||c|c|c|c|}
\hline Tipo de celda & Electrolito & $\begin{array}{c}\text { Temperatura de } \\
\text { operación }\left({ }^{\circ} \mathrm{C}\right)\end{array}$ & Reactivos & Características \\
\hline \hline $\begin{array}{c}\text { Membrana de } \\
\text { intercambio de } \\
\text { protones }\end{array}$ & $\begin{array}{c}\text { Membrana polímero } \\
\text { conductora de } \\
\text { protones }\end{array}$ & $30-100$ & $\begin{array}{c}\text { Comportamiento de } \\
\text { operación muy } \\
\text { flexible, alta } \\
\text { densidad de } \\
\text { potencia }\end{array}$ \\
\hline \hline Ácido fosfórico & $\mathrm{H}_{3} \mathrm{O}_{2}$ (aire) & $\mathrm{H}_{2}$ de reformado/ $/ \mathrm{O}_{2}$ & $\begin{array}{c}\text { Eficiencia limitada, } \mathrm{H}_{2} / \mathrm{O}_{2} \\
\text { problemas de } \\
\text { (aire) }\end{array}$ \\
\hline
\end{tabular}




\begin{tabular}{|c|c|c|c|c|}
\hline Metanol directo & $\begin{array}{l}\text { Membrana polímero } \\
\text { conductora de } \\
\text { protones }\end{array}$ & $50-90$ & $\mathrm{CH}_{3} \mathrm{OH}$ /aire & En desarrollo \\
\hline Alcalina & $\begin{array}{c}\mathrm{KOH} \circ \mathrm{NaOH}(25-50 \\
\%)\end{array}$ & $50-250$ & $\mathrm{H}_{2} / \mathrm{O}_{2}$ & $\begin{array}{c}\text { Alta eficiencia, } \\
\text { adecuada para gases } \\
\text { puros }\end{array}$ \\
\hline Carbonato fundido & $\begin{array}{l}\text { Carbonatos diluidos } \\
\qquad \mathrm{K}_{2} \mathrm{CO}_{3} / \mathrm{LiCO}_{3}\end{array}$ & $600-650$ & Gas natural/carbón & $\begin{array}{c}\text { Control de proceso } \\
\text { complejo, } \\
\text { problemas de } \\
\text { corrosión }\end{array}$ \\
\hline Óxido sólido & $\begin{array}{l}\text { Dióxido de circonio } \\
\text { sólido } \mathrm{CrO}_{2} / \mathrm{Y}_{2} \mathrm{O}_{3}\end{array}$ & $850-1050$ & Gas natural/carbón & $\begin{array}{l}\text { Potencia eléctrica } \\
\text { directa del gas } \\
\text { natural, tecnología } \\
\text { de cerámica (altas } \\
\text { temperaturas) }\end{array}$ \\
\hline
\end{tabular}

Tabla III. Ventajas, inconvenientes y aplicaciones de los diferentes tipos de celdas de combustible.

\begin{tabular}{|c|c|c|c|}
\hline Tipo de celda & Ventajas & Inconvenientes & Aplicaciones \\
\hline $\begin{array}{l}\text { Membrana de } \\
\text { intercambio de } \\
\text { protones }\end{array}$ & $\begin{array}{c}\text { Electrolito sólido reduce corrosión } \\
\text { y mantenimiento, baja } \\
\text { temperatura, arranque rápido, } \\
\text { menores costos, mejores } \\
\text { expectativas y mayor proyección, } \\
\text { diseño compacto }\end{array}$ & $\begin{array}{c}\text { Catalizadores costosos, } \\
\text { sensibles a impurezas en } \mathrm{H}_{2} \mathrm{u} \\
\text { otro combustible, bajo } \\
\text { intervalo de temperatura de } \\
\text { funcionamiento, problemas } \\
\text { por humidificación deficiente y } \\
\text { en exceso }\end{array}$ & $\begin{array}{l}\text { Residencial, automotriz, } \\
\text { portátil, aplicaciones } \\
\text { móviles, generación } \\
\text { descentralizada de } \\
\text { electricidad (pequeñas } \\
\text { plantas), ciclos } \\
\text { combinados de baja } \\
\text { potencia }\end{array}$ \\
\hline Ácido fosfórico & $\begin{array}{l}85 \% \text { eficiencia en cogeneración } \\
\text { de electricidad y calor, puede } \\
\text { utilizar } \mathrm{H}_{2} \text { impuro, tolerancia al } \mathrm{CO} \\
\text { cerca del } 1 \%\end{array}$ & $\begin{array}{c}\text { Catalizador de alto costo }(P t) \text {, } \\
\text { baja corriente y potencia, gran } \\
\text { peso y volumen, grandes } \\
\text { costos de inversión }\end{array}$ & $\begin{array}{c}\text { Aplicaciones industriales, } \\
\text { oficina, generación de } \\
\text { electricidad } \\
\text { descentralizada, vehículos } \\
\text { grandes como autobús y } \\
\text { locomotora }\end{array}$ \\
\hline Metanol directo & $\begin{array}{l}\text { Mayor seguridad por usar metanol } \\
\text { en lugar de } \mathrm{H}_{2} \text {, bajos costos de } \\
\text { instalación de infraestructura, } \\
\text { diseño compacto }\end{array}$ & $\begin{array}{c}\text { Requiere cantidades elevadas } \\
\text { de } P t \text {, bajas densidades de } \\
\text { potencia, estructura de stack } \\
\text { muy compleja, bajas } \\
\text { eficiencias }\end{array}$ & $\begin{array}{l}\text { Automotriz, dispositivos } \\
\text { electrónicos de baja } \\
\text { potencia }\end{array}$ \\
\hline Alcalina & $\begin{array}{l}\text { Reacción catódica más rápida en } \\
\text { el electrolito alcalino, mayor } \\
\text { eficiencia, flexibilidad al uso de } \\
\text { una amplia gama de catalizadores, } \\
\text { menores costos de fabricación }\end{array}$ & $\begin{array}{l}\text { Sensible a impurezas, exige } \\
\text { uso de } \mathrm{H}_{2} \text { de alta pureza y } \\
\text { eliminación del } \mathrm{CO}_{2} \text { de aire y } \\
\text { combustible, tecnología cara }\end{array}$ & $\begin{array}{l}\text { Industria aeroespacial, } \\
\text { militar }\end{array}$ \\
\hline $\begin{array}{l}\text { Carbonato } \\
\text { fundido }\end{array}$ & $\begin{array}{l}\text { Ventajas por alta temperatura de } \\
\text { operación, como mayor eficiencia, } \\
\text { catalizadores más baratos, } \\
\text { silenciosas, cogeneración de } \\
\text { electricidad y calor }\end{array}$ & $\begin{array}{c}\text { Corrosión debido a altas } \\
\text { temperaturas, baja vida útil, } \\
\text { tamaño grande, inversión } \\
\text { elevada }\end{array}$ & $\begin{array}{c}\text { Aplicaciones industriales, } \\
\text { embarcaciones y buques, } \\
\text { generación de } \\
\text { electricidad, ciclos } \\
\text { combinados de media } \\
\text { potencia }\end{array}$ \\
\hline Óxido sólido & $\begin{array}{l}\text { Ventajas por altas temperaturas } \\
\text { de operación y uso de electrolito } \\
\text { sólido, cogeneración de } \\
\text { electricidad y calor }\end{array}$ & $\begin{array}{l}\text { Corrosión debido a altas } \\
\text { temperaturas, baja vida útil, } \\
\text { tamaño grande, altas } \\
\text { temperaturas que facilitan } \\
\text { rupturas de componentes }\end{array}$ & $\begin{array}{c}\text { Aplicaciones industriales, } \\
\text { oficinas, generación de } \\
\text { energía estacionaria de } \\
\text { alta eficiencia }\end{array}$ \\
\hline
\end{tabular}




\section{VII.4. Comportamiento típico de la celda de combustible en operación}

El desempeño de una celda de combustible se puede estudiar y comprender a partir de la relación corriente-potencial, que se conoce como curva de polarización. Generalmente, para comparar la performance o comportamiento en operación de celdas de combustible se utilizan unidades de corriente por unidad de área geométrica, lo que define la densidad de corriente, y se expresa en términos de $\mathrm{A} / \mathrm{cm}^{2}$.

Las curvas de polarización representan el comportamiento de la celda de combustible en régimen estacionario, es decir, cuando la demanda de corriente de una carga externa permanece constante a lo largo del tiempo. Se utilizan para la caracterización de la performance de celdas de combustible, tanto individuales como multimódulos ("stacks").

Las curvas de polarización se determinan experimentalmente por medio de una técnica de medición de estado estacionario, que consiste en registrar los datos una vez que el potencial alcanza un valor estable para un determinado drenaje de corriente. Las pérdidas de energía en una celda de combustible están relacionadas con la magnitud de la potencia generada. De este modo, cuanto mayor es la potencia producida, mayores son las pérdidas. Esto puede observarse en la Figura 7, donde el voltaje, desde su valor en circuito abierto, disminuye con el aumento de corriente. Cuando la corriente fluye, ocurre una desviación del voltaje de circuito abierto, correspondiente al trabajo eléctrico realizado por la celda. La desviación desde los valores de equilibrio se conoce como sobrepotencial, $\eta$. Esta diferencia entre el voltaje de celda teórico y el de operación representa la suma de las pérdidas de energía en la celda de combustible y resulta en un voltaje de celda menor al ideal.

La Figura 7 muestra el perfil de una curva de polarización típica para una celda de combustible, en la que se pueden distinguir diferentes regiones que surgen como resultado de una serie de fenómenos limitantes.

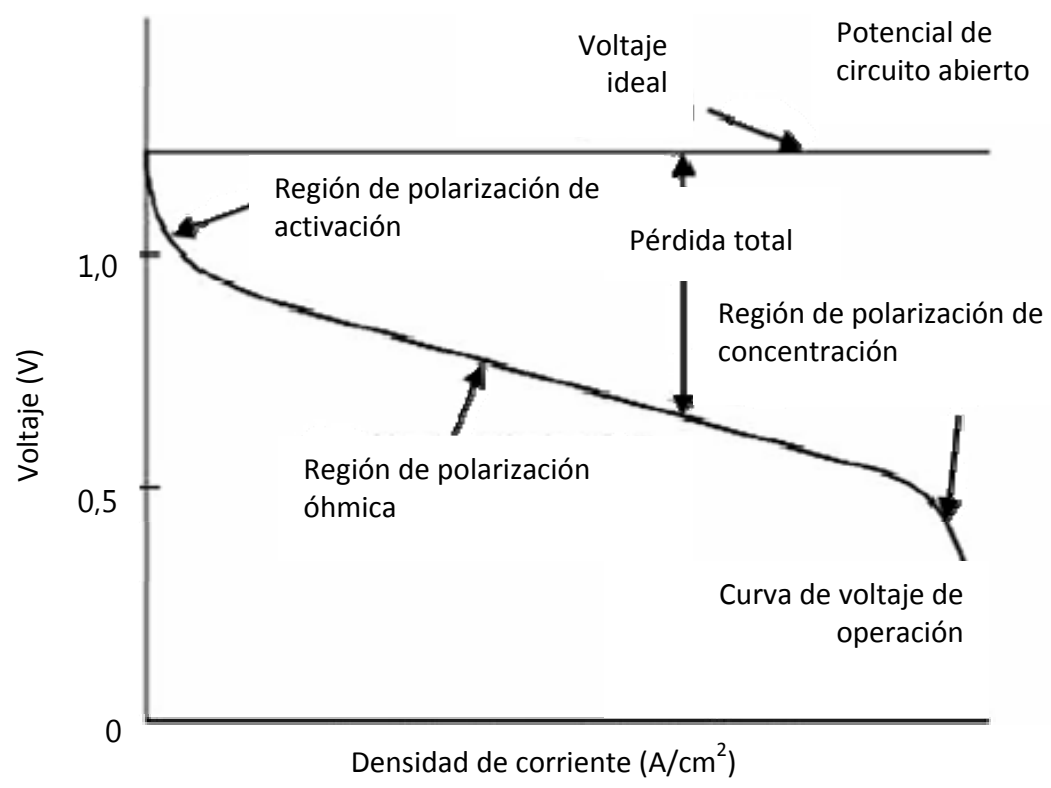

Figura 7. Curva de polarización típica para una celda de combustible [329]. 
A bajas densidades de corriente se encuentra la región de polarización de activación, que corresponde a las pérdidas de energía relacionadas con la transferencia de carga y reacciones químicas asociadas que son función de la naturaleza y estructura superficial del catalizador. Esto se traduce en una caída abrupta del potencial de la celda debido a la cinética de las reacciones electródicas que tienen lugar en la superficie de los electrodos, fundamentalmente por la cinética lenta de la RRO [330]. El desarrollo de catalizadores de mayor actividad electrocatalítica permite disminuir las pérdidas originadas en esta región.

A corrientes intermedias se encuentra la región de polarización óhmica, que representa las pérdidas relacionadas con resistencias al flujo de iones en el electrolito, al flujo de electrones a través del electrodo y a las resistencias de contacto [329]. En esta región la caída de voltaje es proporcional a la densidad de corriente y cumple con la ley de Ohm. La resistencia óhmica depende de la selección de materiales, de la geometría de la celda y de la temperatura. Así, por ejemplo, una membrana de buena conductividad limita estas pérdidas dando una pendiente mucho menor.

A altas densidades de corriente, en la región de polarización de concentración, predominan los efectos por transporte de masa debido a las limitaciones del transporte del gas reactivo hacia los poros de la estructura de la capa difusora de gases y de la capa catalítica, generando una caída drástica de la performance de la celda [331]. De este modo, cuando el aprovisionamiento de los reactivos a los sitios catalíticamente activos no es suficiente, se produce la caída de voltaje dando lugar a esta región característica de las curvas de polarización. La polarización de concentración se origina como resultado de la limitación de las velocidades de transporte de masa de los reactivos y productos que intervienen en la reacción. La aparición de esta zona podría retardarse trabajando en el mejoramiento de la ingeniería de las placas bipolares, la capa difusora de gases y la capa activa, como se describe en capítulos posteriores.

Por lo tanto, el comportamiento en operación de una celda de combustible, queda afectado por la caída óhmica debida a la resistividad del electrolito y a las pérdidas por polarización. Las contribuciones debidas a los sobrepotenciales de activación y de concentración pueden caracterizarse cuantitativamente en términos del conocimiento de la cinética y mecanismos de las reacciones de electrodo [332-334], las predicciones de los modelos para celdas de combustible de electrolito polimérico [302], [335-341] y las predicciones del modelo de película fina/aglomerado inundado para los electrodos de difusión de gas [101], [342-349]. En los estudios anteriormente mencionados y en otros, se ha tratado de explicar los siguientes hechos:

i. el posible cambio de la cinética de la $R R O$ sobre el catalizador $P t / C$ debido a los cambios en el recubrimiento por oxígeno de la superficie de $P t$, manifestándose como un cambio en la pendiente de Tafel en los diagramas de polarización, de $b=2,303(R T / F)$ para potenciales superiores a $0,8 \mathrm{~V}$ a $b=2 \times 2,303(R T / F)$ para potenciales por debajo de 0,8 $\vee$ [306], [307], [350]; 
ii. la existencia de limitaciones difusionales en los canales de gas produciendo efectos pseudos-resistivos a densidades de corriente moderadas y llevando a la aparición de corrientes límites a altas densidades de corriente [302], [351];

iii. la existencia de limitaciones difusionales en los aglomerados inundados de la película catalizadora produciendo la duplicación, con respecto al valor para el catalizador $P t / C$, de las pendientes de Tafel a altas densidades de corriente [302], [336-341], [349];

iv. la existencia de un efecto óhmico limitante en el electrolito dentro de la película catalizadora, que lleva a la duplicación de las pendientes de Tafel a altas densidades de corriente [302], [336-341], [349]; v. la influencia del área superficial efectiva, que usualmente desplaza los efectos limitantes mencionados anteriormente hacia mayores densidades de corriente.

Por otra parte, el producto del potencial y la corriente, para cada punto de la curva, determina la curva de potencia, cuya representación se muestra en la Figura 8 [352].

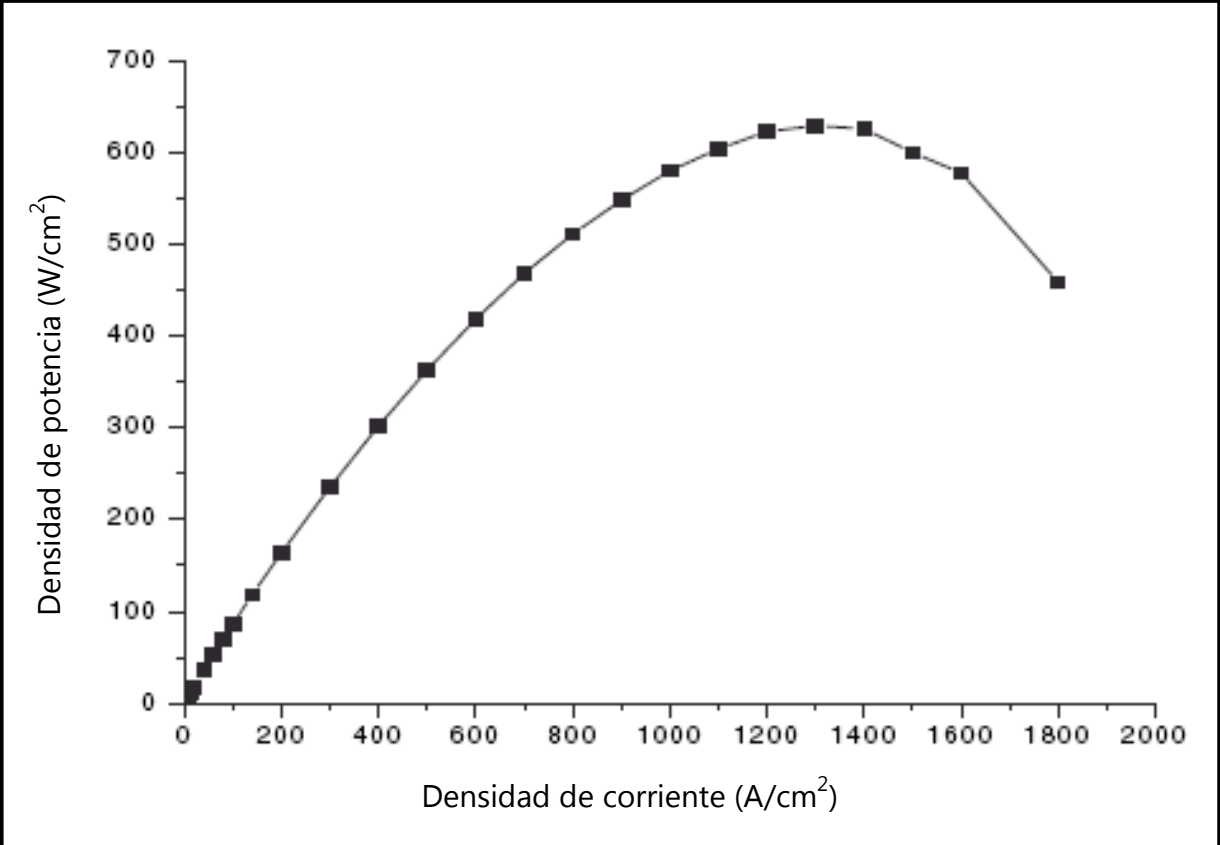

Figura 8. Curva típica de potencia vs. densidad de corriente para una celda de combustible $P E M$ de $\mathrm{H}_{2} / \mathrm{O}_{2}$ operando a $80^{\circ} \mathrm{C}$ y $3 \mathrm{~atm}[352]$.

La potencia aumenta con el aumento de la densidad de corriente hasta alcanzar un máximo, que determina la máxima potencia por unidad de área de la celda de combustible $\left(\mathrm{W} / \mathrm{cm}^{2}\right)$ para las condiciones de operación. El máximo de potencia se debe al compromiso entre el aumento de la potencia al aumentar la corriente y el agotamiento del reactivo al aumentar la corriente I [321], [326], [330], [352]. 


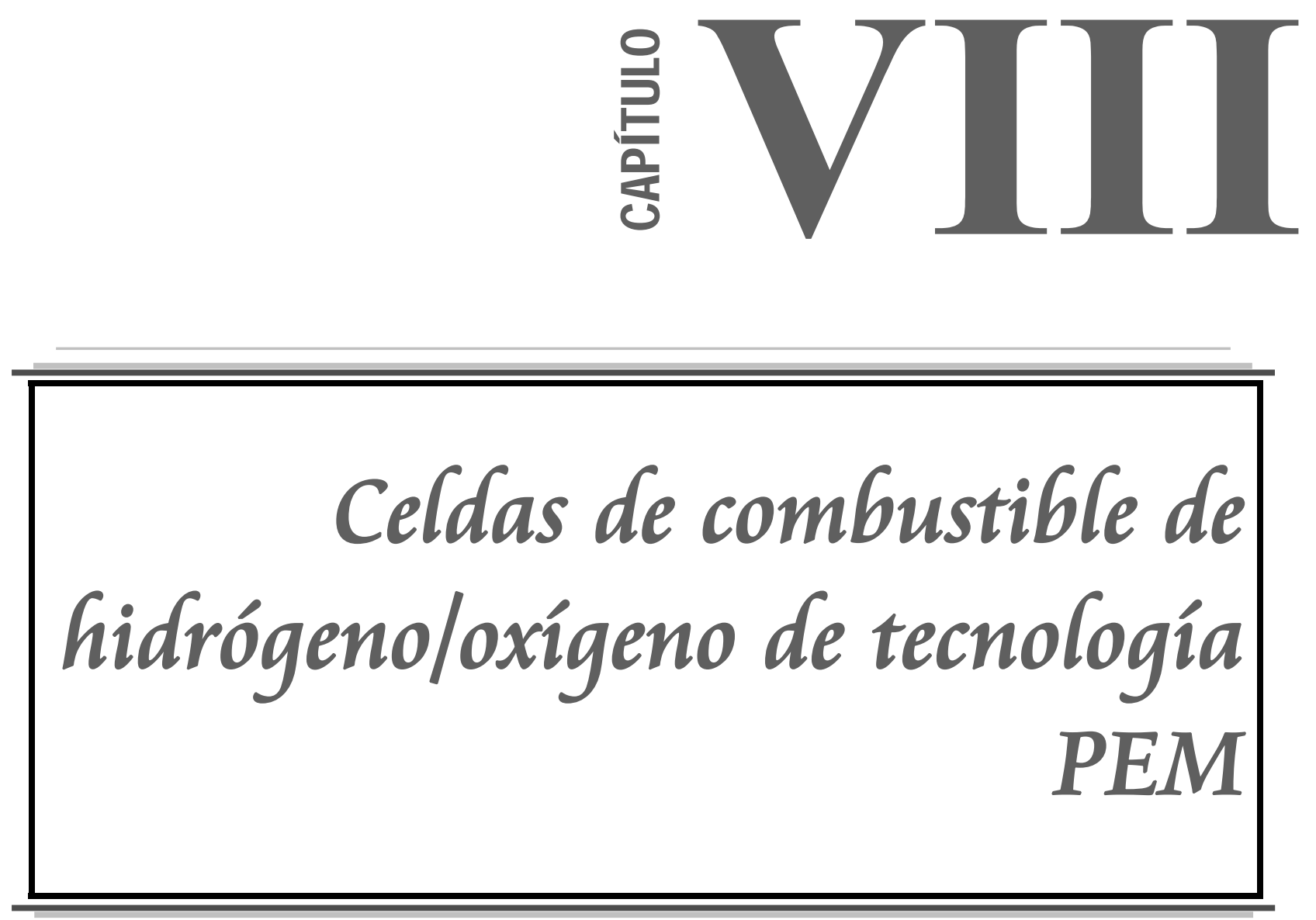


\section{CAPITULO VIII}

\section{Celdas de combustible de hidrógeno/oxígeno de tecnología PEM}

\section{VIII.1. Componentes de una celda PEM}

En este capítulo se hará referencia en particular a las celdas de combustible con tecnología de membrana de intercambio de protones (PEM) que operan a baja temperatura, permitiendo de esta manera la conversión directa de energía química en energía eléctrica. La ausencia de emisiones contaminantes y la alta eficiencia de conversión energética de este tipo de celda han hecho que esta tecnología resulte muy atractiva y pueda ser considerada, actualmente, como una de las alternativas más promisorias para numerosas aplicaciones dentro de las que se destacan las aplicaciones estacionarias y en la industria automotriz.

En la Figura 1 se muestran los componentes básicos de una celda de combustible unitaria de hidrógeno/oxígeno que utiliza la tecnología PEM.

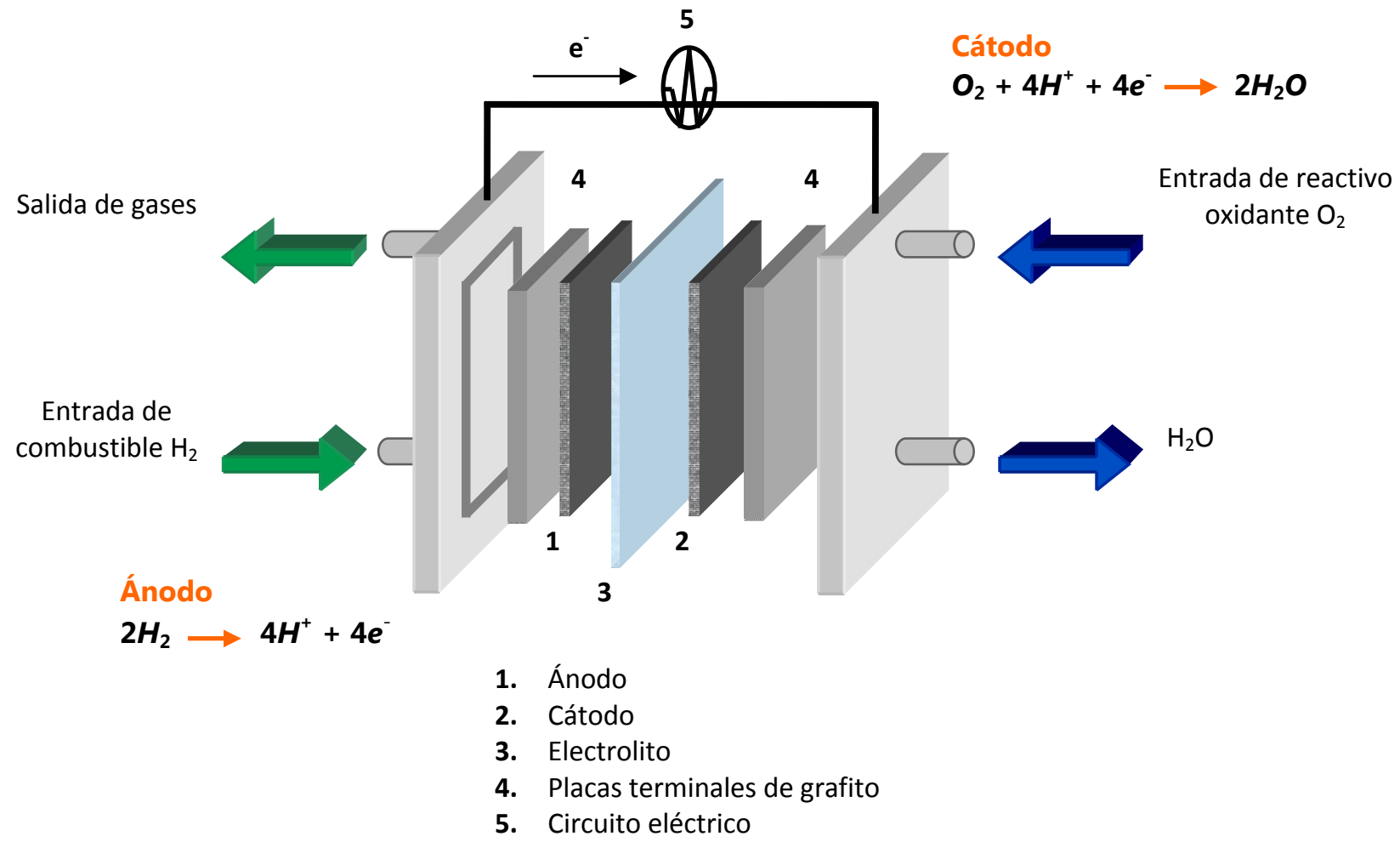

Figura 1. Representación esquemática de una celda de combustible PEM unitaria.

La celda de combustible de membrana de intercambio de protones está conformada por dos electrodos (ánodo y cátodo), separados por un electrolito de membrana polimérica. Cada uno de los electrodos se cubre con una capa catalítica que contiene las partículas de Pt dispersas sobre el soporte 
carbonoso. Los electrodos, el catalizador y la membrana forman juntos el ensamble denominado con el acrónimo MEA ("Membrane-Electrode Assembly"), que constituye el corazón de la celda de combustible (Figura 2). El MEA está estructurado en forma de "sándwich" y suele tener aproximadamente $1 \mathrm{~mm}$ de espesor, dependiendo del tipo de membrana utilizada, la carga de Pt en cada electrodo y la estructura de la capa difusora de gases [323]. Hacia ambos lados del ensamble se encuentran las placas bipolares, cuya descripción y características se darán mas adelante. Si bien el MEA es el componente más importante de la celda de combustible, el diseño de cada uno de los elementos que componen la celda son factores determinantes en su desempeño final. La actividad de los catalizadores, la conductividad de la membrana polimérica, el contenido de agua, el transporte térmico de los gases, etc., gobiernan el rendimiento final del sistema.

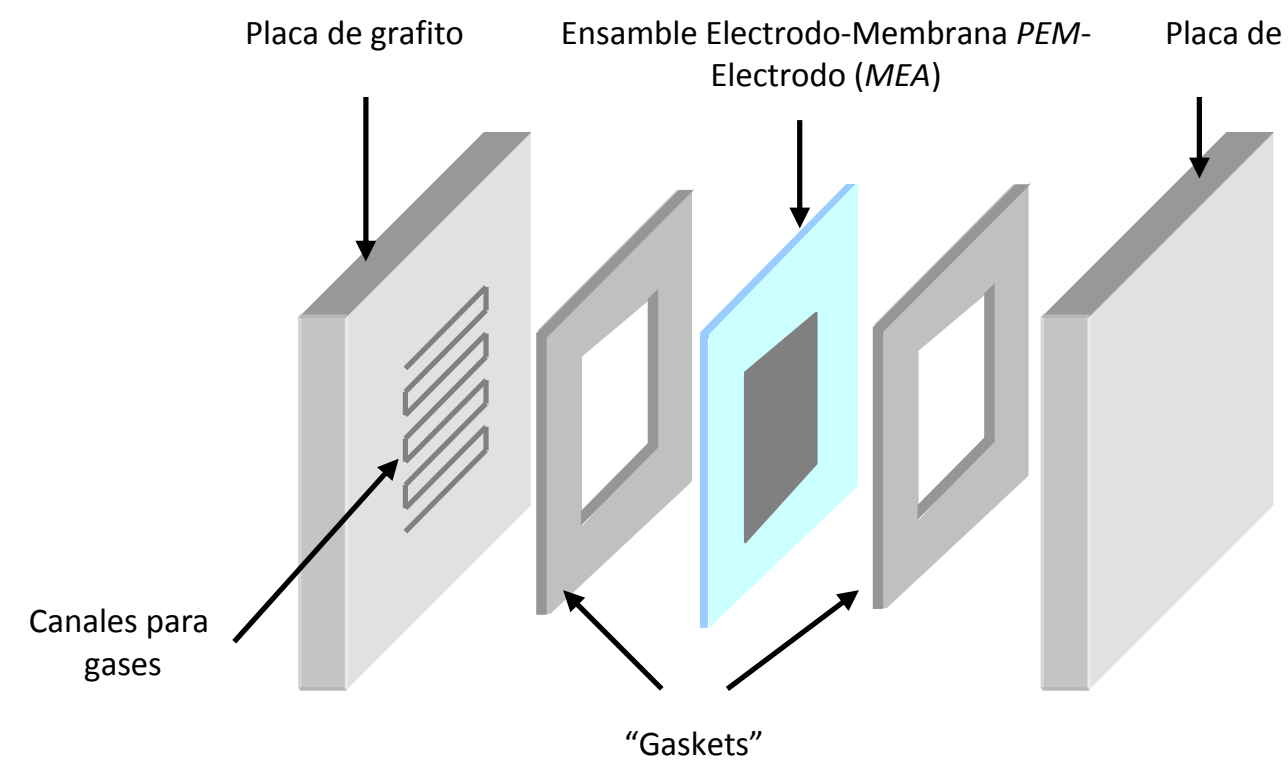

Figura 2. Esquema general de los componentes de una celda de combustible que utiliza la tecnología PEM.

\section{2. Zona de triple fase}

Las partículas de $P t$, el electrolito y el gas reactivo forman una región de tres fases en la cual tiene lugar la reacción electroquímica. El gas reactivo es transportado desde la capa difusora de gases por las regiones hidrofóbicas del electrodo y difunde transversalmente a través del electrolito hasta las partículas del catalizador.

Ambos electrodos, ánodo y cátodo, son estructuras porosas delgadas (del orden de los $10 \mu \mathrm{m}$ ) que consisten en una mezcla de nanopartículas catalizadoras dispersadas en partículas de carbón, que se encuentran en contacto íntimo con el electrolito polimérico.

En la Figura 3 se muestra un esquema idealizado de nanopartículas catalizadoras de $P t$ soportadas sobre partículas de carbón. 


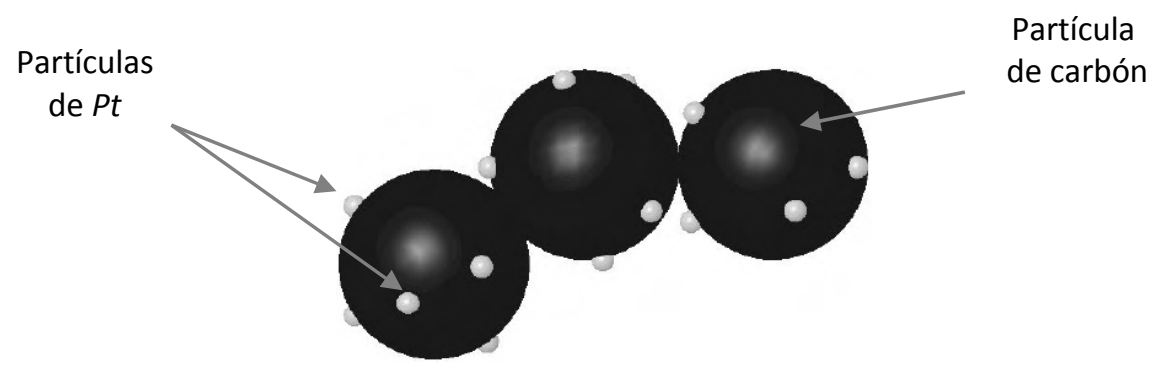

Figura 3. Estructura idealizada de catalizadores de Pt soportados en carbón.

En la Figura 4 se muestra una representación esquemática de la zona trifásica del electrodo integrada por:

a) una fase sólida de carbón que actúa como conductora electrónica al aportar el camino para los electrones,

b) una fase una conductora de iones, el electrolito polimérico, que facilita el camino para que los protones lleguen a los sitios catalíticos,

c) una fase conductora de gases, los poros, que permiten el suministro de los gases a los sitios de reacción.

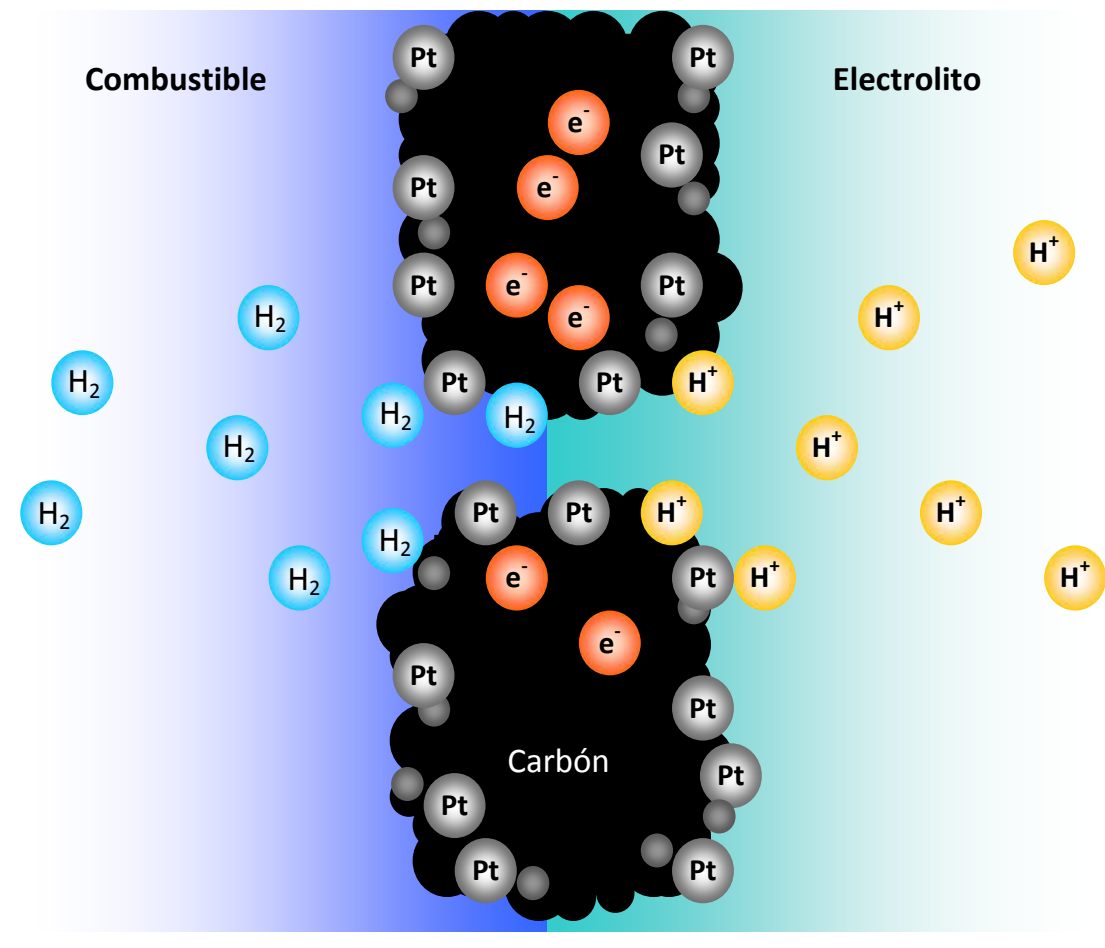

Figura 4. Interfases electroquímicas. Disposición de los materiales en la zona activa del electrodo poroso.

De acuerdo a medidas de porosimetría reportadas por Uchida et al. [353], la estructura porosa del electrodo se caracteriza por una distribución de tamaño de poro bimodal. Se pueden distinguir poros primarios pequeños o microporos de 20 a $40 \mathrm{~nm}$ presentes dentro del aglomerado carbonoso y poros secundarios mas grandes o macroporos de 40 a $200 \mathrm{~nm}$, que forman espacios vacíos entre los 
aglomerados, como se muestra en la Figura 5 [354]. La relación entre los dos tipos de poros depende del contenido de PTFE (politetrafluoroetileno) y del ionómero perfluorosulfónico Nafion.

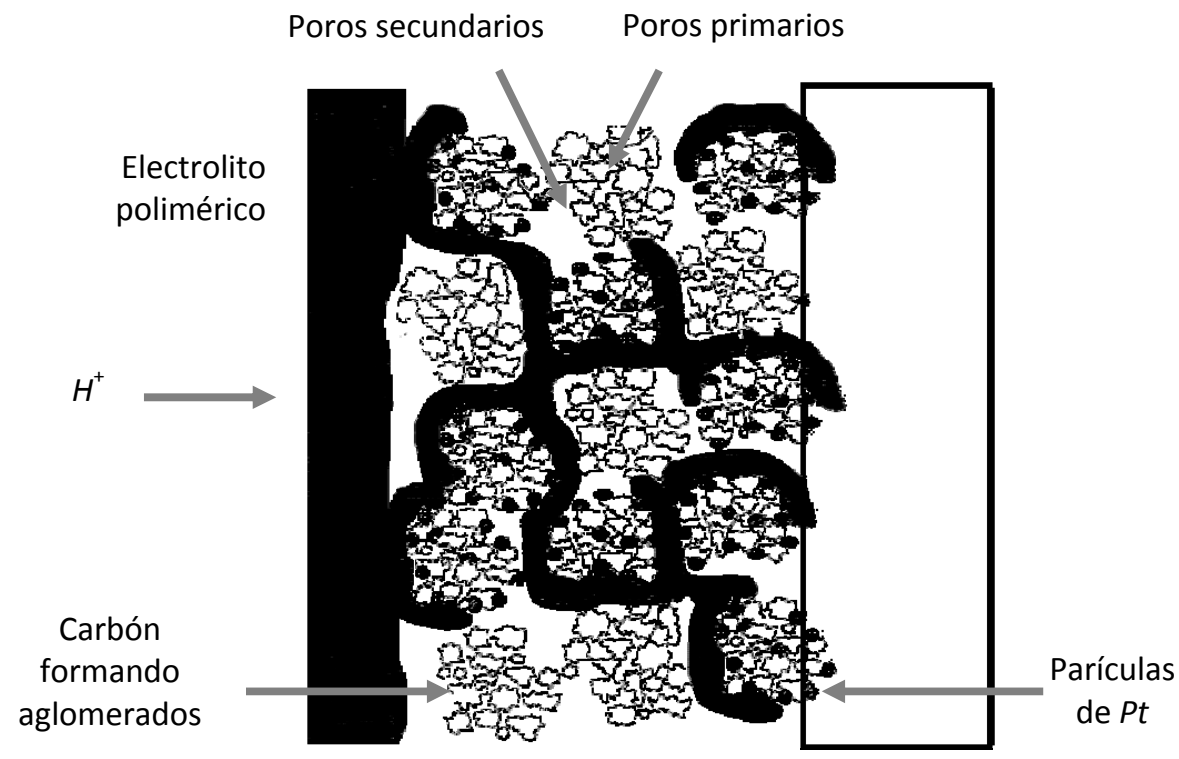

Figura 5. Representación esquemática de la zona de tres fases, exhibiendo las diferentes partes que la constituyen.

\section{VIII.3. Capa difusora de gas (CDG)}

Consiste en una capa porosa que permite el buen reparto de los gases y del agua hacia la capa activa. El material que conforma la capa difusora de gas $(C D G)$ debe ser buen conductor para permitir el movimiento de los electrones entre las placas colectoras y las capas catalíticas. Normalmente, la CDG está formada por material carbonoso, como por ejemplo tela de carbón, que resulta apropiado tanto por sus propiedades conductoras como por su resistencia a la corrosión.

La CDG debe ser además hidrófoba para evitar que los poros que la constituyen sean inundados por el agua que traen los gases humidificados y el agua formada durante la reacción electroquímica. Por ello, por lo general, se elabora a partir de tela de carbón poroso hidrofobizado con PTFE, que es un agente plástico hidrófobo. Se ha demostrado que el tratamiento con PTFE es fundamental para mejorar la evacuación del agua, permitiendo un mejor transporte de masa [317], [355], [356]. Sin embargo, dado que el PTFE aumenta la resistencia óhmica, su empleo no puede ser excesivo. Una posible explicación es que el contenido de PTFE afecta la porosidad de la CDG, de modo que un aumento del contenido de PTFE provoca una disminución de la porosidad total [313]. Se alcanzan valores óptimos con $20 \%$ en volumen de PTFE en la CDG [313], [357], [358].

Para el desarrollo de la $C D G$ se han estudiado varios materiales carbonosos como posibles candidatos, tales como negro de carbono y grafitos, evaluando la mejora en la performance de la celda. Los mejores resultados se obtuvieron utilizando negro de carbono "Shawinigan" en una celda de $\mathrm{H}_{2} /$ aire a una temperatura de operación de $70^{\circ} \mathrm{C}$. El material tiene un alto volumen de poros y un tamaño de 
poro promedio pequeño. El buen comportamiento observado en la celda de combustible se ha atribuido a una disminución de los problemas de transporte de masa, asociados a una mejora en el transporte de agua, según Pasalaqua et al. [320].

En la práctica, para la formación de la $C D G$, una mezcla de polvo de carbono (negro de acetileno "Shawinigan") y teflón se deposita sobre la tela de carbón y se calienta alrededor de $300{ }^{\circ} \mathrm{C}$ obteniéndose una capa de espesor entre 100 y 300 m [321], [323], [359], [360]. El espesor de esta capa debe ser lo más pequeño posible a fin de minimizar la resistencia óhmica y las limitaciones por transporte de masa [317], [361].

Respecto al tamaño medio de poro existen varios trabajos donde se estudia el efecto de la porosidad de los electrodos sobre la performance de la celda de combustible. Se ha encontrado que poros superiores a $60 \mu \mathrm{m}$ dan lugar a la acumulación de gotas de agua, que dificultan el transporte de masa [358].

\section{VIII.4. Capa activa (CA)}

Para favorecer las reacciones electroquímicas que se producen en la celda de combustible se utilizan catalizadores, los cuales participan en la reacción favoreciendo el proceso global pero finalmente no se consumen. El catalizador, generalmente $P t$, disocia la molécula de hidrógeno en dos átomos de hidrógeno, que se adsorben sobre dos sitios del catalizador. Posteriormente, se produce la liberación de un electrón de cada uno de los átomos dando lugar la formación del ión hidrógeno $\mathrm{H}^{+}$.

La estructura de la capa activa o capa catalítica juega un papel importante en las celdas de combustible $P E M$, ya que proporciona el camino para que los gases lleguen a los sitios de catálisis, forma el camino eléctrico que siguen los electrones para salir o entrar en el electrodo y conforma también el camino iónico que necesitan los protones para entrar a la membrana. De este modo, en la capa activa se encuentran presentes las tres interfases antes mencionadas: gas/catalizador, electrolito/catalizador y carbón/catalizador como sitios de reacción. Las partículas de catalizador que se encuentren en la triple fase son aquellas en las que se llevarán a cabo las reacciones electroquímicas y, por lo tanto, a la superficie del conjunto de estas partículas se la conoce como área activa del catalizador. Según datos bibliográficos el espesor de la capa activa suele ser de 1 a $2 \mu \mathrm{m}$ [362], aunque también existen informes sobre espesores que van desde 1 a $50 \mu \mathrm{m}$ [323], [357], [360], [363], [364].

En los estudios iniciales sobre celdas de combustible que operaban a bajas temperaturas se utilizaban altas cargas de $P t$ en los electrodos, del orden de los 25 a $28 \mathrm{mg}$ de $P t / \mathrm{cm}^{2}$ [357], [362] y, como resultado del alto costo del material, esta tecnología era prácticamente inaccesible. A través de los últimos años, el estudio de los materiales de electrodo y el desarrollo de catalizadores soportados han permitido reducir considerablemente la carga de catalizador hasta 0,3-0,4 mg de $P t / \mathrm{cm}^{2}$ y aún 0,05 $\mathrm{mg}$ de $P t / \mathrm{cm}^{2}$, con lo cual el costo del kW es competitivo con el resto de las tecnologías convencionales. Si bien se ha logrado reducir considerablemente la carga de $P t$ utilizado, aún existen pérdidas de tensión 
en una celda en operación que se encuentran en el orden de varios de cientos de $\mathrm{mV}$ a densidades de corrientes típicas de 1-2 A/cm². Gonzalez et al. han estudiado el desempeño de una celda de combustible con electrodos de bajo contenido en $P t$, obteniendo una potencia por unidad de masa de $P t$ del orden de 0,35 kW/g de $P$ t a $0,5 \mathrm{~A} / \mathrm{cm}^{2}$ [365]. En la misma región de densidades de corriente los valores informados por otros autores para altas cantidades de $P t$ son del orden de 0,05 a $0,1 \mathrm{~kW} / \mathrm{g}$ de $P t$ [291-297], con lo cual se ha mostrado que electrodos con bajo contenido de Pt exhiben una mejor utilización del mismo, reportándose mayor generación de potencia por unidad de masa.

En la Tabla I se resumen, en líneas generales, los componentes del MEA y sus principales funciones.

Tabla I. Componentes del MEA y sus principales funciones.

\begin{tabular}{|c|c|}
\hline Componente del MEA & Función \\
\hline Sustrato del ánodo & $\begin{array}{l}\text { Alimentación y distribución del combustible } \\
\text { Conductor de electrones } \\
\text { Remoción del calor de la zona reactiva } \\
\text { Provisión de agua o vapor al electrocatalizador }\end{array}$ \\
\hline Capa de catalizador del ánodo & $\begin{array}{l}\text { Catalizador de la reacción en el ánodo } \\
\text { Conductor de protones a la membrana } \\
\text { Conductor de electrones al sustrato } \\
\text { Transporte de agua }\end{array}$ \\
\hline $\begin{array}{l}\text { Membrana de intercambio de } \\
\text { protones }\end{array}$ & $\begin{array}{l}\text { Conductor de protones } \\
\text { Transporte de agua }\end{array}$ \\
\hline Capa de catalizador del cátodo & $\begin{array}{l}\text { Catalizador de la reacción en el cátodo } \\
\text { Transporte de oxígeno a las zonas de reacción } \\
\text { Conducción de protones desde la membrana a las zonas de reacción } \\
\text { Conducción de electrones desde el sustrato a la zona reactiva } \\
\text { Remoción de agua desde la zona reactiva al sustrato }\end{array}$ \\
\hline Sustrato del cátodo & $\begin{array}{l}\text { Alimentación y distribución del oxidante } \\
\text { Conducción de electrones hacia la zona reactiva } \\
\text { Remoción de calor } \\
\text { Transporte de agua }\end{array}$ \\
\hline
\end{tabular}

\section{VIII.5. Placas monopolares y bipolares}

Las placas monopolares son los elementos a través de los cuales se conducen los gases de entrada a la celda de combustible. Distribuyen el flujo de combustible y oxidante sobre los electrodos, proporcionan rigidez a la celda y pueden incluso actuar como vía de salida de la corriente generada y disipar parte del calor producido.

Físicamente se encuentran a cada lado del MEA, formando una unidad de celda de combustible. Para sistemas que requieren mayores prestaciones se utilizan celdas de combustible acopladas en serie, en cuyo caso las palcas están maquinadas con los canales de ambos lados y se denominan placas bipolares. De este modo, las placas de grafito pueden estar separadas conectadas a electrodos 
individuales, o ser placas únicas conectadas cada una a dos electrodos adyacentes formando placas bipolares.

El diseño de las placas es un aspecto crítico e influye marcadamente en la eficiencia de la celda. Se han ensayado geometrías muy variadas para la distribución de los gases: de puntos, cuadrados, de serpentín, espirales, en cascada, en bloques serie-paralelo, zigzag, etc. [366-369] y se ha evaluado también el efecto de la configuración de los canales sobre la performance global en celdas de combustible PEM [370]. Se han realizado varios estudios mediante simulaciones numéricas sobre la interacción de la capa difusora y el flujo circulando por una placa bipolar de canal serpenteante [371], e incluso se han realizado estudios experimentales [372]. Estudios comparativos de diversas topologías con sus ventajas e inconvenientes pueden encontrarse en varios artículos de revisión [373-375].

Debido a sus características, estas placas representan una parte muy importante del costo total de una celda de combustible. Entre las funciones de las placas de grafito se pueden mencionar:

- Suministro de gases reactivos, tanto el combustible al ánodo como el oxígeno al cátodo.

- Conexión eléctrica entre celdas individuales y en el caso de un "stack" de celdas de combustible cada placa está unida por un lado al ánodo de la celda y por el otro al cátodo de la siguiente.

- Evacuación eficaz del agua y calor acumulados en el cátodo, de manera que no se inunde y perjudique el rendimiento de la celda.

- Resistencia mecánica para el conjunto de la celda, garantizando una fuerza de compresión entre los elementos que la conforman, de modo que se logre eliminar las posibles fugas de los gases que circulan en el MEA.

Estas funciones delimitan el tipo de material apto para ser utilizado en las placas. Existen además ciertos requisitos relacionados con el ambiente en el cual operan las celdas de combustible, así como también restricciones respecto a la manejabilidad y espacio máximo que pueden ocupar, por lo cual se torna aún más estrecha la variedad de materiales aptos para esta aplicación. En base a estas consideraciones, se puede decir que un buen material para utilizar como placa, debe cumplir con las siguientes especificaciones:

- Alta conductividad eléctrica, ya que de este modo se minimiza el sobrepotencial óhmico de la celda.

- Alta impermeabilidad a los reactivos, para impedir la difusión de los gases en su seno. Debido al pequeño tamaño molecular del hidrógeno, muchas veces es necesario realizar procesos de electrodeposición sobre las placas o baños químicos en materiales porosos como grafito [376], [377].

- Fácilmente maquinable.

- Alta resistencia estructural.

- Elevada resistencia a la corrosión.

- Baja resistencia térmica.

- Liviano. 
- Bajo costo.

- Elevada conductividad térmica, ya que debe evacuarse el calor que se produce en la celda cuando se genera alta densidad de corriente.

El grafito es el material que más se ha utilizado debido a sus buenas propiedades frente a la corrosión y su buena conductividad eléctrica. Sin embargo, no se trata de un buen material para mecanizar, es muy frágil y es poroso. Estos problemas se intentan superar aumentando el grosor del material, lo cual se traduce en volúmenes y costos que exceden los esperados para las placas de grafito. De ahí, el interés actual en desarrollar placas con nuevos materiales, tales como metales (aluminio, titanio, aleación acero inoxidable, níquel) y materiales compuestos (carbono-polímero) [378-380].

\section{VIII.6. Colectores de corriente}

El ensamble electrodo-membrana PEM-electrodo y las placas de grafito son colocados entre placas colectoras de corriente, generalmente de material metálico, encargadas de conducir los electrones generados en la celda de combustible para llevarlos a la carga externa. A su vez los colectores de corriente permiten mantener la estructura mecánica de la celda.

\section{VIII.7. Membrana electrolítica}

La membrana electrolítica sirve tanto para separar los gases de alimentación como para actuar como conductora de protones. Actúa de barrera física para prevenir la mezcla directa del combustible y del gas oxidante.

Comercialmente existe gran variedad de membranas disponibles en el mercado, de diferentes espesores y propiedades. Probablemente las más utilizadas para aplicaciones en celdas de combustible de baja temperatura son las membranas Nafion $^{\circledR}$ de DuPont, que se encuentran dentro de las más estudiadas y empleadas como electrolito para celdas de combustible PEM.

Las membranas Nafion $^{\circledR}$ están formadas por una estructura básica de politetrafluoretileno (PTFE) que es químicamente inerte en ambientes oxidantes y reductores. El Nafion ${ }^{\circledR}$ es un polímero sintético de la misma familia que el teflón, al que se le han añadido grupos perfluorovinil éter con grupos sulfonados, es decir que contiene el grupo funcional $\mathrm{HSO}_{3}{ }^{-}$. La estructura del $\mathrm{Nafion}^{\circledR}$ está integrada por una fase conformada por cadenas de fluorocarbono $(C-F)$, en cada una de las cuales hay un grupo sulfónico $\left(\mathrm{HSO}_{3}^{-}\right)$que es fijo y permanece ligado a la misma. Esto confiere a la membrana una mayor durabilidad y evita que se degrade fácilmente, permitiendo su utilización en las celdas de combustible por largos períodos de funcionamiento.

En la Figura 6 se muestra la estructura de la membrana Nafion ${ }^{\circledR}$ donde se puede observar claramente el esqueleto polimérico con grupos funcionales ácidos adjuntos a la cadena de polímero. 


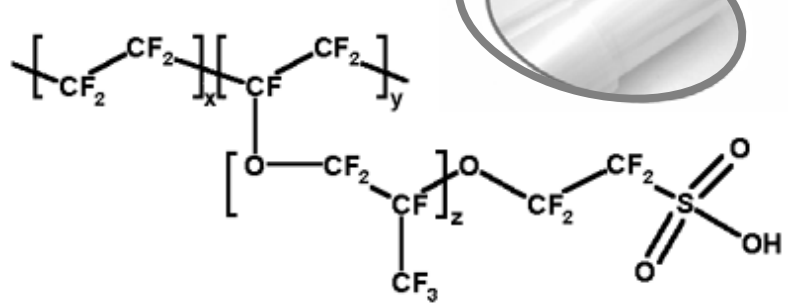

Figura 6. Estructura de la membrana Nafion ${ }^{\circledR}$.

En la Tabla II se muestran ciertas propiedades para los diferentes tipos de membranas Nafion ${ }^{\circledR}$, clasificadas por su espesor, que se encuentran comercialmente. Las membranas más delgadas garantizan mayor conductividad de iones, pero son menos resistentes mecánicamente.

Tabla II. Diferentes tipos de membranas Nafion ${ }^{\circledR}$ de DuPont.

\begin{tabular}{|c|c|c|c|}
\hline Propiedades & $\mathbf{1 1 7}$ & $\mathbf{1 1 5}$ & $\mathbf{1 1 2}$ \\
\hline \hline Espesor $(\mu)$ & 183 & 127 & 51 \\
\hline Tensión de ruptura (MPa) & 43 & 43 & 32 \\
\hline Alargamiento hasta ruptura (\%) & 225 & 225 & 343 \\
\hline Contenido en agua (\%) & 5 & 5 & $5 \pm 3$ \\
\hline \hline Absorción de agua (\%) & 38 & 38 & $50 \pm 5$ \\
\hline \hline Peso base $\left(\mathrm{g} / \mathrm{m}^{2}\right)$ & 360 & 250 & 100 \\
\hline
\end{tabular}

Las membranas para aplicaciones en celdas de combustible PEM deben cumplir básicamente las siguientes funciones:

- Conducción protónica, permitiendo solamente la conducción de iones positivos.

- Aislantes de electrones.

- Separadoras de los gases oxidante y combustible, por lo cual deben ser impermeables a las sustancias reactivas presentes en cada uno de los electrodos.

- Estables (química, térmica y mecánicamente) bajo las condiciones de uso.

En general, las membranas típicas conductoras de protones para aplicación en celdas de combustible constituyen un sistema de dos fases. Existe una fase principal polimérica hidrofóbica que cumple funciones de esqueleto de la membrana y da consistencia, y una segunda fase hidrofílica, dispersa en la primera, que contiene los grupos iónicos y es la responsable de la conductividad protónica.

La Figura 7 muestra una representación esquemática de las fases presentes en la membrana electrolítica conductora de protones. 


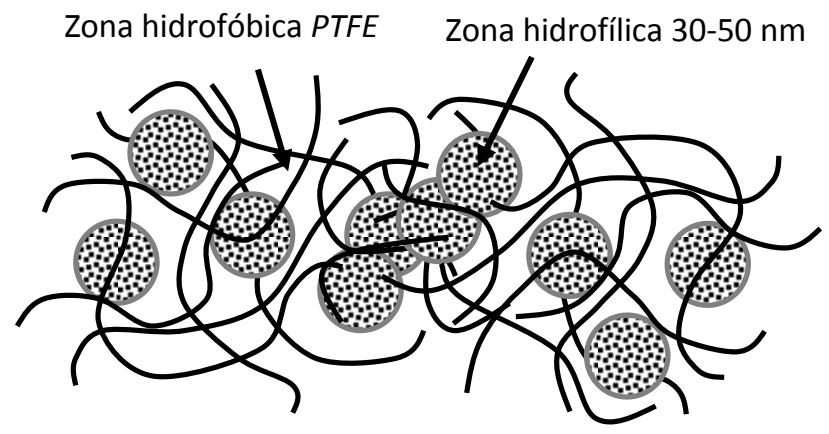

Figura 7. Esquema que muestra las dos fases existentes en la membrana: la hidrofóbica y la hidrofílica.

Para explicar el mecanismo de conductividad protónica del Nafion ${ }^{\circledR}$ se han propuesto varios modelos, aunque ninguno de ellos puede explicar totalmente el comportamiento. Sin embargo, el modelo de tres fases propuesto por Yeager et al. [381] parece el más apropiado, ya que cada una de las zonas definidas han sido detectadas en pruebas experimentales, por lo cual sería un modelo que no está tan alejado de la realidad. En la Figura 8 se muestra una representación conceptual de este modelo.

Las regiones que se distinguen según el modelo de Yeager son:

(A) Una zona relativa a la red generada por los fluorocarbonos, que da consistencia estructural a la membrana y es responsable de sus propiedades mecánicas.

(B) Una zona intermedia con algunos iones y moléculas sueltas.

(C) Una zona de aglomeraciones ("clusters") de iones y moléculas formadas por interacciones electroestáticas, responsables de la conductividad protónica de la membrana. Dentro de estos "clusters" tienden a adherirse también los iones $\mathrm{HSO}_{3}^{-}$que siguen ligados a las extensiones de la red de fluorocarbonos [zona (A)]. Los iones $\mathrm{H}^{+}$forman iones mayores y más estables con moléculas de agua $\left[\mathrm{H}^{+}\right.$ $\left(\mathrm{H}_{2} \mathrm{O}\right)_{n}$ ] y van "saltando" entre grupos $\mathrm{HSO}_{3}$. Con el aumento de humedad las aglomeraciones [zona (C)] se van haciendo más grandes y menos numerosas, ya que se van uniendo entre sí, ofreciendo canales de conducción para los protones.

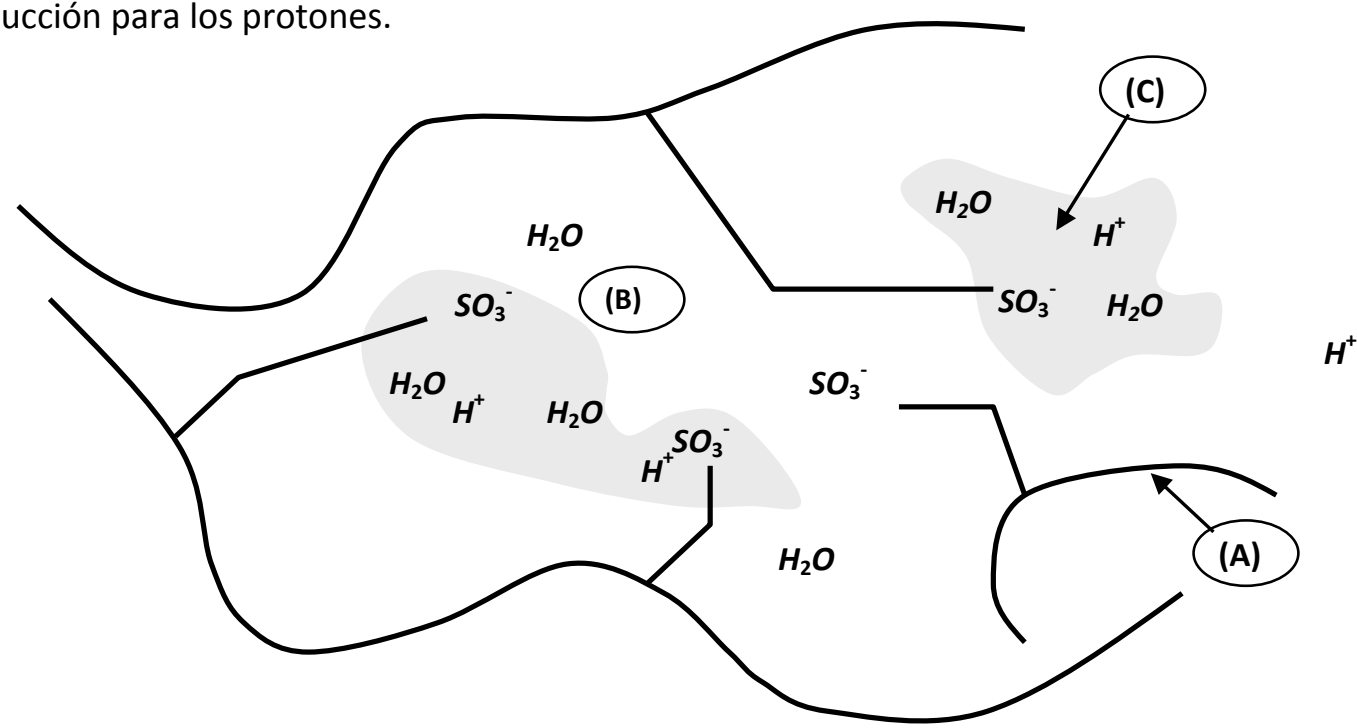

Figura 8. Esquema conceptual del modelo de tres fases de Yeager para explicar la conductividad protónica del Nafion $^{\circledR}$. 
El contenido de humedad es una característica determinante para las membranas Nafion ${ }^{\circledR}$. Si la membrana está muy seca la resistencia aumenta, dando como resultado pérdida de eficiencia energética de la celda, debido a que los protones no pueden fluir a través de ella con facilidad. Por otro lado, el exceso de humedad provoca inundación, lo cual también acarrea pérdida de performance de la celda, al bloquear los sitios activos e impedir el acceso de los gases de reacción. Por lo tanto, en celdas de combustible que utilizan este polímero como electrolito conductor de protones, la adecuada gestión del agua juega un rol muy importante en su desempeño.

Los efectos de la humidificación sobre la conductividad iónica de las membranas Nafion $^{\circledR}$ a diferentes temperaturas han sido informados por varios autores. En particular, se pueden mencionar los trabajos de Sone et al. [382]. Se ha demostrado también que la conductividad iónica de las membranas resulta afectada significativamente por la humidificación y depende fuertemente de su grado de hidratación [339]. La conductividad de las membranas Nafion ${ }^{\circledR}$ alcanza en las mejores condiciones los $10^{-1} \mathrm{~S} / \mathrm{cm}$ y sólo da buenos resultados para alta humedad relativa y hasta temperaturas en el entorno de los $80 \stackrel{\circ}{ }$, por lo que resulta necesario asegurar el correcto mantenimiento del grado de humedad en la membrana. Así por ejemplo, a $80{ }^{\circ} \mathrm{C}$ y con humidificación apropiada, la membrana Nafion ${ }^{\circledR} 117$ exhibe una alta conductividad iónica de aproximadamente $0,17 \mathrm{~S} / \mathrm{cm}$ [383]. Esta necesidad del control constante de la hidratación de la membrana muchas veces introduce complejidades en los sistemas de celdas de combustible, al tener que desarrollar un sistema de gestión de agua específico.

\section{VIII.8. Stack de celdas de combustible}

Para obtener mayores prestaciones de potencia las celdas de combustible se acoplan formando arreglos o "stacks", que son conjuntos de celdas unitarias monopolares conectadas entre sí. Estos módulos multicelda pueden estar conectados en serie o en paralelo. La conexión en paralelo sólo es posible cuando los electrodos tienen una alta conductividad electrónica. Este es el caso de algunos electrodos de celdas alcalinas que utilizan una malla metálica (generalmente de níquel) como soporte. El grafito, comúnmente utilizado en las celdas PEM, no tiene conductividad suficientemente alta como para permitir la conexión entre celdas en paralelo, por lo que suelen conectarse en serie. El arreglo permite cubrir las necesidades de corriente, potencial y potencia requeridos para la operación de un sistema de energía. En los "stacks" de celdas de combustible existen elementos llamados placas bipolares que actúan como contacto eléctrico entre el ánodo de un ensamble ánodo-electrolito-cátodo (MEA) y el cátodo del siguiente [384].

En la Figura 9 se presenta esquemáticamente el principio de operación de un arreglo o "stack" de celdas de combustible. 


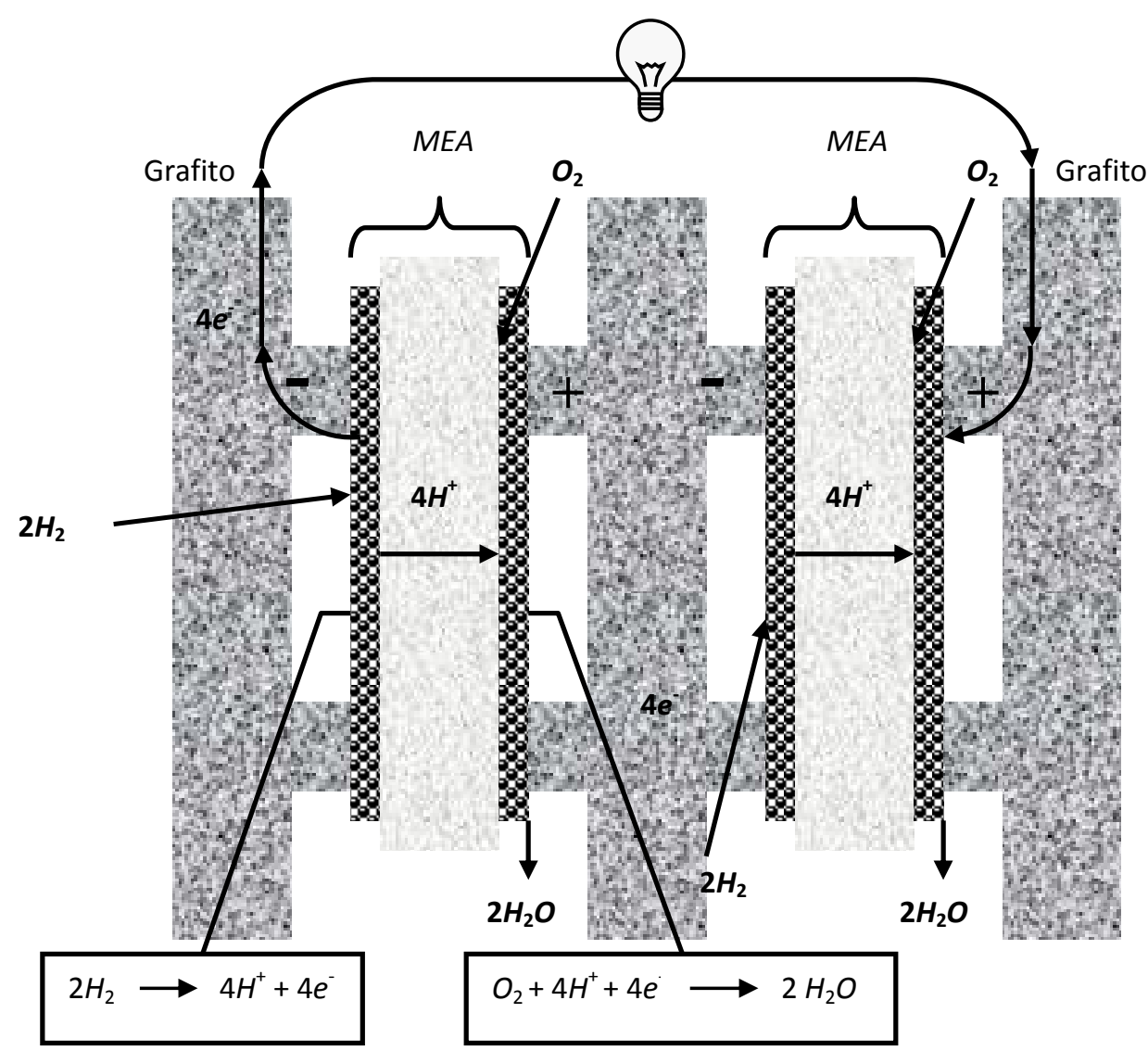

Figura 9. Principio de operación de un arreglo o "stack" de celdas de combustible.

Sobre el primer ánodo se produce la oxidación electroquímica del hidrógeno molecular a protones y electrones. Los protones fluyen a través de la membrana de conducción protónica hacia el primer cátodo. Mientras tanto los electrones fluyen por un circuito externo hacia el último cátodo del arreglo. Los protones generados en el último ánodo y transportados a través de la membrana, junto con los electrones del primer ánodo y el oxígeno molecular reaccionan electroquímicamente para formar agua en el último cátodo. Los electrones liberados en el último ánodo fluyen a través del plato bipolar de grafito hacia el penúltimo cátodo, donde reaccionan con los protones del penúltimo ánodo y el oxígeno para producir también agua y liberar calor. Este proceso se repite hasta que los electrones liberados en el segundo ánodo llegan al primer cátodo cerrando el ciclo en todo el arreglo. 



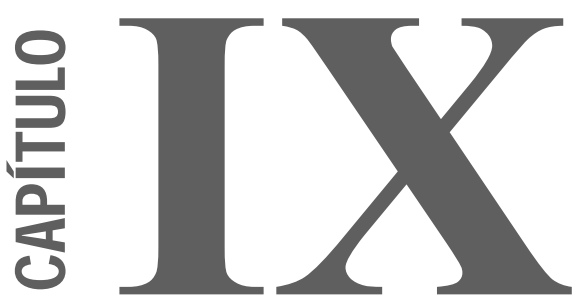

\section{Diseño, construcción y} caracterización de una celda de combustible PEM prototipo de $\mathrm{H}_{2} / \mathrm{O}_{2}$ 


\section{CAPÍTULO IX}

\section{Diseño, construcción y caracterización de una celda de combustible PEM prototipo de $\mathrm{H}_{2} / \mathrm{O}_{2}$}

En esta sección se presenta la preparación, fabricación y caracterización de los distintos componentes de celdas de combustible que utilizan la tecnología de membrana de intercambio de protones (PEM), como así también el diseño y construcción de una celda prototipo de $\mathrm{H}_{2} / \mathrm{O}_{2}$. Los aspectos que se incluyen son:

1. Fabricación de electrodos porosos de difusión de gas de alta actividad catalítica utilizando nanopartículas de Pt policristalinas. Descripción de la metodología empleada para la obtención de los electrodos.

2. Tratamiento de la membrana polimérica conductora de protones para su limpieza e hidratación.

3. Construcción de ensambles electrodo-membrana PEM-electrodo (MEA) a partir de los electrodos porosos desarrollados.

4. Diseño y construcción de un prototipo de celda de combustible unitaria de hidrógeno/oxígeno que opera a baja temperatura.

5. Descripción de la técnica de caracterización voltamperométrica utilizada para la evaluación "in situ" de los electrodos de celdas de combustible de hidrógeno/oxígeno.

6. Estudios de caracterización voltamperométricos "in situ" de los electrodos de la celda prototipo unitaria desarrollada en el laboratorio.

7. Evaluación de la resistencia de la celda de combustible unitaria construida con electrodos porosos de difusión de gas con incorporación de nanopartículas de Pt policristalinas.

\section{IX.1. Fabricación de electrodos porosos de difusión de gas}

Los electrodos porosos de difusión de gas son estructuras complejas y deben cumplir simultáneamente varios requisitos, tales como distribuir uniformemente los gases reactivos en el electrodo y lograr que su concentración sea alta en la interfase triple catalizador/electrolito/gas.

Los electrodos de difusión de gas desarrollados en esta tesis están compuestos por un soporte (tela de grafito), sobre el que se aplica una película compuesta por una mezcla de negro de acetileno "Shawinigan" y politetrafluoroetileno (PTFE), que constituye la capa difusora de gases (CDG). La finalidad principal de la $C D G$ es distribuir uniformemente el gas reactivo sobre el catalizador, tal como se mencionó en capítulos anteriores. Seguidamente se aplica, sobre la $C D G$, una película catalítica que contiene el catalizador de Pt dispersado en carbón Vulcan XC-72 y que conforma la capa activa (CA). De 
esta manera, se obtienen los electrodos porosos de difusión de gas que forman el ánodo y el cátodo de la celda de combustible unitaria.

A continuación se detallan cada una de las etapas y los pasos que se siguieron para la fabricación de los electrodos porosos de difusión de gas, con los que posteriormente se construyen los ensambles MEA.

\section{IX.1.a. Preparación de la capa difusora de gases (CDG)}

Una cantidad conocida de negro de acetileno "Shawinigan" se dispersa en alcohol isopropílico, se humedece con agua destilada y se adiciona suspensión de PTFE (DuPont ${ }^{\circledR}$, TE-3893), que actúa como agente ligante o aglomerante (Ver propiedades del PTFE en la Tabla I).

Tabla I. Propiedades de la dispersión de Teflón ${ }^{\circledR}$ PTFE Grado TE-3893 de DuPont ${ }^{\text {TM }}$.

\begin{tabular}{|c|c|c|c|}
\hline Propiedades & $\begin{array}{l}\text { Método de } \\
\text { testeo }\end{array}$ & Unidad & Valor típico \\
\hline \multicolumn{4}{|l|}{ Generales } \\
\hline $\begin{array}{l}\text { Contenido de sólidos (\% en peso de } \\
\text { PTFE) }\end{array}$ & ISO 12086 & $\%$ & 60 \\
\hline Densidad de la dispersión (60% sólidos) & ISO 8962 & $\mathrm{~g} / \mathrm{cm}^{3}$ & 1,5 \\
\hline $\begin{array}{l}\text { Peso seco de resina ( } 60 \% \text { sólidos)/litro } \\
\text { de dispersión }\end{array}$ & & g & 900 \\
\hline Color & & & blanco \\
\hline $\begin{array}{l}\text { Tamaño de partícula de la dispersión, } \\
\text { diámetro promedio }\end{array}$ & ISO 13321 & $\mu \mathrm{m}$ & 0,210 \\
\hline pH de la dispersión & ISO 976 & & 10,0 \\
\hline Viscosidad método Brookfield (a $25^{\circ} \mathrm{C}$ ) & ISO 2555 & $\mathrm{cP}$ & 25 \\
\hline $\begin{array}{l}\text { Gravedad específica estándar de la resina } \\
\text { sinterizada }\end{array}$ & ISO 12086 & & 2,220 \\
\hline Mecánicas ${ }^{(2)}$ & ISO 12086 & $\%$ & 400 \\
\hline \multicolumn{4}{|l|}{ Máxima elongación } \\
\hline \multicolumn{4}{|l|}{ Eléctricas $^{(2)}$} \\
\hline Permitividad relativa (100 Hz a $600 \mathrm{MHz}$ ) & IEC 250 & & 2,1 \\
\hline Factor de disipación, tg $\delta(1$ kHz) & IEC 250 & & $<0,0003$ \\
\hline $\begin{array}{l}\text { Fuerza dieléctrica (espesor del film 0,05 } \\
\mathrm{mm} \text { ) }\end{array}$ & IEC 243 & $\mathrm{kV} / \mathrm{mm}$ & $>120$ \\
\hline Resistencia por volumen & IEC 93 & Wm & 1013 \\
\hline
\end{tabular}




\begin{tabular}{|c|c|c|}
\hline Térmicas ${ }^{(2)}$ & & \\
\hline Fundido inicial, temperatura de pico & ${ }^{\circ} \mathrm{C}$ & 337 \\
\hline Fundido segundo, temperatura de pico & ${ }^{\circ} \mathrm{C}$ & 327 \\
\hline Fragilidad a la temperatura & ${ }^{\circ} \mathrm{C}$ & $<-75$ \\
\hline Temperatura de servicio continua (máx.) & ${ }^{\circ} \mathrm{C}$ & 260 \\
\hline \multicolumn{3}{|l|}{ Otras propiedades } \\
\hline Absorción de agua & $\%$ & $<0,01$ \\
\hline Resistencia química y a la intemperie & & excelente \\
\hline
\end{tabular}

(1) Norma ASTM.

(2) Pruebas basadas en resultados obtenidos sobre películas finas moldeadas.

La mezcla obtenida se agita en un baño ultrasónico hasta formar una tinta homogénea, que se mantiene en constante agitación hasta el momento de utilizarla para la formación de la CDG. Como soporte de la CDG se utiliza tela de grafito ("carbon cloth" CPW-300 de Textron), que se caracteriza por ser un material de alta conductividad eléctrica. Sobre ambos lados de la tela de grafito se distribuye uniformemente la tinta preparada mediante una técnica de pincelado. Se coloca sobre una placa calefaccionada y se deja secar. A continuación se rola una vez y el procedimiento se repite hasta alcanzar una carga de la tinta preparada de $4 \mathrm{mg} / \mathrm{cm}^{2}$. El conjunto (tela de carbón + tinta formadora de la $C D G$ ) se calienta a $300^{\circ} \mathrm{C}$ en un horno durante 15 minutos y se vuelve a rolar. El efecto combinado de la macro y la microporosidad, característico de los electrodos porosos obtenidos mediante este procedimiento, permite una mejor distribución y alcance de los gases reactivos a los sitios de reacción.

Se debe tener en cuenta que la relación carbón/PTFE tiene gran incidencia en esta etapa. Una baja cantidad de PTFE no otorga la adecuada solidez a la estructura del electrodo, en tanto que cantidades excesivas pueden obstruir los poros, debido a la naturaleza polimérica del PTFE, impidiendo el transporte de los gases a través de la matriz estructural del electrodo.

\section{IX.1.b. Preparación de la capa activa (CA)}

Se prepara una suspensión homogénea con las cantidades deseada del catalizador de $P t$ soportado sobre carbón Vulcan XC-72 y de la solución de Nafion ${ }^{\circledR}$ (marca Aldrich) al 5 \% en peso en forma protonada, en $20 \%$ de agua/alcoholes alifáticos (Ver propiedades de la solución de $\mathrm{Nafion}^{\circledR}$ en la Tabla II). Se utiliza como catalizador Pt al $20 \%$ en la proporción de $1 \mathrm{mg}$ de $P t / \mathrm{cm}^{2}$. La incorporación de la solución de $\mathrm{Nafion}^{\circledR}$ en la $\mathrm{CA}$ facilita la óptima utilización del catalizador, ya que permite el contacto íntimo con la membrana PEM. De esta manera, aumenta el área de contacto entre la membrana y las 
nanopartículas de Pt [320], [385] y se logra obtener mayor continuidad entre el catalizador y el electrolito (membrana polimérica).

La suspensión preparada se mantiene en un baño ultrasónico durante 2 horas. Luego se deposita cuantitativamente sobre uno de los lados de la $C D G$, mediante un procedimiento de pincelado. Una vez seco el electrodo poroso de difusión de gas, que ya tiene la $C D G$ y la $C A$, se impregna con la solución de Nafion ${ }^{\circledR}$ mediante la técnica de pincelado, a fin de que actúe como ligante y facilite el transporte de los cationes desde la superficie del electrodo poroso hasta la membrana de intercambio protónico. Posteriormente se deja secar el electrodo a una temperatura de $100{ }^{\circ} \mathrm{C}$ durante 5 minutos. Se obtienen así electrodos porosos de gran área superficial, que favorecen la reacción heterogénea de conversión de energía.

Tabla II. Composición y propiedades de la solución de Nafion ${ }^{\circledR}$ ("Perfluorinated ion-exchange resin") al $5 \%$ wt

\begin{tabular}{|c|c|c|c|}
\hline Composición & Unidad & Valor & \\
\hline Nafion ${ }^{\circledR}$ en polvo & $\%$ & $\leq 10$ & \\
\hline Agua & $\%$ & $\geq 15 \leq 20$ & \\
\hline 1-Propanol & $\%$ & $\geq 16 \leq 30$ & \\
\hline 2-Propanol & $\%$ & $\geq 15 \leq 30$ & \\
\hline $\begin{array}{l}\text { Mezcla de éteres y otros compuestos } \\
\text { volátiles }\end{array}$ & $\%$ & $\leq 5$ & \\
\hline \multicolumn{4}{|l|}{ Propiedades fisicoquímicas } \\
\hline Estado & & & Líquido \\
\hline Punto de ebullición (1) & ${ }^{\circ} \mathrm{C}$ & 94 & \\
\hline Densidad & $\mathrm{g} / \mathrm{cm}^{3}$ & 0,874 & \\
\hline Punto de destello ${ }^{(2)}$ & ${ }^{\circ} \mathrm{C}$ & 19,44 & \\
\hline Índice de refracción & & 1,379 & \\
\hline
\end{tabular}

(1) $\mathrm{A} 760 \mathrm{mmHg}$

(2) Método de copa cerrada

La impregnación del electrodo con solución la solución de Nafion ${ }^{\circledR}$ sobre la CA de $P t / C$ facilita también la transferencia de los protones generados por la reacción electroquímica, dentro de la membrana polimérica [386]. Se ha mencionado en el capítulo anterior que los electrodos porosos de difusión de gas con solución de Nafion $^{\circledR}$ incorporado y que contienen baja carga de catalizador (0,15 a 0,35 mg de $P t / \mathrm{cm}^{2}$ ), presentan el mismo comportamiento para las reacciones de electrorreducción de oxígeno y electrooxidación de hidrógeno que los electrodos con alta carga de catalizador [290], [299], [353], [387-391]. De ahí, la importancia de la incorporación de la solución de Nafion $^{\circledR}$ a los electrodos 
porosos, que se consigue pincelando el ionómero sobre la $C A$. Se debe tener presente que el incremento en la carga de Nafion ${ }^{\circledR}$ aumenta la conductividad, pero también genera limitaciones óhmicas y de transporte de masa, por efectos de bloqueo del acceso de los gases a los sitios activos. Esto es producido por un aumento del espesor de la capa de Nafion ${ }^{\circledR}$ dentro de los poros de los electrodos. En la bibliografía se encuentran varios trabajos de la influencia del contenido de $\mathrm{Nafion}^{\circledR}$ en los electrodos porosos de celdas de combustible sobre su comportamiento [18-21].

La presencia de una capa de Nafion ${ }^{\circledR}$ que recubra las partículas de Pt en la $C A$ es de gran importancia para construir electrodos de difusión de gas altamente activos [395], [396] que favorezcan el contacto de las tres fases: gas, electrolito (membrana Nafion) y catalizador, necesarios para que tenga lugar la reacción electroquímica. La solución de Nafion ${ }^{\circledR}$ sobre la $C A$ también contribuye a retener la humedad y evitar la deshidratación de la membrana, que ocurre principalmente a altas corrientes. Es por ello que, a fin de lograr un buen desempeño de la celda de combustible, es necesario contar con cantidades óptimas de Nafion $^{\circledR}$ en la CA. Por lo general, la cantidad de Nafion ${ }^{\circledR}$ se expresa en $\mathrm{mg} / \mathrm{cm}^{2}$, es decir, en peso seco de $\mathrm{Nafion}^{\circledR}$ por unidad de área geométrica del electrodo, o bien como porcentaje en peso de Nafion (wt \%) es decir, en peso seco del ionómero dividido el peso total del catalizador Pt/C y del Nafion ${ }^{\circledR}$, multiplicado por 100 [300].

Para calcular el contenido óptimo de Nafion ${ }^{\circledR}$, Antolini et al. [363] sugieren utilizar una ecuación empírica:

$$
\text { Contenido óptimo de Nafion }\left(\mathrm{mg} / \mathrm{cm}^{2}\right)=56 * \frac{L_{P t}}{P_{P t}}
$$

donde $L_{P t}$ es la carga de $P t\left(\mathrm{mg}\right.$ de $\left.P t / \mathrm{cm}^{2}\right)$ y $P_{P t}$ el porcentaje en peso de $P t$ soportado sobre carbón. Pasalaqua et al. [397] han encontrado valores óptimos de Nafion del $33 \mathrm{wt} \%$, al igual que Gamburzev et al. [398], en tanto que Qui et al. [399] han reportado contenidos óptimos del $30 \mathrm{wt} \%$. Otros autores mencionan que el rango óptimo para el contenido de Nafion $^{\circledR}$ estaría entre 27 y $40 \%$ dependiendo de la naturaleza de los electrodos, es decir, del Pt y el soporte carbonoso y de los métodos empleados en la preparación de las tintas [306]. Se debe tener presente que pueden llegar a surgir inconvenientes si se utilizan cantidades fijas de Nafion $^{\circledR}$ sin considerar la carga de Pt utilizada. Así por ejemplo, para electrodos con una dada carga de $P t$, si el contenido de Nafion $^{\circledR}$ que recubre las nanopartículas de $P t$ es muy alto, el espesor de la capa de $\mathrm{Nafion}^{\circledR}$ será muy grande y provocaría alta resistencia por transporte de masa; en tanto que con bajas cantidades de Nafion ${ }^{\circledR}$ el espesor de la película formada sería delgado y la cantidad de Nafion $^{\circledR}$ resultaría insuficiente para establecer un buen contacto trifásico [363]. Por ello es importante considerar el espesor óptimo de la película de Nafion $^{\circledR}$, a fin de lograr una buena performance de la celda de combustible. Watanabe et al. [400] han realizado experiencias sobre electrodos de disco rotante estudiando el efecto del $\mathrm{Nafion}^{\circledR}$ sobre las reacciones de oxidación de hidrógeno y de reducción de oxígeno, determinando un espesor de 0,2 $\mu \mathrm{m}$ de Nafion como óptimo. Para 
valores superiores la velocidad de difusión de los gases reactivos es el factor limitante en la performance de la celda.

De acuerdo a numerosos trabajos de investigación, el contenido de Nafion ${ }^{\circledR}$ necesario para lograr una alta performance de la celda de combustible depende de la carga de $P t$, tal como lo demostrado por Sasikumar et al. [393], quienes estudiaron la dependencia del contenido de Nafion $^{\circledR}$ en la $C A$ sobre el comportamiento de celdas. Estos autores han encontrado una mejora en la performance de la celda con el aumento del contenido de Nafion $^{\circledR}$ hasta el $40 \%$, que luego disminuye con el aumento del contenido del ionómero. Este comportamiento se debería, en principio, al bloqueo de los sitios catalíticos que reducen la permeabilidad del gas e incrementan la polarización por transporte de masa [393]. Por otro lado, la cantidad óptima de Nafion ${ }^{\circledR}$ depende del método de fabricación de los electrodos [399]. Así por ejemplo, para electrodos con diferente carga de $P t\left(0,5 ; 0,25\right.$ y $0,1 \mathrm{mg}$ de $\left.P t / \mathrm{cm}^{2}\right)$, la mejor performance se observó con cargas de $\mathrm{Nafion}^{\circledR}$ de 20, 40 y 50 wt \%, respectivamente [393].

\section{IX.2. Tratamiento de la membrana de intercambio de protones}

Previo al armado de los ensambles, la membrana se sometió a un tratamiento de inmersión en diferentes medios a $80^{\circ} \mathrm{C}$, durante 1 hora en cada uno, de acuerdo a la siguiente secuencia:

i. En agua destilada, para hidratar la membrana y disolver los contaminantes superficiales.

ii. En un baño de $\mathrm{H}_{2} \mathrm{O}_{2} 10$ volúmenes, para remover las impurezas orgánicas presentes en la superficie de la membrana.

iii. En agua tridestilada, para enjuagar la solución de peróxido de hidrógeno repitiendo esta etapa una vez más.

iv. En solución de $\mathrm{H}_{2} \mathrm{SO}_{4} 1 \mathrm{M}$, para remover los contaminantes metálicos presentes en forma iónica y sulfatada en la superficie de la membrana.

v. En agua tridestilada, dos veces, para enjuagar y remover las trazas de ácido sulfúrico de la superficie de la membrana, etapa en la cual a la vez se hidrata la membrana.

La membrana una vez purificada se guarda sumergida en agua tridestilada, en un recipiente cerrado hasta su utilización para la construcción de los ensambles.

Mediante este tratamiento se consigue no sólo purificar la membrana removiendo los contaminantes superficiales sino también enriquecerla con iones $\mathrm{H}^{+}$, a fin de lograr que tenga un óptimo desempeño como conductora de protones.

\section{IX.3. Construcción de ensambles electrodo-membrana PEM- electrodo}

Los ensambles electrodo-membrana PEM-electrodo (MEA) se construyeron en base a los electrodos porosos de difusión de gas desarrollados. A continuación se mencionan los pasos que se 
siguieron para la construcción de los ensambles MEA para una celda de combustible de hidrógeno/oxígeno prototipo, con los cuales se logró una íntima unión de los tres componentes esenciales de la celda, esto es: ánodo, membrana polimérica (electrolito) y cátodo.

Los electrodos de difusión de gas, ánodo y cátodo, son colocados simétricamente con la membrana Nafion 117 entre ellos, de modo que la CA queda en contacto íntimo con la membrana electrolítica. El conjunto de los electrodos así dispuestos en la membrana Nafion 117 se prensa en caliente durante cierto tiempo, controlando la temperatura y la presión mediante dispositivos especiales acoplados a la prensa. Este método de prensado en caliente permitir obtener un electrodo compacto y mecánicamente resistente, con un buen contacto entre la CA de los electrodos (ánodo y cátodo) y la membrana electrolítica.

Las condiciones de prensado en caliente utilizadas fueron producto de una extensa búsqueda bibliográfica y experimental. Se consideraron distintos valores de presión, temperatura y tiempo de prensado, a fin de encontrar un equilibrio óptimo entre resistencia mecánica y porosidad de los electrodos para una adecuada performance de la celda. Finalmente, para los ensambles desarrollados, se utilizaron las siguientes condiciones de trabajo: presión $70 \mathrm{~kg} / \mathrm{cm}^{2}$, temperatura de la prensa $155^{\circ} \mathrm{C}$ y tiempo de prensado 5 minutos. De este modo se obtuvo un ensamble electrodo-membrana PEMelectrodo que exhibió un buen contacto entre sus componentes con una resistencia de contacto despreciable. En esta etapa de prensado resulta determinante la cantidad de PTFE utilizada en la formación de la CDG ya que, durante el prensado en caliente, el PTFE puede dilatarse acumulando tensiones que, al momento de desmontar el electrodo de la prensa, se pueden liberar destruyéndolo.

Si bien el proceso de ensamblado es relativamente sencillo, existen ciertos aspectos que deben considerarse a fin de lograr electrodos con estructura mecánicamente resistente y con superficie homogénea y sin fisuras. Se debe tener en cuenta que el procedimiento de preparación de los ensambles no es una cuestión solamente tecnológica. Algunas de las dificultades que surgen son problemas de ciencia básica. Así, por ejemplo, la preparación de la capa catalíticamente activa implica la obtención de una suspensión con características reológicas óptimas a fin de lograr que el catalizador pueda estar lo más uniformemente distribuido sobre la $C D G$, lo que se logra mediante la técnica de pincelado utilizada. La superación de estos problemas son el resultado del trabajo experimental en base a en sucesivas pruebas que han permitido encontrar las condiciones óptimas para cada etapa de la elaboración de los electrodos porosos de difusión de gas y de los ensambles para la celda de combustible.

En la Figura 1 se muestra esquemáticamente la estructura de los ensambles electrodo-membrana PEM-electrodo obtenidos, siguiendo los pasos anteriormente mencionados. Se ilustra en el centro la membrana PEM y hacia ambos lados los electrodos porosos constituidos por la CA en contacto con la membrana de Nafion 117 y la CDG. Se muestra también el camino seguido por lo gases a través de la estructura porosa del electrodo de difusión de gas. 


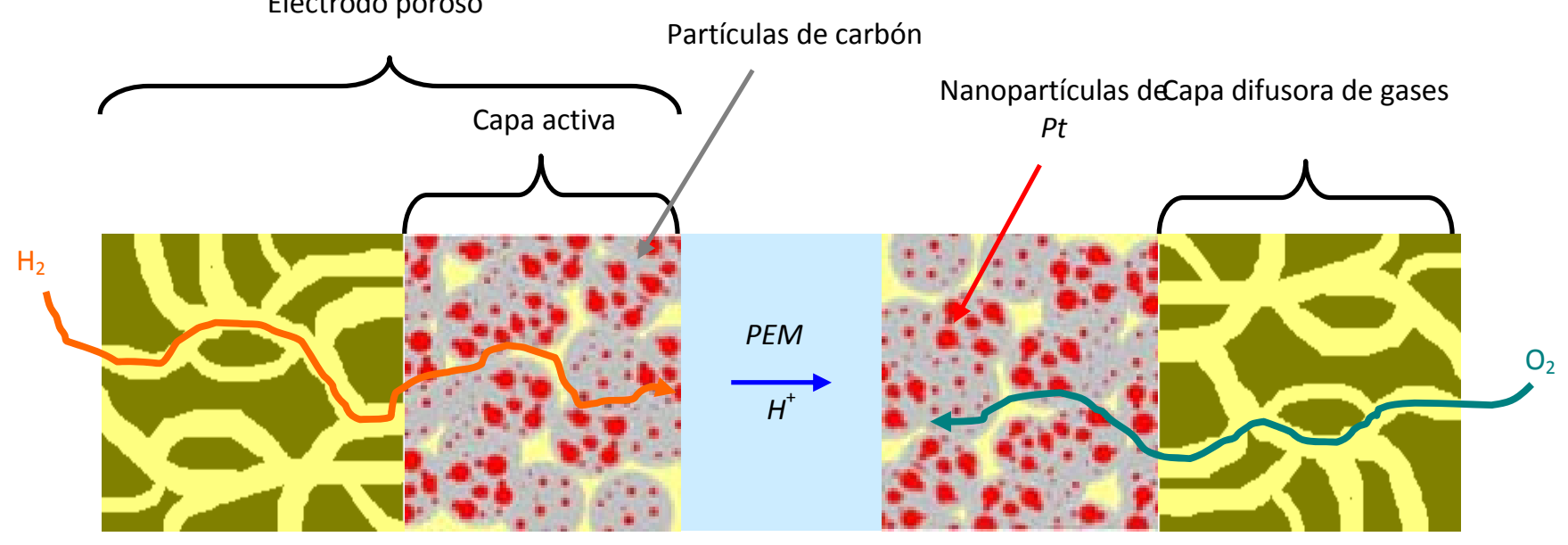

Figura 1. Esquema general de los ensambles electrodo-membrana PEM-electrodo de la celda de combustible de hidrógeno/oxígeno.

La Figura 2 muestra el ensamble electrodo-membrana PEM-electrodo construido para las pruebas en la celda unitaria prototipo, indicando sus dimensiones. También se muestran los "gaskets", que son juntas de silicona que tienen como función compensar la diferencia de espesor que existe entre los electrodos porosos (ánodo+cátodo) y la membrana de Nafion 117. A su vez, estos elementos siliconados actúan como espaciadores, y evitan la compresión indebida del sistema membrana/electrodo cuando el conjunto es comprimido entre las placas de gafito. Por otro lado, los "gaskets" también evitan la mezcla de los gases reactivos [327].

"Gaskets"

Membrana de Nafion

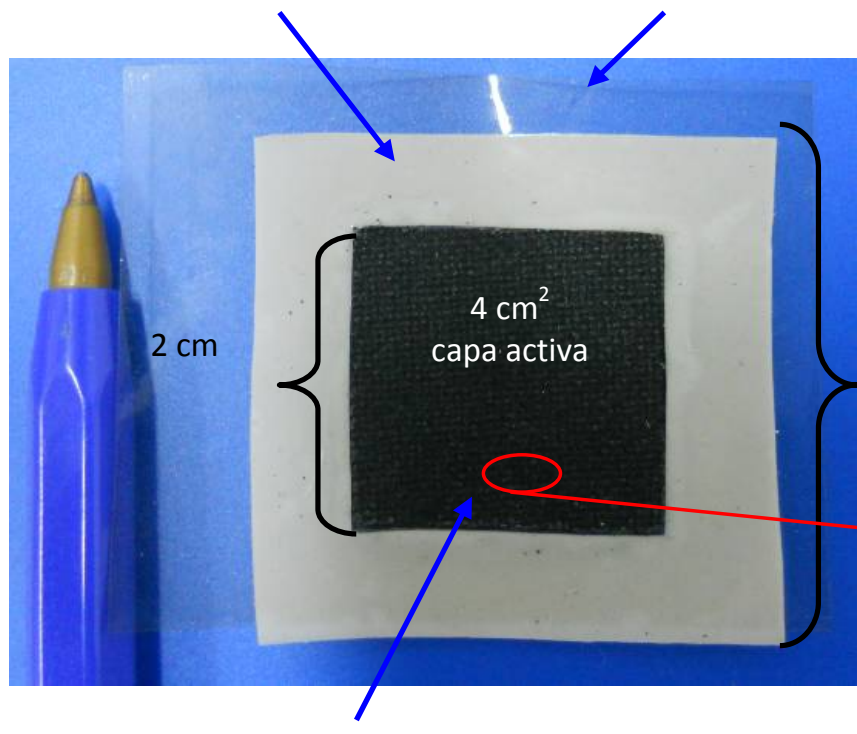

Electrodo poroso: Pt sobre tela de carbón

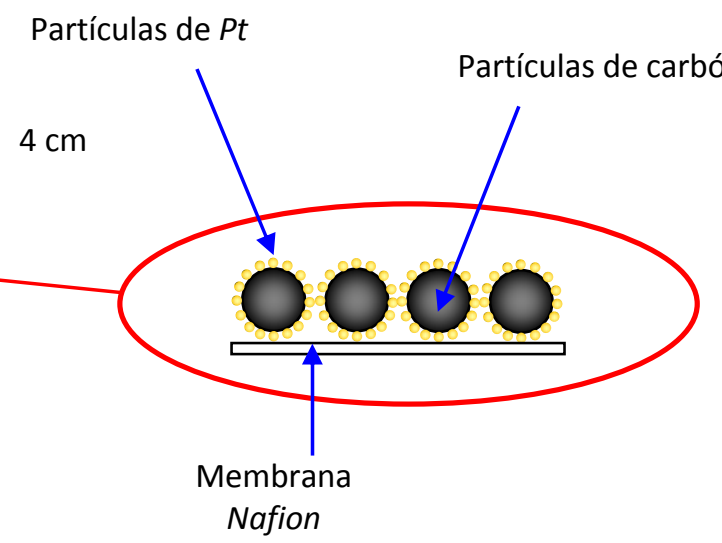

Figura 2. Conjunto ensamble electrodo-membrana PEM-electrodo. 
En la Figura 3 se muestra una representación esquemática de los pasos seguidos para la obtención del ensamble MEA.
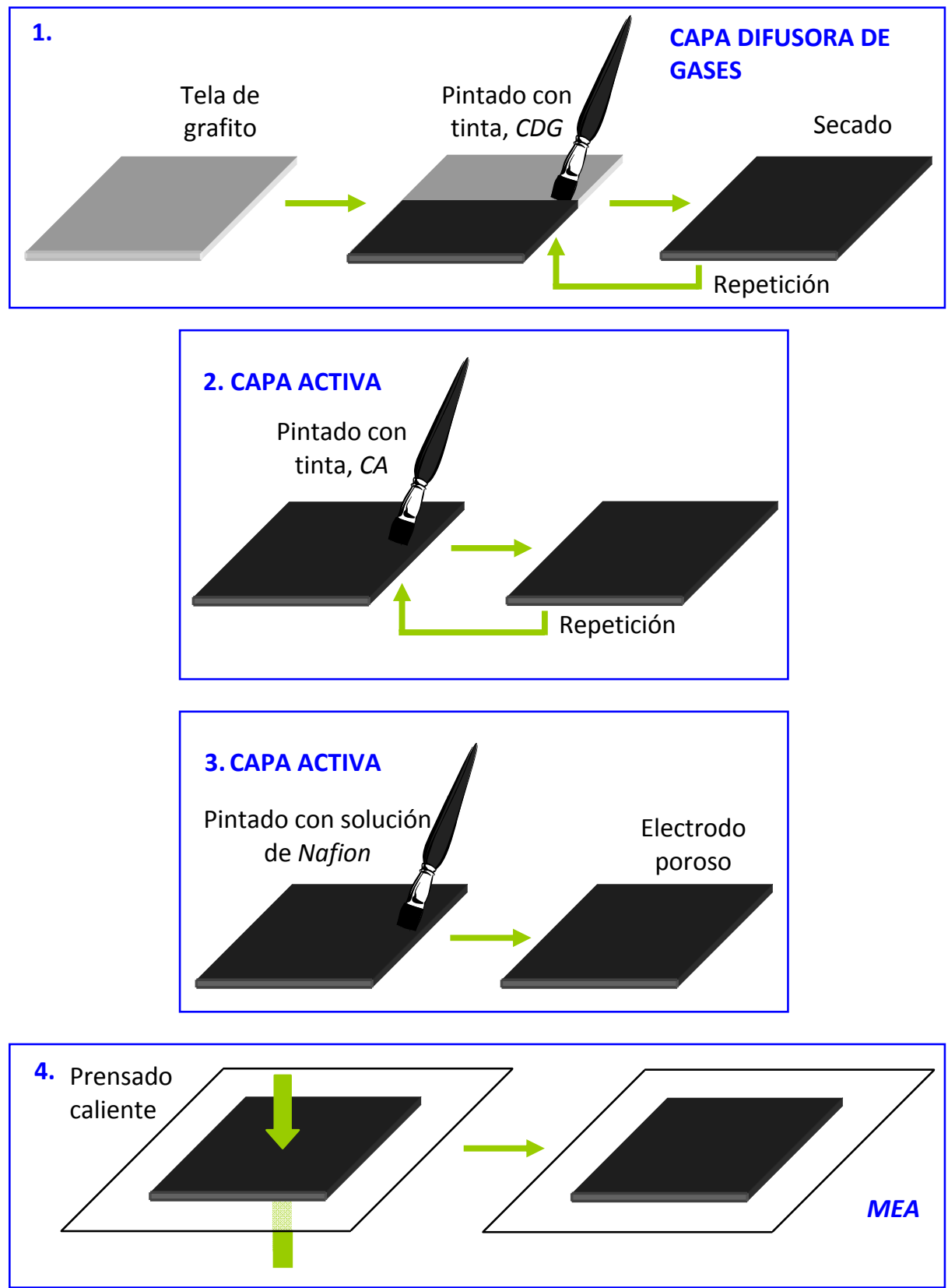

Figura 3. Esquema de la fabricación de electrodos porosos de difusión de gas y construcción de los ensambles MEA.

En la Figura 4 se resume la secuencia completa del proceso de fabricación de los electrodos porosos de difusión de gas y la construcción de los ensambles electrodo-membrana PEM-electrodo (MEA). 


\section{Formación de la CDG}

Negro de acetileno y PTFE en alcohol isopropílico

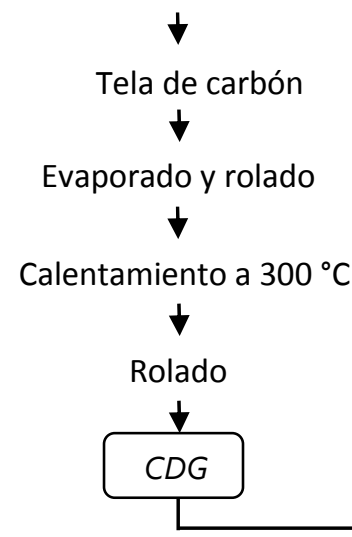

2. Formación de la $C A$

Pt soportado sobre carbón Solución de Nafion al $5 \%$

Agitación de la tinta en ultrasonido

Pintado con la tinta sobre la CDG

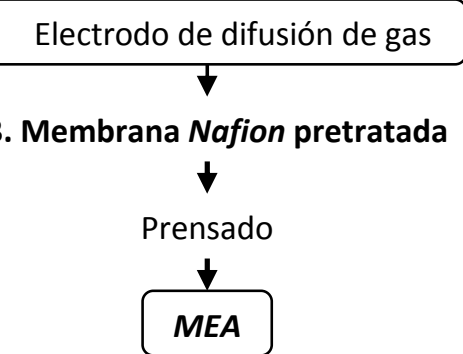

Figura 4. Secuencia de pasos seguidos para la fabricación de electrodos porosos de difusión de gas y construcción de los ensambles electrodo-membrana PEM-electrodo.

IX.4. Diseño y construcción de un prototipo de celda de combustible unitaria de $\mathrm{H}_{2} / \mathrm{O}_{2}$ de baja temperatura

El prototipo de celda unitaria PEM de hidrógeno/oxígeno construido durante el desarrollo de esta tesis se muestra en la Figura 5. Está integrado por dos placas de grafito (a), en las cuales se tornearon orificios para la entrada y salida de gases, canales para flujo de gases siguiendo la geometría serpentín y perforaciones para colocar termocuplas. El ensamble electrodo-membrana PEM-electrodo desarrollado (b), se coloca entre las placas de grafito junto con los "gaskets" de silicona. Seguidamente, hacia ambos lados de las placas de grafito, se encuentran placas de cobre que actúan como colectoras de corriente (c). Separados por un material de teflón aislante (d), se ubican placas de aluminio (e), las cuales mediante tornillos ( $f$ ) ajustados con un torquímetro, permiten el cierre completo de la celda. La celda de combustible prototipo se calefacciona mediante resistencias (g), que se encuentran a ambos lados de la celda en contacto íntimo con las placas de aluminio. Las resistencias calefactoras se controlan mediante un software específico de la unidad de testeo, que permite seleccionar la temperatura de operación de la celda, $\mathrm{T}_{\text {celda }}$ mediante un comando computacional y mantenerla constante con un error inferior a $\pm 0,2^{\circ} \mathrm{C}$. El sensor de temperatura se encuentra ubicado estratégicamente en la celda, de modo que el software sea capaz de identificar rápidamente las variaciones de temperatura de la celda y responder inmediatamente. De este modo, actúa encendiendo o apagando las resistencias acopladas a la celda, para mantener la temperatura en el intervalo de operación deseado. 


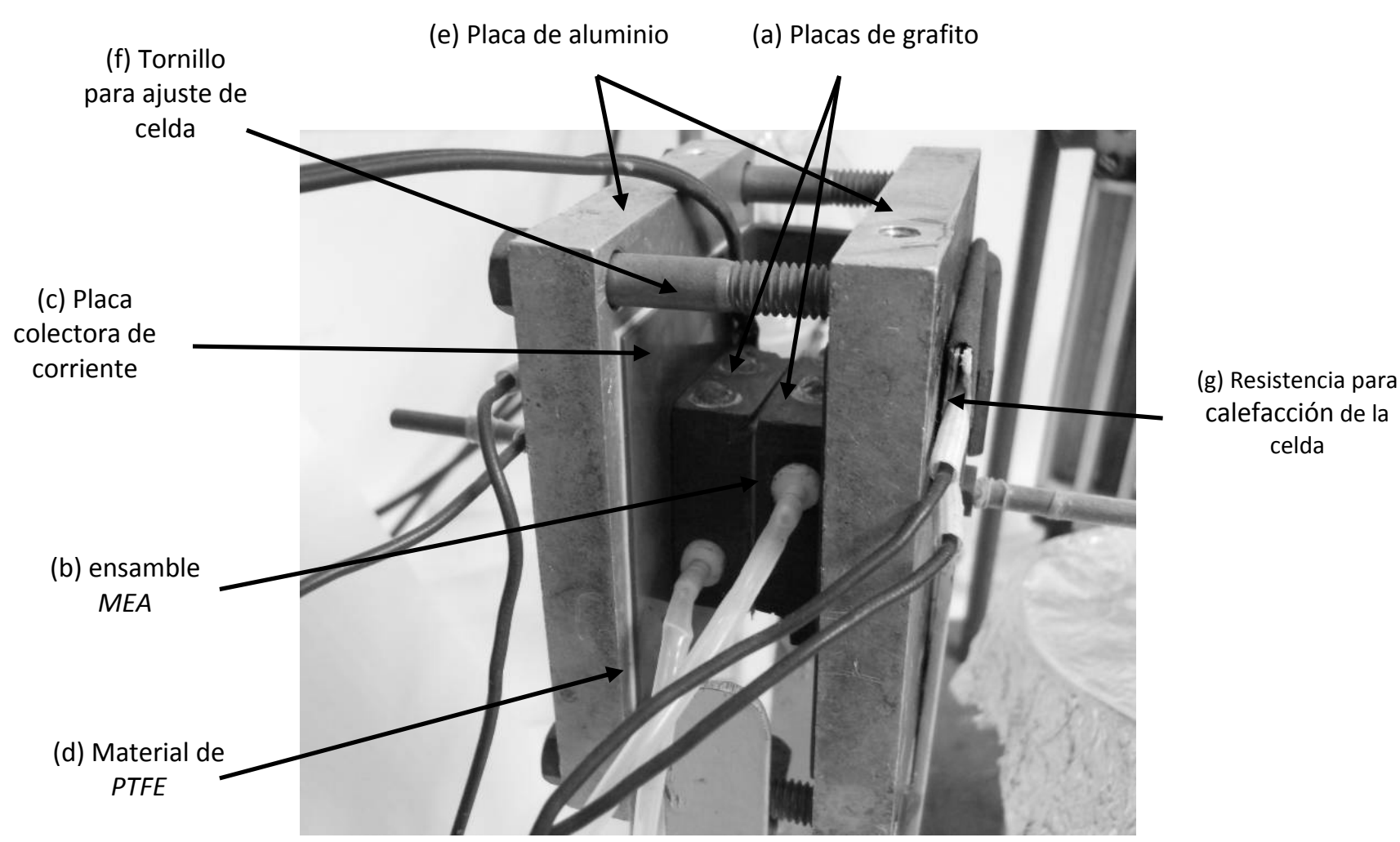

Figura 5. Celda unitaria prototipo.

\section{IX.5. Caracterización voltamperométrica de los electrodos de celdas de combustible tipo PEM}

Los electrodos de celdas de combustible pueden ser examinados mediante experimentos de voltamperometría cíclica "in situ" y "ex situ". En el caso de voltamperometría cíclica "ex situ", también conocido como experimentos "half-cell", las propiedades de los electrodos se evalúan en una celda convencional de tres electrodos, donde la solución acuosa simula el electrolito conductor de protones de la celda PEM. Estos experimentos se caracterizan por ser métodos rápidos de evaluación de los electrocatalizadores utilizados en las celdas, pero no resultan muy apropiados para analizar electrodos de celdas de combustible ya que no simulan las condiciones reales de operación. Por lo tanto, en esta sección, se hará referencia específicamente a la técnica voltamperométrica "in situ" aplicada al estudio de los electrodos de celdas de combustible.

La técnica de voltamperometría cíclica "in situ" se utiliza, en particular, para la determinación del área superficial electroquímicamente activa (ESCA) y constituye, por lo tanto, un aspecto crítico para la performance de una celda de combustible.

\section{IX.5.a. Voltamperometría cíclica "in situ" de los electrodos de celdas de combustible PEM}

Para realizar estudios de voltamperometría cíclica "in situ" es necesario tener en cuenta cual es el electrodo que se desea estudiar. Para el caso de celdas de combustible de hidrógeno/oxígeno interesa 
estudiar, en particular, la reacción de electrorreducción de oxígeno (RRO) que se lleva a cabo en el cátodo. Como se mencionó en capítulos anteriores la $R R O$ se caracteriza por su lenta cinética y es la reacción limitante en celdas de combustible de hidrógeno/oxígeno que operan a baja temperatura. Por lo tanto, para el estudio mediante voltamperometría cíclica "in situ" de la celda unitaria prototipo desarrollada, el cátodo es el electrodo a testear y actúa como electrodo de trabajo, ET. A través del compartimento del ET se hace circular gas nitrógeno de alta pureza. El ánodo actúa como contraelectrodo, $C E$, y se hace circular gas hidrógeno por el correspondiente compartimiento. Debido al sobrepotencial despreciable del $C E$ para las reacciones de oxidación de hidrógeno o desprendimiento de hidrógeno, el CE se utiliza también como electrodo de referencia, ER [401], [402]. Se supone que la polarización del ánodo es despreciable en comparación a la polarización impuesta en el cátodo de la celda de combustible, ET. De este modo, los procesos superficiales que tienen lugar tanto en el ánodo como en el cátodo del MEA, pueden evaluarse mediante la técnica de voltamperometría cíclica "in situ". Por otro lado, teniendo en cuenta que la reacción de desprendimiento de hidrógeno ocurre simultáneamente con la adsorción de hidrógeno a potenciales entre 0,05 V y 0,08 V (ver CAPÍTULO IV) se hace circular gas nitrógeno por el compartimento catódico, a fin de asegurarse que no existen contribuciones de reacciones asociadas a los procesos faradaicos de desprendimiento de hidrógeno.

En la Figura 6 se representa esquemáticamente la celda de combustible alimentada con nitrógeno y oxígeno para las experiencias de voltamperometría cíclica "in situ" realizadas con el ensamble MEA y en la Figura 7 se muestra un esquema del arreglo del sistema utilizado para realizar medidas de voltamperometría cíclica "in situ".

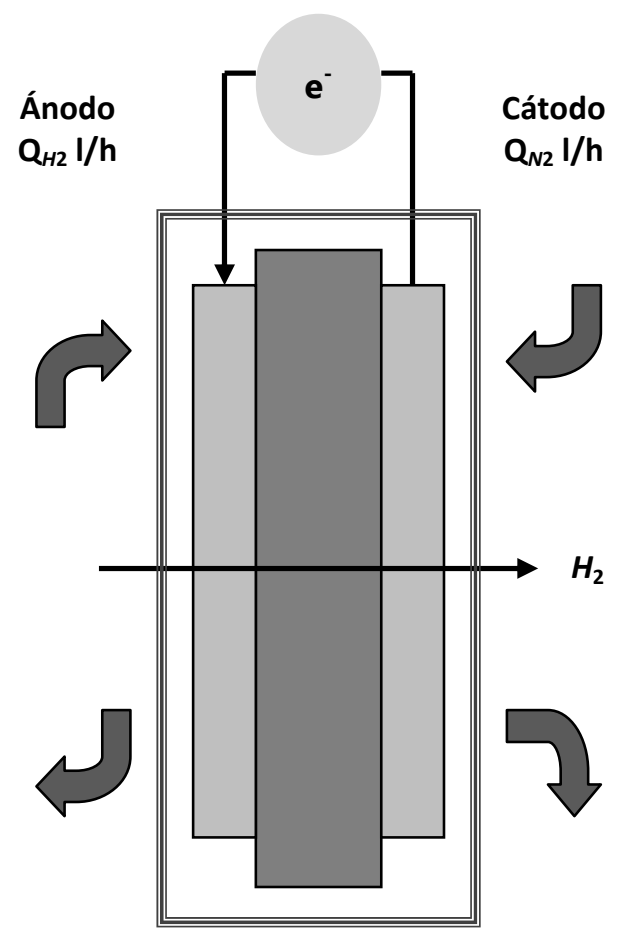

Figura 6. Representación esquemática de una celda de combustible alimentada con $H_{2}$ y $N_{2}$ para evaluación por voltamperometría cíclica "in situ". 


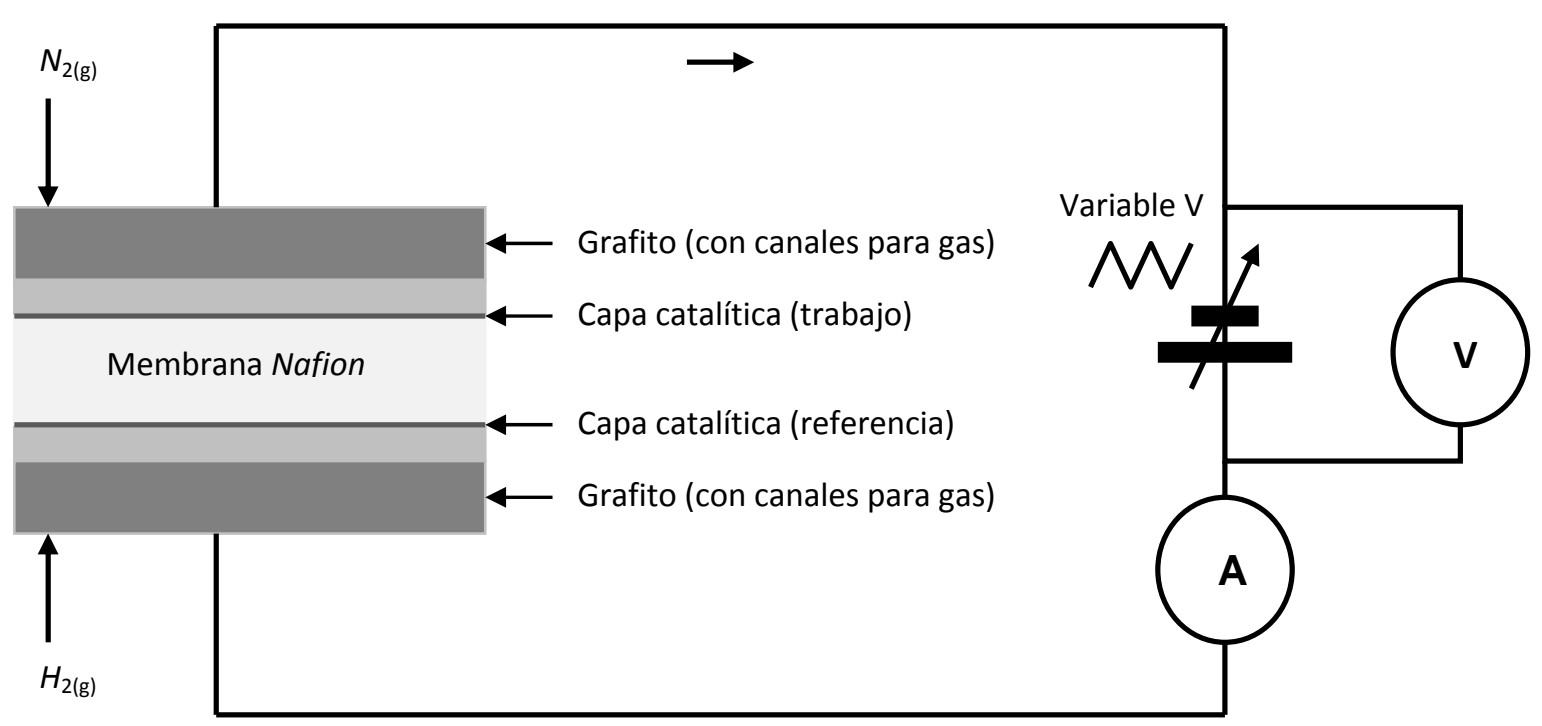

Figura 7. Esquema del arreglo para voltamperometría cíclica utilizado para la caracterización "in situ” de los electrodos de la celda unitaria.

Como se mencionó en capítulos anteriores, a través de la técnica de voltamperometría cíclica, en el caso de metales catalíticamente activos como el Pt, es posible obtener información valiosa mediante la adsorción y desorción de átomos de hidrógeno. Mediante el análisis de la región de electrosorción de hidrógeno se puede determinar el área superficial electroquímicamente activa del catalizador de un electrodo de celda de combustible.

La reacción de electrosorción de hidrógeno es la siguiente [403]:

$$
P t-H_{a d s} \leftrightarrow P t+H^{+}+e^{-}
$$

En las experiencias realizadas el potencial del electrodo de trabajo se barre a $50 \mathrm{mV} / \mathrm{s}$, primero en la dirección anódica para oxidar el hidrógeno adsorbido $H_{a d s}$ a ion $H^{+}$y luego en la dirección catódica para reducir electroquímicamente $H^{+}$a $H_{a d s}$. El voltamperograma exhibe picos asociados con estas reacciones de oxidación y reducción, donde cada pico es indicativo de la adsorción o desorción de hidrógeno sobre un índice cristalino particular de Pt [403]. La densidad de carga de adsorción de hidrógeno de la reacción, $q_{P t}\left(\mathrm{C} / \mathrm{cm}^{2}\right)$, determinada a partir de los voltamperogramas experimentales, se utiliza para calcular el área superficial electroquímicamente activa de los electrodos de celdas de combustible. De esta manera, por integración del área correspondiente a la región de electrodesorción de hidrógeno en los voltamperogramas se calcula la carga correspondiente puesta en juego y, teniendo en cuenta la carga específica para una monocapa de hidrógeno adsorbido sobre Pt policristalino (210 $\mu \mathrm{C} / \mathrm{cm}^{2}$ ) [267], se determina el área superficial electroquímicamente activa (ESCA) [402], [404]:

$$
\operatorname{ESCA}\left(\mathrm{cm}_{P t}^{2} / g_{P t}\right)=\frac{q_{P t}}{\Gamma^{*} L}
$$


siendo $q_{P t}$ la densidad de carga de adsorción de hidrógeno obtenida del voltamperograma $\left(\mathrm{C} / \mathrm{cm}^{2}\right), \Gamma$ la carga específica para una monocapa de hidrógeno adsorbido sobre $P t\left(210 \mu \mathrm{C} / \mathrm{cm}^{2}\right.$ de $\left.P t\right)$ y $L$ el contenido de $P t$ en el electrodo $\left(1,14 \times 10^{-3} \mathrm{~g}\right.$ de $P t / \mathrm{cm}^{2}$ de electrodo). Para los electrocatalizadores incorporados en los electrodos porosos utilizados se obtuvo, a partir de la ecuación (3), un valor de ESCA de $12,85 \mathrm{~m}^{2}$ de $P t / \mathrm{g}$ de $P t$, similar a los informados en la bibliografía [405-407]. Dividiendo el ESCA por el área geométrica del electrodo $\left(4 \mathrm{~cm}^{2}\right)$ se obtiene un factor de rugosado de 3,21.

Por otra parte, el área específica de platino, $A_{p t}$, puede determinarse a partir del valor obtenido del ESCA y de la carga del catalizador, L, mediante la siguiente ecuación [402]:

$$
A_{P t}\left(\mathrm{~cm}_{P t}^{2} / \mathrm{cm}_{\text {electrodo }}^{2}\right)=E C S A^{*} L
$$

De este modo, se obtuvo un valor de $A_{P t}$ de $146,5 \mathrm{~cm}^{2}$ de $P t / \mathrm{cm}^{2}$ de electrodo.

IX.5.b Voltamperometría cíclica "in situ" de los electrodos de la celda de combustible unitaria bajo distintas condiciones de operación

Esta sección se focaliza en el estudio del ensamble electrodo-membrana PEM-electrodo, construido con electrodos porosos con nanopartículas de Pt policristalinas incorporadas, bajo distintas condiciones de operación, aplicando la técnica de voltamperometría cíclica "in situ" antes descripta. Se muestra el efecto del flujo de nitrógeno sobre el ET (cátodo), respecto al perfil de la curva voltamperométrica en la región de adsorción/desorción de hidrógeno y sobre el ESCA. Se trabajó a caudal fijo de hidrógeno $\left(Q_{\mathrm{H} 2}=5 \mathrm{l} / \mathrm{h}\right)$ y a dos caudales diferentes de nitrógeno $\left(Q_{\mathrm{N} 2}=4,5 \mathrm{l} / \mathrm{h}\right.$ y $\mathrm{Q}_{\mathrm{N} 2}=11 \mathrm{l} / \mathrm{h}$ ). En todos los casos los voltamperogramas fueron obtenidos en la zona de potencial de 0,05 $\mathrm{V}$ a $0,8 \mathrm{~V}$, a una velocidad de barrido de $50 \mathrm{mV} / \mathrm{s}$. Las medidas voltamperométricas se realizaron abarcando un amplio rango de condiciones de trabajo, pasando por condiciones críticas tales como alta temperatura de operación de la celda, $\mathrm{T}_{\text {celda }}$ y circulación de gases secos. Para trabajar bajo condiciones de humidificación se utilizó un sistema que consiste en hacer circular los gases a través de burbujeadores que se encuentran sumergidos en un baño de agua a temperatura constante. De este modo, se consigue saturar los gases que pasan por este sistema, logrando humidificarlos antes del ingreso a la celda de combustible. Se seleccionó como temperatura de humidificación de los gases de alimentación $\left(\mathrm{T}_{\text {hum }}\right) 60^{\circ} \mathrm{C}$.

A continuación se presentan algunos resultados obtenidos de los ensayos realizados, bajo condiciones particulares de trabajo que se mencionan en cada caso.

En la Figura 8 se muestra el voltamperograma cíclico obtenido para la celda de combustible unitaria prototipo operando a temperatura ambiente, con humidificación de hidrógeno y bajo caudal de nitrógeno sin humidificación. 


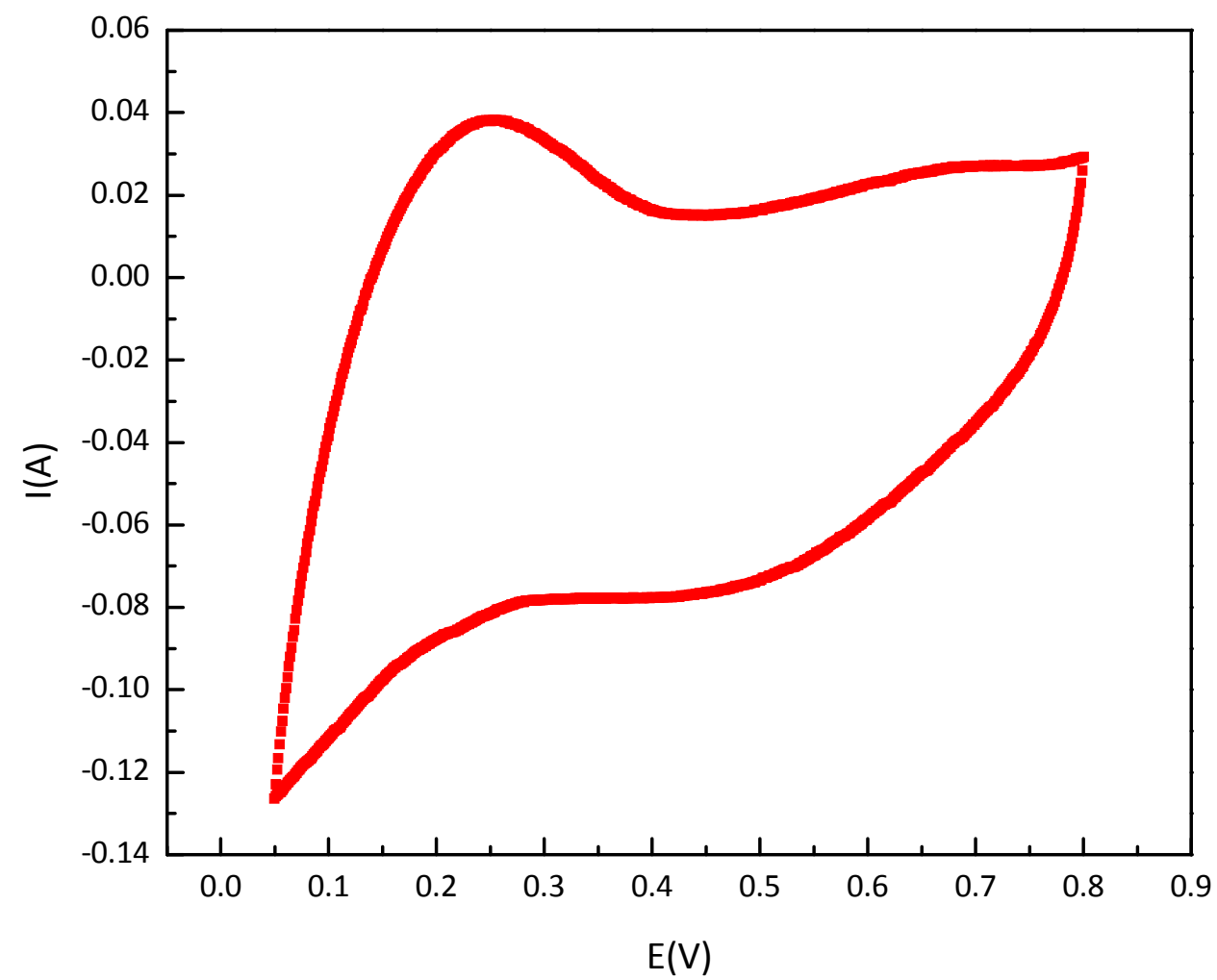

Figura 8. Voltamperograma cíclico "in situ" del ensamble utilizado en la celda de combustible unitaria a $\mathrm{T}_{\text {celda }}=25^{\circ} \mathrm{C}, \mathrm{Q}_{\mathrm{H} 2}=5 \mathrm{l} / \mathrm{h}, \mathrm{Q}_{\mathrm{N} 2}=4,5 \mathrm{l} / \mathrm{h}, \mathrm{T}_{\text {hum H2}}=60^{\circ} \mathrm{C}, \mathrm{N}_{2}$ seco.

Se puede observar que los picos de corriente correspondientes a la zona de desorción de hidrógeno no se encuentran bien definidos. Una posible explicación podría ser la cantidad de PTFE y de la solución de $\mathrm{Nafion}^{\circledR}$ utilizados en la fabricación de los electrodos porosos de difusión de gas. Así, se sabe que la cantidad de PTFE realza el carácter hidrófobo de los electrodos. Cuanto mayor sea la cantidad de PTFE utilizado, mayor será su carácter hidrófobo [321], [357]. Por otro lado, el contenido de PTFE también afecta la microestructura de la CDG de los electrodos. La porosidad de los electrodos disminuye con el aumento del contenido de PTFE, que produce la obstrucción de los poros y afecta la conducción de los gases a los sitios de reacción [313], [358]. Por este motivo, los voltamperogramas cíclicos no muestran una clara definición de los picos de corriente en la región de electrosorción de hidrógeno, debido al carácter hidrofóbico del electrodo y la obstrucción de los poros de la CDG. Si bien el principal "ingrediente" que influye sobre la performance de la celda de combustible es la cantidad de Pt de la CA, Wang et al. [386] han demostrado que, utilizando electrodos que presentan carácter hidrofílico (menor contenido de PTFE), se logran definir mucho mejor los picos de corriente de la región de electrosorción de hidrógeno en comparación con los que se encuentran en electrodos de carácter hidrofóbico. En general, se ha informado que bajas cantidades de PTFE otorgan un mejor comportamiento del electrodo de la celda. Por otro lado, debido a que el PTFE aumenta la resistencia 
óhmica, su cantidad no puede ser excesiva como ya se ha mencionado. De acuerdo a la bibliografía se alcanzan valores óptimos con contenidos alrededor del 20 \% [313], [357], [358].

Los electrodos desarrollados para la celda prototipo evaluada en esta sección tienen un contenido de PTFE en la CDG que se encuentra en el orden del $35 \%$ (considerando como $100 \%$ la masa del grafito + la masa del PTFE). Se ha observado que el contenido de PTFE en la CDG influye sobre la microestructura del electrodo de dos maneras. Por un lado, la porosidad total de la CDG disminuye con el aumento del contenido de PTFE y por otro lado, el área superficial catalítica depende de la macroporosidad de la CDG, la que varía con la carga de PTFE [313]. Estos cambios afectan las propiedades electroquímicas del electrodo. Sería de esperar, por lo tanto, una mayor definición de los picos de corriente en la zona de electroadsorción/electrodesorción de hidrógeno utilizando menores cantidades de PTFE, de modo que no se vea afectada la microestructura porosa del electrodo. Por otro lado, la cantidad de Nafion $^{\circledR}$ utilizada en la $C A$, también podría afectar la forma de los voltamperogramas cíclicos "in situ". En los electrodos porosos desarrollados el contenido de la solución de Nafion $^{\circledR}$ utilizado fue de $2,8 \mathrm{mg} / \mathrm{cm}^{2}$ considerando el peso seco del Nafion $^{\circledR}$ y el área geométrica del electrodo [300]. Esto representa un 35,7 \% teniendo en cuenta el peso seco del ionómero dividido por el peso total del catalizador Pt/C y del Nafion ${ }^{\circledR}$ [300], por lo que se encontraría dentro del rango óptimo mencionado en la bibliografía, tal como se describió anteriormente [306], [393], [397-399]. Si bien la utilización de Nafion $^{\circledR}$ en la capa catalítica tiene dos efectos beneficiosos, que son el aumento en el área electroquímicamente activa y una mejora en la conductividad iónica, se debe tener en cuenta también que altos contenidos de Nafion $^{\circledR}$ [290], [387] pueden dificultar la difusión de los gases en la zona electrolito/catalizador, ya que se produce el bloqueo de los poros de la CDG y se incrementa el espesor de la $C A$, dando como resultado limitaciones en el transporte de masa [408]. Por lo tanto, de acuerdo a los voltamperogramas obtenidos, en los electrodos construidos se evidencia también el efecto de la resistencia de difusión que está afectada por el espesor de la capa de $\mathrm{Nafion}^{\circledR}$, a través de la cual los gases reactivos deben difundir. Según Poltarzewski et al. [306], quienes han estudiado los efectos de la carga y distribución de Nafion $^{\circledR}$ de la capa catalítica, el valor óptimo se encontraría para cargas de Nafion $^{\circledR}$ de $0,9 \mathrm{mg} / \mathrm{cm}^{2}$, con la cual han logrado la más alta actividad electrocatalítica y la menor resistencia iónica. Cargas mayores de Nafion ${ }^{\circledR}$ conducen a un volumen de poro constante y sólo contribuye a un aumento del espesor de la capa del ionómero sobre el electrodo, pero no mejora los efectos de conducción. Es probable que, también por este motivo los picos de corriente correspondientes a la región de hidrógeno, no lleguen a encontrarse completamente definidos.

El ESCA, determinada por voltamperometría cíclica, refleja el área superficial electroquímicamente activa del electrodo para los procesos de adsorción/desorción de hidrógeno sobre $P t$ y la interfase formada con Nafion ${ }^{\circledR}$. Se ha determinado que algunos de los sitios activos, cubiertos por una fina película del ionómero, pueden generar problemas de transporte de masa para la reacción de 
electrorreducción de oxígeno y electrooxidación de hidrógeno [363]. Por tal motivo, es de esperar que el área efectiva para las reacciones involucradas sea menor que la sugerida por voltamperometría cíclica y los picos característicos no estén bien definidos. Se debería, por lo tanto, evaluar la cantidad óptima del ionómero en esta capa a fin de lograr mayor definición de los picos asociados a los procesos de adsorción/desorción de hidrógeno sobre Pt en la interfase con Nafion ${ }^{\circledR}$. Tamizhmani et al. [409] atribuyen la disminución del área superficial electroquímicamente activa a la impregnación del Nafion ${ }^{\circledR}$ sobre la superficie de las nanopartículas catalizadoras de $P t / C$, que bloquea los sitios de $P t$ y conducen a la inaccesibilidad de los protones a la superficie del Pt.

El aumento del caudal de nitrógeno a $Q_{N 2}=11 \mathrm{l} / \mathrm{h}$, manteniendo todas las demás condiciones de trabajo constantes, esto es, temperatura de celda ambiente y humidificación sólo del hidrógeno, no produce variaciones considerables en el perfil del voltamperograma (Figura 9).

El cálculo del área superficial electroquímicamente activa, correspondiente a la zona de electrosorción de hidrógeno, no muestra grandes cambios. Se observa un pequeño aumento en los valores de $E S C A$, en el orden del $5 \%$, variación que se puede considerar prácticamente despreciable. Se debe tener en cuenta que, cuando se utiliza la técnica de voltamperometría cíclica para determinaciones "in situ" del área superficial electroquímicamente activa, los picos asociados al hidrógeno fuerte y débilmente adsorbidos se encuentran, a menudo, enmascarados por la reacción de electrodesprendimiento de hidrógeno y desplazados hacia potenciales menores [410], por lo que cabe esperar que los picos no presenten en esta zona una clara definición.

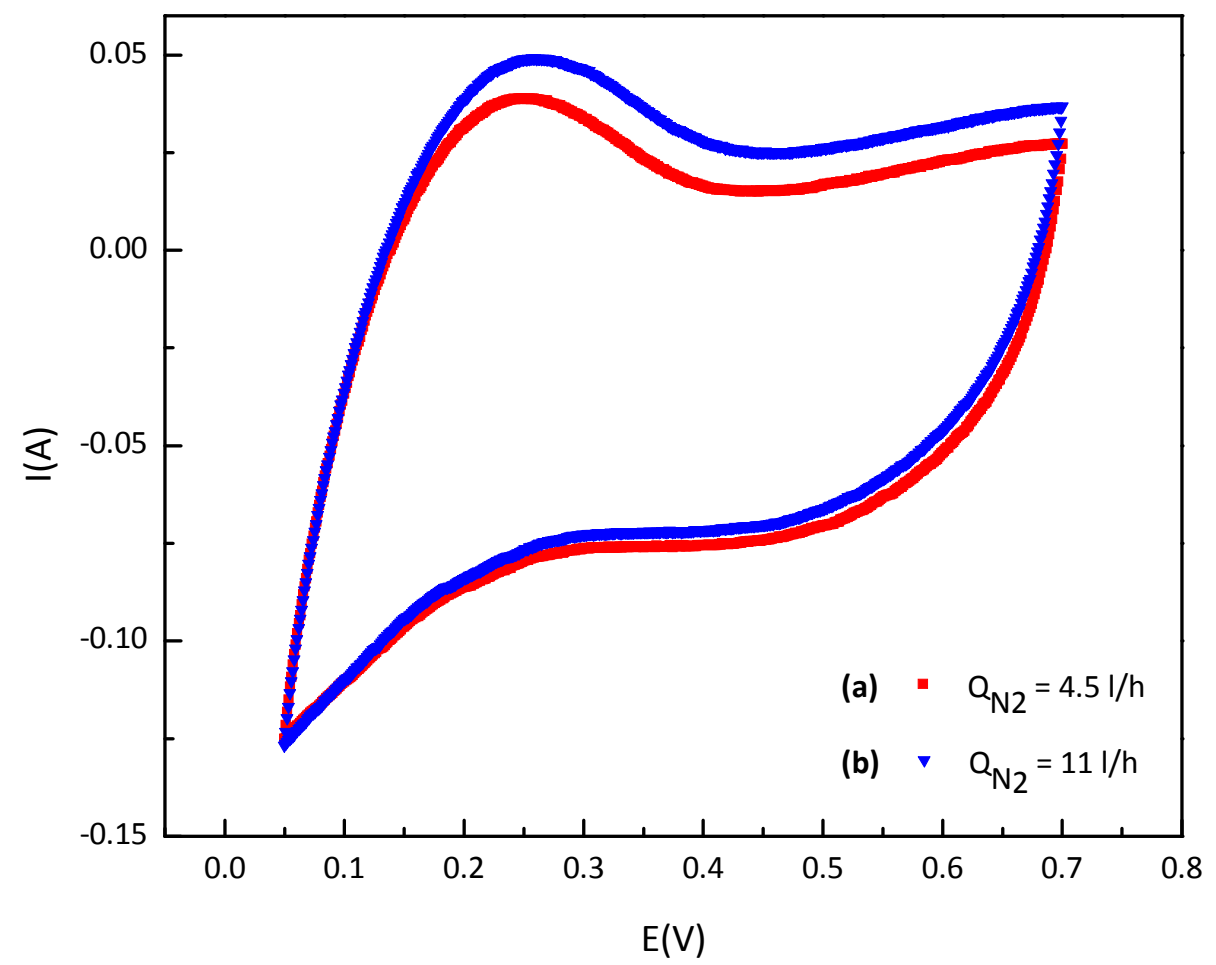

Figura 9. Efecto del aumento del caudal de $N_{2}$ sobre los voltamperogramas a $\mathrm{T}_{\text {celda }}=25^{\circ} \mathrm{C}, \mathrm{Q}_{\mathrm{H} 2}=5 \mathrm{I} / \mathrm{h}$, $\mathrm{T}_{\text {hum H2}}=60^{\circ} \mathrm{C}, N_{2}$ seco. (a) $-Q_{\mathrm{N} 2}=4,5 \mathrm{l} / \mathrm{h}$ y (b) $\nabla Q_{\mathrm{N} 2}=11 \mathrm{l} / \mathrm{h}$. 
La utilización de ambos gases sin humidificación genera una marcada inclinación del voltamperograma (Figura 10), tanto para bajos como altos caudales de nitrógeno $\left(Q_{\mathrm{N} 2}=4,5 \mathrm{I} / \mathrm{h}\right.$ y $\mathrm{Q}_{\mathrm{N} 2}=11 \mathrm{l} / \mathrm{h}$, respectivamente). Este comportamiento podría deberse, en principio, a las condiciones de sequedad generadas por la circulación de ambos gases secos, que producen un aumento en la resistencia de la celda como resultado de la falta de humidificación de la membrana.

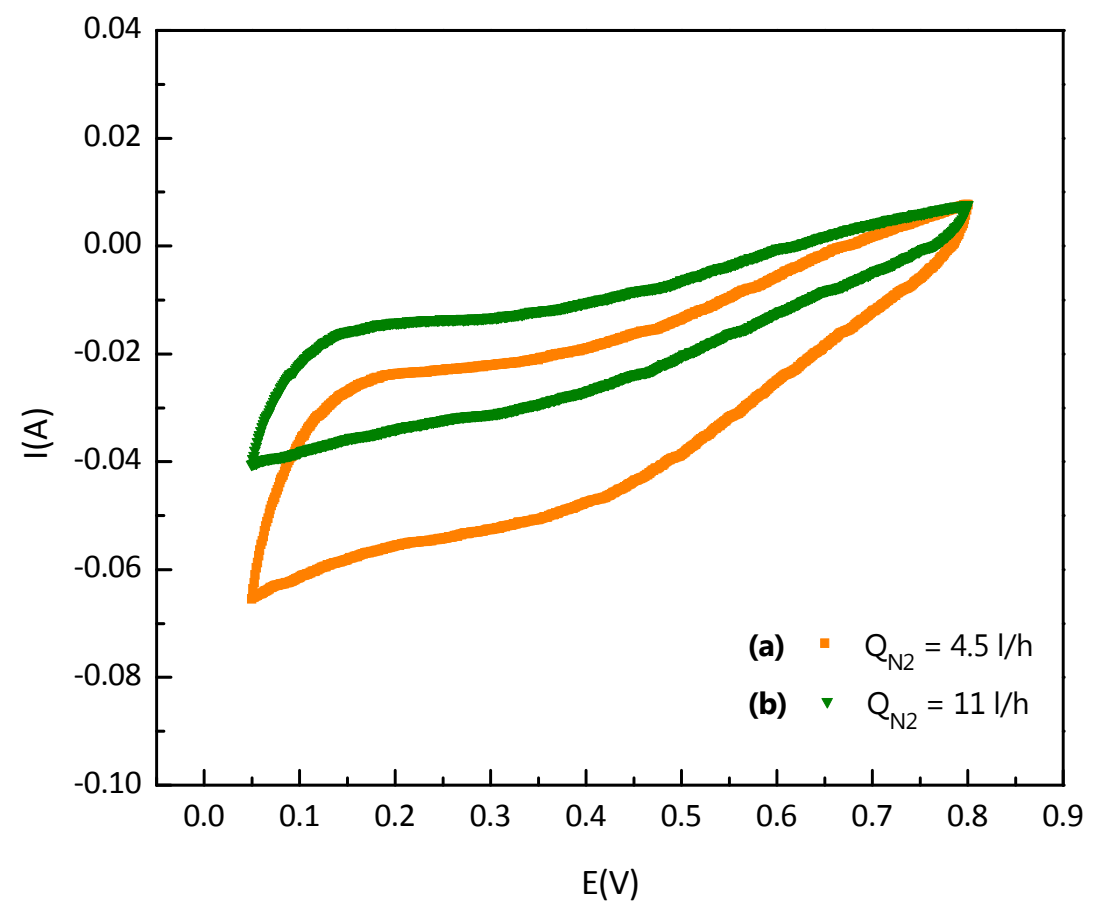

Figura 10. Efecto del aumento del caudal de $N_{2}$ seco sobre los voltamperogramas a $Q_{H 2}=5 \mathrm{l} / \mathrm{h}$ y $\mathrm{T}_{\text {celda }}=25^{\circ} \mathrm{C}$ (a) $\approx Q_{N 2}=4,5 \mathrm{l} / \mathrm{h}$ y (b) $\nabla Q_{N 2}=11 \mathrm{l} / \mathrm{h}$.

Evaluando el perfil del voltamperograma se observa que la zona correspondiente al proceso de electrodesorción de hidrógeno se encuentra totalmente enmascarada, probablemente debido a la alta resistencia de la celda de combustible bajo las condiciones de trabajo, que pueden considerarse extremas respecto al grado de humidificación de los gases. El aumento del caudal de nitrógeno seco se refleja también en una menor área del voltamperograma, indicando altos rasgos resistivos. En general, el aumento del caudal de nitrógeno tiende a enderezar el voltamperograma, pero la zona correspondiente a los picos de electrosorción de hidrógeno continúa enmascarada.

La humidificación de ambos gases permite un rápido reestablecimiento del perfil voltamperométrico (Figura 11), retornando a su forma inicial. Esta respuesta inmediata es un claro indicio de la flexibilidad que presenta el sistema frente a variaciones en las condiciones de humidificación. Esto es posible debido a que el agua que aportan los gases humidificados permite mejorar la hidratación de la membrana polimérica. Por otro lado, se observa también un leve aumento en el cálculo de los valores de ESCA calculados. 


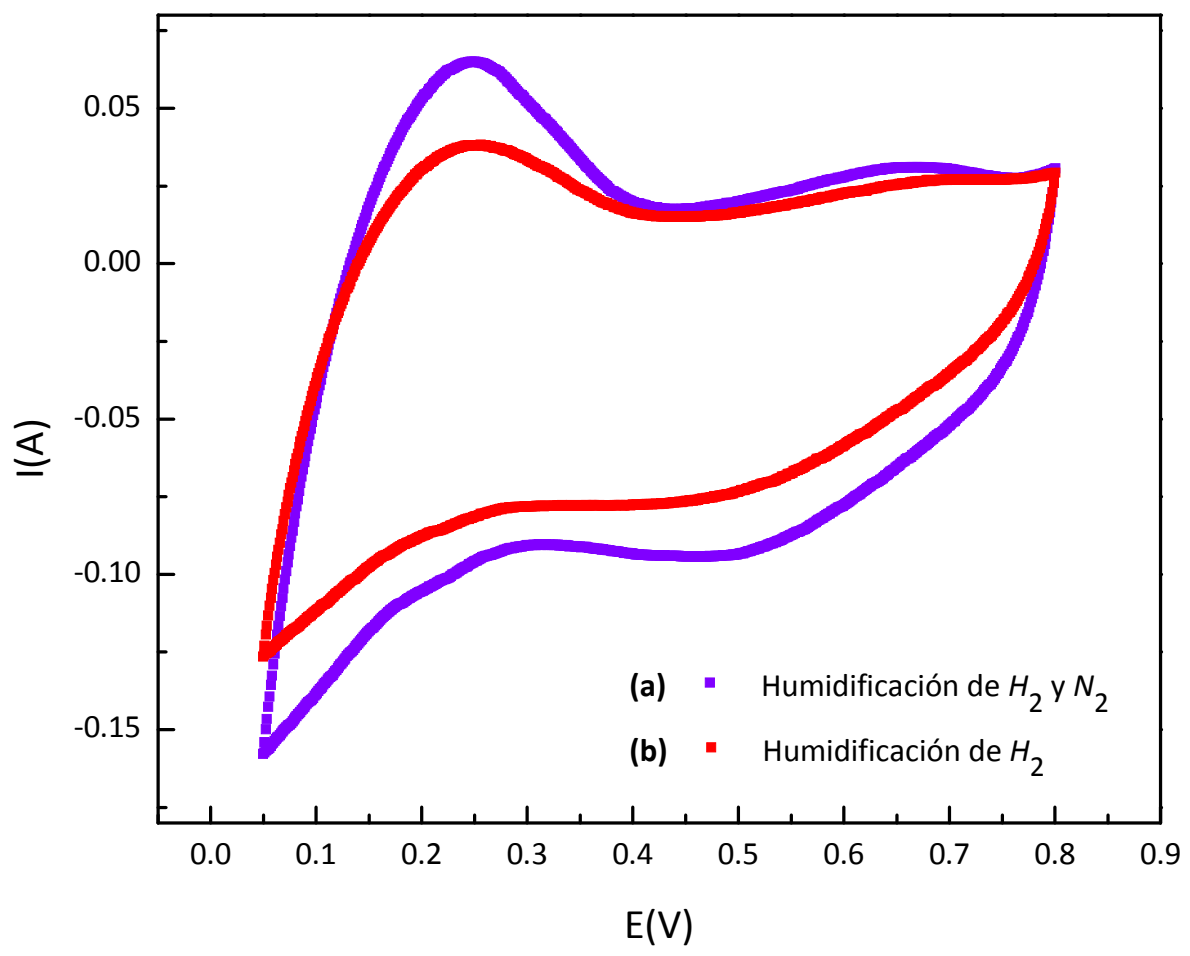

Figura 11. Respuesta voltamperométrica para $Q_{\mathrm{N} 2}=4,5 \mathrm{l} / \mathrm{h}, \mathrm{T}_{\text {celda }}=25{ }^{\circ} \mathrm{C}$ (a) - humidificación de $H_{2}$ y $N_{2}$, (b) - humidificación de $H_{2}$.

El aumento del caudal de nitrógeno, manteniendo todas las demás condiciones iguales, esto es, $\mathrm{T}_{\text {celda }}=25^{\circ} \mathrm{C}$ y humidificación de ambos gases a $\mathrm{T}_{\text {hum }}=60^{\circ} \mathrm{C}$, no produce variación considerable en la región comprendida entre los potenciales $0,05 \vee$ y 0,8 $\vee$ (Figura 12). Por lo tanto, el ESCA es la misma tanto para bajos como altos caudales de nitrógeno.

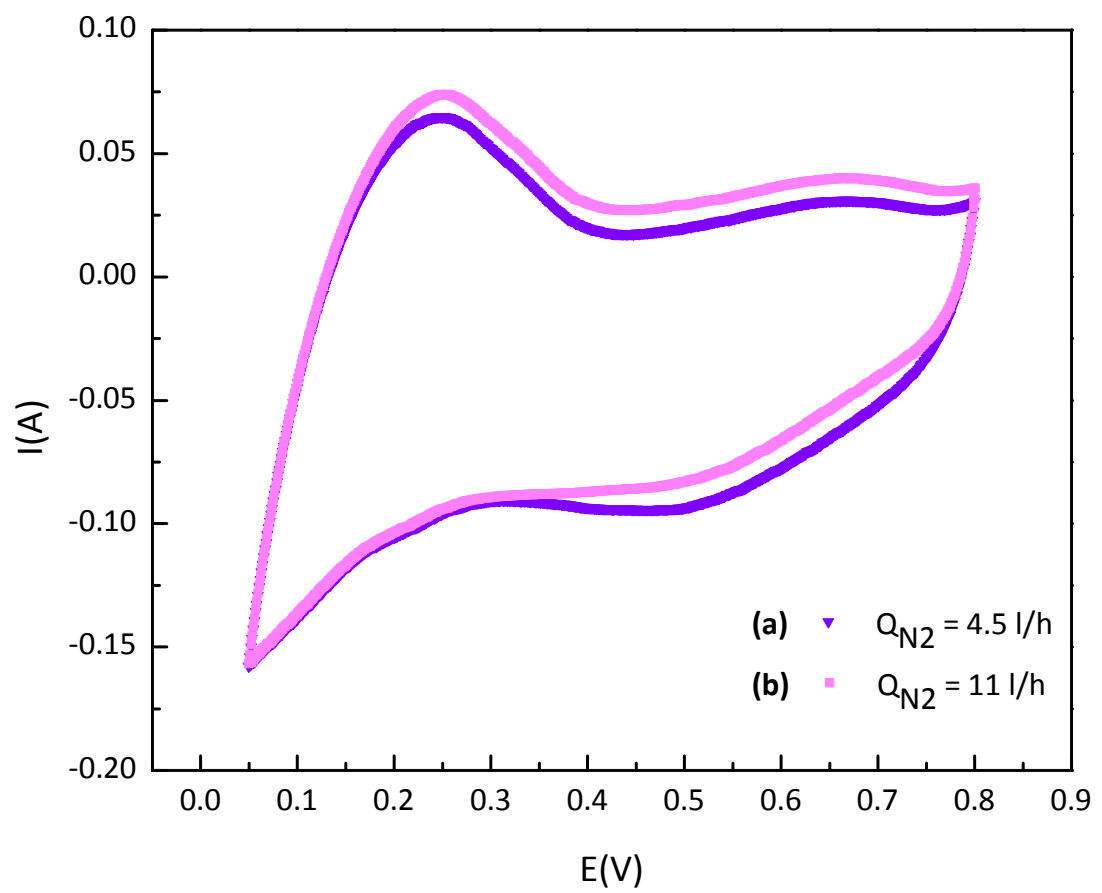

Figura 12. Voltamperogramas cíclicos "in situ" con humidificación de ambos gases a $\mathrm{T}_{\text {hum }}=60^{\circ} \mathrm{C}, \mathrm{T}_{\text {celda }}=25^{\circ} \mathrm{C}$ (a) $\nabla Q_{N 2}=4,5 \mathrm{l} / \mathrm{h}$ y (b) $\approx Q_{N 2}=11 \mathrm{l} / \mathrm{h}$. 
En la Figura 13 se muestran los voltamperogramas obtenidos por efecto de la humidificación de ambos gases o sólo el hidrógeno, para altos y bajos caudales del gas inerte (Figura 13 (a) y (b), respectivamente). En términos generales $y$, de acuerdo a las experiencias realizadas en la celda de combustible unitaria, la humidificación de ambos gases tiene una incidencia poco marcada sobre los perfiles voltamperométricos. Sin embargo, para bajos caudales de nitrógeno, el efecto de humidificar ambos gases permite obtener valores de ESCA algo superiores, como se indica en la Figura 13 (b).
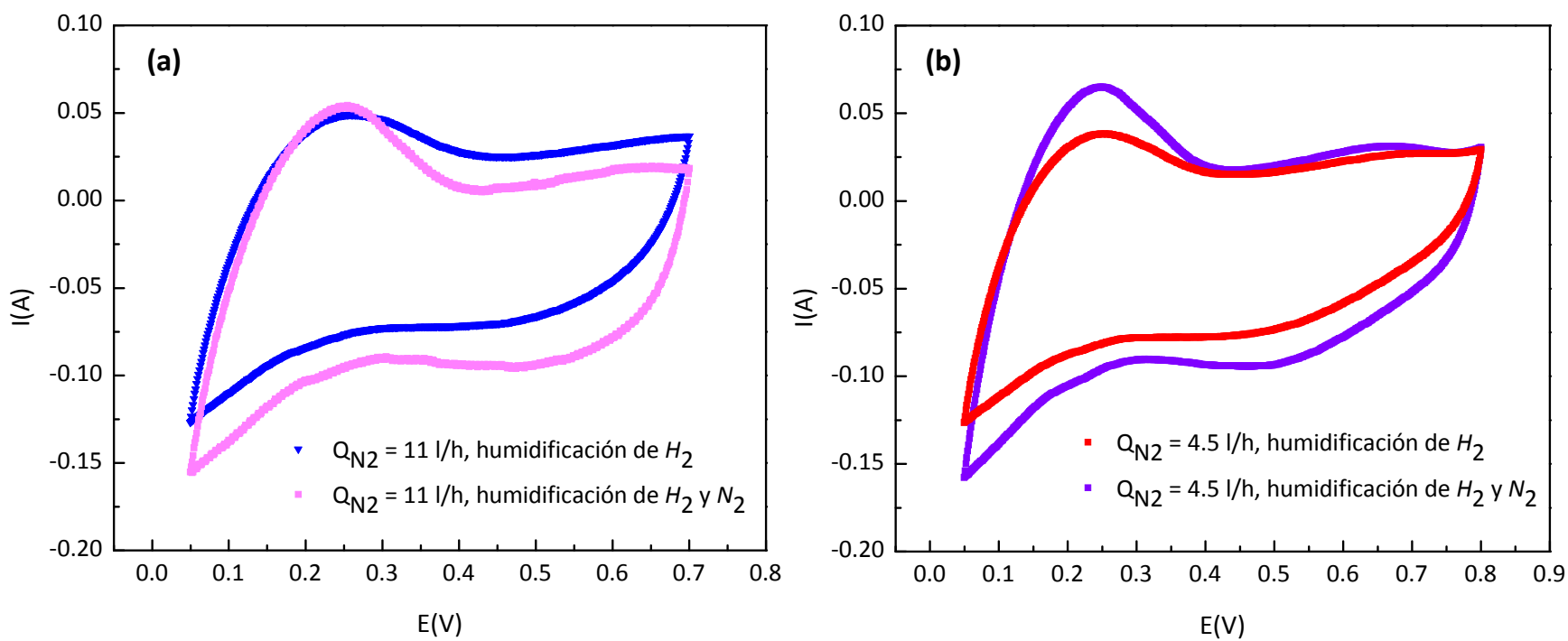

Figura 13. Voltamperogramas "in situ" con humidificación de ambos gases o solo el $H_{2}$ para (a) $Q_{N 2}=11 \mathrm{l} / \mathrm{h}$ y (b) $\mathrm{Q}_{\mathrm{N2}}=4,5 \mathrm{I} / \mathrm{h}$.

El aumento de la temperatura de operación de la celda de combustible a $60^{\circ} \mathrm{C}$ produce un cambio considerable en el perfil del voltamperograma, tal como se puede observar en la Figura 14.

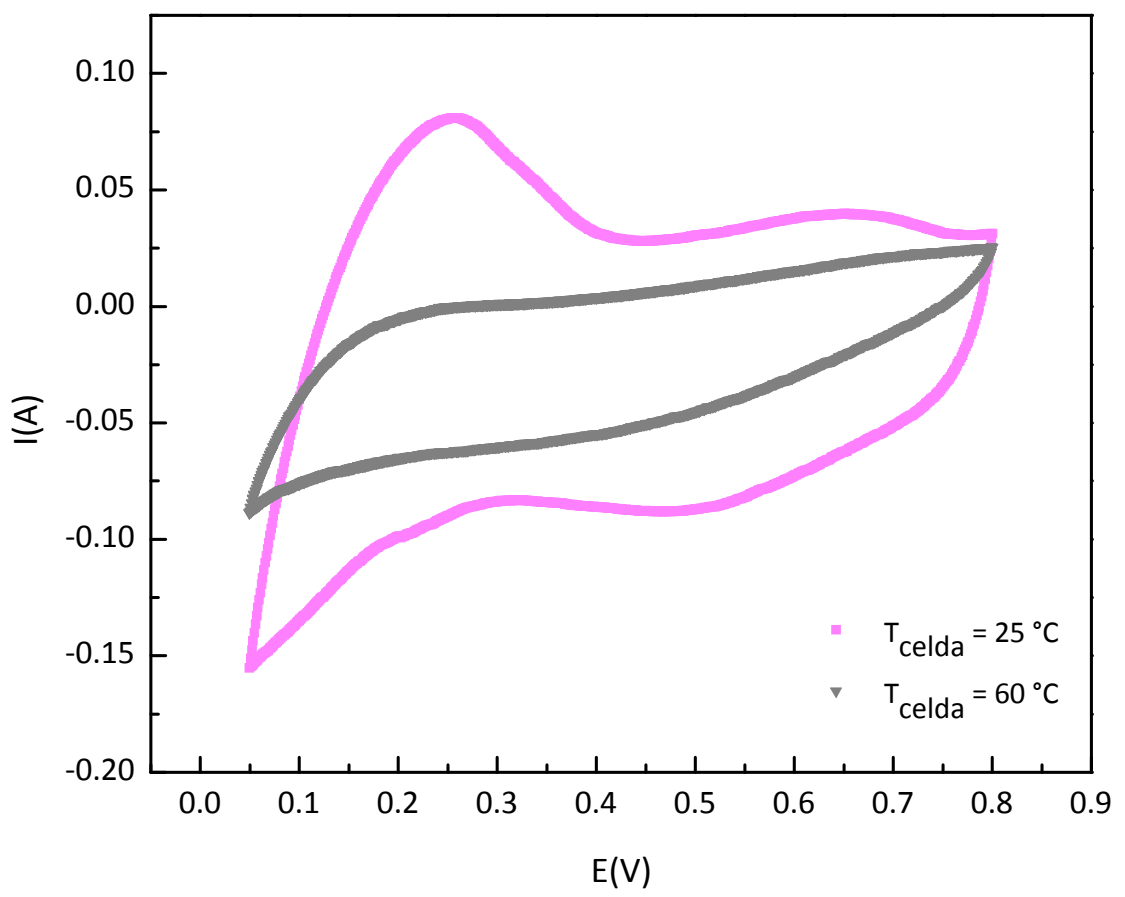

Figura 14. Efecto del aumento de $T_{\text {celda }}$ para $Q_{\mathrm{N} 2}=11 \mathrm{l} / \mathrm{h}$ y humidificación de ambos gases. 
Este comportamiento se podría atribuir al bajo grado de humidificación de la celda de combustible que aumenta los efectos resistivos dando como resultado voltamperogramas inclinados, con pérdida de definición de los picos de corriente correspondientes a la zona de los procesos de electrosorción de hidrógeno, quedando completamente enmascarada esta región. Por lo tanto, esto estaría indicando un aumento en la resistencia de la celda, asociada a una deficiente humidificación.

Se ha demostrado que, para altas temperaturas de operación de la celda $\left(>60^{\circ} \mathrm{C}\right)$, el paso de los gases produce un efecto de secado de los electrodos que es mayor que el efecto de hidratación por el agua producida por la propia reacción electroquímica, razón por la cual es fundamental lograr un adecuado grado de humidificación de los gases antes de su ingreso a la celda [321]. Por otra parte, varios autores [404], [411] afirman que una humidificación insuficiente de la celda de combustible provoca una baja utilización de los catalizadores y que este efecto sería provocado por la inmovilización de los protones en la capa catalítica, debido a la alta deshidratación causada por la baja humedad. Sería por lo tanto de esperar que los picos de corriente en esta región no estén definidos bajo estas condiciones de trabajo.

La Figura 15 muestra los perfiles voltamperométricos de la celda de combustible unitaria como resultado de la disminución de la $T_{\text {celda }}$. Se observa un reestablecimiento gradual de la forma de los voltamperogramas hasta alcanzar finalmente el perfil original, similar al obtenido cuando la celda opera a temperatura ambiente, como se presentó anteriormente. Este comportamiento estaría indicando que, cuánto más alta sea la temperatura de operación de la celda, mayores son los rasgos resistivos que presentan los voltamperogramas cíclicos "in situ", que se traducen en la inclinación del perfil voltamperométrico y en la pérdida de definición de los picos de corriente de la zona de hidrógeno.

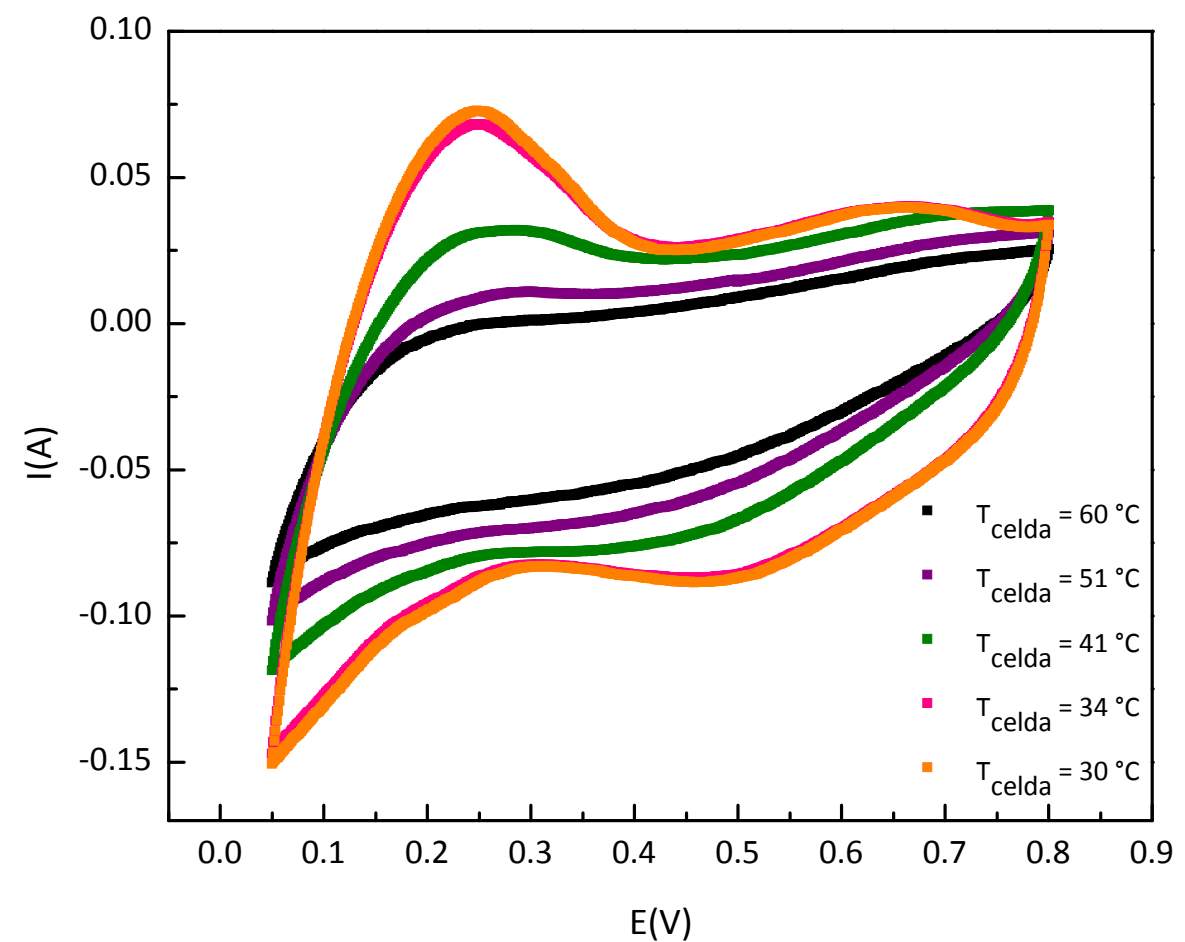

Figura 15. Efecto de la variación de $T_{\text {celda }}$ sobre los voltamperogramas para $Q_{\mathrm{H} 2}=5 \mathrm{l} / \mathrm{h}, Q_{\mathrm{N2}}=11 \mathrm{l} / \mathrm{h}$ humidificados a $\mathrm{T}_{\text {hum }}=60^{\circ} \mathrm{C}$ (tiempo total de la medida 2 horas). 
El mismo comportamiento se observó humidificando solamente el hidrógeno, tanto para bajos como altos caudales de nitrógeno $\left(Q_{N 2}=4,5 \mathrm{l} / \mathrm{h}\right.$ y $Q_{\mathrm{N} 2}=11 \mathrm{l} / \mathrm{h}$, respectivamente), tal como se muestra en la Figura 16 y 17. Esto indica, nuevamente, la gran incidencia de la temperatura de operación de la celda de combustible sobre los efectos resistivos de los voltamperogramas. El comportamiento observado se podría asociar, en principio, con las características resistivas que presentan los voltamperogramas para altas temperaturas de operación.

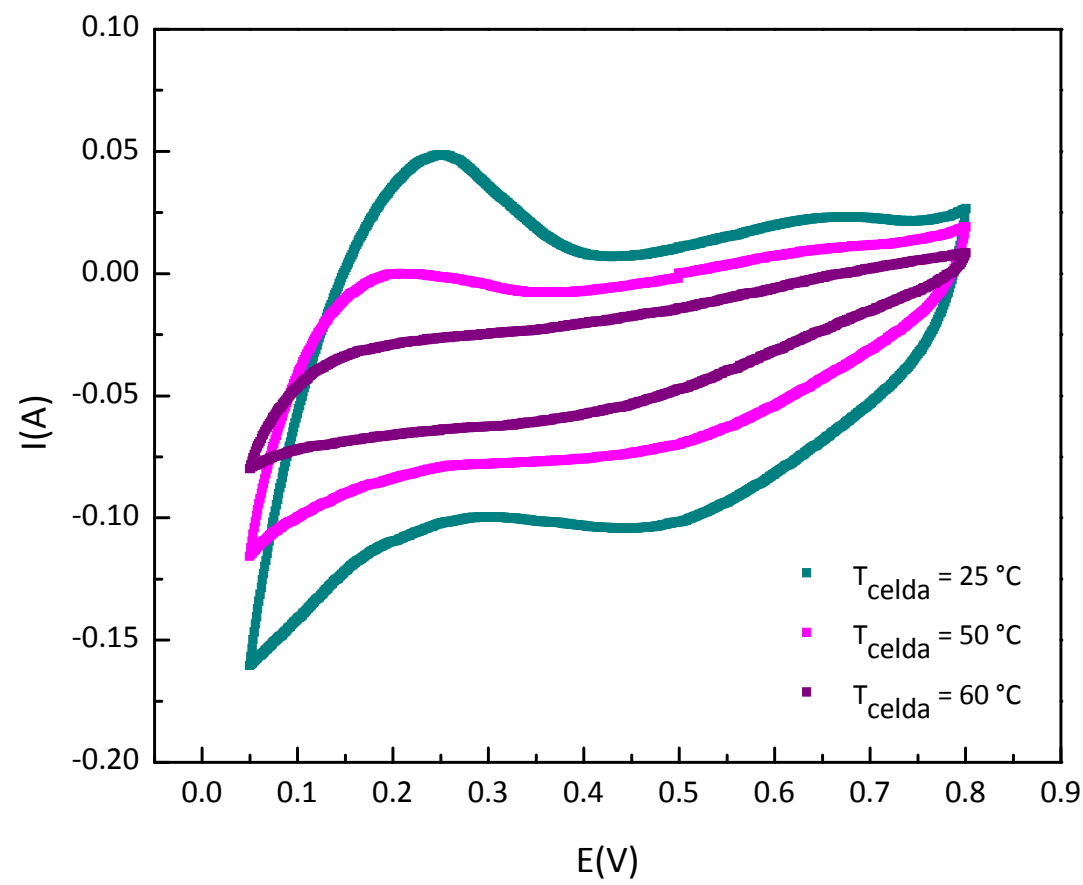

Figura 16. Efecto del aumento de $T_{\text {celda }}$ sobre los voltamperogramas "in situ" para $Q_{\mathrm{N} 2}=4,5 \mathrm{I} / \mathrm{h}$ y humidificación de $H_{2}$ a $\mathrm{T}_{\text {hum } \mathrm{H} 2}=60^{\circ} \mathrm{C}$.

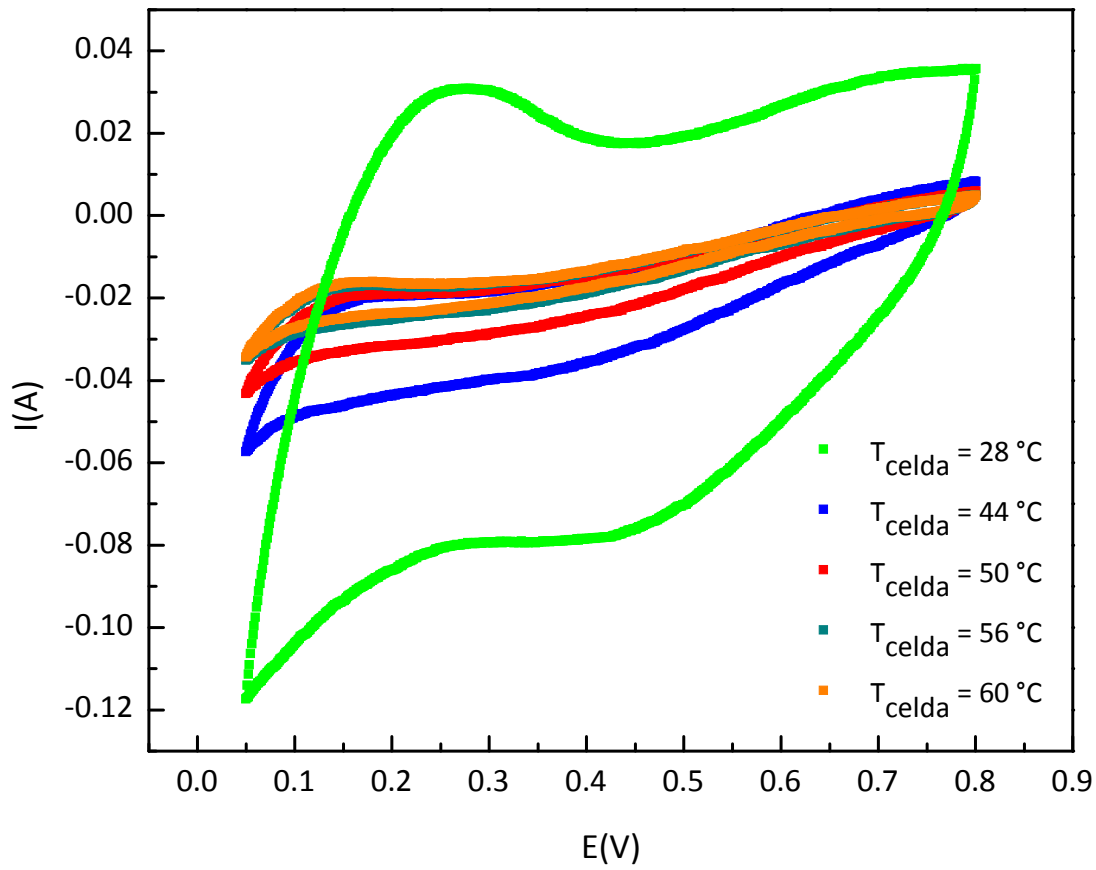

Figura 17. Efecto de la $T_{\text {celda }}$ sobre los voltamperogramas “in situ” para $Q_{N 2}=11 \mathrm{l} / \mathrm{h}$ y humidificación de $H_{2}$ a $\mathrm{T}_{\text {hum H2}}=60^{\circ} \mathrm{C}$. 


\section{IX.5.c. Voltamperometría cíclica "in situ" de los electrodos de la celda de combustible unitaria} para tiempos largos

Se ha evaluado también la respuesta voltamperométrica "in situ" de la celda de combustible unitaria en función del tiempo de operación, durante el cual fue sometida a diversas condiciones de trabajo. Luego de 3 días de operación, retomando las condiciones iniciales de $\mathrm{T}_{\text {celda }}=25{ }^{\circ} \mathrm{C}$, humidificación de hidrógeno, $\mathrm{Q}_{\mathrm{N} 2}=4,5 \mathrm{l} / \mathrm{h}, \mathrm{Q}_{\mathrm{H} 2}=5 \mathrm{l} / \mathrm{h}$, el barrido voltamperométrico en la zona de potenciales de $0,05 \mathrm{~V}$ a $0,8 \mathrm{~V}$, prácticamente no muestra variaciones. En la Figura 18 se indican los voltamperogramas de la celda de combustible unitaria, con nanocristalitas de Pt policristalinas incorporadas, a tiempo inicial y luego de 3 días de operación [(a) y (b), respectivamente]. La celda de combustible presenta las mismas características voltamperométricas al inicio y al final de la medida, aún cuando fue sometida a condiciones extremas de trabajo durante los 3 días de operación. En la zona correspondiente a la electrodesorción de hidrógeno se obtienen corrientes levemente superiores, probablemente por las sucesivas medidas que se fueron realizando en el transcurso de los días, las cuales en cierta manera logran activar los electrodos que conforman el ensamble de la celda.

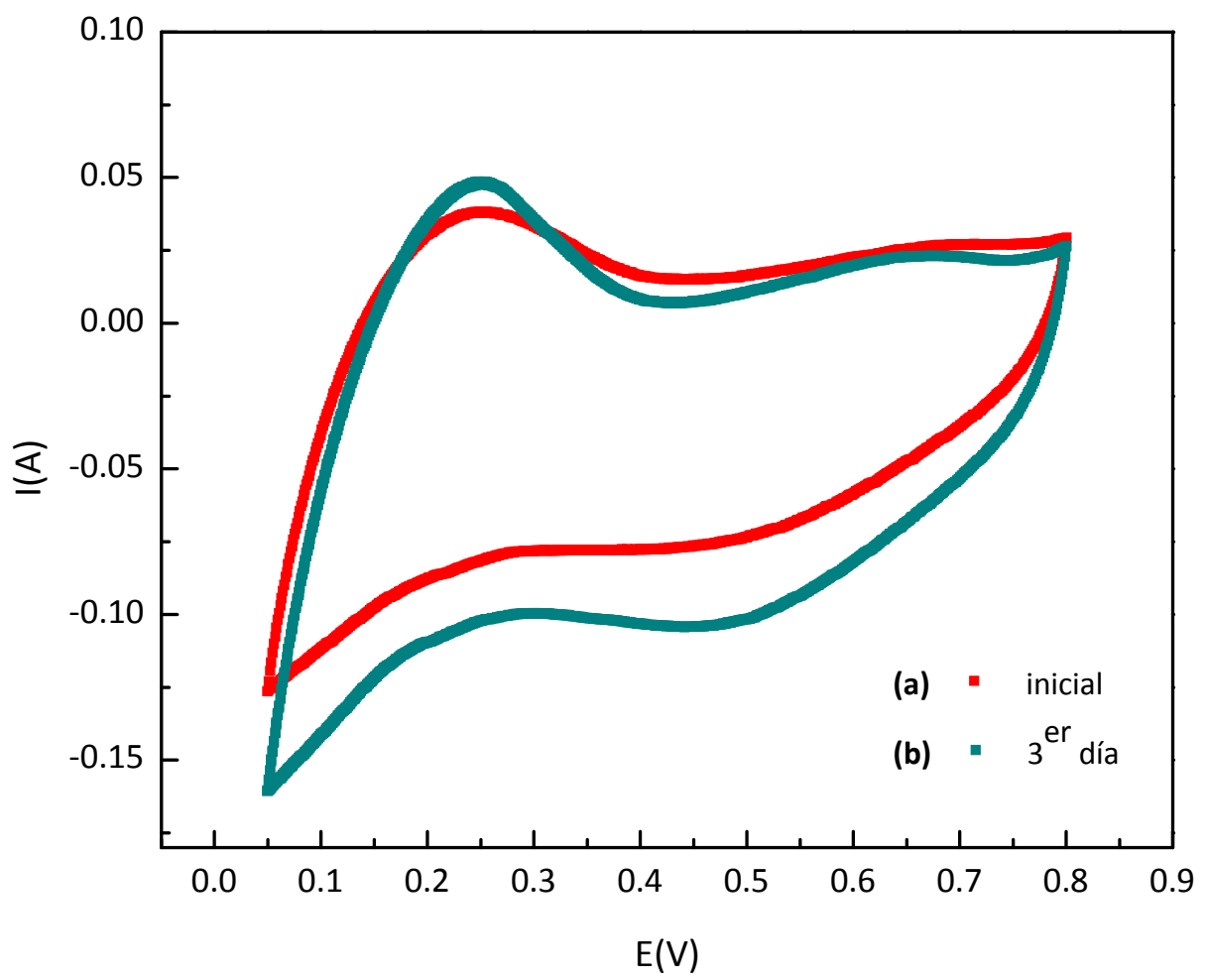

Figura 18. Efecto del tiempo de operación sobre los voltamperogramas “in situ" a $T_{\text {celda }}=25^{\circ} \mathrm{C}, \mathrm{Q}_{\mathrm{H} 2}=4,5 \mathrm{l} / \mathrm{h}$ humidificado a $\mathrm{T}_{\text {hum } \mathrm{H} 2}=60^{\circ} \mathrm{C}, \mathrm{Q}_{\mathrm{N} 2}=4,5 \mathrm{l} / \mathrm{h}(\mathrm{a})$ - inicialmente y (b) - al cabo de 3 días.

Resultados similares fueron encontrados para un alto caudal de nitrógeno, $\left(Q_{N 2}=11 \mathrm{l} / \mathrm{h}\right)$, operando también a $\mathrm{T}_{\text {celda }}=25^{\circ} \mathrm{C}$ y humidificación solamente del gas hidrógeno. 


\section{IX.6. Evaluación de la resistencia de la celda de combustible unitaria, $\mathbf{R}_{\text {celda }}$}

Se ha evaluado la resistencia de la celda de combustible unitaria, $R_{\text {celda, }}$ empleando un ohmímetro marca Agilent 4338B, conectado a los colectores de corriente de la celda unitaria. A continuación se muestran algunos resultados de la determinación de la $R_{\text {celda }}$.

Operando a temperatura ambiente y para un bajo caudal de nitrógeno seco $\left(Q_{\mathrm{N} 2}=4,5 \mathrm{l} / \mathrm{h}\right)$, se registra un valor de resistencia de 1,46 $\Omega$. La circulación de ambos gases humidificados, durante 1 hora aproximadamente, conduce a un valor de $0,56 \Omega$ y si se continúa con la humidificación durante aproximadamente 2 horas la resistencia alcanza un valor final de $0,51 \Omega$, que se puede considerar estable bajo las condiciones de operación. Por lo tanto, la humidificación tanto del hidrógeno como del nitrógeno produce una disminución de la resistencia de la celda que se encuentra en el orden del $65 \%$, respecto al valor encontrado cuando la celda opera con ambos gases secos.

Se ha evaluado también la variación de la resistencia de la celda de combustible en función del tiempo. Para ello, se realizaron medidas bajo distintas condiciones de trabajo y, al cabo de 5 días, se volvieron a repetir las medidas bajo las mismas condiciones antes evaluadas, esto es, $\mathrm{T}_{\text {celda }}=25^{\circ} \mathrm{C}$, gases secos, $Q_{\mathrm{H} 2}=5 \mathrm{l} / \mathrm{h}$ y $Q_{\mathrm{N} 2}=4,5 \mathrm{l} / \mathrm{h}$. Inicialmente se registra un valor de $0,8 \Omega$ y al cabo de 4 horas de funcionamiento la resistencia de la celda aumenta 3,4 veces con respecto al valor correspondiente a tiempo cero, el cual permanece prácticamente constante durante 1 hora bajo las mismas condiciones de operación iniciales (Figura 19).

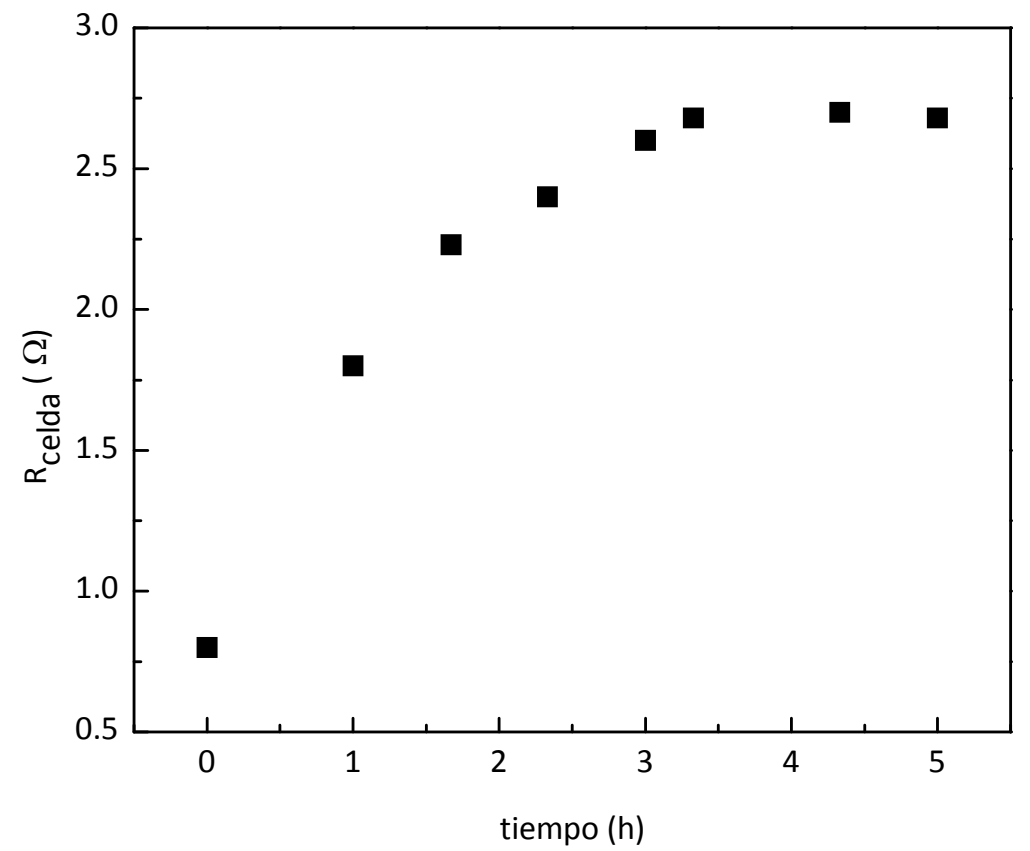

Figura 19. Efecto de la circulación de gases secos sobre la $R_{\text {celda }}$ para $Q_{N 2}=4,5 \mathrm{l} / \mathrm{h}, Q_{H 2}=5 \mathrm{l} / \mathrm{h}$ y $T_{\text {ceda }}=25^{\circ} \mathrm{C}$ después de 5 días de operación.

Comparando los valores de la $R_{\text {celda }}$ para el estado inicial y final de las medidas (día 1 y 5 , respectivamente), bajo las condiciones de trabajo estudiadas con el paso del tiempo de operación, la 
resistencia de la celda de combustible prácticamente se duplica $\left(R_{\text {celda día } 1}=1,46 \Omega\right.$ y $R_{\text {celda día } 5}=2,7 \Omega$ ). Esto podría deberse a que, durante el transcurso de los 5 días, la celda de combustible estuvo operando bajo diferentes condiciones de trabajo incluyendo la circulación de gases húmedos. Por lo tanto, la variación de la $R_{\text {celda }}$ sería debido a la posible formación de una película de óxido generada en los colectores de corriente al trabajar bajo condiciones de humedad.

Se ha evaluado además el efecto del aumento del caudal de nitrógeno sobre la $R_{\text {celda, }} a$ temperatura ambiente y con ambos gases secos $\left(Q_{\mathrm{N} 2}=11 \mathrm{l} / \mathrm{h}\right.$ y $\left.\mathrm{Q}_{\mathrm{H} 2}=5 \mathrm{l} / \mathrm{h}\right)$. Se registra un aumento de la resistencia que se encuentra en el orden del $30 \%$ como resultado del aumento del flujo de nitrógeno.

En la Figura 20 se muestra la variación de la $R_{\text {celda }}$ en función del tiempo de operación. Partiendo de tiempo cero, $R_{\text {celda }}=2,73 \Omega$, se observa un marcado aumento de la resistencia que alcanza un valor de $R_{\text {celda }}=3,3 \Omega$ en aproximadamente 17 minutos, hasta que finalmente, al cabo de 50 minutos, se estabiliza en $R_{\text {celda }}=3,5 \Omega$. Esto representa un valor $28 \%$ más que el de la resistencia inicial correspondiente a tiempo cero.

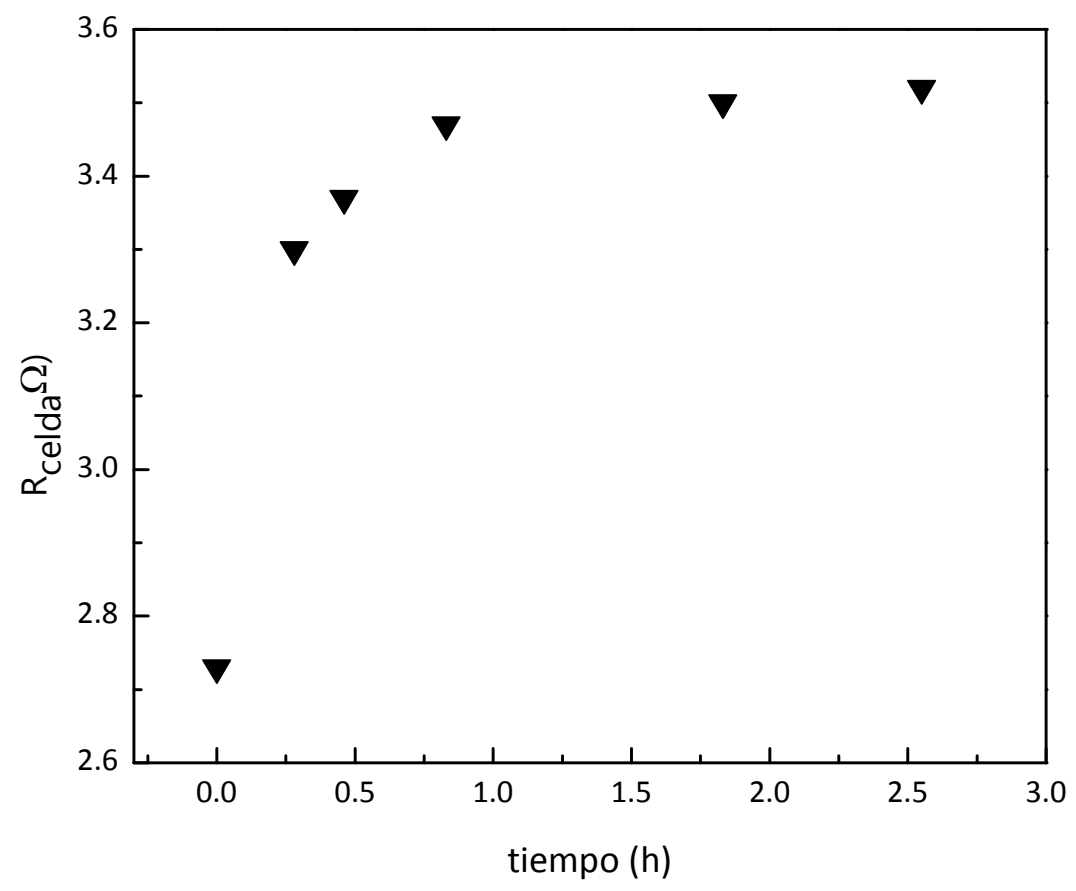

Figura 20. Efecto de la circulación de gases secos sobre la $R_{\text {celda }}$ para $Q_{N 2}=11 \mathrm{l} / \mathrm{h}$ y $T_{\text {ceda }}=25^{\circ} \mathrm{C}$.

En la Figura 21 se representa la variación de la $R_{\text {celda }}$ en función del tiempo de operación para diferentes caudales de nitrógeno $\left(Q_{N 2}=4,5 \mathrm{l} / \mathrm{h}\right.$ y $\left.Q_{N 2}=11 \mathrm{l} / \mathrm{h}\right)$, a $T_{\text {celda }}=25^{\circ} \mathrm{C}$ y con ambos gases secos. Para $Q_{\mathrm{N} 2}=11 \mathrm{l} / \mathrm{h}$, la resistencia logra estabilizarse luego de aproximadamente 1 hora, tiempo a partir del cual no se observan variaciones apreciables, en tanto que cuando la celda de combustible trabaja con $Q_{N 2}=4,5 \mathrm{I} / \mathrm{h}$, se requiere como mínimo 4 horas de operación para que la resistencia alcance un valor constante. 


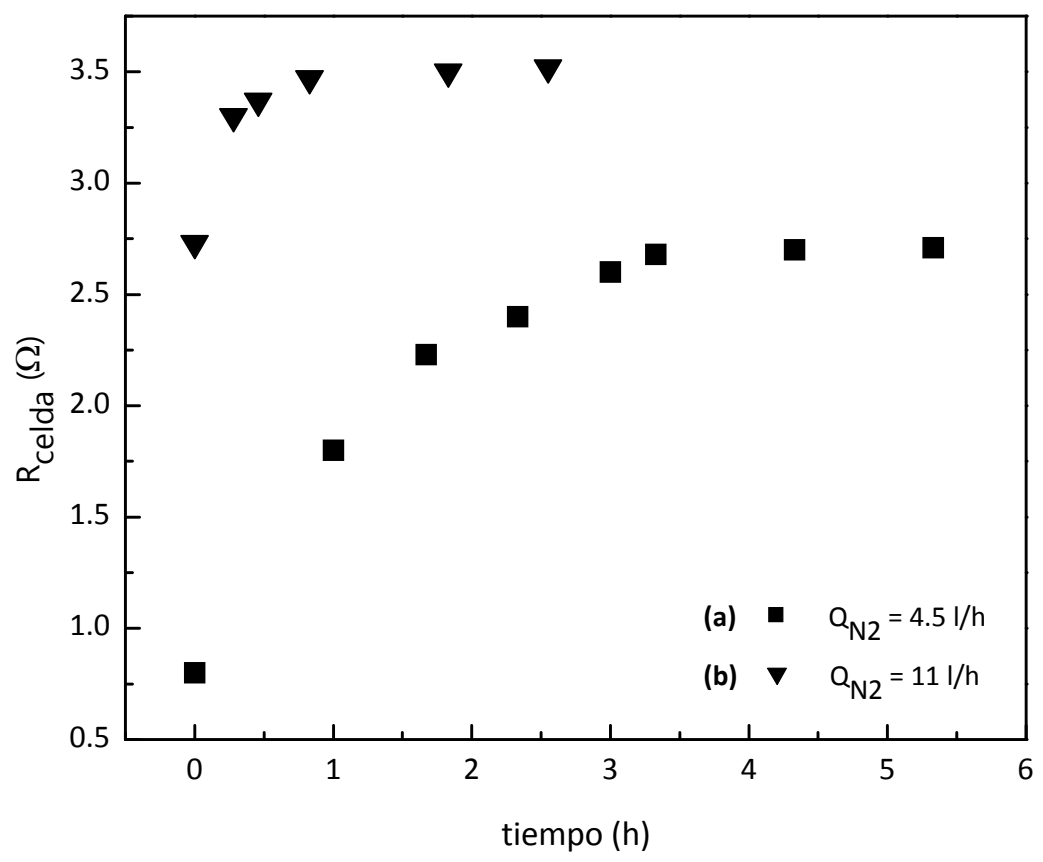

Figura 21. Efecto de la circulación de gases secos sobre la $R_{\text {celda }}$ a $T_{\text {celda }}=25^{\circ} \mathrm{C}$ para (a) $\square Q_{N 2}=4,5 \mathrm{l} / \mathrm{h}$ y (b) $\nabla Q_{N 2}=11 \mathrm{l} / \mathrm{h}$.

Por otra parte, se ha evaluado también el efecto de la humidificación de ambos gases sobre la resistencia de la celda de combustible a temperatura ambiente. Tanto para alto como bajo caudal de nitrógeno la resistencia encontrada es de $0,51 \Omega$, que es un valor estable bajo las condiciones de operación del ensayo, tal como se señaló anteriormente para $Q_{N 2}=4,5 \mathrm{I} / \mathrm{h}$. Por lo tanto, bajo esta situación de humidificación de ambos gases, la resistencia es la misma independientemente del flujo de nitrógeno utilizado.

El aumento de la temperatura de operación de la celda de combustible a $60{ }^{\circ} \mathrm{C}$, humidificando solamente el hidrógeno y a $\mathrm{Q}_{\mathrm{N} 2}=11 \mathrm{l} / \mathrm{h}$, genera un aumento de la resistencia del $71 \%$, respecto al valor encontrado para $\mathrm{Q}_{\mathrm{N} 2}=4,5 \mathrm{l} / \mathrm{h}$, que es de $1,4 \Omega$.

Por otra parte, se ha evaluado el efecto de la disminución de la temperatura de operación de la celda de combustible sobre la resistencia, humidificando el hidrógeno y trabajando con $Q_{\mathrm{N} 2}=11 \mathrm{l} / \mathrm{h}$ (Figura 22). Se observa una marcada caída de la $R_{\text {celda }}$ desde $60{ }^{\circ} \mathrm{C}$ hasta alcanzar un valor aproximadamente constante de $0,65 \Omega$ a $26{ }^{\circ} \mathrm{C}$. Esto representa una disminución del valor de la resistencia del $73 \%$ con respecto al encontrado a $60{ }^{\circ} \mathrm{C}$. En la Figura 22 se distinguen tres zonas, indicadas como (A), (B) y (C). En la zona (A) la temperatura desciende rápidamente en $14{ }^{\circ} \mathrm{C}$, a razón de $1{ }^{\circ} \mathrm{C}$ cada 3 minutos aproximadamente, y se registra una variación de la resistencia de la celda, $\Delta \mathrm{R}_{\text {celda, }}$ igual a $1,18 \Omega$. Para la zona (B) la temperatura también desciende aproximadamente $14{ }^{\circ} \mathrm{C}$ aunque mucho más rápido, es decir, casi $3{ }^{\circ} \mathrm{C}$ por minuto, siendo la $\Delta R_{\text {celda }}=0,52 \Omega$. En la zona (C) la variación de resistencia obtenida es mucho menor, $\Delta \mathrm{R}_{\text {celda }}=0,02 \Omega$ hasta que, finalmente, alcanza un valor de $R_{\text {celda }}=0,65 \Omega$ que se mantiene constante a $T_{\text {celda }}=26^{\circ} \mathrm{C}$. 


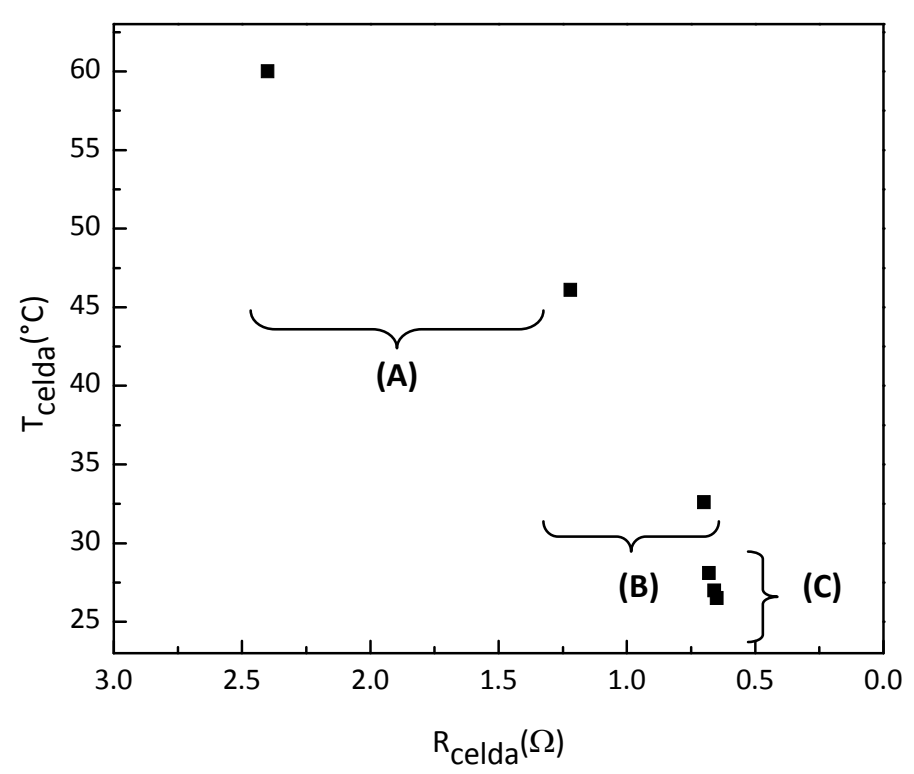

Figura 22. Efecto de la variación de $T_{\text {celda }}$ sobre $R_{\text {celda }}$ para $Q_{N 2}=11 \mathrm{l} / \mathrm{h}$ y humidificación de $H_{2}$.

En la Figura 23 se representa la variación de la $R_{\text {celda }}$ a medida que disminuye la temperatura de la celda de combustible. Inicialmente se observa una disminución abrupta de la resistencia que gradualmente se va estabilizando, hasta llegar a un valor prácticamente constante de 0,65 $\Omega$. Por lo tanto, se concluye que la disminución de la temperatura de operación de la celda de combustible produce también una disminución de su resistencia, hasta finalmente alcanzar un valor constante, característico de las condiciones de temperatura ambiente.

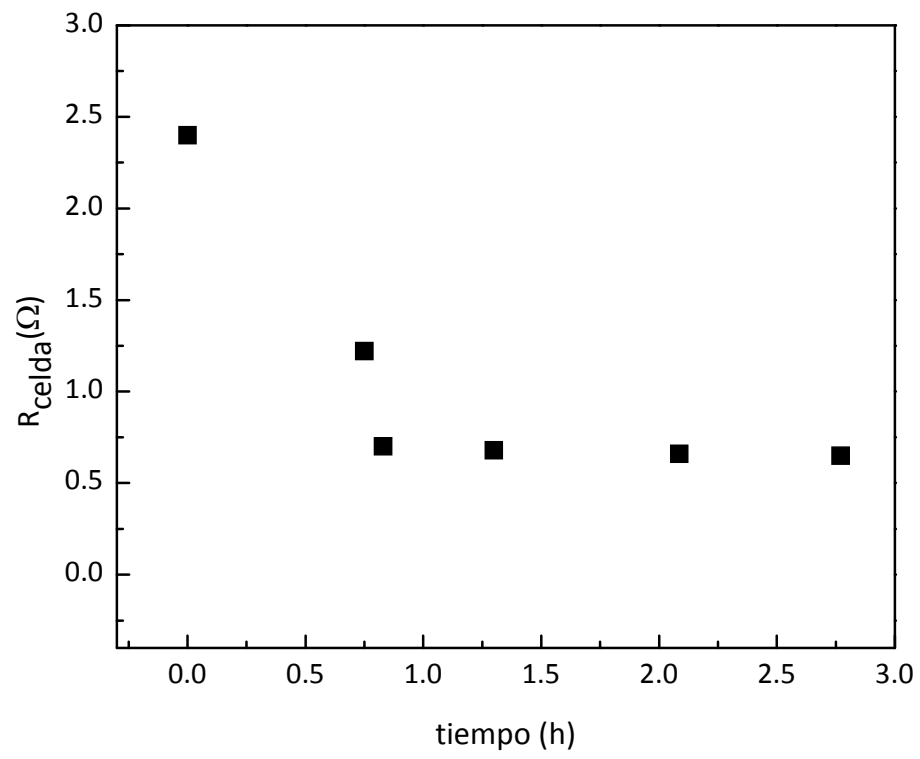

Figura 23. Variación de la $R_{\text {celda }}$ en función del tiempo de enfriamiento de la celda para $Q_{N 2}=11 \mathrm{l} / \mathrm{h}$.

En la Figura 24 se representa la variación de la resistencia de la celda de combustible como resultado del aumento de la temperatura de operación, para $Q_{N 2}=11 \mathrm{l} / \mathrm{h}$ y ambos gases secos. Se observa un aumento gradual de la $\mathrm{R}_{\text {celda }}$ a medida que aumenta la temperatura hasta alcanzar valores de resistencia muy altos asociados a las condiciones extremas de trabajo. 


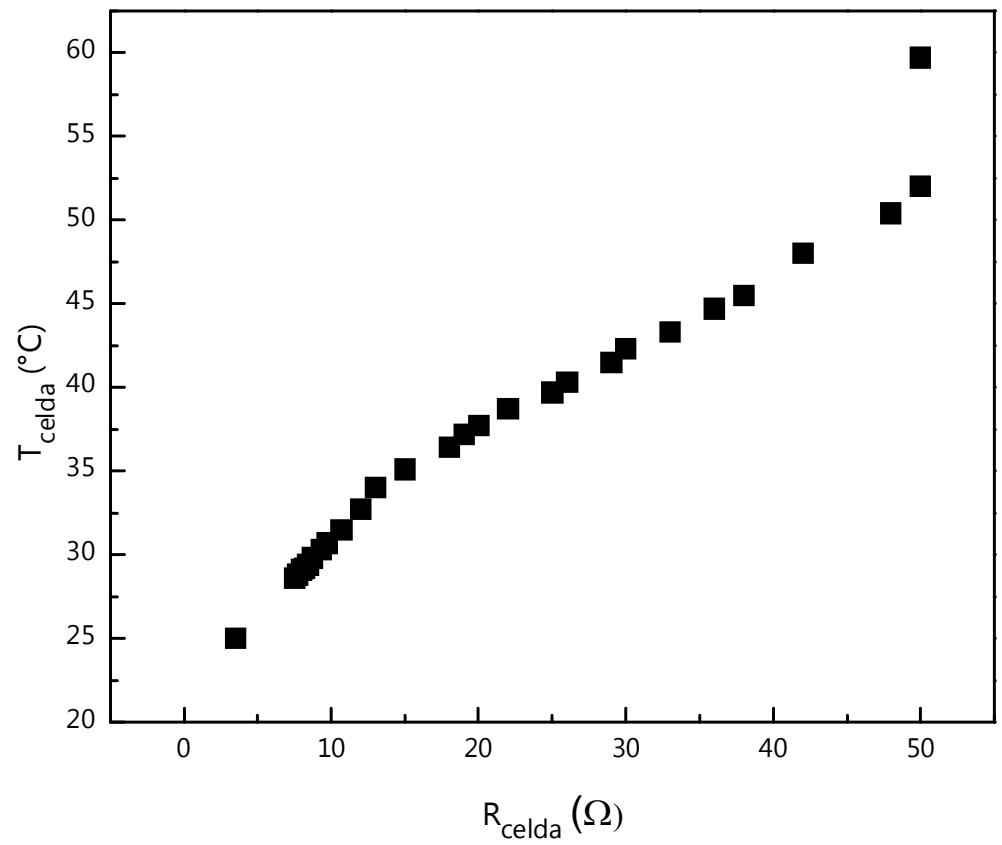

Figura 24. Efecto del aumento de $T_{\text {celda }}$ sobre la $R_{\text {celda }}$ para gases secos y alto caudal de nitrógeno.

El enfriamiento de la celda de combustible, desde $50{ }^{\circ} \mathrm{C}$ a $25^{\circ} \mathrm{C}$, produce una disminución de los valores de resistencia, tal como se observa en la Figura 25 , donde se representa la variación de la $R_{\text {celda }}$ en función del tiempo.

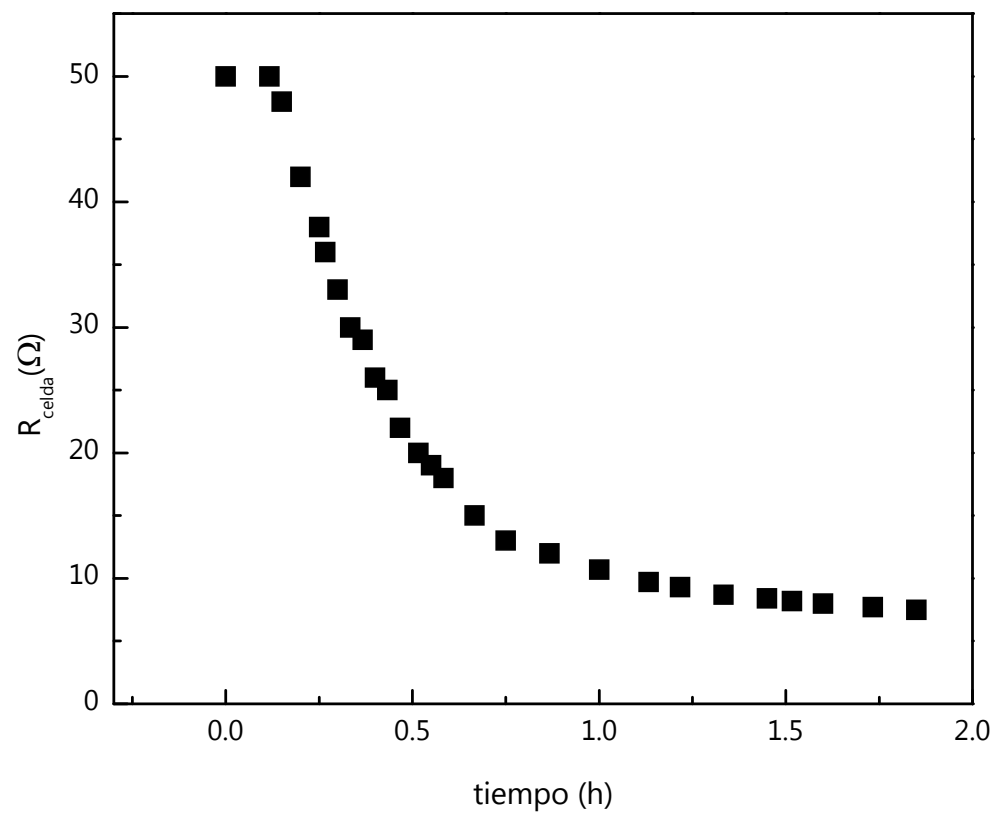

Figura 25. Efecto del enfriamiento de la celda sobre la $R_{\text {celda }}$ para $Q_{N 2}=11 \mathrm{l} / \mathrm{h}$ y gases secos.

La celda se enfría naturalmente en el transcurso de 2 horas aproximadamente, mostrando una variación de tipo exponencial de la $R_{\text {celda }}$ hasta que finalmente alcanza un valor de $R_{\text {celda }}=7,5 \Omega$. De este modo, no se registra el valor de 3,5 $\Omega$, encontrado previamente bajo las mismas condiciones de trabajo (gases secos, alto caudal de nitrógeno, $T_{\text {celda }}=25^{\circ} \mathrm{C}$ ), probablemente debido a las condiciones extremas 
a las que fue sometida la celda de combustible, que generan un aumento de la resistencia por la posible formación de películas de óxido sobre la placa colectora de corriente, además del envejecimiento propio del electrodo.

A fin de evaluar la recuperación de la celda de combustible, una vez alcanzada $\mathrm{T}_{\text {celda }}=25{ }^{\circ} \mathrm{C}$, se hace circular ambos gases humidificados, manteniendo constante los caudales, $Q_{\mathrm{H} 2}=5 \mathrm{l} / \mathrm{h}$ y $Q_{\mathrm{N} 2}=11 \mathrm{l} / \mathrm{h}$. La resistencia de la celda se reduce inmediatamente encontrándose un valor de $0,82 \Omega$. Esto estaría indicando, una vez más, la importancia del adecuado grado de humidificación de los gases antes del ingreso a la celda de combustible, ya que permite disminuir $R_{\text {celda }}$. Luego de aproximadamente 1 hora de humidificación de ambos gases y a temperatura ambiente, se alcanza un valor estable de resistencia de $0,68 \Omega$, que no estaría tan alejado del valor encontrado previamente bajo las mismas condiciones de trabajo (alto caudal de nitrógeno, humidificación de ambos gases y $\mathrm{T}_{\text {celda }}=25^{\circ} \mathrm{C}$ ), situación para la cual se registró un valor de resistencia de 0,51 $\Omega$. Por lo tanto, se concluye que la celda de combustible logra restablecer prácticamente el valor de resistencia característico de las condiciones iniciales de trabajo, por efecto de la utilización de gases humidificados.

El aumento de la temperatura de la celda de combustible a $60{ }^{\circ} \mathrm{C}$, trabajando con humidificación de ambos gases, produce un aumento de la resistencia hasta alcanzar un valor de $0,76 \Omega$, que permanece estable durante 50 minutos aproximadamente. Esto representa un aumento del $49 \%$ respecto al valor de resistencia encontrado para $\mathrm{T}_{\text {celda }}=25{ }^{\circ} \mathrm{C}$, para el mismo caudal de nitrógeno $\left(Q_{N 2}=11 \mathrm{l} / \mathrm{h}\right)$. Por lo tanto $\mathrm{y}$, tal como cabe esperar, se concluye que un aumento de la temperatura de la celda conduce a un aumento de la resistencia. Esto probablemente se debe a efectos de deshidratación de la membrana que se acentúan para $\mathrm{T}_{\text {celda }}=60{ }^{\circ} \mathrm{C}$, aún cuando se trabaja con ambos gases humidificados.

Por otro lado, la disminución de la temperatura de operación de la celda desde $60^{\circ} \mathrm{C}$ a $25{ }^{\circ} \mathrm{C}$ y bajo las mismas condiciones de operación, es decir, alto caudal de nitrógeno y ambos gases humidificados, conduce a un restablecimiento de la resistencia de la celda. Se alcanza nuevamente un valor de $0,52 \Omega$, lo cual que sería coincidente con los valores previamente informados, indicando nuevamente la capacidad de reversibilidad en la respuesta de la celda de combustible frente a variaciones en las condiciones de operación. 



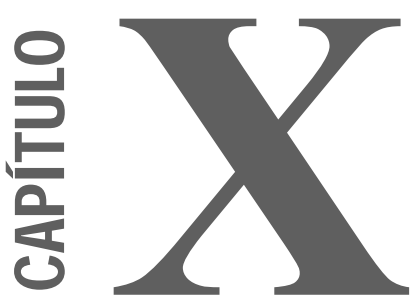

Evaluación del comportamiento en operación de la celda de combustible unitaria prototipo de tecnología PEM 


\section{CAPÍTULOX}

\section{Evaluación del comportamiento en operación de la celda combustible unitaria prototipo de tecnología PEM}

\section{X.1. Consideraciones generales}

En este capítulo se presentan los resultados de la evaluación del comportamiento del módulo unitario de celda de combustible de hidrógeno/oxígeno de tecnología PEM, construido en nuestro laboratorio como parte del desarrollo de la tesis. La celda unitaria prototipo estaba constituida por electrodos porosos de difusión de gas catalizados con nanopartículas de $P t$ policristalinas y una membrana de Nafion 117 como electrolito. Los resultados de la evaluación se compararon con los obtenidos durante el estudio de una celda de combustible unitaria de hidrógeno/oxígeno que utilizaba electrodos porosos con nanopartículas de $P t$ altamente facetadas tipo (111).

Se utilizó una estación de testeo diseñada con los componentes apropiados para permitir tanto el control de los parámetros experimentales de la celda de combustible como así también la adquisición de los datos para la evaluación de su desempeño. La estación de testeo está equipada con controles de temperatura para la celda de combustible y para los humidificadores de los gases reactivos. Esto permite trabajar en un amplio intervalo de temperaturas y condiciones y estudiar el efecto de las variables sobre el comportamiento en operación de la celda de combustible prototipo desarrollada. Las medidas experimentales se llevaron a cabo a $25^{\circ} \mathrm{C}$ y $60^{\circ} \mathrm{C}$ y se compararon las performances de la celda de combustible a estas temperaturas de operación.

Se conoce que la celda de combustible requiere un cuidadoso control del contenido de agua, ya que cualquier deficiencia disminuye la conductividad iónica de la membrana polimérica, que se manifiesta en un aumento de la resistencia. La mejor manera de evitar estos inconvenientes es lograr la adecuada humidificación de los gases reactivos que ingresan a la celda. Por tanto, la celda de combustible unitaria se humidificó mediante el ingreso de los gases reactivos utilizando el mismo sistema que se describió en el capítulo anterior (sección IX.5.b). Se realizaron varios ensayos preliminares a fin de determinar la temperatura a la cual debía encontrarse el sistema de humidificación de los gases de alimentación, de modo que se encuentren saturados con vapor de agua antes del ingreso a la celda. El control de temperatura de los humidificadores se monitoreó mediante un software integrado al sistema de testeo, que incluye sensores ubicados en el baño en el que se encuentra sumergido el sistema de los humidificadores. Estos sensores responden inmediatamente frente a los cambios de temperatura, de modo de se logra mantener constante la temperatura de humidificación a lo largo de las experiencias. Así se asegura, con el ingreso de los gases de alimentación a la celda de combustible, contar con la cantidad de agua necesaria para su adecuado funcionamiento. Esto permite 
evaluar el comportamiento de la celda de combustible unitaria en operación con humidificación y sin humidificación de los gases reactivos. Como resultado de las diferentes pruebas realizadas, se eligió trabajar finalmente con humidificación del gas $\mathrm{H}_{2}$ a $60^{\circ} \mathrm{C}$, temperatura óptima para evitar problemas de inundación o secado de la celda. En la mayoría de las pruebas no se humidificó el $O_{2}$, ya que esto generaba una situación de ahogo de la celda, como se describirá más adelante.

Se trabajó con caudales estequeométricos de los gases, y también con exceso y deficiencia de los mismos. El caudal de los gases de alimentación a la celda de combustible fue controlado manualmente, luego de calibrar los dispositivos de lectura tanto para el hidrógeno como para el oxígeno. Se utilizaron reguladores de presión y medidores de flujo (marca Matheson) para ajustar independientemente la presión y el flujo de gases reactivos. Las medidas de caracterización corriente-potencial fueron realizadas utilizando un potenciostato-galvanostato Autolab y los datos de las curvas de polarización se registraron en un sistema de computación integrado.

En la parte final de este capítulo se describe también un protocolo para la puesta en marcha de celdas de combustible de hidrógeno/oxígeno con tecnología PEM que operan a $60^{\circ} \mathrm{C}$.

\section{X.2. Comportamiento de la celda combustible unitaria bajo diferentes condiciones de operación}

Los estudios sobre el comportamiento en operación de la celda de combustible unitaria construida a partir de los ensambles electrodo-membrana PEM-electrodo desarrollado, se llevaron a cabo mediante mediciones potencial de celda vs. corriente drenada. Se realizaron también medidas de la estabilidad de la celda a tiempos largos y potencial constante $\left(E_{c t e}\right)$ y, periódicamente, se interrumpió $E_{c t e}$ para realizar curvas de polarización y así analizar el desempeño de la celda en operación bajo diferentes condiciones de trabajo.

El área geométrica de los electrodos empleados fue de $4 \mathrm{~cm}^{2}$ y la carga de $P t$ utilizada, tanto para el ánodo como para el cátodo, fue de $1 \mathrm{mg}$ de $P t / \mathrm{cm}^{2}$.

En la Tabla I se muestran las diferentes condiciones estudiadas y posteriormente se presentan los resultados del comportamiento de la celda de combustible prototipo para cada situación mencionada.

Tabla I. Condiciones de operación para la evaluación del comportamiento de la celda de combustible unitaria con nanopartículas de Pt policristalinas.

\begin{tabular}{|c|c|c|c|c|}
\hline Ensayo & $\left.\mathbf{T}_{\text {celda }}{ }^{\circ} \mathbf{C}\right)$ & $\mathbf{Q}_{\mathbf{H 2}}(\mathbf{l} / \mathbf{h})$ & $\mathbf{Q}_{\mathbf{0 2}}(\mathbf{l} / \mathbf{h})$ & Condición de humidificación \\
\hline 1 & 25 & 5 & 4,5 & Gases secos \\
\hline 2 & 25 & 1,33 & 2,66 & Gases secos \\
\hline 3 & 25 & 9 & 4,5 & Gases secos \\
\hline 4 & 25 & 5 & 4,5 & Humidificación de $H_{2}$ \\
\hline
\end{tabular}




\begin{tabular}{|c|c|c|c|c|}
\hline 5 & 60 & 5 & 4,5 & Humidificación de $\mathrm{H}_{2}$ \\
\hline 6 & 60 & 5 & 4,5 & Humidificación de $\mathrm{H}_{2}$ y $\mathrm{O}_{2}$ \\
\hline
\end{tabular}

\section{X.2.a. Ensayo 1: Comportamiento de la celda unitaria a $25^{\circ} \mathrm{C}$ y sin humidificación de gases.}

\section{Activación del electrodo}

Se evaluó el comportamiento en operación de la celda de combustible unitaria, operando a $25^{\circ} \mathrm{C}$ y $\sin$ humidificación de gases, con caudales fijos de gases reactivos $Q_{H 2}=5 \mathrm{l} / \mathrm{h}$ y $Q_{02}=4,5 \mathrm{l} / \mathrm{h}$. Estas condiciones de trabajo, si bien parecen poco favorables para una celda de combustible por la lentitud de las reacciones electródicas a esa temperatura, permiten tener una primera idea del comportamiento general de la celda. Se realizaron diferentes pruebas que permiten la activación de los electrodos porosos de difusión de gas que conforman el ensamble. Una prueba preliminar, luego del ajuste de la celda para evitar posibles fugas, dio como resultado un potencial de circuito abierto, $E_{c a}$, de $0,90 \mathrm{~V}$, que es un resultado satisfactorio, ya que en la bibliografía se informan valores de $E_{c a}$ entre 0,90 y $1,00 \mathrm{~V}$ para celdas de combustible tipo PEM con cargas de catalizador de 0,4 mg de $P t / \mathrm{cm}^{2}$ [412]. Además, es un valor muy cercano al potencial estándar de una celda de hidrógeno/oxígeno, que es de $1,23 \mathrm{~V}$ a 1 atmósfera de presión y $25^{\circ} \mathrm{C}$. Si bien en una celda de combustible en medio ácido el potencial debería ser 1,23 V, difícilmente se observan potenciales superiores a 1,00 V debido a que la reacción de electrorreducción del oxígeno es muy lenta y cualquier reacción paralela como, por ejemplo, la formación de pequeñas cantidades de $\mathrm{H}_{2} \mathrm{O}_{2}$ a través del mecanismo de reducción del oxígeno por 2 electrones, puede hacer disminuir el potencial observado. El mismo efecto de reducción del valor de $E_{c a}$ es producido también por la oxidación de impurezas del electrodo. Por otro lado, si se observan valores de $E_{c a}$ muy inferiores a $0,90 \mathrm{~V}$, podrían indicar una posible mezcla de gases reactivos a través del electrolito. Por lo tanto, se puede utilizar también este criterio del valor de $\mathrm{E}_{\mathrm{ca}}$ para diagnosticar la presencia de mezcla de gases en la celda de combustible.

La curva de polarización (Figura 1), obtenida bajo las condiciones de trabajo mencionadas en esta sección, muestra el perfil típico de una celda de combustible de hidrógeno/oxígeno, donde se distinguen las diferentes regiones características de los fenómenos limitantes descriptos anteriormente (CAPÍTULO VII). La densidad de potencia máxima calculada para esta situación particular de estudio fue de 0,14 $\mathrm{W} / \mathrm{cm}^{2}$ a $i=0,38 \mathrm{~A} / \mathrm{cm}^{2}$. 


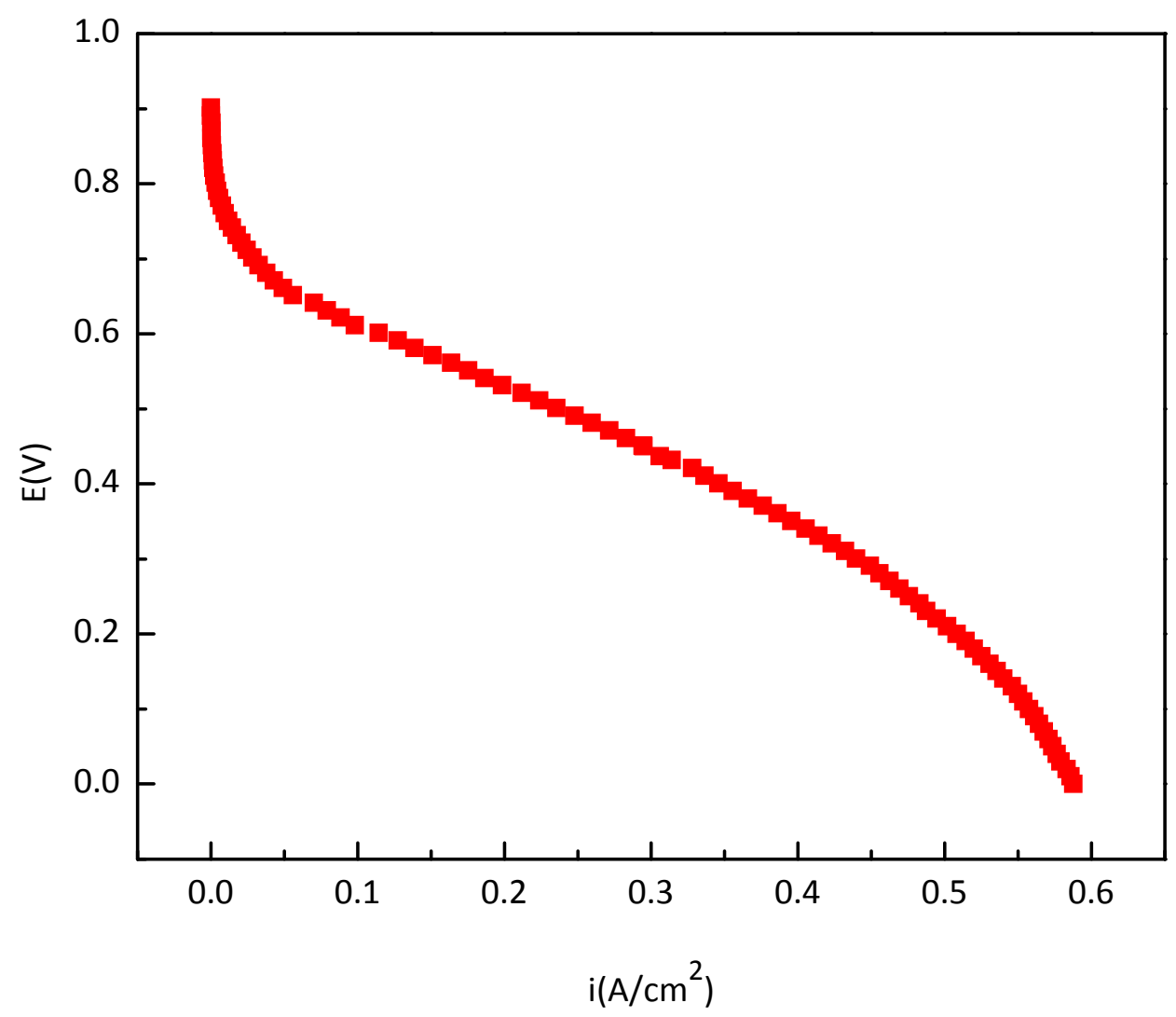

Figura 1. Curva de polarización para la celda de combustible unitaria de hidrógeno/oxígeno a $\mathrm{T}_{\text {celda }}=25^{\circ} \mathrm{C}$ y $\sin$ humidificación de gases.

Se evaluó la estabilidad de la corriente generada por la celda aplicando un potencial constante, $E_{c t e}$ de $0,5 \mathrm{~V}$ durante 100 minutos, registrando la corriente drenada por la celda en función del tiempo. La corriente desciende 0,4 A en este intervalo de tiempo, hasta que finalmente se estabiliza en 1,1 A. Se denominará a este proceso como activación 1 de ahora en adelante.

Las curvas de polarización realizadas posteriormente, bajo las mismas condiciones de trabajo que las mencionadas anteriormente, esto es, $T_{\text {celda }}=25^{\circ} \mathrm{C}$ y gases secos $Q_{\mathrm{H} 2}=5 \mathrm{l} / \mathrm{h}, Q_{\mathrm{O} 2}=4,5 \mathrm{l} / \mathrm{h}$, muestran ciertos cambios. En la Figura 2 se presenta la superposición de las curvas características E vs. i, antes y después del tratamiento por aplicación de $E_{c t e}=0,5 \mathrm{~V}$ (activación 1). Se registra un leve aumento del potencial de circuito abierto, $E_{c a}$ de $60 \mathrm{mV}$ y una mejor definición de las regiones de sobrepotencial de activación y de concentración. La mejora en el comportamiento de la celda de combustible se podría atribuir, en principio, a un efecto de activación de los electrodos de la celda por aplicación de $\mathrm{E}_{\text {cte. }}$. Se calculó una densidad de potencia máxima de $0,18 \mathrm{~W} / \mathrm{cm}^{2}$ a $i=0,48 \mathrm{~A} / \mathrm{cm}^{2}$ luego del proceso de activación 1, que representa un aumento del $22 \%$ con respecto a la primer medida. 


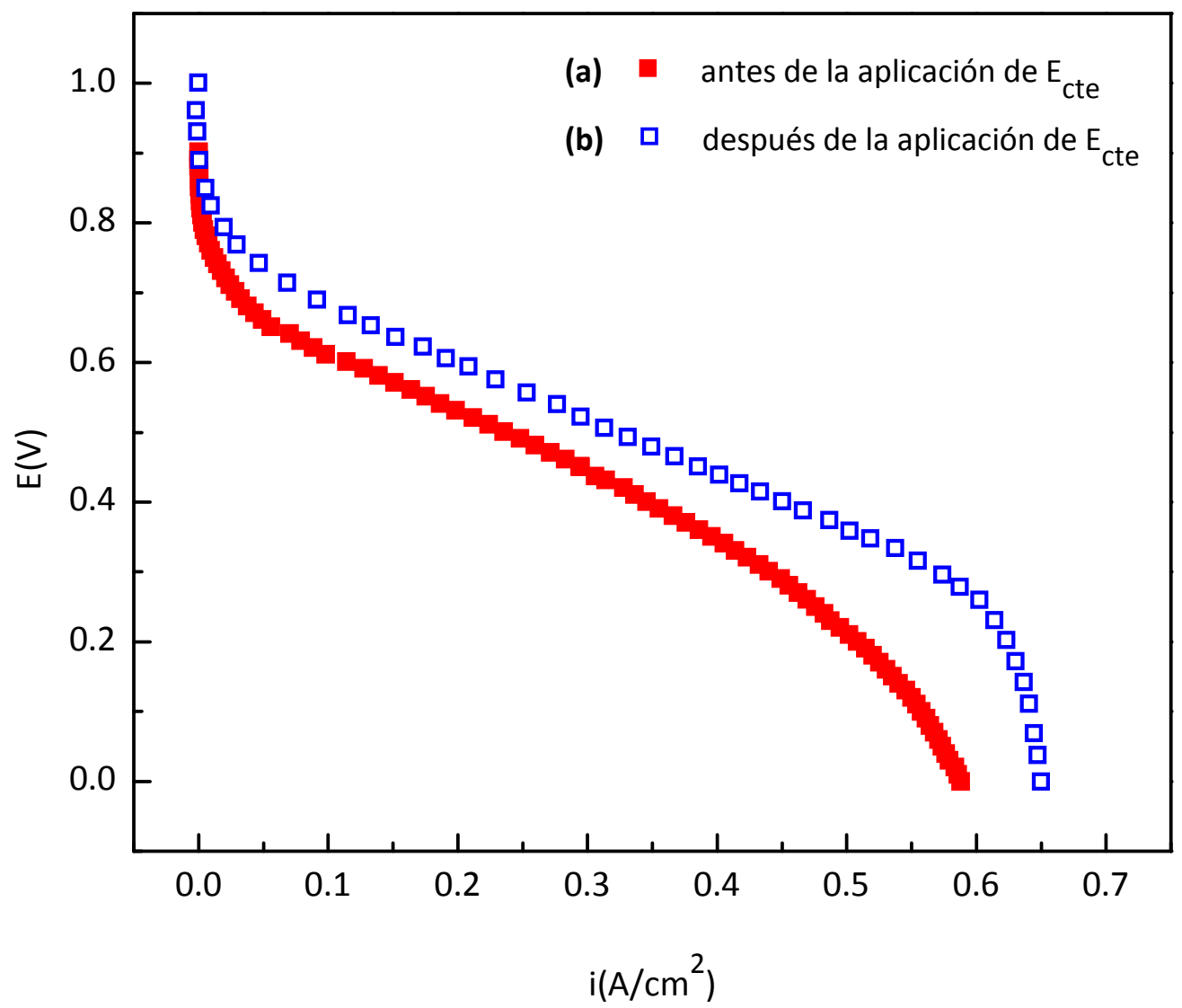

Figura 2. Curvas de polarización bajo condiciones de operación $T_{\text {celda }}=25^{\circ} \mathrm{C}, \mathrm{Q}_{\mathrm{H} 2}=5 \mathrm{I} / \mathrm{h}, \mathrm{Q}_{\mathrm{O2}}=4,5 \mathrm{I} / \mathrm{h}$, gases secos (a) $=$ antes y (b) $\square$ después de la aplicación de $E_{c t e}=0,5 \mathrm{~V}$ (activación 1).

Las curvas de polarización muestran las tres zonas típicas de pérdidas de energía por sobrepotencial de activación (a bajas densidades de corriente), pérdidas por resistencias óhmicas (a densidades de corriente intermedias) y pérdidas por transporte de masa (a altas densidades de corriente). En la primer región, la dependencia del potencial con la corriente sigue la ecuación de Tafel, siendo el sobrepotencial de activación predominante. A continuación de esta región, el potencial disminuye de forma aproximadamente lineal con la corriente. Esta segunda región está dominada por los efectos óhmicos debidos a la resistencia de los materiales conductores al pasaje de la corriente y a la resistencia al transporte de iones en el electrolito. Los materiales utilizados en la celda de combustible unitaria construida son buenos conductores y, por lo tanto, se puede decir que el segundo efecto de resistencia al transporte de iones a través del electrolito es el más importante, lo cual, como se mencionó en capítulos anteriores, está fuertemente influido por el grado de hidratación de la membrana polimérica. Finalmente, para densidades de corrientes mayores, se observa una acentuada caída de potencial debido a limitaciones en el transporte de masa, que pueden ocurrir por diversas situaciones, tales como:

i. el gas reactivo, cuya demanda en esta región de potenciales aumenta notablemente, puede tener acceso limitado al electrodo,

ii. el gas reactivo puede tener acceso limitado al catalizador por procesos de difusión en el electrolito. 
Por otra parte, la conductividad iónica puede limitar el acceso de iones que participan en la reacción, tal como los $H^{+}$, en la reducción de oxígeno.

Si se continúa aplicando un potencial constante, $E_{c t e}$ de $0,5 \mathrm{~V}$ a la celda de combustible y se registra la corriente drenada en función del tiempo, se obtienen gráficas como la presentada en la Figura 3 (designado de ahora en adelante como activación 2). Inicialmente, a tiempo cero, no se drena corriente y el único valor registrado es el correspondiente a $\mathrm{E}_{\mathrm{ca}}$. Cuando la celda comienza a drenar corriente, a $E_{c t e}$, se alcanza inmediatamente un valor de corriente de 1,3 $\mathrm{A}$, que posteriormente se estabiliza en 1,2 A durante 1 hora, tiempo suficiente para demostrar la estabilidad de la corriente alcanzada cuando se trabaja a $E_{\text {cte }}$.

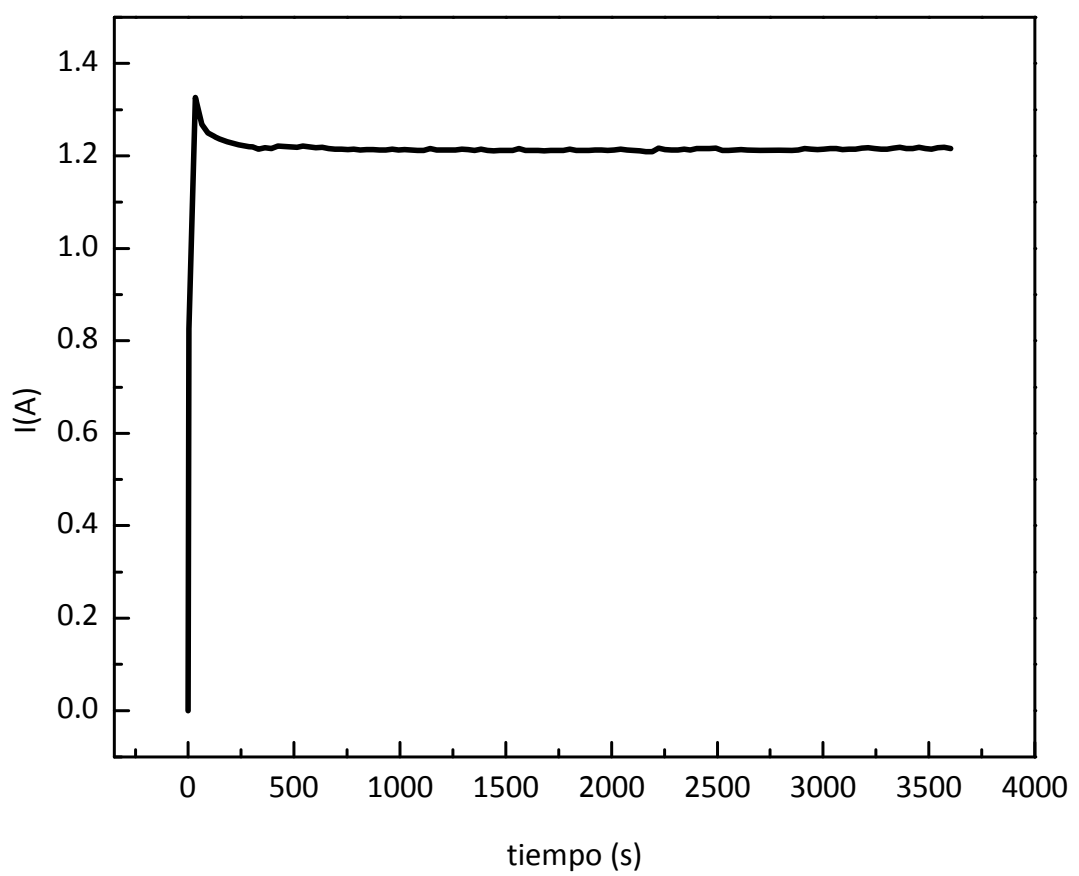

Figura 3. Estabilización de la corriente aplicando $E_{c t e}=0,5 \mathrm{~V}$ (activación 2).

En la Tabla II se muestran los valores de densidad de corriente y de potencial obtenidos antes y después de la aplicación del potencial constante, $E_{c t e}$ de 0,5 V (activación 2). Se registra un leve aumento del $E_{c a}$ que alcanza un valor de 1,04 V y una de densidad de corriente final de 0,65 A/cm².

Tabla II. Valores de potencial y corriente (a) antes y (b) después de la aplicación de $\mathrm{E}_{\mathrm{cte}}=\mathbf{0 , 5} \mathrm{V}$ (activación 2).

\begin{tabular}{|c|c|c|}
\hline Experiencia & $i_{\text {máx }}\left(\mathbf{A} / \mathrm{cm}^{2}\right)$ & $E_{\mathrm{ca}}(\mathbf{V})$ \\
\hline \hline (a) antes de activación 2 (medida inicial) & $0,587 \mathrm{~A} / \mathrm{cm}^{2}$ & 0,9 \\
\hline (b) después de activación 2 & $0,65 \mathrm{~A} / \mathrm{cm}^{2}$ & 1,04 \\
\hline
\end{tabular}


Se ha evaluado también la performance de la celda de combustible unitaria luego de 8 días de operación. Cabe aclarar que durante este período de tiempo la celda fue sometida a diferentes condiciones de trabajo, como por ejemplo, variaciones del caudal de los gases reactivos, variaciones en la temperatura de operación de la celda, distintos grados de humidificación de los gases de alimentación, etc. En las curvas de polarización, en la zona de bajas densidades de corriente, no se observan grandes cambios. Se evidencia una caída de potencial en la zona lineal controlada principalmente por pérdidas óhmicas [Figura 4(c)], probablemente debido a un aumento de la resistencia de la celda. Los valores de las pendientes de esta zona lineal, asociada a efectos óhmicos, registran un incremento que se debería al aumento de la resistencia de la celda de combustible con el transcurso del tiempo de operación. Es así como, inicialmente, la resistencia $\mathrm{R}$, medida a través de la pendiente $E$ vs. i, es de $0,197 \Omega$ y al cabo de 8 días de operación aumenta alcanzando un valor de $0,331 \Omega$.

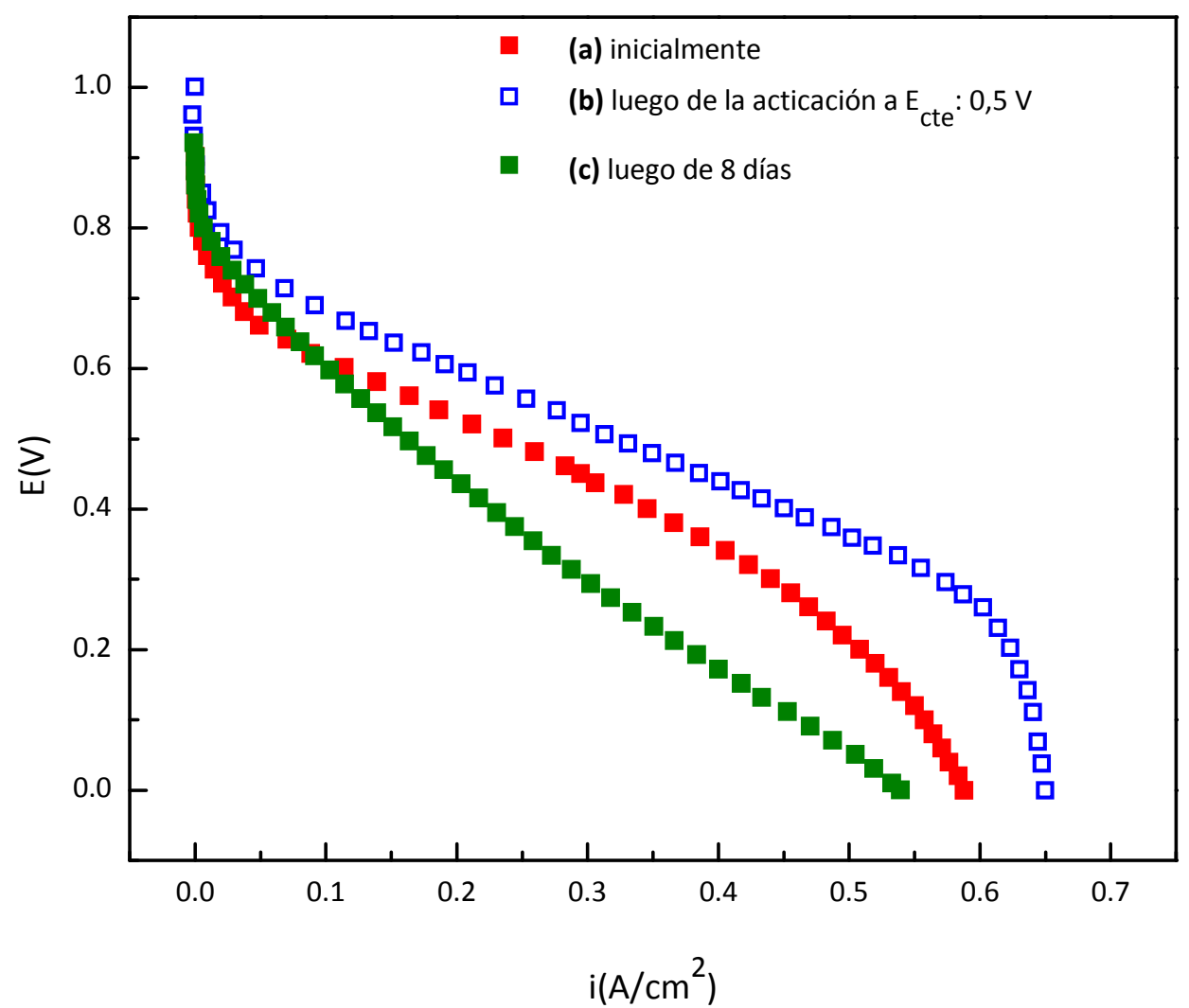

Figura 4. Curvas de polarización de la celda de combustible (a) $\square$ inicialmente, (b) $\square$ luego del proceso de activación 1 por aplicación de $\mathrm{E}_{\mathrm{cte}}=0,5 \mathrm{~V}$ y $(\mathrm{c})$ a luego de 8 días de operación.

La corriente máxima, $I_{\text {máx, }}$ que se puede drenar con la celda de combustible proporciona información acerca del fenómeno de transporte de masa por difusión. A medida que la velocidad de la reacción de transferencia de carga en la superficie de un electrodo sobrepasa a la de transferencia de masa, la concentración de la especie reactiva en la misma desciende a cero y se presenta una corriente máxima o límite que, para el caso analizado, resulta menor al cabo de 8 días de operación, alcanzando un valor $i_{\text {máx }}$ de $0,54 \mathrm{~A} / \mathrm{cm}^{2}$. Por este motivo también, en la región de altas corrientes, no se define bien 
la zona característica del sobrepotencial de concentración. Por otra parte, para corrientes intermedias, se observa que la zona lineal es amplia, debido a que el sobrepotencial óhmico es el que causa mayores pérdidas [Figura 4 (c)]. En contraste, la Figura 4 (b), presenta menor sobrepotencial óhmico, que viene dado por una menor pendiente $y$, por otra parte, se define mejor la zona asociada al sobrepotencial de concentración para altas corrientes drenadas, lo que permite una identificación más clara de $I_{\text {máx}}$.

La densidad de potencia obtenida luego de 8 días de operación muestra una notable disminución. Se calculó un valor de $0,092 \mathrm{~W} / \mathrm{cm}^{2}$ a $i=0,26 \mathrm{~A} / \mathrm{cm}^{2}$, que representa un $49 \%$ menos que los valores obtenidos luego de la aplicación de un potencial constante de activación. Esta disminución en el valor de la densidad de potencia estaría relacionada, en principio, con el aumento de la resistencia de la celda con el transcurso del tiempo de operación.

\section{X.2.b. Ensayo 2: Efecto de la disminución del caudal de $\mathrm{H}_{2}$ y $\mathrm{O}_{2}$}

Se ha estudiado el efecto de la variación de los caudales, tanto del hidrógeno como del oxígeno, sobre el comportamiento de la celda unitaria en operación. Todas las demás condiciones se mantuvieron constantes, esto es, $\mathrm{T}_{\text {celda }}=25{ }^{\circ} \mathrm{C}$ y ambos gases secos. Inicialmente se utilizaron como caudales de alimentación $Q_{\mathrm{H} 2}=1,33 \mathrm{l} / \mathrm{h}$ y $Q_{02}=2,66 \mathrm{l} / \mathrm{h}$. La curva de polarización muestra una caída del potencial de celda (Figura 5), como resultado de la utilización de caudales de gases de alimentación insuficientes.

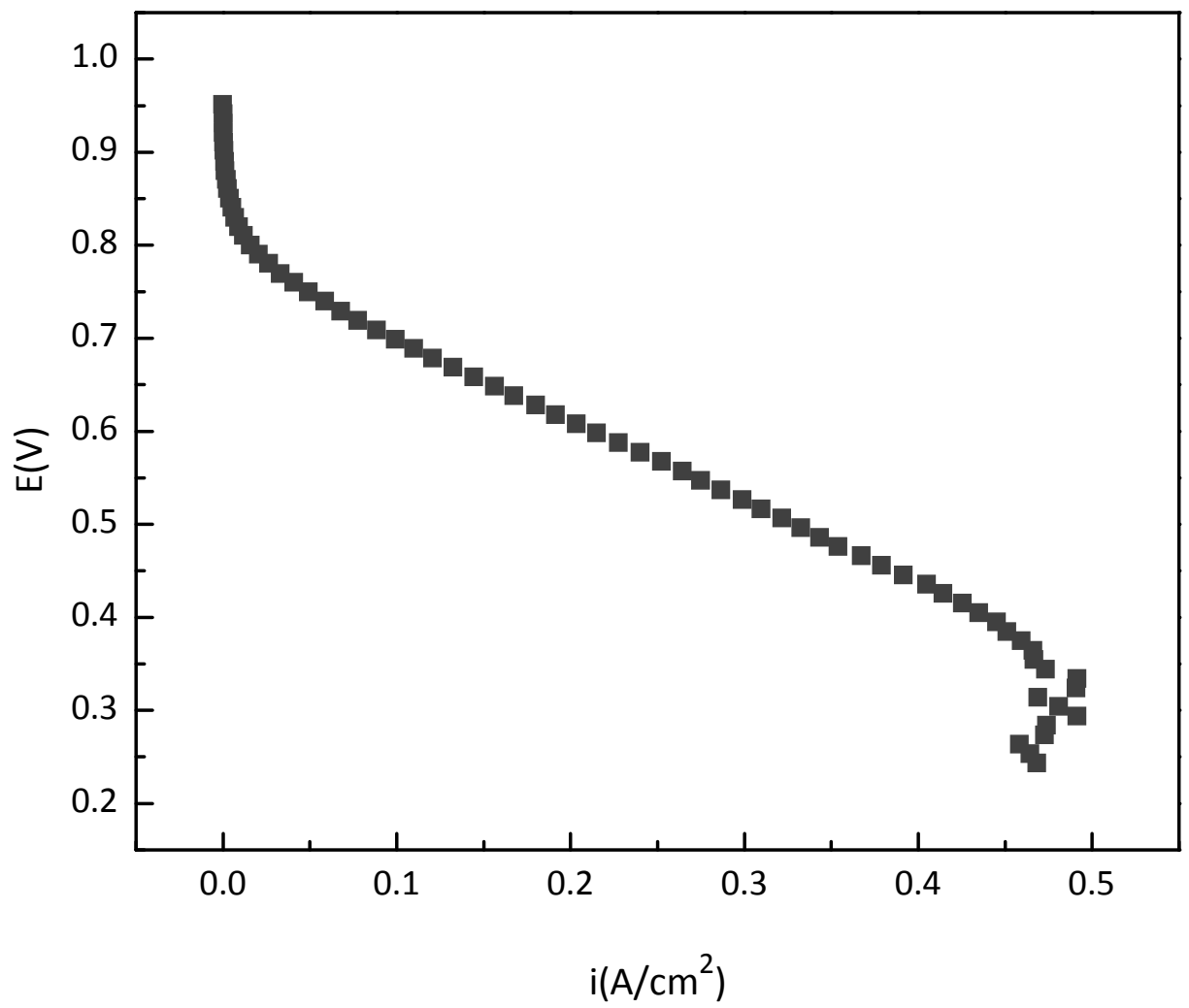

Figura 5. Curva de polarización con deficiencia de gases de alimentación secos, $Q_{\mathrm{H} 2}=1,33 \mathrm{l} / \mathrm{h}$ y $Q_{02}=2,66 \mathrm{l} / \mathrm{h}$ a $\mathrm{T}_{\text {celda }}=25^{\circ} \mathrm{C}$. 
La disminución de los caudales no tiene un efecto apreciable sobre el perfil de la curva de polarización, salvo a altas corrientes donde el potencial disminuye rápidamente. Esto ocurre porque las reacciones se desaceleran notablemente, generando una caída abrupta de la curva característica E vs. i para densidades de corriente que se encuentran en el orden de $0,47 \mathrm{~A} / \mathrm{cm}^{2}$. Por lo tanto, la utilización de caudales bajos de los gases reactivos genera un impacto significativo en el comportamiento de la celda unitaria, registrándose cierta inestabilidad en el sistema y dando lugar, finalmente, a una caída del potencial y disminución de las corrientes drenadas.

La deficiencia de los gases de alimentación, en particular del hidrógeno, se puede evidenciar en las conexiones de salida de los gases, que se encuentran sumergidas en agua. De este modo, trabajando con caudales óptimos, se observa un burbujeo constante en la conexión de salida del gas, en tanto que con caudales deficientes el burbujeo disminuye en la medida en que se drenan mayores corrientes, hasta detenerse por completo, en particular, del lado del ánodo. El potencial cae rápidamente debido a que el hidrógeno, en el compartimiento del ánodo, se consume por completo para densidades de corrientes que se encuentran en el orden de $0,47 \mathrm{~A} / \mathrm{cm}^{2}$. Por otro lado, no se observan limitaciones en la curva de polarización atribuibles al cátodo, dentro del intervalo de corrientes drenadas, por lo que el burbujeo a la salida del compartimiento catódico disminuye pero no se detiene. Se puede definir como punto muerto a la situación para la cual el potencial cae rápidamente y la celda de combustible no puede continuar operando por falta de suministro adecuado de gases de alimentación [413]. De este modo, la celda se ve impedida de operar a corrientes iguales o mayores a las correspondientes al punto muerto.

Alimentando la celda de combustible con caudales de gases $Q_{\mathrm{H} 2}=5 \mathrm{l} / \mathrm{h}$ y $Q_{\mathrm{O} 2}=4,5 \mathrm{l} / \mathrm{h}$ se restablece gradualmente la curva de polarización (Figura 6).

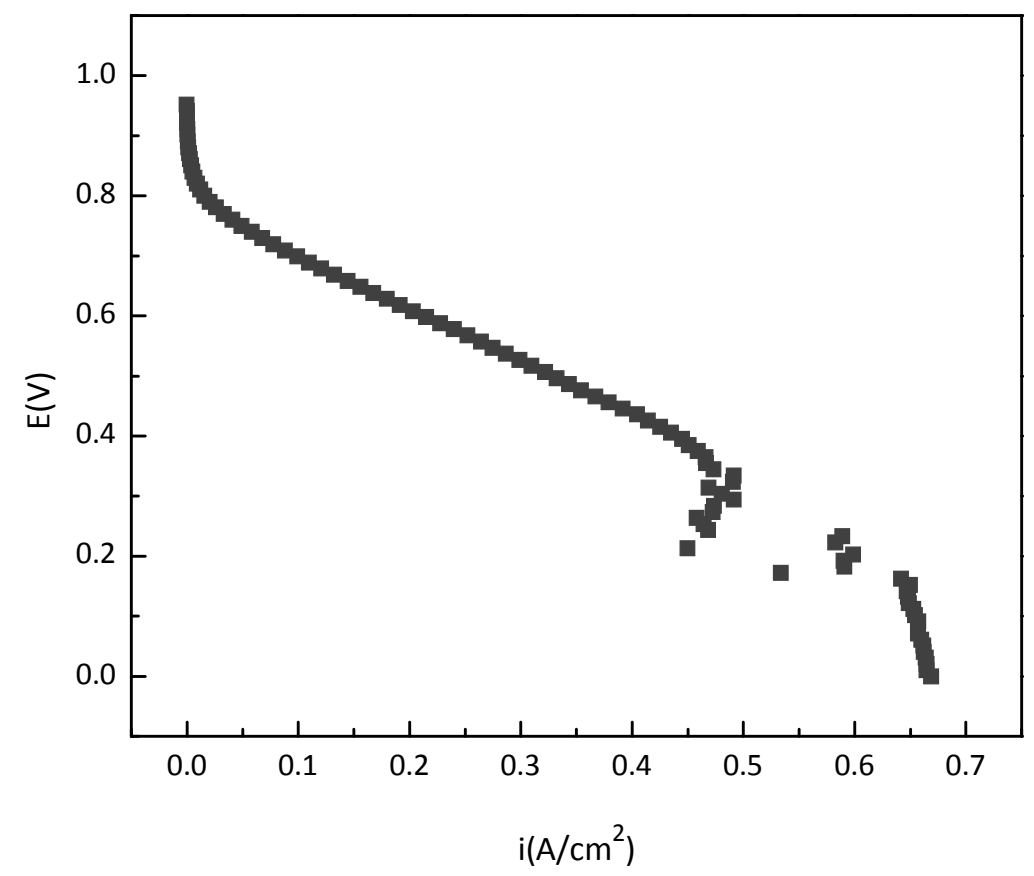

Figura 6. Restablecimiento de la curva de polarización por aumento del caudal de los gases de alimentación $Q_{H 2}=5 \mathrm{I} / \mathrm{h} ; Q_{02}=4,5 \mathrm{l} / \mathrm{h}$, gases secos a $T_{\text {celda }}=25^{\circ} \mathrm{C}$. 
La corriente máxima alcanzada es similar a la encontrada luego del proceso de activación 2, como se indicó en la Figura 4 (b). Por lo tanto, el aumento de los caudales de los gases reactivos, tanto del hidrógeno como del oxígeno, minimizan los efectos limitantes producidos por la insuficiencia de los caudales de gases de alimentación.

La Figura 7 muestra el efecto de la utilización de bajos caudales de gases reactivos sobre la curva de densidad de potencia y el restablecimiento que se consigue aumentando los caudales de los gases de alimentación.

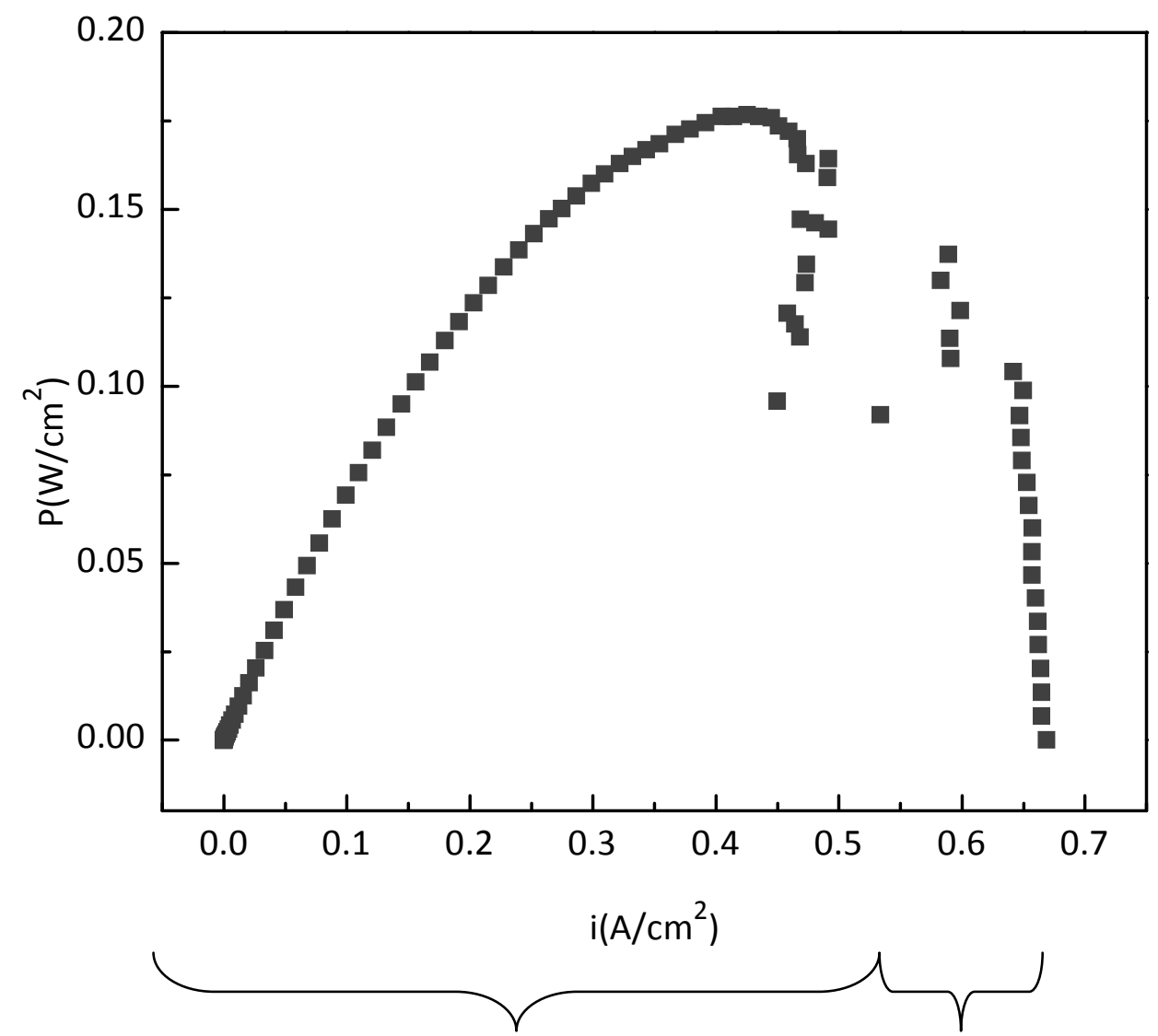

(a)

(b)

Figura 7. Efecto de los caudales $Q_{\mathrm{H} 2}$ y $Q_{\mathrm{O} 2}$ sobre la densidad de potencia de la celda: (a) disminución y (b) aumento de caudales.

\section{X.2.c. Ensayo 3: Efecto del aumento del caudal de $H_{2}$}

Aumentando el caudal de hidrógeno, $Q_{\mathrm{H} 2}$, a $9 \mathrm{l} / \mathrm{h}$ y manteniendo todas las demás condiciones, es decir, gases secos, $\mathrm{T}_{\text {celda }}=25^{\circ} \mathrm{C}$ y $\mathrm{Q}_{02}=4,5 \mathrm{l} / \mathrm{h}$, se obtienen curvas de polarización características para la celda prototipo como la que se muestra en la Figura 8, donde también se presenta la curva de densidad de potencia. La densidad de potencia máxima calculada fue de $0,17 \mathrm{~W} / \mathrm{cm}^{2}$ a una densidad de corriente de aproximadamente $0,44 \mathrm{~A} / \mathrm{cm}^{2}$, que es del mismo orden que la obtenida luego del proceso de activación $1\left(0,18 \mathrm{~W} / \mathrm{cm}^{2}\right.$, Ensayo 1). La máxima densidad de corriente alcanzada fue de $0,609 \mathrm{~A} / \mathrm{cm}^{2}$. 


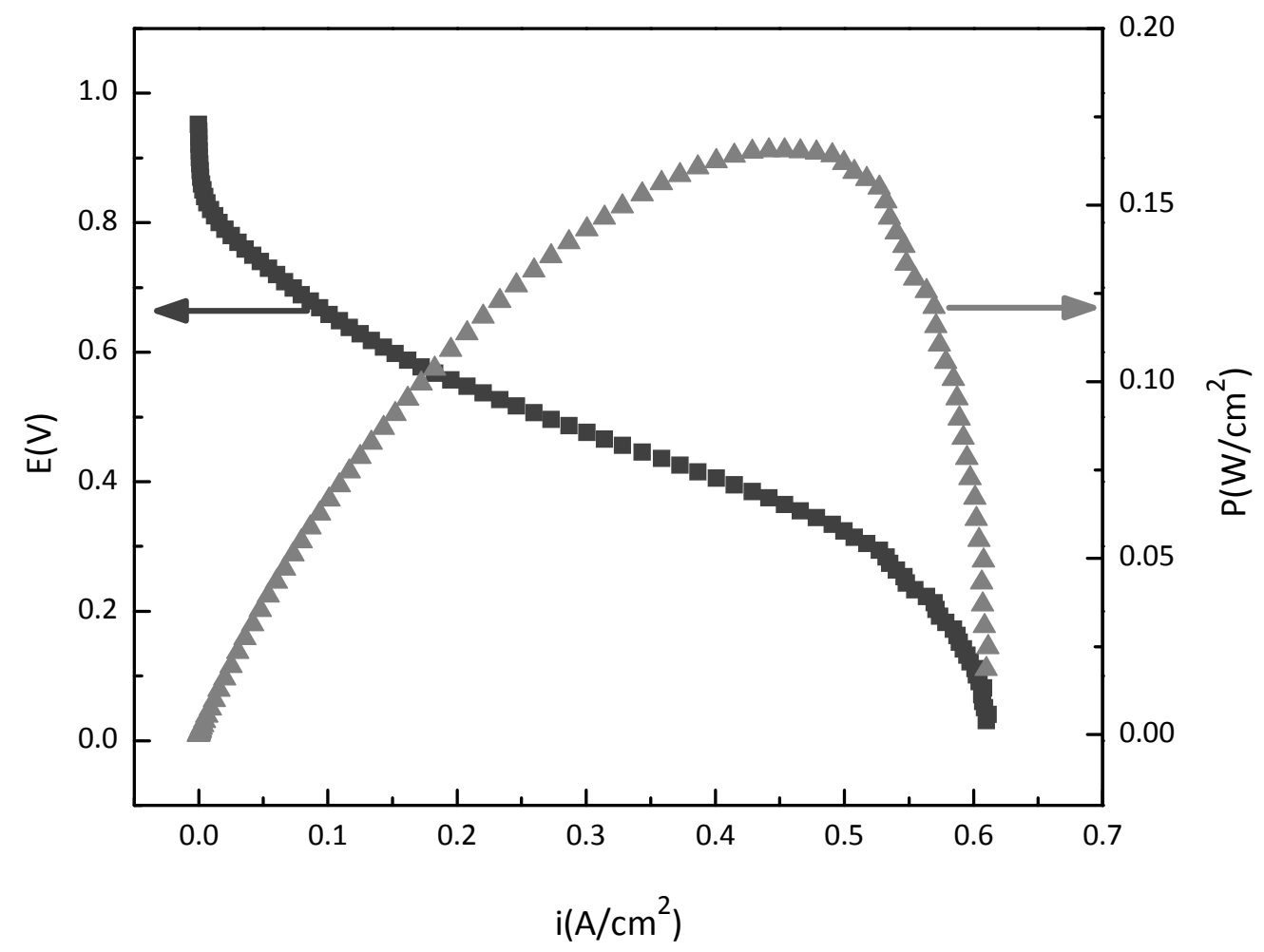

Figura 8. Curvas de polarización y de densidad de potencia para la celda de combustible unitaria a $Q_{\mathrm{H} 2}=9 \mathrm{l} / \mathrm{h}$, $\mathrm{Q}_{02}=4,5 \mathrm{l} / \mathrm{h}$, gases secos $\mathrm{a} \mathrm{T}_{\text {celda }}=25^{\circ} \mathrm{C}$.

\section{X.2.d. Ensayo 4: Efecto de la humidificación del gas $H_{2}$}

Se trabajó a $T_{\text {celda }}=25^{\circ} \mathrm{C}$ y a caudales constantes de gases $Q_{H 2}=5 \mathrm{I} / \mathrm{h}$ y $Q_{02}=4,5 \mathrm{I} / \mathrm{h}$ humidificando el gas hidrógeno. Se comparó el comportamiento de la celda en operación con la situación antes analizada cuando la celda opera bajo las mismas condiciones, pero con gases completamente secos (Ensayo 1). Las curvas de polarización no muestran variaciones apreciables respecto a su perfil, tal como se indica en la Figura 9, donde se presentan las curvas características E vs. i cuando se alimenta a la celda de combustible con hidrógeno humidificado o ambos gases secos. Se observa un leve aumento del $\mathrm{E}_{\mathrm{ca}}$ de $41 \mathrm{mV}$ por efecto de la humidificación del gas hidrógeno. A densidades de corrientes intermedias, del orden de $0,26 \mathrm{~A} / \mathrm{cm}^{2}$, el voltaje de la celda de combustible se incrementa aproximadamente en 71 $\mathrm{mV}$. La densidad de corriente máxima, de aproximadamente $0,54 \mathrm{~A} / \mathrm{cm}^{2}$, es la misma tanto para la condición de humidificación de hidrógeno como para ambos gases secos. Esto podría explicarse considerando el efecto de autohumidificación de la celda de combustible, que se produce principalmente a altas densidades de corriente. Así, como resultado de la propia reacción electroquímica que se lleva a cabo en la celda de combustible, cuando se drenan altas densidades de corriente, se produce agua en el compartimiento catódico. La cantidad de agua generada sería suficiente para permitir que, bajo la condición de operación con gases secos, se obtengan valores de densidad de corriente similares a los encontrados cuando la celda se alimenta con hidrógeno humidificado. 


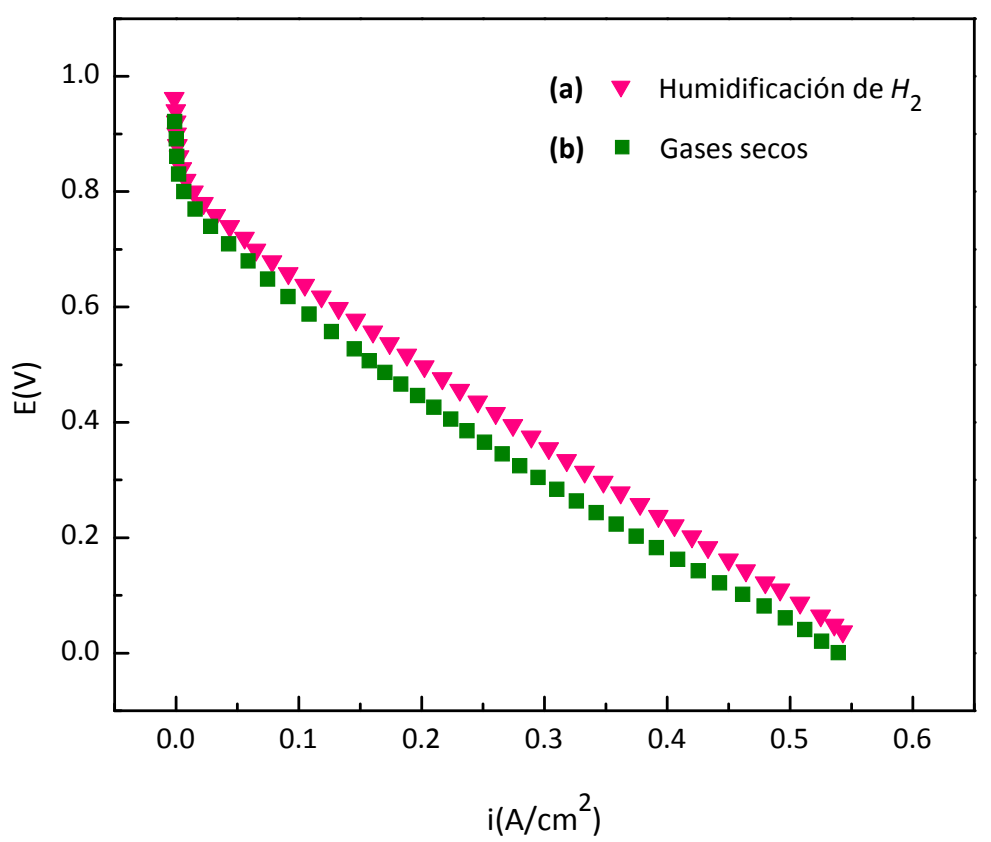

Figura 9. Efecto de la humidificación del $H_{2}$ sobre las curvas de polarización a $T_{\text {celda }}=25^{\circ} \mathrm{C}, Q_{\mathrm{H} 2}=5 \mathrm{l} / \mathrm{h}$, $\mathrm{Q}_{02}=4,5 \mathrm{l} / \mathrm{h}$. (a) $\nabla$ humidificación de $H_{2}$ y (b) $=$ gases secos.

Por otra parte, en la región de altas densidades de corriente, la reacción electroquímica prácticamente se detiene ya que la concentración de los reactivos no es la requerida para llevar a cabo las reacciones de electrodo. La reacción electroquímica no puede mantener la corriente solicitada por la carga por el fenómeno limitante de transporte de masa por difusión. Experimentalmente, para la celda unitaria prototipo no se presenta el segundo "codo" en la región de altas densidades de corriente, el cual sí se encuentra muy bien definido por ejemplo en las Figuras 4 (b) y Figura 8. Respecto a la zona lineal, en la Figura 9 se aprecia que es bastante amplia y esto se debe a que el sobrepotencial óhmico es el que causa las mayores pérdidas de energía en la celda unitaria. Este es un comportamiento característico que se observa en las curvas de polarización obtenidas que se describen a continuación.

\section{X.2.e. Ensayo 5: Efecto de la temperatura de operación de la celda y de la humidificación del gas} $\mathrm{H}_{2}$

Se realizaron medidas a $T_{\text {celda }}=60{ }^{\circ} \mathrm{C}$ y a caudales fijos $Q_{\mathrm{H} 2}=5 \mathrm{l} / \mathrm{h}$ y $Q_{\mathrm{O} 2}=4,5 \mathrm{I} / \mathrm{h}$, con humidificación del gas hidrógeno. Como se mencionó anteriormente, para la humidificación se utiliza un sistema de pasaje del gas a través de burbujeadores, que se encuentran sumergidos en un baño a cierta temperatura y que permiten el arrastre de vapor de agua cuando el gas seco pasa a través del mismo. La curva de polarización obtenida bajo las condiciones de operación mencionadas se muestra en la Figura 10. Como resultado del aumento de la temperatura de operación se observa una respuesta poco esperada para esta primera determinación. Se tienen bajos valores de densidad de corriente drenada, lo cual podría deberse al bajo grado de humidificación, que viene dado por el aumento de $T_{\text {celda, situación }}$ 
para la cual el transporte de agua se torna como efecto limitante. En la celda de combustible predominan los efectos resistivos que provocan una rápida caída del potencial e impiden drenar mayores corrientes.

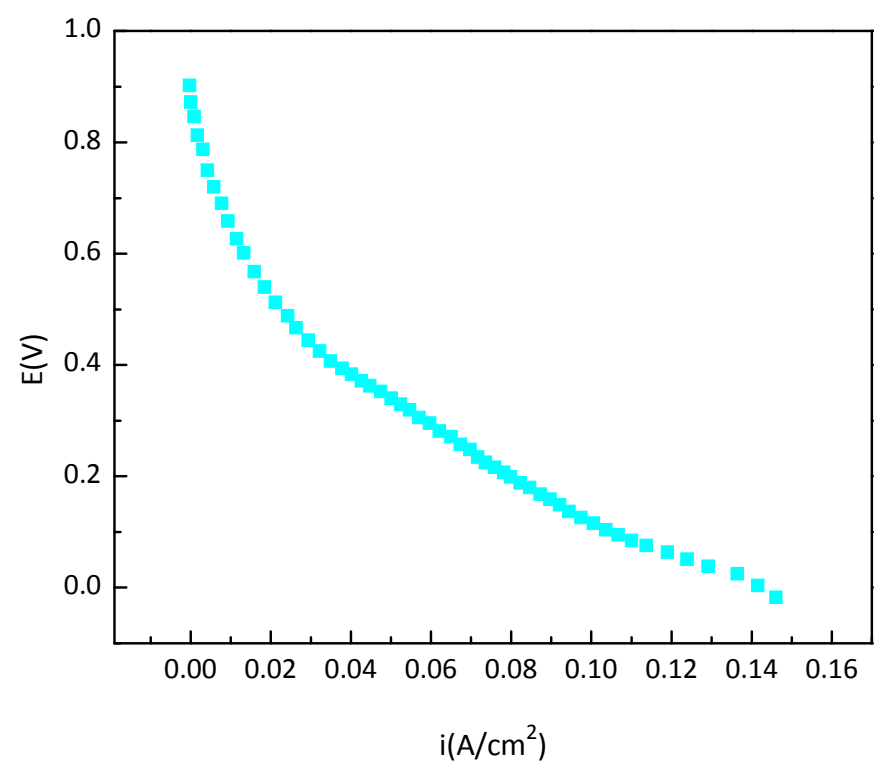

Figura 10. Curva de polarización de la celda unitaria con humidificación de $H_{2}$ y $T_{\text {celda }}=60^{\circ} \mathrm{C}$.

La conducción de protones en la membrana se ve limitada por el contenido de agua en su interior y por la temperatura de operación de $\mathrm{T}_{\text {celda }}=60^{\circ} \mathrm{C}$. Esta limitación puede traducirse como una resistencia al flujo de protones a través de la membrana. Balkin et al. [414] y Amphlett et al. [415] denominan a esta resistencia como resistencia protónica o de membrana.

A fin de mejorar la performance de la celda de combustible unitaria, se continuó alimentando a la celda con hidrógeno humidificado, siendo la temperatura de humidificación, $\mathrm{T}_{\text {humH2 }}$ de $60{ }^{\circ} \mathrm{C}$. Periódicamente, se fueron realizando curvas de polarización para evaluar la mejora en el comportamiento de la celda de combustible con el transcurso del tiempo. También se realizaron medidas aplicando un potencial constante de $0,5 \mathrm{~V}$ con la finalidad de lograr una mayor activación de los electrodos, manteniendo la temperatura de operación de la celda en $60^{\circ} \mathrm{C}$ y humidificando el gas hidrógeno. Las curvas de polarización realizadas posteriormente a la activación antes mencionada (denominada de ahora en adelante activación 3) muestran una mejora en las densidades de corriente drenadas (Figura 11). Esto podría deberse a un efecto combinado del aumento de $T_{\text {celda, }}$ el mayor grado de humidificación alcanzado (que viene dado por el mayor tiempo de funcionamiento con humidificación de hidrógeno) y a la activación de los electrodos por aplicación del potencial constante $\mathrm{E}_{\mathrm{cte}}=0,5 \mathrm{~V}$ (activación 3).

Sin embargo, la densidad de corriente máxima alcanzada no supera a los valores para las situaciones antes estudiadas. Por lo tanto, a fin de obtener mejoras en el comportamiento de la celda unitaria, se continuó con el proceso de activación de los electrodos, para lo cual se aplicó nuevamente 
un potencial constante, $E_{\text {cte, }}$ de $0,5 \mathrm{~V}$, humidificando el gas $H_{2}$ y operando a $T_{\text {celda }}=25{ }^{\circ} \mathrm{C}$, a fin de evitar posibles condiciones de sequedad generadas por la alta temperatura de operación de la celda (activación 4).

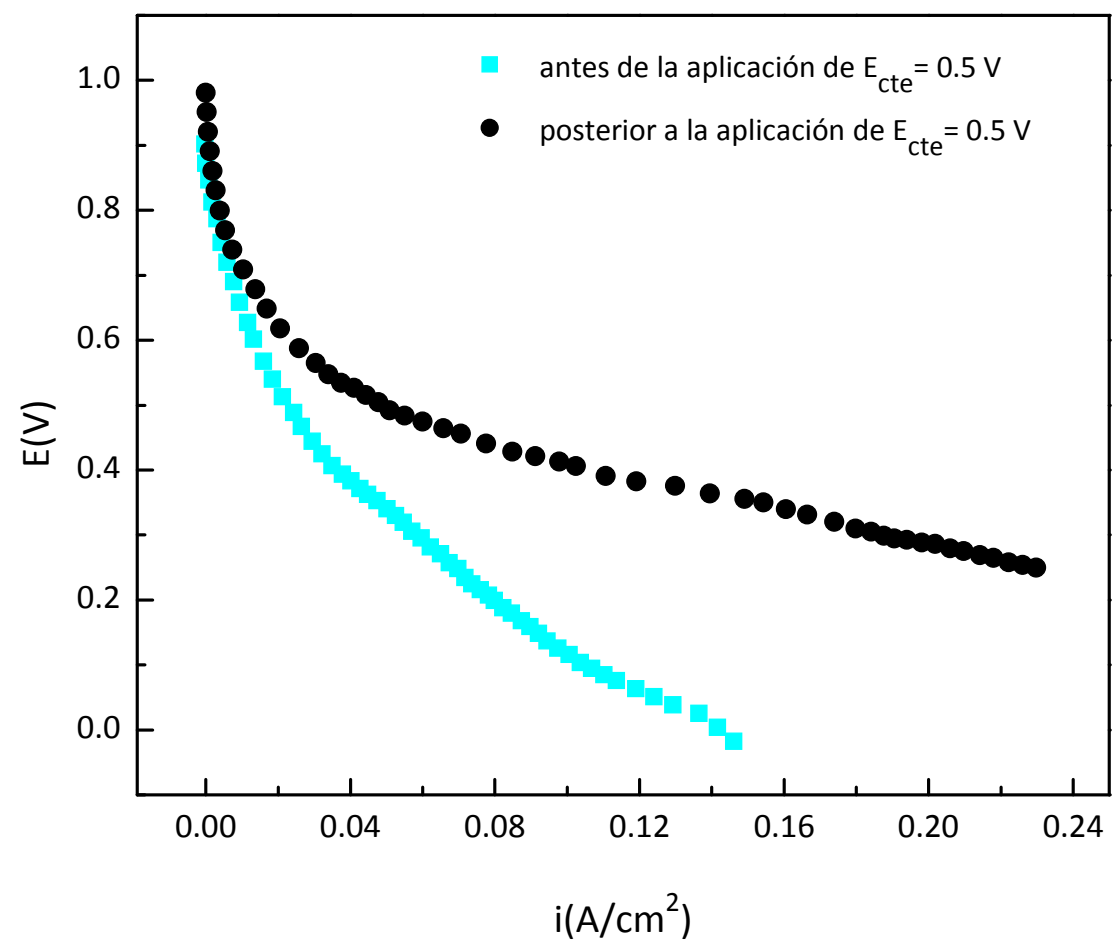

Figura 11. Efecto de la aplicación de $\mathrm{E}_{\text {cte }}=0,5 \mathrm{~V}$ a $\mathrm{T}_{\text {celda }}=60^{\circ} \mathrm{C}$ y mayor tiempo de humidificación de $H_{2}$, posterior a la activación 3.

En la Figura 12 se muestra la evolución de la corriente en función del tiempo, por aplicación de $E_{c t e}=0,5 \mathrm{~V}$. La corriente alcanza una mejora del $59 \%$ en el transcurso de una hora, tiempo suficiente para lograr la estabilización de la corriente final drenada para $E_{c t e}\left(I_{\text {inicial }}=0,49 \mathrm{~A}, \mathrm{I}_{\text {final }}=0,78 \mathrm{~A}\right)$.

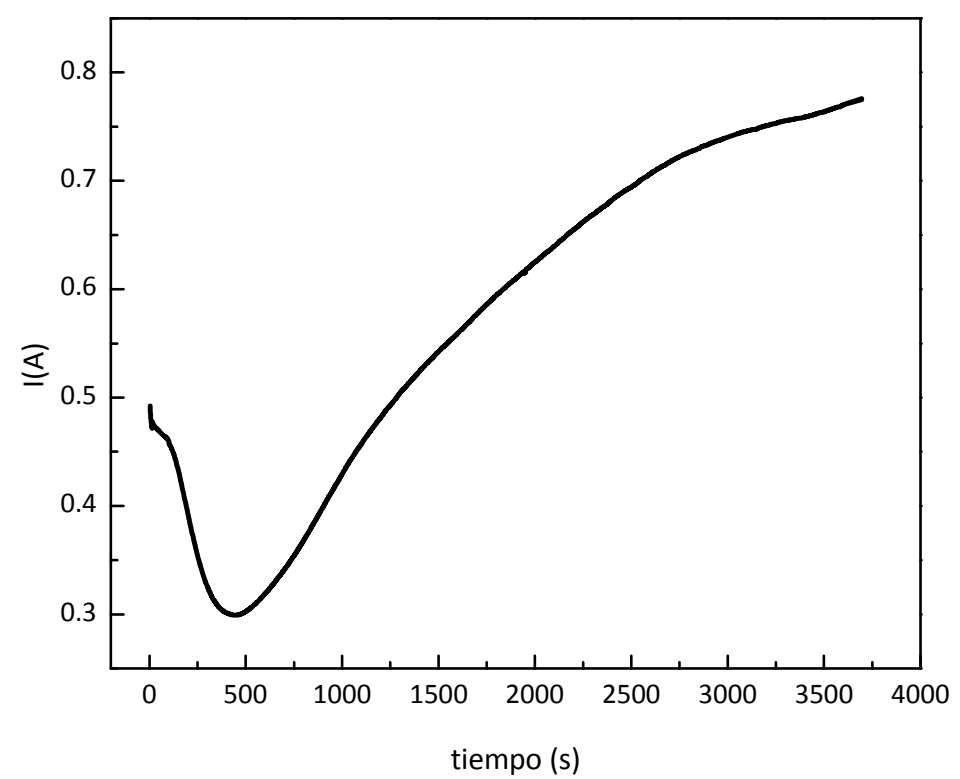

Figura 12. Variación de la corriente drenada por la celda en función del tiempo a $T_{\text {celda }}=25^{\circ} \mathrm{C}, \mathrm{Q}_{02}=4,5 \mathrm{I} / \mathrm{h}$ y $\mathrm{Q}_{\mathrm{H} 2}=5 \mathrm{I} / \mathrm{h}$ humidificado (activación 4). 
Si bien en porcentaje se observa un aumento en la corriente final drenada a $E_{c t e}$, no se logran corrientes finales tan altas como las encontradas cuando la celda opera a $60^{\circ} \mathrm{C}$ luego de la activación 3 . Esto pone de manifiesto una vez más el efecto favorable que tiene el aumento de la temperatura sobre la cinética de las reacciones electródicas y por ende sobre la corriente drenada.

Por otra parte, desde el inicio de la aplicación de $E_{c t e}=0,5 \mathrm{~V}$, la curva I vs. t muestra una abrupta caída hasta los 500 segundos aproximadamente, momento a partir del cual la corriente comienza a aumentar hasta llegar a valores máximos del orden de los 0,78 A. La caída de corriente observada a los 500 segundos coincide con la salida de gotas de agua en el compartimento del hidrógeno, luego del cual la corriente comienza a aumentar. Esto sería el indicio de una condición de ahogo de la celda de combustible, ya que a $E_{c t e}$ la corriente disminuye debido a la cantidad de agua acumulada en los poros del electrodo y los canales de la celda, que impiden el acceso de los gases de alimentación a los sitios de reacción. Una vez eliminada el agua en exceso, mediante la salida de gotas de la celda de combustible, la corriente se va recuperando hasta que alcanza su valor estable en 0,78 A. La curva de polarización obtenida, luego del proceso de activación a $E_{c t e}$, (activación 4) se muestra en la Figura 13 (b). Se evidencia una mejora en la performance de la celda de combustible por efecto del proceso de activación que permite drenar mayores densidades de corriente.

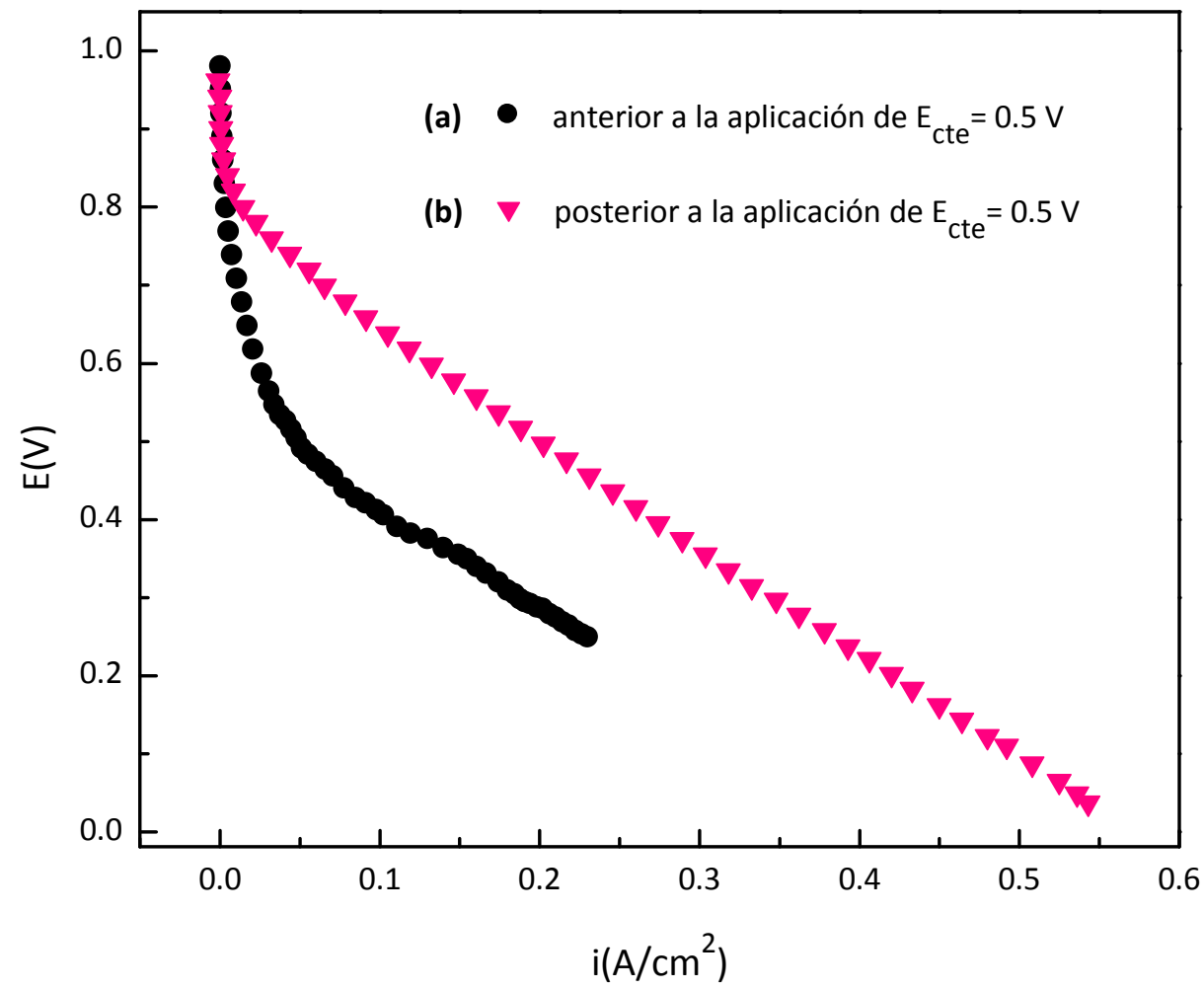

Figura 13. Recuperación de la curva de polarización por aplicación de $E_{c t e}$ a $Q_{\mathrm{H2}}=5 \mathrm{I} / \mathrm{h}$ humidificado, $Q_{02}=4,5 \mathrm{I} / \mathrm{h}$ y $\mathrm{T}_{\text {celda }}=25^{\circ} \mathrm{C}(\mathrm{a}) \bullet$ anterior y $(\mathrm{b}) \nabla$ posterior a la activación 4.

Es probable también que, para la condición de $\mathrm{T}_{\text {celda }}=25^{\circ} \mathrm{C}$, mejore el grado de humidificación con respecto a la de $\mathrm{T}_{\text {celda }}=60{ }^{\circ} \mathrm{C}$. Por lo tanto, las bajas temperaturas de operación de la celda de 
combustible tienen una incidencia favorable en la conductividad iónica de la membrana, que no se ve afectada para el adecuado transporte de protones.

Si se eleva nuevamente la temperatura de operación de la celda de combustible a $\mathrm{T}_{\text {celda }}=60{ }^{\circ} \mathrm{C}$ se obtiene la curva de polarización presentada en la Figura 14.

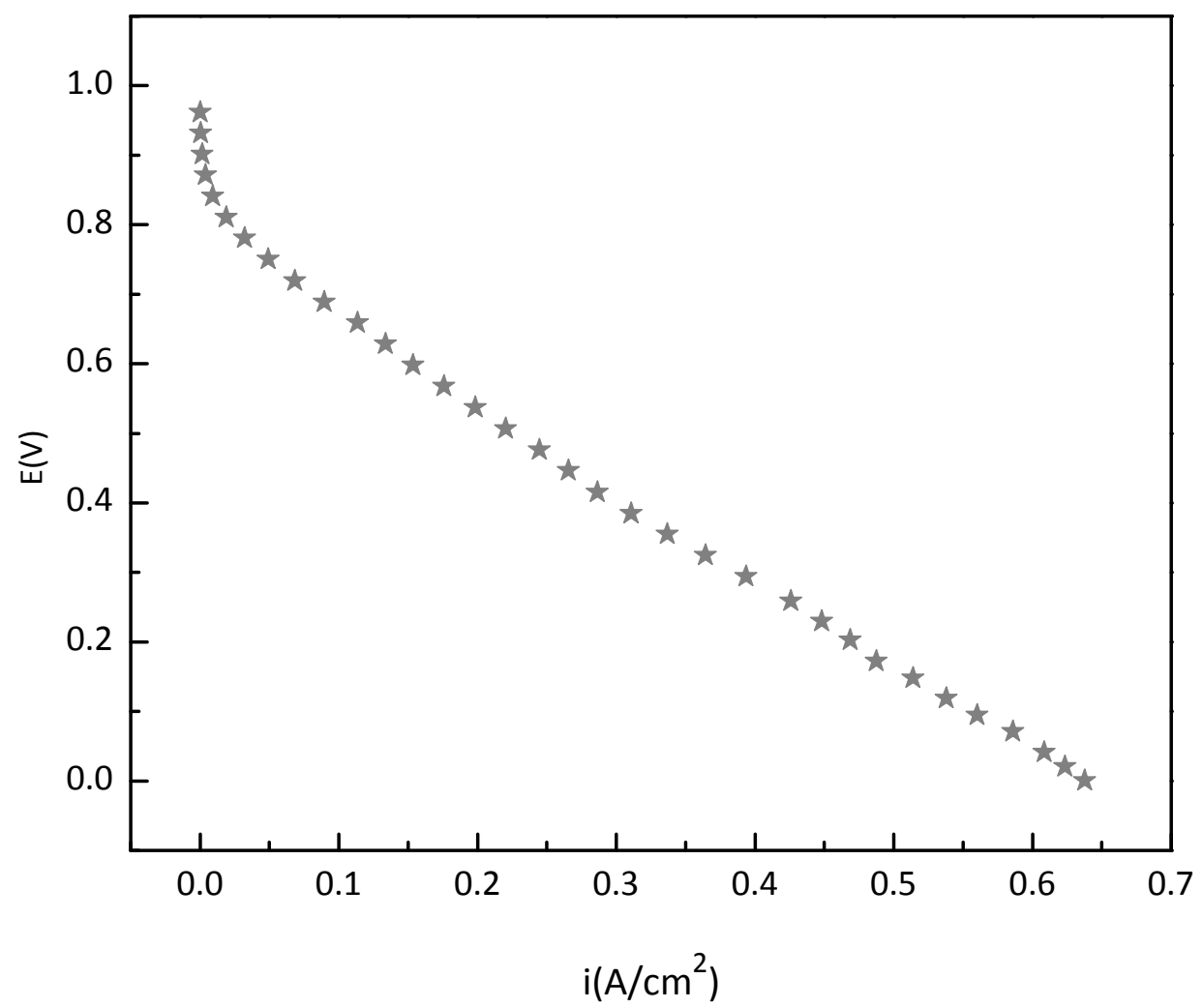

Figura 14 Curva de polarización de la celda unitaria a $T_{\text {celda }}=60^{\circ} \mathrm{C}$, humidificación del $H_{2}, Q_{\mathrm{H} 2}=5 \mathrm{l} / \mathrm{h}$ y $Q_{02}=4,5 \mathrm{l} / \mathrm{h}$.

La densidad de corriente máxima drenada alcanza un valor de $0,64 \mathrm{~A} / \mathrm{cm}^{2}$, que representa un aumento del $76 \%$ respecto a las densidades de corriente informadas al inicio de la sección, bajo las mismas condiciones de operación, esto es, $T_{\text {celda }}=60^{\circ} \mathrm{C}$, humidificación de $H_{2}, Q_{H 2}=5 \mathrm{I} / \mathrm{h}$ y $Q_{02}=4,5 \mathrm{I} / \mathrm{h}$ $\left(i_{\text {inicial }}=0,153 \mathrm{~A} / \mathrm{cm}^{2}, i_{\text {final }}=0,64 \mathrm{~A} / \mathrm{cm}^{2}\right)$. Este aumento en la corriente podría deberse a los tratamientos de activación de los electrodos por aplicación de $E_{c t e}$ (activación 3 y 4) y además a la mejora en el grado de humidificación obtenido en el transcurso del tiempo de operación, ya que en todo momento se trabajó con humidificación del gas hidrógeno.

La Figura 15 muestras las curvas de polarización, bajo las mismas condiciones de operación, como resultado del tiempo de operación a caudal constante de hidrógeno humidificado $Q_{\mathrm{H} 2}=5 \mathrm{l} / \mathrm{h}$ y $\mathrm{T}_{\text {celda }}=60^{\circ} \mathrm{C}$, antes y después de los procesos de activación 3 y 4 aplicando un potencial constante de $0,5 \mathrm{~V}$ [Figura 15 (a) y (b), respectivamente]. 


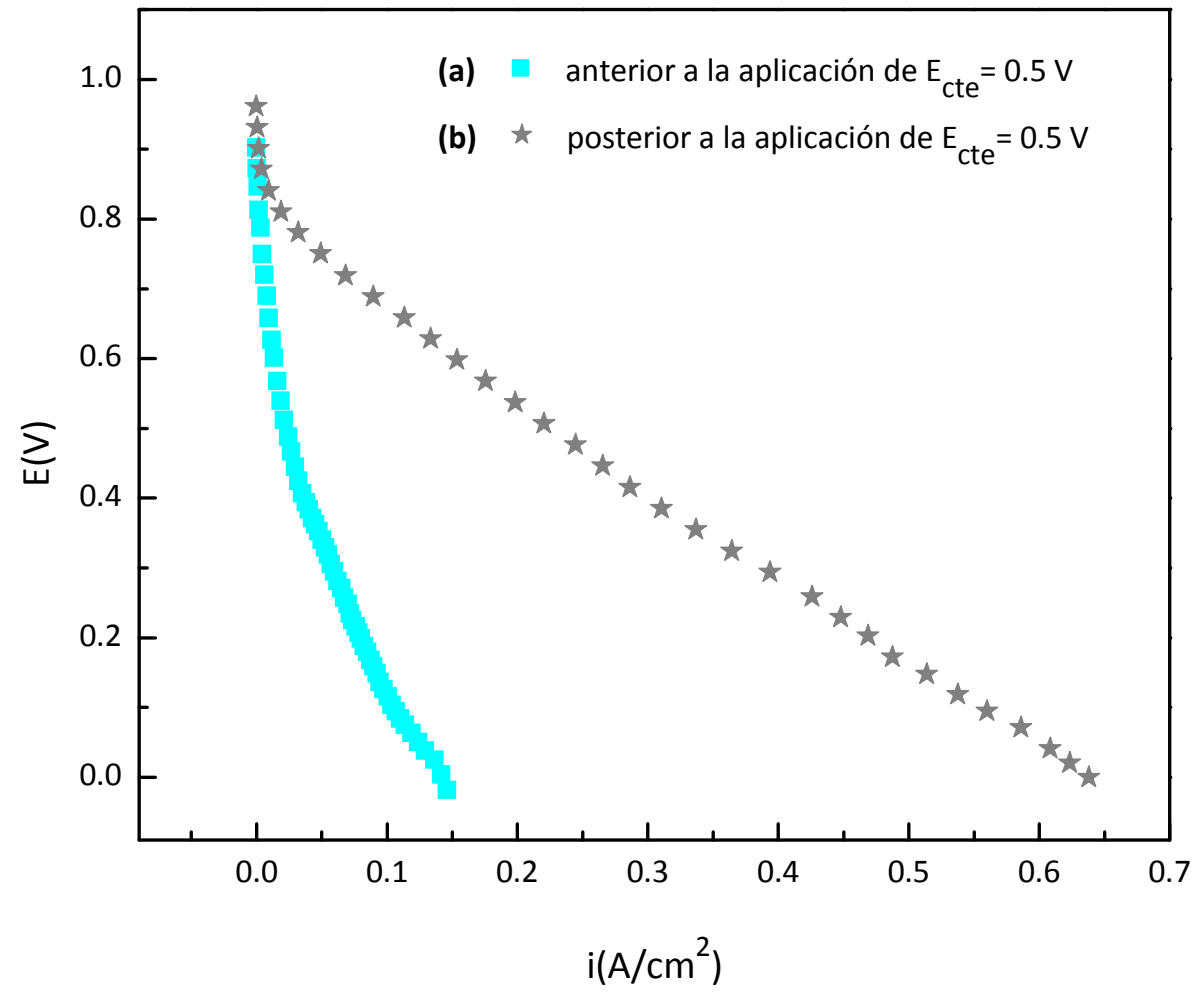

Figura 15. Efecto del grado de humidificación y de la aplicación de $\mathrm{E}_{\mathrm{cte}}=\mathbf{0 , 5} \mathrm{V}$ sobre las curvas de polarización a $\mathrm{T}_{\text {celda }}=60^{\circ} \mathrm{C}$, humidificación del $H_{2}, Q_{\mathrm{H}_{2}}=5 \mathrm{I} / \mathrm{h}$ y $\mathrm{Q}_{02}=4,5 \mathrm{I} / \mathrm{h}(\mathrm{a}) \backsim$ anterior y (b) $\star$ posterior a los procesos de activación.

Si se continúa aplicando un potencial $E_{c t e}$ de $0,5 \mathrm{~V}$, se puede analizar la variación de la corriente en función del tiempo (Figura 16, activación 5). Inicialmente la celda se encuentra a $\mathrm{T}_{\text {celda }}=25^{\circ} \mathrm{C}$ y en tan sólo 1 segundo la corriente experimenta un salto $\Delta \mathrm{I}=0,13 \mathrm{~A}\left(\mathrm{I}_{\text {inicial }}=0,77 \mathrm{~A}, \mathrm{I}_{\text {final }}=0,9 \mathrm{~A}\right)$, para luego estabilizarse en el entorno de 0,85 A aproximadamente a los 500 segundos.

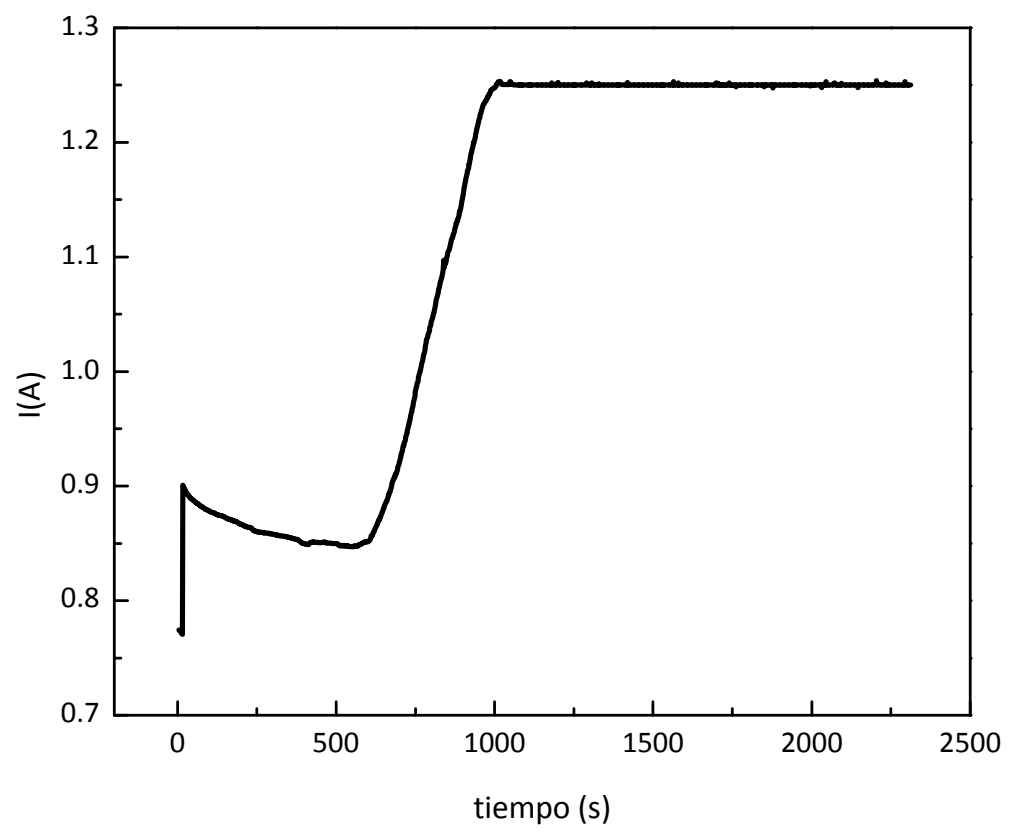

Figura 16. Variación de la corriente en función del tiempo por efecto del aumento de $T_{\text {celda }}$ a $E_{\text {cte }}=0,5 \mathrm{~V}$ (activación 5). 
A partir de ese momento se enciende el control de $T_{\text {celda }}$ que se eleva a $60{ }^{\circ} \mathrm{C}$, permitiendo que la corriente final alcance 1,25 A en 420 segundos permaneciendo estable durante 22 minutos aproximadamente. Por lo tanto, bajo condiciones de operación estabilizadas, se verifica que un aumento de la temperatura genera mayores corrientes. Como se puede apreciar el tiempo de calentamiento de la celda es bastante rápido y se alcanza una condición de corriente estable aproximadamente a los 420 segundos de haber elevado la temperatura de la celda.

A continuación se evaluó el efecto de $\mathrm{T}_{\text {celda }}$ sobre el comportamiento en operación de la celda de combustible unitaria, considerando las dos temperaturas antes ensayadas de $25{ }^{\circ} \mathrm{C}$ y $60{ }^{\circ} \mathrm{C}$. Se mantuvieron todas las demás condiciones constantes, es decir, humidificación del gas hidrógeno y caudales de $\mathrm{Q}_{\mathrm{H} 2}=5 \mathrm{I} / \mathrm{h}$ y $\mathrm{Q}_{\mathrm{O} 2}=4,5 \mathrm{l} / \mathrm{h}$. Las curvas de polarización para la celda operando a $25^{\circ} \mathrm{C}$ y $60^{\circ} \mathrm{C}$ se muestran en la Figura 17 (a) y (b), respectivamente.

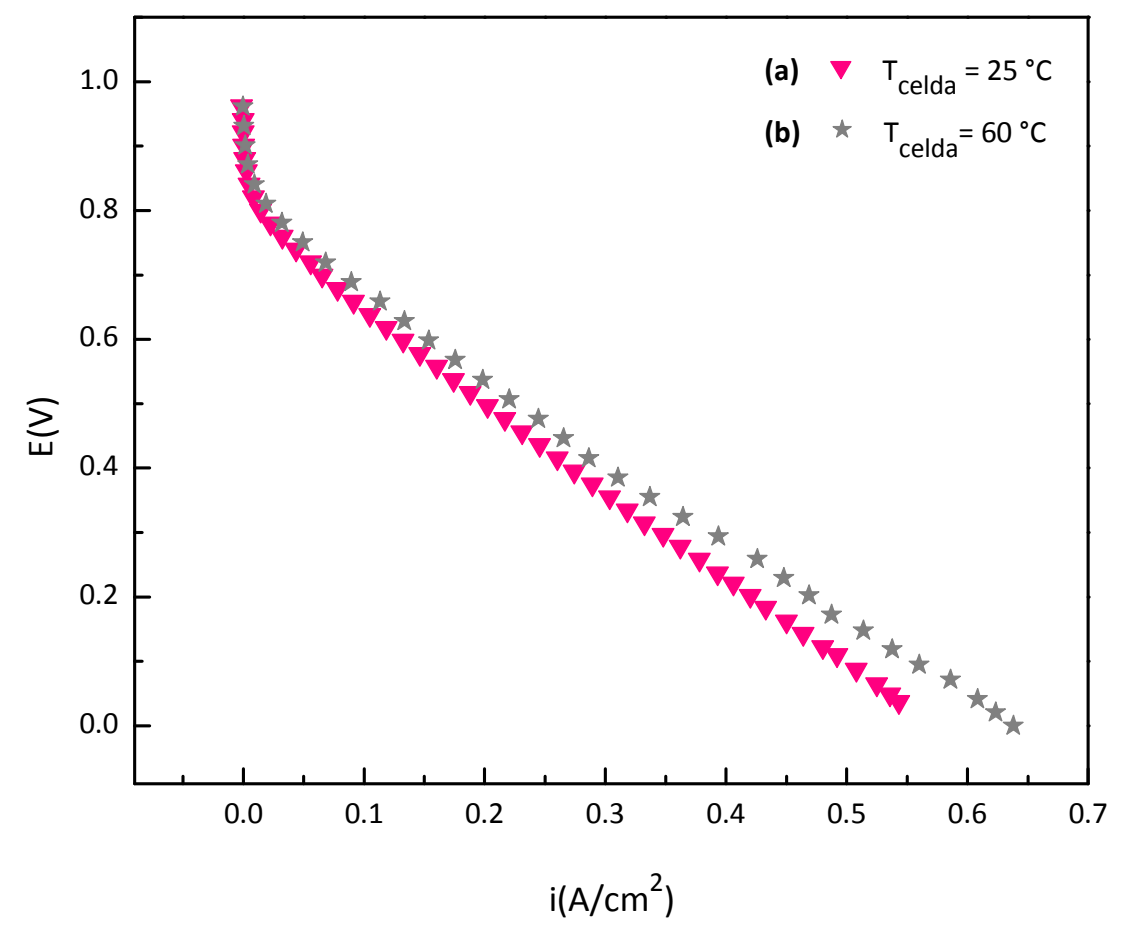

Figura 17. Efecto de $T_{\text {celda }}$ sobre las curvas de polarización para $Q_{H 2}=5 \mathrm{l} / \mathrm{h}$ humidificado y $Q_{02}=4,5 \mathrm{l} / \mathrm{h}$. (a) $\nabla 25^{\circ} \mathrm{Cy}(\mathrm{b}) \star 60{ }^{\circ} \mathrm{C}$.

La densidad de corriente máxima drenada experimenta un aumento de aproximadamente $19 \%$ cuando la celda trabaja a $\mathrm{T}_{\text {celda }}=60{ }^{\circ} \mathrm{C}$, respecto al valor encontrado a $\mathrm{T}_{\text {celda }}=25{ }^{\circ} \mathrm{C}\left(\mathrm{a} 25{ }^{\circ} \mathrm{C}\right.$, $i_{\text {máx }}=0,54 \mathrm{~A} / \mathrm{cm}^{2}$ y a $60{ }^{\circ} \mathrm{C}, i_{\text {máx }}=0,64 \mathrm{~A} / \mathrm{cm}^{2}$ ). El aumento en la performance de la celda unitaria con el aumento de la temperatura se debe, principalmente, a un aumento de la velocidad de los procesos que tienen lugar en los electrodos de la celda de combustible. Operando a altas temperaturas se obtiene una mejor performance de la celda de combustible debido a que se reduce el sobrepotencial catódico [321]. Se ha informado en la bibliografía que los sistemas que operan a altas temperaturas presentan menores pérdidas de energía, esto es, menores sobrepotenciales a bajas corrientes y este 
comportamiento se atribuye, en principio, a la ausencia de contribuciones apreciables del sobrepotencial de activación e indica también una catálisis más eficiente de las reacciones, debido al efecto de la temperatura [87]. Por otra parte, se ha evaluado la resistencia de la celda de combustible cuando opera a $25{ }^{\circ} \mathrm{C}$ y $60{ }^{\circ} \mathrm{C}$ con humidificación del hidrógeno. Se encontró una disminución en los valores de resistencia del orden del $12 \%$ a la mayor temperatura, como se muestra en la Tabla III. Esto podría explicarse por un aumento de la conductividad iónica de la membrana que se ve favorecida por la cantidad de agua generada por la propia reacción electroquímica, que aumenta con el incremento de $T_{\text {celda. }}$ La cantidad de agua generada por la reacción catódica mejora las condiciones de hidratación de la membrana polimérica, por lo cual la conducción protónica ocurre sin impedimento. Esto se refleja en la disminución de la resistencia al flujo de protones a través de la membrana que permite mejorar el comportamiento general de la celda de combustible.

Tabla III. Valores de $\mathrm{R}_{\text {celda }}$ operando con humidificación de $H_{2}$ a: (a) $25^{\circ} \mathrm{C}$ y (b) $60^{\circ} \mathrm{C}$.

\begin{tabular}{|c|c|}
\hline $\mathbf{T}_{\text {celda }}$ & Resistencia $(\Omega)$ \\
\hline $25^{\circ} \mathrm{C}$ & 0,35 \\
\hline $60^{\circ} \mathrm{C}$ & 0,31 \\
\hline
\end{tabular}

Se conoce que en celdas de combustible PEM que operan a temperaturas de $60{ }^{\circ} \mathrm{C}$ es esencial contar con un adecuado sistema de humidificación. En trabajos, como el de Büchi et al. [416], se ha confirmado experimentalmente la necesidad de la humidificación adicional de los gases de alimentación para celdas de combustible PEM que operan a temperaturas de $60^{\circ} \mathrm{C}$ o superiores. Cuando la celda opera a temperatura superior a $60^{\circ} \mathrm{C}$ aumentan los problemas de humidificación. Bajo esta condición es necesario contar con un sistema de humidificación extra, ya que la cantidad de agua producida por la reacción electroquímica es insuficiente para mantener las condiciones óptimas de humidificación. La utilización de un sistema humidificador de los gases de alimentación incrementa los costos y las complejidades del sistema total. Por lo general, estas cuestiones son las que dificultan, en cierta manera, la elección de una temperatura óptima de trabajo para una celda de combustible PEM, ya que existe un compromiso entre el aumento de las velocidades de reacción y los costos adicionales que se requieren para el sistema de humidificación apropiado.

\section{X.2.f. Ensayo 6: Efecto de la temperatura de operación y de la humidificación de ambos gases}

Se estudió el efecto de la humidificación de ambos gases reactivos sobre el comportamiento de la celda unitaria a $60{ }^{\circ} \mathrm{C}$ y alimentada con caudales fijos de $Q_{\mathrm{H} 2}=5 \mathrm{I} / \mathrm{h}$ y $Q_{02}=4,5 \mathrm{I} / \mathrm{h}$. A fin de arrastrar siempre la misma cantidad de agua a la entrada de la celda, los humidificadores de ambos gases se mantuvieron a temperatura constante, $T_{\text {hum }}$, de $60^{\circ} \mathrm{C}$. El sistema de humidificación del gas es el mismo 
tanto para el hidrógeno como para el oxígeno, tal como se describió en secciones anteriores. La Figura 18 muestra una serie de curvas de polarización típicas obtenida bajo las condiciones de operación antes mencionadas. Se registraron bajos valores de densidad de corriente drenada y se observó una alta inestabilidad del sistema. Además, la densidad de corriente no se recupera con el transcurso del tiempo. Esto estaría indicando la presencia de agua en exceso en la celda de combustible, por efecto de la humidificación de ambos gases. Los poros de los electrodos de la celda se llenan de agua, al igual que los canales por donde ingresan los gases, y se produce un estado de inundación general de la celda de combustible. La obstrucción de los poros del electrodo impide que las reacciones se lleven a cabo de manera eficiente, dando como resultado la caída del potencial y bajas densidades de corriente.

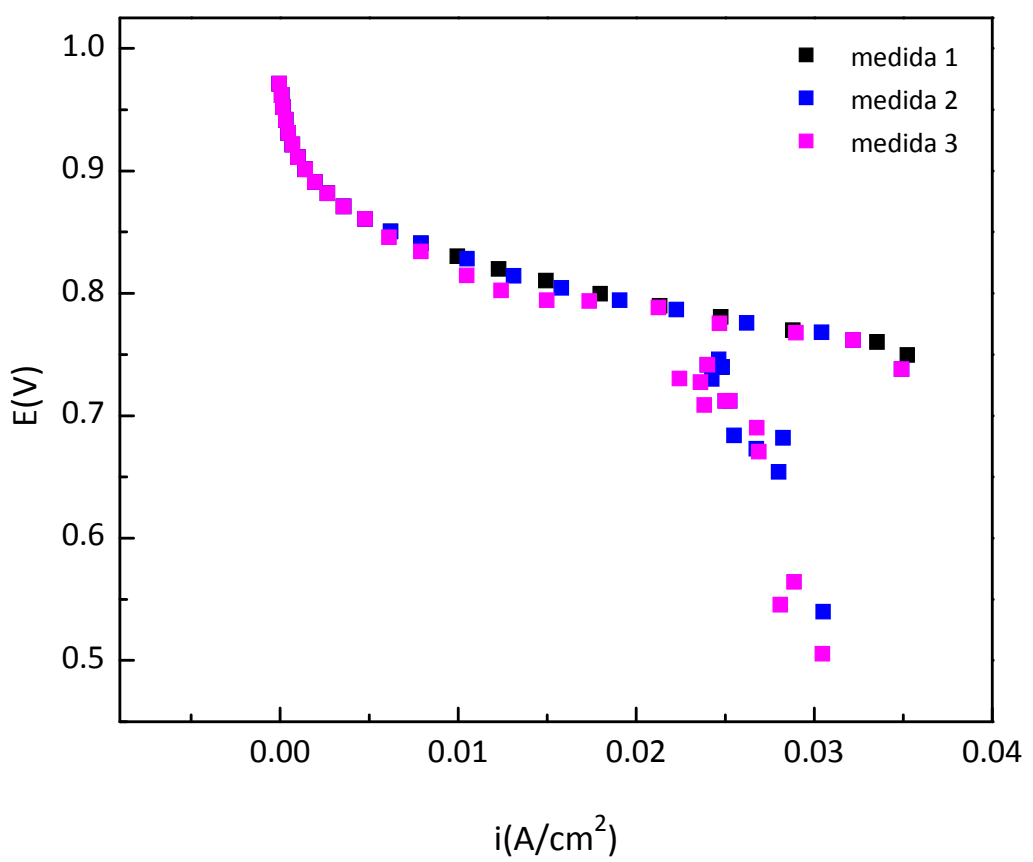

Figura 18. Curvas de polarización de la celda de combustible operando a $\mathrm{T}_{\text {celda }}=60^{\circ} \mathrm{C}$ con humidificación de ambos gases.

El efecto del transporte de agua en el electrolito polimérico ha sido objeto de varios estudios experimentales y teóricos [354], [417-420]. Así, por ejemplo, se ha encontrado que, en condiciones estacionarias, el coeficiente de arrastre de agua por los protones, $n_{d}^{0}$, es de aproximadamente 1 molécula de agua/protón para una membrana completamente hidratada en equilibrio con agua líquida a $50{ }^{\circ} \mathrm{C}$ y de 0,2 moléculas de agua/protón con la membrana en equilibrio con una atmósfera gaseosa saturada con vapor de agua [417]. Por otro lado, se debe tener en cuenta que el agua que se suministra a la membrana para el transporte de los protones proviene del gas saturado con agua que circula a ambos lados del ensamble electrodo-membrana PEM-electrodo y del agua generada por la propia reacción electroquímica de reducción de oxígeno en el cátodo. De este lado de la membrana, la concentración de agua también se eleva debido a las moléculas que llegan del ánodo arrastradas por el transporte de protones. El flujo de agua en la membrana del lado del ánodo depende de la difusión de 
vapor en el hidrógeno gaseoso y de la retrodifusión en la membrana del agua disuelta del lado del oxígeno, por lo que el flujo total depende del espesor de la membrana.

Los resultados mostrados en esta sección indican que no es necesario humidificar ambos gases, ya que cuando esto ocurre la celda se "ahoga". Por otro lado, haciendo circular gases completamente secos se logra restablecer un comportamiento satisfactorio de la celda, ya que se consigue eliminar el exceso de humedad que limita drenar mayores corrientes.

\section{X.3. Evaluación del comportamiento de la celda bajo condiciones particulares de operación}

Se ha evaluado también el impacto de la variación de temperatura y del grado de humidificación de la celda de combustible unitaria sobre su comportamiento en operación. La celda se alimentó con caudales constantes de gases $Q_{\mathrm{H} 2}=5 \mathrm{l} / \mathrm{h}$ y $Q_{\mathrm{O} 2}=4,5 \mathrm{l} / \mathrm{h}$. Se compararon los ensayos 1 y 5 , designados como (a) y (b) en la Tabla IV.

Tabla IV. Condiciones de operación para la evaluación del comportamiento de la celda unitaria.

\begin{tabular}{|c|c|c|}
\hline Condiciones de trabajo & $\mathbf{T}_{\text {celda }}$ & Condición de humidificación \\
\hline (a) Ensayo 1 & $25^{\circ} \mathrm{C}$ & \\
\hline (b) Ensayo 5 & $60^{\circ} \mathrm{C}$ & Gases secos \\
\hline
\end{tabular}

La Figura 19 muestra las curvas de polarización para las dos situaciones bajo estudio.

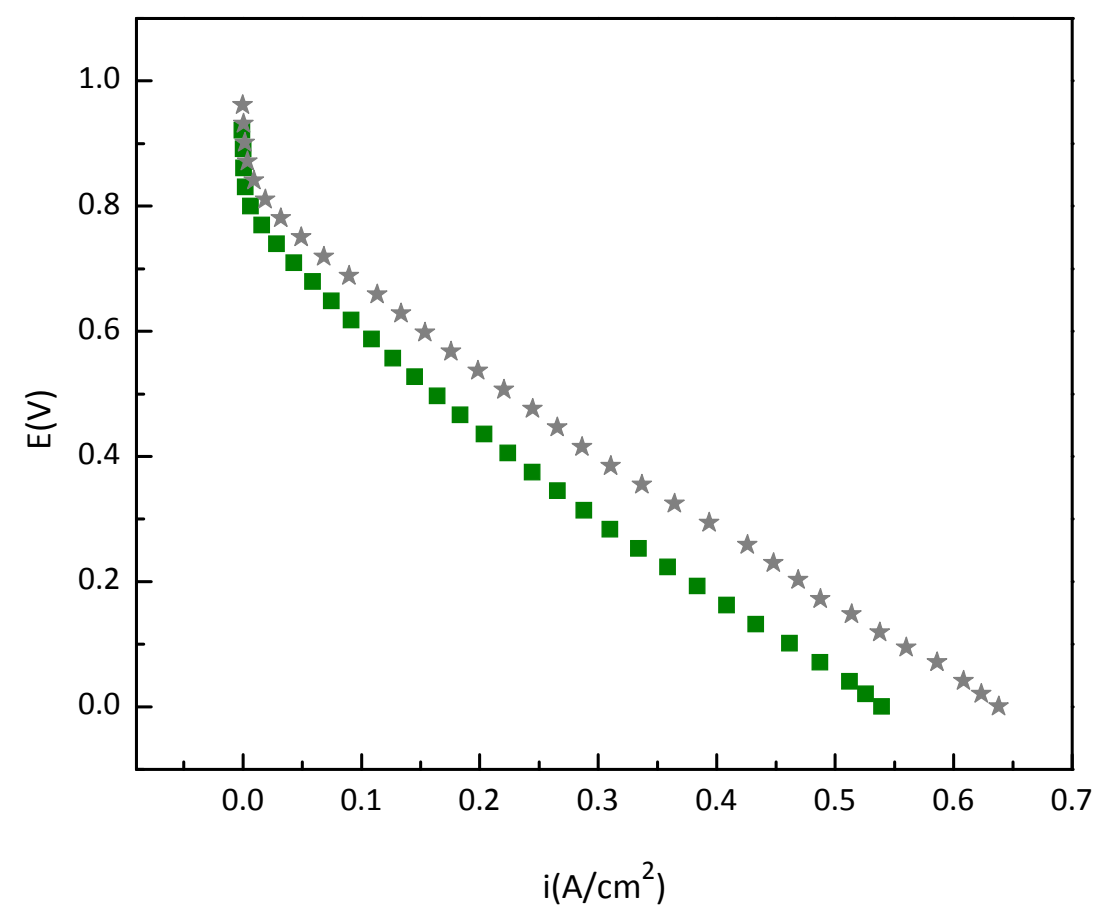

Figura 19. Curvas de polarización para la celda bajo las condiciones particulares de operación, (a) घ y (b) $\star$, indicadas en la Tabla IV. 
Como es de esperar, la celda de combustible unitaria drena mayores densidades de corriente operando a la temperatura más alta $\left(T_{\text {celda }}=60^{\circ} \mathrm{C}\right.$ ) y humidificando del gas hidrógeno (ensayo 5$)$. Se registra un aumento de la densidad de corriente máxima obtenida de aproximadamente $19 \%$, respecto a la alcanzada cuando la celda opera a $\mathrm{T}_{\text {celda }}=25{ }^{\circ} \mathrm{C}$ y $\sin$ humidificación de gases (ensayo 1) (a $25^{\circ} \mathrm{C}$, $i_{\text {máx }}=0,54 \mathrm{~A} / \mathrm{cm}^{2}$ y a $60^{\circ} \mathrm{C}, i_{\text {máx }}=0,64 \mathrm{~A} / \mathrm{cm}^{2}$ ).

Para el ensayo $5\left(\mathrm{~T}_{\text {celda }}=60^{\circ} \mathrm{C}\right.$ y humidificación de $\left.H_{2}\right)$, la celda de combustible unitaria exhibe un potencial de circuito abierto, $\mathrm{E}_{\mathrm{ca}}$, de $0,96 \mathrm{~V}$, que es levemente mayor, del orden del $5 \%$, con respecto al valor de 0,92 V encontrado en el Ensayo 1.

Para bajos valores de densidad de corriente, la diferencia de potencial de celda entre los ensayos 1 y 5 no muestra grandes variaciones para una determinada corriente. Se obtienen valores del orden de $\Delta V \approx 40 \mathrm{mV}$, que aumentan gradualmente a medida que se incrementa la corriente drenada. Para densidades de corriente intermedias y altas $\left(0,3 \mathrm{~A} / \mathrm{cm}^{2}\right.$ y $0,5 \mathrm{~A} / \mathrm{cm}^{2}$, respectivamente) se evidencian aumentos del $26 \%$ y $21 \%$ en potencial, para las respectivas densidades de corrientes.

En general, operando a alta temperatura de celda y con humidificación de $\mathrm{H}_{2}$ se observa una mejora en la performance global de la celda unitaria, debido al aumento en la velocidad de los procesos electródicos que ocurre a alta temperatura y también al aumento de la conductividad iónica de la membrana electrolítica por humidificación del gas hidrógeno.

Se debe tener en cuenta que, tal como lo informado en la bibliografía, el bajo grado de humidificación de la celda de combustible da lugar a una pobre utilización del catalizador [411]. Debido al efecto de deshidratación de la membrana, como consecuencia de la baja humidificación, se produce la inmovilización de los protones, lo que impide que las reacciones electroquímicas ocurran favorablemente. Operando a $\mathrm{T}_{\text {celda }}=60{ }^{\circ} \mathrm{C}$ y con humidificación del $H_{2}$ se tendrían condiciones más propicias para un mejor comportamiento de la celda unitaria. Probablemente, para la condición estudiada a $\mathrm{T}_{\text {celda }}=25^{\circ} \mathrm{C}$ y $\sin$ humidificación del $H_{2}$, no se tendría un adecuado grado de humidificación $y$, aunque los electrocatalizadores de Pt que conforman el electrodo se encuentren en contacto con la membrana polimérica, al no estar esta completamente hidratada, se produce la inmovilización de los protones que impide que la reacción ocurra favorablemente, lo que se traduce en una pérdida de la performance de la celda.

Por lo tanto, en base a los resultados mostrados en esta sección, se puede concluir que la influencia de la temperatura es más importante sobre las pérdidas de energía de la celda que sobre el potencial estándar ideal. El efecto neto es que el potencial de operación aumente con la temperatura para una corriente constante. Este comportamiento se cumple para un amplio rango de densidades de corriente, excepto para las muy bajas, en las que las pérdidas de energía son tan bajas que el efecto sobre el potencial estándar es dominante.

Con respecto a los valores de densidad de potencia, se conoce que para alcanzar potencias altas es necesario que la corriente (para un potencial constante) o el potencial (para una corriente constante) 
sean lo más altos posibles [327]. Para la situación particular analizada en esta sección, la máxima densidad de potencia se logró aumentando la temperatura de operación de la celda de combustible, disminuyendo de este modo las pérdidas de energía por sobrepotenciales de los electrodos. En la Figura 20 se muestran las correspondientes curvas de densidad de potencia vs. densidad de corriente para las condiciones correspondientes a los ensayos 1 y 5 . Se observa que operando a $\mathrm{T}_{\text {celda }}=60{ }^{\circ} \mathrm{C}$ y con humidificación de $\mathrm{H}_{2}$ se obtiene un valor de densidad de potencia $32 \%$ mayor que cuando se opera a temperatura ambiente y sin humidificación de gases.

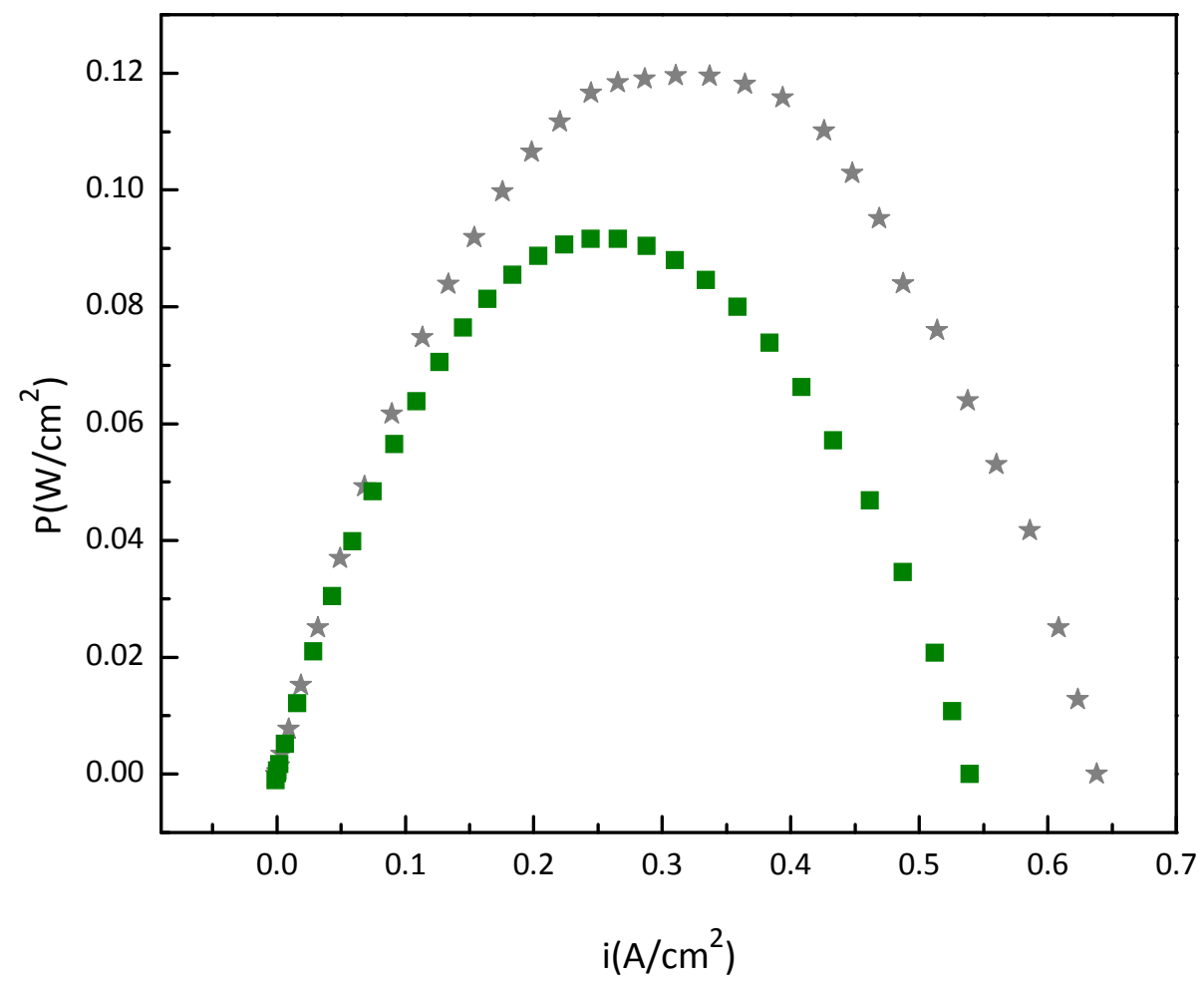

Figura 20. Curvas de densidad de potencia para las condiciones: (a) $a 25^{\circ} \mathrm{C}$, gases secos y (b) $\star 60{ }^{\circ} \mathrm{C}$, humidificación de $\boldsymbol{H}_{2}$.

\section{X.4. Evaluación del comportamiento en operación de la celda de combustible a tiempos largos}

Se evaluó el comportamiento en operación de la celda unitaria para períodos de tiempo de operación largos (Figura 21). Se utilizaron caudales de gases $Q_{\mathrm{H} 2}=5 \mathrm{l} / \mathrm{h}$ y $Q_{02}=4,5 \mathrm{I} / \mathrm{h}$ a $T_{\text {celda }}=60{ }^{\circ} \mathrm{C}$ y humidificación del gas $\mathrm{H}_{2}$. Se observa un efecto desfavorable sobre la performance de la celda (menor drenaje de corriente a potencial constante) a medida que transcurre el tiempo de operación, como resultado del envejecimiento de los electrodos. La corriente máxima drenada por la celda unitaria desciende un $13 \%$ el segundo día de operación, y se mantiene en el mismo orden durante el tercer día. Al cabo del quinto día de operación la corriente máxima disminuye un $23 \%$ respecto al valor inicial, mientras que luego de 14 días de operación la disminución es del 55 \%. La disminución en los valores de corriente máxima estaría relacionada, principalmente, con las pérdidas de energía por sobrepotencial óhmico. A corrientes intermedias el potencial disminuye linealmente con la corriente, determinando la 
zona lineal regida por la ley de Ohm. En esta región, los valores de resistencia no experimentan grandes cambios hasta el quinto día. Posteriormente, aumentan y permanecen prácticamente constantes hasta el día 14.

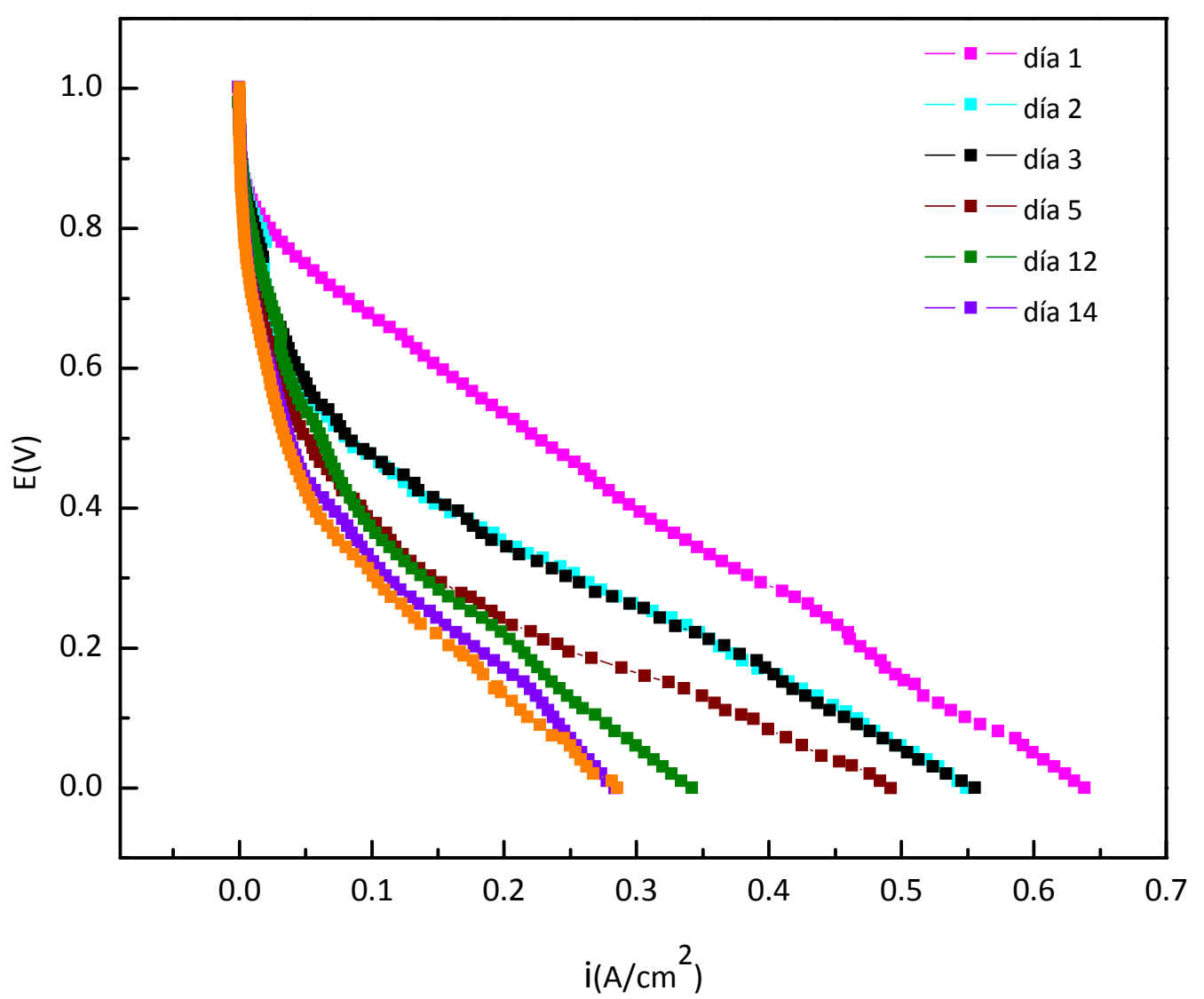

Figura 21. Curvas de polarización para largos períodos de tiempo de operación. $Q_{\mathrm{H} 2}=5 \mathrm{I} / \mathrm{h}, \mathrm{Q}_{\mathrm{O2}}=4,5 \mathrm{l} / \mathrm{h}$, $\mathrm{T}_{\text {celda }}=60^{\circ} \mathrm{C}$, humidificación de $\mathrm{H}_{2}$.

Se continuaron realizando curvas de polarización y ciclos de activación, para lo cual se mantuvo a la celda de combustible a un potencial constante, $E_{c t e}$, de $0,5 \mathrm{~V}$ durante 30 minutos, tiempo durante el cual se registró la estabilización de la corriente. También se aplicaron pulsos cortos de activación a potencial constante y posteriormente se realizaron nuevas curvas de polarización. La Figura 22 muestra las curvas características E vs. i donde se puede observar una mejora en el comportamiento de la celda luego de transcurridos 21 días de operación con respecto al observado a los 14 días, por efecto de la activación de los electrodos (activación 6). Sin embargo, las corrientes máximas drenadas no alcanzaron los valores registrados para el primer día de operación. Este resultado estaría indicando la gran incidencia del aumento de la resistencia de la celda de combustible sobre su comportamiento con el transcurso del tiempo. Por lo tanto, a densidades de corriente intermedias y altas, los procesos electroquímicos son controlados por efectos de polarización óhmica y de transporte de masa, que tienen un marcado efecto en el comportamiento general de la celda de combustible unitaria a tiempos largos de operación. 


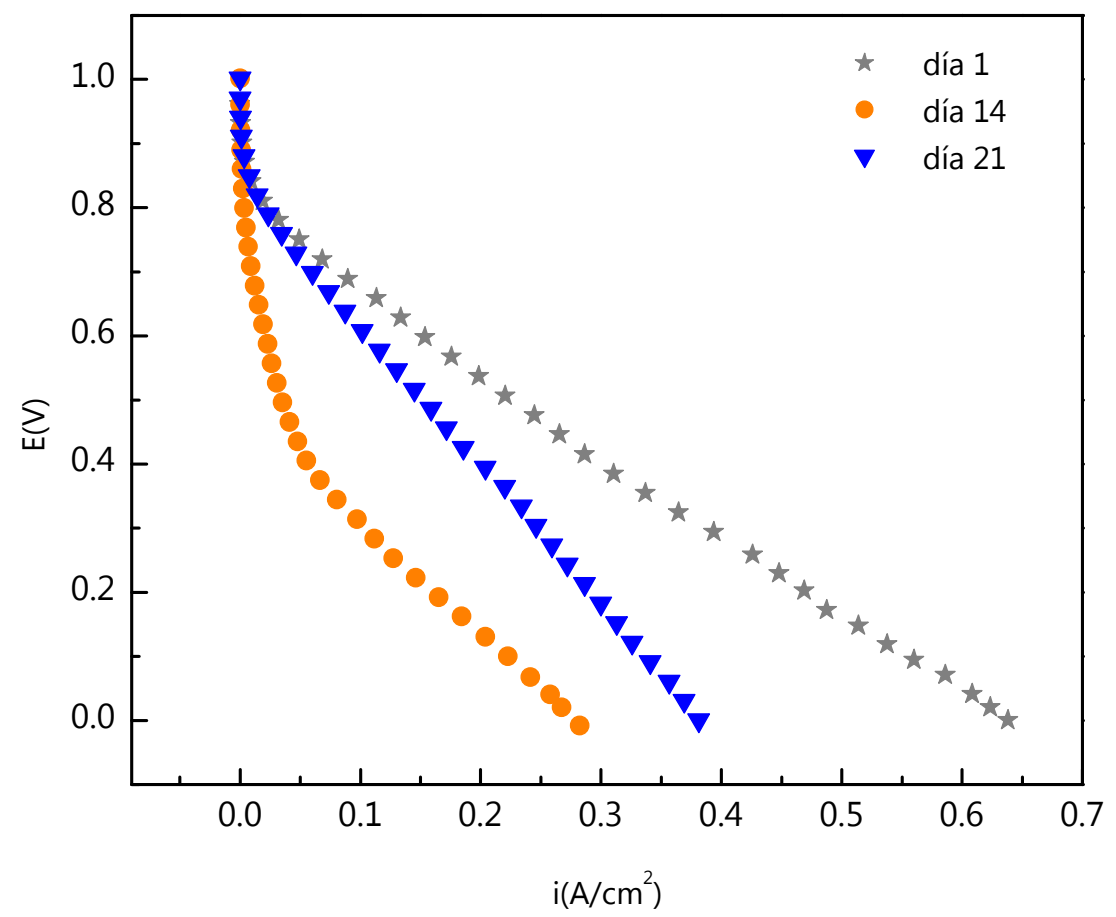

Figura 22. Evolución de las curvas de polarización de la celda por aplicación de pulsos (activación 6).

X.5. Influencia de la morfología de las nanopartículas de Pt sobre el comportamiento en operación de la celda de combustible unitaria de hidrógeno/oxígeno

Como se mencionó anteriormente, una de las principales limitaciones de las celdas de combustible de hidrógeno/oxígeno que operan a baja temperatura está asociada con la cinética lenta del electrodo de oxígeno [421]. Se conoce que el sobrepotenciales de electrorreducción de oxígeno constituye una de las principales contribuciones a las pérdidas de eficiencia y densidad de potencia en celdas de combustible de baja temperatura. Es por ello que resultó interesante estudiar como los electrocatalizadores de $P t$ altamente facetados desarrollados en el transcurso de esta tesis, los cuales son los que exhiben la mayor actividad electrocatalítica para la reacción de electrorreducción de oxígeno, influyen en el comportamiento en operación de la celda de combustible de hidrógeno/oxígeno de tecnología PEM.

A fin de estudiar el efecto de la morfología superficial de las nanocristalitas de $P t$ facetadas sobre la performance de la celda de combustible unitaria de hidrógeno/oxígeno, se construyeron electrodos porosos de difusión de gas incorporando nanopartículas de $P t$ altamente facetadas tipo (111) de alta área superficial. El comportamiento en operación de la celda que utiliza electrodos con nanopartículas de $P t$ facetadas se comparó con la performancede la celda unitaria estudiada en secciones anteriores, que utiliza electrodos porosos preparados con nanopartículas de Pt policristalinas, soportadas sobre carbón Vulcan XC-72.

La preparación de los electrodos porosos de difusión de gas con nanopartículas de $P t$ altamente facetadas tipo (111) de alta área superficial, fue similar al descripto para las nanopartículas de $P t$ 
policristalinas (CAPÍTULO IX, Sección IX.1). Por otra parte, los detalles de preparación y caracterización de las nanopartículas de Pt facetadas según la orientación cristalográfica preferencial (111) se describieron en capítulos anteriores (CAPÍTULO VI). La carga de Pt utilizada para el electrodo poroso de difusión de gas, con nanopartículas de $P t$ facetadas tipo (111) fue de $0,2 \mathrm{mg} / \mathrm{cm}^{2}$. Con respecto a al proceso de fabricación del ensamble $M E A$, el procedimiento utilizado fue el de prensado en caliente, en el cual la membrana de intercambio protónico Nafion 117 se dispone entre los dos electrodos, ánodo y cátodo, y el conjunto se introduce en una prensa que opera a una temperatura de $155^{\circ} \mathrm{C}$. Finalmente, se aplica al ensamble una presión de alrededor de $70 \mathrm{~kg} / \mathrm{cm}^{2}$ durante 5 minutos.

Los dos tipos de electrodos porosos, uno con nanopartículas de $P t$ facetadas tipo (111) y otro con nanopartículas de Pt policristalinas, fueron utilizados como cátodos en la celda de combustible unitaria, exhibiendo ambos un área geométrica de electrodo de $4 \mathrm{~cm}^{2}$.

En todas las pruebas realizadas se humidificó solamente el gas hidrógeno, mediante saturación con vapor de agua a $\mathrm{T}_{\text {hum }}=60^{\circ} \mathrm{C}$. El sistema de humidificación fue similar al previamente descripto (CAPÍTULO IX, sección IX.5.b). En la Figura 23 se muestran las curvas de polarización de celdas de combustible unitarias PEM de hidrógeno/oxígeno con los dos tipos de electrocatalizadores de Pt/C incorporados en los electrodos de difusión de gas: (a) nanopartículas de Pt facetadas tipo (111) de alta área superficial obtenidas por la técnica de OCPR (celda 1) y, (b) nanopartículas de Pt policristalinas comerciales soportadas sobre carbón Vulcan XC-72 (celda 2).

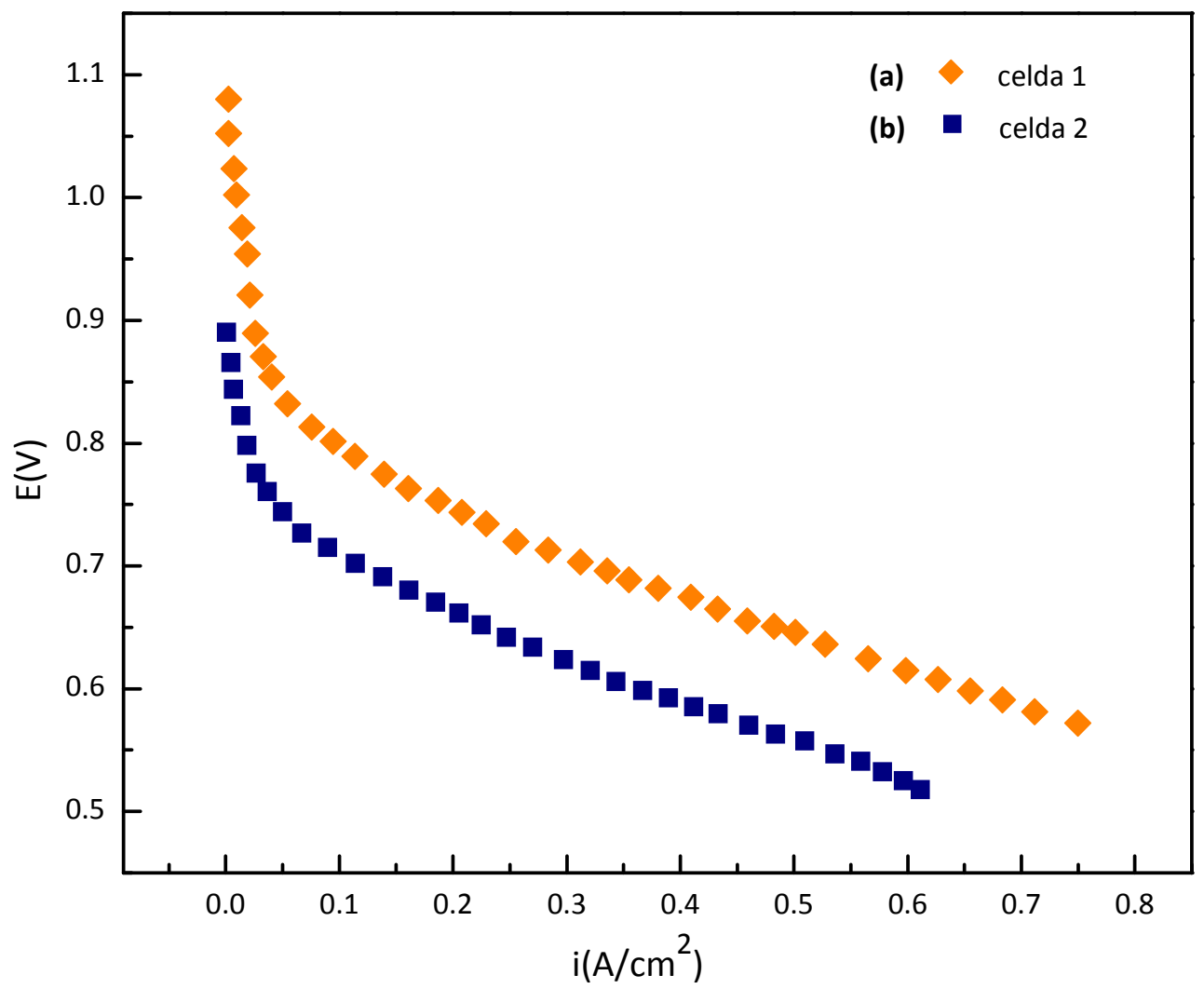

Figura 23. Curva de potencial-densidad de corriente para celdas unitarias de hidrógeno/oxígeno PEM con diferentes electrocatalizadores de Pt: (a) $\diamond$ nanopartículas de Pt facetadas tipo (111) y (b) घ nanopartículas de Pt policristalinas. $\mathrm{T}_{\text {celda }}=60^{\circ} \mathrm{C}$, presión de los gases de entrada $=1 \mathrm{~atm}$. 
La temperatura de operación de la celda fue de $60{ }^{\circ} \mathrm{C}$ y la presión de entrada del gas de 1 atmósfera. En todos los casos de la densidad de corriente está referida al área geométrica del electrodo. Al respecto, se debe notar que no hay una diferencia apreciable entre las área superficiales reales de los dos tipos de electrocatalizadores de $P t$, tal como se estima mediante la correspondiente carga voltamperométrica de la monocapa de hidrógeno adatómico [19], [267].

La celda unitaria con nanopartículas de Pt facetadas tipo (111), llamada celda 1, exhibe el potencial más alto a circuito abierto, que es de 1,08 V. Esto sugiere un aumento en la reversibilidad de la reacción de electrorreducción de oxígeno sobre este tipo de cristalitas de Pt. Además, particularmente a bajas densidades de corriente, en la región controlada por activación, los sobrepotenciales de la celda 1, son significativamente más bajos que los correspondientes a la celda unitaria con nanopartículas de $P t$ policristalinas (celda 2). Tanto para la celda 1 como para la celda 2, a bajas densidades de corriente se observa una pronunciada caída del potencial, debido a la cinética lenta de la reacción de electrorreducción de oxígeno que tiene lugar en el cátodo. En esta zona se establece una relación entre el potencial de la celda y la densidad de corriente de acuerdo a la ecuación de Tafel, determinando la región de sobrepotencial de activación. Por otro lado, en todo el intervalo de densidades de corriente y para un dado potencial de celda, las densidades de corriente obtenidas con la celda 1, que utiliza los electrocatalizadores de $P t$ altamente facetados, son siempre mayores que las obtenidas para la celda 2. Así por ejemplo, para un potencial intermedio de $0,65 \mathrm{~V}$, la densidad de corriente de la celda 1 es aproximadamente el doble que la correspondiente a la celda 2. Esto representa un aumento del $115 \%$ en densidad de corriente cuando la celda de combustible utiliza cristalitas de Pt facetadas tipo (111) $\left(i_{\text {celda1 }}=0,48 \mathrm{~A} / \mathrm{cm}^{2}, i_{\text {celda2 }}=0,22 \mathrm{~A} / \mathrm{cm}^{2}\right)$. Por otro lado, la máxima corriente drenada por la celda 1 es casi un $23 \%$ mayor que la encontrada para la celda $2\left(i_{\text {máx celda1 }}=0,75 \mathrm{~A} / \mathrm{cm}^{2}, i_{\text {máx celda2 }}=0,61 \mathrm{~A} / \mathrm{cm}^{2}\right)$.

La actividad catalítica de las nanopartículas de Pt facetadas tipo (111) para la reacción de electrorreducción de oxígeno en medio ácido, es significativamente más alta que la observada con nanocatalizadores de Pt policristalino altamente dispersados. La mejora en el comportamiento en operación de la celda de combustible que utiliza un cátodo catalizado con nanopartículas de $P t$ facetadas tipo (111) (celda 1) se debe a que resulta favorecida la ruta de cuatro electrones en la reacción global de electrorreducción de oxígeno [126]. Este hecho se asigna, tal como fuera previamente demostrado [19], [126], [160], [258], a la disminución del efecto de bloqueo de la superficie del electrodo por intermediarios peroxídicos producidos durante el proceso de electrorreducción de oxígeno, que favorece de este modo el proceso global de conversión de energía.

X.6. Implementación de la rutina de trabajo para la evaluación del comportamiento de celdas de combustible unitarias

La realización de numerosas pruebas experimentales ha permitido conocer el comportamiento de la celda unitaria prototipo bajo las condiciones más variadas de operación y, en base a ello, elaborar un 
procedimiento para la puesta en marcha de la celda y la evaluación de su comportamiento en operación. Mediante los ensayos realizados con la estación de testeo se pudo determinar la inercia del sistema, sobre todo relacionado con el tiempo necesario para alcanzar la temperatura deseada de operación y la estabilización de las corrientes drenadas, aspectos muy importantes para conocer las condiciones más favorables para la operación de la celda.

La importancia de contar con una rutina de tratamiento previo a la evaluación del comportamiento de la celda es que permite partir de condiciones iniciales de operación estandarizadas. De este modo, siguiendo el protocolo elaborado, se puede evaluar el comportamiento de celdas de combustible y obtener así resultados comparables cuando el testeo se lleve a cabo bajo las mismas condiciones de operación. Mediante la adecuada evaluación de la performance de la celda se pueden obtener conclusiones referidas a su desempeño y las posibles mejoras de su comportamiento en operación.

A continuación se mencionan los pasos que conforman el protocolo de testeo de la celda de combustible:

- La celda a $25^{\circ} \mathrm{C}$ se deja a potencial de circuito abierto, $E_{c a}$, con circulación de gases secos durante 15 minutos, tiempo suficiente para que en la celda no se generen condiciones de sequedad.

- Para lograr un mejor grado de humidificación de la membrana se pueden aplicar los siguientes tratamientos alternativos:

(a) Se aplica un potencial constante, $\mathrm{E}_{\text {cte }}$, de $0,5 \mathrm{~V}$ durante 30 minutos a $\mathrm{T}_{\text {celda }}=25^{\circ} \mathrm{C}$. Luego se corta la tensión, se deja que se estabilice la corriente a cero y se aplica un pulso corto de activación de 3 minutos a $E_{c t e}=0,5 \mathrm{~V}$. Se repite el procedimiento de aplicación del pulso 3 veces. Cuando la celda de combustible drena corriente a $\mathrm{E}_{\mathrm{cte}}=0,5 \mathrm{~V}$ se genera agua por la propia reacción electroquímica que, en el transcurso del tiempo, permite alcanzar el adecuado contenido de humedad para favorecer el pasaje de protones a través de la membrana polimérica hidratada, lo cual resulta necesario para que se lleve a cabo la reacción electroquímica. Por otro lado, al aplicar ciclos cortos, se produce la activación de los electrodos de la celda de combustible.

(b) Los gases de alimentación se saturan con vapor de agua mediante un sistema de humidificación, que consiste en burbujeadores sumergidos en agua a una temperatura igual a la temperatura de la celda, $\mathrm{T}_{\text {celda. }}$. Los controles de temperatura de los humidificadores de gas se encienden antes de aplicar los pulsos de activación del electrodo. Se selecciona como temperatura de humidificación de gas $T_{\text {hum }}=60{ }^{\circ} \mathrm{C}$. De acuerdo a los ensayos realizados se encontró que la humidificación de ambos gases provoca una caída importante del comportamiento en operación de la celda, por lo que se humidifica solamente el hidrógeno. Se deja circular los gases humidificados durante 30 minutos y posteriormente se realizan las medidas.

- La temperatura de operación de la celda de $\mathrm{T}_{\text {celda }}=60^{\circ} \mathrm{C}$ se alcanza en un tiempo relativamente corto. Por lo tanto, el control de temperatura se enciende luego de la aplicación del segundo pulso de 
activación. Se debe tener en cuenta que el adecuado control de $T_{\text {celda }}$ es un aspecto muy importante porque determina la adecuada gestión de la cantidad de agua que favorece el pasaje de los protones del ánodo al cátodo. El encendido del control de temperatura en el momento indicado permite que la cantidad de agua generada hasta ese momento sea la adecuada para el inicio de la medida sin inconvenientes provocados por inundación de los poros o posibles condiciones de sequedad. Se ha verificado que si el control de temperatura se activa antes del segundo pulso, la cantidad de agua generada por la reacción electroquímica no llega a ser suficiente para mantener las condiciones de humidificación, ya que la celda alcanza rápidamente la temperatura de operación de $60{ }^{\circ} \mathrm{C}$ y se comienza a secar por la alta temperatura.

- Se realiza la evaluación de la performance de la celda de combustible unitaria prototipo, registrando la variación de la corriente a distintos valores de potencial y se obtiene la curva de polarización característica de la celda unitaria para las condiciones ensayadas.

Mediante el protocolo de testeo aquí descripto se parte de condiciones estandarizadas de la celda de combustible, aspecto de suma importancia dado que permite realizar medidas confiables y reproducibles. 


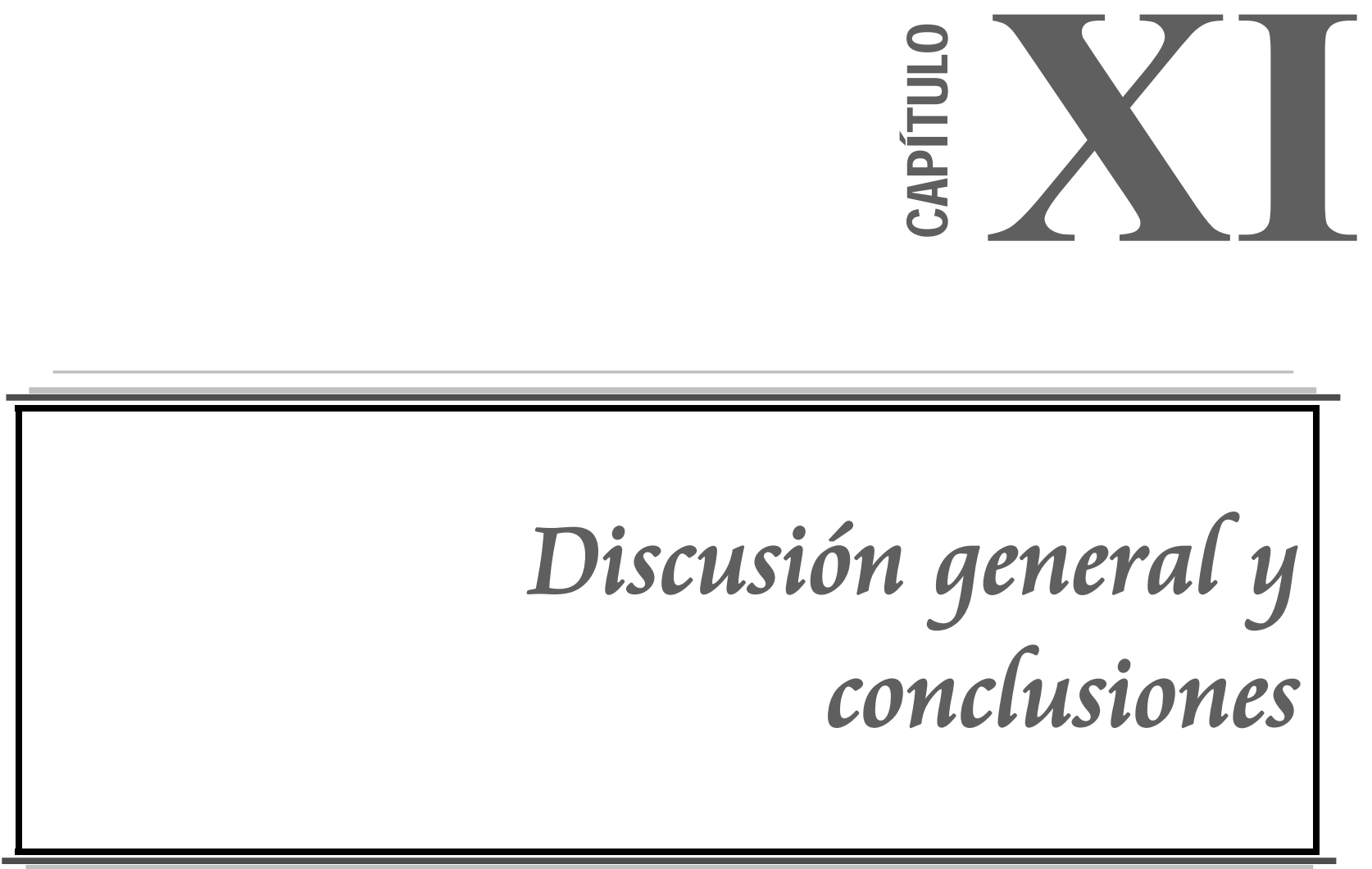


\section{CAPÍTULO XI}

\section{Discusión general y conclusiones}

El objetivo general de la tesis ha sido el desarrollo de electrodos con estructura superficial y composición bien definidas para conducir selectivamente las reacciones electródicas que tienen lugar en las celdas de combustible de hidrógeno/oxígeno a máxima velocidad y con alta eficiencia de conversión. Los principales logros alcanzados comprenden aspectos básicos y aplicados de la conversión electroquímica de energía que se describen a continuación:

1. Obtención de nanopartículas de Pt dispersadas sobre sustratos carbonosos de alta actividad catalítica para la reducción electroquímica de oxígeno.

- Se obtuvieron nanopartículas de Pt de alta área superficial, con morfología y composición bien definidas, dispersadas sobre sustratos carbonosos mediante la técnica de ondas cuadradas de potencial repetitivas $(O C P R)$.

- Por aplicación de una rutina de OCPR bajo las condiciones de operación $E s=0,9 \vee$; Ei $=-0,2 \vee$ y $f=1 \mathrm{kHz}$ se obtuvieron nanopartículas de Pt con morfología cúbica bien definida, características de la orientación cristalográfica preferencial (100).

- Por aplicación de una rutina de $O C P R$ a $E s=1,2 \vee ; E i=-0,2 \vee$ y $f=1 \mathrm{kHz}$ se obtuvieron nanopartículas de $P t$ altamente facetadas con estructuras poliédricas, con predominio de caras triangulares y ángulos agudos, características de la orientación cristalográfica preferencial (111).

- Se implementó una técnica espectrofotométrica para la determinación de la cantidad en masa de $P t$ electrodepositado por aplicación de la técnica de OCPR.

- Se estudió el efecto de la variación de los parámetros operacionales de la OCPR sobre el desarrollo de las nanopartículas de $P$ t. Los resultados más destacados son los siguientes:

a) Efecto del tiempo de electrodepósito a $E s=1,2 \mathrm{~V} ; E i=-0,2 \vee$ y $f=1 \mathrm{kHz}$.

- El tamaño de partícula de los electrodepósitos de Pt disminuye a medida que se reduce el tiempo de electrodeposición hasta alcanzar un tamaño constante de $180 \mathrm{~nm}$.

- La carga voltamperométrica aumenta con el tiempo de electrodepósito, salvo a tiempos grandes (1020 minutos), para los cuales resulta menor que la correspondiente a 30 segundos, debido a un efecto de aglomeración de las nanopartículas electrodepositadas, con disminución del área superficial activa.

- La cantidad neta de Pt electrodepositado determinado espectrofotométricamente aumenta con el tiempo de electrodeposición.

b) Efecto de la variación de $E i$ a $E s=1,2 \vee$ fijo, $f=1 \mathrm{kHz}$ y carga constante. 
- La densidad de recubrimiento de las partículas de Pt electrodepositadas aumenta a medida que Ei aumenta.

- El tamaño de partícula aumenta con el aumento de Ei. El mayor tamaño de partícula $(1100 \mathrm{~nm})$ se obtuvo a $E i=-0,28$ V. Para $E i=-0,24 \vee$ y $E i=-0,26 \vee$ el tamaño permanece constante $(520 \mathrm{~nm})$ y para $E i$ $=-0,2 \vee$ y $E i=-0,05 \vee$ se reduce a $240 \mathrm{~nm}$.

- El mayor número de partículas por unidad de área al menor tamaño de partícula alcanzado $(240 \mathrm{~nm})$ se obtuvo a $E i=-0,2 \mathrm{~V}$.

- La cantidad superficial de Pt electrodepositado a carga constante disminuye exponencialmente con el desplazamiento de Ei hacia valores más negativos.

- La masa de Pt electrodepositado para una misma carga disminuye con el desplazamiento de Ei hacia valores más negativos.

c) Efecto de la variación de $E i$ a $E s=1,38 \mathrm{~V} ; f=1 \mathrm{kHz}$ y $t=5$ minutos.

- La densidad de recubrimiento superficial por las nanopartículas de Pt disminuye con el desplazamiento de $E i$ hacia valores menos negativos.

- El tamaño de partícula disminuye a medida que $E i$ se hace menos negativo. Para $E i=-0,2 \mathrm{~V}$ se obtuvo el menor tamaño de partícula (34 nm).

- La carga voltamperométrica de electrodesorción de hidrógeno disminuye siguiendo una tendencia de tipo lineal a medida que el potencial inferior Ei se hace menos negativo.

d) Efecto de la variación de $E s$ a $E i=-0,2 \mathrm{~V} ; f=1 \mathrm{kHz}$ y $t=5$ minutos.

- El menor tamaño de partícula se encontró para $E s=1,38 \mathrm{~V}$, estimándose un valor de $34 \mathrm{~nm}$.

- La carga voltamperométrica de electrodesorción de hidrógeno disminuye con el aumento de Es.

- La cantidad superficial de Pt disuelto en los hemiciclos anódicos durante la aplicación de la OCPR aumenta con el potencial superior Es.

2. Diseño, construcción y evaluación del comportamiento en operación de electrodos porosos de difusión de gas con nanocatalizadores de Pt (111) incorporados.

- Se diseñaron y construyeron electrodos porosos de difusión de gas catalizados con nanopartículas de Pt altamente facetadas tipo (111), obtenidas por aplicación de la técnica de OCPR. Este tipo de nanopartículas, que son las que presentan la mayor actividad catalítica para la electrorreducción de $\mathrm{O}_{2}$, se usaron como electrocatalizadores no soportados mezcladas con polvos de carbón Vulcan XC-72 y PTFE. La carga de Pt utilizada fue de $0,2 \mathrm{mg} / \mathrm{cm}^{2}$ y el área geométrica de los electrodos de $4 \mathrm{~cm}^{2}$.

- Los electrodos porosos catalizados con las nanopartículas de Pt tipo (111) de alta área superficial se utilizaron como cátodo en una celda de combustible prototipo unitaria de hidrógeno/oxígeno con membrana de Nafion como electrolito, operando a $60^{\circ} \mathrm{C}$ y presión de entrada de gases de 1 atmósfera. 
- La celda de combustible unitaria construida en el laboratorio con nanopartículas de Pt (111) exhibió un potencial de circuito abierto, $E_{c a}$, de 1,08 $\vee$ y densidades de corriente máximas de orden de $0,75 \mathrm{~A} / \mathrm{cm}^{2}$. El comportamiento en operación de la celda unitaria se comparó con la performance de una celda de combustible con electrodos porosos de difusión de gas preparados con nanopartículas policristalinas soportadas sobre carbón Vulcan XC-72 y PTFE. Se encontró una mejora en el comportamiento en operación de la celda que utiliza un cátodo catalizado con nanopartículas de Pt facetadas tipo (111), debido a que resulta favorecida la ruta de 4 electrones en la reacción global de electrorreducción de oxígeno. Esto se debe a que la presencia de este tipo de nanopartículas de platino altamente facetadas en el cátodo disminuyen el efecto de bloqueo de la superficie del electrodo por intermediarios peroxídicos producidos durante el proceso de electrorreducción de oxígeno, favoreciendo de este modo el proceso global de conversión de energía.

\section{Diseño, construcción y evaluación del comportamiento en operación de ensambles electrodo-} membrana PEM-electrodo.

- Se diseñaron y construyeron ensambles electrodo-membrana PEM-electrodo (MEA) utilizando la técnica de aplicación de la capa activa (electrocatalizador-carbón-PTFE) de los electrodos (ánodo y cátodo) sobre ambos lados de la membrana de Nafion y posterior calentamiento bajo presión durante algunos minutos. La carga de catalizador fue de $1 \mathrm{mg}$ de $P t / \mathrm{cm}^{2}$ (Pt policristalino comercial).

- Los electrodos porosos del ensamble fueron caracterizaron mediante voltamperometría cíclica "in situ" que permitió obtener una rápida evaluación de su desempeño en una celda prototipo de $\mathrm{H}_{2} / \mathrm{O}_{2}$. Se determinó el área superficial electroquímicamente activa encontrándose valores similares a los informados en la bibliografía [405-407], para la condición de humidificación de $H_{2}$, alto caudal de $N_{2}$ y $\mathrm{T}_{\text {celda }}=25^{\circ} \mathrm{C}$.

- Se ensayaron diferentes condiciones de trabajo y se evaluó la respuesta voltamperométrica cíclica "in situ" para cada situación de estudio. Se pueden destacar los siguientes aspectos:

a) Se observó poca definición de los picos de corriente correspondientes a la zona de electrosorción de hidrógeno que se podría atribuir, en principio, al contenido de PTFE de la capa difusora de gas y a la cantidad de Nafion $^{\circledR}$ de la capa activa. Cantidades excesivas de PTFE afectan la porosidad de los electrodos que se obstruyen y afectan la conducción de los gases a los sitios de reacción, en tanto que cantidades excesivas de Nafion $^{\circledR}$ en la capa activa recubren las partículas de catalizador impidiendo el adecuado contacto con los gases de reacción, lo que genera baja utilización del catalizador y adiciona resistencia a los electrodos.

b) El aumento de la temperatura de operación de la celda produce inclinación de los voltamperogramas "in situ". Se evidenció pérdida de definición de los picos de corriente correspondientes a la zona de electrosorción de hidrógeno debido al aumento de la resistencia de la 
celda por humidificación deficiente de la membrana Nafion. Los efectos resistivos de la celda se acentúan a alta temperatura de operación.

c) Se logró un rápido restablecimiento de los perfiles voltamperométricos al circular gases húmedos como resultado de la mejora en el grado de humidificación de la membrana, poniendo de manifiesto la capacidad de la celda de retornar a las condiciones iniciales. Del mismo modo, la disminución de la temperatura de operación de la celda a $25{ }^{\circ} \mathrm{C}$ permito alcanzar un valor constante y característico de resistencia de 0,51 $\Omega$.

d) Los voltamperogramas cíclicos "in situ", obtenidos durante las medidas a tiempos largos, no mostraron variaciones considerables, siendo el área superficial electroquímicamente activa prácticamente la misma al inicio y al final del tiempo de estudio.

4. Diseño, construcción y evaluación del comportamiento de un prototipo de celda de combustible unitaria PEM de $\mathrm{H}_{2} / \mathrm{O}_{2}$ con electrodos porosos de difusión de gas catalizados con nanopartículas de Pt policristalinas bajo diferentes condiciones de operación.

- Se evaluó el comportamiento en operación de una celda de combustible unitaria prototipo desarrollada a escala laboratorio con electrodos porosos de difusión de gas e incorporación de nanopartículas de Pt policristalinas comerciales soportadas sobre carbón Vulcan XC-72. Las curvas de polarización mostraron los perfiles típicos para celdas de combustible de hidrógeno/oxígeno donde se distinguieron las diferentes zonas de pérdidas de energía asociadas a los fenómenos limitantes (polarización de activación, óhmica y de concentración). En términos generales, el comportamiento de la celda de combustible bajo polarización fue el resultado de las pérdidas de energía por sobrepotenciales de activación y de concentración y por caída óhmica debido a la resistividad del electrolito.

- Se estudió la influencia de la variación de parámetros tales como temperatura de operación de la celda, grado de humidificación de los gases, caudales de los gases de alimentación, etc., sobre su comportamiento en operación. Los principales resultados y conclusiones fueron los siguientes:

a) Se determinó que el potencial a circuito abierto de la celda, $E_{c a}$, sin humidificación de los gases reactivos, es de $0,90 \mathrm{~V}$ a $25^{\circ} \mathrm{C}$, que es un valor cercano al informado en la bibliografía.

b) El mejor desempeño para la celda de combustible unitaria se obtuvo humidificando sólo el gas hidrógeno. Con humidificación de ambos gases se generan situaciones de inundación que provocan el bloqueo en la entrada de los gases, con lo que disminuye la performance de la celda.

c) En la región lineal de la curva de polarización, a corrientes intermedias, correspondiente a la polarización óhmica se registraron aumentos de la pendiente debido, probablemente, a una mayor resistencia del electrolito por problemas asociados con el transporte de agua. 
d) Se registró una mejora en la performance de la celda de combustible cuando se opera a alta temperatura y con humidificación de hidrógeno, debido al aumento en la velocidad de reacción de los procesos electródicos con la temperatura y al aumento de la conductividad iónica de la membrana electrolítica con la humidificación.

e) La disminución de los caudales de los gases de alimentación no afecta el perfil de las curvas de polarización de la celda de combustible para bajas densidades de corriente. Para la condición de deficiencia de gases se determinó el punto muerto, es decir, el valor de corriente para el cual la tensión cae rápidamente como resultado de la limitación impuesta por el ánodo.

f) Se determinó que la cantidad de agua producida por la reacción electroquímica en el compartimiento catódico no es suficiente para mantener las condiciones ideales de hidratación de la membrana cuando se opera a $60^{\circ} \mathrm{C}$. Por lo tanto, se optó por utilizar un sistema de hidratación forzada que se consiguió saturando el hidrógeno con vapor de agua antes de su ingreso a la celda de combustible, haciéndolo pasar previamente por burbujeadores que se encuentran a alta temperatura.

g) Se determinó que el transporte de agua en la membrana es un factor limitante de la eficiencia de la celda de combustible. La hidratación insuficiente genera dependencia de la resistencia de la membrana con la densidad de corriente, registrándose bajos valores por efecto de secado de la membrana, en tanto que el exceso de humidificación produce caída de la densidad de corriente debido a la inundación de los poros del electrodo y el bloqueo de los sitios activos que se hacen inaccesibles a los gases de reacción.

h) En la evaluación del comportamiento en operación de la celda de combustible a tiempos largos se observó un menor drenaje de corriente a potencial constante a medida que transcurre el tiempo de operación, como resultado del envejecimiento de los electrodos.

\section{Elaboración de un protocolo para el testeo de celdas de combustible de $\mathrm{H}_{2} / \mathrm{O}_{2}$ de electrolito} de polímero sólido.

- Se elaboró un protocolo de testeo para celdas de combustible unitarias de hidrógeno/oxígeno PEM que permite partir de condiciones estandarizadas para la evaluación del comportamiento en operación de la celda de combustible testeada. El protocolo de testeo incluye, además, un procedimiento de activación de los electrodos porosos de celdas de combustible, contando de esta manera con una rutina de tratamiento previo a la evaluación de su comportamiento en operación. 


\section{LISTA DE TABLAS}

\section{CAPÍTULO I}

Tabla I. Evolución de la matriz energética argentina: 1970/2009

\section{CAPÍTULO II}

Tabla I. Preparación de electrocatalizadores de Pt y su desempeño electroquímico

\section{CAPÍTULO IV}

Tabla I. Modos de operación del microscopio electrónico de barrido

\section{CAPÍTULO VII}

Tabla I. Reacciones electroquímicas para los diferentes tipos de celdas de combustible

Tabla II. Principales características de las celdas de combustible en función del electrolito

Tabla III. Ventajas, inconvenientes y aplicaciones de los diferentes tipos de celdas de combustible

\section{CAPÍTULO VIII}

Tabla I. Componentes del MEA y sus principales funciones

Tabla II. Diferentes tipos de membranas Nafion ${ }^{\circledR}$ de DuPont

\section{CAPÍTULO IX}

Tabla I. Propiedades de la dispersión de Teflón ${ }^{\circledR}$ PTFE Grado TE-3898 de DuPont ${ }^{\text {TM }}$

Tabla II. Composición y propiedades de la solución de Nafion ${ }^{\circledR}$ ("Perfluorinated ion-exchange resin") al $5 \%$ wt \%

\section{CAPÍTULOX}

Tabla I. Condiciones de operación para la evaluación del comportamiento de la celda de combustible unitaria con nanopartículas de $P t$ policristalinas

Tabla II. Valores de potencial y corriente (a) antes y (b) después de la aplicación de $E_{c t e}=0,5$ $\mathrm{V}$ (activación 2)

Tabla III. Valores de $\mathrm{R}_{\text {celda }}$ operando con humidificación de $\mathrm{H}_{2}$ a: (a) $25^{\circ} \mathrm{C}$ y (b) $60^{\circ} \mathrm{C}$

Tabla IV. Condiciones de operación para la evaluación del comportamiento de la celda unitaria 


\section{LISTA DE FIGURAS}

\section{CAPÍTULO I}

Figura 1. Ciclo del hidrógeno

\section{CAPÍTULO II}

Figura 1. Gráfica de la densidad de corriente de intercambio para la reacción de desprendimiento de hidrógeno vs. energía de enlace $M-H$ de diferentes materiales

Figura 2. Esquema simplificado de un poro. Representación de la interfase activa (i. a.)

Figura 3. Mecanismo de la $R R O$ sobre superficies metálicas

Figura 4. Curvas de polarización para la electrorreducción de $\mathrm{O}_{2}$ en solución $\mathrm{H}_{2} \mathrm{SO}_{4} 0,5 \mathrm{M}$ a $25^{\circ} \mathrm{C}$ para Pt (100), Pt (111) y Pt policristalino

\section{CAPÍTULO III}

Figura 1. Perfiles $\mathrm{E} / \mathrm{I}$ en $\mathrm{H}_{2} \mathrm{SO}_{4} 0,5 \mathrm{M}$ a $30{ }^{\circ} \mathrm{C}$ : a) electrodo de $P t$ sin tratamiento de $O C P R$ después de $5 \mathrm{~min}$ de ciclado a $0,3 \mathrm{~V} / \mathrm{s}$, b) perfil de electrorreducción a 0,003 V/s inmediatamente después del tratamiento de $\operatorname{OCPR}(E s=2,4 \mathrm{~V} ; E i=0,4 \mathrm{~V}$; período $\tau=560 \mu \mathrm{s}$; tiempo de duración $t=3 \mathrm{~min}$ ), c) electrorreducción de $P t$ después de 5 min de ciclado a 0,3 V/s

Figura 2. Esquema de los patrones superficiales observados por microscopía electrónica de barrido con electrodos esféricos monocristalinos de Pt: (a) esfera monocristalina sin tratar, (b) facetado (100), (c) facetado (111), (d) facetado (110)

Figura 3. Modos de operación en electrólisis pulsante: i. corriente inversa, ii. corriente pulsante, iii. corriente alterna sobrepuesta a una corriente continua, iv. ondas cuadradas de potencial repetitivas

Figura 4. Influencia de la capacidad de la doble capa: (a) efecto despreciable, (b) efecto medio (c) y (d) efecto marcado

\section{CAPÍTULO IV}

Figura 1. Esquema de la perturbación aplicada para una experiencia de voltamperometría cíclica

Figura 2. Esquema de una celda electroquímica: 1. electrodo de trabajo, 2. contraelectrodo, 3. electrodo de referencia

Figura 3. Variación de la pseudocapacidad en función del potencial (Curva $a$ ). Integral de la curva a representando la isoterma electroquímica (Curva $b$ ) para la electrosorción de hidrógeno sobre Pt en $\mathrm{H}_{2} \mathrm{SO}_{4} 4 \mathrm{M}$ a $25^{\circ} \mathrm{C}$

Figura 4. Perfil voltamperométrico que muestra la extrapolación del proceso de adsorción de hidrógeno sobre Pt en $\mathrm{H}_{2} \mathrm{SO}_{4} 0,5 \mathrm{M}$ a $25^{\circ} \mathrm{C}$

Figura 5. Diferentes tipos de átomos superficiales en los planos (110) y (210) en una red fcc. Las coordinaciones de A, B, C y D son $6,7,9$ y 11 respectivamente

Figura 6. Perfiles voltamperométricos para diferentes electrodos monocristalinos de $P t$ y un electrodo de $P t$ poliorientado en $\mathrm{H}_{2} \mathrm{SO}_{4} 0,5 \mathrm{M}, v=50 \mathrm{mV} / \mathrm{s}$

Figura 7. Respuesta voltamperométrica a $0,1 \mathrm{~V} / \mathrm{s}$ registrada en $\mathrm{H}_{2} \mathrm{SO}_{4} \quad 0,5 \mathrm{M}$ a $25{ }^{\circ} \mathrm{C}$, correspondiente a un electrodo de $P t$ polifacetado 
Figura 8. Picos de corriente presentes en la zona de hidrógeno para un electrodo de $P t$ policristalino en $\mathrm{H}_{2} \mathrm{SO}_{4} \quad 0,5 \mathrm{M}$ a $25^{\circ} \mathrm{C}$

Figura 9. Voltamperogramas de $\mathrm{Pt}$ en $\mathrm{H}_{2} \mathrm{SO}_{4}$ 0,5 M. Potenciales límites superiores de barrido desde $0,91 \mathrm{~V}$ hasta $1,66 \mathrm{~V}$, con incrementos de $0,1 \mathrm{~V}, v=50 \mathrm{mV} / \mathrm{s}, A_{G}=0,25 \mathrm{~cm}^{2}$

Figura 10. Respuestas voltamperométricas a $0,1 \mathrm{~V} / \mathrm{s}$ registradas en $\mathrm{H}_{2} \mathrm{SO}_{4} 0,5 \mathrm{M}$ a $25^{\circ} \mathrm{C}$ para electrodos de $P t$ con orientaciones cristalográficas preferenciales tipo (a) (100) y (b) (111)

Figura 11. Señales generadas por la interacción de un haz de electrones con una muestra

Figura 12. (a) Esquema de los componentes de un microscopio electrónico de barrido, (b) fotografía de un microscopio SEM

Figura 13. Detectores de un microscopio electrónico de barrido

Figura 14. Esquema de un microscopio electrónico de transmisión

Figura 15. Formación de la imagen en (a) campo claro y (b) oscuro

Figura 16. Obtención del diagrama de difracción de electrones

Figura 17. Representación de la ley de Bragg

Figura 18. Diagrama de absorción de un haz de luz que atraviesa una cubeta con un camino óptico $l$

\section{CAPÍTULO $V$}

Figura 1. Átomos de carbono con hibridación $\mathrm{sp}$

Figura 2. Dos de las estructuras propuestas para los átomos de carbono $\quad 74$

Figura 3. Átomos de carbono con hibridación $\mathrm{sp}^{2} \quad 74$

Figura 4. Átomos de carbono con hibridación $\mathrm{sp}^{3} \quad 75$

Figura 5. Diamante (a) cúbico y (b) hexagonal 75

Figura 6. Estructura del fullereno C60 75

Figura 7. Diversas estructuras de nanotubos de carbono 76

Figura 8. Esquemas originales de Franklin para las estructuras de carbones no grafíticos: (a) grafitizable y (b) no grafitizable

$\begin{array}{ll}\text { Figura 9. Fibras de carbono con diferentes estructuras } & 77\end{array}$

$\begin{array}{ll}\text { Figura 10. Carbones con diferentes estructuras macroscópicas } & 78\end{array}$

Figura 11. Carbones y sus diferentes estructuras microscópicas $\quad 79$

Figura 12. Estructuras del grafito: (a) hexagonal ( $A B A B)$ y (b) romboédrica ( $A B C A)$

Figura 13. Voltamperograma correspondiente al tratamiento de oxidación del sustrato grafítico 83

Figura 14. Voltamperograma a $0,1 \mathrm{~V} / \mathrm{s}$ del sustrato de grafito en $\mathrm{H}_{2} \mathrm{SO}_{4} 0,5 \mathrm{M}$ (a) $=$ antes y (b) $\nabla$ después del tratamiento de oxidación

Figura 15. Imágenes SEM de electrodepósitos de $P t$ sobre sustrato (a) oxidado y (b) sin oxidar. Condiciones de operación $E i=-0,24 \mathrm{~V} ; E s=1,38 \mathrm{~V} ; f=1 \mathrm{kHz}, t=5 \mathrm{~min}$

Figura 16. Imágenes SEM del sustrato grafítico (a) Magnificación $400 \mathrm{X}$, escala $300 \mu \mathrm{m}$; (b) Magnificación 1600 X, escala $50 \mu \mathrm{m}$; (c) Magnificación 6000 X, escala $20 \mu \mathrm{m}$

Figura 17. Imagen SEM de los electrodepósitos de Pt sobre grafito como sustrato electródico. Magnificación 15000 X, escala $5 \mu \mathrm{m}$

Figura 18. Voltamperograma cíclico a $0,1 \mathrm{~V} / \mathrm{s}$ de un electrodo de grafito en $\mathrm{H}_{2} \mathrm{SO}_{4} 0,5 \mathrm{M}$ a $25^{\circ} \mathrm{C}$ 
Figura 19. Voltamperogramas cíclicos de un electrodo de grafito en $\mathrm{H}_{2} \mathrm{SO}_{4} 0,5 \mathrm{M}$ a $25{ }^{\circ} \mathrm{C}$ registrados a diferentes velocidades de barrido de potencial entre 0,01 y $0,5 \mathrm{~V} / \mathrm{s}$

Figura 20. Gráfica que muestra la dependencia de la corriente capacitiva en función de la velocidad de barrido de potencial para $E_{L}=0,3 \mathrm{~V}$

\section{CAPÍTULO VI}

Figura 1. Esquema del sistema purificador de agua, etapas b)-d)

Figura 2. Electrodo de trabajo para los electrodepósitos de $P t$

Figura 3. Geometría seleccionada para el contraelectrodo de la celda para electrodepositar

Figura 4. Electrodos de referencia (a) para electrodepositar Pt y (b) para voltamperometría cíclica

Figura 5. Celda electroquímica para electrodepositar $P t$

Figura 6. Celda electroquímica para la caracterización voltamperométrica

Figura 7. Sistema de equipos interconectados utilizados en las experiencias

Figura 8. Evolución de la OCPR a la salida del conformador de onda

Figura 9. Espectros de los complejos de Pt con $\mathrm{SnCl}_{2}$ para la solución patrón a diferentes concentraciones

Figura 10. Recta de ajuste para la calibración de la técnica. Verificación de la ley de LambertBeer para $P t$ a $\lambda_{\text {máx }}=402 \mathrm{~nm}$

Figura 11. Voltamperograma cíclico a $0,1 \mathrm{~V} / \mathrm{s}$ correspondiente a electrodepósitos de $P t$ obtenidos por aplicación de una OCPR entre $E s=1,2 \mathrm{~V} ; E i=-0,2 ; f=1 \mathrm{kHz} ; t=5 \mathrm{~min}$

Figura 12. Imagen SEM de electrodepósitos de $P t$ obtenidos bajo condiciones de operación $E s=0,9 \mathrm{~V} ; E i=-0,2 \mathrm{~V}(\langle E\rangle=0,35 \mathrm{~V}) ; f=1 \mathrm{kHz} ; t=5 \mathrm{~min}$

Figura 13. Monocristal ideal facetado en forma perpendicular a las direcciones [100]

Figura 14. Respuesta voltamperométrica a $0,1 \mathrm{~V} / \mathrm{s}$ en $\mathrm{H}_{2} \mathrm{SO}_{4} \quad 0,5 \mathrm{M}$ a $25{ }^{\circ} \mathrm{C}$ de: (a) $\Delta$ electrodepósitos de Pt sobre grafito ( $E s=0,9 \mathrm{~V} ; E i=-0,2 \mathrm{~V} ; f=1 \mathrm{kHz} ; t=10 \mathrm{~min}$ ) y (b) - sustrato grafítico

Figura 15. Imagen SEM de electrodepósitos de Pt obtenidos bajo condiciones $E s=1,2 \mathrm{~V}$; $E i=-0,2 \mathrm{~V} ; f=1 \mathrm{kHz}$. Magnificación $30000 \mathrm{X}$

Figura 16. Imagen SEM de electrodepósitos de Pt obtenidos bajo condiciones $E s=1,2 \mathrm{~V}$; $E i=-0,2 \mathrm{~V} ; f=1 \mathrm{kHz}$. Magnificación $8000 \mathrm{X}$

Figura 17. Monocristal ideal facetado en forma perpendicular a las direcciones [111]

Figura 18. Respuesta voltamperométrica a $0,1 \mathrm{~V} / \mathrm{s}$ en $\mathrm{H}_{2} \mathrm{SO}_{4}$ a $25{ }^{\circ} \mathrm{C}$ de: (a) $\Delta$ electrodepósitos de $P t$ sobre grafito ( $E s=1,2 \mathrm{~V} ; E i=-0,2 \mathrm{~V} ; f=1 \mathrm{KHz} ; t=20 \mathrm{~s}$ ) y (b) $=$ sustrato grafítico

Figura 19. Imágenes TEM de las nanocristalitas de $P t$ electrodepositadas por aplicación de la técnica de $O C P R$

Figura 20. Imagen TEM de las nanocristalitas de Pt electrodepositadas por aplicación de la técnica de $O C P R$

Figura 21. Patrón XRD para diferentes tipos de nanocristalitas de Pt: (a) policristalinas soportadas sobre sustratos de carbono, (b) altamente facetadas con orientación preferencial (111)

Figura 22. Espectros de los complejos de $P t$ con $\mathrm{SnCl}_{2}$ para las soluciones (a) y (b) preparadas a partir de una muestra de Pt electrodepositado 
Figura 23. Rendimiento de la electrodeposición de $P t$ a potencial superior constante en función del potencial inferior $E i$

Figura 24. Imagen SEM de electrodepósitos de $P t$ sobre grafito correspondiente a una muestra bajo tratamiento de $E s=1,2 \mathrm{~V} ; E i=-0,2 \mathrm{~V} ; f=1 \mathrm{kHz}, t=5 \mathrm{~min}$. Magnificación $30000 \mathrm{X}$

Figura 25. Imagen SEM de electrodepósitos de $P t$ sobre grafito correspondiente a una muestra bajo tratamiento de $E s=1,2 \mathrm{~V} ; E i=-0,2 \mathrm{~V} ; f=1 \mathrm{kHz} ; t=30 \mathrm{~s}$. Magnificación $30000 \mathrm{X}$

Figura 26. Efecto del tiempo de electrodeposición sobre el tamaño de partícula para las condiciones de operación $E s=1,2 \mathrm{~V} ; E i=-0,2 \mathrm{~V} ; f=1 \mathrm{kHz}$

Figura 27. Respuesta voltamperométrica de los electrodepósitos de $P t$ para diferentes tiempos de electrodeposición. Condiciones de OCPR Es $=1,2 \mathrm{~V} ; E i=-0,2 \mathrm{~V} ; f=1 \mathrm{kHz}$

Figura 28. Respuesta voltamperométrica de los electrodepósitos de Pt para altos tiempos de electrodeposición

Figura 29. Carga voltamperométrica asociada a la electrodesorción de hidrógeno sobre Pt electrodepositado en grafito en función del tiempo de electrodeposición. Condiciones de la OCPR Es $=1,2 \mathrm{~V} ; E i=-0,2 \mathrm{~V} ; f=1 \mathrm{kHz}$

Figura 30. Posible efecto de aglomeración de partículas de $P t$ a medida que transcurre el tiempo de electrodeposición

Figura 31. Cantidad en masa de Pt electrodepositado en función del tiempo de aplicación de la $O C P R$

Figura 32. Imágenes SEM de nanocristalitas de Pt electrodepositadas por aplicación de OCPR a $1 \mathrm{kHz}$ y $E S=1,2 \mathrm{~V}$ con variación de $E i$ (a) -0,05 V; (b) -0,2 V; (c) -0,24 V; (d) -0,26 V; (e) -0,28 V

Figura 33. Influencia del potencial inferior $E i$ en el tamaño de partícula a $E s=1,2 \mathrm{~V}$

Figura 34. Respuesta voltamperométrica de los electrodepósitos de Pt por aplicación de una $O C P R$ variando $E i$

Figura 35. Carga voltamperométrica asociada a la electrodesorción de hidrógeno sobre $P t$ electrodepositado

Figura 36. Cantidad en masa de Pt electrodepositado en función del potencial inferior

Figura 37. Imágenes SEM de nanocristalitas de $P t$ electrodepositadas por aplicación de OCPR manteniendo fijo $E s=1,38 \mathrm{~V}$ y variando $E i$ (a) $-0,28 \mathrm{~V}$; (b) $-0,26 \mathrm{~V}$; (c) $-0,24 \mathrm{~V}$; (d) $-0,2 \mathrm{~V}$. Magnificación $15000 \mathrm{X}$

Figura 38. Influencia del potencial inferior Ei en el tamaño de partícula para $E s=1,38 \mathrm{~V}$

Figura 39. Respuesta voltamperométrica de los electrodepósitos de Pt por aplicación de OCPR a $1 \mathrm{kHz}$ y a $E s=1,38 \mathrm{~V}$

Figura 40. Carga voltamperométrica asociada a la electrodesorción de hidrógeno sobre Pt electrodepositado

Figura 41. Imágenes SEM de partículas de Pt obtenidas por aplicación de la OCPR manteniendo Ei fijo en $-0,2 \mathrm{~V}$ y variando $E s$ (a) $1,38 \mathrm{~V}$; (b) 1,2 V

Figura 42. Respuesta voltamperométrica de los electrodepósitos de Pt por aplicación de una $O C P R$ variando el límite de potencial superior

Figura 43. Carga voltamperométrica asociada a la electrodesorción de hidrógeno sobre Pt electrodepositado

\section{CAPÍTULO VII}

Figura 1. Batería voltaica en base a reactivos gaseosos propuesta por Grove 
Figura 2: Diseño de la batería gaseosa de Mond y Langer. A: tiras de conducción, E: platos de ebonita, G: cámaras de gas selladas, $\mathrm{H}$ : hidrógeno, $\mathrm{K}$ : marcos de goma, O: oxígeno, $\mathrm{M}$ : plato de cerámica, R: marco de ebonita, S: electrodo

Figura 3. Prototipo construido por Wright y Thomson

Figura 4. Celda de combustible con electrolito de membrana de intercambio de protones desarrollada por General Electric Company

Figura 5. Reacción de los reactivos, $\mathrm{H}_{2}$ y $\mathrm{O}_{2}$, para formar agua

Figura 6. Tipos de celdas de combustible

Figura 7. Curva de polarización típica para una celda de combustible

Figura 8. Curva típica de potencia vs. densidad de corriente para una celda de combustible PEM de $\mathrm{H}_{2} / \mathrm{O}_{2}$ operando a $80^{\circ} \mathrm{C}$ y $3 \mathrm{~atm}$

\section{CAPÍTULO VIII}

Figura 1. Representación esquemática de una celda de combustible PEM unitaria

Figura 2. Esquema general de los componentes de una celda de combustible que utiliza la tecnología PEM

Figura 3. Estructura idealizada de catalizadores de Pt soportados en carbón

Figura 4. Interfases electroquímicas. Disposición de los materiales en la zona activa del electrodo poroso

Figura 5. Representación esquemática de la zona de tres fases, exhibiendo las diferentes partes que la constituyen

Figura 6. Estructura de la membrana Nafion ${ }^{\circledR}$

Figura 7. Esquema que muestra las dos fases existentes en la membrana: la hidrofóbica y la hidrofílica

Figura 8. Esquema conceptual del modelo de tres fases de Yeager para explicar la conductividad protónica del Nafion ${ }^{\circledR}$

Figura 9. Principio de operación de un arreglo o "stack" de celdas de combustible

\section{CAPÍTULO IX}

Figura 1. Esquema general de los ensambles electrodo-membrana PEM-electrodo de la celda de combustible de hidrógeno/oxígeno

Figura 2. Conjunto ensamble electrodo-membrana PEM-electrodo

Figura 3. Esquema de la fabricación de electrodos porosos de difusión de gas y construcción de los ensambles MEA

Figura 4. Secuencia de pasos seguidos para la fabricación de electrodos porosos de difusión de gas y construcción de los ensambles electrodo-membrana PEM-electrodo

Figura 5. Celda unitaria prototipo

Figura 6. Representación esquemática de una celda de combustible alimentada con $\mathrm{H}_{2}$ y $\mathrm{N}_{2}$ para evaluación por voltamperometría cíclica "in situ"

Figura 7. Esquema del arreglo para voltamperometría cíclica utilizado para la caracterización "in situ" de los electrodos de la celda unitaria

Figura 8. Voltamperograma cíclico "in situ" del ensamble utilizado en la celda de combustible unitaria a $\mathrm{T}_{\text {celda }}=25^{\circ} \mathrm{C}, \mathrm{Q}_{\mathrm{H} 2}=5 \mathrm{l} / \mathrm{h}, \mathrm{Q}_{\mathrm{N} 2}=4,5 \mathrm{l} / \mathrm{h}, \mathrm{T}_{\mathrm{Hum} \mathrm{H} 2}=60^{\circ} \mathrm{C}, \mathrm{N}_{2}$ seco 
Figura 9. Efecto del aumento del caudal de $N_{2}$ sobre los voltamperogramas a $\mathrm{T}_{\text {celda }}=25{ }^{\circ} \mathrm{C}$, $Q_{\mathrm{H} 2}=5 \mathrm{I} / \mathrm{h}, \mathrm{T}_{\text {Hum H2 }}=60^{\circ} \mathrm{C}, N_{2}$ seco. (a) $-Q_{\mathrm{N} 2}=4,5 \mathrm{I} / \mathrm{h}$ y (b) $\nabla \mathrm{Q}_{\mathrm{N} 2}=11 \mathrm{I} / \mathrm{h}$

Figura 10. Efecto del aumento del caudal de $N_{2}$ seco sobre los voltamperogramas a $Q_{\mathrm{H} 2}=5 \mathrm{l} / \mathrm{h}$ y $\mathrm{T}_{\text {celda }}=25^{\circ} \mathrm{C}(\mathrm{a})-\mathrm{Q}_{\mathrm{N} 2}=4,5 \mathrm{l} / \mathrm{h}$ y (b) $\nabla \mathrm{Q}_{\mathrm{N} 2}=11 \mathrm{l} / \mathrm{h}$

Figura 11. Respuesta voltamperométrica para $\mathrm{Q}_{\mathrm{N} 2}=4,5 \mathrm{I} / \mathrm{h}, \mathrm{T}_{\text {celda }}=25^{\circ} \mathrm{C}(\mathrm{a})-$ humidificación de $\mathrm{H}_{2}$ y $\mathrm{N}_{2}$, (b) - humidificación de $\mathrm{H}_{2}$

Figura 12. Voltamperogramas cíclicos "in situ" con humidificación de ambos gases a $\mathrm{T}_{\text {hum }}=60^{\circ} \mathrm{C}$, $\mathrm{T}_{\text {celda }}=25^{\circ} \mathrm{C}(\mathrm{a}) \nabla \mathrm{Q}_{\mathrm{N} 2}=4,5 \mathrm{l} / \mathrm{h}$ y $(\mathrm{b}) \approx \mathrm{Q}_{\mathrm{N} 2}=1 \mathrm{l} / \mathrm{h}$

Figura 13. Voltamperogramas "in situ" con humidificación de ambos gases o solo el $H_{2}$ para (a) $\mathrm{Q}_{\mathrm{N} 2}=11 \mathrm{l} / \mathrm{h}$ y $(\mathrm{b}) \mathrm{Q}_{\mathrm{N} 2}=4,5 \mathrm{l} / \mathrm{h}$

Figura 14. Efecto del aumento de $T_{\text {celda }}$ para $Q_{\mathrm{N} 2}=11 \mathrm{l} / \mathrm{h}$ y humidificación de ambos gases

Figura 15. Efecto de la variación de $T_{\text {celda }}$ sobre los voltamperogramas para $Q_{\mathrm{H} 2}=5 \mathrm{l} / \mathrm{h}$, $\mathrm{Q}_{\mathrm{N} 2}=11 \mathrm{l} / \mathrm{h}$ humidificados a $\mathrm{T}_{\text {hum }}=60^{\circ} \mathrm{C}$ (tiempo total de la medida 2 horas)

Figura 16. Efecto del aumento de Tcelda sobre los voltamperogramas "in situ" para $Q_{\mathrm{N} 2}=4,5 \mathrm{I} / \mathrm{h}$ y humidificación de $\mathrm{H}_{2}$ a $\mathrm{T}_{\text {hum } \mathrm{H} 2}=60^{\circ} \mathrm{C}$

Figura 17. Efecto de la $T_{\text {celda }}$ sobre los voltamperogramas "in situ" para $Q_{\mathrm{N} 2}=11 \mathrm{l} / \mathrm{h} \mathrm{y}$ humidificación de $\mathrm{H}_{2}$ a $\mathrm{T}_{\text {hum } \mathrm{H} 2}=60^{\circ} \mathrm{C}$

Figura 18. Efecto del tiempo de operación sobre los voltamperogramas "in situ" a $\mathrm{T}_{\text {celda }}=25^{\circ} \mathrm{C}$, $\mathrm{Q}_{\mathrm{H} 2}=4,5 \mathrm{l} / \mathrm{h}$ humidificado a $\mathrm{T}_{\text {hum H} 2}=60^{\circ} \mathrm{C}, \mathrm{Q}_{\mathrm{N} 2}=4,5 \mathrm{l} / \mathrm{h}(\mathrm{a})$ - inicialmente y $(\mathrm{b})$ - al cabo de 3 días

Figura 19. Efecto de la circulación de gases secos sobre la $R_{\text {celda }}$ para $Q_{\mathrm{N} 2}=4,5 \mathrm{I} / \mathrm{h}, Q_{\mathrm{H} 2}=5 \mathrm{I} / \mathrm{h}$ y $\mathrm{T}_{\text {ceda }}=25^{\circ} \mathrm{C}$ después de 5 días de operación

Figura 20. Efecto de la circulación de gases secos sobre la $R_{\text {celda }}$ para $Q_{N 2}=11 \mathrm{l} / \mathrm{h}$ y $T_{\text {ceda }}=25^{\circ} \mathrm{C}$

Figura 21. Efecto de la circulación de gases secos sobre la $R_{\text {celda }}$ a $T_{\text {celda }}=25{ }^{\circ} \mathrm{C}$ para (a) $\boldsymbol{.} Q_{\mathrm{N} 2}=4,5 \mathrm{l} / \mathrm{h}$ y (b) $\nabla \mathrm{Q}_{\mathrm{N} 2}=11 \mathrm{l} / \mathrm{h}$

Figura 22. Efecto de la variación de $T_{\text {celda }}$ sobre $R_{\text {celda }}$ para $Q_{N 2} 11 \mathrm{l} /$ h y humidificación de $H_{2}$

Figura 23. Variación de la $R_{\text {celda }}$ en función del tiempo de enfriamiento de la celda para $\mathrm{Q}_{\mathrm{N} 2}=11 \mathrm{l} / \mathrm{h}$

Figura 24. Efecto del aumento de $T_{\text {celda }}$ sobre la $R_{\text {celda }}$ para gases secos y alto caudal de nitrógeno

Figura 25. Efecto del enfriamiento de la celda sobre la $R_{\text {celda }}$ para $Q_{N 2}=11 \mathrm{l} / \mathrm{h}$ y gases secos

\section{CAPÍTULOX}

Figura 1. Curva de polarización para la celda de combustible unitaria de hidrógeno/oxígeno a $\mathrm{T}_{\text {celda }}=25^{\circ} \mathrm{C}$ y sin humidificación de gases

Figura 2. Curvas de polarización bajo condiciones de operación $T_{\text {celda }}=25{ }^{\circ} \mathrm{C}, \mathrm{Q}_{\mathrm{H} 2}=5 \mathrm{l} / \mathrm{h}$, $\mathrm{Q}_{02}=4,5 \mathrm{l} / \mathrm{h}$, gases secos $(\mathrm{a})$ - antes y (b) 口 después de la aplicación de $\mathrm{E}_{\mathrm{cte}}=0,5 \mathrm{~V}$ (activación 1 )

Figura 3. Estabilización de la corriente aplicando $E_{c t e}=0,5 \mathrm{~V}$ (activación 2)

Figura 4. Curvas de polarización de la celda de combustible (a) a inicialmente, (b) $\square$ luego del proceso de activación 1 por aplicación de $\mathrm{E}_{\mathrm{cte}}=0,5 \mathrm{~V}$ y (c) - luego de 8 días de operación

Figura 5. Curva de polarización con deficiencia de gases de alimentación secos, $Q_{\mathrm{H} 2}=1,33 \mathrm{l} / \mathrm{h}$ y $\mathrm{Q}_{\mathrm{O2}}=2,66 \mathrm{l} / \mathrm{h}$ a $\mathrm{T}_{\text {celda }}=25^{\circ} \mathrm{C}$

Figura 6. Restablecimiento de la curva de polarización por aumento del caudal de los gases de alimentación $\mathrm{Q}_{\mathrm{H} 2}=5 \mathrm{l} / \mathrm{h} ; \mathrm{Q}_{\mathrm{O} 2}=4,5 \mathrm{l} / \mathrm{h}$, gases secos a $\mathrm{T}_{\text {celda }}=25^{\circ} \mathrm{C}$ 
Figura 7. Efecto de los caudales $\mathrm{Q}_{\mathrm{H} 2}$ y $\mathrm{Q}_{\mathrm{O} 2}$ sobre la densidad de potencia de la celda: (a) disminución y (b) aumento de caudales

Figura 8. Curvas de polarización y de densidad de potencia para la celda de combustible unitaria a $Q_{\mathrm{H} 2}=9 \mathrm{l} / \mathrm{h}, Q_{\mathrm{O} 2}=4,5 \mathrm{l} / \mathrm{h}$, gases secos a $T_{\text {celda }}=25^{\circ} \mathrm{C}$

Figura 9. Efecto de la humidificación del $H_{2}$ sobre las curvas de polarización a $\mathrm{T}_{\text {celda }}=25^{\circ} \mathrm{C}$, $\mathrm{Q}_{\mathrm{H} 2}=5 \mathrm{I} / \mathrm{h}, \mathrm{Q}_{\mathrm{O} 2}=4,5 \mathrm{l} / \mathrm{h}$. (a) $\nabla$ humidificación de $H_{2}$ y (b) $\approx$ gases secos

Figura 10. Curva de polarización de la celda unitaria con humidificación de $H_{2}$ y $T_{\text {celda }}=60^{\circ} \mathrm{C}$

Figura 11. Efecto de la aplicación de $E_{\text {cte }}=0,5 \mathrm{~V}$ a $T_{\text {celda }}=60{ }^{\circ} \mathrm{C}$ y mayor tiempo de humidificación de $\mathrm{H}_{2}$, posterior a la activación 3

Figura 12. Variación de la corriente drenada por la celda en función del tiempo a $\mathrm{T}_{\text {celda }}=25^{\circ} \mathrm{C}$, $\mathrm{Q}_{\mathrm{O} 2}=4,5 \mathrm{l} / \mathrm{h}$ y $\mathrm{Q}_{\mathrm{H} 2}=5 \mathrm{l} / \mathrm{h}$ humidificado (activación 4 )

Figura 13. Recuperación de la curva de polarización por aplicación de $E_{c t e}$ a $Q_{\mathrm{H} 2}=5 \mathrm{l} / \mathrm{h}$ humidificado, $\mathrm{Q}_{02}=4,5 \mathrm{l} / \mathrm{h}$ y $\mathrm{T}_{\text {celda }}=25^{\circ} \mathrm{C}(\mathrm{a}) \bullet$ anterior y (b) $\nabla$ posterior a la activación 4

Figura 14. Curva de polarización de la celda unitaria a $T_{\text {celda }}=60{ }^{\circ} \mathrm{C}$, humidificación del $H_{2}$, $\mathrm{Q}_{\mathrm{H} 2}=5 \mathrm{l} / \mathrm{h}$ y $\mathrm{Q}_{\mathrm{O} 2}=4,5 \mathrm{l} / \mathrm{h}$

Figura 15. Efecto del grado de humidificación y de la aplicación de $E_{c t e}=0,5 \mathrm{~V}$ sobre las curvas de polarización a $\mathrm{T}_{\text {celda }}=60^{\circ} \mathrm{C}$, humidificación del $H_{2}, Q_{\mathrm{H}_{2}}=5 \mathrm{I} / \mathrm{h}$ y $\mathrm{Q}_{\mathrm{O} 2}=4,5 \mathrm{I} / \mathrm{h}(\mathrm{a})$ - anterior y (b) $\star$ posterior a los procesos de activación

Figura 16. Variación de la corriente en función del tiempo por efecto del aumento de $T_{\text {celda }}$ a $\mathrm{E}_{\text {cte }}=0,5 \mathrm{~V}$ (activación 5)

Figura 17. Efecto de $T_{\text {celda }}$ sobre las curvas de polarización para $Q_{\mathrm{H} 2}=5 \mathrm{l} / \mathrm{h}$ humidificado y $\mathrm{Q}_{\mathrm{o} 2}=4,5 \mathrm{l} / \mathrm{h}(\mathrm{a}) \nabla 25^{\circ} \mathrm{C}$ y $(\mathrm{b}) \star 60{ }^{\circ} \mathrm{C}$

Figura 18. Curvas de polarización de la celda de combustible operando a $T_{\text {celda }}=60{ }^{\circ} \mathrm{C}$ con humidificación de ambos gases

Figura 19. Curvas de polarización para la celda bajo las condiciones particulares de operación, (a) $\square$ y (b) $\star$, indicadas en la Tabla IV

Figura 20. Curvas de densidad de potencia para las condiciones: (a) $=25^{\circ} \mathrm{C}$, gases secos y (b) $\star 60^{\circ} \mathrm{C}$, humidificación de $\mathrm{H}_{2}$

Figura 21. Curvas de polarización para largos períodos de tiempo de operación. $Q_{\mathrm{H} 2}=5 \mathrm{l} / \mathrm{h}$, $\mathrm{Q}_{02}=4,5 \mathrm{I} / \mathrm{h}, \mathrm{T}_{\text {celda }}=60^{\circ} \mathrm{C}$, humidificación de $\mathrm{H}_{2}$

Figura 22. Evolución de las curvas de polarización de la celda por aplicación de pulsos (activación 6)

Figura 23. Curva de potencial-densidad de corriente para celdas unitarias de hidrógeno/oxígeno PEM con diferentes electrocatalizadores de $P t:(a) \bullet$ nanopartículas de $P t$ facetadas tipo (111) y (b) nanopartículas de $P t$ policristalinas. $\mathrm{T}_{\text {celda }}=60^{\circ} \mathrm{C}$, presión de los gases de entrada $=1 \mathrm{~atm}$ 


\section{NOMENCLATURA}

CAPÍTULO I

PEM

$R R O$

\section{CAPÍTULO II}

CT

CVD

ECT

$E_{0}$

i.a.

$k_{i}$

$p c$

$R D H$

RH

$\mathrm{ROH}$

\section{CAPÍTULO III}

a

A

$a_{a d}$

$a_{a d, e q}$

c

$c_{i}$

$c_{i}^{*}$

$D$

E

$<E>$

$E_{a}$

$E_{c}$

Ei

Es

$E_{r}$

$f$
"Proton Exchange Membrane"

reacción de reducción de oxígeno

catalizador

deposición química desde fase vapor

electrocatalizador

potencial estándar (V)

interfase activa

constante de velocidad

Pt policristalino

reacción de desprendimiento de hidrógeno

material soporte

reacción de oxidación de hidrógeno

área de los electrodos $\left(\mathrm{cm}^{2}\right)($ ec. 36, ec. 37)

área de la superficie a través de la cual se produce el flujo difusional $\left(\mathrm{cm}^{2}\right)(\mathrm{ec} .18$, ec. 19)

actividad de los adátomos cuando circula corriente (ec. 33)

actividad de los adátomos en el equilibrio $(i=0)$ (ec. 33)

Concentración $\left(\mathrm{mol} / \mathrm{cm}^{3}\right)$ (ec. 31)

concentración de la especie $i\left(\mathrm{~mol} / \mathrm{cm}^{3}\right)$ (ec.18, ec. 19, ec. 20, ec. 21, ec.22, ec. 23 , ec. 24 , ec. 25 , ec. 28 , ec. 29 , ec. 31 )

concentración de la especie $i$ en $x=0\left(\mathrm{~mol} / \mathrm{cm}^{3}\right)$ (ec. 22, ec. 23, ec. 24, ec. 25)

coeficiente de difusión ( $\mathrm{cm}^{2} / \mathrm{s}$ ) (ec. 8 , ec. 18 , ec. 19, ec. 20, ec. 21, ec. 22, ec. 30 , ec. 31)

potencial de operación (V) (ec. 16)

potencial promedio (V) (ec. 6)

potencial anódico (V) (ec. 6, ec. 7)

potencial catódico (V) (ec. 6, ec. 7)

potencial inferior $(\mathrm{V})$

potencial superior $(\mathrm{V})$

potencial de equilibrio (V) (ec. 16)

frecuencia de la OCPR (kHz) (ec. 5, ec. 8) 


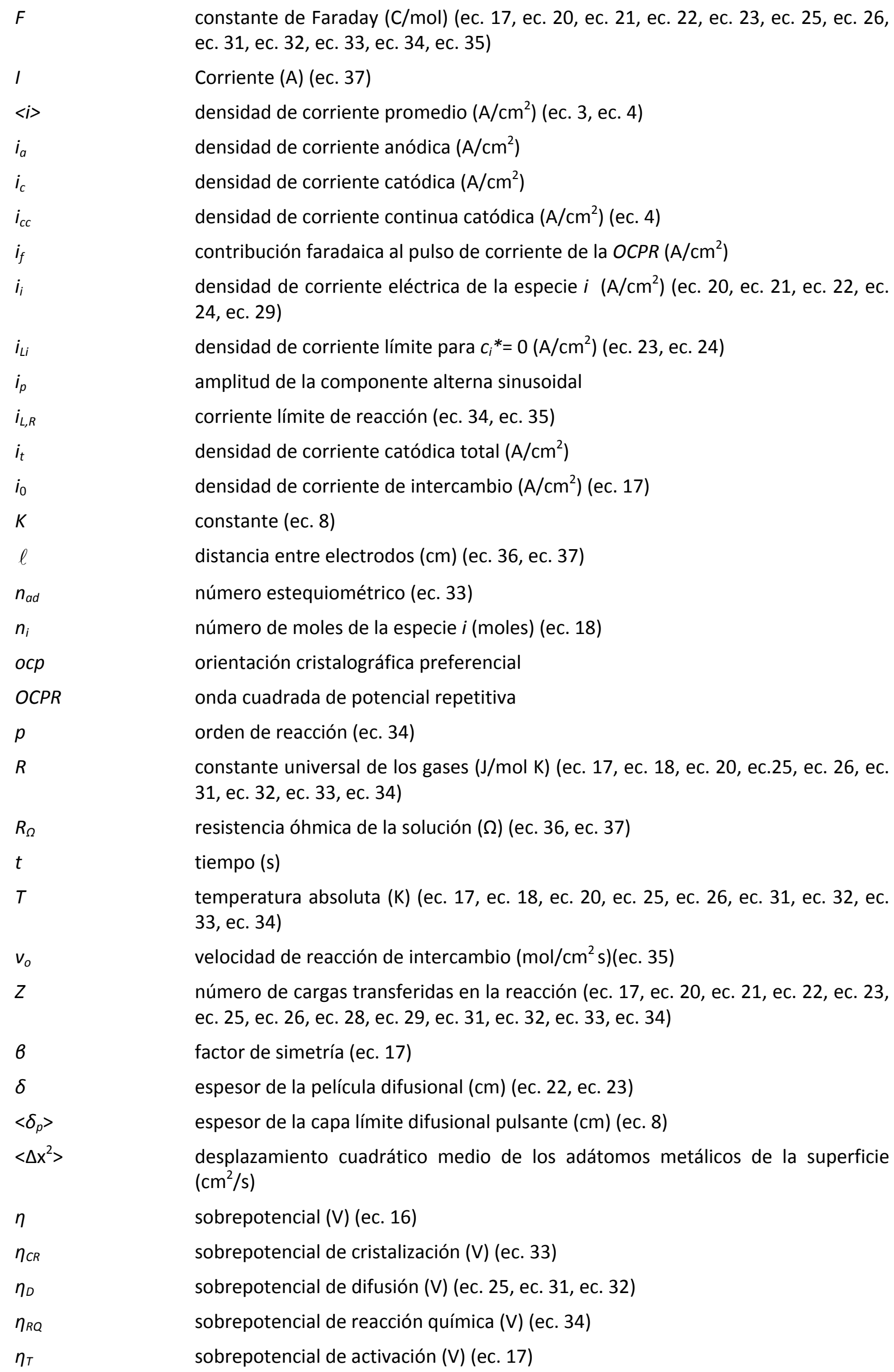

constante de Faraday (C/mol) (ec. 17, ec. 20, ec. 21, ec. 22, ec. 23, ec. 25, ec. 26, ec. 31, ec. 32, ec. 33, ec. 34, ec. 35)

l

$<i>$

$i_{a}$

$i_{c}$

$i_{c c}$

$i_{f}$

$i_{i}$

$i_{L i}$

$i_{p}$

$i_{L, R}$

$i_{t}$

$i_{0}$

K

$\ell$

$n_{a d}$

$n_{i}$

ocp

$O C P R$

$p$

$R$

$R_{\Omega}$

$t$

$T$

$v_{o}$

$Z$

b

$\delta$

$<\delta_{p}>$

$\left\langle\Delta \mathrm{x}^{2}\right\rangle$

$\eta$

$\eta_{C R}$

$\eta_{D}$

$\eta_{R Q}$

$\eta_{T}$

Corriente (A) (ec. 37)

densidad de corriente promedio $\left(\mathrm{A} / \mathrm{cm}^{2}\right)$ (ec. 3, ec. 4)

densidad de corriente anódica $\left(A / \mathrm{cm}^{2}\right)$

densidad de corriente catódica $\left(A / \mathrm{cm}^{2}\right)$

densidad de corriente continua catódica $\left(A / \mathrm{cm}^{2}\right)$ (ec. 4)

contribución faradaica al pulso de corriente de la $\operatorname{OCPR}\left(\mathrm{A} / \mathrm{cm}^{2}\right)$

densidad de corriente eléctrica de la especie $i\left(\mathrm{~A} / \mathrm{cm}^{2}\right)$ (ec. 20, ec. 21, ec. 22, ec. 24, ec. 29)

densidad de corriente límite para $c_{i}^{*}=0\left(\mathrm{~A} / \mathrm{cm}^{2}\right)($ ec. 23, ec. 24$)$

amplitud de la componente alterna sinusoidal

corriente límite de reacción (ec. 34, ec. 35)

densidad de corriente catódica total $\left(\mathrm{A} / \mathrm{cm}^{2}\right)$

densidad de corriente de intercambio $\left(A / \mathrm{cm}^{2}\right)$ (ec. 17)

constante (ec. 8)

distancia entre electrodos (cm) (ec. 36, ec. 37)

número estequiométrico (ec. 33)

número de moles de la especie $i$ (moles) (ec. 18)

orientación cristalográfica preferencial

onda cuadrada de potencial repetitiva

orden de reacción (ec. 34)

constante universal de los gases (J/mol K) (ec. 17, ec. 18, ec. 20, ec.25, ec. 26 , ec. 31 , ec. 32 , ec. 33 , ec. 34)

resistencia óhmica de la solución $(\Omega)$ (ec. 36, ec. 37)

tiempo (s)

temperatura absoluta (K) (ec. 17 , ec. 18 , ec. 20 , ec. 25 , ec. 26 , ec. 31 , ec. 32 , ec. 33, ec. 34)

velocidad de reacción de intercambio $\left(\mathrm{mol} / \mathrm{cm}^{2} \mathrm{~s}\right)(\mathrm{ec} .35)$

número de cargas transferidas en la reacción (ec. 17, ec. 20, ec. 21, ec. 22, ec. 23 , ec. 25 , ec. 26 , ec. 28 , ec. 29 , ec. 31 , ec. 32 , ec. 33 , ec. 34 )

factor de simetría (ec. 17)

espesor de la película difusional (cm) (ec. 22, ec. 23)

espesor de la capa límite difusional pulsante $(\mathrm{cm})(\mathrm{ec} .8)$

desplazamiento cuadrático medio de los adátomos metálicos de la superficie $\left(\mathrm{cm}^{2} / \mathrm{s}\right)$

sobrepotencial (V) (ec. 16)

sobrepotencial de cristalización (V) (ec. 33)

sobrepotencial de difusión (V) (ec. 25, ec. 31, ec. 32)

sobrepotencial de reacción química (V) (ec. 34)

sobrepotencial de activación (V) (ec. 17) 


\section{CAPÍTULO IV}

$a$

a

A

$A_{G}$

$A^{*}$

b

b

$B E I$

BSE

C

c

$C_{B}$

$C_{d c}$

$C_{E L}$

$c_{i}$

$C^{*}$

D

$d_{h k l}$

E

EDS

$E_{i 0}$

$E_{L}$

$E_{\text {min }}$

F

HRTEM

I

$I_{c}$

sobrepotencial óhmico (V) (ec. 37)

conductancia equivalente ( $\mathrm{S} \mathrm{cm} / \mathrm{mol}$ ) (ec. 28 , ec. 29)

potencial químico de la especie $i(\mathrm{~J} / \mathrm{mol} \mathrm{cm})($ ec. 18, ec. 20)

período (s) (ec. 2, ec. 5)

tiempo de aplicación de la OCPR para el hemiciclo anódico (s) (ec. 2, ec. 3, ec. 6) tiempo de aplicación de la OCPR para el hemiciclo catódico (s) (ec. 2, ec. 3, ec. 6) tiempo de transición para $c_{i}^{*}=0$ (ec. 32)

conductividad específica $\left(\Omega^{-1} \mathrm{~cm}^{-1}\right)$ (ec. 27 , ec. 36 , ec. 37)

gradiente de potencial eléctrico $(\mathrm{V} / \mathrm{cm})$ (ec. 27 , ec. 29)

constante de Tafel ( $\mathrm{V} /$ década) (ec. 4)

absortividad (I/g cm) (ec. 32)

absorbancia (ec. 30, ec. 31, ec. 32)

área geométrica del electrodo $\left(\mathrm{cm}^{2}\right)$ (ec. 7 , ec. 12, ec. 14)

área superficial electroquímicamente activa $\left(\mathrm{cm}^{2}\right)$ (ec. 13)

constante de Tafel (V/década) (ec. 4)

longitud de paso de la luz (cm) (ec. 32)

"Backscattered Electron Image"

"Backscattered Electron"

concentración del absorbente (g/l) (ec. 32)

capacidad (F) (ec. 10, ec. 15, ec. 18, ec. 19)

capacidad específica del material de electrodo liso $\left(\mathrm{F} / \mathrm{cm}^{2}\right)($ ec. 13)

capacidad de la doble capa eléctrica (F) (ec. 11)

capacidad determinada experimentalmente al potencial de lectura $E_{L}(\mathrm{~F})$ (ec. 12) concentración de la especie electroactiva en el seno de la solución $\left(\mathrm{mol} / \mathrm{cm}^{3}\right)(\mathrm{ec}$. 7)

capacidad específica del material de electrodo $\left(\mathrm{F} / \mathrm{cm}^{2}\right)($ ec. 12)

coeficiente de difusión $\left(\mathrm{cm}^{2} / \mathrm{s}\right)$ (ec. 7)

distancia entre planos atómicos $(\AA)$

potencial (V) (ec. 5 , ec. 6 , ec. 9 , ec. 10 , ec. 15 , ec. 18 , ec. 19 , ec. 20 , ec. 23 )

"Energy Dispersive Spectroscopy"

potencial inicial (V) (ec. 6, ec. 23)

potencial de lectura (V)

potencial límite para la integración de la corriente de adsorción de hidrógeno en la determinación de $Q_{H, S}(\mathrm{~V})$

constante de Faraday ( $\mathrm{C} / \mathrm{mol})$ (ec. 2, ec. 3, ec. 7)

"High-Resolution Transmission Electron Microscopy"

corriente (A) (ec. 7, ec. 8, ec. 19, ec. 20)

corriente de origen capacitivo (A) (ec. 11) 
$Q_{a}$

$Q_{d}$

$Q_{h}$

$Q_{H, S}$

PDF

$\mathrm{R}$

$R^{*}$

$S E$

SEM

$t$

$T$

$T_{r}$

TEM

$\checkmark$

$X R D$

$Z$

B

$\varepsilon$

$\eta_{T}$

$\theta$

$\theta$

$\theta_{P t}$

$\lambda$

\section{CAPÍtULO V}

$A_{G}$

$A^{*}$

$C_{B}$

$C_{E L}$ densidad de corriente $\left(A / \mathrm{cm}^{2}\right)$ (ec. 2, ec. 3, ec. 4)

densidad de corriente de intercambio $\left(A / \mathrm{cm}^{2}\right)$ (ec. 2, ec. 3)

intensidad de la radiación saliente (ec. 28 , ec. 30 )

intensidad de la radiación entrante (ec. 28 , ec. 30 )

constante $\left(\mathrm{s}^{-1}\right)$ (ec. 7)

camino óptico $(\mathrm{cm})$

orden de la difracción de rayos $X$ (ec. 27)

carga eléctrica acumulada en la doble capa electroquímica (C) (ec. 8, ec. 10, ec. 11 , ec. 15 , ec. 16 , ec. 17 )

carga involucrada en el proceso de adsorción (C)

carga involucrada en el proceso de desorción (C)

densidad de carga voltamperométrica asociada con la electrodesorción de hidrógeno $\left(\mu \mathrm{C} / \mathrm{cm}^{2}\right)$ (ec. 22)

recubrimiento de la superficie del sustrato por hidrógeno (C) (ec. 16, ec. 17, ec. 18, ec. 20)

"Powder Diffraction File"

constante general de los gases (J/mol K) (ec. 2, ec. 3)

factor de rugosado (ec. 14)

"Secondary Electron Image"

"Scanning Electron Microscopy"

tiempo (s) (ec. 5, ec. 6, ec. 8, ec. 9, ec. 11, ec. 19, ec. 20, ec. 23)

temperatura (K) (ec. 2, ec. 3)

transmitancia (ec. 28, ec. 30)

"Transmission Electron Microscopy"

velocidad de barrido (V/s) (ec. 5, ec. 6, ec. 9, ec. 11, ec. 23)

"X Ray Diffraction"

número de electrones intercambiados (ec. 2, ec. 7)

factor de simetría (ec. 2, ec. 3)

absortividad molar $(\mathrm{l} / \mathrm{mol} \mathrm{cm})$

Diferencia entre el potencial aplicado y el potencial reversible (V) (ec. 2, ec. 3, ec. 4)

grado de recubrimiento (ec. 16 , ec. 17 , ec., 18, ec. 20)

ángulo de incidencia de la radiación (ec. 27)

grado de recubrimiento de la superficie de $P t$ por el oxígeno adsorbido

longitud de onda de los rayos $X(\AA ̊)$ (ec. 27)

área geométrica del electrodo $\left(\mathrm{cm}^{2}\right)$ (ec. 1, ec. 2, ec. 3)

área superficial electroquímicamente activa $\left(\mathrm{cm}^{2}\right)$ (ec. 2, ec. 3)

capacidad específica de electrodos de grafito $\left(\mathrm{F} / \mathrm{cm}^{2}\right)($ ec. 2$)$

capacidad determinada experimentalmente al potencial de lectura $E_{L}(\mathrm{~F})($ ec. 1) 


$\begin{array}{ll}C^{*} & \text { capacidad específica del material de electrodo }\left(\mathrm{F} / \mathrm{cm}^{2}\right)(\mathrm{ec} .1, \mathrm{ec} .2) \\ E i & \text { potencial inferior }(\mathrm{V}) \\ E_{L} & \text { potencial de lectura }(\mathrm{V}) \\ E S & \text { potencial superior }(\mathrm{V}) \\ \text { OCPR } & \text { onda cuadrada de potencial repetitiva } \\ P T F E & \text { politetrafluoretileno } \\ R R O & \text { reacción de reducción de oxígeno } \\ R^{*} & \text { factor de rugosado (ec. 3) } \\ S E M & \text { "Scanning Electron Microscopy" } \\ V & \text { velocidad de barrido }(\mathrm{V} / \mathrm{s})\end{array}$

\section{CAPÍTULO VI}

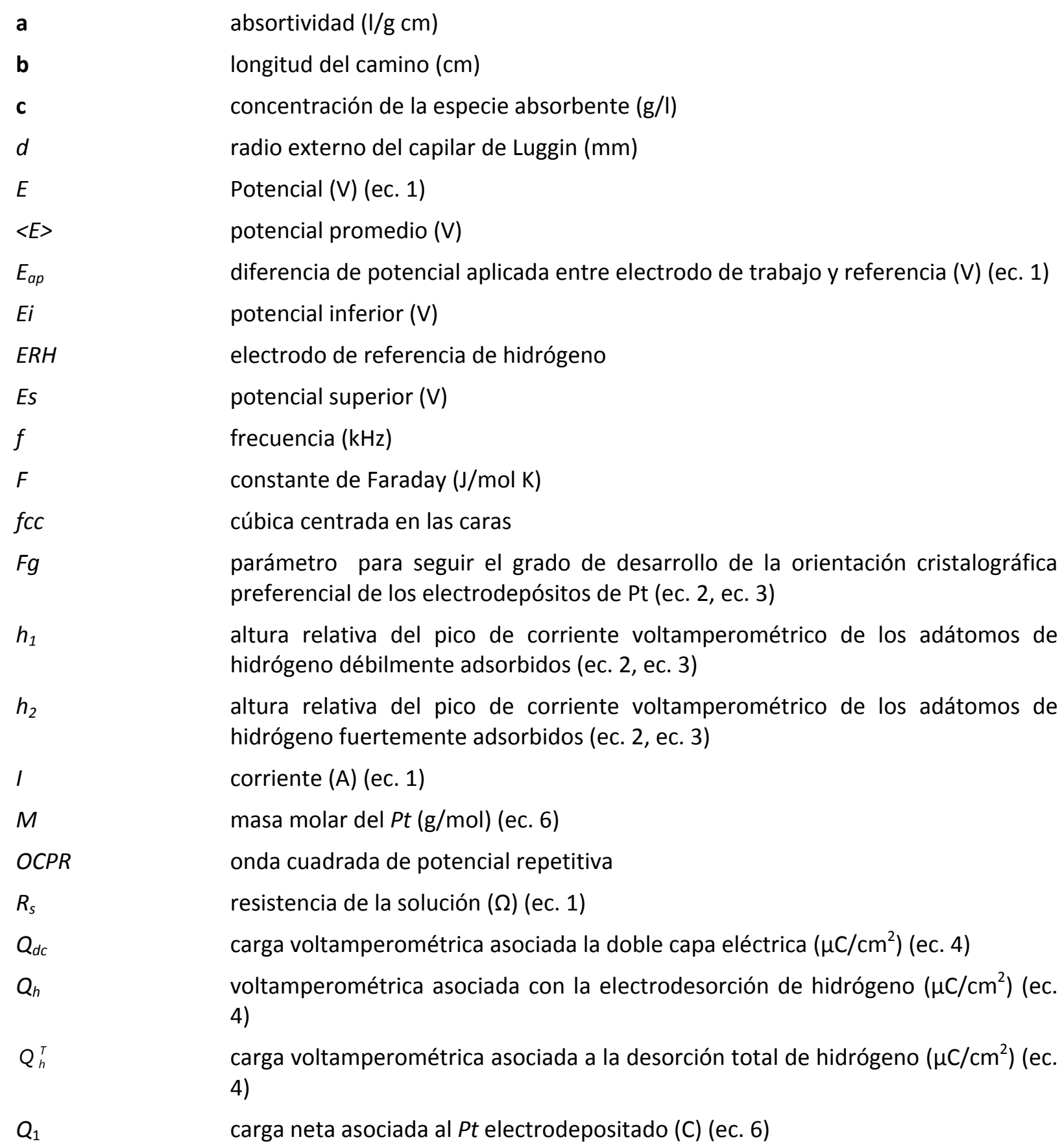


$Q_{2}$

$R$

SEM

$t$

TEM

W

$X R D$

$Z$

$\theta$

$\lambda_{\text {máx }}$

$\tau_{i}$

$\tau_{s}$

\section{CAPÍTULO VII}

AFC

$b$

DMFC

EHN

$\mathrm{E}_{N T}$

$E_{0}$

F

$G_{H 2}$

$H H V_{H 2}$

$\mathrm{H}_{2, \mathrm{c}}$

$\mathrm{H}_{2, \mathrm{e}}$

$\mathrm{H}_{2, \mathrm{~s}}$

I

MCFC

PEMFC

PAFC

$\mathrm{ROH}$

RRO

SOFC

$V_{\text {ideal }}$

$V_{\text {real }}$

$Z$

$\Delta G$

$\Delta H$

$\varepsilon_{p}$

carga neta del proceso global de electrodeposición (C) (ec. 7)

rendimiento del proceso de electrodeposición (\%) (ec. 7)

"Scanning Electron Microscopy"

tiempo ( $\mathrm{min})$

"Transmission Electron Microscopy"

cantidad de Pt electrodepositado (mg) (ec. 6)

"X Ray Diffraction"

número de electrones intercambiados (ec. 6)

ángulo de incidencia

longitud de onda de máxima absorción (nm)

duración del escalón de potencial inferior de la OCPR (s)

duración del escalón de potencial superior de la OCPR (s)

"Alcaline Fuel Cell"

pendiente de Tafel ( $\mathrm{V} /$ década)

"Direct Methanol Fuel Cell"

electrodo de hidrógeno estándar o normalizado

potencial asociado al cambio de entalpía de reacción (V) (ec. 5)

potencial teórico o ideal de celda (V) (ec. 5)

constante de Faraday (C/mol) (ec. 5)

flujo de hidrógeno en el ánodo (mol/h) (ec. 7)

calor cedido en la reacción del hidrógeno para dar vapor de agua (J/mol) (ec. 7)

flujo del gas consumido en la celda (ec. 8)

flujo de gas de hidrógeno a la entrada de la celda (ec. 8)

flujo de gas hidrógeno a la salida de la celda (ec. 8)

corriente (A) (ec. 6, ec. 7)

"Molten Carbonate Fuel Cell"

"Proton Exchange Membrane Fuel Cell"

"Phosphoric Acid Fuel Cell"

reacción de oxidación de hidrógeno

reacción de reducción de oxígeno

"Solid Oxide Fuel Cell"

voltaje ideal (V) (ec. 6)

voltaje real (V) (ec. 6, ec. 7)

número de electrones (ec. 5)

energía libre de Gibbs (kJ/mol) (ec. 4, ec. 6)

entalpía de reacción ( $\mathrm{kJ} / \mathrm{mol}$ ) (ec. 4, ec. 6)

eficiencia real o práctica (ec. 7) 
$\varepsilon_{T}$

$\varepsilon_{v}$

$\eta_{\mathrm{H} 2}$

CAPÍTULO VIII

$C A$

$C D G$

MEA

PEM

PTFE

\section{CAPÍtULO IX}

$A_{P t}$

$C A$

CDG

CE

ESCA

ER

ET

$H_{\text {ads }}$

L

$L_{P t}$

MEA

$P_{P t}$

PTFE

$q_{P t}$

$\mathrm{Q}_{\mathrm{H} 2}$

$\mathrm{Q}_{\mathrm{N} 2}$

$\mathrm{R}_{\text {celda }}$

RRO

$\mathrm{T}_{\text {celda }}$

$T_{\text {hum }}$

$\Gamma$

\section{CAPÍTULOX}

\section{E}

$E_{c a}$

$E_{\text {cte }}$

i eficiencia teórica de conversión (ec. 4, ec. 5)

eficiencia de voltaje (ec. 6)

factor de utilización del hidrógeno en el ánodo (ec. 7, ec. 8)

capa activa

capa difusora de gas

"Membrane - Electrode Assembly"

"Proton Exchange Membrane"

politetrafluoroetileno

área específica de $P t\left(\mathrm{~cm}^{2}{ }_{p t} / \mathrm{cm}^{2}\right.$ electrodo $)$

capa activa

capa difusora de gases

contraelectrodo

área superficial electroquímicamente activa $\left(\mathrm{cm}^{2}{ }_{p t} / \mathrm{g}_{P t}\right)(\mathrm{ec} .3)$

electrodo de referencia

electrodo de trabajo

hidrógeno adsorbido (ec. 2)

contenido de $P t$ en el electrodo $\left(\mathrm{g}_{p_{t}} / \mathrm{cm}^{2}\right.$ electrodo) (ec. 3)

carga de $P t\left(\mathrm{mg}_{P_{t}} / \mathrm{cm}^{2}\right)$ (ec. 1)

"Membrane Electrode Assembly"

porcentaje en peso de Pt soportado sobre carbón (\%) (ec. 1)

politetrafuoloetileno

densidad de carga de adsorción de hidrógeno $\left(\mathrm{C} / \mathrm{cm}^{2}\right)$ (ec. 3)

caudal de hidrógeno $(\mathrm{l} / \mathrm{h})$

caudal de nitrógeno $(\mathrm{l} / \mathrm{h})$

resistencia de celda $(\Omega)$

reacción de reducción de oxígeno

temperatura de operación de la celda de combustible $\left({ }^{\circ} \mathrm{C}\right)$

temperatura de humidificación de los gases de alimentación $\left({ }^{\circ} \mathrm{C}\right)$

carga específica para una monocapa de hidrógeno adsorbido sobre Pt (210 $\mu \mathrm{C} / \mathrm{cm}^{2}$ de $P$ t) (ec. 3 )

potencial de celda (V)

potencial de circuito abierto (V)

potencial constante $(\mathrm{V})$

Densidad de corriente $\left(A / \mathrm{cm}^{2}\right)$ 
$i_{\text {máx }}$

Ifinal

Inicial

$I_{\text {máx }}$

MEA

$n_{d}{ }^{0}$

OCPR

$P$

PEM

$\mathrm{Q}_{\mathrm{H} 2}$

$\mathrm{Q}_{\mathrm{O} 2}$

$T_{\text {celda }}$

$T_{\text {hum }}$

\section{CAPÍTULO XI}

$E_{\text {ca }}$

$E i$

Es

$f$

MEA

OCPR

PEM

PTFE

$t$ densidad de corriente máxima $\left(A / \mathrm{cm}^{2}\right)$

corriente final por aplicación de $E_{c t e}(A)$

corriente inicial por aplicación de $E_{c t e}(A)$

corriente máxima $(A)$

"Membrane Electrode Assembly"

coeficiente de arrastre de agua por los protones

onda cuadrada de potencial repetitiva

densidad de potencia $\left(\mathrm{W} / \mathrm{cm}^{2}\right)$

"Proton Exchange Membrane"

caudal de hidrógeno $(\mathrm{l} / \mathrm{h})$

caudal de oxígeno $(\mathrm{l} / \mathrm{h})$

temperatura de operación de la celda de combustible $\left({ }^{\circ} \mathrm{C}\right)$

temperatura de humidificación $\left({ }^{\circ} \mathrm{C}\right)$

potencial de circuito abierto $(\mathrm{V})$

potencial inferior $(\mathrm{V})$

potencial superior $(\mathrm{V})$

frecuencia $(\mathrm{kHz})$

"Membrane Electrode Assembly"

onda cuadrada de potencial repetitiva

"Proton Exchange Membrane"

politetrafluoroetileno

tiempo ( $\mathrm{min})$ 


\section{BIBLIOGRAFÍA}

[1] P. Hoffmann, Tomorrow's Energy, The MIT Press, Cambridge, Massachusets, 2002.

[2] Q. Schiermeier, J. Tollefson, T. Scully, A. Witze, O. Morton, "Electricity without carbon" Nature, vol. 454, pp. 816-823, 2008.

[3] T. N. Veziroglu, "El sistema energético del hidrógeno y Argentina", Miscelánea N 99, Academia Nacional de Ciencias, Córdoba, 2002.

[4] W. E. Triaca, "Hidrógeno: almacenador y transportador de energía" en Hidrógeno y la energía del futuro, R. A. Dubois, R. J. P. Perazzo, W. Triaca, Eds. Publicaciones Científicas, Academia Nacional de Ciencias Exactas, Físicas y Naturales y Academia Nacional de Ingeniería, pp. 1-8, 2004.

[5] "Secretaría de Energía de la Nación" 2009.

[6] "Políticas energéticas en Argentina" Revista Matices.

[7] "Boletín Energético N 11, CNEA, Ediciones Técnicas" Buenos Aires, 2003.

[8] R. D. G. González-Huerta, M. A. Leyva, O. Solorza-Feria, "Estudio comparativo de la reducción electrocatalítica de oxígeno sobre rutenio y su desempeño en una celda de combustible con membrana polimérica", Journal of the Mexican Chemical Society, vol. 48, pp. 1-6, 2004.

[9] E. Yeager, W. E. O’ Grady, M. Y. C. Woo, P. Hagans, "Hydrogen adsorption on single crystal platinum", Journal of The Electrochemical Society, vol. 125, N² 2, pp. 348-349, 1978.

[10] K. Yamamoto, D. M. Kolb, R. Kötz, G. Lehmpfuhl, "Hydrogen adsorption and oxide formation on platinum single crystal electrodes", Journal of Electroanalytical Chemistry and Interfacial Electrochemistry, vol. 96, № 2, pp. 233-239, 1979.

[11] P. N. Ross, "Structure sensitivity in electrocatalytic properties of Pt", Journal of The Electrochemical Society, vol. 126, № 1, pp. 78-82, 1979.

[12] P. N. Ross, "Hydrogen chemisorption on Pt single cristal surfaces in acid solutions", Surface Science, vol. 102, pp. 463-485, 1981.

[13] J. Clavilier, R. Durand, G. Guinet, R. Faure, "Electrochemical adsorption behaviour of Pt(100) in sulphuric acid solution", Journal of Electroanalytical Chemistry and Interfacial Electrochemistry, vol. 127, N 1-3, pp. 281-287, 1981.

[14] F. T. Wagner, P. N. Ross, "Leed analysis of electrode surfaces: structural effects of potentiodynamic cycling on Pt single crystals", Journal of Electroanalytical Chemistry and Interfacial Electrochemistry, vol. 150, № 1-2, pp. 141-164, 1983.

[15] A. J. Arvia, J. C. Canullo, E. Custidiano, C. L. Perdriel, W. E. Triaca, "Electrochemical faceting of metal electrodes", Electrochimica Acta, vol. 31, № 11, pp. 1359-1368, 1986.

[16] U. A. Paulus, T. J. Schmidt, H. A. Gasteiger, R. J. Behm, "Oxygen reduction on a high-surface area Pt/Vulcan carbon catalyst: a thin-film rotating ring-disk electrode study", Journal of Electroanalytical Chemistry, vol. 495, № 2, pp. 134-145, 2001.

[17] V. S. Murthi, R. C. Urian, S. Mukerjee, "Oxygen reduction kinetics in low and medium temperature acid environment: correlation of water activation and surface properties in supported Pt and Pt alloy electrocatalysts", The Journal of Physical Chemistry B, vol. 108, № 30, pp. 11011-11023, 2004.

[18] J. Solla-Gullón, P. Rodríguez, E. Herrero, A. Aldaz, J. M. Feliu, "Surface characterization of platinum electrodes", Physical chemistry chemical physics, vol. 10, N 10, pp. 1359-1373, 2008. 
[19] J. L. Zubimendi, G. Andreasen, W. E. Triaca, "The influence of Pt crystallite surface morphology on oxygen electroreduction", Electrochimica Acta, vol. 40, № 10, pp. 1305-1314, 1995.

[20] B. E. Conway, Theory and Principles of Electrode Processes, Ronal Pres., New York, 1965.

[21] B. E. Conway, "A profile of electrode kinetics over the past twenty-five years", Journal of The Electrochemical Society, vol. 124, N 12, pp. 410C-421C, 1977.

[22] W. T. Grubb, "Catalysis, electrocatalysis, and hydrocarbon fuel cells", Nature, vol. 198, pp. 883884, 1963.

[23] G. Millazzo, Electrochemistry:Theoretical Principles and Practical Applications, Elsevier. Amsterdam, 1963.

[24] A. M. Kuznetsov, Elektrokhimiya, vol. 9, p. 218, 1963.

[25] A. J. Arvía, M. C. Giordano, Electrocatálisis. Aspectos básicos y sus aplicaciones, Fundación Argentina, 1982.

[26] J. Lipkowski, P. N. Ross, Electrocatalysis, Wiley-VCH, 1998.

[27] S. Trasatti, "Electrocatalysis: understanding the success of DSA ${ }^{\otimes "}$, Electrochimica Acta, vol. 45, $\mathrm{N}^{\circ}$ 15-16, pp. 2377-2385, 2000.

[28] K. Kinoshita, Electrochemical oxygen technology, John Wiley \& Sons Inc., 1992.

[29] S. Trasatti, "Work function, electronegativity, and electrochemical behaviour of metals. III. Electrolytic hydrogen evolution in acid solutions", Electroanalytical Chemistry and InterJacial Electrochemistry, vol. 39, pp. 163-184, 1972.

[30] K. Kordesh, G. Simaner, Fuel cell and their aplications, VCH Publis, New York, pp. 9-21, 1996.

[31] A. Wieckowski, Fuel cell science. Theory, fundamentals, and biocatalysis, Jhon Wiley \& Sons, New Jersey, 2010.

[32] T. Brülle, A. Denisenko, H. Sternschulte, U. Stimming "Catalytic activity of platinum nanoparticles on highly boron-doped and 100-oriented epitaxial diamond towards HER and HOR", Phys. Chem. Chem. Phys., vol. 13, № 28, pp. 12883-12891, 2011.

[33] J. A. Poirier, G. E. Stoner, "Microstructural effects on electrocatalytic oxygen reduction activity of nano-grained thin-film platinum in acid media", Journal of The Electrochemical Society, vol. 141, $N^{\circ} 2$, pp. 425-430, 1994.

[34] M. Watanabe, H. Sei, P. Stonehart, "The influence of platinum crystallite size on the electroreduction of oxygen", Journal of Electroanalytical Chemistry and Interfacial Electrochemistry, vol. 261, № 2, pp. 375-387, 1989.

[35] M. Grzeszczuk, P. Poks, "The HER performance of colloidal Pt nanoparticles incorporated in polyaniline", Electrochimica Acta, vol. 45, № 25-26, pp. 4171-4177, 2000.

[36] A. S. Aricó, P. Cretı, E. Modica, G. Monforte, V. Baglio, V. Antonucci, "Investigation of direct methanol fuel cells based on unsupported Pt-Ru anode catalysts with different chemical properties", Electrochimica Acta, vol. 45, pp. 4319-4328, 2000.

[37] M. Peuckert, T. Yorenda, R. A. Dalla Betta, M. Boudart, "Oxygen reduction on small supported platinum particles", Journal of The Electrochemical Society, vol. 133, № 5, pp. 944-947, 1986.

[38] R. M. Wilenzick, "Uniform microcrystals of platinum and gold", The Journal of Chemical Physics, vol. 47, N², pp. 533-536, 1967.

[39] J. Giner, J. M. Parry, S. M. Smith, "American Chemial Society Simposium on Fuel Cells", Chicago, 1967. 
[40] K. V. Kordesch, R. F. Scarr, "Low cost oxygen electrodes, Contract N DAAK-02-71-C-0297", Union Carbide Corp., Cleveland Ohio, 1972.

[41] N. M. Kagan, G. F. Muchnik, Y. N. Pisarev, Y. A. Kaller, V. A. Panchenko, "Elektrokhimiya”, vol. 9, p. 1948, 1973.

[42] J. Rowbottom, British Patent 992.655. 1963.

[43] Y. Trambouze, Bull. Inst. Int. Froid, Annexe 13. 1969.

[44] A. C. C. Tseung, German Patent 2.119.702. 1971.

[45] T. Kudo, M. Yeshida, O. Okamoto, U.S. Patent 3.804.674. 1974.

[46] J. Bett, J. Lundquist, E. Washington, P. Stonehart, "Platinum crystallite size considerations for electrocatalytic oxygen reduction I", Electrochimica Acta, vol. 18, № 5, pp. 343-348, 1973.

[47] L. J. Bregoli, "Influence of platinum crystallite size on the electrochemical reduction on oxzygen in phosphoric acid", Electrochimica Acta, vol. 23, № 6, pp. 489-492, 1978.

[48] Y. Takasu, Y. Fujii, K. Yasuda, Y. Iwanaga, Y. Matsuda, "Electrocatalytic properties of ultrafine platinum particles for hydrogen electrode reaction in an aqueous solution of sulfuric acid", Electrochimica Acta, vol. 34, ํ3, pp. 453-458, 1989.

[49] S.-A. Sheppard, S. A. Campbell, J. R. Smith, G. W. Lloyd, F. C. Walsh, T. R. Ralph, "Electrochemical and microscopic characterisation of platinum-coated perfluorosulfonic acid (Nafion 117) materials", The Analyst, vol. 123, № 10, pp. 1923-1929, 1998.

[50] K. Kinoshita, J. T. Lundquist, P. Stonehart, "Potential cycling effects on platinum electrocatalyst surfaces", Electroanalytical Chemistry and InterJacial Electrochemistry, vol. 48, N², pp. 157-166, 1973.

[51] J. Clavilier, D. Amand, B. L. Wu, "Electrochemical study of the initial surface condition of platinum surface with (100) and (111) orientations", Journal of Electroanalytical Chemistry, vol. 135, $\mathrm{N}^{\circ} 1$, pp. 159-166, 1982.

[52] S. Mukerjee, "Particle size and structural effects in platinum electrocatalysis", Journal of Applied Electrochemistry, vol. 20, № 4, pp. 537-548, 1990.

[53] M. Kajiwara, S. Uemiya, T. Kojima, "Stability and hydrogen permeation behavior of supported platinum membranes in presence of hydrogen sulfide", International Journal of Hydrogen Energy, vol. 24, N 9, pp. 839-844, 1999.

[54] G. Kokkinidis, A. Papoutsis, D. Stoychev, "Electroless deposition of Pt on Ti-catalytic activity for the hydrogen evolution reaction", Journal of Electroanalytical Chemistry, vol. 486, No 1, pp. 48-55, 2000.

[55] G. Kokkinidis, D. Stoychev, V. Lazarov, A. Papoutsis, "Electroless deposition of Pt on Ti Part II . Catalytic activity for oxygen reduction", Journal of Electroanalytical Chemistry, vol. 511, $\mathrm{N}^{\circ} 1-2$, pp. 20-30, 2001.

[56] M. Sogaard, M. Odgaard, E. M. Skou, "An improved method for the determination of the electrochemical active area of porous composite platinum electrodes", Solid State Ionics, vol. 145, pp. 31-35, 2001.

[57] L. Blum, D. A. Huckaby, N. Marzari, R. Car, "The electroreduction of hydrogen on platinum(111) in acidic media", Journal of Electroanalytical Chemistry, vol. 537, № 1-2, pp. 7-19, 2002.

[58] U. Koponen, H. Kumpulainen, M. Bergelin, J. Keskinen, T. Peltonen, M. Valkiainen, M. Wasberg, "Characterization of Pt-based catalyst materials by voltammetric techniques", Journal of Power Sources, vol. 118, pp. 325-333, 2003. 
[59] K. Morikawa, T. Shirakashi, M. Okada, Advances in Catalysis. Academic Press, New York, 1960.

[60] O. M. Poltorak, V. S. Boronin, "Chemisorption and catalysis on platinised silica gel. I. Dispersion of platinum according to chemisorption data", Russian journal of physical chemistry, vol. $39, \mathrm{~N}^{\circ} 6, \mathrm{pp}$. 1476-1482, 1965.

[61] H. A. Benesi, R. M. Curtis, H. P. Studer, "Preparation of highly dispersed catalytic metals: Platinum supported on silica gel", Journal of Catalysis, vol. 10, № 4, pp. 328-335, 1968.

[62] A. Tomita, Y. Tamai, "Effect of surface groups of carbon on the adsorption and catalytic base hydrolysis of a hexaamminecobalt (III) ion", The Journal of Physical Chemistry, vol. 75, N 5, pp. 649-654, 1971.

[63] T. A. Dorling, B. W. J. Lynch, R. L. Moss, "The structure and activity of supported metal catalysts: V. Variables in the preparation of platinum/silica catalysts", Journal of Catalysis, vol. 20, $\mathrm{N}^{\circ} 2$, pp. 190-201, 1971.

[64] V. A. Alekseenko, N. M. Vasilev, M. M. Senyairn, D. N. Strazhesko, I. A. Tarsovskaya, Russian journal of physical chemistry, vol. 45, p. 57, 1971.

[65] Z. Sulcek, M. Vašák, J. Doležal, "The study of the sorption of complex cations of palladium on silica gel: Ammine complexes and ethylenediamine complexes", Microchemical Jounal, vol. 16, № 2, pp. 210-217, 1971.

[66] K. Kinoshita, P. Stonehart, Modern Aspects of Electrochemistry, cap. 4, vol. 12, p. 183, 1977.

[67] H. I. Zeliger, "Preparation of supported noble metal blacks by wet hydrogen reduction," Journal of Catalysis, vol. 7, № 2, p. 198, 1967.

[68] T. J. Schmidt, H. Noeske, H. A. Gasteiger, R. J. Behm, P. Britz, H. Bönnemann, "PtRu alloy colloids as precursors for fuel cell catalysts: a combined XPS, AFM, HRTEM, and RDE study", Journal of The Electrochemical Society, vol. 145, №3, pp. 925-931, 1998.

[69] S. Nishimura, T. Onoda, A. Nakamura, "Hydrogenation and hydrogenolysis. IV. Catalytic reductions of cinnamyl alcohols and 3-Phenylpropargyl alcohol", Bulletin of the Chemical Society of Japan, vol. $33, \mathrm{~N}^{\circ} 10$, pp. 1356-1359, 1960.

[70] D. W. Mckee, "Interaction of hydrogen and carbon monoxide on platinum group metals", Journal of Catalysis, vol. 8, N³, pp. 240-249, 1967.

[71] D. W. McKee, L. W. Niedrach, J. Paynter, I. F. Danzig, "Electrocatalysts for hydrogen/carbon monoxide fuel cell anode. II. The platinum-rhodium and platinum-iridium systems", Electrochem. Technol., vol. 5, № 9-10, pp. 419-423, 1967.

[72] L. W. Niedrach, D. W. McKee, J. Paynter, I. F. Danzig, "Electrocatalysts for hydrogen/carbon monoxide fuel cell anode", Electrochem. Technol, vol. 5, № 7-8, pp. 318-323, 1967.

[73] D. W. McKee, M. S. Pak, "Electrocatalysts for hydrogen/carbon monoxide fuel cell anodes: IV. Platinum-nickel combinations", Journal of The Electrochemical Society, vol. 116, N 4, pp. 516-520, 1969.

[74] A. P. Gorokhov, A. B. Fasman, D. V. Sokol'skii, "On the effect of the method of preparation on the catalytic activity of platinum black", Kinet. Kataliz., vol. 12, N 3, pp. 690-693, 1971.

[75] M. Kobayashi, T. Shirasaki, "The chemisorption of CO on ruthenium metals and ruthenium-silica catalysts", Journal of Catalysis, vol. 28, №2, pp. 289-295, 1973.

[76] R. Adams, R. L. Shriner, "Platinum oxide as a catalyst in the reduction of organic compounds. III. Preparation and properties of the oxide of platinum pbtained by the fusion of chloroplatinic acid with sodium nitrate", Journal of the American Chemical Society, vol. 45, N 9, pp. 2171-2179, 1923. 
[77] M. Raney, “U.S. Patent 1,563,787" 1925.

[78] M. Raney, “U.S. Patent 1,628,191” 1927.

[79] A. R. Despić, D. M. Drazić, C. B. Petrović, V. L. Vujcić, "New methods of obtaining fuel cell electrodes: I. Aluminum-nickel mixed powder hydrogen electrode", Journal of The Electrochemical Society, vol. 111, №10, pp. 1109-1112, 1964.

[80] H. Krupp, H. Rabenhorst, G. Sandstede, G. Walter, R. McJones, "Raney type transition metals as fuel electrode catalysts", Journal of The Electrochemical Society, vol. 109, N 7, pp. 553-557, 1962.

[81] V. V. Mirkovich, T. A. Wheat, "Use of liquid nitrogen in spray freezing", Am. Ceram. Soc. Bull., vol. $49, N^{\circ} 8$, pp. 724-725, 1970.

[82] D. W. Johnson, P. K. Gallagher, "Kinetics of the decomposition of freeze-dried aluminum sulfate and ammonium aluminum sulfate", Journal of the American Ceramic Society, vol. 54, N 9, pp. 461-465, 1971.

[83] Y. S. Kim, F. R. Monforte, "Theoretically dense (99.9 \%) polycrystalline alumina prepared from cryochemically processed powders", Ceram. Bull., vol. 50, № 6, pp. 532-535, 1971.

[84] S. H. Gelles, F. K. Roehring, "Freeze-drying metals and ceramics", Journal of Metals, vol. 24, N 6, pp. 23-24, 1972.

[85] M. F. Ferrante, R. R. Lowery, G. B. Robidart, "Report of Investigations 7485" U. S., Bureau of Mines, 1971.

[86] J. Prabhuram, T. S. Zhao, C. W. Wong, J. W. Guo, "Synthesis and physical/electrochemical characterization of Pt/C nanocatalyst for polymer electrolyte fuel cells", Journal of Power Sources, vol. 134, N¹, pp. 1-6, 2004.

[87] N. Alonso-Vante, Ed., Electroquímica y electrocatálisis. Materiales: aspectos fundamentales y aplicaciones. Vol. Ib. Buenos Aires, 2003.

[88] V. R. Stamenkovic, B. Fowler, B. S. Mun, G. Wang, P. N. Ross, C. A Lucas, N. M. Marković, "Improved oxygen reduction activity on Pt3Ni(111) via increased surface site availability", Science, vol. 315, N5811, pp. 493-497, 2007.

[89] G. Liu, H. M. Zhang, M. R. Wang, H. X. Zhong, and J. Chen, "Preparation, characterization of ZrOxNy/C and its application in PEMFC as an electrocatalyst for oxygen reduction", Journal of Power Sources, vol. 172, № 2, pp. 503-510, 2007.

[90] H. Zhong, H. Zhang, Y. Liang, J. Zhang, M. Wang, X. Wang, "A novel non-noble electrocatalyst for oxygen reduction in proton exchange membrane fuel cells", Journal of Power Sources, vol. 164, N 2, pp. 572-577, 2007.

[91] D. Strmcnik, M. Escudero-Escribano, K. Kodama, V. R. Stamenkovic, A. Cuesta, N. M. Marković, "Enhanced electrocatalysis of the oxygen reduction reaction based on patterning of platinum surfaces with cyanide", Nature chemistry, vol. 2, N 10, pp. 880-885, 2010.

[92] K. Micka, Trans. SAEST, vol. 6, p. 50, 1971.

[93] A. Winsel, "Beiträge zur kenntnis der stromverteilung in porösen elektroden", Z. Elektrochem., vol. 66, N 4, pp. 287-304, 1962.

[94] J. S. Newman, C. W. Tobias, "Theoretical analysis of current distribution in porous electrodes", Journal of The Electrochemical Society, vol. 109, N¹2, pp. 1183-1191, 1962.

[95] Y. G. Chirkov, Y. A. Chizmadshchev, Izv. Akad. Nauk. SSSR., Ser. Khim., p. 225, 1964.

[96] I. G. Gurevich, Inzehen. Fiz. Sur. Akad. Nauk. BSSR., vol. 2, p. 78, 1959. 
[97] V. S. Markin, Y. A. Chizmadshcev, Y. G. Chirkov, Dokl. Akad. Nauk. SSSR, vol. 150, p. 596, 1963.

[98] F. Helfferich, Ionenaustauscher. Verlag Chemie, Weinheim, 1959.

[99] A. J. Arvía, S. L. Marciano, Los fenómenos de transporte en Electroquímica. CIC, La Plata, 1972.

[100] J. Giner, J. M. Parry, S. Smith, M. Turchan, "Methods for characterizing the structure and electrochemical behavior of teflon-bonded Pt electrodes", Journal of The Electrochemical Society, vol. 116, Nº 12, pp. 1692-1696, 1969.

[101] J. Giner, C. Hunter, "The mechanism of operation of the teflon-bonded gas diffusion electrode: a mathematical model", Journal of The Electrochemical Society, vol. 116, № 8, pp. 1124-1130, 1969.

[102] H. S. Wroblowa, Y. C. Pan, G. Razumney, "Electroreduction of oxygen: a new mechanistic criterion", Journal of Electroanalytical Chemistry and Interfacial Electrochemistry, vol. 69, $\mathrm{N}^{\circ} 2$, pp. 195-201, 1976.

[103] R. W. Zurilla, R. K. Sen, E. Yeager, "The kinetics of the oxygen reduction reaction on gold in alkaline solution", Journal of The Electrochemical Society, vol. 125, N 7, pp. 1103-1109, 1978.

[104] P. N. Ross, P. C. Andriacos, "The effect of $\mathrm{H}_{2} \mathrm{PO}^{4-}$ anion on the kinetics of oxygen reduction on $\mathrm{Pt}^{\prime}$, Journal of Electroanalytical Chemistry and Interfacial Electrochemistry, vol. 154, $\mathrm{N}^{\circ} 1-2$, pp. 205215, 1983.

[105] K. L. Hsueh, E. R. Gonzalez, S. Srinivasan, D. T. Chin, "Effects of phosphoric acid concentration on oxygen reduction kinetics at platinum", Journal of The Electrochemical Society, vol. 131, $\mathrm{N}^{\circ} 4$, pp. 823-828, 1984.

[106] C. F. Zinola, A. M. Castro Luna, W. E. Triaca, A. J. Arvia, "The influence of surface facetting upon molecular oxygen electroreduction on platinum in aqueous solutions", Electrochimica Acta, vol. 39, Nº11-12, pp. 1627-1632, 1994.

[107] J. P. Hoare, "The Electrochemistry of Oxygen" en Interscience, New York, 1968.

[108] A. Damjanovic, Modern Aspects of Electrochemistry, Vol. 5. Plenum Press, New York, p. 369, 1969.

[109] M. R. Tarasevich, A. Sadkowski, E. Yeager, Comprehensive Treatise in Electrochemistry, Vol.7, Ed. Plenum Press, New York, p. 301, 1983.

[110] E. Yeager, "Electrocatalysts for $\mathrm{O}_{2}$ reduction", Electrochimica Acta, vol. 29, N 11, pp. 1527-1537, 1984.

[111] F. E. Kadiri, R. Faure, R. Durand, "Electrochemical reduction of molecular oxygen on platinum single crystals", Journal of Electroanalytical Chemistry, vol. 301, № 1-2, pp. 177-188, 1991.

[112] H. Kita, H. W. Lei, Y. Gao, "Oxygen reduction on platinum single-crystal electrodes in acidic solutions", Journal of Electroanalytical Chemistry, vol. 379, №1-2, pp. 407-414, 1994.

[113] N. M. Marković, R. R. Adžić, B. D. Cahan, E. B. Yeager, "Structural effects in electrocatalysis: oxygen reduction on platinum low index single-crystal surfaces in perchloric acid solutions", Journal of Electroanalytical Chemistry, vol. 377, № 1-2, pp. 249-259, 1994.

[114] N. M. Marković, H. A. Gasteiger, P. N. Ross, "Oxygen reduction on platinum low-index singlecrystal surfaces in Sulfuric acid solution: rotating ring-Pt(hkl) disk studies", The Journal of Physical Chesmistry, vol. 99, №11, pp. 3411-3415, 1995.

[115] N. M. Marković, H. A. Gasteiger, P. N. Ross, "Oxygen reduction on platinum low-index singlecrystal surfaces in alkaline solution: rotating ring disk Pt (hkl) studies", The Journal of Physical Chemistry, vol. 100, № 16, pp. 6715-6721, 1996. 
[116] J. Perez, H. M. Villullas, E. R. Gonzalez, "Structure sensitivity of oxygen reduction on platinum single crystal electrodes in acid solutions", Journal of Electroanalytical Chemistry, vol. 435, $\mathrm{N}^{\circ} 1-2$, pp. 179-187, 1997.

[117] N. Markovic, H. A. Gasteiger, P. N. Ross, "Kinetics of oxygen reduction on Pt(hkl) electrodes: implications for the crystallite size effect with supported Pt electrocatalysts", Journal of The Electrochemical Society, vol. 144, № 5, pp. 1591-11597, 1997.

[118] N. Marković, H. Gasteiger, B. Grgur, P. Ross, "Oxygen reduction reaction on Pt(111): effects of bromide", Journal of Electroanalytical Chemistry, vol. 467, Nº. 1-2, pp. 157-163, 1999.

[119] V. Stamenkovic, N. M. Markovic, P. N. Ross, "Structure-relationships in electrocatalysis: oxygen reduction and hydrogen oxidation reactions on $\mathrm{Pt}(111)$ and $\mathrm{Pt}(100)$ in solutions containing chloride ions", Journal of Electroanalytical Chemistry, vol. 500, № 1-2, pp. 44-51, 2001.

[120] N. M. Markovic, T. J. Schmidt, P. N. Ross, V. Stamenkovic, "Oxygen Reduction on Pt and Pt Bimetallic Surfaces: A Selective Review", Fuel Cells from fundamentals to Systems, Vol. 1., pp. 105116, 2001.

[121] M. D. Maciá, J. M. Campiña, E. Herrero, J. M. Feliu, "On the kinetics of oxygen reduction on platinum stepped surfaces in acidic media", Journal of Electroanalytical Chemistry, vol. 564, pp. 141-150, 2004.

[122] A. Kuzume, E. Herrero, J. M. Feliu, "Oxygen reduction on stepped platinum surfaces in acidic media," Journal of Electroanalytical Chemistry, vol. 599, N², pp. 333-343, 2007.

[123] J. O. Bockris, S. U. M. Khan, Surface Elecrtochemistry, Plenum Press. New York, 1993.

[124] N. M. Markovic, P. N. Ross, "Surface science studies of model fuel cell electrocatalysts", Surface Science Report, vol. 45, N 4-6, pp. 117-229, 2002.

[125] R. Adzic, Electrocatalysis, Wiley-VCH, New York, pp. 197-242, 1998.

[126] C. F. Zinola, A. M. Castro Luna, W. E. Triaca, A. J. Arvía, "Electroreduction of molecular oxygen on preferentially oriented platinum electrodes in acid solution", Journal of Applied Electrochemistry, vol. 24, pp. 119-125, 1994.

[127] D. M. Kolb, "Surface science aspects of interfacial electrochemistry", Journal of vacuum science \& technology. A. Vacuum, surfaces, and films, vol. A4, pp. 1294-1301, 1986.

[128] R. R. Adzic, W. E. O'Grady, S. Srinivasan, "Oxidation of $\mathrm{HCOOH}$ on (100), (110) and (111) single crystal platinum electrodes", Surface Science, vol. 94, N² 2-3, pp. L191-L194, 1980.

[129] R. R. Adzic, A. V. Tripkovic, W. E. O' Grady, "Structural effects in electrocatalysis," Nature, vol. 296, $\mathrm{N}^{\circ}$ 5853, pp. 137-138, 1982.

[130] J. Clavilier, R. Parsons, R. Durand, C. Lamy, J. M. Leger, "Formic acid oxidation on single crystal platinum electrodes. Comparison with polycrystalline platinum", Journal of Electroanalytical Chemistry and Interfacial Electrochemistry, vol. 124, № 1-2, pp. 321-326, 1981.

[131] S. Motoo, N. Furuya, "Electrochemistry of platinum single crystal surfaces: Part II. Structural effect on formic acid oxidation and poison formation on Pt (111), (100) and (110)", Journal of Electroanalytical Chemistry and Interfacial Electrochemistry, vol. 184, № 2, pp. 303-316, 1985.

[132] R. R. Adžić, N. M. Marković, "Structural effects in electrocatalysis: oxygen and hydrogen peroxide reduction on single crystal gold electrodes and the effects of lead ad-atoms", Journal of Electroanalytical Chemistry and Interfacial Electrochemistry, vol. 138, № 2, pp. 443-447, 1982.

[133] R. R. Adzic, A. V. Tripkovic, W. O' Grady, Proceedings of the Simposyum on Electrocatalysis. The Electrochemical Society, Princeton, New Yersey, 1981. 
[134] J. V. Tripkovic, R. R. Adzic, “Extended Abstracts, $38^{\text {th }}$ I.S.E. Meeting," in Extended Abstracts, $38^{\text {th }}$ I.S.E. Meeting, 1987, vol. 4.6.3.

[135] K. Jüttner, "Oxygen reduction electrocatalysis by underpotential deposited metal atoms at different single crystal faces of gold and silver", Electrochimica Acta, vol. 29, N 11, pp. 15971604, 1984.

[136] A. Damjanovic, V. Brusic, "Electrode kinetics of oxygen reduction on oxide-free platinum electrodes", Electrochimica Acta, vol. 12, № 6, pp. 615-628, 1967.

[137] M. Markovic, R. Adzic, B. Cahan, E. B. Yeager, "Extended Abstracts, $42{ }^{\text {nd }}$ ISE Meeting”, p. 138, 1991.

[138] C. J. Smithells, E. A. Brandes, Eds., Metal Referente Book, $5^{\text {th }}$ Ed. Butterworths, London y Boston, p. 291, 1980.

[139] T. Biegler, "Search for surface structural effects in electrocatalysis. I. Smooth platinum electrodes", Australian Journal of Chemistry, vol. 26, № 12, pp. 2571-2585, 1973.

[140] M. F. Stephenopoulos, L. D. Schmidt, "Surface morphology of platinum catalysts", Journal of Catalysis, vol. 49, № 1, pp. 51-82, 1977.

[141] M. F. Stephenopoulos, L. D. Schmidt, "Morphology and etching processes on macroscopic metal catalysts", Progress in Surface Science, vol. 9, № 3, pp. 83-111, 1979.

[142] S. B. Schwartz, L. D. Schmidt, "Is there a single mechanism of catalytic rate oscillations on Pt?", Surface Sciencea, vol. 183, № 1-2, pp. L269-L278, 1987.

[143] A. R. Despic, K. I. Popov, "The effect of pulsating potential on the morphology of metal deposits obtained by mass-transport controlled electrodeposition", Journal of Applied Electrochemistry, vol. 1, N4, pp. 275-278, 1971.

[144] E. Custidiano, A. C. Chialvo, A. J. Arvía, "Changes in the morphology of platinum elecrodeposition induced by fast square wave potential modulation", Journal of Electroanalytical Chemistry and Interfacial Electrochemistry, vol. 196, N² 2, pp. 423-427, 1985.

[145] A. C. Chialvo, W. E. Triaca, A. J. Arvía, "Changes in the electrochemical response of noble metals produced by square-wave potential perturbations: A new technique for the preparation of reproducible electrode surfaces of interest in electrocatalysis", Journal of Electroanalytical Chemistry and Interfacial Electrochemistry, vol. 146, N 1, pp. 93-108, 1983.

[146] A. C. Chialvo, W. E. Triaca, A. J. Arvía, "Changes in the polycrystalline gold electrode surface produced by square wave potential perturbations", Journal of Electroanalytical Chemistry and Interfacial Electrochemistry, vol. 171, № 1-2, pp. 303-316, 1984.

[147] C. L. Perdriel, M. Ipohorski, A. J. Arvía, "Electrochemical faceting of polycrystalline gold in $1 \mathrm{M}$ $\mathrm{H}_{2} \mathrm{SO}_{4}$ ", Journal of Electroanalytical Chemistry and Interfacial Electrochemistry, vol. 215, $\mathrm{N}^{\circ} 1-2$, pp. 317-329, 1986.

[148] A. C. Chialvo, W. E. Triaca, A. J. Arvía, "Cambios estructurales de electrodos de platino platinado producidos por tratamientos electroquímicos y térmicos", Anales de la Asociación Química Argentina, vol. 73, pp. 23-30, 1985.

[149] R. Cerviño, W. E. Triaca, A. J. Arvía, "A novel effect. Changes in the electrochemical response of polycrystalline Platinum promoted by very fast potential perturbations", Journal of The Electrochemical Society, vol. 132, № 1, pp. 266-267, 1985.

[150] J. C. Canullo, W. E. Triaca, A. J. Arvía, "Changes in the electrochemical response of polycrystalline platinum electrodes promoted by fast repetitive square wave potential signals", Journal of Electroanalytical Chemistry and Interfacial Electrochemistry, vol. 175, № 1-2, pp. 337-340, 1984. 
[151] J. P. Hoare, "Some effects of alternating current polarization on the surface of noble metal electrodes", Electrochimica Acta, vol. 9, N 5, pp. 599-605, 1964.

[152] S. Gilman, "Modification of the surface area of platinum electrodes by the application of single pulses", Journal of Electroanalytical Chemistry, vol. 9, № 4, pp. 276-281, 1965.

[153] T. Biegler, "An electrochemical and electron microscopic study of activation and roughening of Platinum electrodes", Journal of The Electrochemical Society, vol. 116, № 8, pp. 1131-1137, 1969.

[154] E. Custidiano, S. Piovano, A. J. Arvia, A. C. Chialvo, M. Ipohorski, "Electrochemical faceting and preferred crystallographic orientation of rhodium electrodes", Journal of Electroanalytical Chemistry and Interfacial Electrochemistry, vol. 221, ํㅜ1-2, pp. 229-238, 1987.

[155] C. L. Perdriel, E. Custidiano, A. J. Arvia, "Modifications of palladium electrode surfaces produced by periodic potential treatments", Journal of Electroanalytical Chemistry and Interfacial Electrochemistry, vol. 246, № 1, pp. 165-180, 1988.

[156] L. Vázquez, J. Gómez, A. M. Baró, N. García, M. L. Marcos, J. González-Velasco, J. M. Vara, A. J. Arvía, J. Presa, A. García, M. Aguilar, "Scanning tunneling microscopy of electrochemically activated platinum surfaces. A direct ex-situ determination of the electrode nanotopography", Journal of the American Chemical Society, vol. 109, № 6, pp. 1730-1733, 1987.

[157] R. M. Cerviño, A. J. Arvia, W. Vielstich, "Scanning electron microscopy and voltammetry of preferentially oriented polycrystalline platinum surfaces", Surface Science, vol. 154, N $\mathrm{N}^{\circ} 2-3, \mathrm{pp}$. 623-628, 1985.

[158] W. E. Triaca, T. Kessler, J. C. Canullo, A. J. Arvía, "A study of the optimal conditions for the development of preferred oriented Platinum surfaces by means of fast square wave potential perturbations", Journal of The Electrochemical Society, vol. 134, N 5, pp. 1165-1172, 1987.

[159] J. C. Canullo, W. E. Triaca, A. J. Arvia, "Electrochemical faceting of single crystal platinum electrodes", Journal of Electroanalytical Chemistry and Interfacial Electrochemistry, vol. 200, No 12, pp. 397-400, 1986.

[160] W. E. Triaca, A. J. Arvia, "The electrochemical facetting of metal surfaces: preferred crystallographic orientation and roughening effects in electrocatalysis", Journal of Applied Electrochemistry, vol. 20, N³, pp. 347-356, 1990.

[161] C. L. Scortichini and C. N. Reilley, "Surface characterization of Pt electrodes using underpotential deposition of $\mathrm{H}$ and Cu: Part I. Pt(100)", Journal of Electroanalytical Chemistry, vol. 139, № 2, pp. 233-245, 1982.

[162] D. Aberdam, C. Corotte, D. Dufayard, R. Durand, R. Faune, and G. Guinet, Proc. 4 th Inter. Conf. On Solid Surface, Cannes. Supp. To Le Vide, Les Couches Minces, vol. 1, N²01, p. 622, 1980.

[163] J. Clavilier, R. Faure, G. Guinet, R. Durand, "Preparation of monocrystalline microelectrodes and electrochemical study of the plane surface cut in the direction of the $\{111\}$ and $\{110\}$ planes", Journal of Electroanalytical Chemistry and Interfacial Electrochemistry, vol. 107, No 1, pp. 205-209, 1980.

[164] B. E. Conway, H. Angerstein-Kozlowska, F. C. Ho, J. Klinger, B. MacDougall, S. Gottesfeld, "Kinetic and optical relaxation studies of adsorbed intermediates in some electrochemical reactions", Faraday Discussions of the Chemical Society, vol. 56, pp. 210-227, 1973.

[165] C. M. Ferro, A. J. Calandra, A. J. Arvía, "Transient changes of intermediate species formed during the electrooxidation and surface electroreduction of gold within a monolayer thickness range", Journal of Electroanalytical Chemistry and Interfacial Electrochemistry, vol. 59, № 3, pp. 239-253, 1975. 
[166] C. L. Perdriel, W. E. Triaca, A. J. Arvía, "Different processes contributing to the development of preferred oriented platinum surfaces by fast periodic potential perturbation techniques", Journal of Electroanalytical Chemistry and Interfacial Electrochemistry, vol. 205, № 1-2, pp. 279-290, 1986.

[167] J. Canullo, Y. Uchida, G. Lehmpfuhl, T. Twomey, D. M. Kolg, "An electron microscopic investigation of the electrochemical facetting of platinum," Surface Scince, vol. 188, № 3, pp. 350-363, 1987.

[168] A. J. Bard, R. Parson, J. Jordan, M. Dekker, Standard potential in aqueous solution. New York, 1985.

[169] A. Visintín, J. C. Canullo, W. E. Triaca, A. J. Arvía, "Changes in real surface area, crystallographic orientation and morphology of platinum electrodes caused by periodic potential treatments: phenomenological approach", Journal of Electroanalytical Chemistry and Interfacial Electrochemistry, vol. 239, № 1-2, pp. 67-89, 1988.

[170] S. L. Marchiano, L. R. Neira, A. J. Arvía, “Modelling of pulsating diffusional boundary layers-I. A reversible metal-metal ion electrochemical reaction under symmetric square wave perturbing potentials at a plane electrode", Electrochimica Acta, vol. 35, N² 2, pp. 483-487, 1990.

[171] N. Ibl, "Some theoretical aspects of pulse electrolysis", Surface Technology, vol. 10, N², pp. 81$104,1980$.

[172] A. J. Bard, L. F. Faulkner, Electrochemical methods. Fundamentals and applications, Jhon Wiley, New York, 1980.

[173] C. I. Elsner, C. L. Perdriel, S. L. Marchiano, A. J. Arvía, "Modelling of pulsating diffusional boundary layers-II. A reversible redox electrochemical reaction involving soluble species in solution. Theory and experimental test”, Electrochimica Acta, vol. 35, N 1, pp. 215-223, 1990.

[174] J. O. Bockris, A. K. N. Reddy, Modern Electrochemistry, Vol II. Plenum Press, New York, 1970.

[175] J. K. Vetter, Electrochemical Kinetics. Academia Press, 1967.

[176] J. O. Bockris, A. K. N. Reddy, Electroquímica Moderna. Reverté, vol. 2, 1980.

[177] W. Forker, Cinética Electroquímica, EUDEB, 1971.

[178] S. Srinivasan, E. Gileadi, "The potential-sweep method: a theoretical analysis," Electrochimica Acta, vol. 11, №3, pp. 321-335, 1966.

[179] M. Pourbaix, Ed., Atlas de Electrochemical Equilibria in Aqueous Solutions. Pergamon Press, p. 322, 1966.

[180] J. M. Hales, R. Greef, "The interpretation of adsorption pseudocapacitance curves as measured by the potential-sweep metho-I", Electrochimica Acta, vol. 12, № 10, pp. 1409-1420, 1967.

[181] C. L. Scortichini, C. N. Reilley, "Surface characterization of Pt electrodes using underpotential deposition of $\mathrm{H}$ and Cu: Part II. Pt(110) and Pt(111)", Journal of Electroanalytical Chemistry and Interfacial Electrochemistry, vol. 139, N² 2, pp. 247-264, 1982.

[182] C. L. Scortichini, C. N. Reilley, "Surface characterization of Pt electrodes using underpotential deposition of $\mathrm{H}$ and $\mathrm{Cu}$ : Part III. Surface improvement of the flame-annealed Pt(100) and Pt(111) electrodes via potential cycling", Journal of Electroanalytical Chemistry and Interfacial Electrochemistry, vol. 139, № 2, pp. 265-274, 1982.

[183] R. M. Cerviño, W. E. Triaca, A. J. Arvía, "Voltammetric comparison between platinum with preferred orientation and platinum single crystal electrodes", Electrochimica Acta, vol. 30, № 10, pp. 1323-1327, 1985. 
[184] R. M. Cerviño, W. E. Triaca, A. J. Arvía, "Electrochemical preparation and characteristics of platinum electrode surfaces with preferred orientations", Journal of Electroanalytical Chemistry and Interfacial Electrochemistry, vol. 182, № 1, pp. 51-60, 1985.

[185] A. V. Tripkovic, R. R. Adzic, "Hydrogen electrosorption of single-crystal platinum stepped surfaces and the effects of oxide formation", Journal of Electroanalytical Chemistry and Interfacial Electrochemistry, vol. 205, № 1-2, pp. 335-342, 1986.

[186] N. Furuya, S. Koide, "Hydrogen adsorption on platinum single-crystal surfaces", Surface Science, vol. 220, N¹, pp. 18-28, 1989.

[187] N. M. Markovic, N. S. Marinkovic, R. R. Adzid, "Electrosorption of hydrogen and sulfuric acid anions on single crystal platinum stepped surfaces Part II. The [110] zone", Journal of Electroanalytical Chemistry and Interfacial Electrochemistry, vol. 314, № 1-2, pp. 289-306, 1991.

[188] R. R. Adzic, "Modern Aspects of Electrochemistry" en Modern Aspects of Electrochemistry. vol 21, B. E. Conway, J. O. Bockris, R. White, Eds. New York: Plenum Press, 1990.

[189] A. Soffer, M. Folman, "The electrical double layer of high surface porous carbon electrode", Electroanalytical Chemistry and InterJacial Electrochemistry, vol. 38, № 1, pp. 25-43, 1972.

[190] K. Kinoshita, J. A. S. Bett, "Potentiodynamic analysis of surface oxides on carbon blacks", Carbon, vol. 11, pp. 403-411, 1973.

[191] M. Breiter, H. Kammermeier, C. A. Knorr, Zeitschrift für Elektrochemie, vol. 60, p. 454, 1956.

[192] M. Breiter, Transactions of the Symposium on Electrode Processes, John Wiley \& Sons, New York, 1961.

[193] D. Gilroy, B. E. Conway, "Surface oxidation and reduction of platinum electrodes: Coverage , kinetic and hysteresis studies", Canadian Journal of Chemistry, vol. 46, pp. 875-890, 1968.

[194] J. Honz, L. Němec, "Dependence of the rate of ionization of hydrogen adsorbed on platinum on the surface coverage with hydrogen", Collection of Czechoslovak Chemical Communications, vol. 34, Nº 7, pp. 2030-2036, 1969.

[195] R. Payne, "Application of the method of time-domain reflectometry to the study of electrode processes", Journal of Electroanalytical Chemistry and Interfacial Electrochemistry, vol. 19, № 1-2, pp. 1-14, 1968.

[196] R. Woods, Chemisorption at electrodes, en Electroanalytical Chemistry, Marcel Dekker, New York, Vol. 9, 1976.

[197] S. Gilman, Electroanalytical Chemistry, Arnold Press, London, vol. 2, pp. 111-192, 1967.

[198] T. Biegler, D. A. J. Rand, R. Woods, "Limiting oxygen coverage on platinized platinum; relevance to determination of real platinum area by hydrogen adsorption", Journal of Electroanalytical Chemistry and Interfacial Electrochemistry, vol. 29, pp. 269-277, 1971.

[199] S. Gilman, "Measurement of hydrogen adsorption by the multipulse potentiodynamic (MPP) method", Journal of Electroanalytical Chemistry, vol. 7, N 5, pp. 382-391, 1964.

[200] J. . E. Benson, M. Boudart, "Hydrogen-oxygen titration method for the measurement of supported platinum surface areas", Journal of Catalysis, vol. 4, N 6, pp. 704-710, 1965.

[201] J. F. Connolly, R. J. Flannery, G. Aronowitz, "Electrochemical measurement of the available surface area of carbon-supported platinum", Journal of The Electrochemical Society, vol. 113, $\mathrm{N}^{\circ} 6, \mathrm{pp}$. 577-580, 1966.

[202] S. Gilman, "Electrochemical surface oxidation of platinum", Electrochimica Acta, vol. 9, № 7, pp. 1025-1046, 1964. 
[203] S. B. Brummer, "The use of large anodic galvanostatic transients to evaluate the maximum adsorption on platinum from formic acid solutions", The Journal of Physical Chemistry, vol. $69, \mathrm{~N}^{\circ}$ 2, pp. 562-571, 1965.

[204] J. Clavilier, D. Armand, S. G. Sun, M. Petit, "Electrochemical adsorption behaviour of platinum stepped surfaces in sulphuric acid solutions", Journal of Electroanalytical Chemistry, vol. 205, $\mathrm{N}^{\circ}$ 1-2, pp. 267-271, 1986.

[205] D. Arrnand, J. Clavilier, "Electrochemical behaviour of the (110) orientation of a platinum surface in acid medium: the role of anions", Journal of Electroanalytical Chemistry and Interfacial Electrochemistry, vol. 263, № 1, pp. 109-126, 1989.

[206] J. Clavilier, K. El Achi, A. Rodes, "In situ characterization of the Pt(S)-[n(111) x (111)] electrode surfaces using electrosorbed hydrogen for probing terrace an step sites", Journal of Electroanalytical Chemistry and Interfacial Electrochemistry, vol. 272, № 1-2, pp. 253-261, 1989.

[207] K. Domke, E. Herrero, A. Rodes, J. M. Feliu, "Determination of the potentials of zero total charge of Pt (100) stepped surfaces in the [011] zone. Effect of the step density and anion adsorption", Journal of Electroanalytical Chemistry, vol. 552, pp. 115-128, 2003.

[208] I. Zúñiga, "Electrocatalizadores de Pt preparados por CVD para la reacción de evolución de hidrógeno", Escuela Superior de Ingeniería Química e Industrias Extractivas, Instituto Politécnico Nacional, 2005.

[209] M. A. Quiroz Alfaro, "Contribución al estudio electroquímico de electrodos de rutenio y platino/rutenio", Universidad Autónoma Metropolitana Iztapalapa, 1985.

[210] A. Damjanovic, A. Dey, J. O. Bockris, "Kinetics of oxygen evolution and dissolution on platinum electrodes", Electrochimica Acta, vol. 11, № 7, pp. 791-814, 1966.

[211] K. J. Vetter, J. W. Schultze, "The kinetics of the electrochemical formation and reduction of monomolecular oxide layers on platinum in $0.5 \mathrm{M} \mathrm{H}_{2} \mathrm{SO}_{4}$ : Part I. Potentiostatic pulse measurements", Journal of Electroanalytical Chemistry and Interfacial Electrochemistry, vol. 34, $\mathrm{N}^{\circ}$ 1, pp. 131-139, 1972.

[212] M. Sistiaga, A. Cuesta, A. R. Pierna, C. Gutiérrez, "Characterization by electrolyte electroreflectance and X-ray photoelectron spectroscopy of amorphous $\mathrm{Ni}_{59} \mathrm{Nb}_{40} \mathrm{Pt}_{1-x} \mathrm{Sn}_{\mathrm{x}}$ alloys and their activation by HF solutions", Surface Science, vol. 410, N²-3, pp. 312-320, 1998.

[213] T. Biegler, R. Woods, "Limiting oxygen coverage on smooth platinum anodes in acid solution", Journal of Electroanalytical Chemistry and Interfacial Electrochemistry, vol. 20, № 1, pp. 73-78, 1969.

[214] M. Rosen, S. Schuldiner, "Mechanisms and Kinetics of $\mathrm{H}_{2}$ Dissociation and Open-Circuit Accumulation of $\mathrm{H}$ Atoms during the Formation of the Equilibrium $\mathrm{H}_{2} / \mathrm{H}^{+}$Electrode on Platinum", Journal of The Electrochemical Society, vol. 117, № 1, pp. 35-43, 1970.

[215] H. A. Laitinen, M. S. Chao, "The Anodic Surface Oxidation of Gold", Journal of The Electrochemical Society, vol. 108, N 8, pp. 726-731, 1961.

[216] S. Schuldiner, T. B. Warner, "Investigations of the kinetics of hydrogen and oxygen reactions on a platinum electrode in acid solution using pulse and decay techniques", Journal of The Electrochemical Society, vol. 112, N², pp. 212-218, 1965.

[217] R. S. Sirohi, M. a. Genshaw, "Electrochemical ellipsometric study of gold", Journal of The Electrochemical Society, vol. 116, № 7, pp. 910-914, 1969.

[218] M. Peuckert, F. P. Coenen, H. P. Bonzel, "XPS study of the electrochemical surface oxidation of Platinum in $1 \mathrm{~N} \mathrm{H}_{2} \mathrm{SO}_{4}$ acid electrolyte", Electrochimica Acta, vol. 29, N 10, pp. 1305-1324, 1984. 
[219] A. Visintin, W. E. Triaca, A. J. Arvia, "Changes in the surface morphology of platinum electrodes produced by the application of periodic potential treatments in alkaline solution", Journal of Electroanalytical Chemistry and Interfacial Electrochemistry, vol. 284, № 2, pp. 465-480, 1990.

[220] J. Clavilier, K. El Achi, A. Rodes, "In situ probing of step and terrace sites on Pt(S)-[n(111)×(111)] electrodes", Chemical Physics, vol. 141, № 1, pp. 1-14, 1990.

[221] A. Rodes, K. El Achi, M. A. Zamakhchari, J. Clavilier, "Hydrogen probing of step and terrace sites on $\mathrm{Pt}(\mathrm{S})-[\mathrm{n}(111) \times(100)] "$, Journal of Electroanalytical Chemistry and Interfacial Electrochemistry, vol. 284, Nº1, pp. 245-253, 1990.

[222] C. Urbina, P. Rodríguez, H. Finol, T. Mérida, M. Ogura, "Introducción a la microscopía electrónica", Universidad Central de Venezuela, 1997.

[223] D. B. Williams, C. B. Carter, Transmission Electron Microscopy, Plenum Press, 1996.

[224] L. E. Murr, Electron and ion microscopy and microanalysis. Principles and applications, $2^{\circ}$ Edición, New York, 1991.

[225] J. Bermúdez, "Métodos de Difracción de Rayos X. Principios y Aplicaciones", Ed. Pirámide, 1981.

[226] B. E. Warren, X-ray Diffraction, Courier Dover Publications, 1990.

[227] C. Suryanarayana, M. G. Norton, X-Ray Diffraction: A Practical Approach, Srpinger, Plenum Press, New York, 1998.

[228] P. W. Atkins, Fisicoquímica, Addison-Wesley Iberoamericaana, 1991.

[229] R. W. Cahan, P. Haasen, E. J. Kramer, Eds., "Material Science and Technology". vol. 2A., VCH, 1993.

[230] G. Talsky, Derivative Spectrophotometry. Low and Higher Order. VCH, Weinheim, 1994.

[231] T. N. Angelidis, E. Skouraki, "Preliminary studies of platinum dissolution from a spent industrial catalyst", Applied Catalysis A: General, vol. 142, Murr L. E., Electron and ion microscopy and microanalysis. Principles and application, pp. 387-395, 1996.

[232] R. E. Franklin, "Crystallite growth in graphitizing and non-graphitizing carbons", Proceedings of the Royal Society of London. Series A, Mathematical and Physical Science, vol. 209, N 1097, pp. 196218, 1951.

[233] M. R. Tarasevich, E. I. Khrushcheva, Modern aspects of electrochemistry, cap. 5, Plenum Press, New York, 1989.

[234] H. Gunasingharn, C. Tan, "Glucose enzyme electrode preparation by the codeposition of platinum and glucose oxidase onto glassy carbon", Electroanalysis, vol. 1, N 3, pp. 223-227, 1989.

[235] I. Hu, D. H. Karweik, T. Kuwana, "Activation and deactivation of glassy carbon electrodes", Journal of Electroanalytical Chemistry, vol. 188, N 1-2, pp. 59-72, 1985.

[236] N. Jia, R. . B. Martin, Z. Qi, M. C. Lefebvre, P. G. Pickup, "Modification of carbon supported catalysts to improve performance in gas diffusion electrodes", Electrochimica Acta, vol. 46, $\mathrm{N}^{\circ} 18$, pp. 2863-2869, 2001.

[237] J. Maruyama, I. Abe, "Cathodic oxygen reduction at the interface between Nafion ${ }^{\circledR}$ and electrochemically oxidized glassy carbon surfaces", Journal of Electroanalytical Chemistry, vol. 527, N 1-2, pp. 65-70, 2002.

[238] B. Šljukić, C. E. Banks, R. G. Compton, "An overview of the electrochemical reduction of oxygen at carbon based modified electrodes", Journal of the Iranian Chemical Society, vol. 2, N¹, pp. 1-25, 2005. 
[239] M. G. Sullivan, R. Kötz, O. Haas, "Thick active layers of electrochemically modified glassy carbon, electrochemical impedance studies", Journal of The Electrochemical Society, vol. 147, $\mathrm{N}^{\circ} 1$, pp. 308-317, 2000.

[240] J. M. Sieben, M. M. E. Duarte, C. E. Mayer, "Preparación electroquímica de electrodos bimetálicos PtRu soportados sobre sustratos carbonosos y su caracterización para la oxidación de metanol en medio ácido", Revista Materia, vol. 13, № 2, pp. 357-364, 2008.

[241] M. M. E. Duarte, C. E. Mayer, "Modificación de electrodos de fibra de grafito por electrooxidación a altos potenciales", Anales de la Asociación Química Argentina, vol. 85, pp. 27-35, 1997.

[242] K. Kinoshita, Carbon Electrochemical and Physicochemical Properties, Wiley \& Sons, New York, 1988.

[243] M. Watanabe, M. Tomikawa, S. Motoo, "Preparation of a high performance gas diffusion electrode", Journal of Electroanalytical Chemistry and Interfacial Electrochemistry, vol. 182, №1, pp. 193-196, 1985.

[244] D. Richard, P. Gallezot, Preparation of Catalysts IV, Elsevier, pp. 71-79, 1987.

[245] K. L. Yeung, E. E. Wolf, "Scanning tunneling microscopy studies of size and morphology of Pt/graphite catalysts", Journal of Catalysis, vol. 135, N 1, pp. 13-26, 1992.

[246] P. L. Antonucci, V. Alderucci, N. Giordano, D. L. Cocke, H. Kim, "On the role of surface functional groups in Pt carbon interaction", Journal of Applied Electrochemistry, vol. 24, $\mathrm{N}^{\circ} 1$, pp. 58-65, 1994.

[247] R. J. Mammone, M. Binder, D. Chu, W. L. Wade, New Materials for Fuel Cells I. E'cole Polytechnique de Montréal, pp. 624-628, 1995.

[248] CATALOG SECTION A-4006 c a, National Trade-Mark, Spectroscopic electrodes.

[249] G. A. W. Rutgers, "Absolute spectroradiometric measurements" en Accuracy in spectrophotometry and luminescence measurements: proceedings of the conference held at the national bureau of standards, R. Mavrodineany, J. I. Shultz, and O. Menis, Eds. Proceedings of the Conference Held at the National Bureau of Standards, Gaithesburg, p. 57, 1973.

[250] B. E. Conway, H. Angerstein-Kozlowska, W. B. A. Sharp, E. E. Criddle, "Ultrapurification of water for electrochemical and surface chemical work by catalytic pyrodistillation", Analytical Chemistry, vol. 45, N², pp. 1331-1336, 1973.

[251] A. Klemenc, Die Behandlung und Reidarstellung von Gasen. Springer-Verlag, Viena, 1948.

[252] G. Brauer, Hansbuch der Praeparativen Anorganischen Chemie, Tomo I. F. Enke Verlag, Stuttgart, 1960.

[253] J. L. Zubimendi, L. Vázquez, P. Ocón., J. M.Vara, W.E.Triaca, R.C.Salvarezza, A.J.Arvía, “Early stages of platinum electrodeposition on highly oriented pyrolitic graphite: scanning tunneling microscopy imaging and reaction pathway", The Journal of Physical Chemistry, vol. 97, № 19, pp. 5095-5102, 1993.

[254] D. M. Donald, Transient techniques in electrochemistry. Plenum Press, New York, 1977.

[255] D. Posadas, Introducción a la Electroquímica, Monografía O.E.A. № 22, 1980.

[256] J. A. von Fraunhofer, C. H. Banks, Potenciostat and its aplications. Butterworths, London, 1972.

[257] "Manual técnico del equipo" [Online] http://www.artisanscientific.com/info/metrohm_autolab_microautolabii_pgstat12_pgstat30_pgstat100_datasheet.p df. 
[258] A. J. Arvia, R. C. Salvarezza, W. E. Triaca, "Noble metal surfaces and electrocatalysis. Review and perspectives", Journal of New Materials for Electrochemical Systems, vol. 7, № 2, pp. 133-143, 2004.

[259] F. G. Will, "Hydrogen adsorption on platinum single crystal electrodes", Journal of The Electrochemical Society, vol. 112, № 4, pp. 451-455, 1965.

[260] P. N. Ross, "The effect of anions on hydrogen chemisorption and oxide formation on Pt in aqueous acids", Journal of Electroanalytical Chemistry and Interfacial Electrochemistry, vol. 76, $\mathrm{N}^{\circ} 1, \mathrm{pp}$. 139-145, 1977.

[261] A. T. Hubbard, R. M. Ishikawa, J. Katekaru, "Study of platinum electrodes by means of electrochemistry and low-energy electron diffraction: Part II. Comparison of the electrochemical activity of $\mathrm{Pt}(100)$ and $\mathrm{Pt}(111)$ surfaces", Journal of Electroanalytical Chemistry and Interfacial Electrochemistry, vol. 86, № 2, pp. 271-288, 1978.

[262] O. I. Milner, G. F. Shipman, "Colorimetric determination of platinum with stannous chloride", Analytical Chemistry, vol. 27, N 9, pp. 1476-1478, 1955.

[263] S. S. Berman, E. C. Goodhue, "A new spectrophotometric procedure for platinum with tin (II) chloride", Canadian Journal of Chemistry, vol. 37, № 2, pp. 370-374, 1959.

[264] F. J. Young, R. D. Gillard, G. Wilkinson, "Complexes of ruthenium, rhodium, iridium, and platinum with tin(II) chloride", Journal of the Chemical Society, vol. 992, Nº, pp. 5176-5189, 1964.

[265] M. Balcerzak, W. Wozniak, "Sensitive flotation-spectrophotometric determination of ruthenium with tin(II) chloride and Rhodamine 6G", Microchemical Journal, vol. 337, № 3, pp. 326-337, 1988.

[266] M. Balcerzak, "Platinum metals-tin(II) chloride complexes. Analytical applications. A review", Analusis, vol. 22, №7, pp. 353-359, 1994.

[267] H. Angerstein-Kozlowska, Comprehensive treatise of electrochemistry, Plenum Press, New York, 1984.

[268] M. Balcerzak, E. Swiecicka, E. Balukiewicz, "Determination of platinum and ruthenium in Pt and PtRu catalysts with carbon support by direct and derivative spectrophotometry", Talanta, vol. 48, No1, pp. 39-47, 1999.

[269] W. Grove, "On voltaic series and the combination of gases by platinum", Philosophical Magazine and Journal of Science, vol. 14, N 86, pp. 127-130, 1839.

[270] W. Grove, "On a gaseous voltaic battery", London and Edinburgh Philosophical Magazine and Journal of Science, vol. 21, № 140, pp. 417-420, 1842.

[271] L. Rayleigh, "On a new form of gas battery", Proceedings of the Cambridge Philosophical Soc., vol. 4, p. 198, 1882.

[272] L. Mond, C. Langer, "A new form of gas battery", Proceedings of the Royal Society of London, vol. $46, N^{\circ} 286,1889$.

[273] C. A. Wright, C. Thompson, "Note on the development of voltaic electricity by atmospheric oxidation of combustible gases and other substances", Proceedings of the Royal Society of London, vol. 46 , pp. 372-376, 1889.

[274] W. T. Grubb, L. W. Niedrach, "Batteries with solid ion-exchange membrane electrolytes: II. Lowtemperature hydrogen-oxygen fuel cells", Journal of The Electrochemical Society, vol. 107, №2, pp. 131-135, 1960.

[275] P. J. Grimwood, J. M. Hacker, B. C. Vorzimmer, "Project Gemini technology and operations: a chronology, part I (B) concept and design, Technical report, http://history.nasa.gov/SP4002/p1b.htm", 1962, [Online]. Available: http://history.nasa.gov/SP-4002/p1b.htm. 
[276] M. Warshay, P. R. Prokopius, "The fuel cell in space: yesterday, today and tomorrow", Journal of Power Sources, vol. 29, pp. 193-200, 1990.

[277] G. Halpert, H. Frank, S. Surampudi, "Batteries and fuel cells in space", The Electrochem. Soc. Interface Fall, vol. 8, ํ3, pp. 25-30, 1999.

[278] A. B. Geiger, A. Tsukada, E. Lehmann, P. Vontobel, and G. Scherer, "In situ investigation of twophase flow patterns in flow fields of PEFC's using neutron radiography", Fuel Cell from Fundamentals to Systems, vol. 2, N², pp. 92-98, 2003.

[279] G. Bender, M. S. Wilson, T. A. Zawodzinski, "Further refinements in the segmented cell approach to diagnosing performance in polymer electrolyte fuel cells", Journal of Power Sources, vol. 123, $N^{\circ} 2$, pp. 163-171, 2003.

[280] K. Tüber, D. Pócza, C. Hebling, "Visualization of water buildup in the cathode of a transparent PEM fuel cell”, Journal of Power Sources, vol. 124, N² 2, pp. 403-414, 2003.

[281] M. M. Mench, Q. L. Dong, C. . Wang, "In situ water distribution measurements in a polymer electrolyte fuel cell", Journal of Power Sources, vol. 124, N 1, pp. 90-98, 2003.

[282] V. Gurau, H. Liu, S. Kakaç, "Two-dimensional model for proton exchange membrane fuel cells", American Institute of Chemical Engineers Journal, vol. 44, N 11, pp. 2410-2422, 1998.

[283] P. Costamagna, "Transport phenomena in polymeric membrane fuel cells", Chemical Engineering Science, vol. 56, $\mathrm{N}^{\circ} 2$, pp. 323-332, 2001.

[284] L. Wang, A. Husar, T. Zhou, H. Liu, "A parametric study of PEM fuel cell performances", International Journal of Hydrogen Energy, vol. 28, №11, pp. 1263-1272, 2003.

[285] S. Gottesfeld, G. Halpert, A. Landgrebe, Eds., Proton conducting fuel cell. The Electrochemical Society, New York, 1995.

[286] M. Uchida, Y. Aoyama, N. Eda, A. Ohta, "New preparation method for polymer-electrolyte fuel cells," Journal of The Electrochemical Society, vol. 142, № 2, pp. 463-468, 1995.

[287] P. G. Dirven, W. J. Engelen, C. J.-M. Van Der Porter, "An oxygen electrode for air-consuming proton exchange membrane fuel cells for transportation applications," Journal of Applied Electrochemistry, vol. 25, № 2, pp. 122-125, 1995.

[288] S. Miachon, P. Aldebert, "Internal hydration $\mathrm{H}_{2} / \mathrm{O}_{2} 100 \mathrm{~cm}^{2}$ polymer electrolyte membrane fuel cell pile a combustible a membrane electrolyte polymere $\mathrm{H}_{2} / \mathrm{O}_{2}$ de $100 \mathrm{~cm}^{2}$ a hydratation interne", Journal of Power Sources, vol. 56, № 1, pp. 31-36, 1995.

[289] T. N. Veziroglu, C. L. Winter, J. P. Baselt, G. Kreysa, Eds., Hydrogen Energy Progress XI, vol. 22, N I. Intenational Association of Hydrogen Energy, 1996, pp. Vol.1-3.

[290] V. A. Paganin, E. A. Ticciarelli, E. R. Gonzalez, "Development and electrochemical studies of gas diffusion electrodes for polymer electrolyte fuel cells", Journal of Applied Electrochemistry, vol. 26, N³, pp. 297-304, 1996.

[291] D. P. Wilkinson, H. H. Voss, K. Prater, "Water management and stack design for solid polymer fuel cells", Journal of Power Sources, vol. 49, N 1-3, pp. 117-127, 1994.

[292] D. R. Bringhton, G. A. Clark, M. J. M. Rowan, P. L. Mart, "1994 Fuel Cell Seminar Abstracts" San Diego, CA, p. 547, 1994.

[293] S. Galli, L. Barberini, "1994 Fuel Cell Seminar Abstracts" San Diego, CA, p. 527, 1994.

[294] W. Urabe, S. Maruyama, A. Kusunoki, J. Ohtuki, "1994 Fuel Cell Seminar Abstracts", San Diego, CA, p. 311, 1994.

[295] F. Vermeulen, "1994 Fuel Cell Seminar Abstracts" San Diego, CA, p. 635, 1994. 
[296] C. Mantegazza, A. Maggiore, Hydrogen Energy Progress XI, vol. 2. International Associations of Hydrogen Energy, p. 1647, 1996.

[297] J. Scholta, M. V. Lüttichau, B. Rohland, Hydrogen Energy Progress XI, vol. 2. Intenational Association of Hydrogen Energy, p. 1957, 1996.

[298] I. D. Raistrick, "Separators and ion exchange membranes" en Proceedings of the Symposium on Diaphragms, Pennington., J. W. Van Zee, R. E. White, Burney, K. Kinoshita, H. S. Burney, Eds. The Electrochemical Society, p. 172, 1986.

[299] S. Srinivasan, E. A. Ticianelli, C. R. Derouin, A. Redondo, "Advances in solid polymer electrolyte fuel cell technology with low platinum loading electrodes", Journal of Power Sources, vol. 22, $\mathrm{N}^{\circ} 3-4$, pp. 359-375, 1988.

[300] E. A. Ticianelli, C. R. Derouin, A. Redondo, S. Srinivasan, "Methods to advance technology of proton exchange membrane fuel cells", Journal of The Electrochemical Society, vol. 135, $\mathrm{N}^{\circ}$ 9, pp. 2209-2214, 1988.

[301] E. A. Ticianelli, C. R. Derouin, S. Srinivasan, "Localization of platinum in low catalyst loading electrodes to to attain high power densities in SPE fuel cells", Journal of Electroanalytical Chemistry, vol. 251, N², pp. 275-295, 1988.

[302] S. J. Ridge, R. E. White, Y. Tsou, R. N. Beaver, G. A. Eisman, "Oxygen reduction in a proton exchange membrane test cell", The Electrochemical Society, vol. 136, № 7, pp. 1902-1909, 1989.

[303] S. Srinivasan, "Fuel cells for extraterrestrial and terrestrial applications", Journal of The Electrochemical Society, vol. 136, N², p. 41C-48C, 1989.

[304] E. A. Ticianelli, J. G. Beery, S. Srinivasan, "Dependence of performance of solid polymer electrolyte fuel cells with low platinum loading on morphologic characteristics of the electrodes", Journal of Applied Electrochemistry, vol. 21, № 7, pp. 597-605, 1991.

[305] R. Liu, W.-H. . Her, P. S. Fedkiw, "In situ electrode formation on a nafion membrane by chemical platinization", Journal of The Electrochemical Society, vol. 139, № 1, pp. 15-23, 1992.

[306] Z. Poltarzewski, P. Staiti, V. Alderucci, W. Wieczorek, N. Giordano, "Nafion distribution in gas diffusion electrodes for solid-polymer electrolyte fuel cell applications", Journal of The Electrochemical Society, vol. 139, № 3, pp. 761-765, 1992.

[307] P. Staiti, Z. Poltarzewski, V. Alderucci, G. Maggio, N. Giordano, A. Fasulo, "Influence of electrodic properties on water management in a solid polymer electrolyte fuel cell" Journal of Applied Electrochemistry, vol. 22, № 7, pp. 663-667, 1992.

[308] M. S. Wilson, S. Gottesfeld, "High performance catalyzed membranes of ultra-low Pt loadings for polymer electrolyte fuel cells", Journal of The Electrochemical Society, vol. 139, N², pp. L28-L30, 1992.

[309] M. S. Wilson, S. Gottesfeld, "Thin-film catalyst layers for polymer electrolyte fuel cell electrodes", Journal of Applied Electrochemistry, vol. 22, № 1, pp. 1-7, 1992.

[310] A. C. Ferreira, S. Srinivasan, A. J. Appleby, The Electrochemical Society Extended Abstracts, St. Louis Meeting, vol. 92, N 1, p. 8, 1992.

[311] M. S. Wilson, F. H. Garzon, K. E. Sickafus, S. Gottesfeld, "Surface area loss of supported platinum in polymer electrolyte fuel cells", Journal of The Electrochemical Society, vol. 140, № 10, pp. 28722877, 1993.

[312] S. Hirano, J. Kim, S. Srinivasan, "High performance proton exchange membrane fuel cells with sputter-deposited Pt layer electrodes", Electrochimica Acta, vol. 42, № 10, pp. 1587-1593, 1997. 
[313] L. Giorgi, E. Antolini, A. Pozio, E. Passalacqua, "Influence of the PTFE content in the difusion layer of low-Pt loading electrodes for polymer electrolyte fuel cells", Electrochimica Acta, vol. 43, N²4, pp. 3675-3680, 1998.

[314] S. Y. Cha, W. M. Lee, "Performance of proton exchange membrane fuel cell electrodes prepared by direct deposition of ultrathin platinum on the membrane surface", Journal of The Electrochemical Society, vol. 146, № 11, pp. 4055-4060, 1999.

[315] F. Lufrano, E. Passalacqua, G. Squadrito, A. Patti, L. Giorgi, "Improvement in the diffusion characteristics of low Pt-loaded electrodes for PEFCs", Journal of Applied Electrochemistry, vol. 29, $\mathrm{N}^{\circ} 4$, pp. 445-448, 1999.

[316] E. Gülzow, M. Schulze, N. Wagner, T. Kaz, R. Reissner, G. Steinhilber, A. Schneider, "Dry layer preparation and characterisation of polymer electrolyte fuel cell components", Journal of Power Sources, vol. 86, $\mathrm{N}^{\circ} 1-2$, pp. 352-362, 2000.

[317] L. R. Jordan, A. K. Shukla, T. Behrsing, N. R. Avery, B. C. Muddle, M. Forsyth, "Diffusion layer parameters influencing optimal fuel cell performance", Journal of Power Sources, vol. 86, $\mathrm{N}^{\circ} 1-2$, pp. $250-254,2000$.

[318] L. R. Jordan, A. K. Shukla, T. Behrsing, N. R. Avery, B. C. Muddle, M. Forsyth, "Effect of diffusionlayer morphology on the performance of polymer electrolyte fuel cells operating at atmospheric pressure", Journal of Applied Electrochemistry, vol. 30, № 6, pp. 641-646, 2000.

[319] M. Maja, C. Orecchia, M. Strano, P. Tosco, M. Vanni, "Effect of structure of the electrical performance of gas diffusion electrodes for metal air batteries", Electrochimica Acta, vol. 46, $\mathrm{N}^{\circ} 2-$ 3, pp. 423-432, 2000.

[320] E. Passalacqua, G. Squadrito, F. Lufrano, A. Patti, L. Giorgi, "Effects of the diffusion layer characteristics on the performance of polymer electrolyte fuel cell electrodes", Journal of Applied Electrochemistry, vol. 31, N4, pp. 449-454, 2001.

[321] J. Larminie, A. Dicks, Fuel cell systems explained, $2^{\text {da }}$ Ed., vol. 93, № 1-2. John Wiley \& Sons Ltd., Chichester, 2003.

[322] F. Barbir, T. Gómez, "Efficiency and economics of proton exchange membrane (PEM) Fuel Cells", International Journal of Hydrogen Energy, vol. 22, № 10-11, pp. 1027-1047, 1997.

[323] J. Zhang, Ed., PEM fuel cell electrocatalysts and catalyst layer: fundamentals ans applications. Springer, Canadá, 2008.

[324] W. E. Triaca, C. E. Mayer, "Conversión electroquímica de energía", Monografías Academia Nacional de Ciencias Exactas Físicas y Naturales, vol. 2, pp. 127-147, 1982.

[325] W. Winkler, "Thermodynamics" en High temperature solid oxide fuel cells: fundamentals, design and applications, S. C. Singhal, K. Kendall, Eds. Elsevier Ltd., Oxford, UK, 2003.

[326] Fuel cell handbook, $7^{\text {th }}$ Ed., $N^{\circ}$ November. EG\&G Technical Services, Inc., Morgantown, West Virginia, 2004.

[327] G. D. J. Harper, Fuel cell projects for the evil genius. The McGraw-Hill Companies, 2008.

[328] S. Srinivasan, R. Mosdale, P. Stevens, C. Yang, "Fuel cells: reaching the era of clean and efficient power generation in the twenty-first century", Annual Review of Energy and the Environment, vol. 24, No 1 , pp. 281-328, 1999.

[329] J. H. Hirschenhofer, D. B. Stauffer, R. R. Engleman, M. G. Klett, Fuel cell handbook, $4^{\text {ta }}$ Ed. 1998.

[330] F. Barbir, Fuel cell: theory and practice, Academic P. Elsevier, New Yersey, 2005.

[331] H. Ju, C. Y. Wang, "Experimental validatiom on a PEM fuel cell model by current distribution data", Journal of The Electrochemical Society, vol. 151, N 11, pp. A1954-A1960, 2004. 
[332] D. B. Sepa, M. V. Vojnovk, A. Damjanovic, "Different views regarding the kinetics and mechanisms of oxygen reduction at Pt and Pd electrodes", Electrochimica Acta, vol. 32, No 1, pp. 129-134, 1987.

[333] A. Parthasarathy, S. Srinivasan, A. J. Appleby, C. R. Martin, "Pressure dependence of the oxygen reduction reaction at the platinum microelectrode/nafion interface: electrode Kinetics and mass transport", Journal of The Electrochemical Society, vol. 139, № 10, pp. 2856-2862, 1992.

[334] D. R. de Sena, E. A. Ticianelli, E. R. Gonzalez, "Characterization of the limiting structural effects on the electrochemical behavior of porous gas diffusion electrodes", Journal of Electroanalytical Chemistry, vol. 357, №1-2, pp. 225-236, 1993.

[335] T. E. Spinger, T. A. Zawodizinski, S. Gottesfeld, "Polymer electrolyte fuel cell model", Journal of The Electrochemical Society, vol. 138, № 8, pp. 2334-2342, 1991.

[336] Y.-M. Tsou, M. C. Kimble, R. E. White, "Hydrogen diffusion, solubility, and water uptake in dow's short-side-chain perfluorocarbon membranes", Journal of The Electrochemical Society, vol. 139, $\mathrm{N}^{\circ}$ 7, pp. 1913-1917, 1992.

[337] F. Fuller, J. Newman, "Experimental determination of the transport number of water in Nafion 117 membrane", Journal of The Electrochemical Society, vol. 139, № 5, pp. 1332-1337, 1992.

[338] T. A. Zawodzinski, "Water uptake by and transport through nafion ${ }^{\circledR} 117$ membranes", Journal of The Electrochemical Society, vol. 140, N 4, pp. 1041-1047, 1993.

[339] T. A. Zawodizinski, T. E. Srpinger, J. Davey, R. Jestel, C. Lopez, J. Valerio, S. Gottesfeld, "A comparative study of water uptake by and transport through ilonomeric fuel cell membranes", Journal of The Electrochemical Society, vol. 140, N 7, pp. 1981-1985, 1993.

[340] T. V. Nguyen, R. E. White, "A water and heat management model for proton exchange membrane fuel cells", Journal of The Electrochemical Society, vol. 140, № 8, pp. 2178-2186, 1993.

[341] T. E. Spinger, T. A. Zawodizinski, S. Gottesfeld, "Modeling and experimental diagnostics in polymer electrolyte fuel cells", Journal of The Electrochemical Society, vol. 140, № 12, pp. 3513-3526, 1993.

[342] S. Srinivasan, H. D. Hurwitz, J. O. Bockis, "Fundamental equations of electrochemical kinetics at porous gas-diffusion electrodes", The Journal of Chemical Physics, vol. 46, N 8, pp. 3108-3122, 1967.

[343] S. Srinivasan, H. D. Hurwitz, "Theory of a thin film model of porous gas-diffusion electrodes", Electrochimica Acta, vol. 12, N 5, pp. 495-512, 1967.

[344] M. B. Cutlip, "An approximate model for mass transfer with reaction in porous gas diffusion electrodes", Electrochimica Acta, vol. 20, pp. 767-773, 1975.

[345] R. P. Iczkowski, M. B. Cutlip, "Voltage losses in fuel cell cathodes", Journal of The Electrochemical Society, vol. 127, ํㅜ 7, pp. 1433-1440, 1980.

[346] P. Björnbom, "Modelling of a double-layered oxygen electrode", Electrochimica Acta, vol. 32, N 1, pp. 115-119, 1986.

[347] T. E. Springer, I. D. Raistrick, "Electrical impedance of a pore wall for the flooded-agglomerate model of porous gas-diffusion electrodes", Journal of The Electrochemical Society, vol. 136, $\mathrm{N}^{\circ} 6$, pp. 1594-1603, 1989.

[348] I. D. Raistrick, "Impedance studies of porous electrodes", Electrochimica Acta, vol. 35, № 10, pp. 1579-1586, 1990.

[349] E. A. Ticiarelli, "A modelling approach to the characterization of the limiting polarization behaviour of gas diffusion electrodes", Journal of Electroanalytical Chemistry, vol. 387, pp. 1-10, 1995. 
[350] R. Liu, W. H. Her, P. S. Fedkiw, "In situ electrode formation on a nafion membrane by chemical platinization", Journal of The Electrochemical Society, vol. 139, N 1, pp. 15-23, 1992.

[351] Y. W. Rho, S. Srinivasan, Y. T. Kho, "Mass transport phenomena in proton exchange membrane fuel cells using $\mathrm{O}_{2} \mathrm{He}, \mathrm{O}_{2} / \mathrm{Ar}$, and $\mathrm{O}_{2} / \mathrm{N}_{2}$ mixtures", Journal of The Electrochemical Society, vol. 141, Nº, pp. 2089-2096, 1994.

[352] S. Srinivasan, "Fuel cells: from fundamentals to applications", Springer, New York, 2006.

[353] M. Uchida, Y. Aoyama, N. Eda, A. Ohta, "Investigation of the microstructure in the catalyst layer and effects of both perfluorosulfonate ionomer and PTFE-loaded carbon on the catalyst layer of polymer electrolyte fuel cells", Journal of The Electrochemical Society, vol. 142, No12, pp. 41434149, 1995.

[354] M. Eikerling, A. A. Kornyshev, "Modelling the performance of the cathode catalyst layer of polymer electrolyte fuel cells", Journal of Electroanalytical Chemistry, vol. 453, N 1-2, pp. 89-106, 1998.

[355] P. M. Wilde, M. Mändle, M. Murata, N. Berg, "Structural and physical properties of GDL and GDL/BPP combinations and their Influence on PEMFC performance", Fuel Cell from Fundamentals to Systems, vol. 4, N³, pp. 180-184, 2004.

[356] S. Shimpalee, U. Beuscher, J. W. Van Zee, "Analysis of GDL flooding effects on PEMFC performance", Electrochimica Acta, vol. 52, N²4, pp. 6748-6754, 2007.

[357] M. Mathias, J. Roth, J. Fleming, W. Lehnert, Handbook of fuel cells-fundamentals, technology and applications, Vol. 3., vol. 3. John Wiley \& Sons Ltd., New York, 2003.

[358] M. Prasanna, H. Y. Ha, E. A. Cho, S. A. Hong, I. H. Oh, "Influence of cathode gas diffusion media on the performance of the PEMFCs", Journal of Power Sources, vol. 131, N 1-2, pp. 147-154, 2004.

[359] K. S. Dhathathreyan, N. Rajalakshmi, "Polymer electrolyte membrane fuel cell”, en Recent trends in Fuel Cell Science and Technology, S. Basu, Ed. Anamaya Publishers, New Delhi, India, 1990.

[360] M. Secanell, R. Songprakorp, N. Djilali, A. Suleman, "Optimization of a proton exchange membrane fuel cell membrane electrode assembly", Structural and Multidisciplinary Optimization, vol. $40, \mathrm{~N}^{\circ}$ 1-6, pp. 563-583, 2010.

[361] G. Lin, T. V. Nguyen, "Effect of thickness and hydrophobic polymer content of the gas diffusion layer on electrode flooding level in a PEMFC", Journal of The Electrochemical Society, vol. 152, $\mathrm{N}^{\circ}$ 10, pp. A1942-A1948, 2005.

[362] D. Sánchez Portillo, "Estudio de las modificaciones a introducir en un automóvil que incorpore la tecnología de pila de combustible", 2005.

[363] E. Antolini, L. Giorgi, A. Pozio, E. Passalacqua, "Influence of nafion loading in the catalyst layer of gas-diffusion electrodes for PEFC", Journal of Power Sources, vol. 77, N² 2, pp. 136-142, 1999.

[364] G. M. Ortíz, "Aplicación de materiales nanoestructurados en celdas de combustible como una fuente alterna de energía", México, 2006.

[365] E. R. González, E. A. Ticianelli, H. M. Villullas, Materiales y Procesos Electródicos I, pp. 29-64, 2002.

[366] S. Gamburzev, C. Boyer, A. J. Appleby, "Low platinum loading, lightvveight PEM fuel cells", Fuel Cells Bulletin, vol. 2, № 6, pp. 6-8, 1999.

[367] A. Kumar, R. G. Reddy, "Effect of channel dimensions and shape in the flow-field distributor on the performance of polymer electrolyte membrane fuel cells", Journal of Power Sources, vol. 113, $\mathrm{N}^{\circ}$ 1, pp. 11-18, 2003.

[368] K. Zhukovsky, a Pozio, "Maximum current limitations of the PEM fuel cell with serpentine gas supply channels", Journal of Power Sources, vol. 130, N 1-2, pp. 95-105, 2004. 
[369] F. Barreras, A. Lozano, L. Valiño, R. Mustata, C. Marín, “Fluid dynamics performance of different bipolar plates", Journal of Power Sources, vol. 175, N², pp. 841-850, 2008.

[370] Y.-G. Yoon, W.-Y. Lee, G.-G. Park, T.-H. Yang, C.-S. Kim, "Effects of channel configurations of flow field plates on the performance of a PEMFC" Electrochimica Acta, vol. 50, No 2-3, pp. 709-712, 2004.

[371] H. Dohle, R. Jung, N. Kimiaie, J. Mergel, M. Müller, "Interaction between the diffusion layer and the flow field of polymer electrolyte fuel cells-experiments and simulation studies", Journal of Power Sources, vol. 124, № 2, pp. 371-384, 2003.

[372] F. Barreras, A. Lozano, L. Valiño, C. Marín, A. Pascau, "Flow distribution in a bipolar plate of a proton exchange membrane fuel cell: experiments and numerical simulation studies", Journal of Power Sources, vol. 144, № 1, pp. 54-66, 2005.

[373] L. Carrette, K. A. Friedrich, U. Stimming, "Fuel cells-fundamentals and applications", Fuel Cells, vol. 1, No 1, pp. 5-39, 2001.

[374] P. Costamagna, S. Srinivasan, "Quantum jumps in the PEMFC science and technology from the 1960 s to the year 2000 Part II . Engineering, technology development and application aspects", Journal of Power Sources, vol. 102, pp. 253-269, 2001.

[375] X. Li, I. Sabir, "Review of bipolar plates in PEM fuel cells: flow-field designs", International Journal of Hydrogen Energy, vol. 30, ํㅜ 4, pp. 359-371, 2005.

[376] V. Mehta, J. S. Cooper, "Review and analysis of PEM fuel cell design and manufacturing", Journal of Power Sources, vol. 114, N 1, pp. 32-53, 2003.

[377] J. S. Cooper, "Design analysis of PEMFC bipolar plates considering stack manufacturing and environment impact", Journal of Power Sources, vol. 129, N² 2, pp. 152-169, 2004.

[378] D. J. L. Brett, N. P. Brandon, "Review of materials and characterization methods for polymer electrolyte fuel cell flow-field plates", Journal of Fuel Cell Science and Technology, vol. 4, № 1, pp. 29-44, 2007.

[379] R. Yeetsorn, M. W. Fowler, C. Tzoganakis, "A review of thermoplastic composites for bipolar plate materials in PEM fuel cells" en Nanocomposites with Unique Properties and Applications in Medicine and Industry, J. Cuppoletti, Ed. 2011.

[380] S. Karimi, N. Fraser, B. Roberts, F. R. Foulkes, "A review of metallic bipolar plates for proton exchange membrane fuel cells: materials and fabrication methods", Advances in Materials Science and Engineering, vol. 2012, pp. 1-22, 2012.

[381] H. L. Yeager, A. Steck, "Cation and Water Diffusion in Nafion Ion Exchange Membranes: Influence of Polymer Structure", Journal of The Electrochemical Society, vol. 128, № 9, pp. 1880-1884, 1981.

[382] Y. Sone, P. Ekdunge, D. Simonsson, "Proton conductivity of Nafion 117 as measured by a fourelectrode AC impedance method", Journal of The Electrochemical Society, vol. 143, $\mathrm{N}^{\circ} 4$, pp. 1254-1259, 1996.

[383] G. Hoogers, Fuel cell technology handbook. Boca Raton, 2003.

[384] M. Cifrain, K. Kordesch, "Hydrogen/oxygen (air) fuel cells with alkaline electrolytes, en: Handbook of fuel cells-Fundamentals, Technology and Applications" en Handbook of Fuel Cell Fundamentals, Technology and Applications, vol. 1, W. Vielstich, A. Lamm, and H. A. Gasteiger, Eds. Chinchester: Jhon Wiley \& Son LTD, 2003, pp. 267-280.

[385] Z. Qi, A. Kaufman, "Quick and effective activation of proton-exchange membrane fuel cells", Journal of Power Sources, vol. 114, pp. 21-31, 2003. 
[386] M. Wang, K. Woo, T. Lou, Y. Zhai, D. Kim, "Defining catalyst layer ingredients in PEMFC by orthogonal test and C-V method", International Journal of Hydrogen Energy, vol. 30, $\mathrm{N}^{\circ} 4$, pp. 381-384, 2005.

[387] A. B. LaConti, A. R. Fragala, J. R. Boyack, Electrode materials and processes for energy conversion and storage. The Electrochemical Society Softbound Proceedings Series, Princeton, New York, 1977.

[388] A. J. Appleby, E. B. Yeager, "Energy II" en Assessment of Research Needs for Advanced Fuel Cell, S. S. Penner, Ed. 1986.

[389] I. D. Rastrick, Diphragms separators, and ion exange membrane. The Electrochemical Society Softbound Proceeding Series, Pennington, New York, 1988.

[390] E. Passalacqua, F. Lufrano, G. Squadrito, A. Patti, L. Giorgi, "Influence of the structure in low-Pt loading electrodes for polymer electrolyte fuel cells", Electrochimica Acta, vol. 43, No 24, pp. 3665-3673, 1998.

[391] J. M. Song, S. Y. Cha, W. M. Lee, "Optimal composition of polymer electrolyte fuel cell electrodes determined by the AC impedance method", Journal of Power Sources, vol. 94, N 1, pp. 78-84, 2001.

[392] S. Lee, S. Mukerjee, J. Mcbreen, Y. Rho, Y. Kho, T. Lee, "Effects of Nafion impregnation on performances of PEMFC electrodes", Electrochimica Acta, vol. 43, №24, pp. 3693-3701, 1998.

[393] G. Sasikumar, J. . Ihm, H. Ryu, "Dependence of optimum Nafion content in catalyst layer on platinum loading", Journal of Power Sources, vol. 132, N 1-2, pp. 11-17, 2004.

[394] D. Song, Q. Wang, Z. Liu, M. Eikerling, Z. Xie, T. Navessin, S. Holdcroft, "A method for optimizing distributions of Nafion and Pt in cathode catalyst layers of PEM fuel cells" Electrochimica Acta, vol. 50, N 16-17, pp. 3347-3358, 2005.

[395] M. Inaba, M. Uno, J. Marayama, A. Tasaka, K. Katakura, Z. Ogumi, "Hydrogen oxidation on partially immersed Nafion ${ }^{\circledR}$-coated electrodes", Journal of Electroanalytical Chemistry, vol. 147, N1ㄴ 1-2, pp. 105-111, 1996.

[396] G. G. Scherer, "Interfacial aspects in the development of polymer electrolyte fuel cell", Solid, vol. 94, N¹-4, pp. 249-257, 1997.

[397] A. E Passalacqua, F. Lufrano, G. Squadrito, A. Patti, L. Giorgi, "Nafion content in the catalyst layer of polymer electrolyte fuel cells: effects on structure and performance", Electrochimica Acta, vol. 46, $\mathrm{N}^{\circ}$ 6, pp. 799-805, 2001.

[398] S. Gamburzev, A. J. Appleby, "Recent progress in performance improvement of the proton exchange membrane fuel cell (PEMFC)", Journal of Power Sources, vol. 107, № 1, pp. 5-12, 2002.

[399] Z. Qi, A. Kaufman, "Low Pt loading high performance cathodes for PEM fuel cells", Journal of Power Sources, vol. 113, №1, pp. 37-43, 2003.

[400] M. Watanabe, H. Igarashi, K. Yosioka, "An experimental prediction of the preparation condition of Nafion-coated catalyst layers for PEFCs", Electrochimica Acta, vol. 40, №3, pp. 329-334, 1995.

[401] X. Cheng, B. Yi, M. Han, J. Zhang, Y. Qiao, J. Yu, "Investigation of platinum utilization and morphology in catalyst layer of polymer electrolyte fuel cells", Journal of Power Sources, vol. 79, $\mathrm{N}^{\circ}$ 1, pp. 75-81, 1999.

[402] K. Cooper, "In situ PEM fuel cell, Electrochemical Surface Area and Catalyst Utilization Measurement", Fuel Cell Testing \& Monitoring, pp. 28-30, 2009. 
[403] K. Kinoshita, P. Stonehart, "Preparation and characterization of highly dispersed electrocatalytic materials" en Modern Aspectos of Electrochemistry, J. O. M. Bockris, B. E. Conway, Eds. Plenum Press, New York, 1977, pp. 183-266.

[404] S. Wasterlain, D. Candusso, D. Hissel, F. Harel, P. Bergman, P. Menard, M. Anwar, "An experimental study of the temperature, relative humidity and flow rate effects on the performances of a single PEMFC", Hyper Article en Ligne, 2008.

[405] M. Ciureanu, H. Wang, "Electrochemical impedance study of electrode-membrane assemblies in PEM fuel cells: I. Electro-oxidation of $\mathrm{H}_{2}$ and $\mathrm{H}_{2} / \mathrm{CO}$ mixtures on Pt-based gas-diffusion electrodes", Journal of The Electrochemical Society, vol. 146, № 11, pp. 4031-4040, 1999.

[406] A. Pozio, M. D. Francesco, A. Cemmi, F. Cardellini, L. Giorgi, "Comparison of high surface Pt/C catalysts by cyclic voltammetry", Journal of Power Sources, vol. 105, pp. 13-19, 2002.

[407] J. Xie, D. L. Wood III, D. M. Wayne, T. A. Zawodzinski, P. Atanassov, R. L. Borup, "Durability of PEFCs at high humidity conditions", Journal of The Electrochemical Society, vol. 152, $\mathrm{N}^{\circ} 1$, pp. A104-A113, 2005.

[408] P. Gode, F. Jaouen, G. Lindbergh, A. Lundblad, G. Sundholma, "Influence of the composition on the structure and electrochemical characteristics of the PEFC cathode", Electrochimica Acta, vol. 48, No28, pp. 4175-4187, 2003.

[409] G. Tamizhmani, J. . Dodelet, D. Guay, "Crystallite size effects of carbon-supported Platinum on oxygen reduction in liquid acids", Journal of The Electrochemical Society, vol. 143, No 1, pp. 18-23, 1996.

[410] M. Uchimura, S. S. Kocha, "The impact of cycle profile on PEMFC durability", ECS Transactions, vol. 11, N 1, pp. 1215-1226, 2007.

[411] R. Jiang, H. R. Kunz, J. M. Fenton, "Investigation of membrane property and fuel cell behavior with sulfonated poly(ether ether ketone) electrolyte: Temperature and relative humidity effects", Journal of Power Sources, vol. 150, pp. 120-128, 2005.

[412] H. Olender, J. McBreen, W. E. O'Grady, S. Srinivasan, K. V. Kordesch, "Design of a cell for electrode kinetic investigations of fuel cell reactions", Journal of The Electrochemical Society, vol. 129, N¹, pp. 135-137, 1982.

[413] D. Chu, R. Jiang, "Performance of polymer electrolyte membrane fuel cell (PEMFC) stacks-Part I. Evaluation and simulation of an air-breathing PEMFC stack", Journal of Power Sources, vol. 83, pp. 128-133, 1999.

[414] A. R. Balkin, "Modelling a 500 W Polymer Electrolyte Membrane Fuel Cell", University of Technology, 2002.

[415] J. C. Amphlett, R. M. Baumert, R. F. Mann, B. A. Peppley, P. R. Roberge, J. T. Harris, "Performance modeling of the ballard mark IV solid polymer electrolyte fuel cell: I. Mechanistic model development", Journal of The Electrochemical Society, vol. 142, N 1, pp. 1-8, 1995.

[416] F. N. Büchi, "Operating proton exchange membrane fuel cells without external humidification of the reactant gases", Journal of The Electrochemical Society, vol. 144, № 8, pp. 2767-2772, 1997.

[417] T. E. Springer, T. A. Zawodzinski, M. S. Wilson, S. Gottesfelld, "Characterization of polymer electrolyte fuel cells using AC impedance spectroscopy", Journal of The Electrochemical Society, vol. 143, N², pp. 587-599, 1996.

[418] T. Okada, G. Xie, O. Gorseth, S. Kjelstrup, N. Nakamura, T. Arimura, "Ion and water transport characteristics of Nafion membranes as electrolytes", Electrochimica Acta, vol. 43, №24, pp. 3741-3747, 1998. 
[419] D. Sena, E. Ticianelli, V. Paganin, E. Gonzalez, "Effect of water transport in a PEFC at low temperatures operating with dry hydrogen", Journal of Electroanalytical Chemistry, vol. 477, $\mathrm{N}^{\circ} 2$, pp. 164-170, 1999.

[420] T. Freire, E. Gonzalez, "Effect of membrane characteristics and humidification conditions on the impedance response of polymer electrolyte fuel cells", Journal of Electroanalytical Chemistry, vol. 503, N¹-2, pp. 57-68, 2001.

[421] T. J. Schmidt, "Characterization of high-surface-area electrocatalysts using a rotating disk electrode configuration", Journal of The Electrochemical Society, vol. 145, N 7, pp. 2354-2358, 1998. 